\title{
DEVELOPMENT AND PROCESS EVALUATION OF IMPROVED \\ FISCHER-TROPSCH SLURRY CATALYSTS
}

\author{
Final Report \\ Apri1 1990 \\ Prepared For
}

U.S. Department of Energy

Pittsburgh Energy Technology Center

Work Performed Under Contract No. DE-AC22-85PC80011

\author{
Report Prepared By \\ Dragomir B. Bukur \\ Doble Mukesh \\ Snehal A. Patel \\ Michael P. Rosynek* \\ William H. Zimmerman \\ Contributors \\ William P. Addiego* \\ Xiaosu Lang \\ Chiuping Li* \\ Joseph A. Ross in \\ E. Benjamin Yeh* \\ Department of Chemical Engineering \\ Department of Chemistry* \\ Texas A\&M University \\ College Station, Texas 77843 \\ Economic Evaluation Prepared By \\ Lyndon J. Kellogg \\ Air Products and Chemicals, Inc. \\ 7201 Hamilton Boulevard \\ Allentown, Pennsyivania 18195-1501
}

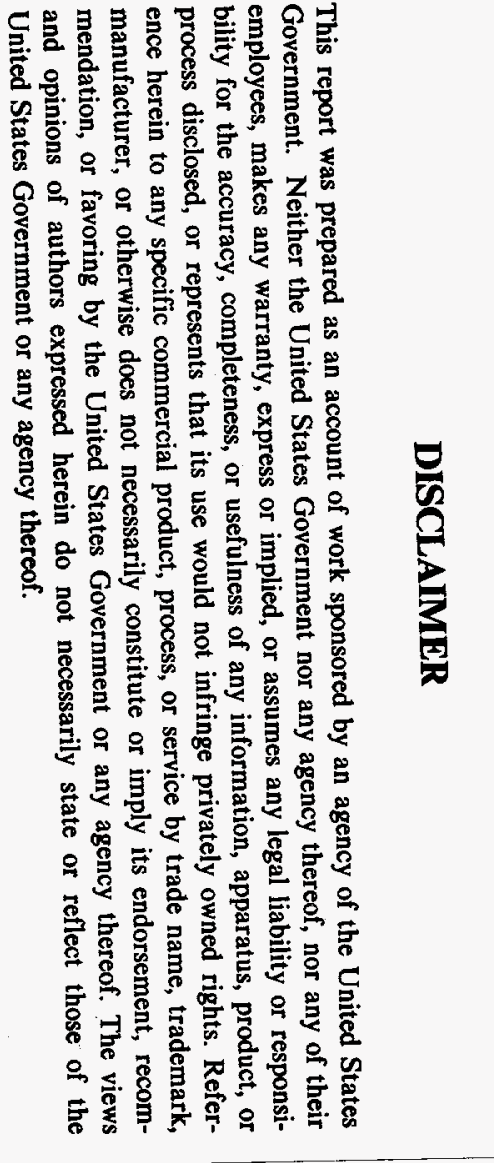




\section{DISCLAIMER}

Portions of this document may be illegible in electronic image products. Images are produced from the best available original document. 


\section{DISCLAIMER}

This report was prepared as an account of work sponsored by the United States Government. Neither the United States nor the United States Department of Energy, nor any of their employees, makes any warranty, expressed or implied, or assumes any legal liability or responsibility for the accuracy, completeness, or usefulness of any information, apparatus, product, or process disclosed, or represents that its use would not infringe privately owned rights. Reference herein to any specific commercial product, process, or service by trade name, mark, manufacturer, or otherwise, does not necessarily constitute or imply its endorsement, recommendation, or favoring by the United States Government or any agency thereof. The views and opinions of authors expressed herein do not necessarily state or reflect those of the United States Government or any agency thereof. 


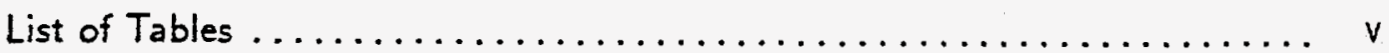

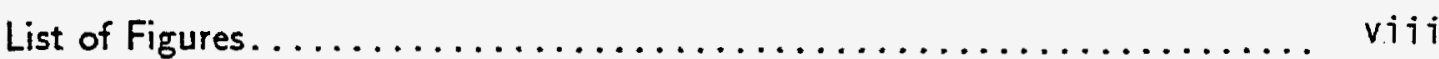

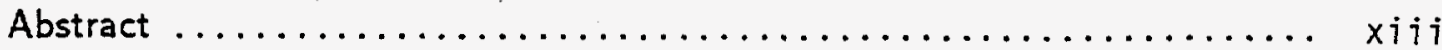

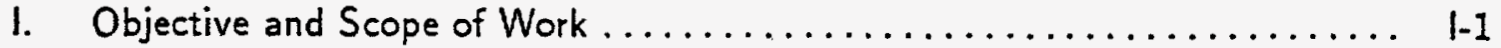

II. Executive Summary ............................

1. Summary of Accomplishments .....................

2. Recommendations for Future Work .................. $\|$ I- 6

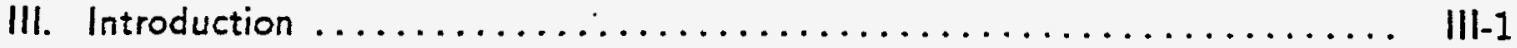

1. Summary of Previous Work with Iron Catalyst .............. III-2

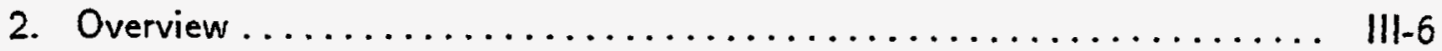

IV. Experimental............................. IV

1. Fixed Bed and Slurry Reactor Systems .................. IV-I

2. Experimental Procedure and Product Collection............... IV 6

2.1 Fixed Bed Operating Procedure .................. IV 6

2.2 Slurry Reactor Operating Procedure $\ldots \ldots \ldots \ldots \ldots \ldots \ldots \ldots$ IV-6

3. Product Aralysis Scheme $\ldots \ldots \ldots \ldots \ldots \ldots \ldots \ldots \ldots \ldots \ldots$ IV -7

3.1 Response Factors and Retention Times .............. IV-9

4. Data Reduction System ........................ IV-10

5. Coding System for Runs . ...................... IV-12

V. Task 2. Slurry Catalyst Development.................... V-1

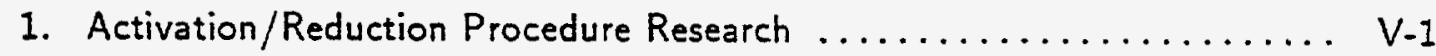

1.1 Literature Review ....................... V-1

1.2 Experimental Procedure ..................... V-3

1.3 Results............................ $V-3$

1.4 Discussion $\ldots \ldots \ldots \ldots \ldots \ldots \ldots \ldots \ldots \ldots \ldots \ldots \ldots \ldots \ldots \ldots \ldots \ldots \ldots$

1.5 Related Studies............................. V-28

1.6 Additional Tests with the $100 \mathrm{Fe} / 3 \mathrm{Cu} / 0.2 \mathrm{~K}$ Catalyst ........ V-28

1.7 Activation Studies with the $100 \mathrm{Fe} / 3 \mathrm{Cu} / 0.5 \mathrm{~K}$ Catalyst ........ V-30

1.8 Summary ........................... $V .33$ 
TABLE OF CONTENTS, cont'd

Page
Promoter Effect Researeh

2. Promoter Effect Research ....................... V-36

2.1 Fixed Bed Reactor Tests with Hydrogen Activated Catalysts ....... V-36

2.1.1 Literature Review ..................... V-36

2.1.2 Experimental Procedure $\ldots \ldots \ldots \ldots \ldots \ldots \ldots \ldots \ldots \ldots, V-37$

2.1 .3 Results and Discussion................... V-38

2.1.4 Summary......................... V-62

2.2 Fixed Bed Reactor Tests of Catalysts Activated with Carbon Monoxide ............................... V-62

2.3 Promoter Effect/Kinetic Studies in Stirred Tank Slurry Reactors .... . V-63

2.3.I Run SA-05-2957 with the $100 \mathrm{Fe} / 0.3 \mathrm{Cu} / 0.2 \mathrm{~K}$ Catalyst .... V-68

2.3.2 Run SA-25-3657 with the $100 \mathrm{Fe} / 3.0 \mathrm{Cu} / 0.2 \mathrm{~K}$ Catalyst .... V V-77

2.3.3 Run SB-07-0458 with the $100 \mathrm{Fe} / 0.3 \mathrm{Cu} / 0.5 \mathrm{~K}$ Catalyst .... V-81

2.3.4 Run SA-07-0468 with the $100 \mathrm{Fe} / 0.3 \mathrm{Cu} / 0.5 \mathrm{~K}$ Catalyst .... V-88

$\begin{array}{ll}2.3 .5 & \text { Summary } \quad V-97\end{array}$

3. Slurry Reactor Kinetic Studies . . . . . . . . . . . . . . . . . V-98

3.1 Kinetics Background ......................... V-98

3.2 Results and Discussion....................... V-110

3.3 Summary ............................ V-129

4. Binder/Support Effect Research ....................... V-134

4.1 Results and Discussion...................... V-135

4.2 Summary............................. V-145

VI. Task 3. Process Evaluation Research ...................... VI-1

1. Fixed Bed Reactor Tests with Silica Containing Catalysts ........... VI-I

1.1 Run FA-63-1308 with the $100 \mathrm{Fe} / 5 \mathrm{Cu} / 4.2 \mathrm{~K} / 8 \mathrm{SiO}_{2}$ Catalyst ..... VI-1

1.2 Run FB-99-1588 with the Ruhrchemie LP $33 / 81$ Catalyst . . . . . . . VI-10

1.3 Run FB-66-1948 with the $100 \mathrm{Fe} / 5 \mathrm{Cu} / 4.2 \mathrm{~K} / 24 \mathrm{SiO}_{2}$ Catalyst .... VI-14

2. Fixed Bed Reactor Tests with Unsupported Precipitated Iron Catalysts.... VI-25

2.1 Runs FA-15-1698/FA-15-1768 with the $100 \mathrm{Fe} / 1 \mathrm{Cu} / 0.2 \mathrm{~K}$ Catalyst. VI-25

2.2 Runs FB-27-2438/FA-27-2518 with the $100 \mathrm{Fe} / 3 \mathrm{Cu} / 0.5 \mathrm{~K}$ Catalyst . VI-29 
3. Stirred Tank Slurry Reactor Tests with Silica. . . . . VI-40 Containing Catalysts

3.1 Run SA-99-0888 with the Ruhrchemie LP 33/81. . . VI-40 Catalyst

3.2 Run SB-66-2468 with the $100 \mathrm{Fe} / 5 \mathrm{Cu} / 4.2 \mathrm{~K} /$. . . VI-48 $24 \mathrm{SiO}_{2}$ Catalyst

4. Stirred Tank Slurry Reactor Tests with Unsupported . . VI-60 Precipitated Iron Catalysts

4.1 Run SB-27-2168 with the $100 \mathrm{Fe} / 3 \mathrm{Cu} / 0.5 \mathrm{~K}$ Catalyst VI-60

4.2 Run SB-25.2-2878 with the $100 \mathrm{Fe} / 3 \mathrm{Cu} / 0.5 \mathrm{~K}$. . VI-69 Catalyst

5. Summary

VII. Catalyst Synthesis and Characterization Methods. . . . . VII-1

1. Catalyst Preparation and Analysis.......... VII-1

2. Reduction Studies. . . . . . . . . . . . V VII-5

3. Surface Characterization ............ VII-11

4. Summary of Results and Discussions . . . . . . . . VII-14

4.1 Reduction Behavior of Precipitated Iron ..... . VII-14 Catalysts

4.2 The Oxidation States of Surface Iron. . . . . . VII-24

5. Conclusions. . . . . . . . . . . . . VII-26

VIII. Task 4. Economic Evaluation. . . . . . . . . . . VIII-I

1. Executive Summary. ............... VIII-1

1.1 Background. . . ............... VIII-1

1.2 Synthesis Gas Production. . . . . . . . . . . VIII-3

I.3 F-T Synthesis and Product Upgrading ....... . VIII-3

2. Introduction/Background. . . . . ......... VIII-5

3. Scope of the Present Study . . . . . . . . . . . . VIII-6

4. Catalyst Comparison. ................ VIII-9

5. Synthesis Gas Production.... . . . . . . . . VIII-9

6. Capital Investment ............. VIII-12 
TABLE OF CONTENTS, cont'd

Page

7. Required Revenues. ............... . VIII-12

8. Product Revenues............... . VIII-15

9. Results................... VIII-15

IX. References . . . . . . . . . . . . . . . . . . IX-1

Appendix 1. - 1985 Economic Evaluation Report. . . . . . A.1-1

Appendix 2. - Revised Product Cost Summary . . . . . . . A.2-1 


\section{LIST OF TABLES}

Page

III-1 Comparitive Catalyst Performance Data III-4

IV-1 Catalyst Codes for Run Designations IV-13

V.1-1 Activation Conditions and Test Designations V-4

V.1-2 Start-up Time/Temperature Schedule used during Conditioning Period V-5 following Activation Treatment

V.1-3 Results Summary of Catalysts Tests using CO Activations V-6

V.1-4 Results Summary of Catalysts Tests using $\mathrm{H}_{2}$ or $\mathrm{H}_{2}+\mathrm{CO}$ Activations $\quad \mathrm{V}-7$

V.1-5 Effect of Reduction Procedures on Catalyst Activity and Selectivity (100 V-31

$\mathrm{Fe} / 3 \mathrm{Cu} / 0.2 \mathrm{~K}$ )

V.1-6 Effect of Reduction Procedures on Catalyst Activity and Selectivity (100 V-34

$\mathrm{Fe} / 3 \mathrm{Cu} / 0.5 \mathrm{~K}$ )

V.2-1 Effect of Promoters on Catalyst Activity and Selectivity at $250^{\circ} \mathrm{C}, 1.48 \mathrm{~V}-43$ $\mathrm{MPa}, \mathrm{H}_{2} / \mathrm{CO}=1, \mathrm{SV}=2 \mathrm{~N} / /$ g-cat.h

V.2-2 Chain Growth Probability Factors for Different Catalysts V-48

V.2-3 Summary of Fixed Bed Tests and Testing Conditions for Promoter Effect V-64 Research

V.2-4 Effect of Promoters on Catalyst Performance

$V-65$

V.2-5 Summary of Results for Slurry Run SA-05-2957 (100 Fe/0.3 Cu/0.2 K) V

V.2-6 Summary of Results for Slurry Run SA-25-3657 (100 Fe/3 Cu/0.2 K) V

V.2-7 Major Events in Run SA-25-3657 (100 Fe/3 Cu/0.2 K)

$V-80$

$V-82$

V.2-8 Wax and Solids Inventory for Run SA-25-3657 (100 Fe/3 Cu/0.2 K)

V.2-9 Summary of Results for Slurry Run SB-07-0458 (100 Fe/0.3 Cu/0.5 K) V-83

V.2-10 Major Events in Run SB-07-0458 (100 Fe/0.3 Cu/0.5 K) V-87

V.2-11 Comparitive Catalyst Performance Data for Tests Conducted in Slurry Reac- V-89 tors

V.2-12 Summary of Results for Slurry Run SA-07-0468 (100 Fe/0.3 Cu/0.5 K) V-90

V.2-13 Major Events in Run SA-07-0468 (100 Fe/0.3 Cu/0.5 K)

$V-95$

V.2-14 Wax and Solids Inventory for Run SA-07-0468 (100 Fe/0.3 Cu/0.5 K) V-96

V.3-1 Summary of Kinetic Data for Run SA-05-2957 (100 Fe/0.3 Cu/0.2 K) V-99

V.3-2 Summary of Kinetic Data for Run SB-07-0458 (100 Fe/0.3 Cu/0.5 K) V-100

V.3-3 Summary of Kinetic Data for Run SA-99-0888 (Ruhrchemie LP 33/81) V-101

V.3-4 Summary of Kinetic Data for Run SB-66-2468 (100 Fe/5 Cu/4.2 K/24 V-102 $\mathrm{SiO}_{2}$ )

V.3-5 Summary of FT Kinetic Expression and Parameter Values from the V-108 Literature 
LIST OF TABLES, cont'd

V.3-6 Summary of FT First Order Rate Constants

$V-111$

V.3-7 Summary of FT Kinetic Parameter Estimates

$V-116$

V.3-8 Summary of WGS First Order Rate Constants

$V-128$

V.3-9 Summary of WGS Kinetic Parameter Estimates

$V-130$

V.4-1 Summary of Fixed Bed Tests and Testing Conditions for Binder Support

V-136

Research

V.4-2 Summary of Binder Support Catalyst tests

$V-137$

V.4-3 Catalyst Stability Comparison before and after Process Variable Studies

$V-140$

Vl-1 Summary of Results for Fixed Bed Run FB-63-1308 (100 Fe/5 Cu/4.2 K/8

VI-2

VI-2 Summary of Results for Fixed Bed Run FB-99-1588 (Ruhrchemie LP 33/81)

VI-3 Summary of Results for Fixed Bed Run FB-66-1948 (100 Fe/5 Cu/4.2 K/24 $\left.\mathrm{SiO}_{2}\right)$

V1-4 Summary of Results for Fixed Bed Runs FA-15-1698 and FA-15-1768 (100 $\mathrm{Fe} / 1 \mathrm{Cu} / 0.2 \mathrm{~K})$

Vl-5 Summary of Results for Fixed Bed Run FB-27-2438 (100 Fe/3 Cu/0.5 K) VI-34

VI-6 Summary of Results for Fixed Bed Run FA-27-2518 (100 Fe/3 Cu/0.5 K)

VI-36

VI-7 Major Events Occurring in Run SA-99-0888 (Ruhrchemie LP 33/81)

VI-41

VI-8 Summary of Results for Slurry Run SA-99-0888 (Ruhrchemie LP 33/81)

VI-42

VI-9 Major Events Occurring in Run SB-66-2468 (100 Fe/5 Cu/4.2 K/24 SiO 2 )

VI-53

VI-10 Summary of Results for Slurry Run SB-66-2468 (100 Fe/5 Cu/4.2 K/24

VI-54 $\left.\mathrm{SiO}_{2}\right)$

VI-1I Major Events Occurring in Run SB-27-2168 (100 Fe/3 Cu/0.5 K)

Vl-65

VI-12 Summary of Results for Slurry Run SB-27-2168 (100 Fe/3 Cu/0.5 K)

VI-13 Major Events Occurring in Run SB-25.2-2878 (100 Fe/3 Cu/0.2 K)

VI-66

VI-71

VI-14 Summary of Results for Slurry Run SB-25.2-2878 (100 Fe/3 Cu/0.2 K) VI-72

VI-15 Activity and Selectivity Comparison of $\mathrm{SiO}_{2}$ Containing Catalysts VI-77

VII-1 Compositions of Synthesized Precipitated Iron Catalysts

VII-4

VII-2 Surface Area of Synthesized Precipitated Iron Catalysts

VII-6

VII-3 Time Required for Completion of Second Step of Iron Reduction at $300^{\circ} \mathrm{C}$

VII-23

VII-4 Summary of XPS results of Precipitated Iron Catalysts

VII-25 
VIII-1 Capital Investment Summary for Liquid Fuels Synthesis . . VIII-7

VIII-2 Annual Costs for Fischer-Tropsch Synthesis. . . . . . . VIII-8

VIII-3 Catalyst Comparison ................. VIII-11

VIII-4 Capital Investment Summary. . . . . . . . . . . . VIII-13

VIII-5 Required Revenues ................ . VIII-14

VIII-6 Projected Revenues in 1990/1995/2000.......... . VIII-16

VIII-7 1990 Product Prices \& Revenues Based on 1985 Projection . . VIII-17 Vs. 1990 Projection

VIII-8 Product Revenue Cost Breakdown. . . . . . . . . . . VIII-18

VIII-9 Product cost Summary. . . . . . . . . . . . . . . VIII-19

VIII-10 Product Cost Summary. . . . . . . . . . . . . . . VIII-20 


\section{LIST OF FIGURES}

Page

IV-1 Schematic of the fixed bed reactor system IV-2

IV-2 Schematic of the slurry bed reactor system IV-4

IV-3 G.C. analysis scheme IV-8

IV-4 Flow diagram of the mass balance computer program IV-11

V.1-1 Volumetric contractions during conditioning period for the CO activation V-9

V.1-2 Comparison of activity and stability for the $\mathrm{CO}$ activation procedures V-10

V.1-3 Comparison of hydrocarbon distribution and olefin selectivity for the CO V-12 activation procedures

V.1-4 Anderson-Schulz-Flory plot for the products obtained in test A-3077 at $92 \quad$ V-14 $h$ on stream

V.1-5 Volumetric contractions during conditioning period for the $\mathrm{H}_{2}$ Activation V-16 procedures

V.1-6 Comparison of activity and stability for the $\mathrm{H}_{2}$ activation procedures $V-17$

V.1-7 Comparison of hydrocarbon distribution and olefin selectivity for the $\mathrm{H}_{2}$ V-18 activation procedures

V.1-8 Comparison of activity and stability for selected activation procedures V-19

V.1-9 Comparison of hydrocarbon distribution and olefin selectivity for selected V-21 activation procedures

V.1-10 Effect of activation conditions on activity and stability of the $100 \mathrm{Fe} / 3 \quad$ V-29 $\mathrm{Cu} / 0.2 \mathrm{~K}$ catalyst

V.1-11 Effect of activation conditions on activity and stability of the $100 \mathrm{Fe} / 3 \quad$ V.33 $\mathrm{Cu} / 0.5 \mathrm{~K}$ catalyst

V.2-1 Promoter effects on catalyst activity and stability $(a)\left(\mathrm{H}_{2}+\mathrm{CO}\right)$ conversion vs. reaction temperature, and $(b)\left(\mathrm{H}_{2}+\mathrm{CO}\right)$ conversion vs. time on stream $\left(250^{\circ} \mathrm{C}\right)$

V.2-2 Effect of promoters and temperature on water-gas-shift activity V-44

V.2-3 Anderson-Schulz-Flory distribution for catalysts promoted with copper and potassium

V.2-4 Effect of potassium content and gas space velocity on hydrocarbon selectivity for (a) singly promoted $\mathrm{Fe} / \mathrm{K}$ catalysts, and (b) doubly promoted $\mathrm{Fe} / \mathrm{Cu} / \mathrm{K}$ catalysts

V.2-5 Effect of potassium content and reaction temperature on hydrocarbon selectivity for (a) singly promoted $\mathrm{Fe} / \mathrm{K}$ catalysts, and (b) doubly promoted $\mathrm{Fe} / \mathrm{Cu} / \mathrm{K}$ promoted $\mathrm{Fe} / \mathrm{Cu} / \mathrm{K}$ catalysts

V.2-6 Effect of potassium content on olefin selectivity for (a) singly promoted $\mathrm{Fe} / \mathrm{K}$ catalysts, and (b) doubly promoted $\mathrm{Fe} / \mathrm{Cu} / \mathrm{K}$ catalysts, and comparison with results for un promoted iron 
V.2-7 Effect of process conditions on olefin selectivity. Influence of temperature (a) $100 \mathrm{Fe} / 1 \mathrm{~K}$ catalyst (c) $100 \mathrm{Fe} / 3 \mathrm{Cu} / 0.2 \mathrm{~K}$ catalyst, influence of gas space velocity (b) $100 \mathrm{Fe} / 1 \mathrm{~K}$ catalyst (d) $100 \mathrm{Fe} / 3 \mathrm{Cu} / 0.2 \mathrm{~K}$ catalyst

V.2-8 Effect of potassium content on 2-olefin selectivity for (a) singly promoted $\mathrm{Fe} / \mathrm{K}$ catalysts, and (b) doubly promoted $\mathrm{Fe} / \mathrm{Cu} / \mathrm{K}$ catalysts, and comparison with results for unpromoted iron

V.2-9 Effect of process conditions on 2-olefin selectivity. Influence of temperature (a) $100 \mathrm{Fe} / 1 \mathrm{~K}$ catalyst (c) $100 \mathrm{Fe} / 3 \mathrm{Cu} / 0.2 \mathrm{~K}$ catalyst, influence of gas space velocity (b) $100 \mathrm{Fe} / 1 \mathrm{~K}$ catalyst (d) $100 \mathrm{Fe} / 3 \mathrm{Cu} / 0.2 \mathrm{~K}$ catalyst

V.2-10 Effect of promoters and temperature on oxygenates selectivity

V.2-11 Effect of promoters on alcohol selectivity

V.2-12 Effect of potassium (100 Fe/1 Cu/ $/ x \mathrm{~K}, \mathrm{x}=0, .2, .8)$ on (a) hydrocarbon

V.61 distribution, and (b) olefin selectivity (at $235^{\circ} \mathrm{C}, 1.48 \mathrm{MPa}, \mathrm{SV}=2 \mathrm{~N} / \mathrm{g}$ cat.h)

V.2-13 Promoter effects on (100 Fe/3 $\left.\mathrm{Cu}_{/} / \mathrm{KK}, \mathrm{x}=.2, .5\right)$ (a) hydrocarbon distribution (b) olefin selectivity (at $235^{\circ} \mathrm{C}, 1.48 \mathrm{MPa}, \mathrm{SV}=2 \mathrm{NI} / \mathrm{g}$-cat.h)

V.2-14 Space time yield as a function of pressure at constant $\mathrm{P} / \mathrm{SV}\left(250^{\circ} \mathrm{C}\right.$, $\mathrm{H}_{2} / \mathrm{CO}=0.67$ \& 1 )

V.3-1 FT first order plot for $100 \mathrm{Fe} / 0.3 \mathrm{Cu} / 0.2 \mathrm{~K}(\mathrm{SA}-05-2957)$ and $100 \mathrm{Fe} / 0.3$ $\mathrm{Cu} / 0.5 \mathrm{~K}$ (SB-07-0458) catalysts

V.3-2 FT first order plot for Ruhrchemie LP 33/81 (SA-99-0888) and $100 \mathrm{Fe} / 5$ $\mathrm{Cu} / 4.2 \mathrm{~K} / 24 \mathrm{SiO}_{2}$ (SB-66-2468) catalysts

V.3-3 Arrhenius plot of the FT first order rate constants

$V-66$

$V-67$

V.76

$\mathrm{V}-112$

V-113

$V-114$

V.3-4 Linear plot of the FT rate expression given by Eqn. V.3-6 $\left(\mathrm{H}_{2} \mathrm{O}\right.$ intibition)

$V-117$

V.3-5 Linear plot of the FT rate expression given by Eqn. V.3-15 $\left(\mathrm{H}_{2} \mathrm{O}\right.$ inhibition)

$V-118$

V.3-6 Linear plot of the FT rate expression given by Eqn. $V .3-19\left(\mathrm{CO}_{2}\right.$ inhibition $)$

$V-121$

V.3-7 Parity plot of the FT rate expression given by Eqn. V.3-20 ( $\mathrm{H}_{2} \mathrm{O}$ inhibition)

V.3-8 Comparison of measured $\mathrm{PCO}_{2} \mathrm{P}_{\mathrm{H}_{2}} / \mathrm{P}_{\mathrm{CO}} \mathrm{P}_{\mathrm{H}_{2} \mathrm{O}}$ ratios to equilibrium

$\mathrm{V}-122$

$V-124$

V.3-9 WGS first order plot for the $100 \mathrm{Fe} / 0.3 \mathrm{Cu} / 0.2 \mathrm{~K}(\mathrm{SA}-05-2957) 100 \mathrm{Fe} / 0.3$

$V-125$

$\mathrm{Cu} / 0.5 \mathrm{~K}$ (SB-07-0458) catalysts

V.3-10 WGS First order plot for the Ruhrchemie LP 33/81 (SA-99-0888) 100 Fe/5 V-126 Cu/4.2 K (SB-66-2468) catalysts

V.3-11 Arrhenius plot of the WGS first order rate constants

V.4-1 Comparison of $\left(\mathrm{H}_{2}+\mathrm{CO}\right)$ conversions for the binder/support catalysts and Ruhrchemie LP $33 / 81\left(250^{\circ} \mathrm{C}, 1.48 \mathrm{MPa}, \mathrm{H}_{2} / \mathrm{CO}=1\right)$

V.4-2 Effect of binder/support and temperature on water-gas-shift activity (2 V-141 $\mathrm{Nl} / \mathrm{g}$-cat.h, $1.48 \mathrm{MPa}, \mathrm{H}_{2} / \mathrm{CO}=1$ ) 


\section{LIST OF FIGURES, cont'd}

Page

V.4-3 Weight percent hydrocarbon distribution of binder/support catalysts and

V-142

Ruhrchemie LP $33 / 81\left(235^{\circ} \mathrm{C}, 1.48 \mathrm{MPa}, 2 \mathrm{NI} / \mathrm{g}\right.$-cat.h, $\left.\mathrm{H}_{2} / \mathrm{CO}=1\right)$

V.4-4 Weight percent hydrocarbon distribution of binder / support catalysts and Ruhrchemie LP $33 / 81\left(250^{\circ} \mathrm{C}, 1.48 \mathrm{MPa}, 2 \mathrm{NI} /\right.$ g-cat.h, $\left.\mathrm{H}_{2} / \mathrm{CO}=1\right)$

VI-1 Stability plot, $\left(\mathrm{H}_{2}+\mathrm{CO}\right)$ conversion vs time on stream for run FA-63-1308

$\mathrm{V}-143$

VI-2 Effect of time on stream on $100 \mathrm{Fe} / 5 \mathrm{Cu} / 4.2 \mathrm{~K} / 8 \mathrm{SiO}_{2}$ catalyst selectivity for run FA-63-1308 $\left(235^{\circ} \mathrm{C}, 1.48 \mathrm{MPa}, 2 \mathrm{NI} / \mathrm{g}\right.$-cat.h, $\mathrm{H}_{2} / \mathrm{CO}=1$ (48$240,662 \mathrm{~h}$ ) and $0.67(337-528 \mathrm{~h}))$

V1-3 Anderson-Schulz-Flory distribution for run FA-63-1308-1, total products excluding unrecovered wax

VI-4 Anderson-Schulz-Flory distribution for run FA-63-1308-4, total products excluding unrecovered wax

V1-5 Anderson-Schulz-Flory distribution for run FA-63-1308-8, total products excluding unrecovered wax

VI-6 Stability plot, $\left(\mathrm{H}_{2}+\mathrm{CO}\right)$ conversion vs time on stream for run FB-99-1588

VI-7 Effect of time on stream on Ruhrchemie LP 33/81 selectivity for run FB99-1588 $\left(250^{\circ} \mathrm{C}, 1.48 \mathrm{MPa}, 2 \mathrm{NI} / \mathrm{g}\right.$-cat.h, $\mathrm{H}_{2} / \mathrm{CO}=1(71-427 \mathrm{~h})$ and 1.0 $(528,623 h))$

VI-8 Comparison of fixed bed and slurry reactor selectivity with Ruhrchemie LP $33 / 81$ catalyst $(F B=F B-99-1588, S A=S A-99-0888)\left(250^{\circ} \mathrm{C}, 1.48 \mathrm{MPa}, 2\right.$ $\mathrm{NI} / \mathrm{g}$-cat.h, $\mathrm{H}_{2} / \mathrm{CO}=0.67$ (FB-2 and SA-3) and 1.0 (FB-6 and SA-12))

VI-9 Stability plot, $\left(\mathrm{H}_{2}+\mathrm{CO}\right)$ conversion vs time on stream for run FB-66$1948\left(100 \mathrm{Fe} / 5 \mathrm{Cu} / 4.2 \mathrm{~K} / 24 \mathrm{SiO}_{2}\right)$ and comparison to runs $\mathrm{FB}-99-1588$ (Ruhrchemie LP 33/81) and FA-63-1308 (100 Fe/5 Cu/4.2 K/8 SiO $)$

VI-10 Effect of time on stream on catalyst selectivity for run FB-66-1948 (100 $\left.\mathrm{Fe} / 5 \mathrm{Cu} / 4.2 \mathrm{~K} / 24 \mathrm{SiO}_{2}\right)\left(250^{\circ} \mathrm{C}, 1.48 \mathrm{MPa}, 2 \mathrm{Nl} /\right.$ g-cat.h, $\left.\mathrm{H}_{2} / \mathrm{CO}=0.69\right)$

VI-11 Effect of process conditions on catalyst activity and selectivity for run FB$66-1948\left(100 \mathrm{Fe} / 5 \mathrm{Cu} / 4.2 \mathrm{~K} / 24 \mathrm{SiO}_{2}\right)$

VI-12 Comparison of catalyst selectivity for $100 \mathrm{Fe} / 5 \mathrm{Cu} / 4.2 \mathrm{~K} 8$ and $24 \mathrm{SiO}_{2}$ catalyst and Ruhrchemie LP $33 / 81$ (1.48 MPa, $2 \mathrm{NI} / \mathrm{g}$-cat.h, $\mathrm{H}_{2} / \mathrm{CO}=0.67$ )

VI-13 Stability plot, $\left(\mathrm{H}_{2}+\mathrm{CO}\right)$ conversion vs time on stream for run FA-15-1698 and FA-15-1768 (100 Fe/1 Cu/0.2 K) catalysts $\left(235^{\circ} \mathrm{C}, 1.48 \mathrm{MPa}, 2 \mathrm{NI} / \mathrm{g}\right.$ cat.h)

VI-14 Comparison of catalyst selectivity in runs FA-15-1698 and FA-15-1768 (100 $\mathrm{Fe} / 1 \mathrm{Cu} / 0.2 \mathrm{~K}$ catalyst, $235^{\circ} \mathrm{C}, 1.48 \mathrm{MPa}, 2 \mathrm{NI} / \mathrm{g}$-cat. $\mathrm{h}, \mathrm{H} / \mathrm{CO}=0.71$ )

VI-15 Selectivity comparison for fixed bed tests of $100 \mathrm{Fe} / 1 \mathrm{Cu} / 0.2 \mathrm{~K}$ catalyst $\left(235^{\circ} \mathrm{C}, 1.48 \mathrm{MPa}, 2 \mathrm{NI} / \mathrm{g}\right.$-cat.h, $\left.\mathrm{H}_{2} / \mathrm{CO}=1.0\right)$

VI-8

VI-9

VI-13

VI-15

VI-16

V1-22

VI-23

VI-24

VI-26

VI-30

VI-31

V1-32 
VI-16 Stability plot, $\left(\mathrm{H}_{2}+\mathrm{CO}\right)$ conversion vs time on stream for runs FB-27-2438

VI-38 and FB-27-2518 (100 Fe/3 Cu/0.5 K, $260^{\circ} \mathrm{C}, 1.48 \mathrm{MPa}, 2 \mathrm{NI} / \mathrm{g}$-cat.h, $\mathrm{H}_{2} / \mathrm{CO}=0.67$ )

VI-17 Effect of time on stream on catalyst selectivity for runs FB-27-2438 and FB-27-2518 (100 Fe/3 Cu/0.5 K; $260^{\circ} \mathrm{C}, 1.48 \mathrm{MPa}, 2 \mathrm{Nl} /$ g-cat. $h, \mathrm{H}_{2} / \mathrm{CO}$ $=0.67$ )

VI-18 Stability plot, $\left(\mathrm{H}_{2}+\mathrm{CO}\right)$ conversion vs time On stream for run SA-99-0888

VI-19 Effect of time on stream on Ruhrchemie LP $33 / 81$ selectivity for run SA$99-0888\left(250^{\circ} \mathrm{C}, 1.48 \mathrm{MPa}, 2 \mathrm{NI} / \mathrm{g}\right.$-cat.h, $\left.\mathrm{H}_{2} / \mathrm{CO}=0.67\right)$

VI-20 Effect of temperature on Ruhrchemie LP $33 / 81$ selectivity for run SA-990888 (1.48 $\mathrm{MPa}, \mathrm{H}_{2} / \mathrm{CO}=0.67$ )

VI-21 Effect of space velocity on Ruhrchemie LP 33/81 selectivity for run SA-990888 (1.48 MPa, $\mathrm{H}_{2} / \mathrm{CO}=0.67$ )

VI-22 Effect of feed ratio and pressure on Ruhrchemie LP $33 / 81$ selectivity for run SA $-99-0888$ at $250^{\circ} \mathrm{C}$

VI-23 Catalyst activity for run SB-66-2468 (weights indicate amount of wax withdrawn $(-)$ or added $(+))$. 0 to $240 \mathrm{~h}$ on stream $\left(250^{\circ} \mathrm{C}, 1.48 \mathrm{MPa}\right.$, $2 \mathrm{NI} / \mathrm{g}$-cat. $h, \mathrm{H}_{2} / \mathrm{CO}=0.67$ )

VI-24 Catalyst activity for run SB-66-2468 (weights indicate amount of wax withdrawn $(-)$ or added $(+)) .240$ to $480 \mathrm{~h}$ on stream $\left(250^{\circ} \mathrm{C}, 1.48 \mathrm{MPa}\right.$, $2 \mathrm{NI} /$ g-cat. $h, \mathrm{H}_{2} / \mathrm{CO}=0.67$ )

VI-25 Stability plot, $\left(\mathrm{H}_{2}+\mathrm{CO}\right)$ conversion vs time on stream for run SB-66-2468 and $\left(250^{\circ} \mathrm{C}, 1.48 \mathrm{MPa}, 2 \mathrm{NI} / \mathrm{g}\right.$-cat.h, $\left.\mathrm{H}_{2} / \mathrm{CO}=0.67\right)$

VI-26 Effect of time on stream on $100 \mathrm{Fe} / 5 \mathrm{Cu} / 4.2 \mathrm{~K} / 24 \mathrm{SiO}_{2}$ catalyst selectivity for run SB-66-2468 $\left(250^{\circ} \mathrm{C}, 1.48 \mathrm{MPa}, 2 \mathrm{Nl} / \mathrm{g}\right.$-cat.h, $\left.\mathrm{H}_{2} / \mathrm{CO}=0.69\right)$

VI-27 Comparison of fixed bed and slurry reactor selectivity with $100 \mathrm{Fe} / 5 \mathrm{Cu} / 4.2$ $\mathrm{K} / 24 \mathrm{SiO}_{2}$ catalyst ( $\left.\mathrm{FB}=\mathrm{FB}-66-1948, \mathrm{SB}=\mathrm{SB}-66-2468\right)\left(250^{\circ} \mathrm{C}, 1.48 \mathrm{MPa}\right.$, $\mathrm{H}_{2} / \mathrm{CO}=.69, \mathrm{SV}=2 \mathrm{NI} / \mathrm{g}$-cat.h (FB-1 and SB-1) and 4.0 (FB-6 and SB-6))

VI-28 Effect of space velocity on $100 \mathrm{Fe} / 5 \mathrm{Cu} / 4.2 \mathrm{~K} / 24 \mathrm{SiO}_{2}$ catalyst selectivity for run SB-66-2468 $\left(250^{\circ} \mathrm{C}, 1.48 \mathrm{MPa}, \mathrm{H}_{2} / \mathrm{CO}=0.69\right)$

VI-29 Stability plot, $\left(\mathrm{H}_{2}+\mathrm{CO}\right)$ conversion vs time on stream for run SB-27-2168 $\left(260^{\circ} \mathrm{C}, 1.48 \mathrm{MPa}, 2.3-3.0 \mathrm{NI} / \mathrm{g}\right.$-cat.h)

VI-30 Activity plot, \% contraction vs. time on stream for run SB-25.2-2878, weights indicate wax withdrawn $(-)$ or added $(+)$ to reactor

VI-31 Stability plot, $\left(\mathrm{H}_{2}+\mathrm{CO}\right)$ conversion vs time on stream for run SB-25.2-2878

VII-1 Effect of reaction pH on copper content of precipitated iron catalysts at $80^{\circ} \mathrm{C}$ 
VII-2 TPR Profiles of potassium free pre-calcined iron catalysts containing the

VII-8 indicated levels of copper promoter (in parts by weight per 100 parts $\mathrm{Fe}$ )

VII-3 TPR profiles of copper free pre-calcined iron catalysts containing the

VII-9 indicated levels of potassium promoter (in parts by weight per 100 parts $\mathrm{Fe}$ )

VII-4 isothermal reduction profiles in $\mathrm{H}_{2}$ at $300^{\circ} \mathrm{C}$ of: (a) $100 \mathrm{Fe}$; (b) $100 \mathrm{Fe} / 0.3$ $\mathrm{Cu}$; (c) $100 \mathrm{Fe} / 1.0 \mathrm{Cu}$; (d) $100 \mathrm{Fe} / 3.0 \mathrm{Cu}$

VII-5 Isothermal reduction profiles in $\mathrm{H}_{2}$ at $300^{\circ} \mathrm{C}$ of: (a) $100 \mathrm{Fe} / 0.2 \mathrm{~K}$; (b) 100 $\mathrm{Fe} / 1.0 \mathrm{~K}$; (c) $100 \mathrm{Fe} / 2.0 \mathrm{~K}$ VII-6 Isothermal reduction profiles in $\mathrm{CO}$ at $300^{\circ} \mathrm{C}$ of: (a) $100 \mathrm{Fe}$; (b) $100 \mathrm{Fe} / 0$

VII-12

VII-13 $\mathrm{Cu} / 0.2 \mathrm{~K}$

VII-7 XPS Spectra of unpromoted $100 \mathrm{Fe}$ precipitate in $\mathrm{Fe} 2 \mathrm{p}$ region: (a) following calcination for $5 \mathrm{~h}$ at $300^{\circ} \mathrm{C}$; (b) following subsequent exposure to $\mathrm{H}_{2}$ for $5 \mathrm{~h}$ at $300^{\circ} \mathrm{C}$

VII-8 XPS Spectra of unpromoted $100 \mathrm{Fe}$ precipitate in $\mathrm{Fe} 2 \mathrm{p}$ region: (a) following calcination for $5 \mathrm{~h}$ at $300^{\circ} \mathrm{C}$ and subsequent reduction in $\mathrm{CO}$ for $5 \mathrm{~h}$ at $300^{\circ} \mathrm{C}$; (b) following subsequent exposure to $2 / 1$ mixture of $\mathrm{H}_{2} / \mathrm{CO}$ at $250^{\circ} \mathrm{C}$ and 1 atm

VII-9 XPS spectra of $100 \mathrm{Fe} / 5 \mathrm{Cu} / 4.2 \mathrm{~K} / 8 \mathrm{SiO}_{2}$ in $\mathrm{Fe} 2 \mathrm{p}$ region: (a) following exposure to $\mathrm{H}_{2}$ at $300^{\circ} \mathrm{C} ;$ (b) following subsequent exposure to $\mathrm{H}_{2} / \mathrm{CO}$ at $250^{\circ} \mathrm{C}$

VII-10 XPS spectra of $100 \mathrm{Fe} / 5 \mathrm{Cu} / 4.2 \mathrm{~K} / 8 \mathrm{SiO}_{2}$ in $\mathrm{Fe} 2 \mathrm{p}$ region: (a) following exposure to $\mathrm{CO}$ at $300^{\circ} \mathrm{C}$; (b) following subsequent exposure to $\mathrm{H}_{2} / \mathrm{CO}$ at $250^{\circ} \mathrm{C}$

VII-11 XPS spectra of $100 \mathrm{Fe} / 5 \mathrm{Cu} / 4.2 \mathrm{~K} / 8 \mathrm{SiO}_{2}$ in $\mathrm{K} 2 \mathrm{p}$ region: (a) following exposure to $\mathrm{CO}$ at $300^{\circ} \mathrm{C}$; (b) following subsequent exposure to $\mathrm{H}_{2} / \mathrm{CO}$ at $250^{\circ} \mathrm{C}$

VII-12 Influence of copper promoter on TPR peak maximum for the first step of iron reduction:

VII-13 influence of $\mathrm{SiO}_{2}$ support on TPR peak maximum for the first step of iron reduction:

VIII-1 F-T STurry Phase Flow Sheet

VII-16

VII-17

VII-18

VII-19

VII-20

VII-21

VIII -10 


\section{ABSTRACT}

This report describes results of a study aimed at developing and evaluating improved catalysts for a slurry Fischer-Tropsch (FT) process for converting synthesis gas to high quality transportation fuels (gasoline and distillate). The improvements in catalyst performance were sought by studying effects of pretreatment conditions, promoters and binders/supports. A total of 20 different, iron based, catalysts were evaluated in 58 fixed bed reactor tests and 10 slurry reactor tests. The major accomplishments and conclusions are summarized below.

The pretreatment conditions (temperature, duration and the nature of reducing gas) have significant effect on catalyst performance (activity, selectivity and stability) during FischerTropsch synthesis. One of precipitated unsupported catalysts had hydrocarbon selectivity similar to Mobil's I-B catalyst in high wax mode operation, and had not experienced any loss in activity during 460 hours of testing under variable process conditions in a slurry reactor.

The effect of promoters (copper and potassium) on catalyst performance during FT synthesis has been studied in a systematic way. It was found that potassium promotion increases activities of the FT and water-gas-shift (WGS) reactions, the average molecular weight of hydrocarbon products, and suppresses the olefin hydrogenation and isomerization reactions.

The addition of binders/supports (silica or alumina) to precipitated $\mathrm{Fe} / \mathrm{Cu} / \mathrm{K}$ catalysts, decreased their activity but improved their stability and hydrocarbon selectivity. The performance of catalysts of this type was very promising and additional studies are recommended to evaluate their potential for use in commercial slurry reactors.

Kinetic parameters for the FT and WGS reactions were determined from slurry reactor tests with four catalysts in which the catalyst activity was fairly stable with time on stream.

The catalytic studies were complemented with characterization studies which provided valuable information on the effects of copper and potassium promoters, and of silica and alumina supports on reduction behaviors (temperature programmed and isothermal reduction) and surface properties (X-ray photoelectron spectroscopy). 


\section{OBJECTIVE AND SCOPE OF WORK}

The objective of this contract is to develop a consistent technical data base on the use of iron-based catalysts in Fischer-Tropsch (FT) synthesis reactions. This data base will be developed to allow the unambiguous comparison of the performance of these catalysts with each other and with state-of-the-art iron catalyst compositions. Particular attention will be devoted to generating reproducible kinetic and selectivity data and to developing reproducible improved catalyst compositions. To accomplish these objectives, the following specific tasks will be undertaken.

\section{TASK 1 - Project Work Plan}

The objective of this task is to establish a detailed project work plan covering the entire period of performance of the contract. This includes estimated costs and manhours expended by month for each task.

\section{TASK 2 - Slurry Catalyst Improvement}

The primary purpose of this task is to develop improved iron-based catalysts, both precipitated and supported, that show enhanced activity and selectivity in slurry phase testing. This will be accomplished by gaining systematic understanding of the role of promoters, binders, supports and activation procedures in determining the activity and selectivity of iron-based catalysts. The catalyst development program will incorporate extensive physical and chemical characterization of these materials with the objective to establish correlations between the physical/chemical properties of these catalysts and the corresponding catalytic behavior for synthesis gas conversion.

\section{TASK 3 - Process Evaluation Research}

The purpose of this task is to subject the most improved catalysts (based on activity and selectivity) to a thorough process evaluation. This involves long term stability studies, investigation of a wide range of process variables, and determination of kinetic parameters.

\section{TASK 4 - Economic Evaluation}

The aim of this task is to develop the relative economic impact for each improved catalyst composition and compare these economics with the economics of using the base case catalyst. Data obtained from Tasks 2 and 3 will be used to generate a product yield structure, FT reactor residence time, and key process flow rates. These economic studies will include relative capital costs, operating costs, and required revenues for each catalyst, as well as a sensitivity study of the assigned relative values of the principal products (i.e., diesel and gasoline). 


\section{EXECUTIVE SUMMARY}

Slurry phase Fischer-Tropsch processing is considered a potentially economic method to convert coal-derived synthesis gas into liquid fuels. Largely due to its relatively simple reactor design, improved thermal efficiency, and ability to process $\mathrm{CO}$-rich synthesis gas, the slurry process has several potential advantages over conventional vapor phase processes.

While advances have been made in slurry phase Fischer-Tropsch technology, further work is required to more thoroughly evaluate its potential as a viable technology. Therefore, Air Products proposed a program to develop a consistent process/economic data base for a variety of iron-based catalysts. This data base allows unambiguous comparison of the performance of the new catalysts tested, both with each other and with the state-of-the-art catalyst compositions. Particular attention was paid to extracting kinetic and selectivity data, developing improved compositions/process parameters, and to performing process economic comparisons. The effects of activation/reduction procedures, promoters and binders/supports on catalyst activity, selectivity and stability were investigated in a systematic way.

\subsection{Summary of Accomplishments}

Key accomplishments in individual areas of research are summarized below.

Activation / Reduction Procedure Research

The catalytic behavior of a precipitated promoted iron catalyst $(100 \mathrm{Fe} / 3 \mathrm{Cu} / 0.2 \mathrm{~K})$ during the Fischer-Tropsch synthesis was studied in a fixed bed reactor following different pretreatments in either $\mathrm{CO}, \mathrm{H}_{2}$, or syngas with $\mathrm{H}_{2} / \mathrm{CO}=0.68$. The results show that activation parameters (temperature, pressure, duration and/or the nature of reducing gas) have significant effects on catalyst activity, stability, and selectivity during the synthesis. Activations with $\mathrm{CO}$ or syngas minimize production of gaseous hydrocarbons and produce more liquid products and more wax. However, these treatments usually yield catalysts that deactivate fairly rapidly during the synthesis. Good stability can be achieved with the right combination of activation parameters (temperature and duration). Reductions with $\mathrm{H}_{2}$ resulted in constant or gradually increasing activity over a $120 \mathrm{~h}$ period of synthesis. The selectivity of $\mathrm{H}_{2}$ reduced catalysts is less desirable than that of $\mathrm{CO}$ reduced catalysts, as more gaseous and less high molecular weight hydrocarbons are produced. Similar trends were observed in tests with another precipitated iron catalyst $(100 \mathrm{Fe} / 3 \mathrm{Cu} / 0.5 \mathrm{~K})$.

However, hydrocarbon selectivities in a stirred tank slurry bed reactor test of the 100 $\mathrm{Fe} / 0.3 \mathrm{Cu} / 0.5 \mathrm{~K}$ catalyst were not influenced by the reductant type $\left(\mathrm{H}_{2}\right.$ vs $\left.\mathrm{CO}\right)$. Hydrogen 
activated catalyst displayed no loss in activity during $\mathbf{4 6 0}$ hours of testing under different process conditions. Its hydrocarbon selectivity was very similar to that of the Mobil's I-B catalyst in a high wax mode of operation (low methane and $C_{2}-C_{4}$ gaseous hydrocarbons). Additional slurry reactor tests with this and other precipitated catalysts are needed to confirm these findings.

\section{Promoter Effect Research}

The effect of potassium and copper promotion on activity and selectivity of precipitated iron catalysts for the Fischer-Tropsch synthesis were studied in a fixed bed reactor at 200 psig, $235^{\circ} \mathrm{C}$ to $265^{\circ} \mathrm{C}$ using synthesis gas with an $\mathrm{H}_{2}: \mathrm{CO}$ molar feed ratio of $1: 1$.

It was found that promotion of iron with potassium in the range $0.2-1 \mathrm{wt} \%,(100 \mathrm{Fe} / \mathrm{xK}$, $x=0.2,0.5$ and 1.0$)$ increases activity of the Fischer-Tropsch(FT) and Water-Gas-Shift (WGS) reactions, and the average molecular weight of hydrocarbon and other organic (primarily alcohols) products. It also suppresses olefin hydrogenation and isomerization reactions. Potassium promotion inhibits iron reduction, and as a result, the potassium promoted catalysts require longer times to achieve the steady state activity.

Promotion of iron with copper $(100 \mathrm{Fe} / 3 \mathrm{Cu}$ ) also increases the rates of the FT and WGS reactions. Copper is a more effective promoter than potassium in increasing the rate of $\mathrm{FT}$ reaction, whereas the opposite applies to WGS activity. Also, promotion with copper facilitates reduction of iron and thus decreases the time required to achieve the steady state activity. In the presence of copper, the hydrocarbon product distribution shifts toward higher molecular weight products, but the magnitude of changes is significantly smaller than that observed with potassium promotion. Copper promotion slightly enhances the secondary reactions (olefin hydrogenation and isomerization).

The FT activity of the two doubly promoted catalysts $(100 \mathrm{Fe} / 3 \mathrm{Cu} / 0.2 \mathrm{~K}$ and $100 \mathrm{Fe} / 3$ $\mathrm{Cu} / 0.5 \mathrm{~K}$ ) was independent of their potassium content and higher than that of any of the singly promoted catalysts. In tests over a long period of time (up to 460 hours on stream) the catalyst with higher potassium content lost about $9 \%$ of its maximum activity, whereas the $100 \mathrm{Fe} / 3 \mathrm{Cu} / 0.2 \mathrm{~K}$ catalyst lost only $2 \%$. The WGS activity of the doubly promoted catalysts was similar to that of the $\mathrm{Fe} / \mathrm{K}$ catalysts. Selectivity behavior of the doubly promoted catalysts was strongly influenced by their potassium content. The catalyst containing $0.2 \mathrm{wt} \% \mathrm{~K}$ had selectivities (hydrocarbon product distribution, olefin content) similar to that obtained with the $100 \mathrm{Fe} / 3 \mathrm{Cu}$ catalyst, whereas the $100 \mathrm{Fe} / 3 \mathrm{Cu} / 0.5 \mathrm{~K}$ catalyst had selectivities similar to that obtained with the $100 \mathrm{Fe} / 0.5 \mathrm{~K}$ catalyst. This shows that, in the presence of copper, higher 
potassium loadings are needed to achieve promotional effects on product selectivity.

The optimal promoter levels have not been determined. Obviously higher potassium loadings are needed if the objective is to minimize light gas production, however, the rate of catalyst deactivation increases with potassium addition and it is necessary to achieve a balance between these two conflicting trends. The role of copper is still not completely understood and more detailed studies are required to elucidate its role in Fischer-Tropsch synthesis.

\section{Binder / Support Effect Research}

The effect of addition of silica and alumina as binders (promoters) on catalytic behavior of precipitated iron catalyst with composition $100 \mathrm{Fe} / 5 \mathrm{Cu} / 4.2 \mathrm{~K}$ was studied in a fixed bed reactor. It was found that catalyst activity decreases with addition of either silica or alumina, but its stability increases. Catalysts containing $25 \mathrm{~g}$, or more, of $\mathrm{SiO}_{2}$ per $100 \mathrm{~g}$ of Fe had very good stability, whereas the catalysts with smaller amounts of binder ( 8 parts of $\mathrm{SiO}_{2}$, or $\mathrm{Al}_{2} \mathrm{O}_{3}$, per 100 parts of $\mathrm{Fe}$ ) deactivated during synthesis. The unsupported catalyst (i.e., the catalyst without any binder) had a similar deactivation rate as the two catalysts with small amounts of binder. The water-gas-shift activity decreases with the addition of silica, due to its interaction with potassium, rendering the latter less effective in promoting the WGS reaction.

Hydrocarbon selectivity of all these catalysts was good (low $C_{1}-C_{4}$ fraction) due to their high potassium content. The addition of binder slightly improved the hydrocarbon selectivity of the unsupported catalyst.

\section{Slurry Reactor Kinetic Studies}

Kinetic parameters for the Fischer-Tropsch and water-gas-shift reactions were determined from slurry reactor tests with four catalysts $(100 \mathrm{Fe} / 0.3 \mathrm{Cu} / 0.2 \mathrm{~K}, 100 \mathrm{Fe} / 0.3 \mathrm{Cu} / 0.5 \mathrm{~K}, 100$ $\mathrm{Fe} / 5 \mathrm{Cu} / 4.2 \mathrm{~K} / 24 \mathrm{SiO}_{2}$ and Ruhrchemie LP 33/81). The latter catalyst has a composition similar to the silica containing catalyst synthesized in our laboratory. Only selected mass balances, those made during portions of tests where catalyst activity was fairly stable, were used in the analysis.

Several rate expressions, which included $\mathrm{H}_{2} \mathrm{O}$ and/or $\mathrm{CO}_{2}$ inhibition, were used for each catalyst to model the FT and WGS reaction rates. In all cases, the FT rates were approximately first order with respect to $\mathrm{H}_{2}$, but better fits were obtained using rate expressions which contain water and/or $\mathrm{CO}_{2}$ inhibition. The results showed that water inhibits the $F T$ reaction more strongly than does $\mathrm{CO}_{2}$, and for all catalysts the following rate expression provided a good fit 
of the data

$$
\mathrm{r}_{\mathrm{CO}+\mathrm{H}_{2}}=\mathrm{k}_{\mathrm{O}} \mathrm{P}_{\mathrm{CO}} \mathrm{P}_{\mathrm{H}_{2}} /\left(\mathrm{P}_{\mathrm{CO}}+\mathrm{aP} \mathrm{H}_{2} \mathrm{O}\right)
$$

Other models provided a better fit of the data for some of the catalysts ( $100 \mathrm{Fe} / 5 \mathrm{Cu} / 4.2$ $\mathrm{K} / 24 \mathrm{SiO}_{2}$ and $100 \mathrm{Fe} / 0.3 \mathrm{Cu} / 0.5 \mathrm{~K}$ ), however, even in these cases the above model was quite adequate. The existing data base is insufficient to statistically discriminate among the rival models. Additional experiments would be required to perform such an analysis, however this is difficult to accomplish with catalysts that deactivate fairly rapidly. The underlying causes of the deactivation are not well understood.

The kinetics of the WGS reaction were also studied. A simple first order in CO rate expression provided the best fit to the data obtained with three ( $100 \mathrm{Fe} / 0.3 \mathrm{Cu} / 0.5 \mathrm{~K}, 100$ $\mathrm{Fe} / 5 \mathrm{Cu} / 4.2 \mathrm{~K} / 24 \mathrm{SiO}_{2}$ and Ruhrchemie catalyst), of the four catalyst tested, whereas for the $100 \mathrm{Fe} / 0.3 \mathrm{Cu} / 0.2 \mathrm{~K}$ catalyst the following rate expression provided the best fit

$$
r_{W G S}=k_{w, 0}\left(P_{C O} P_{\mathrm{H}_{2} \mathrm{O}}-P_{\mathrm{CO}_{2}} P_{\mathrm{H}_{2}} / K_{\mathrm{P}}\right) /\left(P_{C O} P_{\mathrm{H}_{2}}-b P_{\mathrm{H}_{2} \mathrm{O}}\right)
$$

The first order in $\mathrm{CO}$ kinetics provided a good fit of the data with this catalyst as well.

\section{Process Evaluation Studies}

Several unsupported $(\mathrm{Fe} / \mathrm{Cu} / \mathrm{K})$ and silica containing catalysts $\left(\mathrm{Fe} / \mathrm{Cu} / \mathrm{K} / \mathrm{SiO}_{2}\right)$ were tested in fixed bed and slurry bed reactors to determine their activity, selectivity and stability with time on stream, and as a function of process conditions. Major highlights from these studies are

- Catalysts containing about 24 parts of $\mathrm{SiO}_{2}$ per 100 parts of $\mathrm{Fe}$ had exhibited very good stability, over 400-500 hours on stream, in both fixed bed and slurry reactor tests, but they were less active than unsupported catalysts. Also, their selectivity toward liquid hydrocarbon products $\left(C_{5}-\right)$ was not as high as that achieved in Mobil's bubble column slurry reactor in high wax mode of operation $(70-75 \%$ vs. $86 \%)$ and methane yields were higher ( $5-6 \%$ vs. $2.7 \%$ ).

- The $100 \mathrm{Fe} / 5 \mathrm{Cu} / 4.2 \mathrm{~K} / 24 \mathrm{SiO}_{2}$ catalyst, synthesized at Texas A\&M University, had higher activity $(\sim 20 \%)$ than commercial Ruhrchemie LP 33/81 catalyst (the state-of-theart catalyst). This catalyst was used initially at SASOL in fixed bed (ARGE) reactors. Both catalysts had similar hydrocarbon selectivities during tests in fixed bed and slurry bed reactors, but the catalyst activity was higher in a fixed bed reactor . 
- Catalysts with low silica content $\left(100 \mathrm{Fe} / 5 \mathrm{Cu} / 4.2 \mathrm{~K} / 8 \mathrm{SiO}_{2}\right)$ or without any silica (100 $\mathrm{Fe} / 3 \mathrm{Cu} / 0.2 \mathrm{~K}$ or $0.5 \mathrm{~K}$, and $100 \mathrm{Fe} / 1 \mathrm{Cu} / 0.2 \mathrm{~K}$ ) had high initial activity, but lacked good stability. Catalyst deactivation was fairly rapid in both fixed bed and slurry bed reactor tests. Hydrocarbon selectivities in some of the tests were better (less $\mathrm{CH}_{4}$ and gaseous hydrocarbons) than those obtained in tests with the catalysts having about 25 parts of $\mathrm{SiO}_{2}$ per 100 parts of $\mathrm{Fe}$. However, stability of these catalysts needs to be improved by using different activation procedures and/or by modifications in their composition.

Catalyst Characterization

One of the tasks of this project was to characterize the precipitated iron catalysts prepared, in order to determine the effects of copper and potassium promoters and of $\mathrm{SiO}_{2}$ and $\mathrm{Al}_{2} \mathrm{O}_{3}$ supports on reduction behaviors and surface properties. A variety of physical and chemical techniques was used to provide a complete characterization of each catalyst prepared. The elemental composition of each synthesized catalyst was determined by atomic absorption spectroscopy; total surface areas and pore size/volume distributions were obtained from physical adsorption and mercury porosimetry measurements, respectively. Reducibilities of bulk iron and copper were studied by temperature-programmed and isothermal reduction methods, using both $\mathrm{H}_{2}$ and $\mathrm{CO}$ reductants. X-ray photoelectron spectroscopy was used to examine surface oxidation states of catalyst components and the influence of promoters, supports, and reduction conditions on surface iron behaviors. Major conclusions from these studies are

- Temperature-programmed and isothermal reduction measurements showed that the promotional effect of copper on the reduction of iron increased with increasing copper content up to 3 wt \% Cu.

- The time required for completion of iron reduction at $300^{\circ} \mathrm{C}$ in either $\mathrm{H}_{2}$ or $\mathrm{CO}$ decreased with increasing copper content.

- The presence of potassium adversely influenced the reducibility in $\mathrm{H}_{2}$ of the precipitated iron catalysts, both with and without copper, possibly due to blockage of nucleation sites by surface potassium. By contrast, the time required for completion of iron reduction by $\mathrm{CO}$ decreased in the presence of potassium.

- $\mathrm{SiO}_{2}$ and $\mathrm{Al}_{2} \mathrm{O}_{3}$ supports exerted an inhibiting effect on the reduction of iron that increased with increasing support content. The inhibition effect was less pronounced for the alumina support than for the silica support.

- X-ray photoelectron spectroscopic results showed that treatments of the precipitated iron 
catalysts at $300^{\circ} \mathrm{C}$ in $\mathrm{H}_{2}$ resulted in marked differences in surface composition than those resulting from treatment in $\mathrm{CO}$. The surfaces of $\mathrm{H}_{2}$-reduced samples were largely covered by a layer of unreduced iron oxide; however, the surfaces of the $\mathrm{CO}$-reduced samples possessed substantial amounts of zero-valent iron.

- Water, generated by reduction of $\mathrm{Fe} / \mathrm{Cu}$ precipitates in $\mathrm{H}_{2}$, caused extensive migration and surface spreading of potassium promoter, an effect not observed when reduction occurred in $\mathrm{CO}$.

\subsection{Recommendations for Future Work}

Some promising results in the area of improved catalyst performance were achieved during the course of work on this contract which warrant additional studies.

(1) Our comprehensive studies of the effect of pretreatment conditions (nature of reductant, temperature and duration) on subsequent catalyst performance have shown that pretreatment conditions can be used to alter hydrocarbon selectivity and/or to provide better stability. With $\mathrm{CO}$ and/or syngas pretreatment it is difficult to achieve catalyst stability over a long period of time. The optimal activation parameters seem to be dependent upon both catalyst composition and reaction conditions and need to be determined by a trial-and-error procedure. In contrast, catalysts activated with hydrogen have high activity and long term stability. More work should be done in slurry reactors using $\mathrm{H}_{2}$ activations . with both unsupported and silica containing catalysts.

Activation studies in fixed bed and slurry bed reactors should be accompanied by comprehensive catalyst characterization studies in order to gain understanding of the underlying reasons for differences in catalytic behavior following different pretreatments.

(2) Addition of silica to potassium promoted precipitated iron catalysts improves catalyst stability without any adverse effect on product selectivity. Further improvements in catalyst performance (enhanced activity and/or selectivity toward transportation fuels) can be achieved by a judicious choice of silica content and promoter levels. Additional studies are needed to assess the potential for use of these catalysts in slurry reactors.

(3) It is recommended that future studies focus more on thorough evaluation of a few selected catalysts (unsupported and silica containing), rather than on a cursory examination of a large number of catalysts. Also, detailed catalyst characterization studies after the catalyst pretreatment and during the synthesis should play an important role in future studies. 


\section{INTRODUCTION}

Several technologies are currently available or are under development for conversion of coalderived synthesis gas to liquid transportation fuels or fuel precursors. Technologies that have been commercially proven or that are close to commercialization include fixed and fluidized bed Fischer-Tropsch (FT) synthesis, methanol synthesis (fixed bed and slurry phase), and Mobil's methanol to gasoline (MTG) process. Of these technologies, FT hydrocarbon synthesis produces the widest slate of products and has been in operation for the longest period. F-T hydrocarbon synthesis was first developed and practiced in Germany during the 1930 s and 1940 s using cobalt catalysts. Subsequently, the process was commercialized on a large scale by SASOL in South Africa. The SASOL process includes both tubular fixed bed (ARGE) and circulating fluidized bed (Synthol) operation and uses promoted iron catalysts (Dry, 1981).

Of the various indirect liquefaction technologies, Fischer-Tropsch synthesis offers many advantages. While hydrocarbon production is generally nonselective and is governed by the so-called Schulz-Flory distribution, the Fischer-Tropsch process has the ability to produce a range of gaseous and liquid hydrocarbon products easily upgraded via conventional refining operations. The fluidized bed reactors at SASOL, for example, maximize gasoline yields while the fixed bed process produces predominantly diesel fuel and hydrocarbon waxes.

In the late 1940s, slurry phase Fischer-Tropsch technology was developed in Germany (Kölbel and Ralek, 1980). Slurry processing provides the ability to more readily remove the heat of reaction, minimizing the temperature rise across the reactor and eliminating localized hot spots. As a result of the improved temperature control, yield losses to methane are reduced and catalyst deactivation due to coking is significantly decreased. This, in turn, allows much higher conversions per pass, minimizing synthesis gas recycle, and offers the potential to operate with $\mathrm{CO}$-rich synthesis gas feeds without the need for prior water-gas shift. Due to the simpler reactor design, capital investment in a slurry phase Fischer-Tropsch reactor is expected to be substantially smaller than in conventional fixed-or fluidized-bed systems. (Gray et al. 1980; Thompson et al., 1981). The slurry process has the ability to produce a variable product slate via changes in catalyst and/or process conditions. One can either maximize the gasoline production or the production of diesel fuels and waxes. This flexibility in the product slate is unique to the slurry phase process.

Economic evaluations of the slurry phase Fischer-Tropsch process have been limited to studies incorporating Kölbel's published data from the Rheinpreussen slurry demonstration 
plant (Gray, et al., 1980; Thompson et al., 1981) and a techno-economic assessment of Mobil's two-stage slurry Fischer-Tropsch/ZSM-5 process (EI Sawy et al., 1984). Sufficient data from processes demonstrated on a large scale are not available to allow an adequate correlation of economic parameters with catalyst activities and selectivities. Furthermore, the relative economic merits of various Fischer-Tropsch product slates have not been adequately quantified. Also, it should be kept in mind that all subsequent attempts to reproduce Kölbel's results (activities and selectivities) were unsuccessful (e.g., Mitra and Roy, 1963; Farley and Ray, 1964; Kuo, 1983, 1985; Zarochak and McDonald, 1987). In all these studies one or more of the following had occurred: (1) catalyst deactivation; (2) catalyst activity was lower than in Kölbel's study; and (3) selectivity was inferior to that reported by Kölbel et al. (1955). The most successful study in a bubble column slurry reactor, other than Kölbel's original work, was made by Mobil (Kuo, 1983, 1985). Even this work was hampered by a variety of operational problems and only a few runs lasted sufficiently long to obtain reliable information on the product distribution and catalyst activity.

III.1. Summary of Previous Work with Iron Catalysts

This summary will focus on results illustrating the current industrial practice (SASOL), the most successful slurry bubble column operation (Rheinpreussen demonstration plant unit) and representative examples of other studies conducted in slurry bed reactors (bubble columns or stirred tank). Process conditions, hydrocarbon product distribution, product yields and information related to catalyst activity, for selected studies, are summarized in Table III-1.

The fixed bed (Arge) reactor at SASOL is used to maximize production of diesel fuel ( $\mathrm{C}_{12^{-}}$ $\mathrm{C}_{18}$ ) and heavy hydrocarbon waxes. This gives low yield of methane $(2 \%)$ and other light hydrocarbons $\left(C_{2}-C_{4}=11.5 \%\right)$, and high yield of $C_{12}+$ products $(68 \%)$. The useful lifetime of the catalyst is reported to be between 9 and 12 months. The entrained bed operation in the Synthol reactor is aimed at maximizing gasoline $\left(\mathrm{C}_{5}-\mathrm{C}_{11}\right.$ hydrocarbons) production, and as a consequence of the high operating temperature the yield of methane is high $(10.6 \%)$ and the yieid of $\mathrm{C}_{12}-$ products is low $(11.7 \%)$. The useful lifetime of the catalyst is about 6 weeks.

The Rheinpreussen demonstration plant performance is regarded as the most successful slurry reactor operation to date (Kölbel et al., 1955). A high single pass conversion was achieved and the catalyst activity was high (STY $=0.106 \mathrm{~mol} / \mathrm{g}$-cat.h). Results shown in Table III-I are for the gasoline mode of production, and as can be seen the yield of $\left(C_{5}-C_{11}\right)$ hydrocarbons obtained in the Rheinpreussen demonstration plant is the highest of all. This was also 
accompanied by low yield of methane + ethane ( $3.2 \%$ only). This product distribution is very unusual and could not be reproduced in any other subsequent studies. In all other studies (regardless of the reactor type) such low methane yields were accompanied by high yields of $\mathrm{C}_{12}+$ products. It should be noted that the reported total yield was only $181 \mathrm{~g} / \mathrm{Nm}^{3}$, which indicates some problems with the product collection and/or analysis. If one assumes that the hydrocarbon yield is $200 \mathrm{~g} / \mathrm{Nm}^{3}$, and that all missing hydrocarbons are $\mathrm{C}_{12}+$, this gives $21.5 \%$ yield of $\mathrm{C}_{12}+$ hydrocarbons. However, even the latter value is still much lower than expected based on low yield of $\mathrm{CH}_{4} \div \mathrm{C}_{2} \mathrm{H}_{6}$. Kölbel and co-workers have not provided any information on the catalyst aging and deactivation. Based on sketchy information given in the literature, Poutsma (1980) estimated that the catalyst lifetime was about 38 days.

Kunugi, who spent several years working with Kölbel, initiated research on FT synthesis in Japan in the early 60's. Sakai and Kunugi (1974) claimed that they were able to verify Kölbel's results related to the yield of hydrocarbons and product selectivities. However, their results shown in Table III-I, do not reflect this claim. Their product distribution is in agreement with the other studies, i.e., low methane yield gives rise to high yield of $C_{12}-$ products.

Selectivities reported by Mobil workers (Kuo, 1983; 1985) for two modes of operation, lowand high-wax mode, follow the usual trends. In the low-wax mode of operation, which was aimed at maximizing the gasoline fraction, methane selectivity was relatively high $(7.9 \%)$ and selectivity of $\mathrm{C}_{12}+$ was relatively low $(26.1 \%)$. On the other hand, in the high-wax mode, the selectivity of methane was low $(2.7 \%)$ and the yield of $C_{12}+$ products was high (68.1\%). These trends are qualitatively similar to those obtained in the commercial operation at SASOL. It is interesting to note that the catalyst composition was the same in both modes of operation, and yet significantly different selectivities were obtained. The only major difference between the two catalysts was in the total surface area. The operating conditions and activation procedures were similar in both cases. Some differences in performance were observed in other runs when a new batch of catalyst was used. This shows that subtle differences in preparation and/or activation may have a significant effect on catalyst activity and stability. Although Mobil's study is regarded as the most successful slurry phase operation after the Rheinpreussen demonstration plant, it was hampered by a variety of operational problems and only 2 out of 13 runs had relatively long periods of steady-state operation. In the run designated CT 256-3 (low-wax mode of operation) the process conditions were fairly constant from 8 to 46 days on stream: $P=1.48 \mathrm{MPa}, \mathrm{H}_{2} / \mathrm{CO}=0.67-0.70, \mathrm{~T}=259-261^{\circ} \mathrm{C}$, and the $\left(\mathrm{H}_{2}-\mathrm{CO}\right)$ conversion was 
'Table III-1. Comparative Catalyst Performance Data

\begin{tabular}{|c|c|c|c|c|c|c|}
\hline & \multicolumn{2}{|c|}{ SASOL (Dry, 1981) } & \multirow{2}{*}{$\begin{array}{l}\text { Kölbel et al. (1955) } \\
\text { Rheinpreussen Plant }\end{array}$} & \multirow{2}{*}{$\begin{array}{c}\text { Sakai and } \\
\text { Kunugi (1974) }\end{array}$} & \multicolumn{2}{|c|}{ MOBIL (Kuo, 1985) } \\
\hline & Arge & Synthol & & & CT $250-3$ & CT 256-13 \\
\hline $\begin{array}{l}\text { Catalyst } \\
\text { Reactor 'Type }{ }^{a}\end{array}$ & $\begin{array}{l}\text { Pptd. } \\
\text { FB }\end{array}$ & $\begin{array}{l}\text { Fused } \\
\text { CFB }\end{array}$ & $\begin{array}{c}100 \mathrm{Fe} / 0.1 \mathrm{Cu} / .05-0.5 \mathrm{~K}_{2} \mathrm{O} \\
\mathrm{BCSR}\end{array}$ & $\begin{array}{c}100 \mathrm{Fe} / 0.3 \mathrm{Cu} / .6-1.2 \mathrm{~K}_{2} \mathrm{O} \\
\text { BCSR }\end{array}$ & $\begin{array}{c}\mathrm{Fe} / \mathrm{Cu} / \mathrm{K}_{2} \mathrm{O} \\
\mathrm{BCSR}\end{array}$ & $\begin{array}{c}\mathrm{Fe} / \mathrm{Cu} / \mathrm{K}_{2} \mathrm{O} \\
\mathrm{BCSR}\end{array}$ \\
\hline \multicolumn{7}{|l|}{ Conditions } \\
\hline Temperature, ${ }^{\circ} \mathrm{C}$ & 220 & $\overline{325}$ & 268 . & 273 & 260 & 258 \\
\hline Pressure, atm & 25 & 25 & 12 & 10.8 & 15 & 15 \\
\hline $\mathrm{SV}, \mathrm{Nl} / \mathrm{g} \cdot \mathrm{Fe} / \mathrm{h}$ & - & - & 3.4 & 12.1 & 2.6 & 2.4 \\
\hline $\mathrm{II}_{2} ; \mathrm{CO}$ ratio & $1.3-2.0$ & $>2.0$ & 0.67 & 0.52 & 0.67 & 0.67 \\
\hline \multicolumn{7}{|l|}{ Activily } \\
\hline $\mathrm{CO}+\mathrm{II}_{2}$ conv. (\%) & - & - & 89.0 & $78.5(\mathrm{CO})$ & 86.8 & 82.2 \\
\hline $\mathrm{mol} / \mathrm{g}-\mathrm{cat} / \mathrm{h}$ & - & - & .106 & - & .070 & .061 \\
\hline $\mathrm{Nm}^{3} / \mathrm{kg}-\mathrm{Fe} / \mathrm{h}$ & - & - & 3.02 & - & 2.25 & 1.97 \\
\hline \multicolumn{7}{|l|}{ Selectivity, wt.\% } \\
\hline $\mathrm{C}_{1}$ & 2.0 & 10.6 & $3.2\left(\mathrm{CH}_{4}+\mathrm{C}_{2} \mathrm{H}_{6}\right)$ & 2.3 & 7.8 & 2.7 \\
\hline $\mathrm{C}_{2}-\mathrm{C}_{4}$ & 11.2 & 35.2 & 31.3 & 8.2 & 24.5 & 11.1 \\
\hline$C_{5}-C_{11}$ & 18.6 & 42.5 & 53.6 & $4.7\left(C_{5}-C_{9}\right)$ & 41.5 & 18.1 \\
\hline $\mathrm{C}_{12}-\mathrm{C}_{18}$ & 14.5 & 7.5 & 10.0 & $12.8\left(\mathrm{C}_{10}-\mathrm{C}_{18}\right)$ & 15.4 & 10.2 \\
\hline $\mathrm{C}_{19}+$ & 53.7 & 4.2 & 1.9 & 71.9 & 10.8 & 57.9 \\
\hline $\mathrm{C}_{12}+$ & 68.2 & 11.7 & 11.9 & $84.7\left(\mathrm{C}_{10}+\right)$ & 26.2 & 68.1 \\
\hline \multicolumn{7}{|l|}{ Producl Yjeld } \\
\hline $\mathrm{g}$-IIC/N $\mathrm{m}^{3}$ converted & - & - & 178 & 151.8 & 197 & 206 \\
\hline $\mathrm{g}-11 \mathrm{C} / \mathrm{g}-\mathrm{Fe} / \mathrm{h}$ & 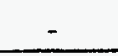 & 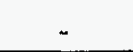 & .57 & - & .37 & .41 \\
\hline
\end{tabular}

a FB - fixed bed, CFB - circulating fluidized bed, BCSR - bubble column slurry reactor 
Table III-1. (contd.) Comparative Catalyst Performance Data

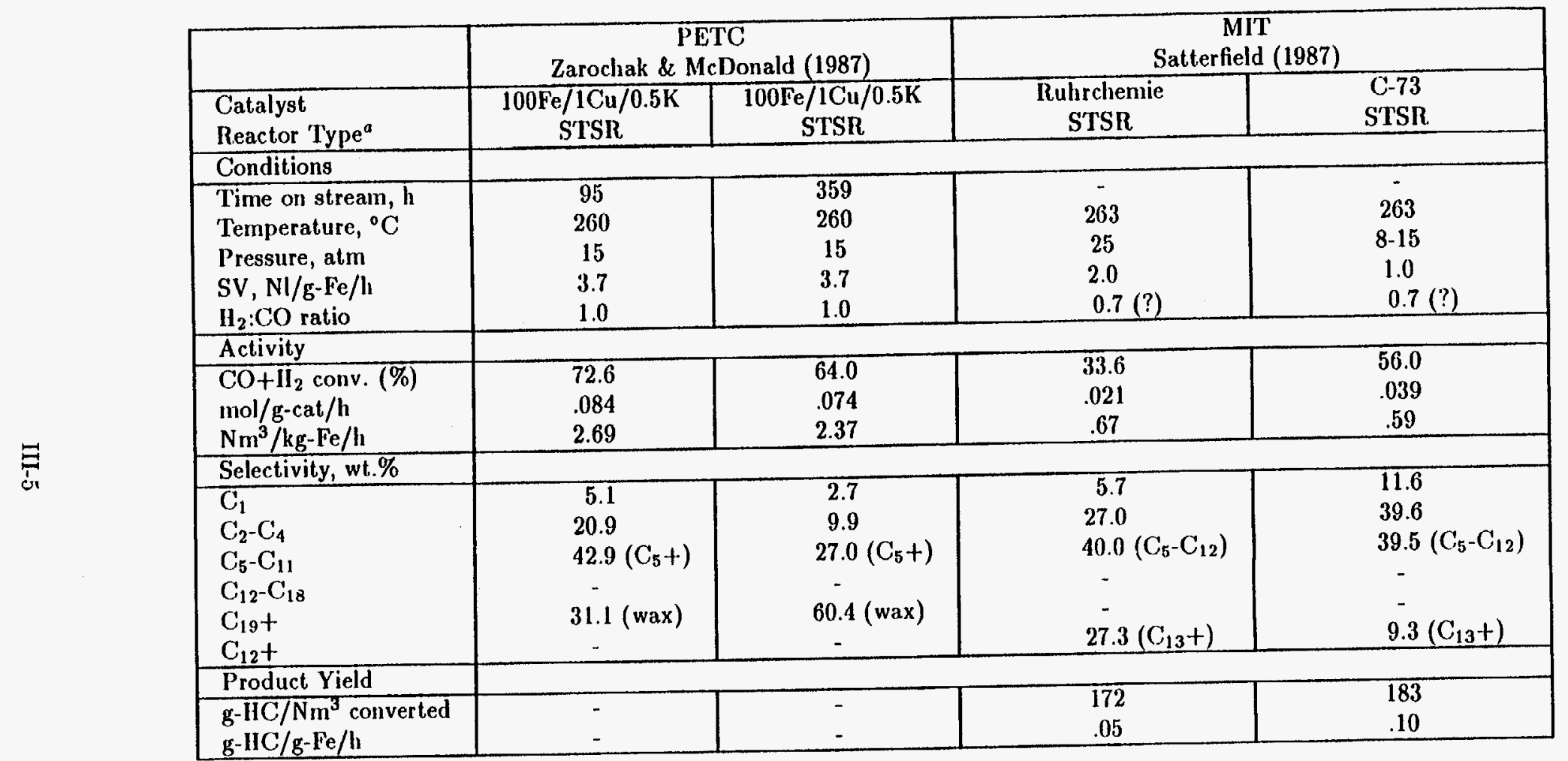

${ }^{a}$ STSR - stirred tank slurry resctor 
maintained at about $87 \%$ by gradually decreasing the gas space velocity from 2.6 to $2.2 \mathrm{NI} / \mathrm{g}$ $\mathrm{Fe} / \mathrm{h}$. After 46 days the loss in activity was compensated by raising the operating temperature $\left(261-266^{\circ} \mathrm{C}\right)$ and by decreasing the gas flow rate. Mobil (Kuo, 1983, p. 211) estimates a catalyst life of 60-70 days. The longest period of operation in the high wax mode was 35 days. At $1.48-1.65 \mathrm{MPa}, 257^{\circ} \mathrm{C}, \mathrm{H}_{2} / \mathrm{CO}=0.7$ and $2.4 \mathrm{NI} / \mathrm{g}-\mathrm{Fe} / \mathrm{h}$ the $\left(\mathrm{H}_{2}+\mathrm{CO}\right)$ conversion was $83 \%$ (1.48 MPa) at $9 \mathrm{DOS}$ (days on stream) and it decreased to $79.0 \%$ at $28 \mathrm{DOS}(\mathrm{P}=1.65 \mathrm{MPa}$ ), indicating some catalyst deactivation. After that, conversion started to decrease more rapidly reaching $67.9 \%$ at 34 DOS, which was followed by catalyst settling and termination of the run.

Results from the most successful run at the US DOE Pittsburgh Energy Technology Center (PETC) are shown in Table III-1. This run is characterized by a relatively low catalyst deactivation rate. However, the hydrocarbon product distribution changed dramatically during the run, and more higher molecular weight hydrocarbons were produced as the catalyst aged. Product distributions at 95 and $359 \mathrm{~h}$ on stream exhibit the usual trend, i.e., low methane yield co. incides with high yield of heavy hydrocarbons. Different activation (pretreatment) procedures with this and similar catalysts resulted in much higher deactivation rates.

Finally, results obtained by Satterfield and co-workers at MIT with commercial catalysts: C-73 (fused iron catalyst for ammonia synthesis) and the Ruhrchemie catalyst (precipitated iron catalyst that was used initially in the Arge reactors at SASOL), are also included for comparison. Selectivity of the Ruhrchemie catalyst is similar to that of the Mobil catalyst I-B in a low wax mode, whereas selectivity of the $C-73$ catalyst is similar to that obtained from the Synthol reactor at SASOL. Activities of these two catalysts are significantly lower than those of the other catalysts listed in Table III-1.

\section{III.2. Overview}

Results obtained by Kölbel and co-workers on the catalyst productivity and selectivity, have not been achieved in any of the subsequent studies. The catalyst employed in Rheinpreussen demonstration plant produced simultaneously low yields of methane - ethane and $\mathrm{C}_{12}$ - products, and high yield of gasoline $\left(C_{5}-C_{11}\right)$. In all other studies, a low yield of methane was accompanied by a high yield of $\mathrm{C}_{12}-$ products (mostly wax). The useful lifetime of catalysts with $\mathrm{CO}$ rich syngas in slurry bed reactors appears to be 30-60 days. However, there are no data on actual aging rates. In relatively long runs, loss in activity was compensated for by increasing reaction temperature and/or by decreasing gas space velocity. The maximum yield of transportation fuels, $C_{5}-C_{18}$ hydrocarbons, based on classical Anderson-Schulz-Flory (ASF) 
distribution, is about $66 \%$, corresponding to $\alpha=0.816$ (chain growth probability factor). This yield was nearly achieved in Rheinpreussen demonstration plant, and was slightly exceeded in Mobil's low wax operation mode. An alternative way to increase total transportation fuel yield is through maximization of the reactor-wax yield, while simultaneously minimizing the light gas yield. The reactor-wax can be easily upgraded via conventional processes into high quality diesel fuel. The overall goal of our study was to develop improved catalysts which would show enhanced activity and/or better selectivity (low methane and high wax yield) in comparison to the known catalysts for Fischer-Tropsch synthesis. 


\section{EXPERIMENTAL}

\section{IV.1. Fixed Bed and Slurry Reactor Systems}

\section{Fixed Bed Reactor}

Two gas phase reactors were used for catalyst testing. A simplified flow diagram of one of these reactors is shown in Figure IV-1.

A section of the system, including the preheater, reactor, exit line, system pressure regulator, and product traps, is assembled in a vertical configuration with flow in a downward direction. Inert ( $\mathrm{N}_{2}$ or $\left.\mathrm{He}\right)$ and process $\left(\mathrm{H}_{2}, \mathrm{CO}\right.$ or premixed synthesis gas) gases are delivered to the reactor through a thermal mass flow controller equipped with a digital meter readout. Flow ranges are $0-500$ SCCM. Two purification traps are located upstream of the flow controller. One is filled with copper alumina catalyst and the other is filled with alumina beads, for removing traces of oxygen and for decomposing carbonyls present in the feed gas mixture, respectively.

The reactors are made of 0.500 in OD by 0.049 in wall 316 SS seamless tubing with flange connections welded at either end with an effective bed volume of $30 \mathrm{cc}$. Two aluminum heating blocks, 2.5 in $O D$ by 0.5 in ID are bolted to the reactor tube and wrapped with a heating tape. A thermocouple is located inside each heating block midway along its length and midway across its radius. This thermocouple serves as the sensor for a temperature programmer, which is capable of multiramp operation at effective heating rates from 0 to about $30^{\circ} \mathrm{C} / \mathrm{min}$. Actual bed temperatures are monitored by thermocouples installed radially in the reactor tube. The five thermocouples are spaced at 2.5 in intervals to span the entire bed length. A reactor bypass is valved into the system and is used for calibration of feed gas flow and composition. The exit line, including the body of the system back pressure regulator (BPR), is wrapped with heating tape from the reactor to the product trap. A temperature controller is used to maintain the temperature at about $110^{\circ} \mathrm{C}$.

Two product collection traps are located downstream of the reactor (high pressure traps) and two low pressure traps are located downstream of the BPR. Product flow may be directed to either trap by turning two 3-way ball valves. In this manner, one trap can serve for product collection during material balance periods (SS trap) while the second trap can serve as a waste trap (USS trap) for collecting products during times when material balances are not necessary (e.g., during changes in reactor conditions). High pressure traps are maintained at $140-210^{\circ} \mathrm{C}$ to remove high molecular weight products which are solids at room temperature. The low 


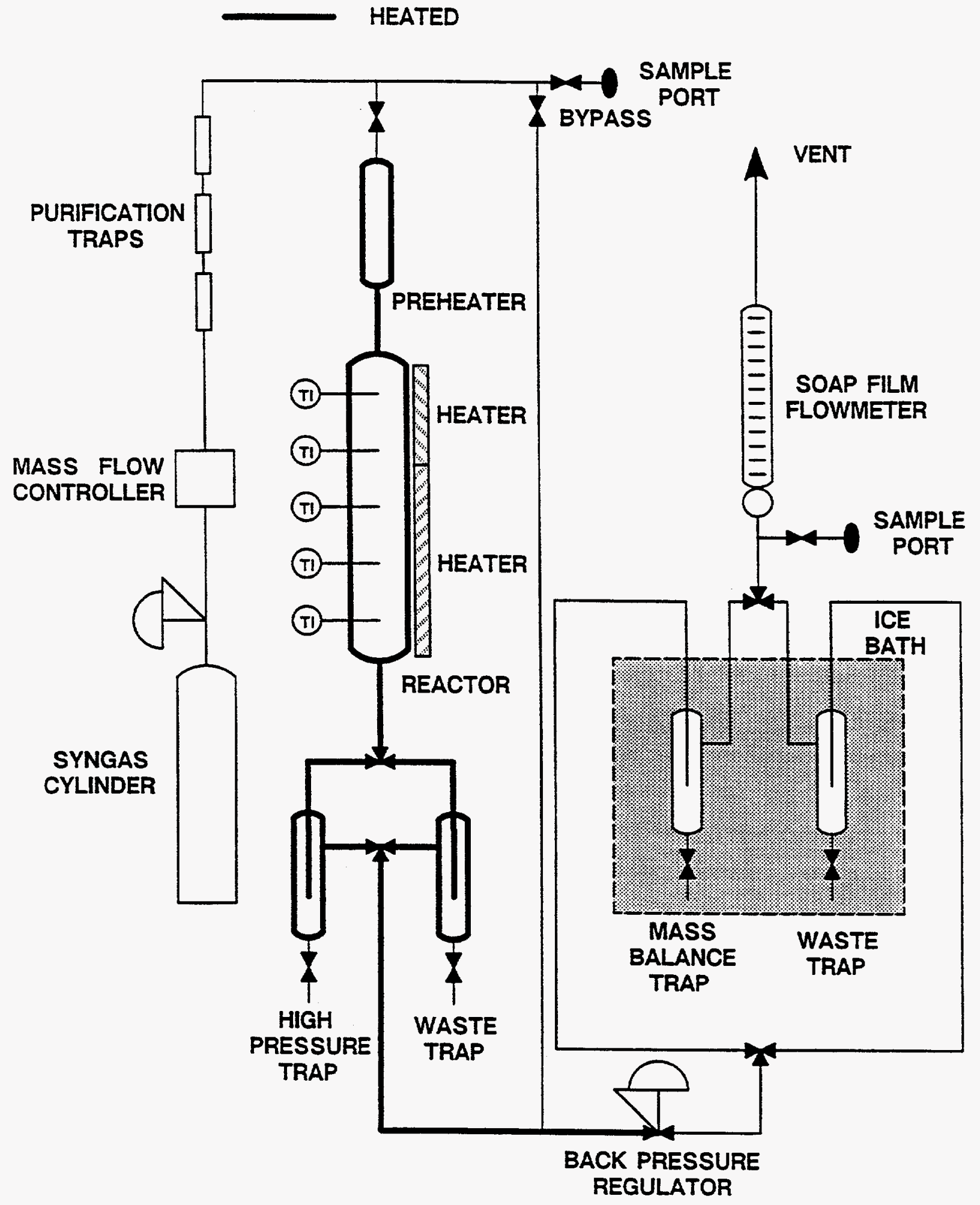

Figure $N-1$. Schematic of the fixed bed reactor system 
pressure traps are immersed in an ice water bath so as to condense out organics. While the low pressure steady state trap is made of glass, the other traps are constructed of 304 stainless steel. Each trap has a volume of approximately $75 \mathrm{ml}$. Following the ice traps, noncondensed gas is directed to either a wet test meter or a soap bubble meter. A septum tee is located just before the wet test meter so that gas samples may be taken. Additional components are included in the system for reasons of safety, process control and convenience.

Pressure relief valves and gauges are located on both high and low pressure sides of the system. The pressure switch located on the high pressure side shuts off power and gas flow to the system in the event either a high or low setpoint is exceeded. A low setpoint bypass permits operation at ambient pressures. Each heated zone is protected by a temperature alarm in addition to a controller. Separate thermocouples are used for the alarms, which shut off the system if a high setpoint is exceeded. Solenoid shutoff valves are located on all gas lines supplying the reactor. A multipoint recorder provides a permanent record of system pressure and temperatures during a run.

\section{Slurry Reactor Apparatus}

Two slurry reactors were employed for long term catalyst testing and kinetic studies. A schematic representation of one of these 1-liter Autoclave reactors is shown in Figure IV-2. Feed $\mathrm{CO}$ and $\mathrm{H}_{2}$ are supplied to the system after passing through a series of oxygen removal, drying, and carbonyl removal traps. The gas flow rate and $\mathrm{H}_{2}$ to $\mathrm{CO}$ feed ratio are controlled using a mass flow controller for each feed gas. The reactor is fully baffled, and the gas inlet point is directly beneath the flat bladed impeller to maximize gas shear.

Products, together with unreacted synthesis gas, are taken overhead through a heated partial reflux condenser, maintained at a temperature of about $200^{\circ} \mathrm{C}$ in order to return vaporized slurry oil to the reactor and minimize the carry over of high boiling products. As gases rise in the condenser they become enriched in low boiling point species, while the high boiling species condense. When enough liquid has condensed, the pressure head developed in the condenser allows for a continuous return of liquid to the reactor. An internal thermocouple is situated along the condenser height to monitor temperature changes. This allows for close temperature control to prevent liquid accumulation due to too low a temperature, and oil carry over and cracking due to too high a temperature.

The slurry level in the reactor is controlled by withdrawing accumulated reactor wax at the end of each mass balance period. The reactor wax is removed either through a $5 \mu \mathrm{m}$, 


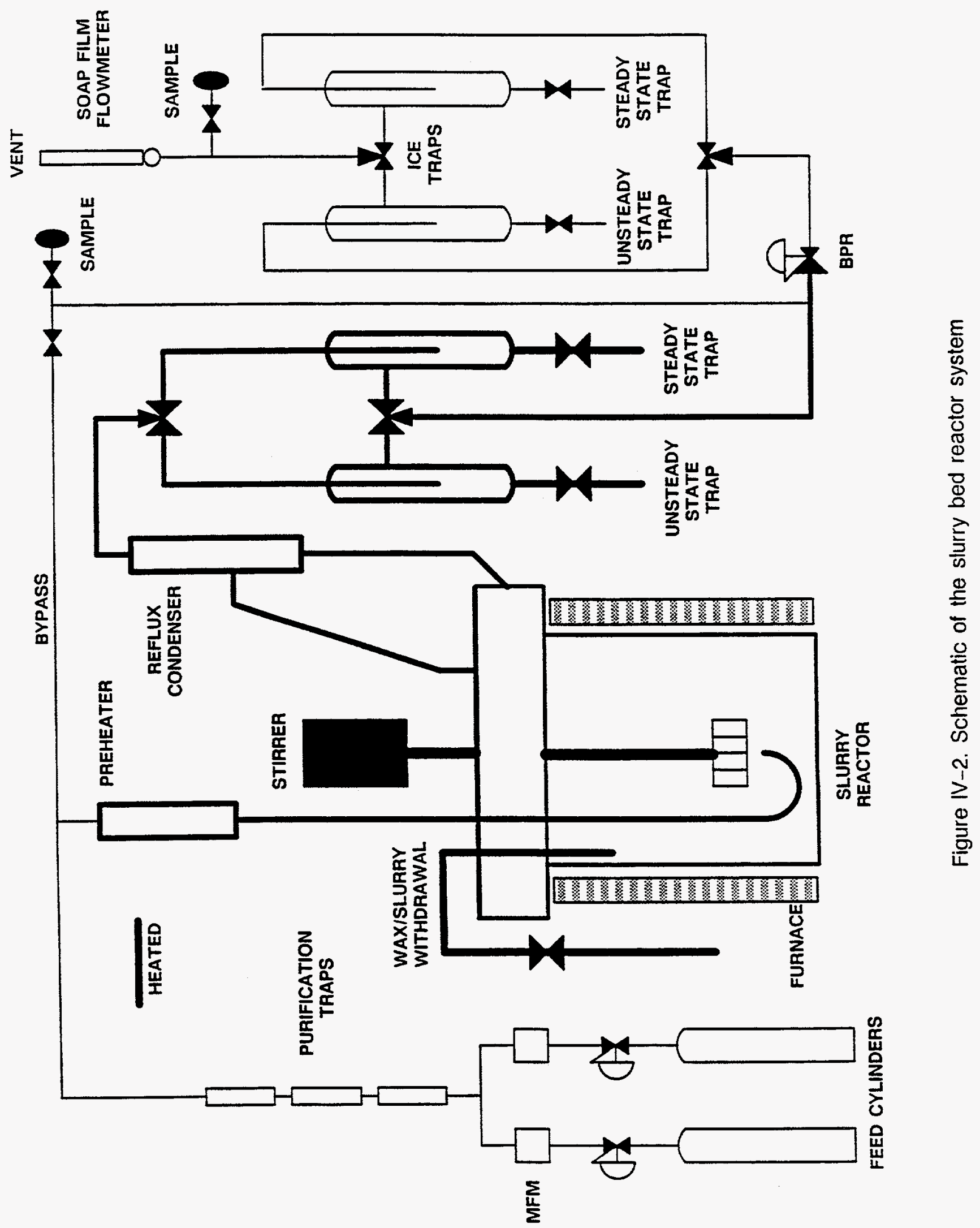


0.5 " OD metal filter located internal to the reactor, or through a dip tube into an external settling tank, which is located vertically at the top of the reactor. The rise in slurry level is due to the accumulation of high molecular weight products in the reaction during synthesis. By determining the amount of reactor wax withdrawn to maintain a constant level at a particular set of process conditions, the higher molecular weight hydrocarbons that do not distill with the gas phase product can be quantitatively included in the material balance. This procedure is essential for obtaining an accurate overall product distribution.

The product stream from the partial reflux condenser flows via heated lines to either a SS or an USS high pressure trap, back pressure regulator, and then to either a SS or an USS low pressure trap. The high pressure traps are maintained at a temperature of about $90^{\circ} \mathrm{C}$ with heating tapes, while the low pressure traps are placed in an ice bath. During a mass balance period, flow is diverted to the SS traps, and during USS and change over periods the product gases flow through the USS traps. The uncondensable gas is directed to either a wet test meter or a soap bubble meter.

Both of the 1-iiter reactor systems are designed to run continuously and automatically, with a minimum of required operator attendance. The reactor head and reactor furnace temperature are controlled from separate, independent controllers; other heaters for the preheater, reflux condenser, high pressure traps and outlet lines are controlled by separate variacs. All system temperatures are monitored by type $J$ or type $E$ thermocouples. System pressure is monitored with a pressure transducer on the reactor inlet line, and the feed flowrate is obtained as a $0-5$ $V$ signal from the mass flow controller.

The slurry reactor $A$ utilizes a multipoint recorder for recording the system temperatures and pressures during a run. The slurry reactor $B$ utilizes an IBM-PC based data acquisition/control system to monitor process variables, implement alarms, and provide simple temperature control. All computer interface hardware was purchased from Interactive Microware, Inc. (State College, $P A)$. An ADALAB-PC board provides for the interface between the computer and reactor system. Additional 16-channel and 32-channel multiplexer boards provide up to 48 channels of analog input, 8 bits of digital input, and 8 bits of digital output. An additional 8 bits of digital output are available directly from the ADALAB-PC board. A 16-channel relay board, using the 16 bits of digital output, is used to drive relays for alarms and temperature control. In the event of an excessively high reactor temperature, or abnormally high or low system pressure, the computer initiates a controlled shutdown by cutting all power to heaters and turns off the 
reactor stirrer.

\section{IV.2. Experimental Procedure and Product Collection}

\section{IV.2.1. Fixed Bed Operating Procedure}

Prior to loading, the catalyst is crushed and sieved to $30 / 60$ mesh. A 3 to $5 \mathrm{cc}$ sample of catalyst and $24 \mathrm{cc}$ of glass beads of the same mesh size range are mixed and loaded into the reactor using glass wool plugs to fix and contain the catalyst bed. In order to minimize axial temperature gradient, catalyst loading is varied along the length of the reactor, with dilute catalyst concentrations at the inlet region of the bed. The system is then pressurized to 600 psig and leak tested. Following depressurization, the reactor is heated to $150^{\circ} \mathrm{C}$ and purged with helium for 2 hours. Depending upon the activation procedure being used, the appropriate gas is introduced and the temperature raised to the desired value. Following activation (reduction), the flow is switched to helium and the bed is cooled down to $190^{\circ} \mathrm{C}$. The system is then pressurized to a desired operating pressure, the helium flow is cut off, and synthesis gas is introduced at a desired gas space velocity. The bed temperature is gradually increased to the desired value and then the reactor is allowed to run uninterrupted for at least $40 \mathrm{~h}$ before making the first mass balance.

To begin the material balance, the gas flow is diverted to tared sample (SS) traps. Material balance periods are typically 6-8 hours in length. During this time, two exit gas samples are analyzed by GC. The product flow rate is periodically measured and recorded. At the completion of the balance, product flow is diverted to the waste traps. The low pressure steady state product trap is removed from the system and is allowed to equilibrate to room temperature. The external surface of the trap is wiped clean and the weight of the trap is recorded. The contents of the trap are then drained and separated into an aqueous and organic layer. The trap is then washed with hot toluene and purged with $N_{2}$, and is then tared and replaced into the system. The contents of the high pressure SS trap are drained and weighed. These products are generally solid at ambient temperature. The liquid and solid products collected are analyzed by gas chromatography.

\section{IV.2.2. Slurry Reactor Operating Procedure}

The catalyst is generally ground to less than 325 mesh, and is loaded into the reactor with an excess of n-octacosane (or FT-300 paraffin wax). n-octacosane is purified with tetrahydrofuran and air dried prior to use. The system is then pressurized to 600 psig and leak tested. Following depressurization, the reactor is heated to $150^{\circ} \mathrm{C}$ and purged with helium for 2 hours. 
Depending on the activation procedure being used, appropriate gas is introduced and the reactor temperature raised to the desired value. Following activation, excess wax is withdrawn from the reactor. The flow is switched to helium and the bed is cooled down to less than $220^{\circ} \mathrm{C}$. The system is then pressurized to the desired operating pressure, the helium flow is cut off, and the synthesis gas feed is introduced at desired flow rate. Then, the reactor temperature is increased to the desired value.

The reactor is allowed to run uninterrupted for at least $40 \mathrm{~h}$ before initiating the first mass balance. The tasks related to products collection are similar to those described for fixed bed reactor. At the end of mass balance period, the excess wax is withdrawn from the reactor to estimate the wax production.

\section{V.3. Product Analysis System}

A versatile analytical and computerized data handling system has been developed for this program. The system consists of four separate gas chromatographs linked to a data acquisition system (Figure IV-3).

(a) Product Gas

Unreacted $\mathrm{H}_{2}, \mathrm{CO}$ and product $\mathrm{CO}_{2}$ and $\mathrm{C}_{1}-\mathrm{C}_{5}$ hydrocarbons are analyzed on the Carle AGC-400 chromatograph. Small amounts of $C_{6}$ and higher hydrocarbons, and light oxygenates which are not condensed in the cold trap, are analyzed by a Sigma 1B chromatograph equipped with a Porapak $Q$ column. Analyses from the Carle and Sigma $1 B$ are combined using suitable tie components.

(b) Aqueous Phase

The liquid product is separated into two parts, an aqueous and organic layer. Each of these layers is analyzed independently. The aqueous layer is analyzed on a $0.2 \%$ Carbowax 1500 on Carbopack $C\left(6^{\prime} \times 2 \mathrm{~mm}\right.$ glass column) using an FID. This column is housed in the Sigma IB chromatograph. The aqueous layer is analyzed for $C_{1}$ to $C_{6}$ alcohols, $C_{2}$ to $C_{4}$ aldehydes, $\mathrm{C}_{3}-\mathrm{C}_{6}$ ketones and carboxylic acids. The water content of the sample is determined using a Karl-Fischer titrator.

\section{(c) Organic Phase}

The organic sample dissolved in $\mathrm{CS}_{2}$ is separated on a $.20 \mathrm{~mm} \times 30 \mathrm{~m}$ fused silica column coated with $0.1 \mu \mathrm{m}$ DB-5 (J\&W Scientific) and analyzed on an FID. located within the Sigma 1 chromatograph. The organic sample is analyzed for $C_{5}$ to $C_{30}$ hydrocarbons, $C_{4}$ to $C_{11}$ alcohols, $C_{3}$ to $C_{6}$ ketones and $C_{2}-C_{6}$ aldehydes. 


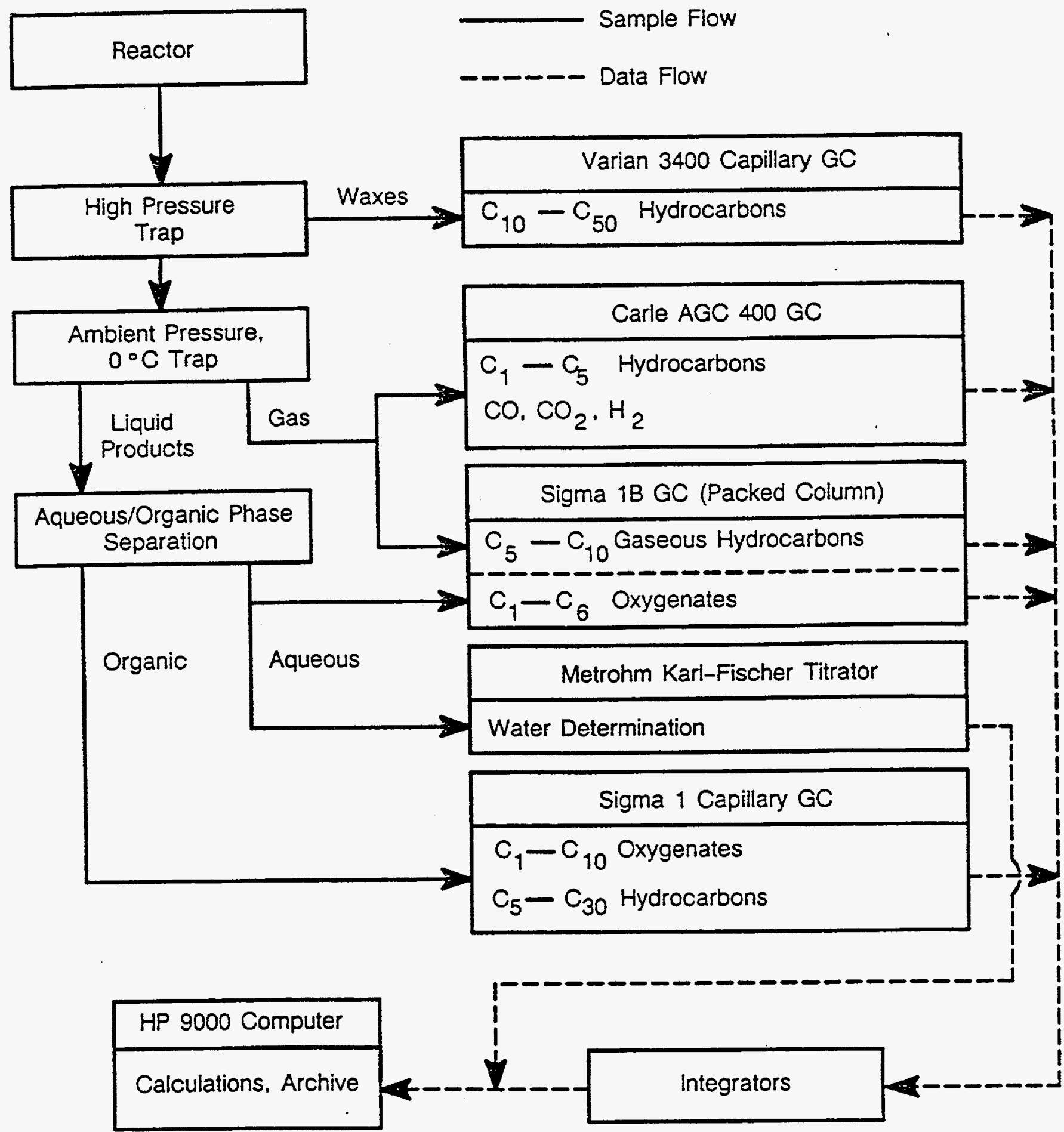

Figure IV-3. G. C. analysis scheme 
(d) Wax Fraction

The wax fraction, dissolved in $\mathrm{CS}_{2}$ or other organic solvent is analyzed on the Varian 3400 chromatograph. Here, a $10 \mathrm{~m} \times 0.53 \mathrm{~mm}$ fused silica column coated with $0.25 \mu \mathrm{m}$ RSL-150 (Alltech) and an FID are employed. The wax fraction is analyzed for hydrocarbons up to $C_{60}$.

For all samples, components were initially identified by mass spectrometry, peak spiking, and/or retention time comparisons to known standards.

\section{IV.3.1. Response Factors and Retention Times}

Response factors and retention times were determined for a large number of gas and aqueous phase components. Analyzed gas mixtures were used as standards for gas phase calibration while aqueous phase calibration standards were prepared from mixtures of pure components. Gas phase calibration involved injection of the analyzed gas mixture into the chromatograph using a gas tight syringe. Response factors for these components were determined from the following equations:

$$
\begin{array}{ll}
R F_{i}^{\prime}=A R E A_{i} /(\text { Mole } \%)_{i} N_{i} & (I V-1) \\
R F_{i}=R F_{i}^{\prime} / R F_{\text {ref }}^{\prime} & \text {. }(I V-2)
\end{array}
$$

where: $\mathrm{RF}^{\prime}$ is the response factor relative to the sample; AREA is the peak area of integration; (Mole \%) $i$ is the concentration of component $i$ in the standard; $N_{i}$ is the number of carbon atoms in component $i\left(\mathrm{~N}=\mathrm{I}\right.$ for $\left.\mathrm{H}_{2}\right)$; $R F^{\prime}$ ref is the response factor of a reference component and $R_{i}$ is the calculated, normalized response factor of species $i$.

For gas phase analyses, the standards provided a range of concentrations which allowed for check of linearity in the detector signal. It was determined that all responses were linear over the ranges of interest ( 0.1 to 10 mole percent for hydrocarbons, 1 to 50 percent for $\mathrm{CO}, \mathrm{H}_{2}$ ).

Response factors and retention times for aqueous phase components expected in FischerTropsch product were obtained using a Sigma 1B chromatograph equipped with an FID. Standards were prepared by combining known quantities of pure components. Response factors were calculated using equations IV-1 and IV-2. 1-hexanol was used as the reference component, due to its relatively low volatility. Mixtures of selected components were diluted in excess of a factor of 50 with respect to $n$-hexanol so as to check for response linearity. The detector response was determined to be linear over the range of interest. Response factors and retention 
times for organic phase components of interest expected in Fischer-Tropsch product were obtained using a Sigma 1 chromatograph equipped with an FID. These components include $\mathrm{C}_{6}$ $C_{30}$ n-paraffins, $C_{6}-C_{20} \alpha$-olefins, $C_{4}-C_{10}$ n-alcohols and $C_{6}-C_{8}$ aromatics. Response factors for these components were determined from equations VI-1 and VI-2. Typically all n-paraffins and 1-olefins present in the calibration sample whose $\mathrm{RF}_{1}$, value was $10 \%$ of the average were used in calculation of RF' ${ }_{\text {ref }}$.

Response factors for hydrocarbons from $C_{7}$ up to $C_{20}$ were found to be approximately equal to 1.0. Response factors for $C_{6}$ to $C_{8}$ aromatics were determined relative to n-paraffins. Response factors for these components were found to be 1.0 . Response factors for $C_{4}$ to $C_{10}$ $n$-alcohois were determined relative to $n$-paraffins.

Response factors and retention times for the wax phase components of interest expected in a Fischer-Tropsch product were obtained using a Varian 3400 GC equipped with an FID. The wax standard used contained selected $C_{16}-C_{44}$ n-paraffins and 1-eicosene $\left(C_{20}\right)$ in approximately equal weight fractions dissolved in $\mathrm{CS}_{2}$ to about $6 \mathrm{mg} / \mathrm{ml}$. An internal standard ( $\mathrm{n}$-hexadecane) was used to calculate absolute weight fractions of wax samples. The wax, with approximately $10 \mathrm{wt} \% \mathrm{n}$-hexadecane, was dissolved in $\mathrm{CS}_{2}$. The presence of the internal standard permits absolute weight fractions to be calculated directly from the peak areas and response factors of a given sample.

\section{N.4. Data Reduction System}

Perkin Elmer Sigma 1B, Sigma 15 and Hewlett-Packard 3390 integrators are used to collect and integrate the data obtained from the gas chromatographs. The results are then transferred to a Hewlett-Packard (HP) 9000 series mini computer for further analysis and reduction. The overall flow of data and results is shown in Figure IV-4. The data reduction system consists of peak identification routines and mass balance programs.

Peak identification programs identify gas and liquid phase Fischer-Tropsch product composition on the basis of the retention times of the components. By using the software, the product analysis is done automatically. After data processing, the output is checked for possible errors in identification.

The mass balance program uses templates to prompt the operator to enter the needed information: run designations, catalyst, reactor unit, temperatures, pressure, flow rates, sample time, weight of samples collected, and the locations of peak analysis files from the chromatographs. Compound names, formulas, molecular weights, and calibration data for each 


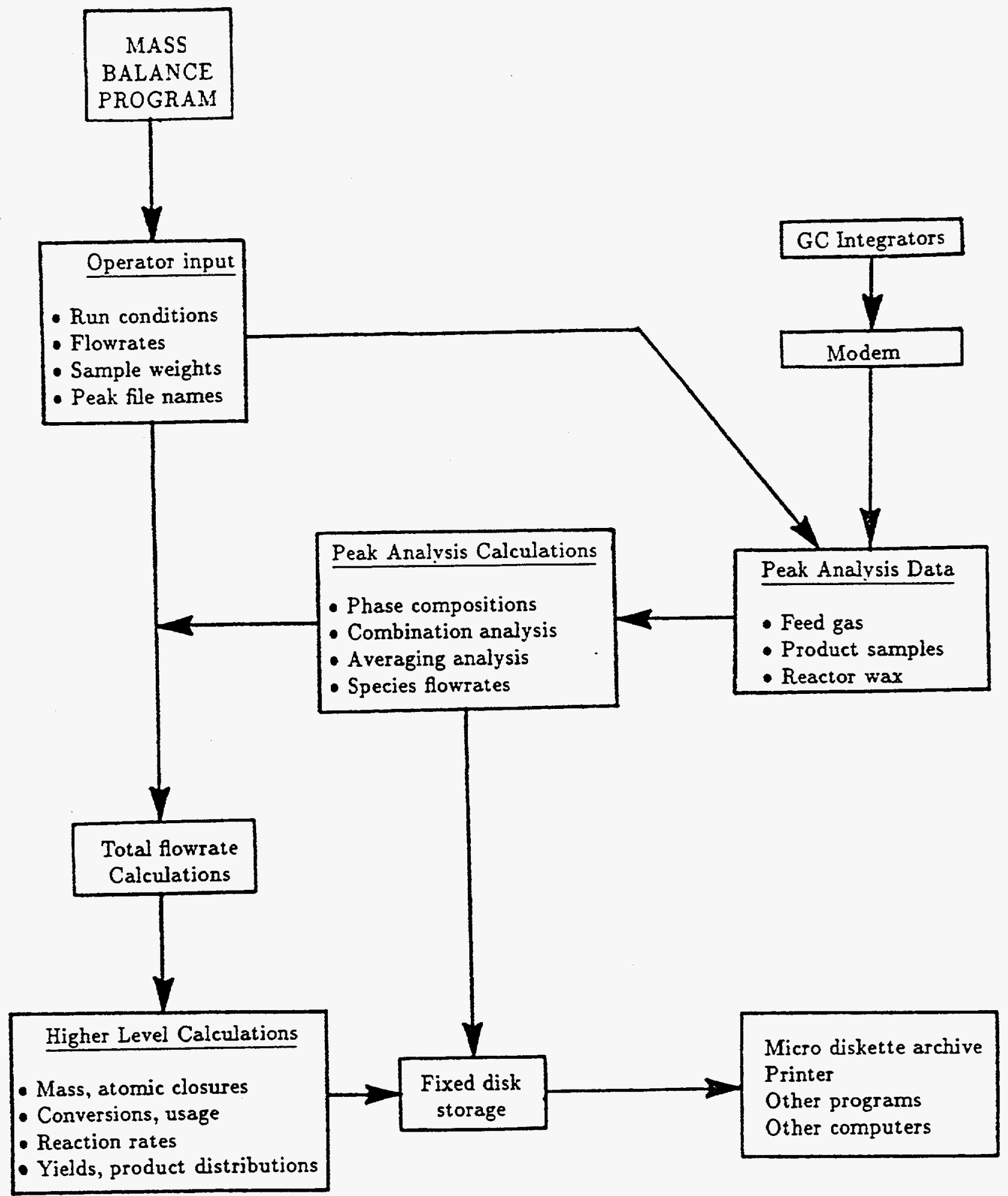

Figure IV-4. Flow diagram of the mass balance computer program 
chromatograph are stored in data base files. The operator supplied data and peak analysis data along with calculated results are stored on fixed disk. For safe keeping, these files are also stored on removable microdiskettes.

The program is designed to handle up to 50 classes of products, with up to 100 members in each class. At the present time, the program considers paraffins, olefins, alcohols, and their major isomers, certain aromatics, organic acids, aldehydes, ketones, and esters, as well as $\mathrm{H}_{2}$, $\mathrm{H}_{2} \mathrm{O}, \mathrm{CO}, \mathrm{CO}_{2}$, and $\mathrm{N}_{2}$.

Five types of streams: feed gas, aqueous liquid product, organic liquid product, reactor tail gas, and reactor wax are considered by the program. The program uses peak area files transferred from the chromatograph integrators and data base GC calibration files to determine the composition of each stream. Using measured sample weights, the program can calculate individual species flow rates and arrive at total inlet and outlet mass and mole flows of all identified compounds. Combination of two different analyses of the same phase, which occurs for the gas product stream, and averaging of multiple analyses, is done automatically. The material balance program calculates mass and atomic balance closures, yields and selectivities of products, and lumps products according to carbon numbers. These data are useful for comparison of results obtained under different process conditions and are presented in the form of tables. The program also calculates the Anderson-Schulz-Flory (ASF) chain growth parameter and produce ASF plots from which deviations from the ASF distribution can be observed.

IV.5. Coding System for Runs

All run numbers have the following format:

$$
\text { (Reactor Unit)-(Catalyst)-(Date)(Year) }
$$

(Reactor Unit) refers to the reactor system used during the run: FA or FB for fixed bed reactors $A$ or $B$, respectively; $S A$ or $S B$ for slurry reactors $A$ or $B$ respectively. (Catalyst) is a two digit code used to reference each catalyst. This code is suffixed with a '.2' when catalyst from a second batch is used. The codes for the commercial, promoter effect series and binder/support precipitated catalysts are given in Table IV.1. (Date) refers to the day of the year corresponding to the start data of the run. Finally (Year) corresponds to the last digit in the year of the start date, (e.g., 7 for 1987, 8 for 1988, etc.). For example, a run using United Catalyst C-73 fused iron in fixed bed reactor A, beginning March 22, 1987 would be designated as: FA-01-0817. 
Table IV-5. Catalyst Codes for Run Designations

Nominal Compositions

\begin{tabular}{|c|c|c|c|c|}
\hline $\mathrm{Fe}$ & $\mathrm{Cu}$ & $\mathrm{K}$ & Support & Code \\
\hline \multicolumn{3}{|c|}{ United Catalyst C-73 } & & 01 \\
\hline 100 & 0.0 & 0.00 & & 00 \\
\hline 100 & 0.0 & 0.01 & & 41 \\
\hline 100 & 0.0 & 0.02 & & 42 \\
\hline 100 & 0.0 & 0.05 & & 43 \\
\hline 105 & 0.0 & 0.10 & & 44 \\
\hline 100 & 0.0 & 0.20 & & 45 \\
\hline 100 & 0.0 & 0.50 & & 46 \\
\hline 100 & 0.0 & 1.00 & & 47 \\
\hline 100 & 0.0 & 2.00 & & 48 \\
\hline 100 & 0.3 & 0.00 & & 32 \\
\hline 100 & 0.3 & 0.05 & & 03 \\
\hline 100 & 0.3 & 0.20 & & 05 \\
\hline 100 & 0.3 & 0.50 & & 07 \\
\hline 100 & 1.0 & 0.00 & & 33 \\
\hline 100 & 1.0 & 0.05 & & 13 \\
\hline 100 & 1.0 & 0.20 & & 15 \\
\hline 100 & 1.0 & 0.50 & & 17 \\
\hline
\end{tabular}

IV -13 
Table IV-5. (cont'd) Catalyst Codes for Run Designations

Nominal Compositions

\begin{tabular}{lllll}
$\mathrm{Fe}$ & $\mathrm{Cu}$ & $\mathrm{K}$ & Support & Code \\
\hline 100 & 3.0 & 0.00 & 34 \\
100 & 3.0 & 0.05 & 23 \\
100 & 3.0 & 0.20 & 25 \\
100 & 3.0 & 0.50 & 27 \\
100 & 10. & 0.00 & 35 \\
100 & 20. & 0.00 & & 36 \\
100 & 5.0 & 4.20 & & 31 \\
100 & 5.0 & 4.20 & $8 \mathrm{SiO}_{2}$ & 63 \\
100 & 5.0 & 4.20 & $25 \mathrm{SiO}_{2}$ & 66 \\
100 & 5.0 & 4.20 & $100 \mathrm{SiO}_{2}$ & 69 \\
100 & 5.0 & 4.20 & $8 \mathrm{Al}_{2} \mathrm{O}_{3}$ & 73 \\
100 & 5.0 & 4.20 & $20 \mathrm{Al}_{2} \mathrm{O}_{3}$ & 76 \\
$\mathrm{Ruhrchemie}$ & & & & 99 \\
\hline
\end{tabular}




\section{Task 2 SLURRY CATALYST DEVELOPMENT}

\section{Activation / Reduction Procedure Research}

\section{V.1.1. Literature Review}

The most common catalysts for $\mathrm{CO}$ hydrogenation (Fischer-Tropsch synthesis) are group VIII elements: cobalt, nickel, ruthenium and iron. Before synthesis a catalyst precursor is subjected to a pretreatment, the purpose of which is to bring the catalyst into an active form for synthesis. Cobalt, nickel and ruthenium are almost always reduced in flowing $\mathrm{H}_{2}$ at 200 $-450^{\circ} \mathrm{C}$ to the zero-valent metallic state. During the synthesis, under a variety of process conditions, these catalysts remain in the zero-valent state (Anderson, 1956). However, the purpose of pretreatment for iron catalysts is not so clear. Reduction in $\mathrm{H}_{2}$ may lead to the zero-valent state, but during the synthesis the metallic iron is rapidly converted to a carbide phase or phases (e.g., Amelse et al., 1978; Raupp and Delgass; 1979, Dry, 1981). At high $\left(\mathrm{H}_{2}+\mathrm{CO}\right)$ conversions, the reaction mixture becomes more oxidizing (relatively high $\mathrm{H}_{2} \mathrm{O} / \mathrm{H}_{2}$ and $\mathrm{CO}_{2} / \mathrm{CO}$ ratios) and magnetite $\left(\mathrm{Fe}_{3} \mathrm{O}_{4}\right)$ is also formed (e.g., Anderson, 1956; Dry, 1981; Satterfield et al., 1986). Other pretreatments have also been employed, such as $\mathrm{CO}$ reduction (activation), synthesis gas treatment (induction), and/or $\mathrm{H}_{2}$ reduction followed by $\mathrm{CO}$ or viceversa. These activations often yield a better catalyst than that obtained by $\mathrm{H}_{2}$ reduction, but the catalyst composition still changes during synthesis. Numerous studies have been published concerning correlations between phases present in the iron catalyst and its reaction behavior, as summarized, for example, by Dwyer and Hardenbergh (1984) and Satterfield et al. (1986a). However, there is no clear consensus as to which of the phases is responsible for catalyst activity. The two extreme views are that the active phase(s) is (are) either (a) iron carbides (e.g., Amelse et al., 1978; Raupp and Delgass, 1979; Niemantsverdriet et al., 1980); or (b) iron oxides (Reymond et al., 1982; Blanchard et al., 1982). Based on the extensive studies at the U.S. Bureau of Mines and the previous German work, the following iron phases were found to be catalytically active: metallic $\alpha-\mathrm{Fe}$, various carbides, nitrides and carbonitrides, and $\mathrm{Fe}_{3} \mathrm{O}_{4}$ (Hofer 1956, p. 434). During synthesis, industrial catalysts consist of mixtures of carbides and magnetite, and in general there is no clear correlation between the catalyst bulk composition and its activity and/or selectivity (Dry, 1981, p. 197; Anderson, 1984, p. 56). Thus, the objectives of the catalyst pretreatment in the case of iron are not clear. The general goals of a successful pretreatment are to obtain high activity, the desired selectivity, and long life (high stability). The effective activation procedures for iron catalysts have been developed 
empirically. There have been only a few studies on the effect of activation parameters on subsequent catalyst activity, selectivity, and stability during the synthesis.

In early work with alkalized precipitated catalysts at Kaiser Wilhelm Institute in Germany, it was found that reduction with $\mathrm{H}_{2}$ at $360^{\circ} \mathrm{C}$ was not effective, and further studies focused on activations with carbon monoxide and $\mathrm{CO}$ rich synthesis gas, (Anderson, 1956 pp. 176180). They investigated the effects of activation temperature $\left(255-450^{\circ} \mathrm{C}\right)$ and pressure $(0.01$ - 1.5 MPa) on catalyst activity and stability. The optimal activation parameters were: $\mathrm{CO}$ at $0.01 \mathrm{MPa}$ (subatmospheric pressure) and $325-345^{\circ} \mathrm{C}$. These activation conditions gave high $\left(\mathrm{H}_{2}+\mathrm{CO}\right)$ conversions and constant catalyst activity for 80-120 days in fixed bed reactor tests.

In studies with a precipitated iron catalyst at the U.S. Bureau of Mines, several activation procedures were employed with different reducing agents: $\mathrm{H}_{2}, \mathrm{CO}$, and $\mathrm{H}_{2} / \mathrm{CO}=1$ or 2 (Anderson, 1956, p. 183-184; Anderson, 1984, pp. 56-58). It was found that catalysts activated with syngas or $\mathrm{CO}$ had higher activity and produced less light hydrocarbons than $\mathrm{H}_{2}$ reduced catalysts.

Recent work at the Pittsburgh Energy Technology Center has focused on the effect of catalyst pretreatment on the catalyst's synthesis behavior in a stirred tank slurry reactor (Pennline et al., 1987; Zarochak and McDonald, 1986, 1987). In studies with a precipitated iron-manganese catalyst, Pennline et al. found that pretreatment with $\mathrm{H}_{2}$ or $\mathrm{H}_{2} / \mathrm{CO}=1$ syngas at $275^{\circ} \mathrm{C}$ resulted in completely inactive catalysts during the synthesis. Activations with $\mathrm{CO}$ were more successful, and changes in activation temperature or pressure had some effect on the catalyst activity and selectivity. Zarochak and Anderson employed activations with syngas $\left(\mathrm{H}_{2} / \mathrm{CO}=0.7\right.$ or 1 ) and $\mathrm{CO}$ in studies with $\mathrm{Fe}-\mathrm{Cu}-\mathrm{K}_{2} \mathrm{O}$ catalyst. Following activation the catalyst deactivated, sometimes rather rapidly, during the synthesis. The rate of deactivation was affected both by pretreatment and by reaction conditions during the synthesis. In Mobil's work on development of the two-stage process for synthesis gas conversion to gasoline, in-situ activations, in a slurry bubble column reactor, with syngas $\left(\mathrm{H}_{2} / \mathrm{CO}=2 / 3\right)$ at $280^{\circ} \mathrm{C}, 1.1-1.5 \mathrm{MPa}$ for $2-10 \mathrm{~h}$, were found to be effective in producing an active and stable catalyst (Kuo, 1983).

The information on the effect of reduction parameters on catalytic behavior during the synthesis for $\mathrm{H}_{2}$ reductions is rather scarce. Reductions at relatively high temperatures were not successful as noted earlier. Dry (1981, p. 179) states that low temperatures $\left(180-220^{\circ} \mathrm{C}\right)$ and high linear velocities are needed to achieve high surface areas after the reduction.

In this section we present results of a comprehensive study on the effect of activation pa- 
rameters (temperature, pressure, duration and nature of the reducing gas) on catalyst activity, selectivity, and stability. Eleven different activation procedures were employed, and the catalyst $(100 \mathrm{Fe} / 3 \mathrm{Cu} / 0.2 \mathrm{~K})$ was subsequently tested in a fixed bed reactor. Two tests were also conducted in a stirred tank slurry reactor to determine whether the same trends are observed in both types of reactors.

\section{V.1.2. Experimental Procedure}

Typically, $3.5 \mathrm{~g}$ of the catalyst $(3 \mathrm{cc}$ ) was diluted $1: 8$ by volume with glass beads of the same size range ( $30 / 60$ mesh) and charged into the reactor. All tests were conducted with a catalyst from a singie batch, having a composition of $100 \mathrm{Fe} / 3 \mathrm{Cu} / 0.2 \mathrm{~K}$ (expressed in parts of metal by weight) as determined by atomic absorption spectroscopy (Varian Spectra AA 30). Eleven sets of activation conditions were employed to evaluate the effect of activation parameters (gas type, temperature, duration and pressure) on subsequent catalyst performance. All activations were conducted at a gas space velocity of $3 \mathrm{NI} / \mathrm{g}$-cat.h and atmospheric pressure, except in test A-3517 where the activation was conducted at $1.48 \mathrm{MPa}(200 \mathrm{psig})$. Test identifications and activation conditions are shown in Table V.1-1.

Following activation (reduction), the flow was switched to helium and the bed was cooled down to $190^{\circ} \mathrm{C}$. The system was then pressurized to $1.48 \mathrm{MPa}$, the helium flow was cut off, and synthesis gas $\left(\mathrm{H}_{2}: \mathrm{CO}=1: 1\right)$ was introduced at a gas space velocity of $2 \mathrm{NI} / \mathrm{g}$-cat.h. The bed temperature was gradually increased to $250^{\circ} \mathrm{C}$ following the time temperature schedule listed in Table V.1-2 (conditioning period). During the conditioning period, the bed temperature was monitored frequently to prevent development of hot spots, and the volumetric gas contraction was recorded periodically. After achievement of the final reaction temperature, $250^{\circ} \mathrm{C}$, the tests were conducted over a $120 \mathrm{~h}$ period, during which time two mass balances were made at approximately 40 and $90 \mathrm{~h}$ on stream. The tail gas was analyzed frequently throughout the entire test.

\section{V.1.3. Results}

Selected results from catalytic tests are summarized in Table V.1-3 (activations with $\mathrm{CO}$ ) and Table V.1-4 (activations with $\mathrm{H}_{2}$ and syngas). Activation parameters investigated were: temperature $\left(250\right.$ vs. $280^{\circ} \mathrm{C}$ for both $\mathrm{H}_{2}$ and $\mathrm{CO}$, and $310^{\circ} \mathrm{C}$ with $\mathrm{CO}$ only), duration ( 8 and $24 \mathrm{~h}$ ), pressure ( 0.1 vs. $1.48 \mathrm{MPa}$, with $\mathrm{CO}$ only), and gas composition ( $\mathrm{CO}, \mathrm{H}_{2}$ and $\left.\mathrm{H}_{2} / \mathrm{CO}=0.68\right)$. 
Table V.1-1. Activation conditions and test designations.

\begin{tabular}{|c|cccc|}
\hline \multicolumn{5}{|c|}{ Conditions } \\
\hline Test & Temperature $\left({ }^{\circ} \mathrm{C}\right)$ & Pressure $(\mathrm{MPa})$ & Reductant & Duration $(h)$ \\
\hline $\mathrm{A}-2737$ & 250 & 0.10 & $\mathrm{CO}$ & 8 \\
$\mathrm{~B}-2857$ & 250 & 0.10 & $\mathrm{CO}$ & 24 \\
$\mathrm{~A}-3077$ & 280 & 0.10 & $\mathrm{CO}$ & 8 \\
$\mathrm{~A}-2967$ & 280 & 0.10 & $\mathrm{CO}$ & 24 \\
$\mathrm{~A}-2847$ & 310 & 0.10 & $\mathrm{CO}$ & 8 \\
$\mathrm{~A}-3517$ & 280 & 1.48 & $\mathrm{CO}$ & 24 \\
$\mathrm{~B}-3087$ & 250 & 0.10 & $\mathrm{H}_{2}$ & 8 \\
$\mathrm{~A}-3237$ & 250 & 0.10 & $\mathrm{H}_{2}$ & 24 \\
$\mathrm{~B}-2957$ & 280 & 0.10 & $\mathrm{H}_{2}$ & 8 \\
B-3227 & 280 & 0.10 & $\mathrm{H}_{2}$ & 24 \\
B-3377 & 280 & 0.10 & $\mathrm{H}_{2} / \mathrm{CO}=0.68$ & 24 \\
& & & & \\
\hline
\end{tabular}

(a) Space velocity $=3.0 \mathrm{Nl} / \mathrm{g}$-cat $\cdot h$ for all tests 
Table V.1-2. Start-up time/temperature schedule used during conditioning period following activation treatment.

\begin{tabular}{|c|cc|}
\hline Time on stream $(h)$ & Temperature $\left({ }^{\circ} \mathrm{C}\right)^{(a)}$ & Duration $(h)$ \\
\hline 0 & Reduction-190 & 1 \\
1 & 190 & 1 \\
2 & $190-200$ & 1 \\
3 & 200 & 1 \\
4 & $200-210$ & 1 \\
7 & 210 & 3 \\
8 & $210-220$ & 1 \\
11 & 220 & 3 \\
12 & $220-230$ & 1 \\
23 & 230 & 11 \\
24 & $240-240$ & 1 \\
28 & 240 & 4 \\
30 & $240-250$ & \\
& & \\
\hline
\end{tabular}

(a) $1.48 \mathrm{MPa}, 2.0 \mathrm{Nl} / \mathrm{g}$-cat $\cdot h, \mathrm{H}_{2} / \mathrm{CO}=1.0$ 
Table V.1-3. Results summary of catalyst tests using $\mathrm{CO}$ activations.

\begin{tabular}{|c|c|c|c|c|c|c|c|c|c|c|c|c|}
\hline 'Trut (n) & \multicolumn{2}{|c|}{$A-2737$} & \multicolumn{2}{|c|}{ B-2857 } & \multicolumn{2}{|c|}{ A-3077 } & \multicolumn{2}{|c|}{$A-2967$} & \multicolumn{2}{|c|}{$A-2817$} & \multicolumn{2}{|c|}{$A-3517$} \\
\hline Time on stream $(h)$ & 43 & 91 & 43 & 91 & 43 & 92 & 44 & 93 & 43 & 81 & 43 & 91 \\
\hline $\mathrm{CO}$ conversion $(\%)$ & 91.4 & 86.9 & 63.6 & 56.0 & 76.6 & 68.6 & 88.6 & 84.1 & 85.1 & 77.7 & 76.5 & 68.6 \\
\hline $\mathrm{II}_{2}+\mathrm{CO}$ conversion (\%) & 78.6 & 73.1 & 56.9 & 50.0 & 68.6 & 61.2 & 76.2 & 74.5 & 71.4 & 64.8 & 65.1 & 58.5 \\
\hline$r_{\mathrm{CO}_{2}} /\left(-r_{\mathrm{CO}}\right)$ & 0.44 & 0.44 & 0.39 & 0.40 & 0.42 & 0.43 & 0.41 & 0.41 & 0.44 & 0.45 & 0.47 & 0.45 \\
\hline \multicolumn{13}{|l|}{ Weight \% of hydrocarbons } \\
\hline $\mathrm{CH}_{4}$ & 11.2 & 10.8 & 5.5 & 8.2 & 7.2 & 6.7 & 7.1 & 7.7 & 6.1 & 6.0 & 6.5 & 5.8 \\
\hline $\mathrm{C}_{2}-\mathrm{C}_{4}$ & 31.9 & 32.9 & 20.6 & 29.1 & 27.0 & 26.8 & 25.8 & 27.8 & 24.8 & 23.8 & 26.4 & 26.1 \\
\hline $\mathrm{C}_{5}-\mathrm{C}_{11}$ & 29.8 & 30.3 & 38.4 & 30.6 & 30.7 & 33.2 & 22.7 & 30.4 & 30.7 & 28.9 & 26.3 & 24.9 \\
\hline $\mathrm{C}_{12}+$ & 27.1 & 26.0 & 35.5 & 32.1 & 35.1 & 33.3 & 44.4 & 34.1 & 38.4 & 41.3 & 40.8 & 43.2 \\
\hline \multicolumn{13}{|l|}{ Olefin content (Wright \%) } \\
\hline $\mathrm{C}_{2}-\mathrm{C}_{4}$ & 63 & 64 & 70 & 72 & 70 & 71 & 69 & 68 & 77 & 78 & 78 & 76 \\
\hline $\mathrm{C}_{5}-\mathrm{C}_{11}$ & 49 & 53 & 58 & 62 & 60 & 61 & 56 & 59 & 60 & 66 & 67 & 68 \\
\hline 2-Butene/1-Butene ratio & 0.49 & 0.45 & 0.26 & 0.21 & 0.24 & 0.22 & 0.27 & 0.30 & 0.06 & 0.06 & 0.06 & 0.06 \\
\hline
\end{tabular}

(a) Nominal process conditions: $250{ }^{\circ} \mathrm{C}, 1.48 \mathrm{Ml} \mathrm{l}^{\prime} \mathrm{a}, 2.0 \mathrm{Nl} / \mathrm{g}$-cat $\cdot h, \mathrm{H}_{2} / \mathrm{CO}=1.0$ 
Table V.1-4. Results summary of catalyst tests using $\mathrm{H}_{2}$ or $\mathrm{H}_{2}+\mathrm{CO}$ activations.

\begin{tabular}{|c|c|c|c|c|c|c|c|c|c|}
\hline Test ${ }^{(a)}$ & B-3087 & \multicolumn{2}{|c|}{$A-3237$} & \multicolumn{2}{|c|}{ B-2957 } & \multicolumn{2}{|c|}{ B-3227 } & \multicolumn{2}{|c|}{ B-3377 } \\
\hline Time on stream $(h)$ & 43 & 42 & 90 & 45 & 92 & 42 & 91 & 40 & 86 \\
\hline CO conversion (\%) & 81.1 & 79.0 & 85.7 & 61.2 & 67.5 & 31.0 & 33.1 & 76.0 & 67.2 \\
\hline $\mathrm{H}_{2}+\mathrm{CO}$ conversion $(\%)$ & 65.2 & 62.9 & 70.2 & 48.0 & 53.3 & 26.0 & 27.1 & 64.6 & 58.4 \\
\hline$r_{\mathrm{CO}_{2}} /\left(-r_{\mathrm{CO}}\right)$ & 0.49 & 0.50 & 0.50 & 0.54 & 0.54 & 0.50 & 0.51 & 0.45 & 0.46 \\
\hline \multicolumn{10}{|l|}{ Weight \% of hydrocarbons } \\
\hline $\mathrm{CHI}_{4}$ & 14.2 & 12.4 & 14.7 & 14.0 & 12.9 & 10.7 & 11.7 & 7.1 & 6.5 \\
\hline $\mathrm{C}_{2}-\mathrm{C}_{4}$ & 39.9 & 38.9 & 42.8 & 45.2 & 39.6 & 39.3 & 38.4 & 30.5 & 27.0 \\
\hline $\mathrm{C}_{5}-\mathrm{C}_{11}$ & 39.4 & 42.2 & 32.7 & 36.9 & 33.0 & 39.6 & 34.3 & 31.8 & 32.7 \\
\hline $\mathrm{C}_{12}+$ & 6.5 & 6.5 & 9.8 & 3.9 & 14.5 & 10.4 & 15.6 & 30.6 & 33.8 \\
\hline \multicolumn{10}{|l|}{ Olefin content (Weight \%) } \\
\hline $\mathrm{C}_{2}-\mathrm{C}_{4}$ & 65 & 70 & 68 & 75 & 77 & 72 & 75 & 76 & 76 \\
\hline $\mathrm{C}_{5}-\mathrm{C}_{11}$ & 58 & 65 & 64 & 63 & 64 & 66 & 68 & 72 & 69 \\
\hline 2-Butene/1 Butene ratio & 0.09 & 0.05 & 0.07 & 0.03 & 0.02 & 0.03 & 0.03 & 0.07 & 0.06 \\
\hline
\end{tabular}

(1) Nominal process conditions: $250{ }^{\circ} \mathrm{C}, 1.48 \mathrm{MPa}, 2.0 \mathrm{Nl} / \mathrm{g}$-cat $\cdot h, \mathrm{H}_{2} / \mathrm{CO}=1.0$ 


\section{Activations with $\mathrm{CO}$}

Catalyst activity, measured by volumetric gas contraction, as a function of time on stream during the conditioning period is shown in Figure V.1-1. Volumetric contraction, defined as: $100 \times$ (Inlet flow rate-Outlet flow rate)/(Inlet flow rate) varies nearly linearly with respect to syngas $\left(\mathrm{H}_{2}+\mathrm{CO}\right)$ conversion and is a convenient measure of catalyst activity. At a given temperature and time on stream, the volumetric gas contraction is essentially independent of activation procedure employed. Any differences in results may be attributed to non-uniformity in the bed temperature and/or fluctuations in the tail gas flow rate, since the system was not at steady state during these measurements. At the end of the conditioning period the catalyst activity was nearly the same for all six activation procedures employed.

The catalyst activity, measured by $\left(\mathrm{H}_{2} \div \mathrm{CO}\right)$ conversion, as a function of time on stream during the steady state period $\left(250^{\circ} \mathrm{C}, 1.48 \mathrm{MPa}, 2 \mathrm{Nl} / \mathrm{g}\right.$ - cat.h and $\left.\mathrm{H}_{2} / \mathrm{CO}=1\right)$ is shown in Figure V.1-2. The initial activity of the catalyst was high and similar for all $\mathrm{CO}$ activation procedures employed. The syngas and $\mathrm{CO}$ conversions for different activation procedures at $1-2 \mathrm{~h}$ at the process conditions were: $75-84 \%$ and $87-97 \%$, respectively. The activations at $250^{\circ} \mathrm{C}$ for $8 \mathrm{~h}$ and $280^{\circ} \mathrm{C}$ for $24 \mathrm{~h}$ (both at atmospheric pressure) resulted in the highest catalyst activity and stability during the catalytic tests, however the activity declined with time on stream for all $\mathrm{CO}$ activations. The loss in activity expressed as a percentage of the initial $\left(\mathrm{H}_{2}+\mathrm{CO}\right.$ ) conversion, over the $120 \mathrm{~h}$ test period, ranged from $10 \%$ (test A-2967) to $45 \%$ (test B-2857). The activation at $250^{\circ} \mathrm{C}$ for $24 \mathrm{~h}$ resulted in the most rapid catalyst deactivation at the synthesis conditions, but the underlying reasons for this behavior are not yet understood. This activation procedure and subsequent catalytic testing were repeated in run B-0098. Similar results were obtained during this test: the $\left(\mathrm{H}_{2}+\mathrm{CO}\right)$ conversion declined from an initial value of $75.4 \%$ to $51.5 \%$ at $120 \mathrm{~h}$ on stream, which represents a $32 \%$ loss in activity. The latter value is lower than that obtained in test B-2857, but is still high in comparison to the other activations with $\mathrm{CO}$ at atmospheric pressure.

The ratio of $\mathrm{CO}_{2}$ production $\left(\mathrm{CCO}_{2}\right)$ to total $\mathrm{CO}$ consumption $\left(-\mathrm{r}_{\mathrm{CO}}\right)$ represents a measure of the water gas shift (WGS) activity and is listed in Table V.1-3. This ratio did not vary much with time on stream nor with the activation procedure. The catalyst activated at $1.48 \mathrm{MPa}$ and $280^{\circ} \mathrm{C}$ for $24 \mathrm{~h}$ (A-3517) had the highest WGS activity, whereas the lowest WGS activity was observed in test B-2857. However, the difference between these two extreme cases was only $15 \%$. 


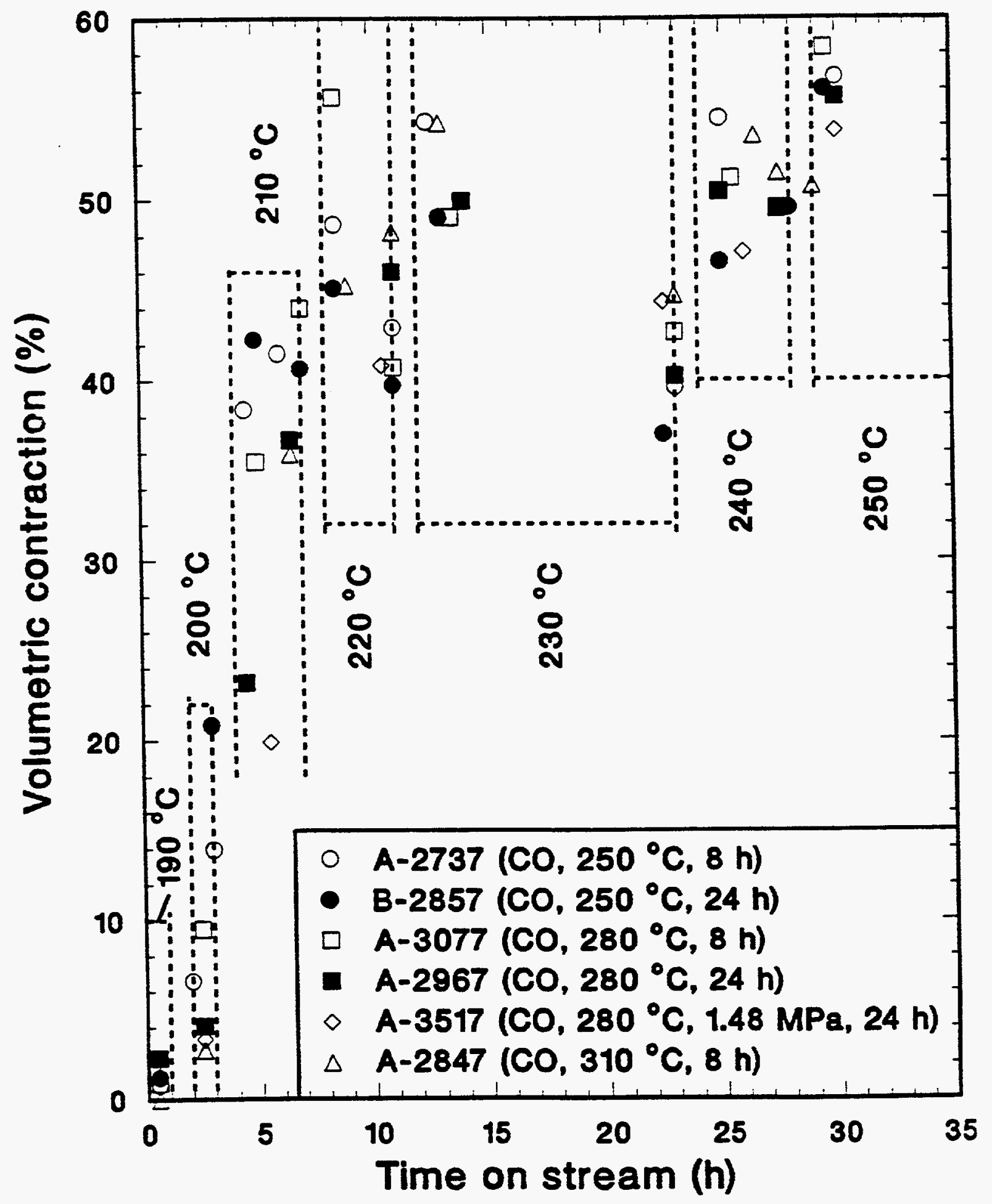

Figure V.1-1. Volumetric contractions during conditioning period for the $\mathrm{CO}$ activation procedures. 


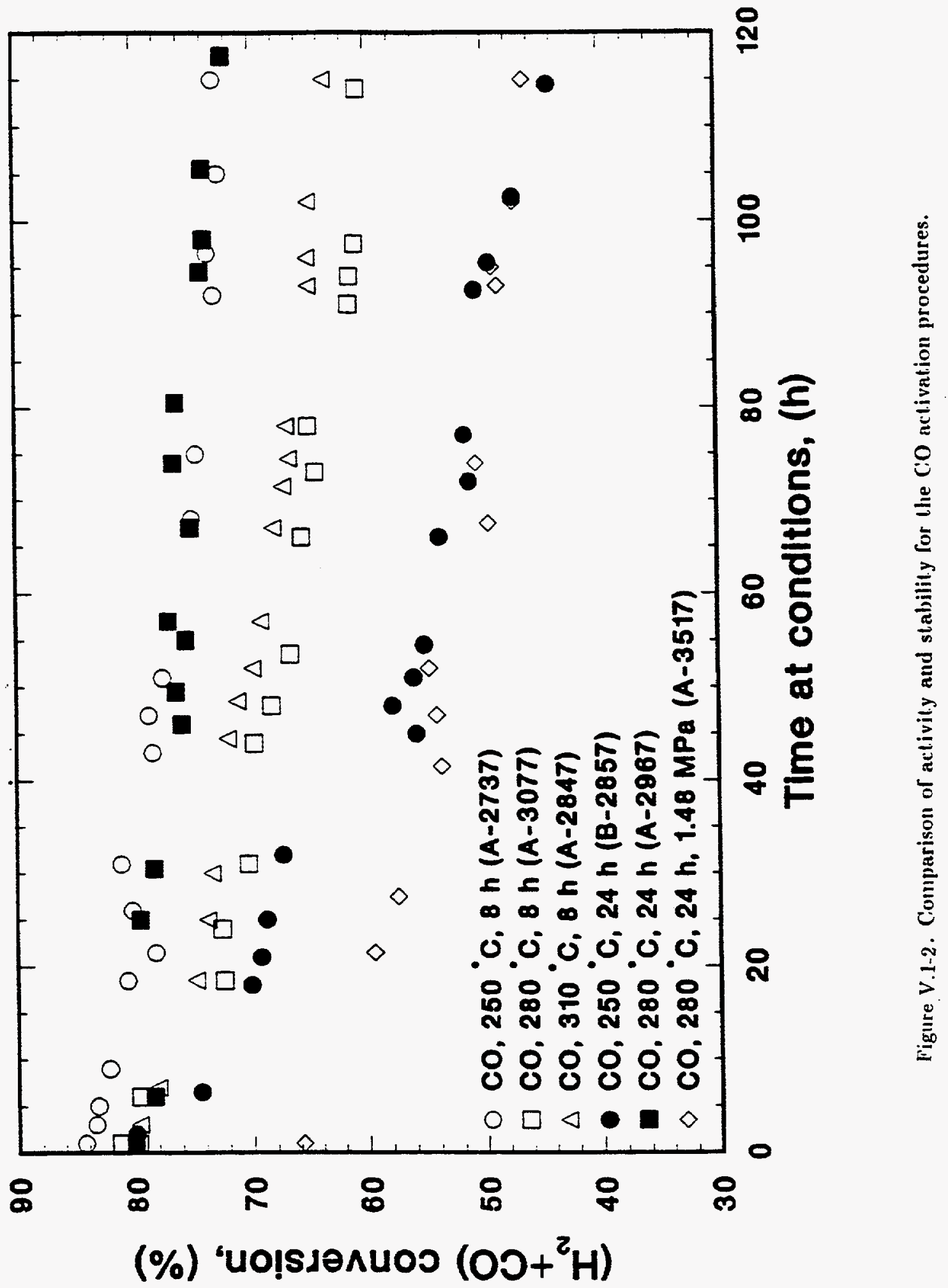


Selectivity

The hydrocarbon product distribution, the fraction of olefins in light hydrocarbons, and the olefin isomerization activity (expressed as 2-butene/. 1-butene ratio) obtained during the two mass balances for each of the six activation treatments are given in Table V.1-3. Although the catalyst activity decreased with time on stream, selectivities remained relatively stable between the two balances performed at approximately 43 and $91 \mathrm{~h}$ on stream. Thus, the average values for the hydrocarbon product distribution and the $(1+2)$-olefins/n-paraffin ratios (or the olefin content in a given carbon number range) from balances 1 and 2 can be used for comparison of different activation procedures (Figure V.1-3).

Hydrocarbon product selectivity improved with the increase in activation temperature at 8 $h$ activation durations. The catalyst activated at higher temperature produced less methane and $C_{2}-C_{4}$ products. The (1+2)-olefins/n-paraffin ratios (Fig.V.1.3) and the olefin content of $C_{2}-C_{4}$ and $C_{5}-C_{11}$ hydrocarbons (Table V.1.3) increased, whereas the 2-butene/1-butene ratio decreased as the activation temperature increased. Since paraffins and $\beta$-olefins are produced primarily via secondary reactions, this means that activations at higher temperature (280 and $310^{\circ} \mathrm{C}$ ) tend to suppress these secondary reactions. At $24 \mathrm{~h}$ reduction durations, comparisons can be made at 250 and $280^{\circ} \mathrm{C}$. With the longer duration, higher activation temperature favors a more stable catalyst, while the selectivities were similar (Table V.1.3 and Fig.V.1.3). These trends are not the same as those observed at $8 \mathrm{~h}$ durations, indicating that the effects of activation temperature and duration can not be separated.

The effect of activation duration can be seen at 250 and $280^{\circ} \mathrm{C}$. At $250^{\circ} \mathrm{C}$, the $24 \mathrm{~h}$ duration (B-2857) produced the least stable of all the catalysts, however, the selectivity is better than with the $8 \mathrm{~h}$ activation as less methane and $C_{2}-C_{4}$ products are produced. The stability with a $280^{\circ} \mathrm{C}$ reduction is superior when a longer duration (24 h) is used (Fig. V.1-1), whereas the selectivity is not strongly affected by duration (A-3077 vs. A- 2967). On the basis of the overall catalyst performance (stability and product selectivity) the activation at $280^{\circ} \mathrm{C}$ for $24 \mathrm{~h}$ (A-2967) produced the best results of all five activations with $\mathrm{CO}$ at atmospheric pressure.

The effect of pressure during activation was determined at these optimal values of activation temperature and duration in test A-3517. Higher pressures are needed for in-situ activations in slurry reactors to reduce losses of liquid medium due to evaporation. The catalyst activated at ambient pressure was found to be more active and more stable than the catalyst activated at 

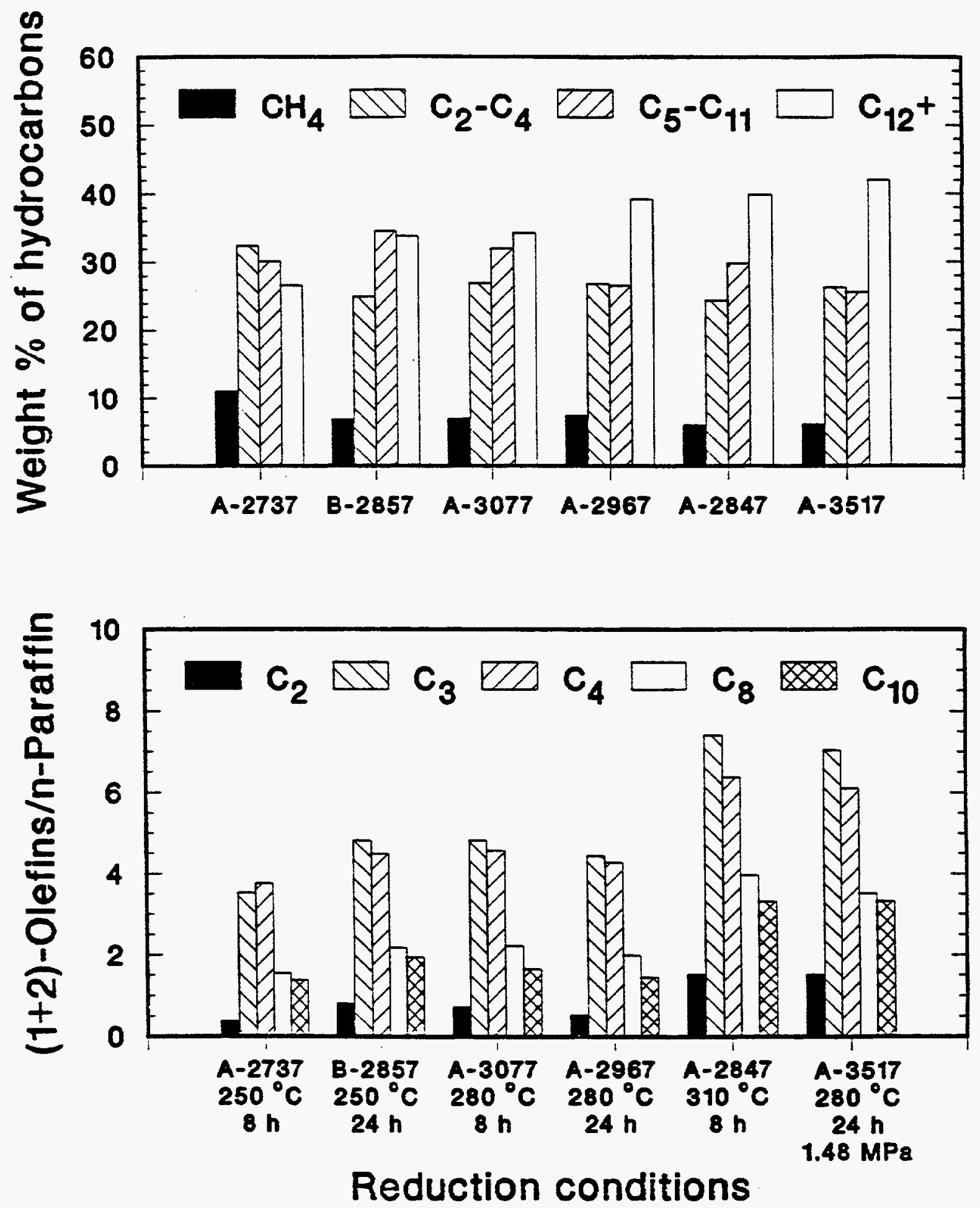

Figure V.1-3. Comparison of hydrocarbon distribution and olefin selectivity for the CO activation procedures. 
high pressure (Fig. V.1-2). The activation pressure did not have a strong effect on hydrocarbon product selectivity, as shown in Figure V.1-3 and Table V.1-3. The weight percent hydrocarbon distribution obtained using different activation pressures was nearly the same for both procedures, although some shifting between higher molecular weight products $\left(C_{5}, C_{11}, C_{12}+\right)$ is evident. The $(1+2)$-olefins/n-paraffin ratios and the olefin content in $C_{2}-C_{4}$ and $C_{5}-C_{11}$ hydrocarbons were higher for the catalyst activated at higher pressure, however, this may have been caused in part by the significantly higher conversions obtained with the ambient pressure reduction. As the $\left(\mathrm{H}_{2}+\mathrm{CO}\right)$ conversion increases, the partial pressure of $\mathrm{H}_{2}$ relative to $\mathrm{CO}$ also increases (as long as the usage ratio is lower than the feed ratio). Also, higher conversions lead to longer residence times in the reactor due to gas contraction upon reaction. Both of these effects (the increase in the $\mathrm{H}_{2} / \mathrm{CO}$ partial pressure ratio and the longer residence time) favor hydrogenation of olefinic products at high $\left(\mathrm{H}_{2}+\mathrm{CO}\right)$ conversion, decreasing the $(1+2)$ olefins / $n$-paraffin ratio. The isomerization activity (2-butene/1-butene) was significantly lower for the catalyst activated at $1.48 \mathrm{MPa}$.

The products of the Fischer-Tropsch synthesis follow the Anderson- Schulz-Flory (ASF) distribution, which may be characterized either by a single value of the chain growth probability factor or by two values (Huff and Satterfield, 1984). We found that whenever all products collected were analyzed, including those in the high pressure trap, at least two chain growth probabilities are needed to characterize the product distribution. An example of the ASF plot is shown in Fig. V.1-4, for the data from test A- 3077, balance 2. The two- $\alpha$ model of Huff and Satterfield was found to accurately represent these data:

$$
x_{n}=\beta\left(1-\alpha_{1}\right) \alpha_{1}^{n-1}+(1-\beta)\left(1-\alpha_{2}\right) \alpha_{2}^{n-1}
$$

where $x_{n}$ is the mole fraction of products containing $n$ carbon atoms (hydrocarbon and oxygenate), $\beta$ is the fraction of type / sites on the catalyst and $\alpha_{1}$ and $\alpha_{2}$ are the chain growth probabilities associated with the type I and type II sites, respectively. The negative deviations from the ASF distribution in the $C_{6}-C_{8}$ range are caused by product loss due to evaporation, while positive deviations at $C_{46}+$ are due to errors in the $\mathrm{GC}$ peak integration (high base-line shift).

Activations with $\mathrm{H}_{2}$

The changes in catalyst activity with time on stream during the unsteady state conditioning period and the steady state synthesis period are shown in Figures V.1-5 and V.1-6, respectively. 




Figure V.1-4. Anlerson-Schulz Flory plot for the products obtained in test $\Lambda-3077$ at $92 \mathrm{~h}$ on stream. 
In contrast to the behavior of $\mathrm{CO}$ reduced catalyst, the activities of the $\mathrm{H}_{2}$ reduced catalyst, measured by volumetric contraction, during the conditioning period were strongly influenced by activation conditions (temperature and/or duration) and increased in the following order $\left(280^{\circ} \mathrm{C}, 24 \mathrm{~h}\right)<\left(280^{\circ} \mathrm{C}, 8 \mathrm{~h}\right)<\left(250^{\circ} \mathrm{C}, 24 \mathrm{~h}\right)<\left(250^{\circ} \mathrm{C}, 8 \mathrm{~h}\right)$. This order continued throughout the steady state period (Fig. V.1-6), but the activity of the catalyst reduced at $250^{\circ} \mathrm{C}$ for $24 \mathrm{~h}$ approached that of the catalyst reduced at $250^{\circ} \mathrm{C}$ for $8 \mathrm{~h}$. The latter test (B3087) was prematurely terminated due to a flow interruption which occurred at approximately $80 \mathrm{~h}$ on stream (before the second mass balance was completed). All four reductions with $\mathrm{H}_{2}$ lead to either a constant or a gradually increasing activity during the synthesis. The activities of the catalyst reduced at $250^{\circ} \mathrm{C}$ ( 8 and $24 \mathrm{~h}$ durations) were significantly higher than those resulting from activation at $280^{\circ} \mathrm{C}$. Also, the shorter $8 \mathrm{~h}$ reduction at $280^{\circ} \mathrm{C}(\mathrm{B}-2957)$ produced a significantly more active catalyst than the $24 \mathrm{~h}$ reduction at the same temperature.

As with the $\mathrm{CO}$ activated catalyst, selectivity did not change significantly between the two mass balances (See Table V.1-4). The effects of reduction temperature and duration on catalyst selectivity may be studied in Figure V.1-7 (the average values from the two mass balances were used for this comparison) and in Table V.1-4. The hydrocarbon weight percent distribution was not strongly affected by the $\mathrm{H}_{2}$ reduction procedure followed, regardless of the reduction conditions. The $(1+2)$-olefins/n-paraffin ratios did not change significantly with the duration of the reduction, however, the ratios decreased as the reduction temperature decreased from 280 to $250^{\circ} \mathrm{C}$, at both 8 and $24 \mathrm{~h}$ reduction durations. This trend may be caused, in part, by the significantly higher $\left(\mathrm{H}_{2}+\mathrm{CO}\right)$ conversions obtained with the catalysts reduced at $250^{\circ} \mathrm{C}$.

WGS activity was not affected much by differences in reduction parameters, and the ratio $\left(\mathrm{CO}_{2}\right) /\left(-\mathrm{r}_{\mathrm{CO}}\right)$ only varied between 0.49 and 0.54 . The olefin isomerization activity decreased with the increase in reduction temperature, but again this could have been caused at least in part by the decreased $\alpha$-olefin concentration at lower $\left(\mathrm{H}_{2} \div \mathrm{CO}\right)$ conversions (i.e., higher reduction temperature).

Comparison of Activations with $\mathrm{CO}, \mathrm{H}_{2}$ and Syngas

The activities of the catalyst activated with $\mathrm{CO}, \mathrm{H}_{2}$ and syngas $\left(\mathrm{H}_{2} / \mathrm{CO}=0.68\right)$ at atmospheric pressure and $280^{\circ} \mathrm{C}$ for $24 \mathrm{~h}$ are compared in Figure V.1-8. The $\mathrm{CO}$ activated catalyst was more active and stable than the catalyst activated with the $\mathrm{CO}$ rich syngas, whereas the $\mathrm{H}_{2}$ reduced catalyst showed high stability but a very low activity, about $30 \%\left(\mathrm{H}_{2}+\mathrm{CO}\right)$ conversion throughout the run. The change in activity with time on stream for the $\mathrm{H}_{2}$ reduced catalyst 


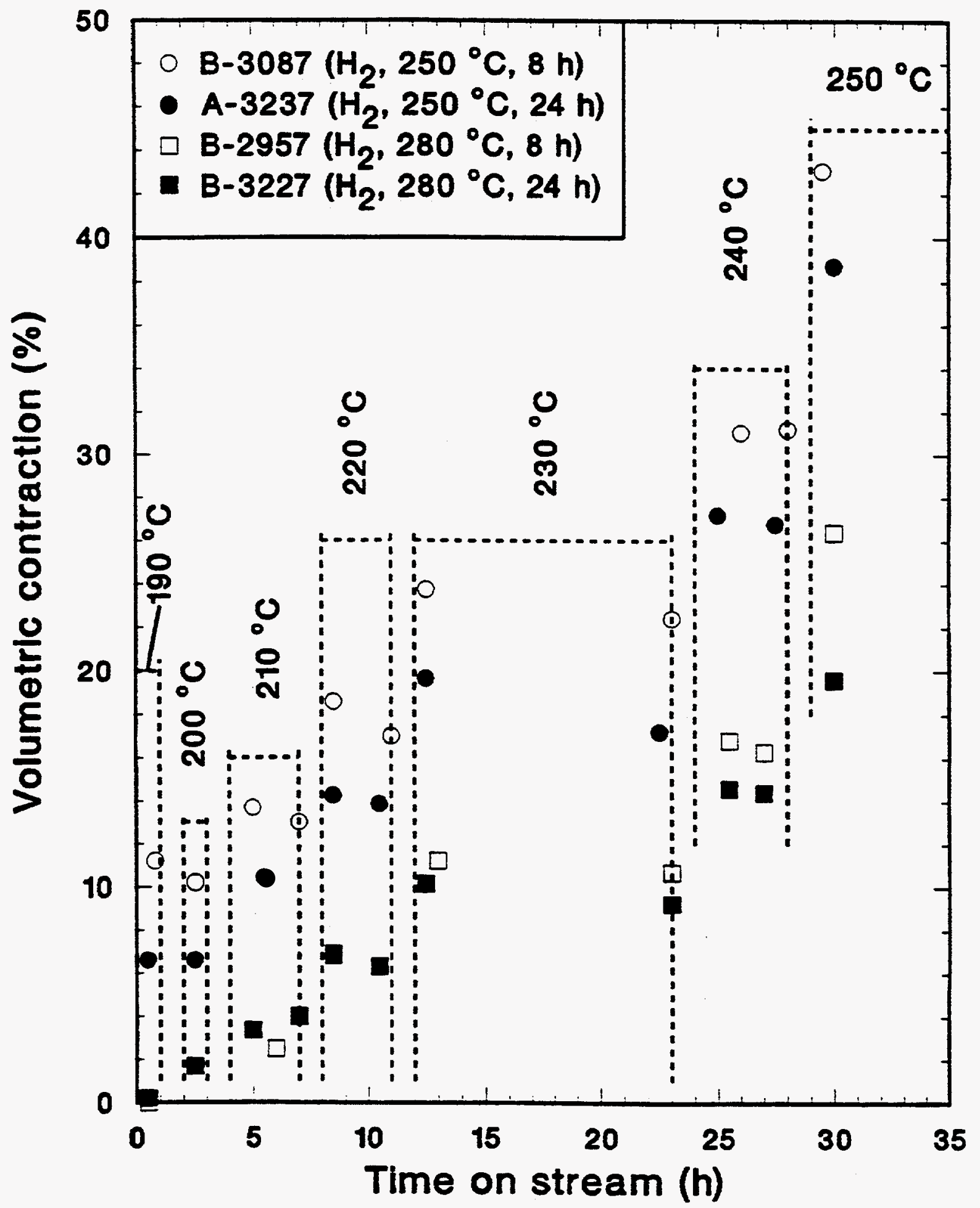

Figure V.1-5. Volumetric contractions during conditioning period for the $\mathrm{H}_{2}$ activation procedures. 


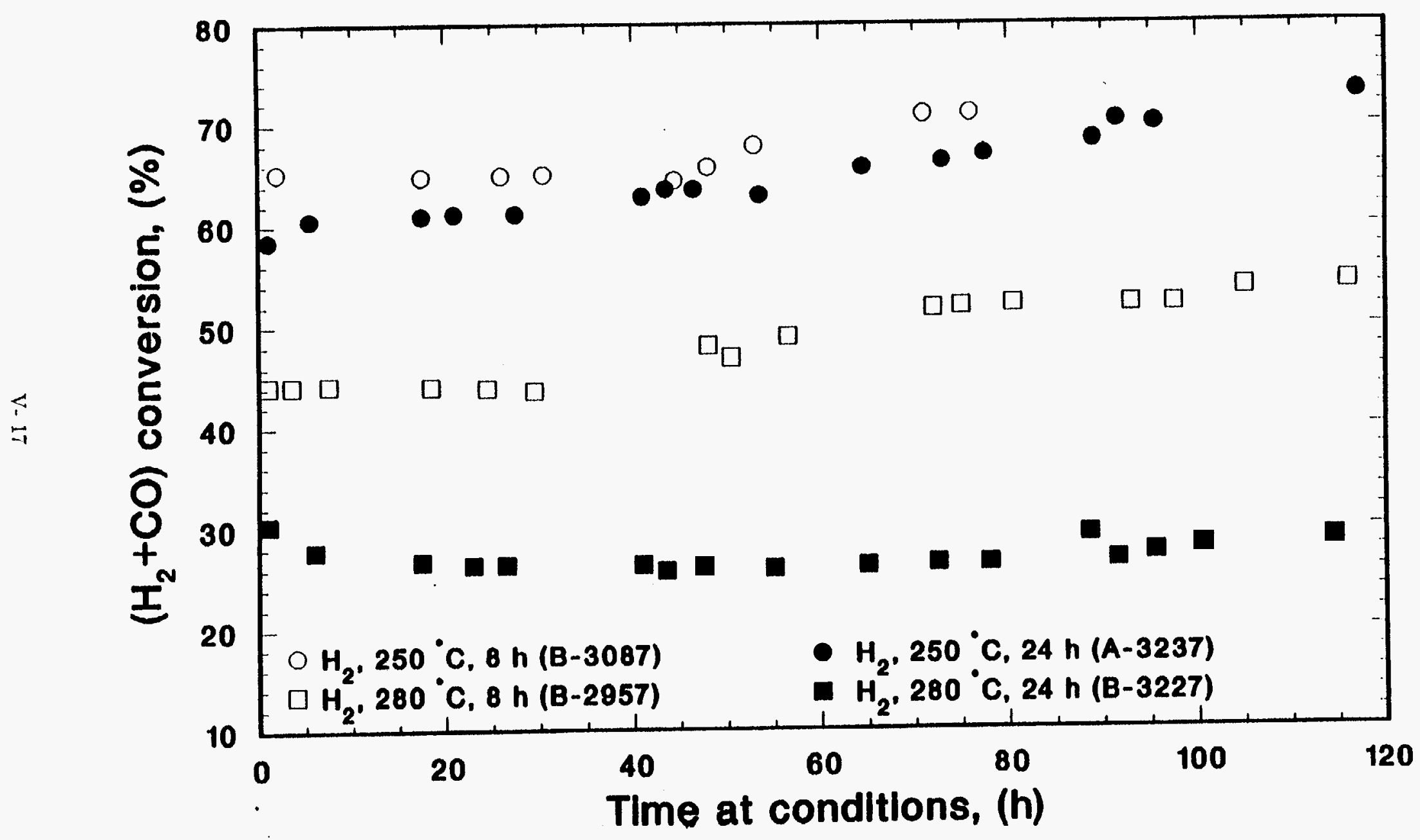

Figure V.1-6. Comparison of activity and stability for the $\mathrm{II}_{2}$ activation procedures. 

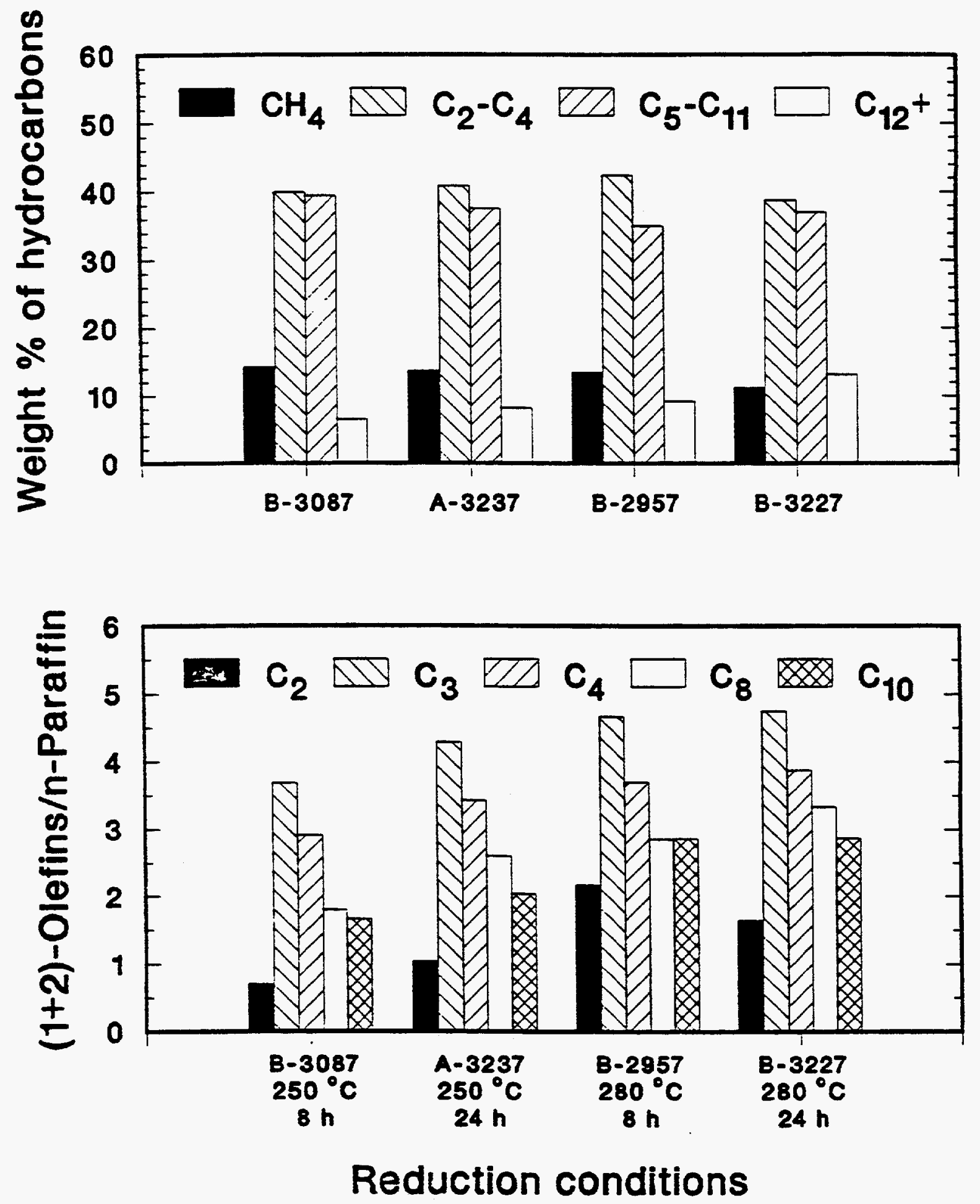

Figure V.1-7 - Comparison of hydrocarbon distribution and olefin selectivity for the $\mathrm{H}_{2}$ activation procedures. 


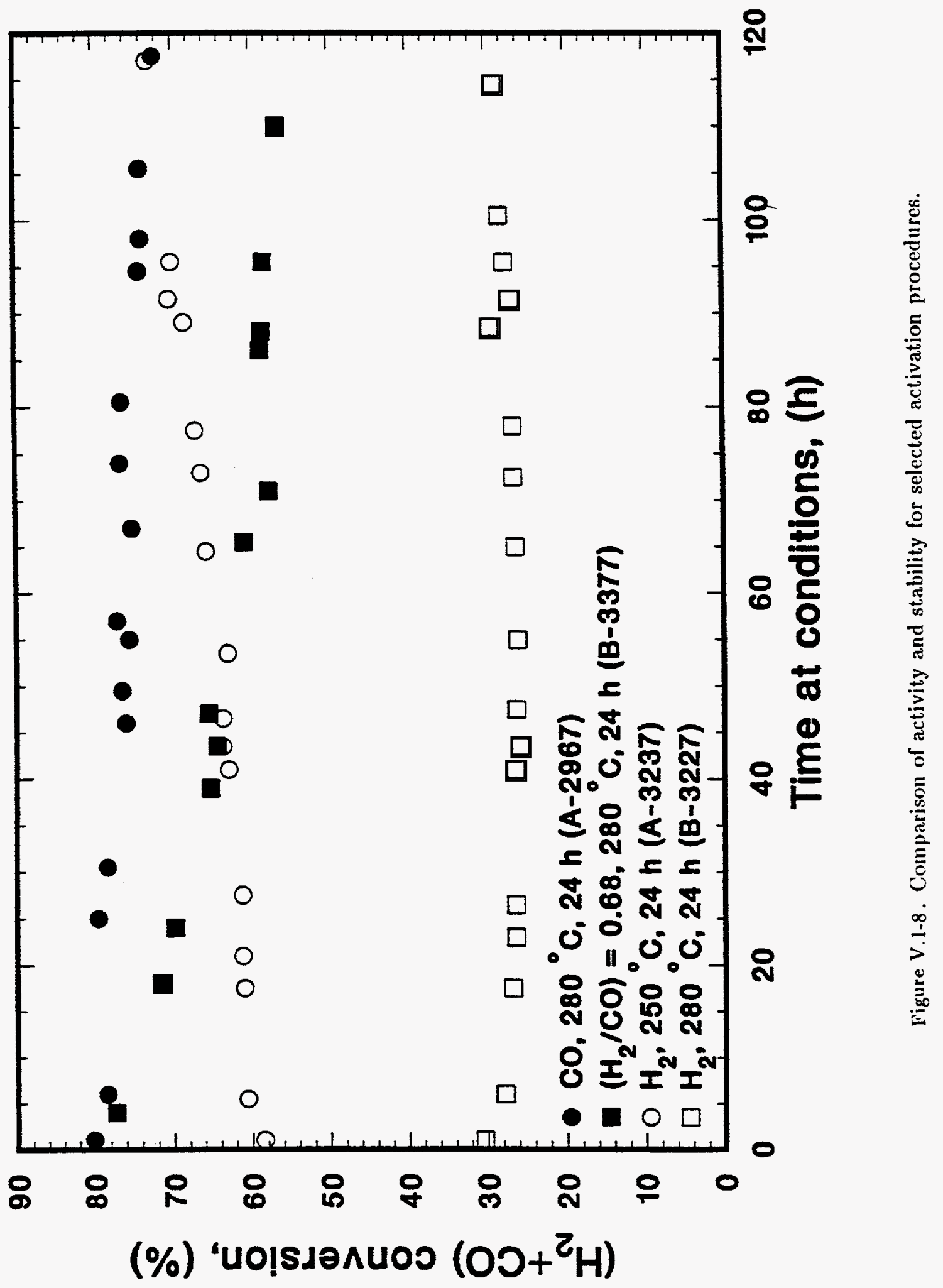


at $250^{\circ} \mathrm{C}$ for $24 \mathrm{~h}$ (A-3237) is also included for comparison. The activity of the catalyst during the latter test was initially lower than that of the $\mathrm{CO}$ activated catalyst, but after about $100 \mathrm{~h}$ at conditions the two activities were nearly the same. By referring to Tables V.1-3 and V.1-4, it may be seen that activations with $\mathrm{H}_{2}$ give the highest $\mathrm{rCO}_{2} /\left({ }^{\mathrm{CO}}\right)$ ratios (i.e., the highest WGS activity) followed by $\mathrm{H}_{2} / \mathrm{CO}=0.68$ and $\mathrm{CO}$ activations.

A comparison of the effect of reductant (gas) type on catalyst selectivity is given in Figure V.1-9 for the same four tests shown in Figure V.1-8. The weight percent hydrocarbon distribution obtained in tests following the $\mathrm{CO}$ and syngas activations were similar, with some minor shifting of products between the $C_{5}-C_{11}$ and $C_{12}+$ product ranges. The catalyst reduced with $\mathrm{H}_{2}$ favored the formation of methane and $\mathrm{C}_{2}-\mathrm{C}_{4}$ products, with correspondingly lower weight percents of the higher molecular weight products $\left(C_{5}+\right)$. The $(1+2)$-olefins/n-paraffin ratios were higher for the catalyst activated with synthesis gas, compared to the catalyst activated with either $\mathrm{H}_{2}$ or $\mathrm{CO}$, particularly the $\mathrm{CO}$ activated catalyst. These ratios are somewhat enhanced by the low conversions obtained in tests with the synthesis gas or $\mathrm{H}_{2}\left(280^{\circ} \mathrm{C}, 24 \mathrm{~h}\right)$ activated catalyst, which may be seen by comparing olefin selectivities from tests A-2967 and A-3237 at approximately equal $\left(\mathrm{H}_{2}+\mathrm{CO}\right)$ conversions. In this case the olefin selectivity of the $\mathrm{H}_{2}$ activated catalyst is only slightly greater $\left(\mathrm{C}_{5}-\mathrm{C}_{11}\right.$ fraction only) than that of the $\mathrm{CO}$ activated catalyst. The olefin isomerization activity of the $\mathrm{CO}$ activated catalyst is significantly greater than that of the catalyst activated by either $\mathrm{H}_{2}$ or syngas regardless of the conversion level (see Tables V.1-3 and V.1-4).

On the basis of catalyst activity, stability, and selectivity, $\mathrm{CO}$ activation at atmospheric pressure, and $280^{\circ} \mathrm{C}$ for $24 \mathrm{~h}$ was found to be the most desirable of the eleven activations that were employed in this study.

\section{Slurry Bed Reactor Tests}

In order to determine whether the trends found in fixed bed reactor tests remain the same during the synthesis in slurry phase, two tests were conducted in a 1 liter stirred tank siurry reactor (Autoclave Engineers). A precipitated catalyst with composition $100 \mathrm{Fe} / 0.3 \mathrm{Cu} / 0.5 \mathrm{~K}$ was employed in both tests. The catalyst was activated in $\mathrm{H}_{2}$ for $24 \mathrm{~h}$ (test SB-0458) or in $\mathrm{CO}$ for $16 \mathrm{~h}$ (test SA-0468) both at $280^{\circ} \mathrm{C}, 0.79 \mathrm{MPa}$ and $3 \mathrm{Nl} / \mathrm{g}$-cat.h. (see Section V.2.3) Following activation, the catalyst was tested at $250^{\circ} \mathrm{C}, 1.48 \mathrm{MPa}, 2 \mathrm{Nl} / \mathrm{g}$-cat.h and $\mathrm{H}_{2} / \mathrm{CO}=1.0$ (the same process conditions used in the fixed bed reactor tests). The $\left(\mathrm{H}_{2}+\mathrm{CO}\right)$ conversions at about $40 \mathrm{~h}$ on stream were 24.8 and $74.8 \%$ for the $\mathrm{H}_{2}$ and $\mathrm{CO}$ reduced catalysts, 

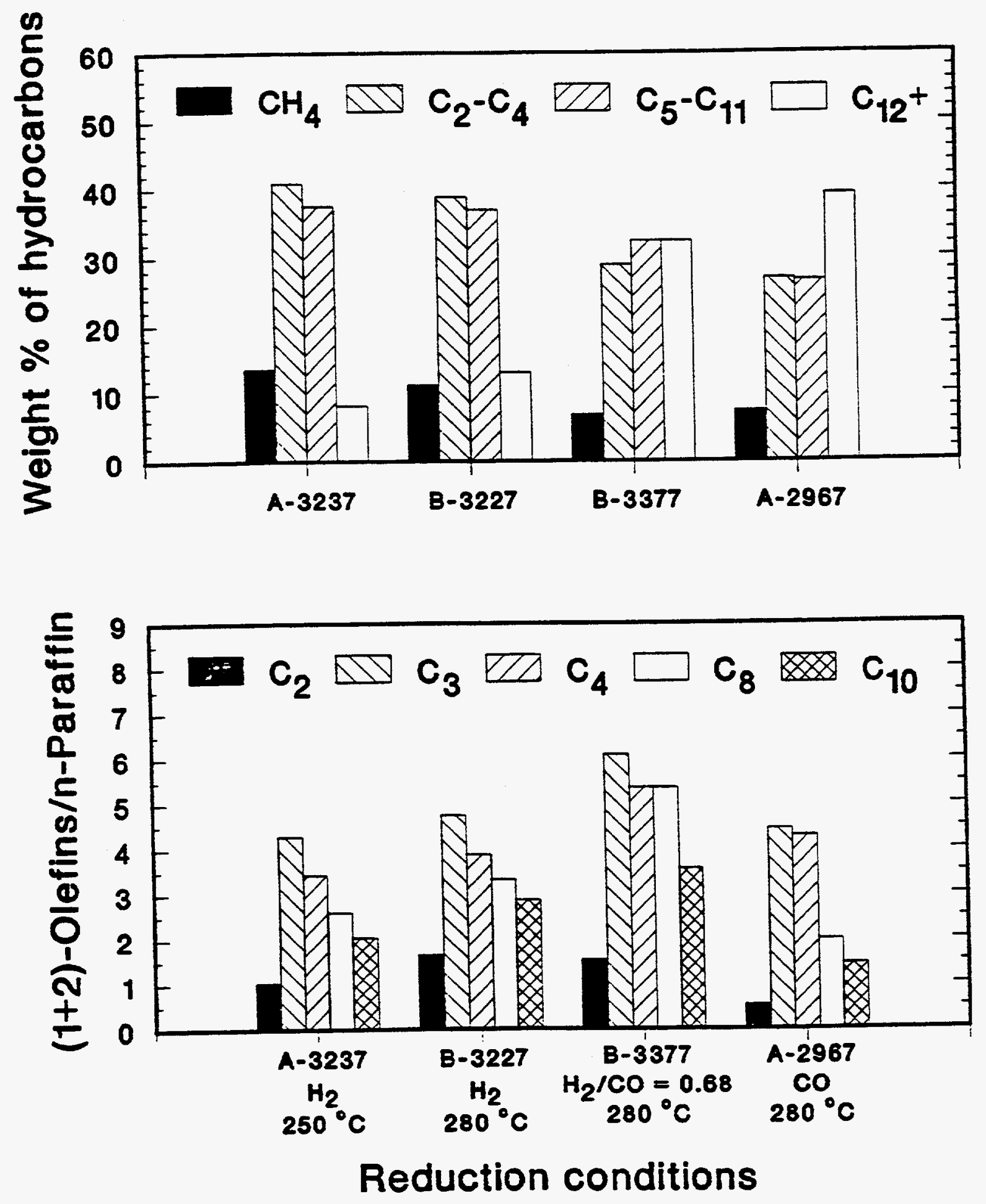

Figure V.1-9 . Comparison of hydrocarbon distribution and olefin selectivity for selected activation procedures. 
respectively. These conversions are similar to those obtained in fixed bed tests when similar activations procedures were employed. After the first mass balance, the process conditions (temperature, gas flow rate or $\mathrm{H}_{2} / \mathrm{CO}$ feed ratio) were varied in both tests. The base-line conditions were repeated later during the test to determine the extent of catalyst deactivation. The $\left(\mathrm{H}_{2}+\mathrm{CO}\right)$ conversion increased with time on stream from $24.8 \%$ at $40 \mathrm{~h}$ to $35.5 \%$ at 428 $h$ in the test with the $\mathrm{H}_{2}$ activated catalyst, whereas the $\mathrm{CO}$ activated catalyst deactivated significantly during the synthesis. In the latter case, the $\left(\mathrm{H}_{2}+\mathrm{CO}\right)$ conversion at $437 \mathrm{~h}$ on stream was only $17.4 \%$. During the first mass balance ( $40 \mathrm{~h}$ on stream) the hydrocarbon distributions were similar: $4.6\left(\mathrm{CH}_{4}\right), 25.0\left(\mathrm{C}_{2}-\mathrm{C}_{4}\right), 22.7\left(\mathrm{C}_{5}-\mathrm{C}_{11}\right)$, and $47.7 \%\left(\mathrm{C}_{12}+\right)$ for $\mathrm{H}_{2}$ reduced catalyst compared to $6.9\left(\mathrm{CH}_{4}\right), 22.3\left(\mathrm{C}_{2}-\mathrm{C}_{4}\right), 20.4\left(\mathrm{C}_{5}-\mathrm{C}_{11}\right)$, and $50.4 \%\left(\mathrm{C}_{12}+\right)$ for $\mathrm{CO}$ reduced catalyst. This trend is different than that observed in fixed bed reactor tests, where $\mathrm{CO}$ activated catalyst produced significantly less methane and $\mathrm{C}_{2}-\mathrm{C}_{4}$ products than $\mathrm{H}_{2}$ activated catalyst.

The two slurry reactor tests show that activation procedures have the same effect on catalyst activity and stability as that found in fixed bed reactor tests. However, the trends in catalyst selectivity were not the same. The differences in selectivity trends may be caused by the different catalyst compositions used in the slurry $(100 \mathrm{Fe} / 0.3 \mathrm{Cu} / 0.5 \mathrm{~K})$ and fixed bed $(100 \mathrm{Fe} / 3 \mathrm{Cu} / 0.2 \mathrm{~K})$ tests.

\section{Catalyst Characterization Studies}

The catalyst $(100 \mathrm{Fe} / 3 \mathrm{Cu} / 0.2 \mathrm{~K})$ used for the activation studies in fixed bed reactors was characterized using temperature-programmed reduction (TPR), isothermal reduction and $X$-ray photoelectron spectroscopy (XPS). A brief description of procedures and summary of pertinent results is given below.

Temperature-programmed and isothermal reduction studies were performed using both $5 \%$ $\mathrm{H}_{2} / \mathrm{N}_{2}$ and $5 \% \mathrm{CO} / \mathrm{He}$ mixtures as reducing agents at atmospheric pressure. The consumption of $\mathrm{H}_{2}$ or $\mathrm{CO}$ was measured by the change in thermal conductivity of the effluent gas stream. Catalyst sample weights of 10 to $15 \mathrm{mg}$ and reductant flow rates of $12 \mathrm{cc} / \mathrm{min}$ were used in all experiments. A temperature program rate of $20^{\circ} \mathrm{C} / \mathrm{min}$ from room temperature to $800^{\circ} \mathrm{C}$ was used in TPR experiments, or to $300^{\circ} \mathrm{C}$ in isothermal reductions. The latter temperature was maintained for $12 \mathrm{~h}$ or $8 \mathrm{~h}$ in reductions with $\mathrm{H}_{2}$ and $\mathrm{CO}$, respectively.

TPR reduction studies of calcined samples (in air at $300^{\circ} \mathrm{C}$ for $16 \mathrm{~h}$ ) have revealed that reduction of $\mathrm{Fe}_{2} \mathrm{O}_{3}$ occurs in two steps (1) $\mathrm{Fe}_{2} \mathrm{O}_{3} \rightarrow \mathrm{Fe}_{3} \mathrm{O}_{4}$, and (2) $\mathrm{Fe}_{3} \mathrm{O}_{4} \rightarrow \mathrm{Fe}$, and that 
both steps of iron reduction occur more rapidly in $\mathrm{CO}$ than in $\mathrm{H}_{2}$. The same behavior and trends were also observed under isothermal reductions. The times required for completion of iron reduction to the zero-valent state were found to be: 300 and $60 \mathrm{~min}$, for $\mathrm{H}_{2}$ and $\mathrm{CO}$ reductants, respectively.

These two techniques, TPR and isothermal reduction, can differentiate the reducibility of the bulk composition but do not provide information on the surface composition after reduction. XPS studies complement these reduction studies by providing information about the identity of the surface iron phases. XPS measurements were performed using a Hewlett-Packard Model 5950 A ESCA spectrometer, which was equipped with an Al $K_{\alpha} X$-ray source monochromator used at a $1250.0 \mathrm{eV}$ accelerator potential setting. Samples were in the form of pressed disks, and were handled under a dry, $\mathrm{O}_{2}$-free $\mathrm{N}_{2}$ atmosphere during spectrometer loading to prevent surface reoxidation due to atmospheric $\mathrm{H}_{2} \mathrm{O}$ and $\mathrm{O}_{2}$.

XPS studies of the calcined catalyst sample after isothermal reduction with $\mathrm{H}_{2}$ or $\mathrm{CO}$ at $300^{\circ} \mathrm{C}$ for $12 \mathrm{~h}$ have revealed the following. The surface of $\mathrm{H}_{2}$ reduced catalyst consists of approximately $45 \% \mathrm{Fe}_{2+} / \mathrm{Fe}_{3}$ - iron, and $55 \%$ of zero valent iron, which is in contrast with the result obtained from the isothermal reduction. This is probably due to reoxidation of surface iron by water, a byproduct of reduction in $\mathrm{H}_{2}$. On the other hand, $\mathrm{CO}$ treatment leads to quantitative reduction of iron to the zero valent metallic state. This treatment also results in deposition of surface carbon.

The activation parameters (temperature, gas flow rate and duration) employed in characterization studies were not the same as those employed in the fixed bed catalytic studies, but they nevertheless provide useful information on the qualitative differences between $\mathrm{H}_{2}$ and $\mathrm{CO}$ reductions.

\section{V.1.4. Discussion}

\section{CO Activations}

The major findings from our catalytic tests conducted at $250^{\circ} \mathrm{C}, 1.48 \mathrm{MPa}, 2 \mathrm{NI} / \mathrm{g}$-cat.h, and $\mathrm{H}_{2} / \mathrm{CO}=1$, following activations with $\mathrm{CO}$ under different conditions, are: (1) The catalyst displayed high initial activity, which decreased with time on stream; (2) Catalyst stability and selectivity were affected by differences in the activation parameters (temperature, pressure and duration). Activation at atmospheric pressure $(0.1 \mathrm{MPa})$ gave a more stable catalyst than that at $1.48 \mathrm{MPa}$, whereas the effects of activation temperature and duration on catalyst stability and selectivity could not be separated. 
Pichler, as described by Storch et al. (1951, pp. 290-297) and Anderson (1956, pp. 176-180), used $\mathrm{CO}$ and syngas activations in studies with alkalized precipitated iron catalysts with and without $\mathrm{Cu}$ promoter. He studied the effects of activation (induction) pressure and temperature on catalyst activity and stability. The length of induction was 25 hours with a gas flow of $0.4 \mathrm{NI} / \mathrm{gFe} . \mathrm{h}$, and subsequent synthesis was conducted with $\mathrm{H}_{2} / \mathrm{CO}=2 / 3$ gas at $1.52 \mathrm{MPa}, 2350 \mathrm{C}$ and $0.4 \mathrm{NI} / \mathrm{gFe} / \mathrm{h}$. He found that activation with $\mathrm{CO}$ was superior to that with $\mathrm{H}_{2} / \mathrm{CO}=2 / 3$ syngas, and that the optimum pretreatment conditions were $325^{\circ} \mathrm{C}$ and $0.01 \mathrm{MPa}$ (absolute). Activation with $\mathrm{CO}$ at atmospheric pressure $(0.1 \mathrm{MPa}$ ) was not greatly inferior in terms of catalyst activity and stability during the synthesis, whereas activation at 1.5 $\mathrm{MPa}$ (synthesis pressure) led to lower activity and rapid deactivation with time on steam. Characterization studies of activated catalysts, by acid decomposition and thermomagnetic methods, revealed that lower induction pressures result in higher carbide content (Hägg or $\chi$ carbide) and lower concentrations of free carbon deposited on the catalyst. Activations at temperatures in the range $255-305^{\circ} \mathrm{C}$ led to catalyst deactivation, whereas catalyst activated at 325 and $345^{\circ} \mathrm{C}$ displayed high stability at gas contractions of $52-55 \%$ (high $\left(\mathrm{H}_{2}+\mathrm{CO}\right)$ conversions) over 120 and 80 days of synthesis, respectively. Characterization studies revealed that the catalyst activated at high temperatures $\left(325-345^{\circ} \mathrm{C}\right)$ was converted almost completely to Hägg carbide, whereas activations at lower temperatures resulted in formation of a mixture of hexagonal carbides, magnetite and free carbon. On the basis of these results, it was speculated that Hägg carbide is the active phase which resists chemical change during the synthesis. The loss of activity was believed to be related to progressive conversion of Hägg carbide to magnetite.

Zarochak and McDonald $(1986,1987)$ used $\mathrm{CO}$ activation at $280^{\circ} \mathrm{C}, 1.48 \mathrm{MPa}, 1.3 \mathrm{NI} / \mathrm{g}-$ cat.h for $24 \mathrm{~h}$ in their studies with a precipitated $100 \mathrm{Fe} / 1 \mathrm{Cu} / 0.5 \mathrm{~K}$ catalyst. As revealed by Mössbauer spectroscopy, the catalyst was essentially completely reduced/carbided to $\chi$-carbide during $24 \mathrm{~h} \mathrm{CO}$ activation. Following the in situ activation in a slurry reactor, the catalyst was tested at a gas space velocity of approximately $2.5 \mathrm{NI} / \mathrm{g}$-cat.h, $260^{\circ} \mathrm{C}, 1.48 \mathrm{MPa}$ using a synthesis gas with an $\mathrm{H}_{2} / \mathrm{CO}$ feed ratio of 1 or 0.7 . In the test with $1: 1$ syngas, $\mathrm{CO}$ conversion decreased slowly from $88.8 \%$ at $95 \mathrm{~h}$ to $80.4 \%$ at $359 \mathrm{~h}$, whereas in the test with $\mathrm{H}_{2} / \mathrm{CO}=0.7$ syngas, catalyst deactivation was much higher. The $\mathrm{CO}$ conversion was about $80 \%$ at $100 \mathrm{~h}$ but only $25 \%$ at $260 \mathrm{~h}$ on stream. This shows that catalyst stability is not determined solely by the pretreatment, but also by process conditions (oxidizing/reducing environment) during 
the synthesis.

On the basis of results from the literature and the present study it seems difficult to maintain a constant catalyst activity over a long period of time. Pichler was able to achieve high stability over a long period of time with $\mathrm{CO}$ pretreatments at 325 and $345^{\circ} \mathrm{C}$ and subatmospheric pressure. These conditions (high temperature and low pressure) are not suitable for in-situ activations in slurry reactors and thus were not employed initially in our study. We have also used Pichler's type of activation, pure $\mathrm{CO}$ at $0.1 \mathrm{MPa}, 335^{\circ} \mathrm{C}$, and $3 \mathrm{NI} / \mathrm{g}$-cat.h, in a study with another precipitated iron catalyst $(100 \mathrm{Fe} / 3 \mathrm{Cu} / 0.5 \mathrm{~K})$. Subsequent synthesis was conducted at $1.48 \mathrm{MPa}, 260^{\circ} \mathrm{C}, 2 \mathrm{NI} / \mathrm{g}$-cat.h and $\mathrm{H}_{2} / \mathrm{CO}=0.64$ in a fixed bed reactor, but the catalyst deactivated rather rapidly. Initial $\left(\mathrm{H}_{2}+\mathrm{CO}\right)$ conversion was $74.2 \%$ but decreased to $50 \%$ after 70 hours at the process conditions (See Section VI.2.2).

In addition to the observed strong effect on catalyst stability, the activation parameters also influence the product selectivity. The activation temperature and duration largely determine the initial state of the catalyst, including bulk phases, surface oxidation states of iron and promoters, carbon deposited, and crystallite size. Although, the catalyst composition (bulk and surface) varies during the synthesis, it is clear that its initial state has a marked influence on the product selectivity. Detailed characterization studies of catalysts after activation and during the synthesis are necessary to try to explain differences in product selectivities arising from the use of different activation parameters.

$\mathrm{H}_{2}$ Activations

Four different activations with $\mathrm{H}_{2}$ as reducing agent were employed in the present study, and their effect on catalyst activity, stability, and selectivity during the synthesis may be summarized as follows: (1) Catalyst activity was either constant or gradually increased with time on stream (up to 120 hours) for all four reductions; (2) Activity was higher when the catalyst was reduced at lower temperature and/or when a shorter duration was employed. The latter effect was particularly evident for the two activations conducted at $280^{\circ} \mathrm{C}$; (3) The hydrocarbon product distributions were similar for all four activations, whereas the olefin content was lower and olefin isomerization was higher for activations conducted at $250^{\circ} \mathrm{C}$.

Pichler found that hydrogen reduction at high temperature (about $360^{\circ} \mathrm{C}$ ) is not effective in producing an active catalyst. Pennline et al. reported that activation with $\mathrm{H}_{2}$ at $275^{\circ} \mathrm{C}$ and $1.48 \mathrm{MPa}$ yielded an inactive catalyst (precipitated $\mathrm{Fe} / \mathrm{Mn}$ catalyst). Scheuermann (Anderson, 1956, pp.180-181) found that reduction in $\mathrm{H}_{2}$ at lower temperatures $\left(180-220^{\circ} \mathrm{C}\right.$ ) gives better 
activity than does reduction at $300^{\circ} \mathrm{C}$. All these results, including the ones obtained in our study, point to the fact that reductions in $\mathrm{H}_{2}$ at lower temperature result in improved activity. This can be explained by the fact that water vapor generated by reduction of iron in $\mathrm{H}_{2}$ enhances the rate of sintering, and this results in the formation of large crystallites and loss of active sites for the synthesis reaction. At higher activation temperature, the water is released more rapidly during the reduction and its partial pressure is higher than that occurring during the reduction at lower temperatures. Both of these effects, higher temperature and higher $\mathrm{H}_{2} \mathrm{O}$ concentration, would contribute to a larger degree of sintering and thus decrease catalyst activity. Similarly, longer duration will have a detrimental effect on catalyst activity due to a loss of active surface sites. Dry (1981, p. 179) states that high linear velocities of hydrogen are needed to obtain higher surface areas after the reduction, as this will result in rapid removal of water vapor. It should be noted, however, that after reduction to metallic iron is complete, continued treatment in $\mathrm{H}_{2}$ should not produce additional hydrothermal effects, such as waterinduced sintering, since byproduct water is no longer being generated. This is in contrast to the case for activation in $\mathrm{CO}$, where deposition of surface carbon or formation of carbides continues to occur, even after iron reduction is complete.

If the loss of activity is primarily caused by sintering, this can explain the fact that different reduction procedures did not have a significant effect on hydrocarbon selectivity. In other words, different pretreatments led to different numbers of active sites, which affects activity, but there is no change in the nature of the sites and thus no effect on product selectivity. Differences in olefin selectivity (lower olefin content and higher isomerization activity for activations at $250^{\circ} \mathrm{C}$ in comparison to those conducted at $280^{\circ} \mathrm{C}$ ) are at least partly caused by differences in conversions, as explained earlier (higher conversions favor secondary reactions).

In the absence of catalyst characterization following the reduction and after the synthesis, it is difficult to explain why the catalyst displayed a constant or gradually increasing activity during 120 hours of synthesis. A possible explanation was given by Dry (1981, p. 181) who reported that the activity of the partly reduced $\mathrm{Fe}-\mathrm{Cu}-\mathrm{SiO}_{2}-\mathrm{K}_{2} \mathrm{O}$ catalyst increases somewhat during several days of synthesis due to further reduction/carbiding which results in continued creation of active sites.

\section{Effect of the Reducing Gas}

Three different gases were employed for catalyst activation in the present study: $\mathrm{CO}(6$ activations), $\mathrm{H}_{2}$ (4 activations) and syngas with $\mathrm{H}_{2} / \mathrm{CO}=0.68$ ( 1 activation). Catalyst activity, 
stability, and selectivity during the synthesis were strongly affected by the nature of the reducing gas. The major findings from catalytic tests are: (1) Catalyst activated in $\mathrm{CO}$ or syngas had initially higher activity than the catalyst activated in $\mathrm{H}_{2}$, but the activity of the former decreased with time on stream, whereas the activity of the latter remained constant or gradually increased with time on stream; (2) $\mathrm{CO}$ and syngas activations favor the production of higher molecular weight products in comparison to $\mathrm{H}_{2}$ activations; (3) Water-gas-shift activity was higher with $\mathrm{H}_{2}$ activations than with $\mathrm{CO}$ activations.

In the early studies at Ruhrchemie (Anderson, 1956 pp.181-182) it was found that the catalyst pretreatment in syngas $\left(\mathrm{H}_{2} / \mathrm{CO}=1.3\right)$ yieids less methane and more high molecular weight products in comparison to the $\mathrm{H}_{2}$ reduction. The same trend was observed in studies conducted at the U.S. Bureau of Mines with a precipitated catalyst having a composition $100 \mathrm{Fe} / 10 \mathrm{Cu} / 0.5 \mathrm{~K}_{2} \mathrm{CO}_{3}$ (Anderson, $1984 \mathrm{pp} .56-58$ ). Activations with either syngas $\left(\mathrm{H}_{2} / \mathrm{CO}=2\right)$ or pure $\mathrm{CO}$ resulted in similar hydrocarbon product distributions and produced less gaseous hydrocarbons and more higher molecular products than did the $\mathrm{H}_{2}$ reduced catalyst. Thus the trends observed in our study concerning the effect of the reducing gas on catalyst selectivity and activity are in agreement with results from the literature. The reasons for the observed differences in selectivity resulting from the use of different reductants are not well understood. It appears that different activations lead to formation of different active sites and/or ensembles of sites on the catalyst surface.

In order to explain the observed differences in the catalyst activity for the FT and WGS reaction, some speculation concerning the nature of bulk phases of the catalyst after activation and during the synthesis is required. It will be assumed that $\mathrm{H}_{2}$ activations lead to formation of magnetite and metallic iron, whereas $\mathrm{CO}$ activations lead to formation of iron carbides and magnetite. The relative fractions of these phases are a function of activation temperature and duration. During the synthesis, metallic iron is converted rapidly to iron carbides, which in turn may be partially oxidized to magnetite (Anderson, 1956; Dry, 1981). The used catalyst consists of a mixture of iron carbides and magnetite.

Our results show that $\mathrm{CO}$ activated catalyst has higher initial activity than $\mathrm{H}_{2}$ reduced catalyst, which may indicate that iron carbides are more active for the synthesis than is magnetite and/or $\alpha-\mathrm{Fe}$. This is in agreement with results obtained at the U. S. Bureau of Mines (Anderson, 1984, p. 47) with a fused iron catalyst, where it was found that the catalysts converted to $\mathrm{Hägg}$ carbide are initially more active than $\mathrm{H}_{2}$ reduced (either partially or com- 
pletely) catalysts. A possible explanation for the observed activity trends may be given in terms of the competition model of Niemantsverdriet and van der Kraan (1981). In this model, the surface carbon (carbidic or active carbon) obtained by $\mathrm{CO}$ dissociation is the intermediate for FT synthesis. This surface species can participate in three reactions: (1) formation of bulk carbides; (2) hydrocarbon synthesis (by combining with surface hydrogen atoms); and (3) formation of inactive carbon (deactivation). Thus, during the synthesis with a partially carbided catalyst ( $\mathrm{CO}$ activations), more of the surface carbon is available for FT synthesis, whereas with $\mathrm{H}_{2}$ reduced catalysts some of the surface carbon is consumed to form the bulk carbides. Therefore, the rate of FT synthesis will be initially lower with $\mathrm{H}_{2}$ reduced catalysts. The $\mathrm{CO}$ reduced catalysts lose activity more rapidly from the blocking of active sites by inactive carbon and possibly also by high molecular weight hydrocarbons (recall that $\mathrm{CO}$ activated catalyst produced much more $\mathrm{C}_{12}+$ products than $\mathrm{H}_{2}$ activated catalyst).

The higher WGS activity of $\mathrm{H}_{2}$ activated catalysts, in comparison to carbided catalysts, was also observed in several previous studies with iron catalysts (Kölbel and Engelhardt, 1949; Anderson, 1984 (p. 45); Schultz et al., 1955). It was inferred that carbides are less active for the WGS than are reduced iron or magnetite. However, in a recent study by Satterfield et al. (1986b), with a fused iron catalyst, the WGS activity could not be correlated with a bulk concentration of magnetite.

Detailed catalyst characterization studies after activation and during the synthesis are needed to help explain catalytic results and provide a basis for development of improved catalysts.

\section{V.1.5. Related Studies}

In this section we present additional results which illustrate effects of activation parameters and reactor type on catalyst activity and hydrocarbon selectivities. These results were obtained from runs which were not specifically designed to study effects of activation parameters in a systematic way, as it was done in the previous section, but are included here since they extend the existing data base and provide some general trends.

\section{V.1.6. Additional Tests with the $100 \mathrm{Fe} / 3 \mathrm{Cu} / 0.2 \mathrm{~K}$ Catalyst}

The activity and stability of this catalyst as a function of time on stream during runs FB0029 and SA-3657 (Promoter Effect Research - Sections V.2.1 and V.2.3, respectively) and SB-2878 (Process Evaluation Research - Section V1.4.2) is shown in Figure V.1-10. Hydrogen reduced catalyst had high activity and excellent stability during the fixed bed test, but it 


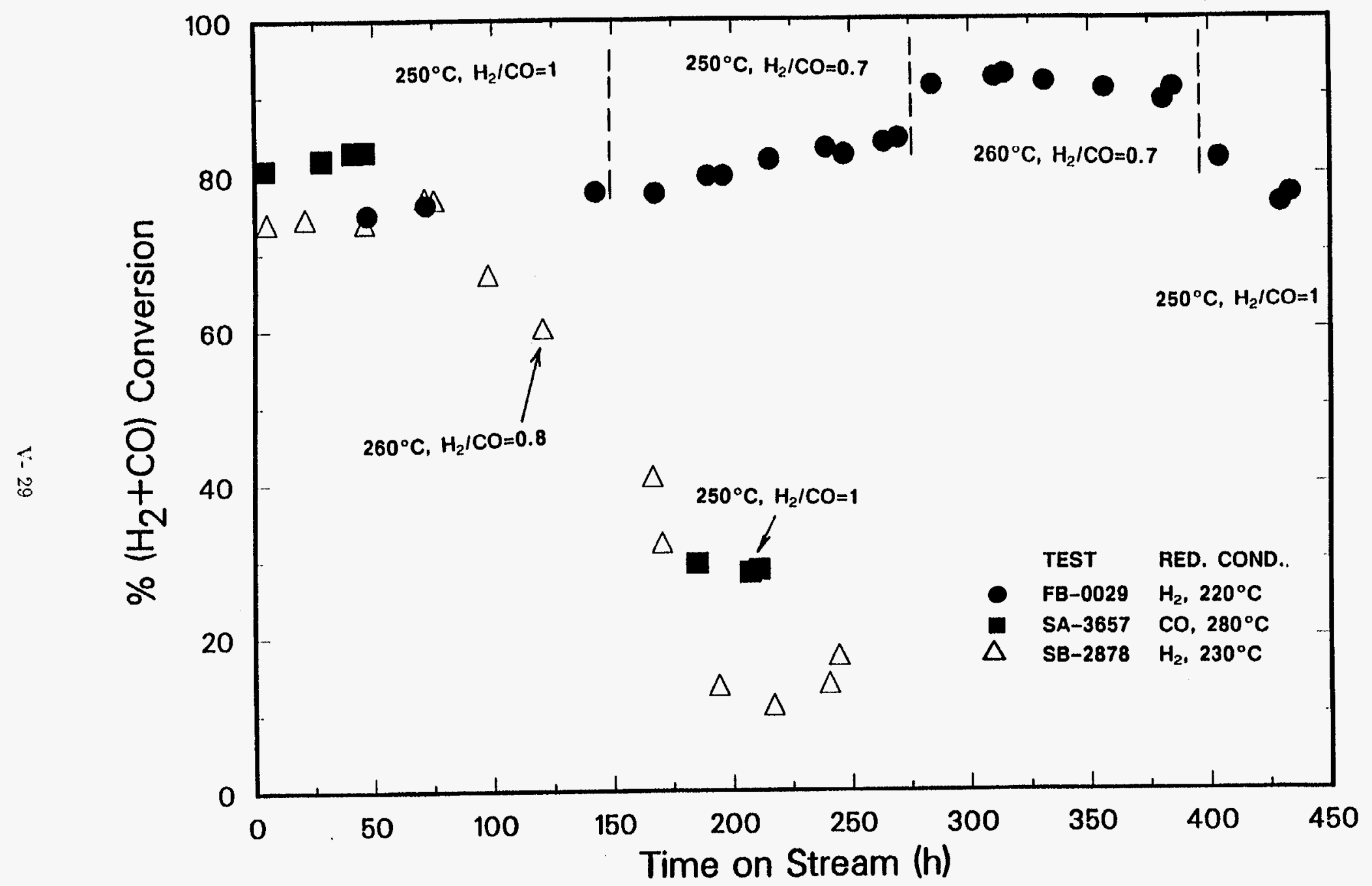

Figure V.1-10. Effect of activation conditions on activity and stability of the $100 \mathrm{Fe} / 3 \mathrm{Cu} / 0.2 \mathrm{~K}$ catalyst 
deactivated rather rapidly in a slurry bed reactor test. The catalyst activated with $\mathrm{CO}$ had higher initial activity than the $\mathrm{H}_{2}$ reduced catalyst, but it also deactivated rapidly (between 50 and 170 hours the catalyst was tested at different process conditions: SV=4 NI/g-cat.h at $250^{\circ} \mathrm{C}$, or SV $=2 \mathrm{NI} / \mathrm{g}$-cat.h at $235^{\circ} \mathrm{C}$ ).

Selected results from these tests and from some of the fixed bed reactor tests of this catalyst that were described in the previous section, are shown in Table V.1-5. Results show that catalyst activity decreases as the activation temperature increases, which is related to the enhanced catalyst sintering in the presence of $\mathrm{H}_{2} \mathrm{O}$ as discussed in section V.1.4 of this report. Catalyst reduced with $\mathrm{H}_{2}$ at $220^{\circ} \mathrm{C}$ had the same activity as that obtained when $\mathrm{CO}$ activation at $280^{\circ} \mathrm{C}$ was employed (the optimal activation procedure for this catalyst). However, the $\mathrm{H}_{2}$ reduced catalyst produced significantly more $\mathrm{CH}_{4}$ and light hydrocarbons than the $\mathrm{CO}$ activated catalyst. Hydrocarbon selectivities of $\mathrm{H}_{2}$ reduced catalysts show the following trend; The light gas fraction $\left(C_{2}-C_{4}\right)$ increases, whereas $C_{12}+$ fraction decreases as the reduction temperature increases. Methane yield of the catalyst reduced with $\mathrm{H}_{2}$ at $220^{\circ} \mathrm{C}$ was higher than that obtained in tests where higher reduction temperatures $\left(250\right.$ and $280^{\circ} \mathrm{C}$ ) were employed. It is interesting to note that catalysts from two different batches were employed in these tests. Tests FB-0029 and SB-2878 were conducted with catalyst from a new batch, whereas all other tests were conducted using catalyst from the first batch.

Results from two slurry bed reactor tests with the $100 \mathrm{Fe} / 3 \mathrm{Cu} / 0.2 \mathrm{~K}$ catalyst are also included in Table V.1-5 to illustrate effect of reactor type on activity and hydrocarbon product selectivity. The slurry bed operation gave better selectivity (less $\mathrm{CH}_{4}$ and $\mathrm{C}_{2}-\mathrm{C}_{4}$ hydrocarbons) in comparison to fixed bed reactor tests, with both $\mathrm{H}_{2}$ (Runs FB-0029 vs SB-2878) and CO (Runs FA-2967 vs SA-3657) activated catalysts, whereas the catalyst activity and stability were better in fixed bed reactor tests. During the run SA-3657, initial selectivity at $44 \mathrm{~h}$ on stream, was inferior to that obtained in the fixed bed run FA-2967, however it improved with time on stream (see Table V.2-7, Section V.2.3) even though the catalyst had partially deactivated. Hydrocarbon distribution at $91 \mathrm{~h}$ on stream ( $\mathrm{SV}=4 \mathrm{~N} / \mathrm{g}$-cat.h) had less methane and $\mathrm{C}_{2}-\mathrm{C}_{4}$ hydrocarbons, in comparison to the run FA-2967 in a fixed bed reactor.

\section{V.1.7. Activation Studies with the $100 \mathrm{Fe} / 3 \mathrm{Cu} / 0.5 \mathrm{~K}$ Catalyst}

This catalyst was evaluated in several runs : FB-3368 (Promoter Effect Research - Section V.2.2), FB-2438, FA-2518 and SB-2168 (Process Evaluation Research - Sections VI.2.1 and VI.4.1) using different activation procedures. Figure V.1-11 shows catalyst activity as a 
Table V.1-5. Erect of reduction procedure on calalyst activity and selectivity $(100 \mathrm{Fe} / 3 \mathrm{Cu} / 0.2 \mathrm{~K})^{a}$

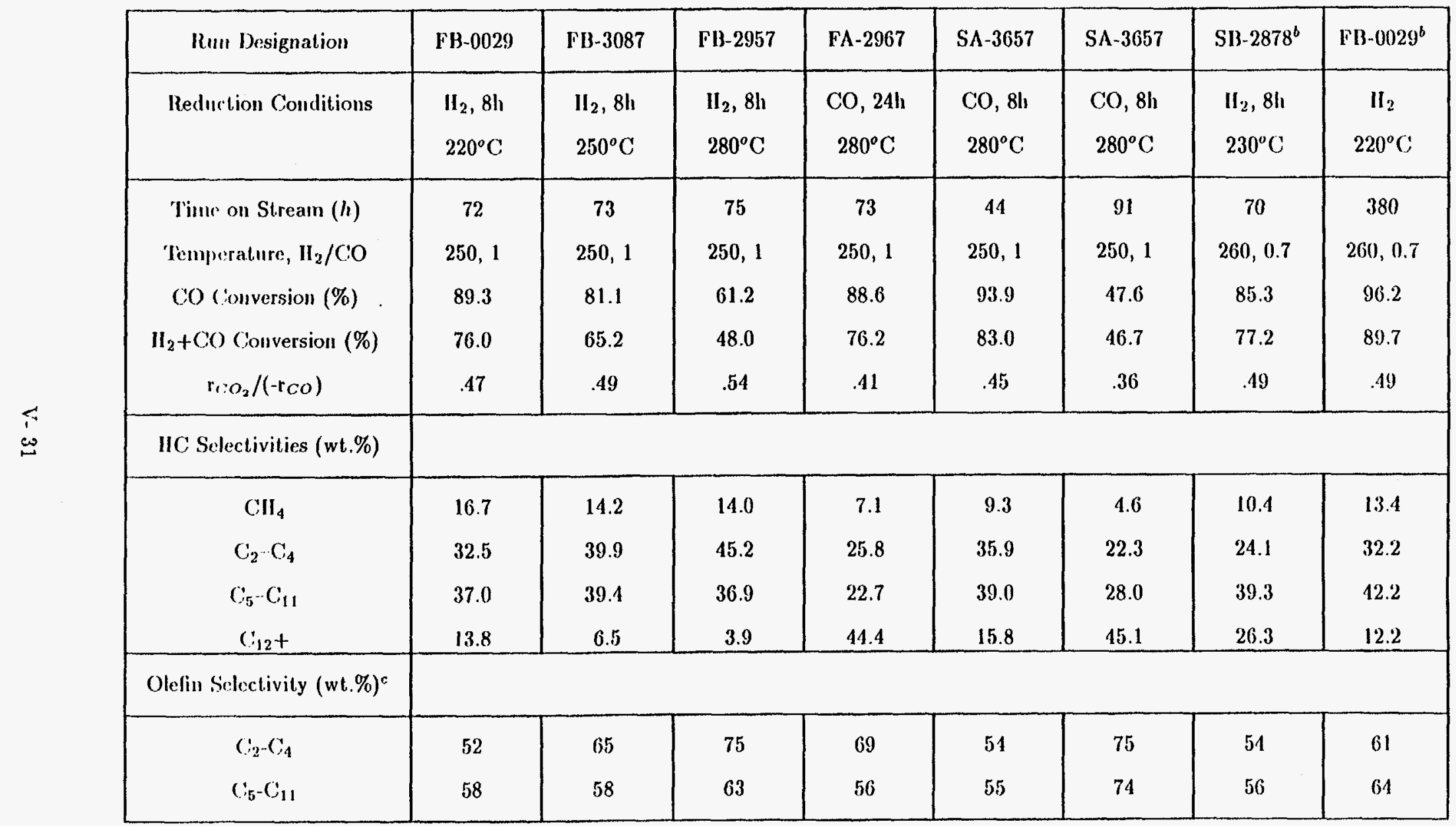

${ }^{a}$ all tests were made at 200 psig and SV $=2 \mathrm{NI} / \mathrm{g}$-cat.h

${ }^{b}$ catalyst. from the second batch was used in these runs

${ }^{c} 100^{*}$ Olelin/(Olefin+Paraffin) 


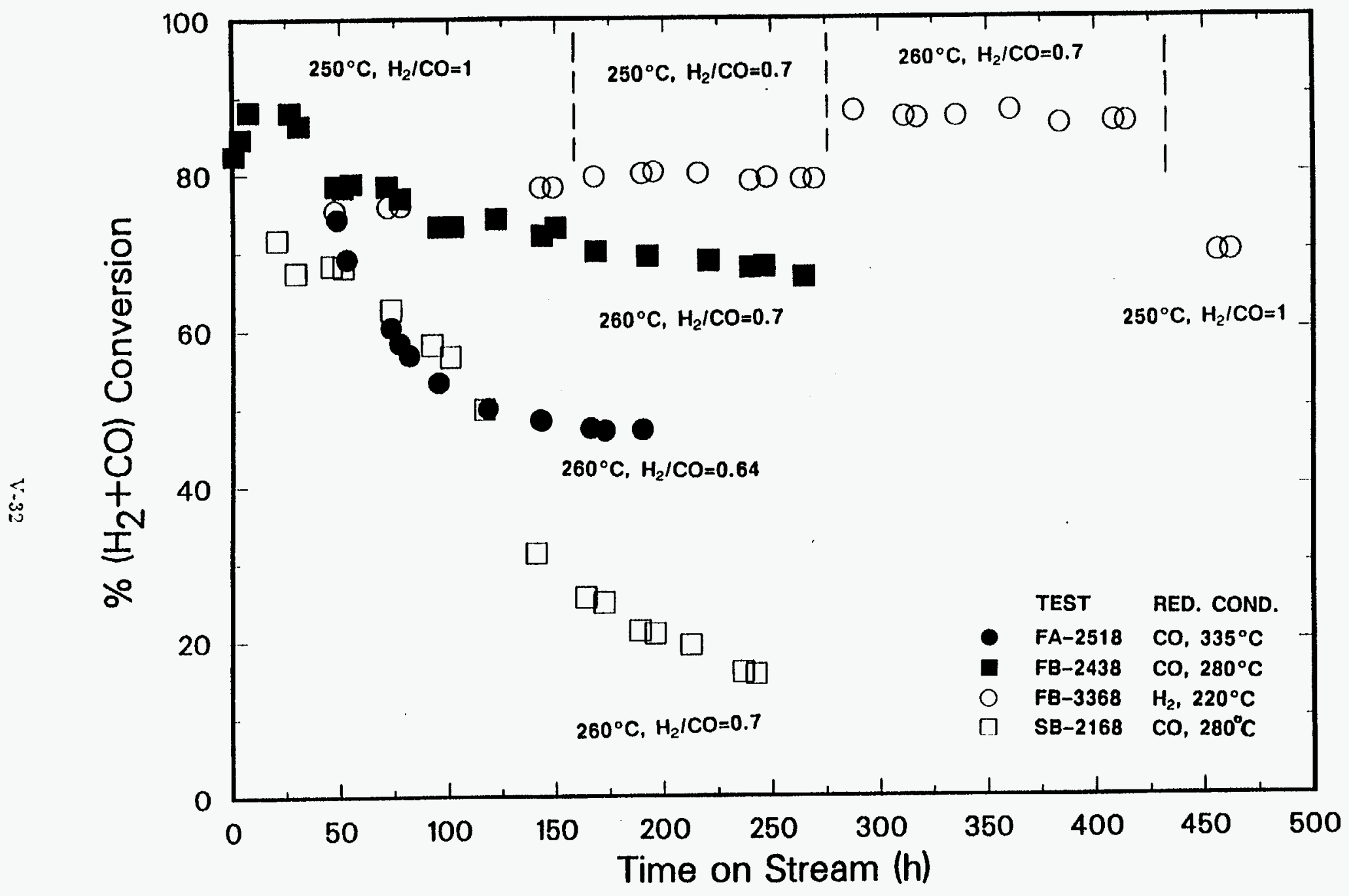

Figure V.1-11. Effect of activation conditions on activity and stability of the $100 \mathrm{Fe} / 3 \mathrm{Cu} / 0.5 \mathrm{~K}$ catalyst 
function of time on stream. The reduction with $\mathrm{H}_{2}$ at $220^{\circ} \mathrm{C}$ gave high activity and excellent stability over a long period of time, whereas the $\mathrm{CO}$ activated catalyst had high initial activity but it deactivated with time on stream. The rate of deactivation is a function of activation temperature and duration. In the slurry bed reactor test (Run SB-2168) the catalyst was accidentally exposed to a mixture of $\mathrm{CO}$ and helium at $260^{\circ} \mathrm{C}$ for about $27 \mathrm{~h}$ following the $\mathrm{CO}$ activation at $280^{\circ} \mathrm{C}$ for $12 \mathrm{~h}$, which might have accelerated its deactivation. The catalyst activated with $\mathrm{CO}$ at $335^{\circ} \mathrm{C}$ for $24 \mathrm{~h}$ (optimal Pichler's activation discussed in Section V.1.4) also deactivated rather rapidly during synthesis.

Hydrocarbon selectivities obtained during these four tests are shown in Table V.1-6. Similar trends were observed as in tests with the $100 \mathrm{Fe} / 3 \mathrm{Cu} / 0.2 \mathrm{~K}$ catalyst, i.e., (1) $\mathrm{H}_{2}$ reduced catalyst favored production of lower molecular weight products (FB-3368 vs. FB-2438) and (2) less methane and gaseous hydrocarbons were produced in a slurry reactor than in a fixed bed reactor (SB-2168 vs. FB-2438).

Pichier's activation procedure (FA-2518) produced more methane than the $\mathrm{H}_{2}$ reduced catalyst, but the total fraction of gaseous hydrocarbons $\left(C_{1}-C_{4}\right)$ was lower with the $C O$ activated catalyst.

\section{V.1.8. Summary}

On the basis of tests with several precipitated catalysts $(100 \mathrm{Fe} / 3 \mathrm{Cu} / 0.2 \mathrm{~K}$ or $0.5 \mathrm{~K}$ and $100 \mathrm{Fe} / 0.3 \mathrm{Cu} / 0.5 \mathrm{~K}$ ) the following observations regarding effects of activation parameters and/or reactor type (slurry vs. fixed bed reactor) on catalyst activity and selectivity during Fischer-Tropsch synthesis can be made.

(1) Activation parameters (temperature, duration, pressure and the nature of reducing gas) have strong influence on catalyst activity, selectivity and stability for the Fischer-Tropsch synthesis reaction.

(2) Catalysts activated with $\mathrm{CO}$ were initially more active than catalysts activated with $\mathrm{H}_{2}$, however the activity of $\mathrm{CO}$ activated catalysts declined with time while the activity of $\mathrm{H}_{2}$ activated catalysts increased or remained constant. The activity of the $\mathrm{H}_{2}$ reduced catalysts can be improved by using lower reduction temperatures.

(3) The $\mathrm{CO}$ activated catalysts produced less methane and other gaseous hydrocarbons than $\mathrm{H}_{2}$ reduced catalysts in fixed bed reactor studies.

(4) Slurry bed operation gives better selectivity (less methane and gaseous hydrocarbons) than the fixed bed under the same process conditions. Also, the effect of reducing gas $\left(\mathrm{H}_{2}\right.$ 


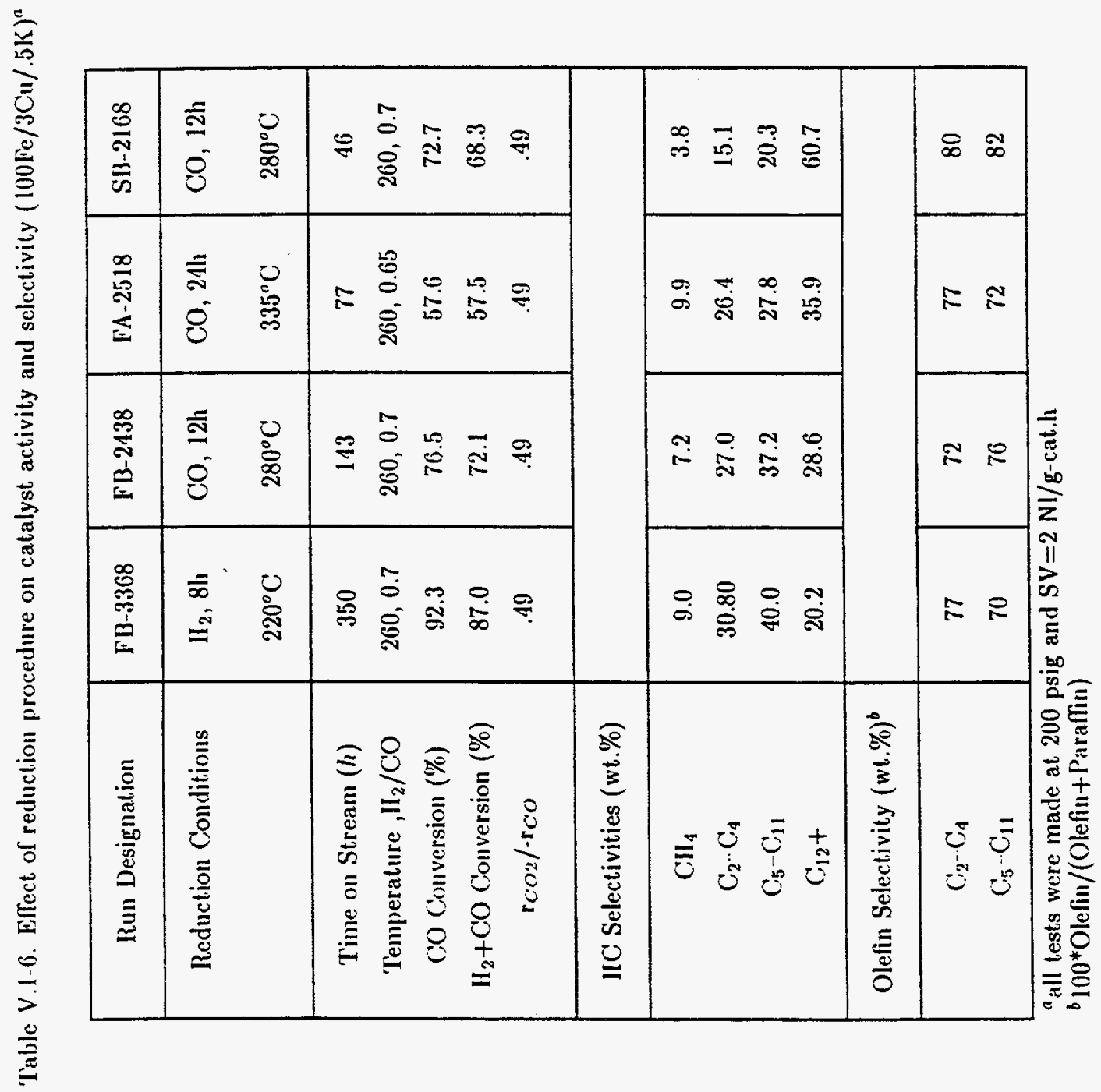


v5. $\mathrm{CO}$ ) on product selectivity seems to be less pronounced in slurry bed reactors, but additional tests are needed to confirm these trends. Activity maintenance is more difficult to achieve in slurry bed reactors due to problems associated with wax removal. Hydrocarbon selectivities in a stirred tank reactor test with the $100 \mathrm{Fe} / 0.3 \mathrm{Cu} / 0.5 \mathrm{~K}$ catalyst, were similar regardless of the reducing gas employed $\left(\mathrm{H}_{2}\right.$ or $\left.\mathrm{CO}\right)$.

(5) The $\mathrm{CO}$ and syngas activations produce catalysts with high activity and good selectivity. However, these catalysts do not have good stability and their performance deteriorates with time on stream.

(6) Detailed catalyst characterization studies are needed to help explain the observed differences in results following different activation procedures. 


\section{V.2. Promoter Effect Research}

\section{V.2.1. Fixed Bed Reactor Tests with Hydrogen Activated Catalysts}

\section{V.2.1.1. Literature Review}

It is well known that the stronger bases of the Group IA metals, especially potassium, are essential promoters in iron catalysts for Fischer-Tropsch synthesis. They have a marked effect on both the activity and selectivity of iron catalysts. Other promoters and/or carriers ( $\mathrm{CuO}$, Group $\mid \mathrm{l}$ metal oxides, $\mathrm{Al}_{2} \mathrm{O}_{3}$ and $\mathrm{SiO}_{2}$ ) are added mainly to facilitate iron reduction, stabilize a high metal surface area, improve the mechanical properties, or to modify the selectivity by a small amount, however their effects are usually small in comparison to that of potassium (Anderson, 1956; Dry, 1981).

The overall effects of potassium on the behavior of iron catalysts have been extensively investigated and are well established. Kölbel (1960) reported results of chemisorption measurements with $\mathrm{CO}$ and $\mathrm{H}_{2}$ on reduced precipitated iron catalyst, and of changes in electrical resistance upon $\mathrm{CO}$ and $\mathrm{H}_{2}$ chemisorption on evaporated iron films and foils. He found that potassium promotion increases $\mathrm{CO}$ chemisorption and decreases $\mathrm{H}_{2}$ chemisorption. This was explained by the fact that potassium donates electrons to iron facilitating $\mathrm{CO}$ chemisorption, since $\mathrm{CO}$ tends to accept electrons from iron. On the other hand, hydrogen at higher surface coverages donates electrons to iron (electron affinity decreases upon $\mathrm{H}_{2}$ chemisorption) and the presence of electron donating alkali would be expected to weaken the iron-hydrogen bond. The net result of potassium promotion is a strengthening of the $\mathrm{Fe}-\mathrm{C}$ bond, and weakening of the $\mathrm{C}-\mathrm{O}$ and $\mathrm{Fe}-\mathrm{H}$ bonds. These findings have been confirmed in several subsequent studies on different types of iron surfaces (e.g., Dry et. al., 1969; Benziger and Madix, 1980; Arakawa and Bell, 1983).

The effect of potassium on activity and product selectivity has been studied over a variety of iron based catalysts (e.g., Anderson et al., 1952; Anderson, 1956; Kölbel and Giehring 1963; Dry and Oosthuizen, 1968; Bonzel and Krebs, 1981; Dry, 1981; Arakawa and Bell, 1983; Dictor and Bell, 1986; Donnelly and Satterfield, 1989). General observations regarding the effect of potassium promotion on iron catalysts for the FT synthesis include: (1) increase in average molecular weight (chain length) of hydrocarbon products (i.e., decrease in production of methane and light gases); (2) increase in olefin selectivity; (3) increase in activity for the water-gas-shift (WGS) reaction; (4) increase in carbon deposition and catalyst deactivation rate; and (5) increase in FT activity at low potassium concentrations, followed by decrease at 
higher levels of promotion.

Copper has been widely used as one of promoters for FT synthesis on iron catalysts, particularly in bubble column slurry reactors (Kölbel and Ralek, 1980; Deckwer et al., 1982; Kuo, 1985). Its function is to decrease the temperature required for reduction of iron oxides. While several studies have been made of the individual effect of potassium promotion on unsupported iron, only a few investigations have been reported for copper promotion of precipitated iron catalysts that contain no potassium.

Kölbel et al. (1951) observed increase in the overall activity at very low levels (ca. 0.1 wt \%) of copper promotion, with no further effects at higher copper loadings. Wachs et al. (1984) reported that product distributions do not change appreciably when copper is incorporated into an iron catalyst for experiments in a differential fixed bed reactor ( $\mathrm{CO}$ conversion less than $1 \%)$.

Although the qualitative effects of potassium promotion on catalyst activity and selectivity have been clearly established in the above studies, the data illustrating quantitative effects at conditions of industrial relevance (elevated pressure, $\mathrm{CO}$ rich feed gas, high reactant conversions, steady state operation in the absence of significant catalyst deactivation) are still lacking. The present study was undertaken to provide detailed information on (I) individual effects of potassium and copper promotion (singly promoted $\mathrm{Fe} / \mathrm{K}$ and $\mathrm{Fe} / \mathrm{Cu}$ catalysts), and (2) combined promotional effects of copper and potassium (doubly promoted $\mathrm{Fe} / \mathrm{Cu} / \mathrm{K}$ catalysts) on activity and product selectivity of precipitated iron catalysts for Fischer-Tropsch synthesis at process conditions representative of industrial practice. Particular attention was given to the effects of promoters, reaction temperature and gas space velocity on FT and WGS activity, hydrocarbon product distribution, and olefin and oxygenates selectivities as a function of carbon number.

\section{V.2.1.2. Experimental Procedure}

Typically, $3.5 \mathrm{~g}$ of the catalyst $(3 \mathrm{cc}$ ) was diluted 1:8 by volume with glass beads of the same size range (30/60 mesh) and charged into the reactor. All catalysts were reduced with hydrogen at $220^{\circ} \mathrm{C}, 500 \mathrm{cc} / \mathrm{min}$ and atmospheric pressure for 8 hours.

Seven catalysts were employed in the present study: an unpromoted iron, copper promoted catalyst ( $100 \mathrm{Fe} / 3 \mathrm{Cu}$, in parts per weight), three potassium promoted catalysts ( $100 \mathrm{Fe} / \mathrm{K} \mathrm{K}$, where $x=0.2,0.5$ and 1.0$)$, and two doubly promoted catalysts $(100 \mathrm{Fe} / 3 \mathrm{Cu} ; 0.2 \mathrm{~K}$ or $0.5 \mathrm{~K})$. Concentrations of promoters in the two doubly promoted catalysts were chosen to be the same 
as those of the singly promoted catalysts, in order to study their combined effect and provide means of comparison with the singly promoted catalysts.

Following reduction, the flow was switched to helium and the bed was cooled down to $190^{\circ} \mathrm{C}$. The system was then pressurized to $1.48 \mathrm{MPa}$, the helium flow was cut off, and synthesis gas $\left(\mathrm{H}_{2}: \mathrm{CO}=1: 1\right)$ was introduced at a gas space velocity (SV) of $2 \mathrm{~N} / \mathrm{g}$-cat.h. The bed temperature was gradually increased to $250^{\circ} \mathrm{C}$ over a period of $30 \mathrm{~h}$. The first mass balance was conducted after additional $40 \mathrm{~h}$ on stream. Catalytic tests typically lasted about $170 \mathrm{~h}$, during which time five mass balances were made. One of these balances was a repeat of the base set of conditions: $1.48 \mathrm{MPa}, 2 \mathrm{Nl} / \mathrm{g}$-cat. $\mathrm{h}$ and either $235^{\circ} \mathrm{C}$ (100 Fe/1 K catalyst) or $250^{\circ} \mathrm{C}$ (for the other six catalysts), whereas others were conducted at different process conditions. The effect of reaction temperature $\left(235,250\right.$ and $265^{\circ} \mathrm{C}$ ) was studied at $S V=2$ $\mathrm{NI} / \mathrm{g}$-cat.h, and the effect of gas flow rate $(\mathrm{SV}=2$ and $4 \mathrm{NI} / \mathrm{g}$-cat.h; or $1 \mathrm{NI} / \mathrm{g}$-cat.h for the unpromoted catalyst) was studied at $250^{\circ} \mathrm{C}$. Tests with the two doubly promoted catalysts had longer duration (about $460 \mathrm{~h}$ ) and no balances were made at $265^{\circ} \mathrm{C}$. Instead, several mass balances were made with $\mathrm{H}_{2} / \mathrm{CO}=0.67$ feed gas at $250^{\circ} \mathrm{C}$ and $260^{\circ} \mathrm{C}$, between about 150 and $400 \mathrm{~h}$ on stream. Results at these process conditions have been presented in Sections V.1.6 and V.1.7 of this report.

\section{V.2.1.3. Results and Discussion}

\section{Activity and Stability of Catalysts}

Effects of reaction temperature and time on stream at $250^{\circ} \mathrm{C}$ on FT activity, measured by $\left(\mathrm{H}_{2}+\mathrm{CO}\right)$ conversion, are shown in Figures V.2-1a and V.2-1b, respectively. $\left(\mathrm{H}_{2}+\mathrm{CO}\right)$ conversion increases with the addition of either copper or potassium, but copper has a more pronounced effect on catalyst activity than does potassium at all three reaction temperatures. The activity increases significantly with increasing potassium content up to $0.5 \mathrm{~g}$ of $\mathrm{K}$ per 100 $\mathrm{g}$ of iron, but beyond this promoter concentration the effect is small $(0.5 \mathrm{~K}$ vs. $1 \mathrm{~K}$ per $100 \mathrm{Fe})$. A synergistic effect is observed with doubly promoted catalysts, which have higher activity than singly promoted catalysts. Also, activities of the two doubly promoted catalysts were similar at both, $235^{\circ} \mathrm{C}$ and $250^{\circ} \mathrm{C}$, i.e., the activity was independent of potassium content of the catalyst. $\left(\mathrm{H}_{2}+\mathrm{CO}\right)$ conversion increases with increasing reaction temperature, as expected.

In several previous studies with iron catalysts (Anderson et al., 1952; Anderson, 1956; Kölbel 1960, Kölbel and Giehring, 1963; Dry, 1981), it was reported that the overall catalyst activity either increases with potassium promotion or it passes through a maximum as a function 

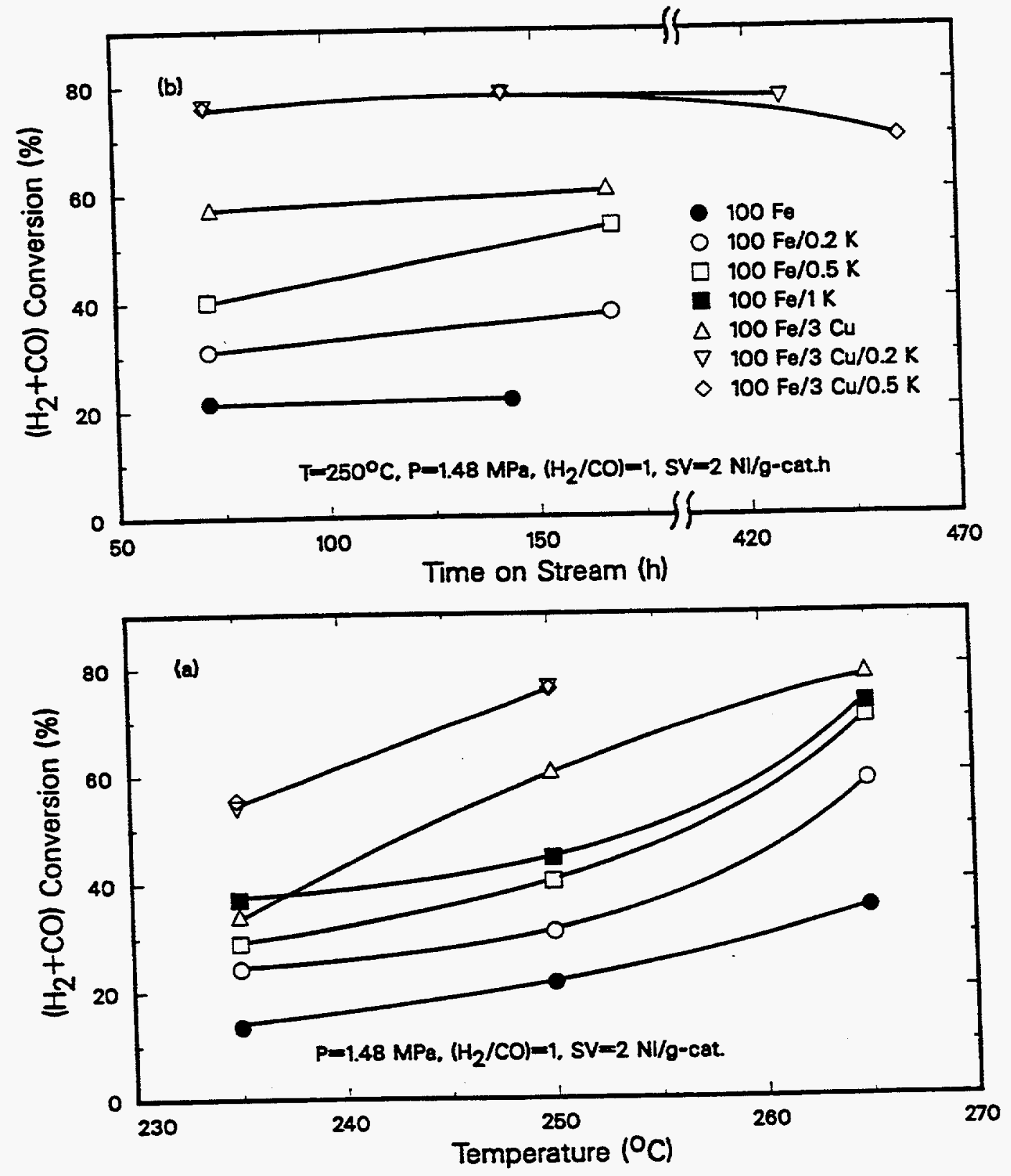

Figure V.2-1. Promoter effects on catalyst activity and stability, (a) $\left(\mathrm{H}_{2}+\mathrm{CO}\right) \mathrm{Con}-$ version vs. reaction temperature, and (b) $\left(\mathrm{H}_{2}+\mathrm{CO}\right)$ Conversion vs. time on stream at $250^{\circ} \mathrm{C}$. 
of potassium loading. On the other hand, Pichler (1952) reported that potassium in $0-5 \mathrm{wt} \%$ $\mathrm{K}_{2} \mathrm{CO}_{3}$ range, had no effect on activity, whereas Arakawa and Bell (1983) and Dictor and Bell (1986) found that the activity of $\mathrm{Fe} / \mathrm{K}$ catalysts was lower than that of the unpromoted catalyst. Arakawa and Bell employed an alumina supported catalyst containing $20 \%$ by weight of iron and $\mathrm{K} / \mathrm{Fe}$ atomic ratios of $0.022-0.20$. The latter ratios correspond to catalyst compositions of approximately $1.5-15 \mathrm{~g}$ of $\mathrm{K}$ per $100 \mathrm{~g}$ of $\mathrm{Fe}$, and are significantly higher than those employed in previous studies including the present one. At the lowest potassium loading ( $100 \mathrm{Fe} / 1.5 \mathrm{~K}$ ) the activity of the promoted catalyst was similar to that of the unpromoted catalyst. Lower activities were obtained at high potassium loadings which is consistent with results obtained in other studies. Dictor and Bell conducted experiments in a stirred tank slurry reactor at low $\mathrm{CO}$ conversions (less than $5 \%$ ) with unpromoted hematite $\left(\mathrm{Fe}_{2} \mathrm{O}_{3}\right)$ powder, and potassium promoted $\mathrm{Fe}_{2} \mathrm{O}_{3}(100 \mathrm{Fe} / 0.8 \mathrm{~K}$ ). In this study, the catalysts were not activated prior to exposure to the synthesis gas $\left(\mathrm{H}_{2} / \mathrm{CO}=3\right)$ at $250^{\circ} \mathrm{C}$ and $8 \mathrm{~atm}$, and it is possible that they had not reached their steady state activity.

The increase in catalyst activity with addition of potassium has been explained in terms of its structural and/or chemical promotional effects. Kölbel and co-workers $(1960,1963)$ made extensive characterization studies of catalysts with and without alkali, and found that potassium added in small amounts stabilizes surface area of the precipitated iron oxyhydrides and protects it against recrystalization during calcination. Reduced catalysts had maximum metal dispersion at potassium loadings of 0.15 and $0.3 \mathrm{wt} \%$. The maxima in catalyst activity during synthesis were observed at these potassium loadings. Kölbel (1960) postulated that the reduced catalysts containing potassium had a much higher concentration of active sites than an unpromoted catalyst. At higher promoter concentrations, the active sites may be covered by potassium resulting in decline of the catalyst activity. Furthermore, increase in potassium fosters carbon deposition which blocks the active surface area leading to further deciine in activity.

An alternative explanation for the promotional effect of alkali on the rate of $F T$ was given by Dry and co-workers (Dry and Oosthuizen, 1968; Dry et al., 1969), who conducted studies on alkali promoted magnetite. They found that addition of alkali causes a decrease in surface area, which lead them to postulate that the promotional effect must be chemical in nature. As stated earlier, potassium promotion strengthens the metal-carbon bond, and weakens the carbon-oxygen bond. The latter facilitates removal of oxygen by hydrogen which is an essential 
step in FT. According to Dry et al. (1969) the addition of alkali increases the rate of FT by increasing the rate of formation of the intermediate hydroxyl surface complexes.

The increase in activity with copper addition that was found in the present study, is in agreement with results obtained by Kölbel et al. (1951) at $230^{\circ} \mathrm{C}, \mathrm{H}_{2} / \mathrm{CO}=2$ and atmospheric pressure. Kölbel et al. observed an increase in overall activity at very low promoter levels (ca. $0.1 w t \%$ of $\mathrm{Cu}$ ), and further increases in the copper level had no additional effect. Deckwer et al. (1982) reported that $100 \mathrm{Fe} / 5.3 \mathrm{Cu}$ catalyst had activity comparable to that of alkali promoted iron catalysts employed in previous studies of FT in slurry reactors, but they did not report any results for an unpromoted catalyst. The reasons for increased catalyst activity with the addition of copper are not clearly understood. It is known that copper facilitates reduction of iron, and that the total surface area of the catalyst decreases with the extent of metal reduction (Dry, 1981). This suggests that the higher activity of $\mathrm{Fe} / \mathrm{Cu}$ catalysts relative to unpromoted iron may be attributed to differences in the size and number of $\alpha-\mathrm{Fe}$ and/or iron carbide crystallites during synthesis.

The effect of time on stream on FT activity at $250^{\circ} \mathrm{C}$ and $2 \mathrm{NI} / \mathrm{g}$-cat.h is illustrated in Figure V.2-1b. The activity of all catalysts during the first mass balance at $250^{\circ} \mathrm{C}$ ( 72 hours on stream) was lower than the activity at 142-168 hours when the base conditions were repeated. The increase in activity was rather small, less than $5 \%$, for the two doubly promoted catalysts, the unsupported iron catalyst and the $100 \mathrm{Fe} / 3 \mathrm{Cu}$ catalyst. This means that these catalysts had achieved their steady state activity after about 40 hours at $250^{\circ} \mathrm{C}$. However, catalysts promoted with potassium alone showed a marked increase in activity over the same period of time as shown in Figure V.2-1b $(100 \mathrm{Fe} / 0.5 \mathrm{~K})$ and Table V.2-1 $(100 \mathrm{Fe} / 0.2 \mathrm{~K})$. Also, $\left(\mathrm{H}_{2} \div \mathrm{CO}\right)$ conversions, in tests with the $100 \mathrm{Fe} / 1 \mathrm{~K}$ catalyst at $235^{\circ} \mathrm{C}$, were 23.5 and $37 \%$ at 48 and 168 hours on stream, respectively.

This increase in activity with time on stream is typical for hydrogen activated catalysts which are not reduced completely to zero valent state (Dry, 1981; Bukur et al. 1989). The catalyst activity increases during synthesis due to further reduction/carbiding which results in continued creation of active sites. Temperature programmed and isothermal reduction studies revealed that potassium inhibits reduction of iron when $\mathrm{H}_{2}$ is used as reductant, whereas copper facilitates the iron reduction even in the presence of potassium (Section VII). This explains the fact that the induction period during FT synthesis is much longer for $\mathrm{Fe} / \mathrm{K}$ catalysts than with those containing copper.

$$
V-41
$$


The two doubly promoted catalysts were tested over a longer period of time. These two catalysts were exposed to the synthesis gas with $\mathrm{H}_{2}: \mathrm{CO}=2: 3$ molar feed ratio at $250^{\circ} \mathrm{C}$ and $260^{\circ} \mathrm{C}$ between about 150 and 400 hours on stream, and then the base conditions $\left(250^{\circ} \mathrm{C}\right.$, $\mathrm{H}_{2}: \mathrm{CO}=1: 1$ ) were repeated. Results at the base conditions at $428-456 \mathrm{~h}$ on stream are also shown in Figure V.2-1b and in Table V.2-1. The catalyst with lower potassium content (100 $\mathrm{Fe} / 3 \mathrm{Cu} / 0.2 \mathrm{~K}$ ) had exhibited remarkable stability and its activity at $430 \mathrm{~h}$ on stream was nearly the same as its maximum activity at about $143 \mathrm{~h}$ on stream $\left(76.8\right.$ vs. $78.1 \%\left(\mathrm{H}_{2}+\mathrm{CO}\right)$ conversion). The catalyst with higher potassium content $(100 \mathrm{Fe} / 3 \mathrm{Cu} / 0.5 \mathrm{~K})$ had lost nearly $9 \%$ in activity between 143 and $457 \mathrm{~h}$ on stream. Although this represents a rather small loss in activity, particularly in view of the fact that the catalyst was exposed to a variety of process conditions during this period of time, the observed trend is nevertheless consistent with literature findings concerning the effect of potassium on catalyst stability. As stated earlier the addition of potassium fosters carbon deposition, and the latter leads to catalyst deactivation by blocking the active sites on the surface (e.g., Kölbel et al., 1951; Anderson et al., 1952; Dry, 1981; Bonzel and Krebs, 1981; Arakawa and Bell, 1983).

The FT reaction on iron catalysts is accompanied by a reversible water-gas-shift (WGS) reaction. One measure of the WGS activity is the $\mathrm{CO}_{2}$ selectivity defined as the rate of $\mathrm{CO}_{2}$ production divided by the total rate of $\mathrm{CO}$ consumption (or $\% \mathrm{CO}$ converted to $\mathrm{CO}_{2}$ ). This assumes that all of $\mathrm{CO}_{2}$ is produced by the WGS reaction. Another measure of the extent of WGS reaction, expressed as $\mathrm{PCO}_{2} /\left(\mathrm{PCO}_{2}+\mathrm{P}_{\mathrm{H}_{2} \mathrm{O}}\right)$, is also shown in Table V.2-1. The WGS activity of selected catalysts as a function of reaction temperature is shown in Figure V.2-2. The WGS reaction proceeds nearly to completion $\left(\mathrm{CO}_{2}\right.$ selectivity is approximately 0.5$)$ at all reaction temperatures $\left(235-265^{\circ} \mathrm{C}\right)$ with catalysts which contain potassium as promoter. The WGS activity of the unpromoted iron catalyst increases markedly with the reaction temperature, but even at $265^{\circ} \mathrm{C}$ the $\mathrm{CO}_{2}$ selectivity is only 0.41 . The WGS activity of the $100 \mathrm{Fe} / 3 \mathrm{Cu}$ catalyst is significantly greater than that of the unpromoted iron, and approaches the limiting value at $265^{\circ} \mathrm{C}$. These results show that both copper and potassium promote the WGS activity of the catalyst, with potassium being the more effective promoter. All catalysts, except the unpromoted iron catalyst attain their steady state WGS activity after about $40 \mathrm{~h}$ at $250^{\circ} \mathrm{C}$ (i.e., 72 hours on stream) as can be seen from Table V.2-I by comparing $\mathrm{CO}_{2}$ selectivities at 72 and $142-168$ hours on stream.

Our results concerning the promotional effect of potassium on the WGS activity are in 
Table V.2-1 Effect of Promoters on Catalyst Activity and Selectivity at $250^{\circ} \mathrm{C}, 1.48 \mathrm{MPa}, \mathrm{H}_{2} / \mathrm{CO}=1, \mathrm{SV}=2 \mathrm{Nl} / \mathrm{a}-\mathrm{cat} . \mathrm{h}^{a}$

\begin{tabular}{|c|c|c|c|c|c|c|c|c|c|c|c|c|c|c|c|}
\hline Calalyst $^{b}$ & $100 /$ & $10 / 0$ & $100 / c$ & $0 / 0.2$ & $100 / 0$ & $0 / 0.5$ & $100 / 0 / 1.0$ & 100 & $13 / 0$ & & $00 / 3 / 0$ & & & $00 / 3 / 0$ & \\
\hline Time on Stream $(h)$ & & & 72 & 168 & 72 & 168 & 95 & 73 & 167 & 72 & 143 & 429 & 72 & 143 & 450 \\
\hline $\mathrm{II}_{2}+\mathrm{CO}$ Conversion (\%) & & & & 37.8 & 40.2 & 53.8 & 44.4 & 57.3 & 60.6 & 76.0 & 78.1 & 76.8 & 75.9 & 78.3 & 69.6 \\
\hline CO Conversion (\%) & 21.3 & 22.4 & 37.1 & 45.0 & 50.5 & 61.9 & 55.0 & 65.9 & 70.8 & 89.3 & 91.3 & 90.2 & 91.0 & 93.8 & 83.9 \\
\hline Wxtent of WGS $\left(\frac{p_{\mathrm{CO}_{2}}}{p_{\mathrm{H}_{2} \mathrm{O}}+p_{\mathrm{CO}_{2}}}\right)$ & 0.43 & 0.52 & 0.91 & 0.94 & 0.97 & 0.81 & 0.89 & 0.83 & 0.87 & 0.91 & 0.93 & 0.91 & 0.92 & 0.92 & 0.97 \\
\hline IIC Selectivities (wt.\%) & & & & & & & & & & & & & & & \\
\hline $\mathrm{CHI}_{4}$ & & & 14.2 & 12.3 & 11.5 & 9.2 & 10.3 & 17.1 & 16.6 & 16.7 & 10.2 & 15.7 & 11.6 & 11.9 & 12.6 \\
\hline $\mathrm{C}_{2} \cdot \mathrm{C}_{4}$ & 40.5 & 39.1 & 32.2 & 32.4 & 25.2 & 20.8 & 24.9 & 37.9 & 35.6 & 32.5 & 29.9 & 27.4 & 30.4 & 32.1 & 35.9 \\
\hline $\mathrm{C}_{5}-\mathrm{C}_{11}$ & 30.1 & 32.6 & 33.9 & 37.0 & 29.9 & 34.2 & 28.1 & 32.6 & 39.5 & 37.0 & 37.2 & 37.4 & 39.9 & 40.7 & 41.2 \\
\hline $\mathrm{C}_{12}+$ & 6.8 & 7.6 & 19.7 & 18.3 & 33.4 & 35.8 & 36.7 & 12.4 & 8.3 & 13.8 & 16.7 & 19.5 & 18.1 & 15.3 & 10.3 \\
\hline (O Conversion to Products (\%) & & & & & & & & & & & & & & & \\
\hline Ilydrocarbolls & 58.0 & 59.0 & 46.1 & 45.6 & 45.8 & 47.5 & 50.9 & 50.7 & 50.4 & 49.5 & 47.2 & 48.5 & 46.1 & 45.4 & 47.1 \\
\hline Oxygenates & 5.5 & 4.5 & 2.7 & 3.0 & 2.7 & 2.3 & 3.4 & 2.1 & 2.3 & 2.5 & 2.1 & 1.8 & 4.4 & 5.1 & 4.5 \\
\hline $\mathrm{CO}_{2}$ & 29.2 & 32.6 & 48.5 & 48.7 & 46.9 & 48.0 & 49.1 & 44.2 & 47.6 & 47.2 & 48.2 & 48.0 & 48.2 & 47.6 & 49.7 \\
\hline Unaccounted & 7.3 & 3.9 & 2.7 & 2.7 & 4.6 & 2.2 & -3.4 & 3.0 & -0.3 & 0.8 & 2.5 & 1.7 & 1.3 & 1.9 & -1.3 \\
\hline Olefin Selectivity & & & & & & & & & & & & & & & \\
\hline $\mathrm{C}_{2} \mathrm{C}_{4}(\mathrm{wt} . \%)$ & 56.7 & 57.4 & 71.0 & 72.2 & 71.7 & 72.5 & 74.0 & 51.6 & 50.3 & 52.0 & 49.8 & 54.5 & 73.8 & 72.7 & 69.9 \\
\hline$C_{5} C_{11}(w t . \%)$ & 61.0 & 61.6 & 63.0 & 64.8 & 67.2 & 68.2 & 69.9 & 54.7 & 54.5 & 58.4 & 56.3 & 59.4 & 70.0 & 69.7 & 69.0 \\
\hline 2-Butene/1-Butene & .23 & .27 & .15 & .11 & .03 & .05 & .06 & .52 & .49 & .19 & .32 & .54 & .03 & .03 & .05 \\
\hline
\end{tabular}




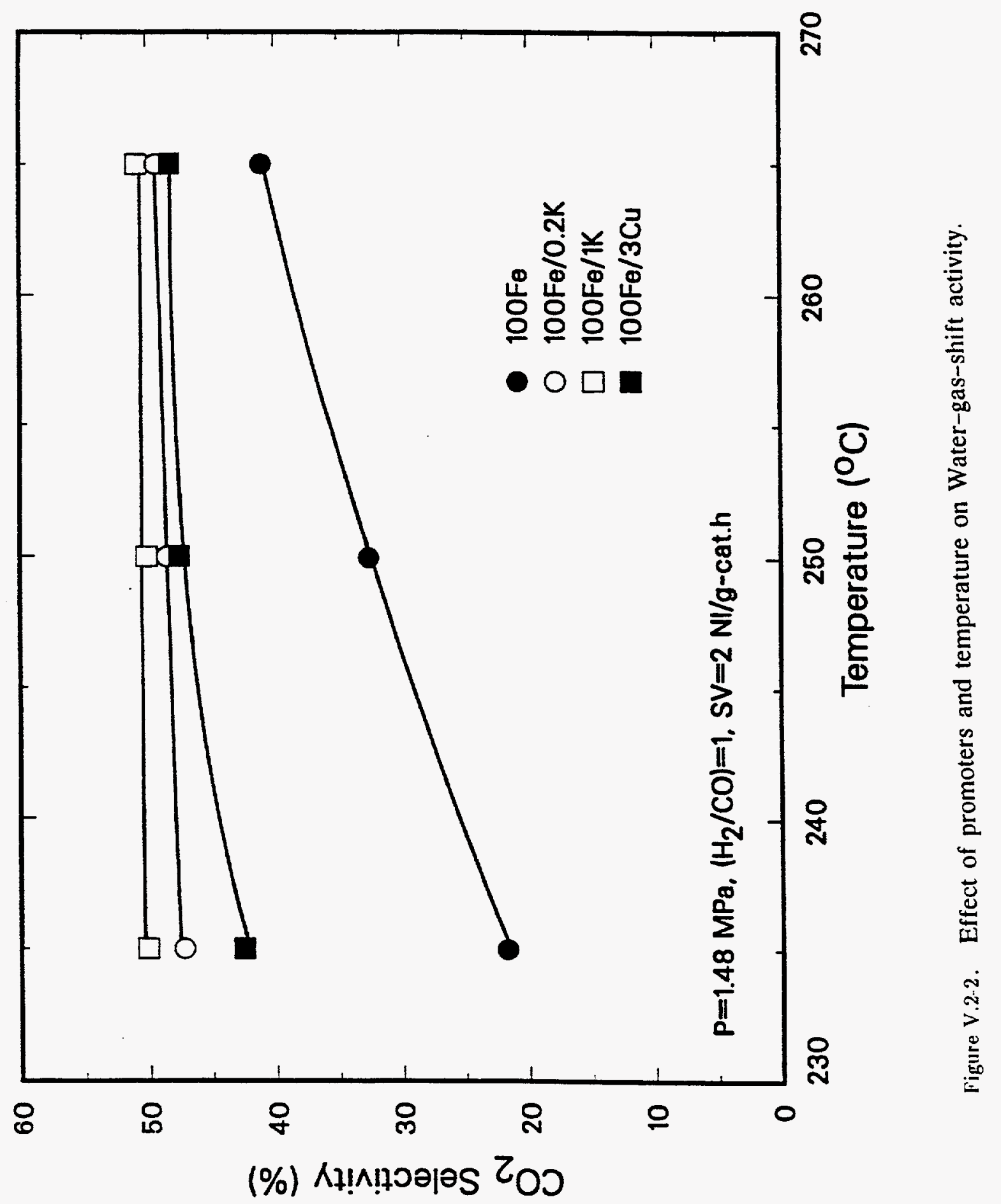


agreement with previous studies (Anderson et al., 1952; Arakawa and Bell, 1983; Dictor and Bell, 1986), but the mechanism by which potassium promotes the WGS activity of iron catalysts is not well understood. We are not aware of any results illustrating the effect of copper on the WGS activity during Fischer-Tropsch synthesis. However, copper is a well known WGS catalyst and the observed effect is as expected.

Reproducibility of Results

Before describing results on catalyst selectivity we shall briefly address the important issue of reproducibility of experimental data. In our study, the reproducibility was checked by performing at least two mass balances under the same set of process conditions. As described above, the activity of the catalyst promoted with copper (either singly or doubly) and the unpromoted iron catalyst did not change significantly with time on stream (72 and 143-168 hours). Table V.2-1 shows that product selectivities (hydrocarbon distribution, olefin and oxygenates selectivities) were similar during the two mass balances at the base conditions. With the two doubly promoted catalysts the base conditions were repeated one more time after $430-456$ hours on stream, and activities and selectivities were similar to those obtained in the previous two mass balances.

The activity of the three catalysts promoted with potassium alone increased markedly with time on stream (Figure V.2-1b and Table V.2-1). This indicates that these catalysts were undergoing changes in composition with time on stream, leading to increase in the number of active sites. However, there was no significant effect of time on product selectivities for all three $\mathrm{Fe} / \mathrm{K}$ catalysts, which means that the nature of catalyst sites (or ensembles of sites) did not change significantly with time on stream.

\section{Carbon Number Product Distribution}

Total product distributions obtained for the various catalysts could not be described by a uniform chain growth probability factor- $\alpha$. The Anderson-Schulz-Flory plots (mole fraction vs. carbon number) showed two distinct regions of different slopes, and the data were fitted using the three parameter model of Huff and Satterfield (1984) (see Section V.1.3).

Recently, Donnelly et al. (1988) proposed an alternative three parameter model, which is not based on the assumption of existence of the two types of sites. However, the values of $\alpha_{1}$ and $\alpha_{2}$ obtained from this model and from the previous one are identical. The third parameter in the latter model is the break point between two regions with distinct values of $\alpha$. This parameter, designated as $\xi$ by Donnelly et al., is related to $\beta$ and if one knows one of them the other one can be calculated. 
Representative results, for the three catalysts containing copper, are shown in Figure V.2-3. As can be seen the experimental data are well represented by the above model. The model parameters were estimated using a nonlinear regression subroutine NLIN of the SAS software package. The values of $\alpha_{1}, \alpha_{2}$ and $\beta$ for all catalysts are summarized in Table V.2-2 together with $95 \%$ confidence interval limits for these parameters. In the case of the unpromoted iron, the amount of higher molecular weight products collected was too small for accurate determination of model parameters. For products with carbon number greater than 17 , the estimated value of $\alpha_{2}$ (using the asymptotic method) was greater than 1 . The latter value is an indication of problems with product collection and/or analysis. Several authors have reported two chain growth probabilities ("double- $\alpha$ " phenomenon) for unpromoted iron catalysts (Dictor and Bell, 1986; Itoh et al., 1988; Malessa and Baerns, 1988; Donnelly and Satterfield, 1989).

As can be seen from Table V.2-2, no discernible trends can be detected in values of model parameters with the promoter concentrations. In particular, specification of the two chain growth probability values alone (as has been common in the literature) may lead to erroneous conclusions about the product distribution. For example, the values of $\alpha_{1}$ and $\alpha_{2}$ for the $100 \mathrm{Fe} / 3 \mathrm{Cu}$ catalyst are greater than the corresponding values for the $100 \mathrm{Fe} / 3 \mathrm{Cu} / 0.2 \mathrm{~K}$ catalyst (Figure V.2-3 and Table V.2-2). From this one may conclude that the former catalyst produces more higher molecular weight products than the latter (the higher value of $\alpha$ implies higher probability for the chain growth). However, this conclusion would not be correct as can be seen from Table V.2-1 and Figure V.2-4 where hydrocarbon product distributions for these two catalysts are given. These results can be explained by examining values of the third parameter, $\beta$, for these two catalysts. The fraction of sites of type 1 (i.e., sites where the lower molecular weight hydrocarbons are produced) is 0.76 for the doubly promoted catalyst, and 0.99 for the $100 \mathrm{Fe} / 3 \mathrm{Cu}$ catalyst. This means that with the $100 \mathrm{Fe} / 3 \mathrm{Cu}$ catalyst the majority of products are produced on the type 1 site, and therefore this catalyst produces more low molecular weight products than the $100 \mathrm{Fe} / 3 \mathrm{Cu} / 0.2 \mathrm{~K}$ catalyst, even though both $\alpha_{1}$ and $\alpha_{2}$ are higher for the former than for the latter. Thus, in order to characterize the carbon number product distribution of a given catalyst, it is essential to report values of all three parameters $\left(\alpha_{1}, \alpha_{2}\right.$ and $\left.\beta\right)$. Comparisons of product distributions on different catalysts cannot be made on the basis of values of $\alpha_{1}$ and $\alpha_{2}$ alone.

Hydrocarbon Product Distribution

Figures V.2-4 and V.2-5 show that the average molecular weight of hydrocarbon products 




Figure V.2-3 . Anderson-Schulz-Flory distributions for catalysts promoted with copper and potassium. 
Table V.2-2. Chain Growth Probability Factors for Different Catalysts ${ }^{a}$

\begin{tabular}{|c|c|c|c|}
\hline Catalyst & $\begin{array}{c}\alpha_{1} \\
(95 \% \mathrm{CI})^{b} \\
\end{array}$ & $\begin{array}{c}\alpha_{2} \\
(95 \% \mathrm{Cl})^{b}\end{array}$ & $\begin{array}{c}\beta \\
(95 \% \mathrm{Cl})^{b} \\
\end{array}$ \\
\hline $100 \mathrm{Fe}$ & $\begin{array}{c}0.56^{c} \\
(0.45-0.67)\end{array}$ & $d$ & ${ }_{-} d$ \\
\hline $100 \mathrm{Fe} / 0.2 \mathrm{~K}$ & $\begin{array}{c}0.61 \\
(0.52-0.69)\end{array}$ & $\begin{array}{c}0.84 \\
(0.81-0.88)\end{array}$ & $\begin{array}{c}0.88 \\
(0.78-0.99)\end{array}$ \\
\hline $100 \mathrm{Fe} / 0.5 \mathrm{~K}$ & $\begin{array}{c}0.68 \\
(0.65-0.70)\end{array}$ & $\begin{array}{c}0.94 \\
(0.92-0.97)\end{array}$ & $\begin{array}{c}0.96 \\
(0.95-0.98)\end{array}$ \\
\hline $100 \mathrm{Fe} / 1.0 \mathrm{~K}$ & $\begin{array}{c}0.66 \\
(0.64-0.68)\end{array}$ & $\begin{array}{c}0.88 \\
(0.87-0.90)\end{array}$ & $\begin{array}{c}0.88 \\
(0.84-0.92)\end{array}$ \\
\hline $100 \mathrm{Fe} / 3 \mathrm{Cu}$ & $\begin{array}{c}0.63 \\
(0.62-0.65)\end{array}$ & $\begin{array}{c}0.91 \\
(0.88-0.94)\end{array}$ & $\begin{array}{c}0.99 \\
(0.99-1.00)\end{array}$ \\
\hline $100 \mathrm{Fe} / 3 \mathrm{Cu} / 0.2 \mathrm{~K}$ & $\begin{array}{c}0.62 \\
(0.53-0.70)\end{array}$ & $\begin{array}{c}0.79 \\
(0.78-0.80)\end{array}$ & $\begin{array}{c}0.76 \\
(0.66-0.86)\end{array}$ \\
\hline $100 \mathrm{Fe} / 3 \mathrm{Cu} / 0.5 \mathrm{~K}$ & $\begin{array}{c}0.69 \\
(0.68-0.71)\end{array}$ & $\begin{array}{c}0.93 \\
(0.87-0.99)\end{array}$ & $\begin{array}{c}0.98 \\
(0.97-1.00)\end{array}$ \\
\hline
\end{tabular}

a Parameters estimated from products with carbon numbers in the range $\mathrm{C}_{3}-\mathrm{C}_{30}$

${ }^{b} \mathbf{9 5 \%}$ Confidence interval

$c$ Asymptotic $\alpha$ value, based on the slope of the product distribution

$d$ The three-parameter model could not be used with this catalyst 

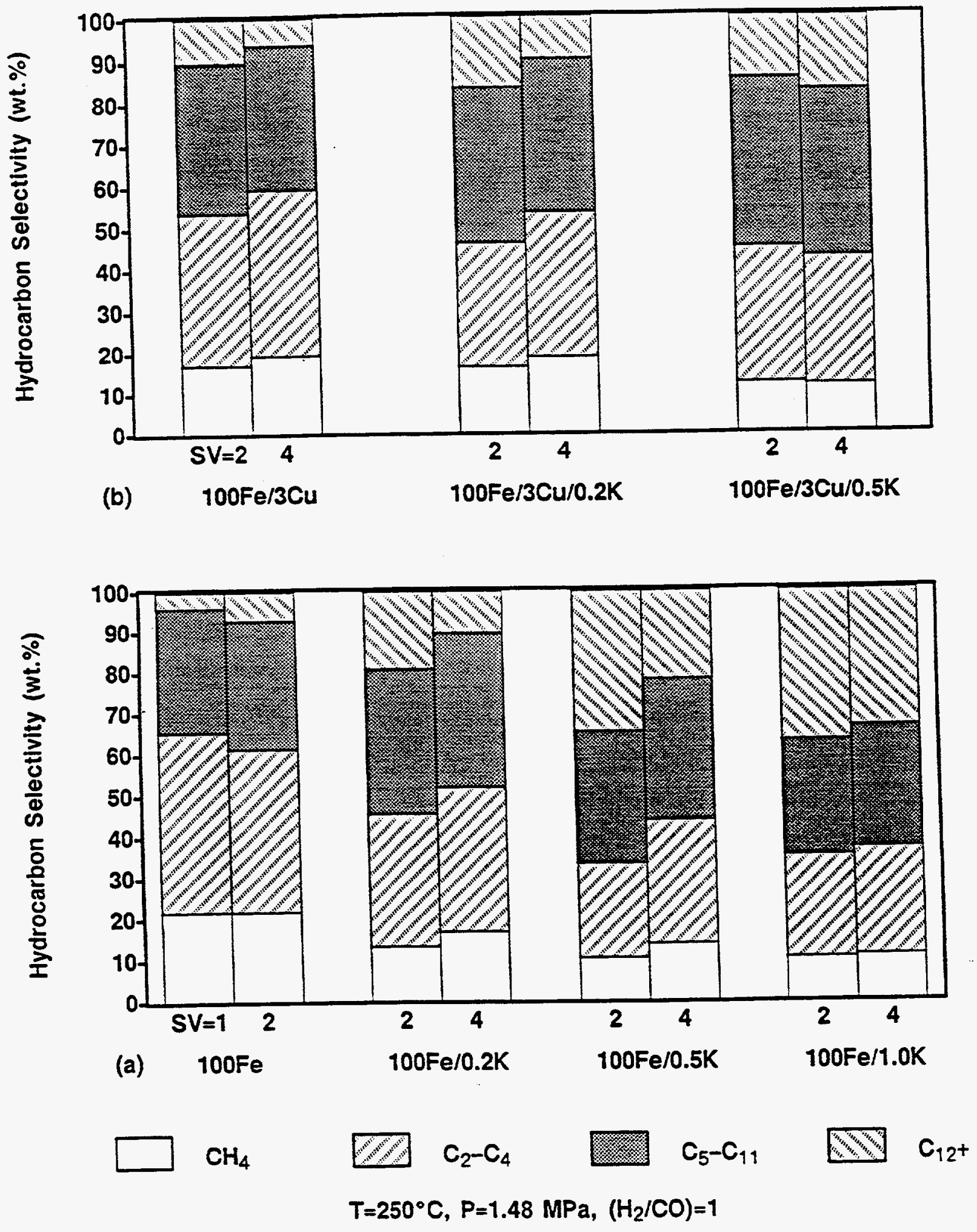

Figure V.2-4. Effect of potassium content and gas space velocity on hydrocarbon selectivity for (a) singly promoted $\mathrm{Fe} / \mathrm{K}$ catalysts, and (b) doubly promoted $\mathrm{Fe} / \mathrm{Cu} / \mathrm{K}$ catalysts. 

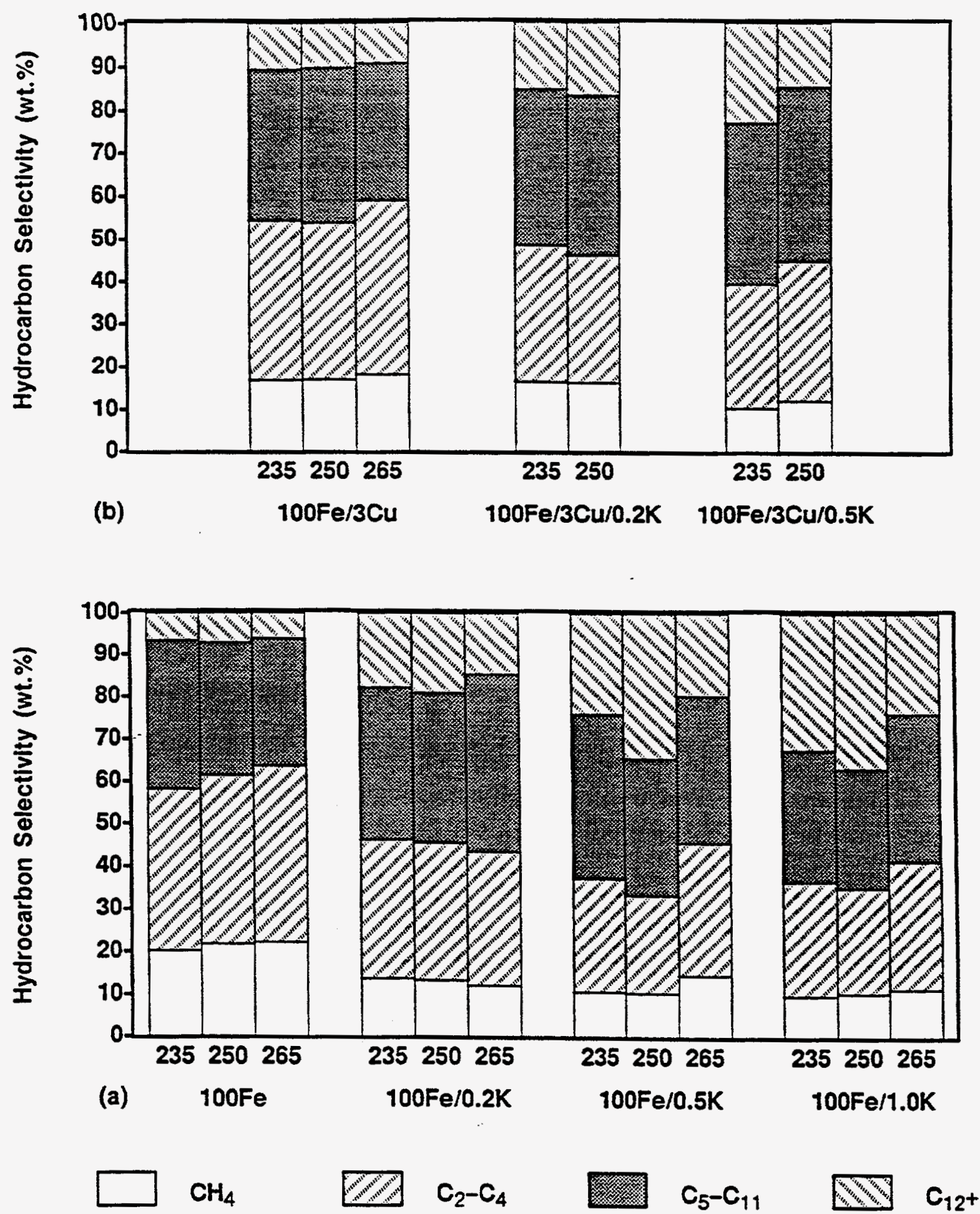

$P=1.48 \mathrm{MPa},\left(\mathrm{H}_{2} / \mathrm{CO}\right)=1, \mathrm{SV}=2 \mathrm{Nl} / \mathrm{g}$-cat.h

Figure V.2-5 . Effect of potassium content and reaction temperature on hydrocarbon selectivity for (a) singly promoted $\mathrm{Fe} / \mathrm{K}$ catalysts, and (b) doubly promoted $\mathrm{Fe} / \mathrm{Cu} / \mathrm{K}$ catalysts. 
increases with addition of either copper or potassium to the unpromoted catalyst. Potassium is a more effective promoter than copper in reducing methane and gaseous hydrocarbon production, while shifting selectivity toward higher molecular weight hydrocarbons (in particular the $\mathrm{C}_{12}+$ fraction). The effect of potassium on hydrocarbon selectivity observed in the present study is in agreement with results obtained in several earlier studies with a variety of iron catalysts (Anderson et al., 1952; Pichler, 1952; Dry, 1981; Arakawa and Bell, 1983; Dictor and Bell, 1986). The increase in average molecular weight of hydrocarbon products is due to increased $\mathrm{CO}$ and lower $\mathrm{H}_{2}$ surface coverage in the presence of potassium. Since chain termination results from the hydrogenation of the iron-carbon bond, the presence of potassium enhances the probability of continued chain growth, i.e., formation of higher molecular weight products (Kölbel and Giehring, 1963; Dry et al., 1969).

The effect of copper on hydrocarbon product distribution during FTS was not studied extensively. Murata (1942), as reported by Anderson (1956, p. 132), made an early study of multipromoted iron-based catalysts and found that the yield of $C_{5}+$ hydrocarbon products increased with increasing copper content up to about $10 \mathrm{wt} \%$, above which no further selectivity changes occurred. Recently Wachs et al. (1984) reported results from experiments in a fixed bed reactor at $265^{\circ} \mathrm{C}, 7$ atm and $\mathrm{H}_{2} / \mathrm{CO}=3$ at high space velocities (differential $\mathrm{CO}$ conversions) with unpromoted $\mathrm{Fe}$ and $100 \mathrm{Fe} / 1.4 \mathrm{Cu}$ catalysts. They found no effect of copper on the product distribution. Additional studies with $\mathrm{Fe} / \mathrm{Cu}$ catalysts are required in order to elucidate the role of copper in Fischer-Tropsch synthesis.

In our study, it was found that both copper and potassium enhance the selectivity of higher molecular weight products, however the anticipated synergistic effect was not observed in experiments with the two doubly promoted catalysts. Instead, hydrocarbon selectivity of these two catalysts was largely determined by their potassium content, as shown in Figures V.2-4 and V.2-5. Kölbel and Giehring (1963) studied the effect of potassium promotion on activity and selectivity of a precipitated $\mathrm{Fe} / \mathrm{Cu}$ catalyst containing approximately $0.2 \mathrm{wt} \%$ of copper $(100 \mathrm{Fe} / 0.2 \mathrm{Cu} /(0-0.6) \mathrm{K})$. They observed also an increase in the formation of higher molecular weight hydrocarbons with increasing potassium content of the catalyst. This general trend was somewhat altered with time on stream, due to more rapid deactivation of catalysts with higher alkali content. They reported that catalysts tend to make more $\mathrm{CH}_{4}$ and other gaseous hydrocarbons as their activity decreased. A similar trend with time on stream was observed in our study with the $100 \mathrm{Fe} / 3 \mathrm{Cu} / 0.5 \mathrm{~K}$ catalyst (see Table V.2-1). 
The effects of gas space velocity and reaction temperature on hydrocarbon product distribution are illustrated in Figures V.2-4 and V.2-5, respectively. Changes in process conditions had a rather small effect on hydrocarbon product distribution. With the increase in gas space velocity a slight shift toward higher molecular weight products was observed with the unpromoted iron and the $100 \mathrm{Fe} / 3 \mathrm{Cu} / 0.5 \mathrm{~K}$ catalysts, whereas the opposite trend was observed with all other catalysts. The increase in reaction temperature causes the shift toward lower molecular weight products.

Olefin Content (Hydrogenation Activity)

The effect of promoters on olefin selectivity, expressed as a mass fraction of linear olefins in total hydrocarbon product of the same carbon number, is shown in Figures V.2-6a and V.2-6b. All curves are bell shaped, i.e., the olefin content increases from $C_{2}$ to $C_{3} / C_{4}$, reaches a maximum value, and then decreases with increasing carbon number. This shape results from secondary hydrogenation of olefins. Ethylene is more reactive than other low molecular weight olefins, whereas the increase in hydrogenation activity (i.e., lower olefin content) of higher molecular weight olefins may be attributed to their increased reactivity or to greater adsorptivity of long chain molecules.

Potassium promotion suppresses secondary hydrogenation of olefins and the olefin content increases with the potassium loading as shown in Figures V.2-6a and V.2-6b. This is particularly evident for products which are more susceptible to hydrogenation $\left(C_{2}\right.$ and $\left.C_{6} \dot{T}\right)$. The catalyst containing about $1 \mathrm{wt} \%$ of $K$ has the highest olefin content, and the latter does not vary markedly with carbon number. With doubly promoted catalysts potassium promotion becomes effective only at higher loadings. The $100 \mathrm{Fe} / 3 \mathrm{Cu} / 0.5 \mathrm{~K}$ catalyst has similar olefin content as the $100 \mathrm{Fe} / 0.5 \mathrm{~K}$ catalyst, while the olefin content obtained with the $100 \mathrm{Fe} / 3 \mathrm{Cu} / 0.2$ $K$ catalyst is nearly the same as that of the unpromoted iron catalyst (Figure V.2-6b). The addition of copper to the unpromoted iron results in increased hydrogenation activity (Figure V.2-6b).

Similar results, concerning the promotional effect of potassium on olefin content and/or its dependence on carbon number, have been reported earlier in the literature (Anderson et al., 1952; Kölbel and Giehring, 1963, Shuiz et al., 1982; Dictor and Bell, 1986; Donnelly and Satterfield; 1989). The influence of potassium on secondary hydrogenation of olefins is consistent with its effect on the strength of $\mathrm{H}_{2}$ and $\mathrm{CO}$ chemisorption. In the presence of potassium the $\mathrm{CO}$ chemisorption is increased whereas that of $\mathrm{H}_{2}$ is weakened. This results in 


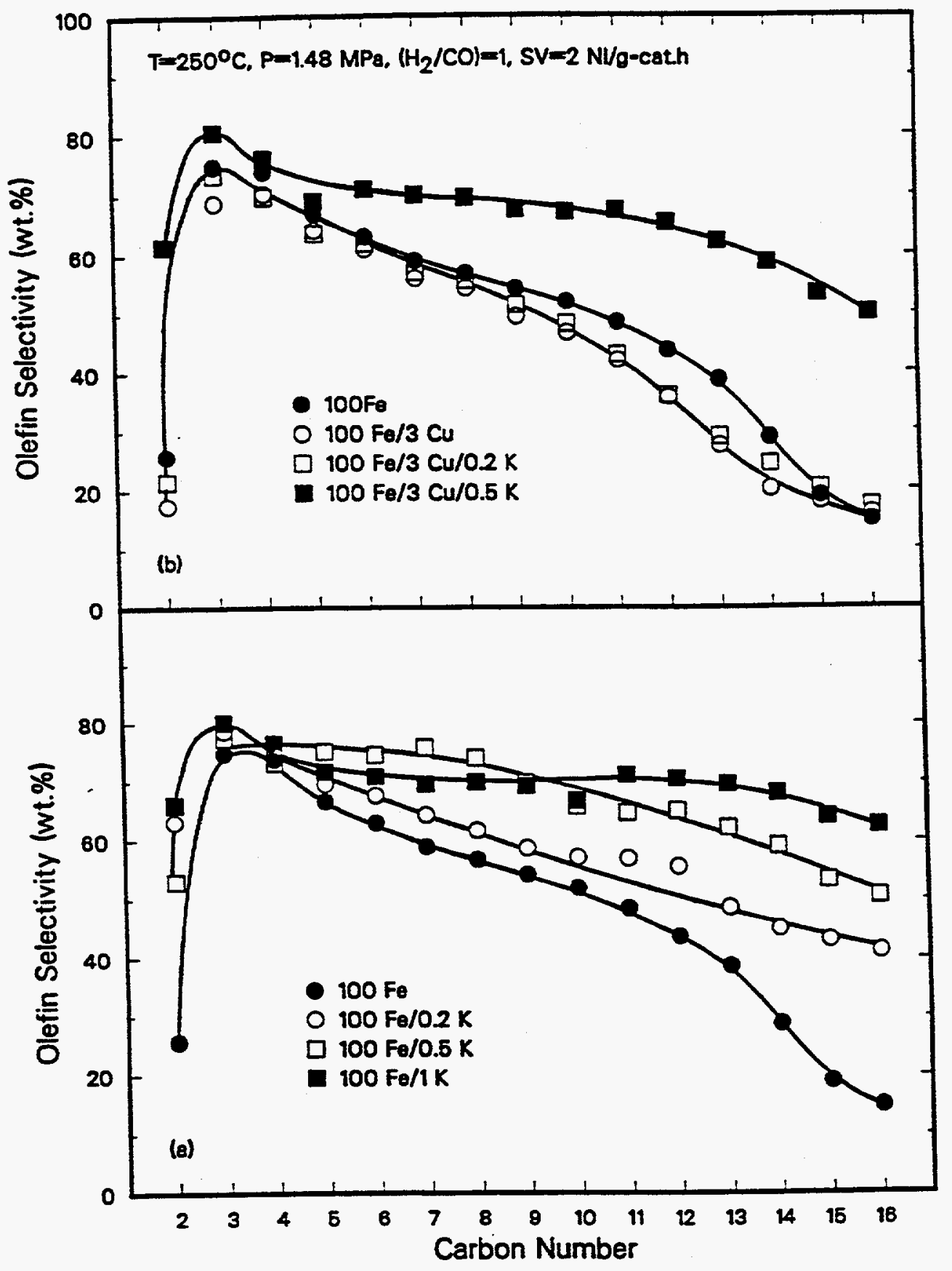

Figure V.2-6. Effect of potassium content on olefin selectivity for (a) singly promoted $\mathrm{Fe} / \mathrm{K}$ catalysts, (b) doubly promoted $\mathrm{Fe} / \mathrm{Cu} / \mathrm{K}$ catalysts, and comparison with results for unpromoted iron. 
lower surface concentration of $\mathrm{H}_{2}$ and consequently in lower hydrogenation activity (i.e., higher olefin content) of potassium promoted catalysts.

Effect of Process Conditions on Olefin Selectivity

The effects of reaction temperature and gas space velocity (gas flow rate) on olefin selectivity of two catalysts $(100 \mathrm{Fe} / 1 \mathrm{~K}$ and $100 \mathrm{Fe} / 3 \mathrm{Cu} / 0.2 \mathrm{~K}$ ) are illustrated in Figures (V.2-7a-V.2-7d). The other catalysts followed the same trends observed with either $100 \mathrm{Fe} / 1$ $\mathrm{K}$ or $100 \mathrm{Fe} / 3 \mathrm{Cu} / 0.2 \mathrm{~K}$ but the effects of process conditions were less pronounced. Results obtained with the $100 \mathrm{Fe} / 1 \mathrm{~K}$ catalyst illustrate the behavior of catalysts having low hydrogenation activity $(100 \mathrm{Fe} / 0.5 \mathrm{~K}, 100 \mathrm{Fe} / 3 \mathrm{Cu} / 0.5 \mathrm{~K})$ whereas results from tests with the 100 $\mathrm{Fe} / 3 \mathrm{Cu} / 0.2 \mathrm{~K}$ catalyst illustrate the behavior of catalysts with higher hydrogenation activity (unpromoted iron and $100 \mathrm{Fe} / 3 \mathrm{Cu}$ ).

The olefin content of the $100 \mathrm{Fe} / 1 \mathrm{~K}$ catalyst increased with temperature, whereas the gas flow rate did not have marked effect on olefin selectivity. In studies with the $100 \mathrm{Fe} / 3 \mathrm{Cu} / 0.2$ $K$ catalyst the olefin content decreased slightly with increase in temperature, and increased $\left(C_{2}, C_{7}-C_{14}\right)$ with increase in space velocity.

The trends shown in Figure V.2-7 can be explained by considering possible effects of reaction temperature and space velocity on primary and secondary reactions. With increasing temperature rates of both primary and secondary reactions are expected to increase, and as a result the olefin selectivity may either increase, decrease or remain constant depending on relative rates of 1-olefin formation (primary reaction) and olefin hydrogenation (secondary reaction). Therefore, the olefin selectivity will increase with increasing temperature on catalysts with high potassium content (low hydrogenation activity), whereas it will remain constant or decrease on catalysts without potassium or those with low potassium content (high hydrogenation activity).

On the other hand, the increase in space velocity will favor primary reactions. Thus, one may expect either an increase (catalysts with relatively high hydrogenation activity) or no change (catalysts with low hydrogenation activity) in olefin selectivity with increasing space velocity.

Results from earlier studies with iron catalysts are generally in agreement with those obtained in the present study and with the preceding discussion. For example, an increase in olefin selectivity with increasing temperature was reported by Dictor and Bell (1986) and Donnelly and Satterfield (1989) on Fe/K catalysts, whereas no effect (Donnelly and Satterfield) or the opposite trend (Dictor and Bell) was found with unpromoted iron catalysts. Schulz et al. 

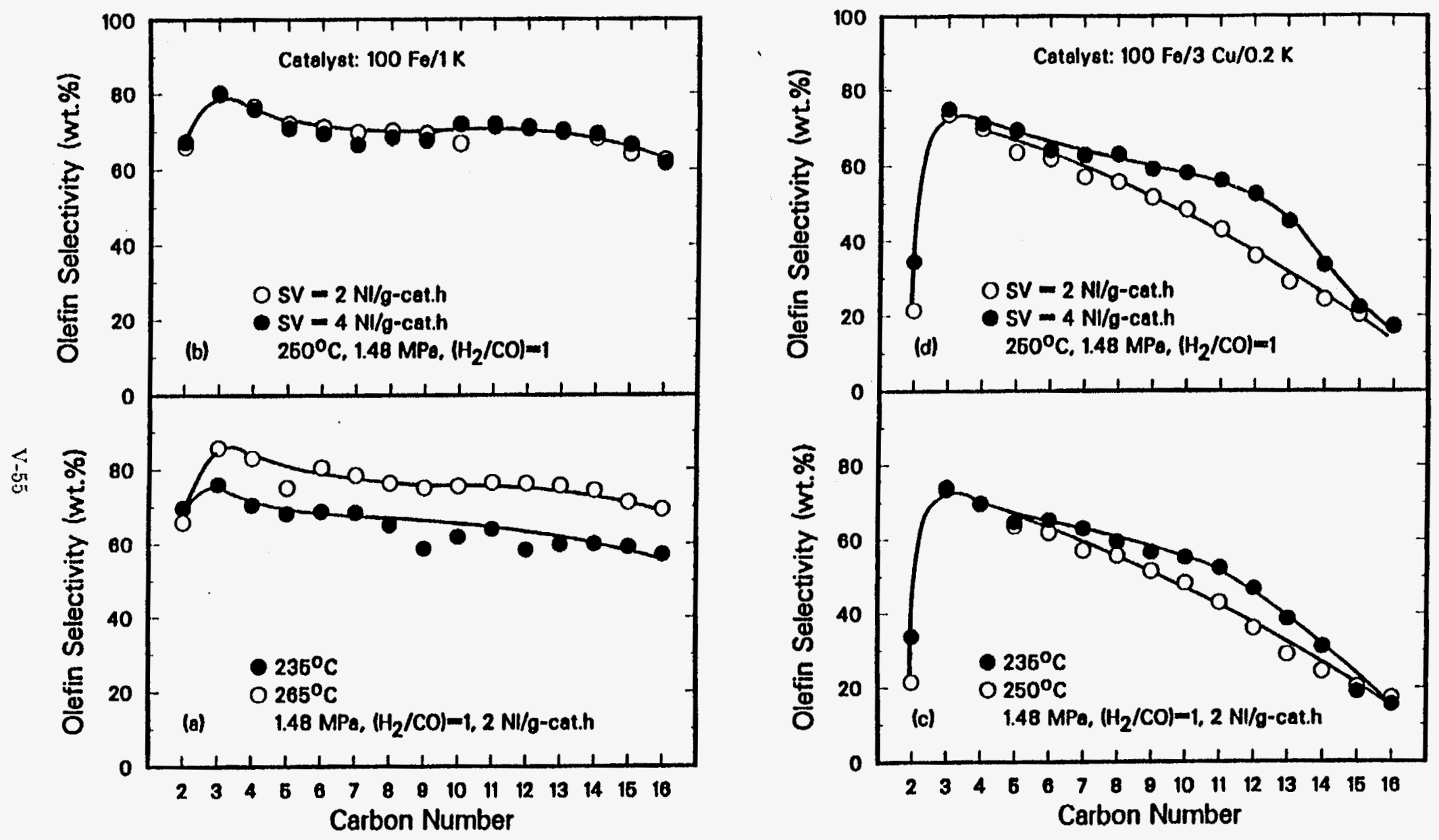

Figure V.2-7. Effect of process conditions on olefin selectivity Influence of temperature, (a) $100 \mathrm{Fe} / 1 \mathrm{~K}$ catalyst, (c) $100 \mathrm{Fe} / 3 \mathrm{Cu} / 0.2 \mathrm{~K}$ catalyst, Influence of gas space velocity; (b) $100 \mathrm{Fe} / 1 \mathrm{~K}$ catalyst, (d) $100 \mathrm{Fe} / 3 \mathrm{Cu} / 0.2 \mathrm{~K}$ catalyst. 
(1982) reported decrease in olefin selectivity with increasing temperature on an alkalized iron catalyst $\left(100 \mathrm{Fe} / 50\right.$ Aerosil/ $10 \mathrm{Al}_{2} \mathrm{O}_{3} / 0.3 \mathrm{~K}$ ). In the latter case the effectiveness of potassium promotion was considerably reduced by presence of silica and alumina as structural promoters.

Increase in olefin selectivity with increasing space velocity was reported in studies by Arakawa and Bell (1983) for both alkali promoted and unpromoted catalysts, and Dictor and Bell (1986) on an unpromoted catalyst, whereas no effect was observed in the latter study with the $100 \mathrm{Fe} / 0.8 \mathrm{~K}$ catalyst, and in the study by Donnelly and Satterfield (1989) with the Ruhrchemie, unpromoted and $100 \mathrm{Fe} / 1 \mathrm{~K}$ catalysts.

\section{Olefin Isomerization}

Figure V.2-8 illustrates the effect of promoters on olefin isomerization as a function of carbon number. As can be seen, potassium promotion suppresses isomerization of 1-alkenes and for a given catalyst the fraction of 2-alkenes (i.e., isomerization activity) increases with carbon number. For catalysts with higher potassium content (ca. $0.5-1$ wt $\%$ of $K$ ) the 2-olefins comprise 2 - $5 \%$ of total linear olefins, which suggest that some of the 2-olefins are also formed by primary reactions. The addition of copper enhances the isomerization activity of the unpromoted catalyst (Figure V.2-8b), and has similar effect at low levels of potassium promotion (compare results for $100 \mathrm{Fe} / 0.2 \mathrm{~K}$ and $100 \mathrm{Fe} / 3 \mathrm{Cu} / 0.2 \mathrm{~K}$ catalysts). However, as the potassium content increases, the effect of copper diminishes, and the fraction of 2-olefins is nearly identical for the two catalysts containing ca. $0.5 \mathrm{wt} \%$ of $\mathrm{K}$.

The observed effects of promoters on the extent of isomerization reaction are consistent with the results presented above for olefin hydrogenation, indicating that these two secondary reactions may occur via a common set of intermediates. The latter possibility was suggested by Dictor and Bell (1986) who also proposed a plausible reaction scheme involving an adsorbed primary 1-olefin in a vicinity of an adsorbed hydrogen atom. Therefore, the same arguments that were used above to explain the effects of potassium and carbon number (i.e., molecular weight of olefin) on olefin selectivity can be used to explain the observed effects on olefin isomerization selectivity.

The influence of reaction conditions (temperature and space velocity) was also investigated, and an illustration of the results is presented in Figure V.2-9. Variations in process conditions had negligible effect on olefin isomerization selectivity of the $100 \mathrm{Fe} / 1 \mathrm{~K}$ catalyst. This catalyst has relatively high potassium concentration which suppresses secondary reactions and thus changes in process conditions have very small effect on selectivity. In runs with the $100 \mathrm{Fe} / 3$ 


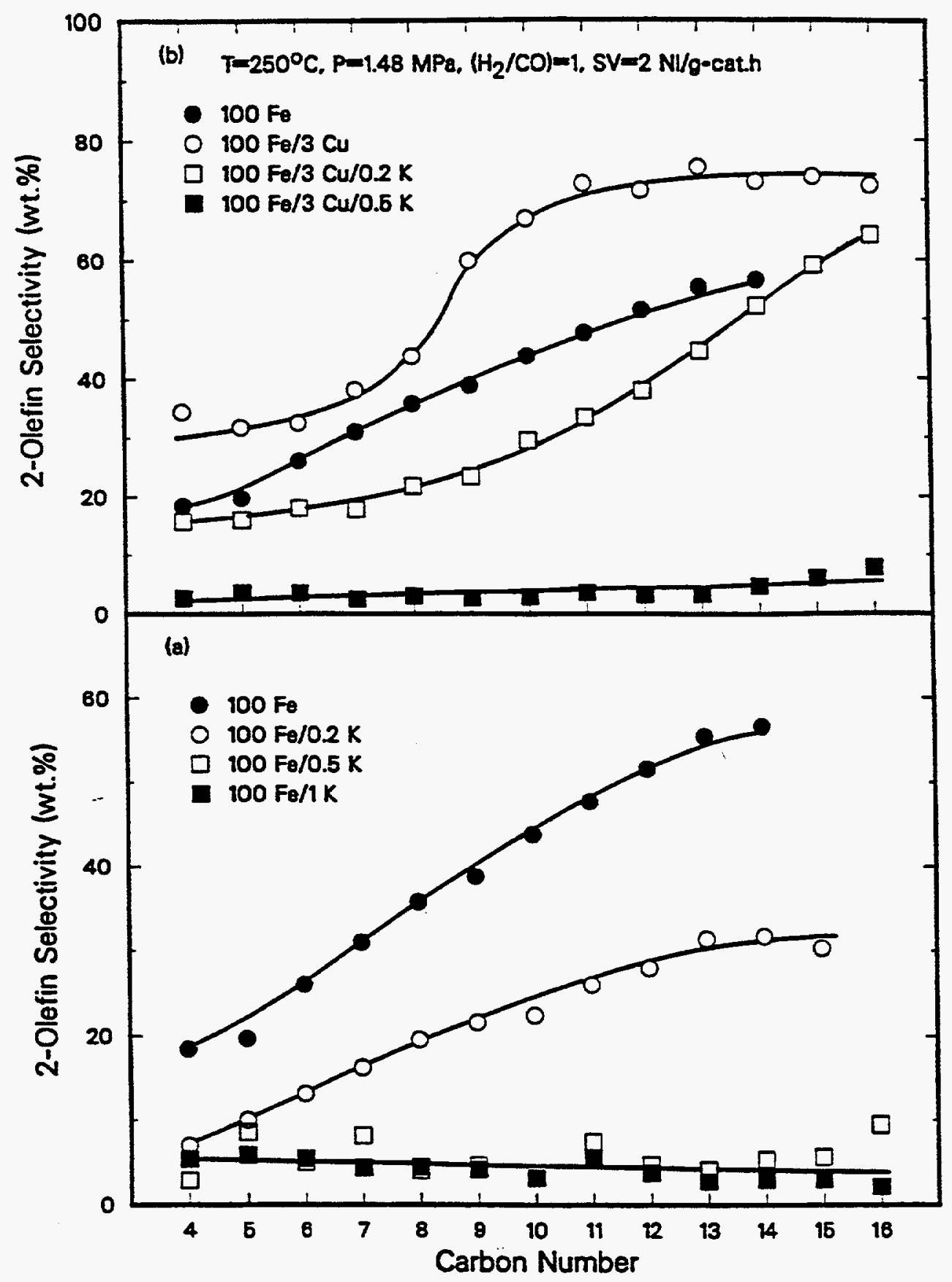

Figure V.2-8. Effect of potassium content on 2-olefin selectivity for (a) singly promoted $\mathrm{Fe} / \mathrm{K}$ catalysts, (b) doubly promoted $\mathrm{Fe} / \mathrm{Cu} / \mathrm{K}$ catalysts, and comparison with results for unpromoted iron. 

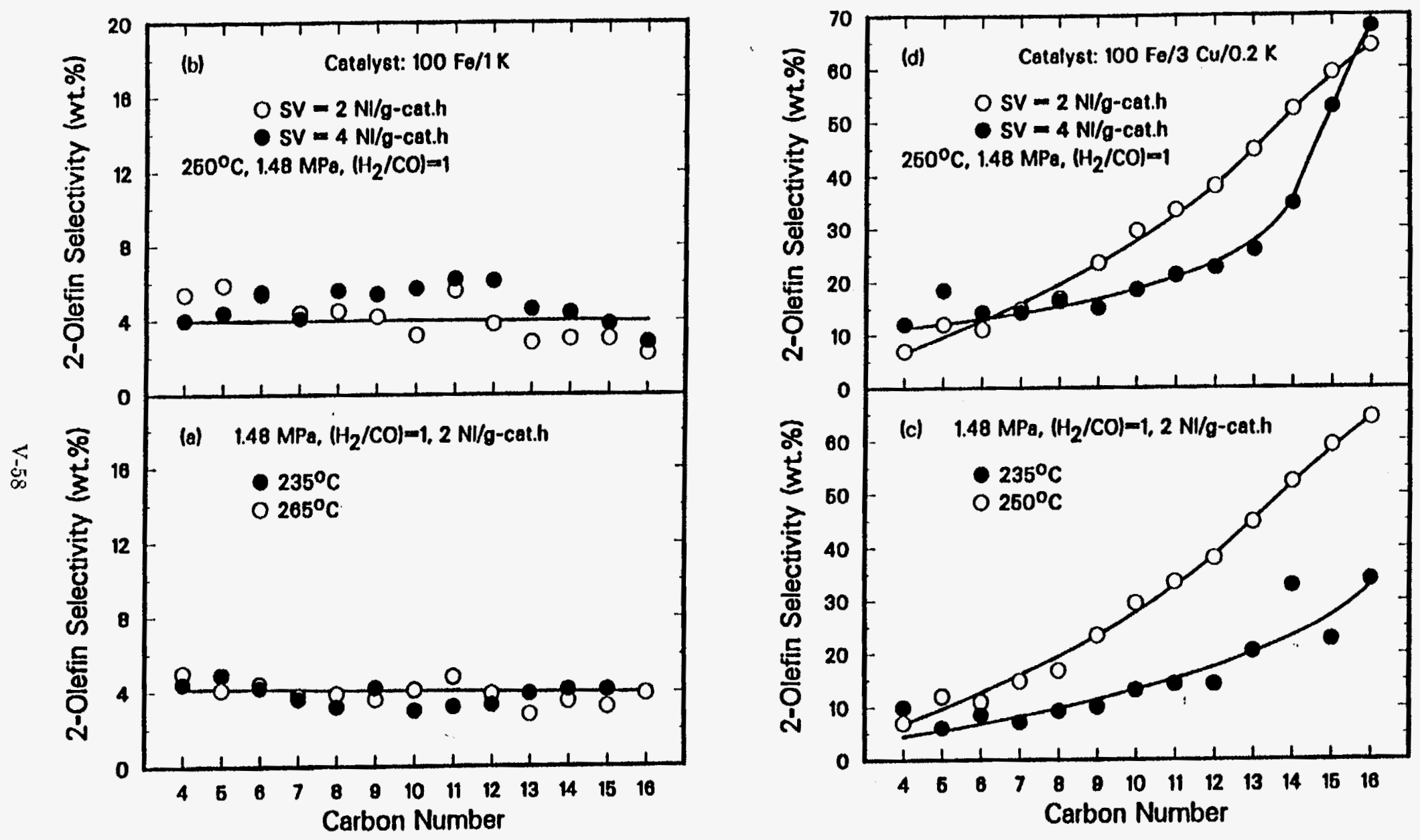

Figure V.2-9. Effect of process conditons on 2-olefin selectivity

Influence of temperature, (a) $100 \mathrm{Fe} / 1 \mathrm{~K}$ catalyst, (c) $100 \mathrm{Fe} / 3 \mathrm{Cu} / 0.2 \mathrm{~K}$ catalyst,

Influence of gas space velocity; (b) $100 \mathrm{Fe} / 1 \mathrm{~K}$ catalyst, (d) $100 \mathrm{Fe} / 3 \mathrm{Cu} / 0.2 \mathrm{~K}$ catalyst. 
$\mathrm{Cu} / 0.2 \mathrm{~K}$ catalyst increase in temperature increased the olefin isomerization, whereas increase in space velocity resulted in decrease of olefin isomerization. Both of these observations may be explained in terms of preceding discussion on effects of temperature and space velocity on secondary reactions. Results with other catalysts follow trends observed with either $100 \mathrm{Fe} / 1$ $\mathrm{K}$ or $100 \mathrm{Fe} / 3 \mathrm{Cu} / 0.2 \mathrm{~K}$ catalyst, depending on potassium content of the catalyst.

General trends observed in the present study, on the effects of potassium promotion and reaction conditions on the internal olefin selectivity, are in agreement with those reported in the earlier studies by Schulz and Gokcebay (1984), Dictor and Bell (1986) and Donnelly and Satterfield (1989). In the last study the focus was placed on $C_{4}$ olefins only, whereas results illustrating the selectivity of internal olefins as a function of carbon number were presented in the first two studies.

\section{Oxygenates Selectivity}

The selectivity of oxygenates, expressed as percent of $\mathrm{CO}$ converted to oxygenates, is shown in Figure V.2-10 for several catalysts as a function of reaction temperature. Oxygenates comprise only a small fraction of products formed and consist primarily of normal alcohols, and small amounts of aldehydes. No clearly discernible trends are observed in oxygenates selectivity as a function of promoter concentrations, temperature and space velocity. In general, the highest oxygenates selectivity was obtained with the unpromoted catalyst and the $100 \mathrm{Fe} / 3$ $\mathrm{Cu} / 0.5 \mathrm{~K}$ catalyst. At some process conditions $\left(235\right.$ and $\left.250^{\circ} \mathrm{C}\right)$ the selectivity of oxygenates increased with potassium concentration in the 0.2 to $1 \mathrm{wt} \%$ range.

An increase in oxygenates with increasing potassium promotion was reported by Anderson et al. (1952) and Dry (1981). Arakawa and Bell (1983) reported increase in ethanol concentration but no effect on methanol, whereas Dictor and Bell (1986) found that potassium promotion suppresses methanol formation and enhances the rate of formation of aldehydes. Both Donnelly and Satterfield (1989), and Dictor and Bell (1986) reported that methanol is essentially the only oxygenated product produced over unpromoted iron whereas other oxygenates were produced on $\mathrm{Fe} / \mathrm{K}$ catalysts. In contrast to this, in the present study with unpromoted iron catalyst we found not only methanol but other oxygenates as well. In agreement with these authors we found that potassium promotion suppresses formation of methanol and increases selectivity of higher molecular weight alcohols (Figure V.2-11).

From the above, it appears that there are some conflicting reports regarding the effect of potassium on oxygenates selectivity which are to some extent caused by inaccuracies in

$$
V-59
$$




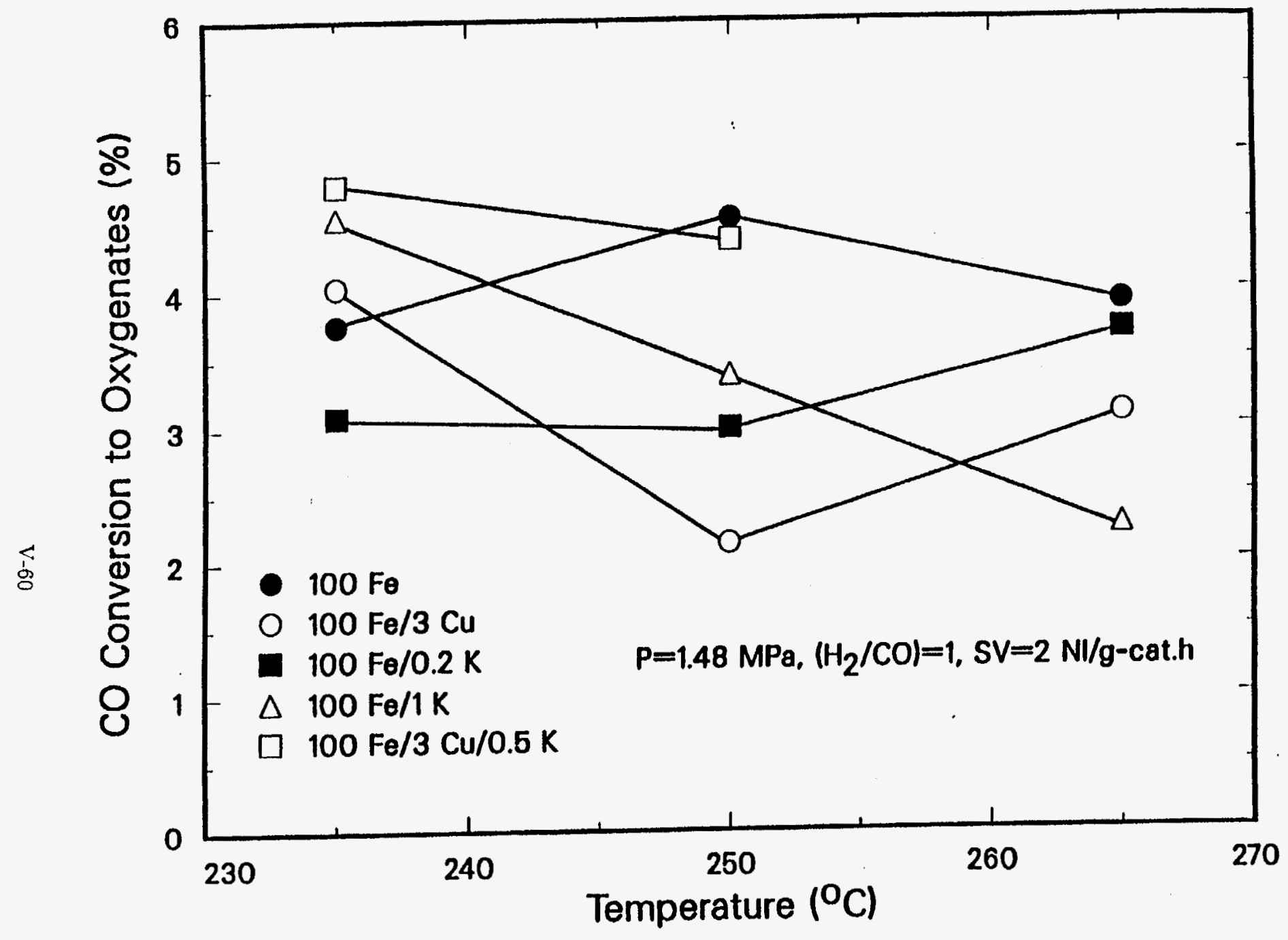

Figure V.2-10 Effect of promoters and temperature on oxygenates selectivity. 


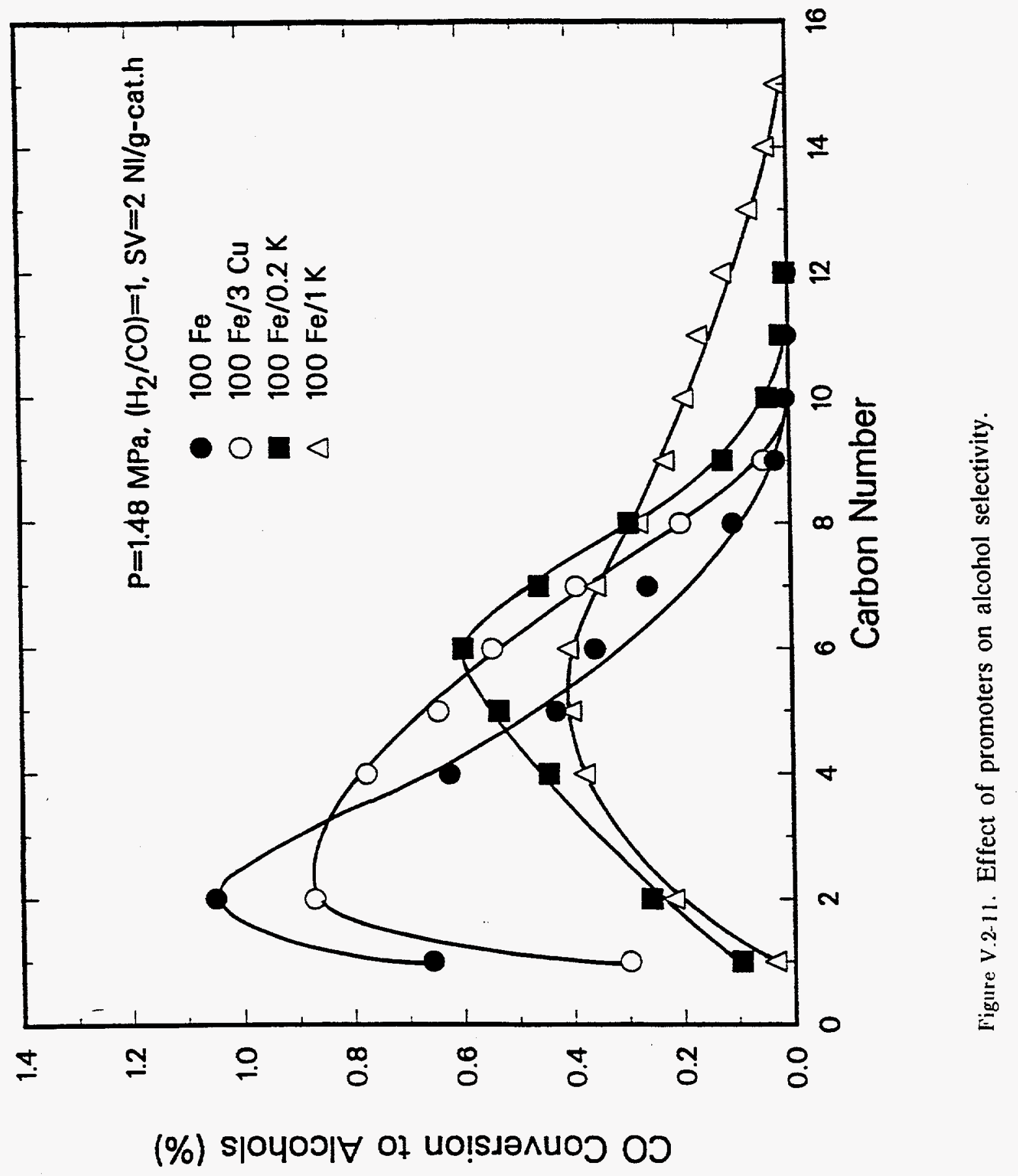


analytical techniques and/or by differences in the way the selectivities were reported (relative quantities vs. concentrations in the product stream).

\section{V.2.1.4. Summary}

Promotion of iron with potassium in the range $0.2-1 \mathrm{wt} \%$, increases activity of the FischerTropsch and water-gas-shift reactions, and the average molecular weight of hydrocarbon and other organic (primarily alcohols) products. It also causes suppression of olefin hydrogenation and isomerization reactions. Potassium promotion inhibits iron reduction and as a result the potassium promoted catalysts require longer time to achieve the steady state activity.

Promotion of iron with copper $(100 \mathrm{Fe} / 3 \mathrm{Cu})$ also increases rates of FT and WGS reactions. Copper is a more effective promoter than potassium in increasing the rate of $F T$, whereas the opposite applies to the WGS activity. Also, promotion with copper facilitates reduction of iron and thus decreases time required to achieve the steady state activity. In the presence of copper, the hydrocarbon product distribution shifts toward higher molecular weight products, but the magnitude of changes is significantly smaller than that observed with potassium promotion. Copper promotion enhances slightly the secondary reactions (olefin hydrogenation and isomerization).

The FT activity of the two doubly promoted catalysts $(100 \mathrm{Fe} / 3 \mathrm{Cu} / 0.2 \mathrm{~K}$ and $100 \mathrm{Fe} / 3$ $\mathrm{Cu} / 0.5 \mathrm{~K}$ ) was independent of their potassium content and higher than that of any of the singly promoted catalysts. In tests over a long period of time (up to 460 hours on stream) the catalyst with higher potassium content lost about $9 \%$ of its maximum activity, whereas the $100 \mathrm{Fe} / 3 \mathrm{Cu} / 0.2 \mathrm{~K}$ catalyst lost only $2 \%$. The WGS activity of the doubly promoted catalysts was similar to that of the $\mathrm{Fe} / \mathrm{K}$ catalysts. Selectivity behavior of the doubly promoted catalyst was strongly influenced by their potassium content. The catalyst containing $0.2 \mathrm{wt} \% \mathrm{~K}$ had selectivities (hydrocarbon product distribution, olefin content) similar to that obtained with the $100 \mathrm{Fe} / 3 \mathrm{Cu}$ catalyst, whereas the $100 \mathrm{Fe} / 3 \mathrm{Cu} / 0.5 \mathrm{~K}$ catalyst had selectivities similar to that obtained with the $100 \mathrm{Fe} / 0.5 \mathrm{~K}$ catalyst. This shows that, in the presence of copper, higher potassium loadings are needed to achieve promotional effects on product selectivity.

\section{V.2.2. Fixed bed Reactor Tests of Catalysts Activated with Carbon Monoxide}

These tests were conducted during the early period of this contract before the two zone temperature control was employed, and consequently significant axial temperature gradients were often observed. Also, the catalysts deactivated with time on stream. Only selected results, obtained in the absence of large temperature gradients and during early periods of tests, will 
be discussed.

Eight precipitated catalysts were tested to study the effect of copper and potassium promotion on catalyst activity and selectivity in fixed bed reactors. The catalysts were calcined before use, with air at $300^{\circ} \mathrm{C}$ and ambient pressure for $5 \mathrm{~h}$. They were ground to $30 / 60$ mesh, and diluted 1:7 with glass beads of the same mesh size range before loading the reactor. Reduction of the catalysts was performed using pure $\mathrm{CO}$ at $4-4.5 \mathrm{NI} / \mathrm{g}-\mathrm{Fe} \cdot \mathrm{h}, 280^{\circ} \mathrm{C}$, and ambient pressure for $8 \mathrm{~h}$. The process conditions employed during these tests are listed in Table V.2-3.

The effect of potassium promotion at $235^{\circ} \mathrm{C}, 1.48 \mathrm{MPa}(200 \mathrm{psig}), 2 \mathrm{Nl} / \mathrm{g}$-cat.h and $\mathrm{H}_{2} / \mathrm{CO}=1$ for catalysts containing either 1 or 3 parts of $\mathrm{Cu}$ per 100 parts of $\mathrm{Fe}$ are shown in Table V.2-4 and Figures V.2-12 and V.2-13. As shown in Table V.2-4, FT activity (i.e., $\left(\mathrm{H}_{2}+\mathrm{CO}\right)$ conversion) increased initially with potassium addition, and then decreased for the $100 \mathrm{Fe} / 1 \mathrm{Cu} / \mathrm{xK}(\mathrm{x}=0,0.2$ and 0.8$)$ catalyst, whereas an increase in activity was observed with the $100 \mathrm{Fe} / 3 \mathrm{Cu} / \mathrm{xK}(\mathrm{x}=0.2$ or 0.5$)$ catalyst. However these trends might have been affected by non-uniformities in temperature and/or pressure in these tests. The WGS activity of all catalysts, measured by extent of the WGS, increased with potassium loading.

The effect of potassium on hydrocarbon and olefin selectivities for the catalysts containing 1 and 3 parts of $\mathrm{Cu}$ per 100 parts of $\mathrm{Fe}$ is shown in Figures V.2-12 and V.2-13, respectively. The trends with potassium loading are qualitatively the same irrespective of the copper content of the catalyst, i.e., the production of methane and gaseous hydrocarbons decreases, whereas the olefin selectivity increases with addition of potassium. Similar trends were observed at other process conditions.

In summary, promotional effects of potassium observed with the $\mathrm{CO}$ activated catalysts are similar to those found in tests with the $\mathrm{H}_{2}$ reduced catalysts. Catalyst activity and selectivity displayed no discernible trends with copper promotion.

\section{V.2.3. Promoter Effect / Kinetic Studies in Stirred Tank Slurry Reactors}

Four of the most active doubly promoted precipitated $\mathrm{Fe} / \mathrm{Cu} / \mathrm{K}$ catalysts were tested in stirred tank slurry reactors. These tests had a dual purpose: (1) to determine promoter effects in slurry phase, and (2) to determine kinetic parameters from tests at different process conditions. These goals were not completely achieved due to a lack of catalyst stability with time on stream and problems with quantification of the high molecular weight products (wax) which accumulate in the reactor. In two of the four tests, catalyst activity increased with time on stream (Runs SA-05-2957 and SB-07-0458), whereas in the other two, catalysts deactivated 
'Table V.2-3. Summary of fixed bed tests and testing conditions for promoter effect reseaclı. ${ }^{a}$

\begin{tabular}{|c|c|c|c|c|c|c|}
\hline Test ID & Catalyst & $\begin{array}{c}220^{\circ} \mathrm{C} \\
1.48 \mathrm{MPa} \\
2 \mathrm{Nl} / \mathrm{g} \text {-cat.h } \\
\end{array}$ & $\begin{array}{c}235^{\circ} \mathrm{C} \\
1.48 \mathrm{MPa} \\
2 \mathrm{Nl} / \mathrm{g} \text {-cat.h }\end{array}$ & $\begin{array}{c}235^{\circ} \mathrm{C} \\
1.48 \mathrm{MPa} \\
4 \mathrm{~N} / \mathrm{g} \text {-cat.h }\end{array}$ & $\begin{array}{c}250^{\circ} \mathrm{C} \\
1.48 \mathrm{MPa} \\
2 \mathrm{~N} 1 / \mathrm{g} \text {-cat.h } \\
\end{array}$ & $\begin{array}{c}235^{\circ} \mathrm{C} \\
2.86 \mathrm{MPa} \\
4 \mathrm{Nl} / \mathrm{g} \text {-cat.h } \\
\end{array}$ \\
\hline FB-05-2287 & $100 / .3 / .2$ & $48(1)^{d}$ & $96(2)^{d}$ & $121(3)^{b, d}$ & & \\
\hline FB-07-2657 & $100 / .3 / .5$ & $46(1)^{c}$ & $94(2)^{c}$ & & $118(3)^{b, c, d}$ & \\
\hline FB-33-2287 & $100 / 1 / 0$ & $49(1)$ & $73(2)$ & & & \\
\hline FA-13-2217 & $100 / 1 / .05$ & $37(1)$ & $61(2)$ & & & \\
\hline FA-15-2097 & $100 / 1 / .2$ & $40(1)$ & $64(2)$ & $88(3)$ & $134(5)^{b}$ & $184(6)$ \\
\hline FA-17-2367 & $100 / 1 / .8$ & $36(1)$ & $60(2)^{d}$ & $84(3)^{d}$ & $131(5)$ & $147(6)^{b}$ \\
\hline FB-25-2447 & $100 / 3 / .2$ & $33(1)$ & $58(2)$ & $83(3)$ & $107(4)^{d}$ & $131(5)$ \\
\hline FA-27-2557 & $100 / 3 / .5$ & $38(1)$ & $63(2)$ & $87(3)$ & $111(4)$ & $135(5)$ \\
\hline
\end{tabular}

a Time on stream, h (balance period) are indicated; $\mathrm{H}_{2} / \mathrm{CO}=1$ for all tests

- Catalyst had partially deactivated

${ }^{c} \mathrm{SV}=3 \mathrm{Nl} / \mathrm{g}$-cat.h for this test

${ }^{d}$ Large axial temperature gradient 
'Table V.2-4. Effect of promoters on catalyst performance ${ }^{a}$

\begin{tabular}{|c|c|c|c|c|c|}
\hline Run Designation & A-2287 & A-2097 & A-2367 & B-2447 & A-2557 \\
\hline Catalyst & $100 / 1 / 0$ & $100 / 1 / .2$ & $100 / 1 / .8$ & $100 / 3 / .2$ & $100 / 3 / .5$ \\
\hline Time on Stream $(h)$ & 73 & 64 & 60 & 58 & 63 \\
\hline CO Conversion (\%) & 41.6 & 82.3 & 68.2 & 54.6 & 74.3 \\
\hline $\mathrm{II}_{2}+\mathrm{CO}$ Conversion (\%) & 45.5 & 72.9 & 56.1 & 54.5 & 62.9 \\
\hline Extent of WGS $\left(\mathrm{p}_{\mathrm{CO} 2} / \mathrm{p}_{\mathrm{CO} 2}+\mathrm{p}_{\mathrm{H} 2 \mathrm{O}}\right)$ & .36 & .77 & .74 & .60 & .85 \\
\hline IC Selectivities (wt.\%) & & & & & \\
\hline $\mathrm{CH}_{4}$ & 9.6 & 9.9 & 6.9 & 7.8 & 5.8 \\
\hline $\mathrm{C}_{2}-\mathrm{C}_{4}$ & 35.5 & 33.3 & 30.9 & 37.3 & 25.2 \\
\hline $\mathrm{C}_{5}-\mathrm{C}_{11}$ & 26.8 & 25.6 & 21.3 & 29.6 & 22.4 \\
\hline $\mathrm{C}_{12}+$ & 28.1 & 31.2 & 40.9 & 25.3 & 46.6 \\
\hline CO Conversion to Products (\%) & & & & & \\
\hline Ilydrocarbons & 62.10 & 55.3 & 43.6 & 36.9 & 47.3 \\
\hline Oxygenates & 3.2 & 1.2 & 1.6 & 1.7 & 0.01 \\
\hline $\mathrm{CO}_{2}$ & 29.14 & 40.6 & 43.1 & 35.1 & 41.7 \\
\hline Unaccounted & 5.6 & 2.9 & 11.7 & 19.6 & 9.6 \\
\hline Olefin Selectivity & & & & & \\
\hline $\mathrm{C}_{2}-\mathrm{C}_{4}(\mathrm{wt} \%)$ & 67.5 & 68.4 & 75.7 & 75.3 & 75.6 \\
\hline$C_{5}-C_{11}(w t \%)$ & 56.9 & 62.3 & 67.6 & 68.4 & 72.5 \\
\hline 2-Butene/1-Butene & .37 & .29 & .08 & .12 & .06 \\
\hline
\end{tabular}

${ }^{a}$ all tests were made at $200 \mathrm{psig}, \mathrm{SV}=2 \mathrm{Nl} / \mathrm{g}$-cat.h, $235^{\circ} \mathrm{C}$ 

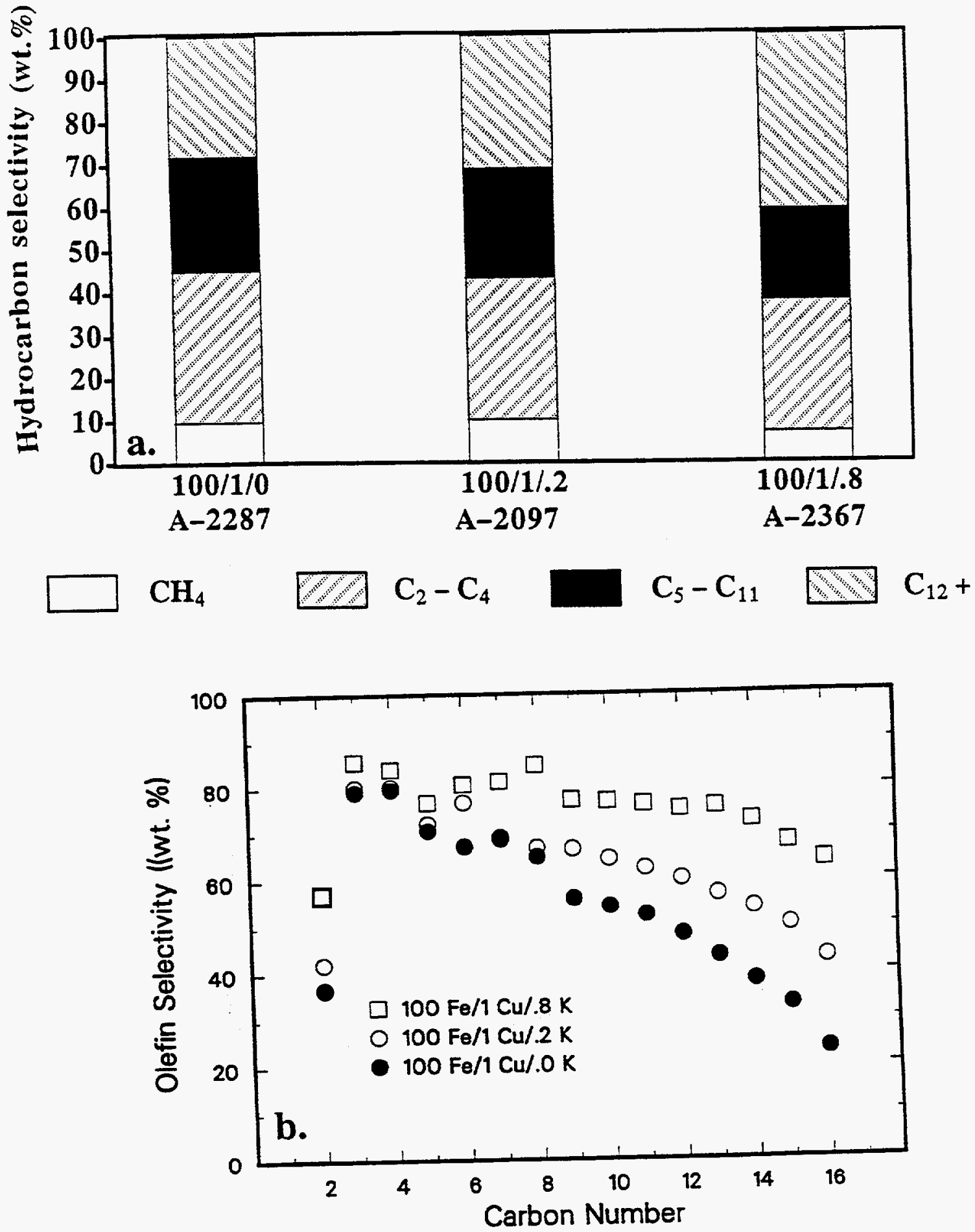

Figure V-2.12. Effect of potassium content on (a) hydrocarbon distribution, and (b) olefin selectivity $\left(235^{\circ} \mathrm{C}, 1.48 \mathrm{MPa}, \mathrm{H}_{2} / \mathrm{CO}=1, \mathrm{SV}\right.$ $=2 \mathrm{Nl} / \mathrm{g}$-cat.h; catalyst composition given as parts by weight of $\mathrm{Fe} / \mathrm{Cu} / \mathrm{K}$ ). 

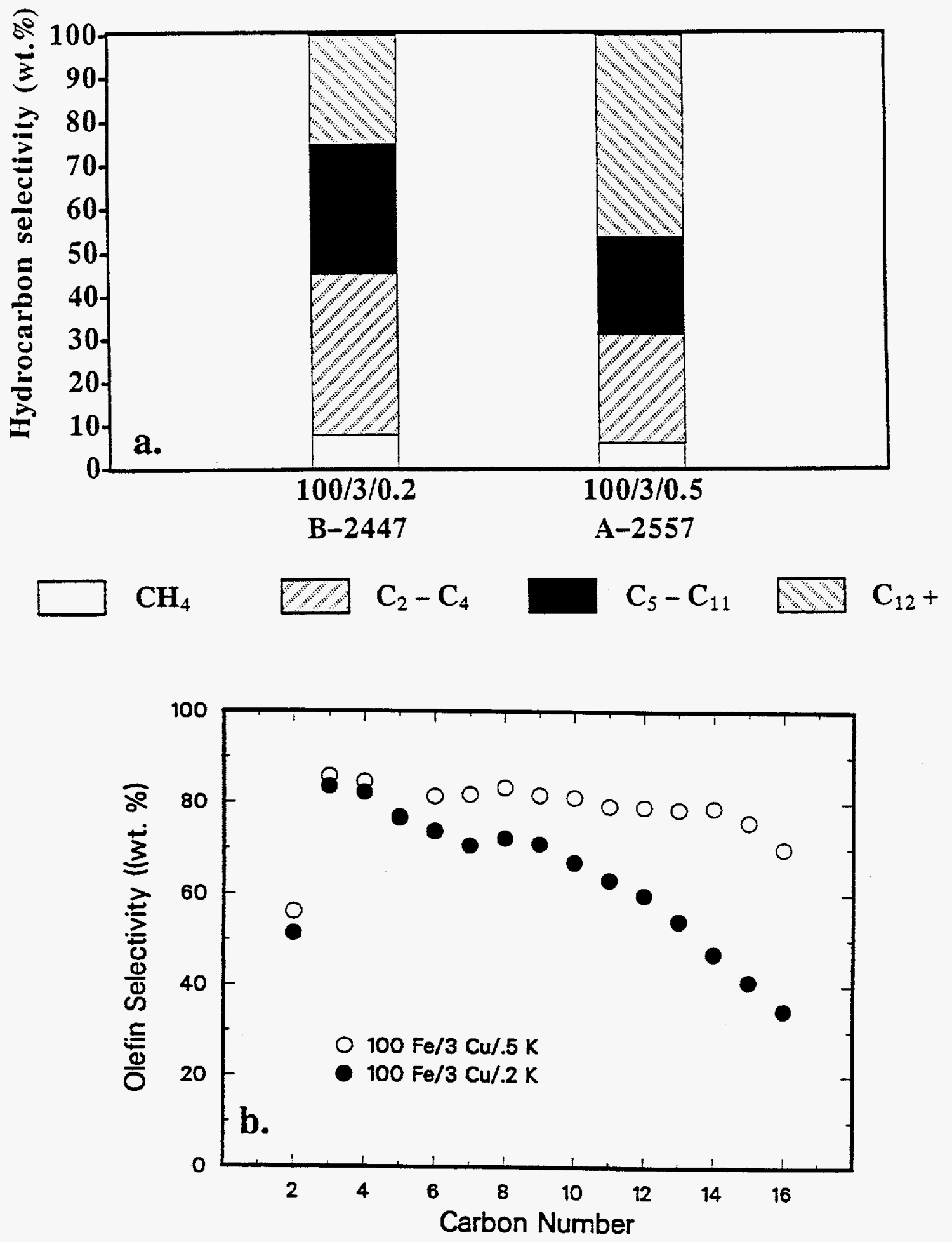

Figure V-2.13. Promoter effects on (a) hydrocarbon distribution, and (b) olefin selectivity $\left(235^{\circ} \mathrm{C}, 1.48 \mathrm{MPa}, \mathrm{H}_{2} / \mathrm{CO}=1, \mathrm{SV}=2 \mathrm{Nl} / \mathrm{g}-\right.$ cat.h; catalyst composition given as parts by weight of $\mathrm{Fe} / \mathrm{Cu} / \mathrm{K}$ ). 
rather rapidly with time on stream (Runs SA-25-3657 and SA-07-0468). Also, during run SA$05-2957$ ( $100 \mathrm{Fe} / 0.3 \mathrm{Cu} / 0.2 \mathrm{~K}$ catalyst), the wax was withdrawn only three times during the test which prevented us from obtaining accurate mass balance closures and hydrocarbon product selectivities. Results from the latter portions of runs SA-05-2957 and SB-070458 were used to estimate kinetic parameters of the FT and WGS reactions (see Section V.3 of this report). In this section, the results from these four slurry reactor tests will be described, followed by a brief summary of the major findings.

\section{V.2.3.1. Run SA - $05-2957$ with the $100 \mathrm{Fe} / 0.3 \mathrm{Cu} / 0.2 \mathrm{~K}$ Catalyst}

This run was made as a retest of the unsuccessful run SA-05-2777, using the $100 \mathrm{Fe} / 0.3$ $\mathrm{Cu} / 0.2 \mathrm{~K}$ catalyst. A hard paraffin wax (FT-300, from Dura Commodities, New York) was used as the slurry liquid, and an excess of wax was loaded with catalyst ( $<325$ mesh) into the reactor prior to reduction. The catalyst was reduced in situ using $\mathrm{CO}$ at $250^{\circ} \mathrm{C}$. Following reduction, the excess wax was withdrawn from the reactor to a preset static slurry volume of about $440 \mathrm{~cm}^{3}$. A total of 18 mass balances were made during the run, and the run was voluntarily terminated after about 550 hours of operation. The results obtained during the run are summarized in Table V.2-5.

Wax which accumulated in the reactor during the synthesis was withdrawn only three times during the course of the run, with withdrawals of 163,395 , and $148 \mathrm{~g}$ of wax after balances 7, 12 , and 18 , respectively. Several methods were tested to allocate the wax collected over multiple periods to individual mass balances. The simplest was to assume that the wax was accumulated in the reactor at a constant rate between withdrawals, regardless of operating conditions. Under this assumption, the rate of wax accumulation in the reactor was $0.79 \mathrm{~g} / \mathrm{h}$ in balances $1-7,2.2 \mathrm{~g} / \mathrm{h}$ in balances $8-12$, and $0.55 \mathrm{~g} / \mathrm{h}$ in balances 13-18. This method of wax allocation often gave poor mass closures and unrealistic estimates of total product yield.

Two methods of wax allocation based on mass closures were also tried. The first method assumed that the amount of wax produced at a given set of conditions was proportional to discrepancy of the total closure obtained during the mass balance period. The amount of wax needed to obtain $100 \%$ closure for all balances was then normalized to agree with the actual amount of wax withdrawn. The second allocation method distributed the wax in order to optimize the carbon and hydrogen atomic closures obtained during the mass balance periods. With the exception of balance 12, this method gave good total mass closures, and in most cases, reasonable values for the total yield. Balance 12 had inherently poor atomic $\mathrm{C}-\mathrm{H}$ closures, 
'Table V.2-5. Summary of results for slurry run SA-05-2957.

Reactor volume: $442 c c^{b}$

\begin{tabular}{|c|c|c|c|c|c|c|}
\hline Period & 1 & 2 & 3 & 4 & 5 & 6 \\
\hline Date & $10 / 26 / 87$ & $10 / 27 / 87$ & $10 / 29 / 87$ & $10 / 30 / 87$ & $10 / 31 / 87$ & $11 / 01 / 87$ \\
\hline 'Jime on Stream $(h)$ & 33.0 & 56.5 & 106.0 & 129.0 & 153.0 & 177.0 \\
\hline Balance Duration ( $h$ ) & 6.0 & 6.0 & 6.0 & 6.0 & 6.0 & 6.0 \\
\hline A verage Temperature $\left({ }^{\circ} \mathrm{C}\right)$ & 220 & 235 & 250 & 250 & 250 & 261 \\
\hline Pressure $\left(M P^{\prime} a\right)$ & 1.48 & 1.48 & 1.48 & 1.48 & 1.48 & 1.48 \\
\hline $\mathrm{H}_{2} / \mathrm{CO}$ Feed Ratio & 1.02 & 1.02 & 1.02 & 1.02 & 1.02 & 1.02 \\
\hline Space Velocity $(N I / g \text {-cat } \cdot h)^{a}$ & 2.00 & 2.00 & 2.00 & 4.00 & 1.01 & 2.00 \\
\hline Space Velocity $(N l / g-\mathrm{Fe} \cdot h)$ & 2.87 & 2.87 & 2.87 & 5.75 & 1.45 & 2.87 \\
\hline GHSV $\left(h^{-1}\right)^{6}$ & 117 & 117 & 117 & 234 & 59 & 117 \\
\hline CO Conversion (\%) & 18.4 & 37.1 & 66.9 & 46.0 & 87.0 & 85.9 \\
\hline $\mathrm{II}_{2}+\mathrm{CO}$ Conversion (\%) & 22.4 & 36.2 & 55.6 & 40.9 & 68.8 & 70.3 \\
\hline $\mathrm{I}_{2} / \mathrm{CO}$ Usage & 1.45 & .97 & .68 & .79 & .60 & .65 \\
\hline $\mathrm{STY}\left(\text { mols } \mathrm{II}_{2}+\mathrm{CO} / g-\mathrm{cal} \cdot h\right)^{a}$ & .020 & .032 & .050 & .073 & 031 & .063 \\
\hline$P_{\mathrm{CO}_{3}} \cdot P_{\mathrm{H}_{2}} / P_{\mathrm{CO}} \cdot P_{\mathrm{H}_{2} \mathrm{O}}$ & .9 & 2.0 & 5.0 & 6.0 & 45.9 & 37.9 \\
\hline \multicolumn{7}{|l|}{ Weight \% of Outlet } \\
\hline $\mathrm{H}_{2}$ & 5.06 & $\overline{4.44}$ & 3.68 & $\overline{4.38}$ & 3.29 & 3.03 \\
\hline $\mathrm{H}_{2} \mathrm{O}$ & 3.51 & 4.58 & 6.00 & 2.63 & 2.17 & 2.19 \\
\hline $\mathrm{CO}$ & 76.2 & 58.8 & 29.8 & 50.1 & 11.9 & 12.9 \\
\hline $\mathrm{CO}_{2}$ & 8.80 & 21.2 & 42.6 & 31.5 & 63.5 & 62.2 \\
\hline Ilydrocarbons & 2.72 & 6.63 & 17.3 & 7.09 & 18.5 & 18.3 \\
\hline Oxygenates & .30 & .31 & .57 & .21 & .38 & .32 \\
\hline $\mathrm{Wax}^{\mathrm{c}}$ & 3.36 & 4.01 & .00 & 4.08 & .30 & 1.02 \\
\hline \multicolumn{7}{|l|}{ Yield $\left(\mathrm{g} / \mathrm{N}^{3} \mathrm{H}_{2}+\mathrm{CO}\right.$ Converted $)$} \\
\hline $\mathrm{CH}_{4}$ & 8.82 & 8.03 & 12.1 & 7.84 & 22.3 & 22.5 \\
\hline $\mathrm{C}_{2}-\mathrm{C}_{4}$ Ilydrocarbons & 34.8 & 27.4 & 39.4 & 28.8 & 57.8 & 58.0 \\
\hline $\mathrm{C}_{5}-\mathrm{C}_{11}$ Ilydrocarbons & 33.4 & 50.5 & 79.3 & 45.2 & 69.9 & 60.9 \\
\hline $\mathrm{C}_{12}+$ Ilydrocarbons & 103 & 109 & 83.0 & 100 & 35.1 & 45.1 \\
\hline $\operatorname{Wax}^{c}$ & 99.3 & 73.3 & .0 & 66.5 & 2.97 & 9.85 \\
\hline Oxygenates & 8.95 & 5.63 & 6.99 & 3.49 & 3.75 & 3.06 \\
\hline Total & 189 & 200 & 221 & 185 & 189 & 190 \\
\hline \multicolumn{7}{|l|}{$1+2$ Olefins/n-Paraffin Ratio } \\
\hline $\mathrm{C}_{2}$ & 1.54 & 2.55 & .87 & 2.78 & .26 & .24 \\
\hline $\mathrm{C}_{3}$ & 4.80 & 5.40 & 4.04 & 4.93 & 2.20 & 2.39 \\
\hline $\mathrm{C}_{4}$ & 4.10 & 4.33 & 3.28 & 3.83 & 2.17 & 2.44 \\
\hline $\mathrm{C}_{8}$ & 2.38 & 3.18 & 2.03 & 2.14 & 1.00 & .98 \\
\hline $\mathrm{C}_{10}$ & 1.58 & 3.51 & 1.12 & 2.11 & .95 & .87 \\
\hline
\end{tabular}

a Based on unreduced catalyst. "Based on static slurry volumo 
Table V.2-5 (cont'd). Summary of results for slurry run SA-05-2957.

\begin{tabular}{|c|c|c|c|c|c|c|}
\hline Period & 7 & 8 & 9 & 10 & 11 & 12 \\
\hline Date & $11 / 02 / 87$ & $11 / 04 / 87$ & $11 / 05 / 87$ & $11 / 06 / 87$ & $11 / 07 / 87$ & $11 / 08 / 87$ \\
\hline T'ime on Stream $(h)$ & 201.0 & 248.5 & 272.5 & 297.0 & 321.0 & 345.0 \\
\hline Balauce Duration $(h)$ & 6.0 & 6.0 & 6.0 & 6.0 & 6.0 & 6.0 \\
\hline Average Temperature $\left({ }^{\circ} \mathrm{C}\right)$ & 250 & 220 & 235 & 250 & 250 & 250 \\
\hline Pressure $(M P a)$ & .79 & 1.48 & 1.48 & 1.48 & 1.48 & 1.48 \\
\hline $\mathrm{H}_{2} / \mathrm{CO}$ Feed Ratio & 1.02 & .67 & .69 & .71 & .72 & .65 \\
\hline Space Velocity $(N I / g \text {-cat } \cdot h)^{a}$ & 1.05 & 2.00 & 2.11 & 2.03 & 4.07 & 1.02 \\
\hline GIISV $\left(h^{-1}\right)^{b}$ & 62 & 117 & 117 & 113 & 225 & 56 \\
\hline CO Conversion (\%) & 79.0 & 21.3 & 42.8 & 76.2 & 50.2 & 73.0 \\
\hline $\mathrm{II}_{2}+\mathrm{CO}$ Conversion (\%) & 61.1 & 20.5 & 40.6 & 70.2 & 49.4 & 80.8 \\
\hline $\mathrm{II}_{2} / \mathrm{CO}$ Usage & .56 & .60 & .61 & .58 & .69 & .83 \\
\hline $\mathrm{STY}\left(\mathrm{mols} \mathrm{II}_{2}+\mathrm{CO} / g-\mathrm{cal} \cdot h\right)^{a}$ & .029 & .018 & .038 & .064 & .090 & .037 \\
\hline$P_{\mathrm{CO}_{2}} \cdot P_{\mathrm{H}_{2}} / P_{\mathrm{CO}} \cdot P_{\mathrm{H}_{2} \mathrm{O}}$ & 45.6 & 3.5 & 5.6 & 18.8 & 9.7 & 5.2 \\
\hline \multicolumn{7}{|l|}{ Weight \% of Outlet } \\
\hline $\mathrm{I}_{2}$ & 3.84 & 3.79 & 2.97 & 1.86 & 2.49 & .33 \\
\hline $\mathrm{HI}_{2} \mathrm{O}$ & 1.38 & 1.03 & 1.69 & 1.37 & 1.15 & .80 \\
\hline $\mathrm{CO}$ & 19.4 & 77.08 & 54.4 & 22.7 & 46.5 & 25.8 \\
\hline $\mathrm{CO}_{2}$ & 56.1 & 12.7 & 30.2 & 55.1 & 36.5 & 57.7 \\
\hline Hydrocarbons & 16.4 & 2.24 & 3.59 & 11.5 & 4.20 & 9.19 \\
\hline Oxygenates & .18 & .05 & .22 & .19 & .14 & .15 \\
\hline $\mathrm{Wax}^{c}$ & 2.68 & 3.18 & 6.85 & 7.26 & 9.06 & 6.03 \\
\hline \multicolumn{7}{|l|}{ Yield $\left(g / \mathrm{Nm}^{3} \mathrm{II}_{2}+\mathrm{CO}\right.$ Converted $)$} \\
\hline $\mathrm{CH}_{4}$ & 23.1 & 2.93 & 3.25 & 4.90 & 3.31 & 3.38 \\
\hline $\mathrm{C}_{2}-\mathrm{C}_{4}$ IIydrocarbons & 55.7 & 14.6 & 14.4 & 18.5 & 13.4 & 20.7 \\
\hline $\mathrm{C}_{5}-\mathrm{C}_{11}$ Hydrocarbons & 12.0 & 27.2 & 23.8 & 42.3 & 25.0 & 37.3 \\
\hline $\mathrm{C}_{12}+$ IIydrocarbons & 68.5 & 158 & 158 & 140 & 168 & 87.7 \\
\hline $\operatorname{Wax}^{c}$ & 29.2 & 119 & 131 & 79.4 & 143 & 59.1 \\
\hline Oxygenates & 1.95 & 1.95 & 4.18 & 2.10 & 2.26 & 1.47 \\
\hline Total & 211 & 205 & 203 & 207 & 211 & 151 \\
\hline \multicolumn{7}{|l|}{$1+2$ Olefins/n-Paralfin Ratio } \\
\hline$\overline{\mathrm{C}_{2}}$ & .26 & 1.46 & 2.66 & 1.64 & 3.36 & 1.14 \\
\hline $\mathrm{C}_{3}$ & 2.26 & 4.16 & 4.89 & 5.59 & 5.95 & 5.76 \\
\hline $\mathrm{C}_{4}$ & 2.46 & 3.20 & 3.77 & 4.47 & 4.46 & 4.63 \\
\hline $\mathrm{C}_{8}$ & .63 & 2.08 & 2.29 & 2.78 & 2.39 & 2.51 \\
\hline $\mathrm{C}_{10}$ & .62 & 1.29 & 2.70 & 2.43 & 2.43 & 2.38 \\
\hline
\end{tabular}

a Based on unreduced catalyst

${ }^{b}$ Bitsed on static slurry volume

Calculated wax produced during balance 
'Tuble V.2-5 (cont'd). Summary of results for slurry run SA-05-2957.

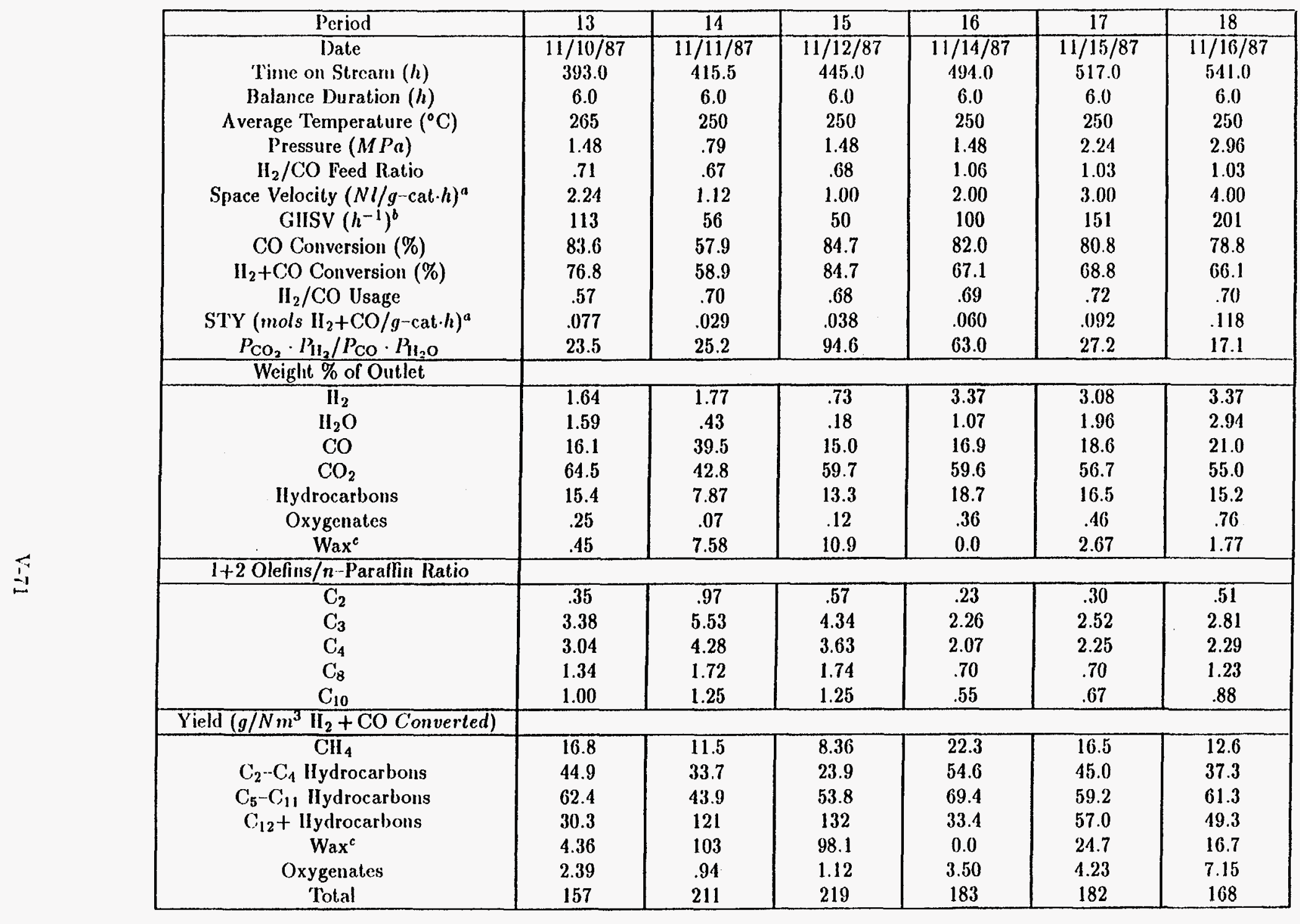

${ }^{a}$ Based on unreduced catalyst $\quad$ b Based on static slurry volume 
'Table V.2-5 (cont'd). Summary of results for slurry run S $4-(15-2957$.

\begin{tabular}{|c|c|c|c|c|c|c|}
\hline Period & 1 & 2 & 3 & 1 & 5 & 6 \\
\hline \multicolumn{7}{|c|}{ Weight \% of IIydrocarbons } \\
\hline CII4 & 4.91 & 4.12 & 5.66 & 4.31 & 12.0 & 12.1 \\
\hline Blhane & 2.93 & 1.22 & 2.54 & 1.11 & 6.74 & 6.54 \\
\hline Etlıylene & 4.21 & 2.90 & 2.05 & 2.89 & 1.66 & 1.48 \\
\hline Propane & 1.12 & .84 & 1.44 & 1.03 & 3.85 & 3.63 \\
\hline Propylene & 5.13 & 4.32 & 5.56 & 4.85 & 8.09 & 8.28 \\
\hline$n$-IButane & 1.10 & .85 & 1.54 & 1.18 & 3.29 & 3.13 \\
\hline $1+2$ Butenes & 4.34 & 3.53 & 4.87 & 4.37 & 6.90 & 7.36 \\
\hline $\mathrm{C}_{4}$ Isomers & .52 & .41 & .44 & .39 & .71 & .67 \\
\hline n-Pentane & 1.53 & 1.13 & 1.91 & 1.56 & 3.50 & 3.37 \\
\hline 1+2 Pentenes & 4.44 & 5.69 & 5.20 & 4.32 & 7.44 & 6.49 \\
\hline $\mathrm{C}_{5}$ Isomers & .48 & .31 & .64 & .29 & 2.30 & 2.03 \\
\hline$n$-Ilexane & 1.39 & .98 & 1.25 & 1.11 & 2.85 & 2.11 \\
\hline $1+2$ Il exenes & 3.51 & 2.61 & 3.15 & 3.17 & 3.06 & 2.76 \\
\hline $\mathrm{C}_{6}$ Isomers & .00 & 1.43 & .68 & .59 & .60 & .44 \\
\hline$n$-IIeptane & 1.22 & .90 & .85 & .79 & 1.92 & 1.61 \\
\hline 1+2 Ifeptenes & 2.36 & 1.80 & 1.85 & 2.33 & 1.87 & 1.67 \\
\hline $\mathrm{C}_{7}$ Isomers & .04 & .95 & .38 & .49 & .54 & .39 \\
\hline n-Octane & .55 & .41 & .63 & .81 & 1.69 & 1.47 \\
\hline $1+2$ Octenes & 1.29 & 1.29 & 1.26 & 1.70 & 1.65 & 1.42 \\
\hline $\mathrm{C}_{8}$ Isomers & .05 & .21 & .24 & .32 & .46 & .20 \\
\hline$n$-Nonane & .19 & .36 & 1.89 & .51 & 1.51 & 1.36 \\
\hline $1+2$ Nonenes & .36 & 1.55 & 2.32 & 1.25 & 1.45 & 1.25 \\
\hline $\mathrm{C}_{9}$ Isomers & .07 & .09 & .18 & .12 & .52 & .23 \\
\hline$n$-Decane & .19 & .62 & 3.09 & .77 & 1.49 & 1.45 \\
\hline $1+2$ Decenes & .30 & 2.13 & 3.41 & 1.60 & 1.40 & 1.24 \\
\hline $\mathrm{C}_{10}$ Isomers & .08 & .12 & .22 & .22 & .41 & .27 \\
\hline$n$-Vudecane & .19 & .82 & 3.75 & .91 & 1.41 & 1.47 \\
\hline 1+2 Undecenes & .24 & 2.38 & 3.77 & 1.70 & 1.28 & 1.14 \\
\hline $\mathrm{C}_{11}$ Isomers & .09 & .16 & .42 & .28 & .44 & .29 \\
\hline $\mathrm{C}_{2}-\mathrm{C}_{4}$ & 19.4 & 14.1 & 18.4 & 15.8 & 31.2 & 31.1 \\
\hline$C_{5} C_{11}$ & 18.6 & 26.0 & 37.1 & 24.9 & 37.8 & 32.7 \\
\hline $\mathrm{C}_{12}+$ & 57.2 & 55.9 & 38.8 & 55.0 & 19.0 & 24.2 \\
\hline $\mathrm{Wax}^{c}$ & 55.2 & 37.7 & .00 & 36.5 & 1.61 & 5.28 \\
\hline
\end{tabular}

${ }^{c}$ Calculated wax produced during balance 
Table V.2-5 (cont'd). Summary of results for slurry run SA-05-2957.

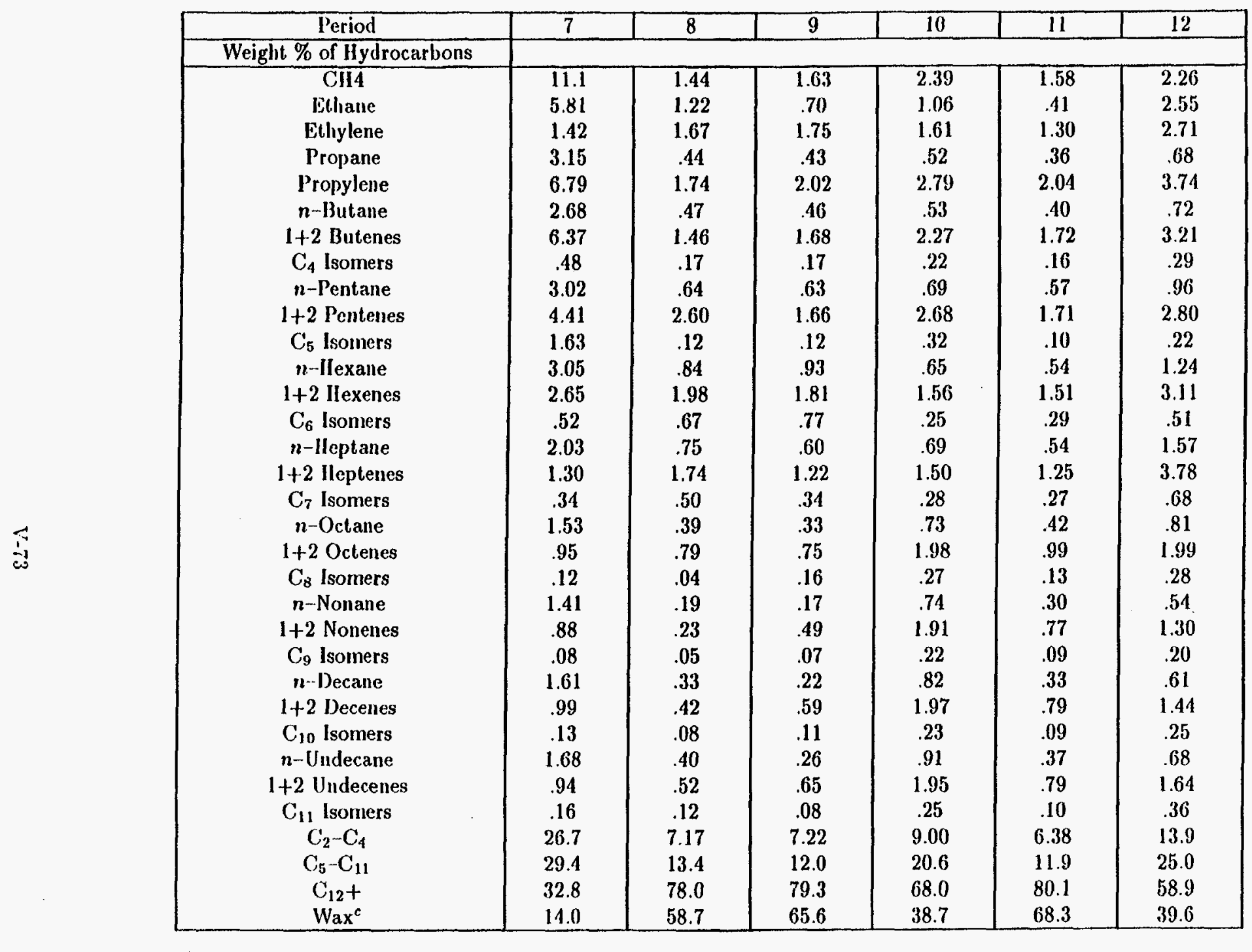

c Calculated wax produced during balance 
Table V.2-5 (cont'd). Summary of results for slurry run SA-05-2957.

\begin{tabular}{|c|c|c|c|c|c|c|}
\hline Period & 13 & 14 & 15 & 16 & 17 & 18 \\
\hline \multicolumn{7}{|c|}{ Weight \% of Ilydrocarbons } \\
\hline $\mathrm{CII4}$ & 10.9 & 5.46 & 3.84 & 12.4 & 9.28 & 7.88 \\
\hline Ethane & 6.01 & 2.65 & 1.78 & 6.92 & 5.45 & 4.22 \\
\hline Ethylene & 1.96 & 2.39 & .94 & 1.50 & 1.54 & 2.02 \\
\hline Propane & 2.56 & .88 & .81 & 3.65 & 2.89 & 2.41 \\
\hline Propylene & 8.26 & 4.66 & 3.37 & 7.87 & 6.97 & 6.47 \\
\hline$n$-Butane & 2.47 & 1.02 & .86 & 3.26 & 2.50 & 2.35 \\
\hline $1+2$ Butenes & 7.24 & 4.20 & 3.01 & 6.53 & 5.42 & 5.20 \\
\hline $\mathrm{C}_{4}$ Isomers & .56 & .26 & .18 & .67 & .57 & .55 \\
\hline$n$-Pentane & 2.86 & 1.36 & 1.00 & 3.47 & 2.62 & 2.46 \\
\hline 1+2 Pentenes & 5.93 & 4.22 & 2.87 & 6.11 & 5.04 & 5.21 \\
\hline $\mathrm{C}_{5}$ Isomers & .87 & .30 & .30 & .63 & .56 & .59 \\
\hline$n$-Ilexane & 2.75 & 1.25 & 1.08 & 3.25 & 2.30 & 2.11 \\
\hline $1+2$ llexenes & 4.61 & 3.32 & 3.04 & 3.47 & 3.34 & 3.50 \\
\hline $\mathrm{C}_{6}$ Isomers & .69 & .59 & .78 & .57 & .44 & .40 \\
\hline$n$-lleptane & 1.81 & .88 & 1.11 & 2.87 & 1.99 & 2.09 \\
\hline $1+2$ lleptenes & 2.50 & 1.95 & 1.78 & 2.17 & 2.09 & 2.47 \\
\hline $\mathrm{C}_{7}$ Isomers & 1.09 & .42 & .31 & .47 & .44 & .60 \\
\hline n-Octane & 1.73 & .73 & 1.20 & 2.47 & 1.88 & 2.15 \\
\hline $1+2$ Octenes & 2.28 & 1.23 & 2.04 & 1.71 & 1.29 & 2.60 \\
\hline $\mathrm{C}_{8}$ Isomers & .25 & .22 & .17 & .25 & .23 & .38 \\
\hline$n$-Nonane & 2.11 & .55 & 1.23 & 2.29 & 1.99 & 2.13 \\
\hline $1+2$ Nonenes & 2.33 & .75 & 1.74 & 1.30 & 1.50 & 2.13 \\
\hline $\mathrm{C}_{9}$ Isomers & .16 & .09 & .19 & .21 & .14 & .34 \\
\hline$n$-Decane & 2.16 & .65 & 1.30 & 2.41 & 2.18 & 2.30 \\
\hline $1+2$ Decenes & 2.13 & .80 & 1.61 & 1.32 & 1.43 & 1.99 \\
\hline$C_{10}$ lsomers & .18 & .11 & .14 & .18 & .20 & .35 \\
\hline$n$-Undecane & 2.04 & .68 & 1.28 & 2.24 & 2.16 & 2.34 \\
\hline $1+2$ Undecenes & 1.73 & .72 & 1.38 & 1.02 & 1.23 & 1.73 \\
\hline $\mathrm{C}_{11}$ Isomers & .16 & .12 & .15 & .20 & .25 & .30 \\
\hline $\mathrm{C}_{2}-\mathrm{C}_{4}$ & 29.1 & 16.1 & 11.0 & 30.4 & 25.3 & 23.2 \\
\hline $\mathrm{C}_{5}-\mathrm{C}_{11}$ & 40.4 & 20.9 & 24.7 & 38.6 & 33.3 & 38.2 \\
\hline $\mathrm{C}_{12}+$ & 19.6 & 57.6 & 60.5 & 18.6 & 32.1 & 30.7 \\
\hline$W_{a x}{ }^{c}$ & 2.82 & 49.1 & 45.0 & 0.0 & 13.9 & 10.4 \\
\hline
\end{tabular}

c Calculated wax produced during balance 
thus the total closure allocation was used to estimate the amount of wax accumulated during this period. The optimized $\mathrm{C}$-H closure allocation was used for all remaining periods.

The effect of space velocity was studied at $250^{\circ} \mathrm{C}, 1.48 \mathrm{MPa}$ with nominal $\left(\mathrm{H}_{2} / \mathrm{CO}\right)$ feed ratios of 1.0 (balances 5, 3 and 16, and 4) and 0.67 (balances 12 and 15, 10, and 11) at 1 , 2 , and $4 \mathrm{~N} / \mathrm{g}$-cat.h. The $\left(\mathrm{H}_{2}+\mathrm{CO}\right)$ conversion decreased approximately linearly with space velocity. The catalyst appeared to become more active with time on stream, as shown by the $\left(\mathrm{H}_{2}+\mathrm{CO}\right)$ conversions obtained in balances 3 and 16 at $250^{\circ} \mathrm{C}, 1.48 \mathrm{MPa},\left(\mathrm{H}_{2} / \mathrm{CO}\right)=1$ with $2 \mathrm{NI} / \mathrm{g}$-cat.h space velocity. During balance 3 (approximately $106 \mathrm{~h}$ on stream) the $\left(\mathrm{H}_{2}+\mathrm{CO}\right)$ conversion was $55.6 \%$, while during balance 16 (approximately $494 \mathrm{~h}$ on stream) the conversion had increased to $67.1 \%$. At the same process conditions using a $0.67\left(\mathrm{H}_{2} / \mathrm{CO}\right)$ feed ratio, the $\left(\mathrm{H}_{2}+\mathrm{CO}\right)$ conversion was roughly constant at 345 and 445 hours on stream, 80.8 (balance 12) and $84.7 \%$ (balance 15), respectively. The increasing catalyst activity may be due to continuing catalyst activation during synthesis testing. The in situ catalyst reduction conditions of $250^{\circ} \mathrm{C}$ for $8 \mathrm{~h}$ may not have completely reduced the catalyst, however, catalyst activation would have continued at the elevated synthesis temperature with the synthesis feed gas.

At the same process conditions, the $\left(\mathrm{H}_{2} / \mathrm{CO}\right)=0.67$ feed ratio favored higher conversions over the $\left(\mathrm{H}_{2} / \mathrm{CO}\right)=1$ feed ratio. Also, the lower feed ratio accelerated wax production. During balances 8-12, of $91 \mathrm{~h}$ duration, $395 \mathrm{~g}$ of wax were produced, whereas during balances 1-7, of $177 \mathrm{~h}$ duration, only $163 \mathrm{~g}$ of wax were produced. Balances 8-12 were all made using the lower $\left(\mathrm{H}_{2} / \mathrm{CO}\right)$ feed ratio, and balances $1-7$ were made using an $\left(\mathrm{H}_{2} / \mathrm{CO}\right)=1$ feed ratio. Also, balances $1-7$ consisted of 5 balances (1-5) at the same temperature, pressure, and space velocity as balances $8-12$, plus two additional balances at other process conditions. Thus wax production must have been much higher at the lower feed ratio.

A plot of the space time yield versus pressure is given in Figure V.2-14. The space time yield was found to vary roughly linearly with pressure over the range of pressures studied. The precipitated catalyst did not deactivate at high pressure in the slurry reactor, as was found in the fixed bed tests of these catalysts.

Comparison of hydrocarbon selectivities at different process conditions is difficult due to the approximate nature of wax allocation, which may have had a significant effect on the results. Methane yield varied from $1.4 \%$ (balance 8 ) to $12.1 \%$ (balance 6 ), whereas the yield of $\mathrm{C}_{2}-\mathrm{C}_{4}$ hydrocarbons was between 6.4 and $31.1 \%$ (balances 11 and 6 , respectively). Inspite of some uncertainties in hydrocarbon selectivities it is clear that much less $\mathrm{CH}_{4}$ and gaseous 


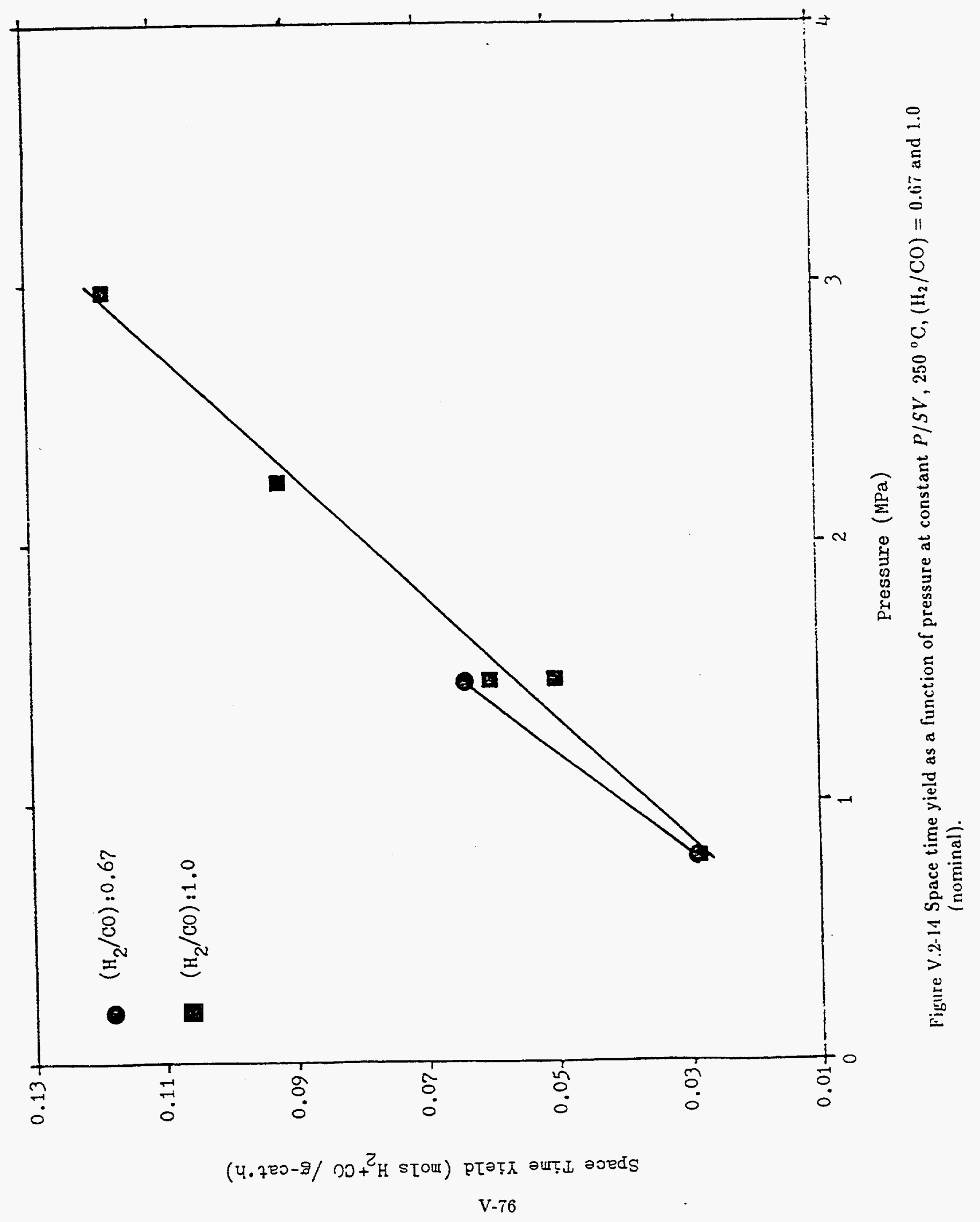


hydrocarbons $\left(\mathrm{C}_{2}-\mathrm{C}_{4}\right)$ were produced when the $\mathrm{CO}$ rich feed gas was used $\left(\mathrm{H}_{2} / \mathrm{CO}=0.67\right)$. Reproducibility of results for balances at the same process conditions $\left(250^{\circ} \mathrm{C}, 200\right.$ pisg, $2 \mathrm{NI} / \mathrm{g}$ cat.h) was not good with $\mathrm{H}_{2} / \mathrm{CO}=1$ feed gas (balances 3 and 16), but was quite satisfactory with $\mathrm{H}_{2} / \mathrm{CO}=0.67$ feed (balances 12 and 15 ).

\section{V.2.3.2. Run SA $-25-3657$ with the $100 \mathrm{Fe} / 3 \mathrm{Cu} / 0.2 \mathrm{~K}$ Catalyst}

Run SA-25-3657 was performed to test the precipitated $100 \mathrm{Fe} / 3 \mathrm{Cu} / 0.2 \mathrm{~K}$ catalyst under a variety of process conditions. Excess purified n-octacosane $\left(C_{28}\right.$. Humphry Chemical) was loaded with catalyst ( $<325$ mesh) into the reactor prior to reduction, and the catalyst was reduced in situ with $\mathrm{CO}$ at $280^{\circ} \mathrm{C}$. Following reduction, the excess wax was withdrawn from the reactor to the preset static slurry volume of $478 \mathrm{cc}$. Eight material balances were made during this run, which was terminated voluntarily after $430 \mathrm{~h}$ of operation. The results obtained in each of the eight balances are summarized in Table V.2-6.

A power loss occurred at about $129 \mathrm{~h}$ on stream, causing a flow interruption to the reactor. The reactor also cooled from 235 to $80^{\circ} \mathrm{C}$. Power was restored after $5 \mathrm{~h}$, and the reactor was brought to its original temperature over $a \mathrm{~h}$ period. The catalyst was deactivating prior to the power failure, and continued to deactivate once the run continued. The deactivation made it difficult to determine what effect the interruption had on catalyst performance. Table V.2-7 lists the major events occurring during run SA-25-3657.

The initial catalyst activity was very good, with an $\left(\mathrm{H}_{2}+\mathrm{CO}\right)$ conversion during balance 1 $\left(250^{\circ} \mathrm{C}, 1.48 \mathrm{MPa},\left(\mathrm{H}_{2} / \mathrm{CO}\right)=1,2 \mathrm{NI} / \mathrm{g}\right.$-cat.h $)$ of $83.0 \%$. No signs of deactivation were observed before the end of period 1 ( $50 \mathrm{~h}$ on stream), but after the wax withdrawal and an increase in space velocity to $4 \mathrm{NI} / \mathrm{g}$-cat.h a sharp decline in activity occurred. Over the 46 $h$ period these conditions were maintained, the gas contraction decreased steadily from 48 to $36 \%$. The process conditions of balance 1 were repeated during balance 4 , by which time the $\left(\mathrm{H}_{2}+\mathrm{CO}\right)$ conversion decreased from 83.0 to $28.5 \%$.

In all cases, feed gas with $\left(\mathrm{H}_{2} / \mathrm{CO}\right)=0.67$ (nominal) gave product distributions with lower methane yield $(3.2-4 \%)$. In addition, the lower feed ratio produced larger amounts of high molecular weight products $\left(C_{12}+\right)$. Catalyst deactivation may have skewed the selectivity trends of the run. For example, the methane and $C_{2}-C_{4}$ product fractions decreased as the catalyst deactivated between balances 1 and 4 . The more active catalyst produced $9.31 \%$ methane and $35.9 \% \mathrm{C}_{2}-\mathrm{C}_{4}$, as compared to $4.87 \%$ and $21.7 \%$, respectively, during balance 
Table V.2-6. Summary of results for slurry run $S \Lambda-25-3657$.

Catalyst: $38.4 g^{u}, 100 \mathrm{Fe} / 3 \mathrm{Cu} / 0.2 \mathrm{~K}$ Reactor volume: 438. $c c^{b}$

Slırry liquid: $307 g, n-$ Octacosanc

\begin{tabular}{|c|c|c|c|c|c|c|c|c|}
\hline Period & 1 & 2 & 3 & 4 & 5 & 6 & 7 & 8 \\
\hline Date & $1 / 3 / 88$ & $1 / 5 / 88$ & $1 / 8 / 88$ & $1 / 10 / 88$ & $1 / 12 / 88$ & $1 / 12 / 88$ & $1 / 16 / 88$ & $1 / 18 / 88$ \\
\hline Time on Stream (h) & 44.0 & 91.0 & 158.5 & 206.0 & 254.0 & 302.0 & 350.0 & 398.0 \\
\hline Balance Duration (h) & 6.0 & 6.0 & 6.0 & 6.0 & 6.0 & 6.0 & 6.0 & 6.0 \\
\hline A verage Temperature $\left({ }^{\circ} \mathrm{C}\right)$ & 250. & 250. & 235. & 250. & 250. & 250. & 265. & 235. \\
\hline Pressure $\left(M I I^{\prime} a\right)$ & 1.48 & 1.48 & 1.48 & 1.48 & 1.48 & 1.48 & 1.48 & 1.18 \\
\hline $\mathrm{II}_{2} / \mathrm{CO}$ Feed Ialio & .994 & .994 & .980 & 1.01 & .663 & .682 & .678 & .669 \\
\hline Space Velocity $(N l / g \text {-cat } \cdot h)^{u}$ & 2.02 & 4.03 & 2.01 & 2.00 & 1.01 & 2.01 & 2.02 & 1.01 \\
\hline Space Velocity $(N \mid / g-\mathrm{Fe} \cdot h)$ & 2.96 & 5.93 & 2.95 & 2.94 & 1.48 & 2.96 & 2.96 & 1.49 \\
\hline GIISV $\left(h^{-1}\right)^{b}$ & 177. & 350. & 174. & 173. & 86.0 & 171. & 171. & 85.6 \\
\hline CO Conversion (\%) & 93.9 & 47.6 & 15.5 & 28.3 & 48.3 & 16.6 & 27.8 & 10.8 \\
\hline $\mathrm{II}_{2}+\mathrm{CO}$ Conversion (\%) & 83.0 & 46.7 & 21.4 & 28.5 & 44.8 & 18.6 & 29.3 & 13.9 \\
\hline $\mathrm{H}_{2} / \mathrm{CO}$ Usage & .762 & .957 & 1.74 & 1.02 & .543 & .893 & .770 & 1.14 \\
\hline $\mathrm{S}^{\prime} \mathrm{IY}^{\prime}\left(\mathrm{mols} \mathrm{II}_{2}+\mathrm{CO} / g \text {-cat } \cdot h\right)^{u}$ & .075 & .084 & .019 & .025 & .020 & .017 & .026 & .006 \\
\hline$P_{\mathrm{CO}_{2}} \cdot P_{\mathrm{H}_{2}} / P_{\mathrm{CO}} \cdot P_{\mathrm{H}_{2} \mathrm{O}}$ & 22.6 & 1.53 & .321 & .647 & .806 & .442 & 1.01 & .434 \\
\hline Weight \% of Outlet & & & & & & & & \\
\hline $\mathrm{II}_{2}$ & 1.93 & 3.68 & $\overline{4.82}$ & 5.08 & $3 . \overline{33}$ & 3.79 & $\overline{3.24}$ & 3.72 \\
\hline $\mathrm{II}_{2} \mathrm{O}$ & 5.30 & 6.93 & 5.46 & 6.49 & 7.62 & 3.37 & 3.67 & 2.78 \\
\hline $\mathrm{CO}$ & 5.86 & 49.7 & 79.6 & 70.3 & 59.6 & 82.3 & 70.2 & 84.7 \\
\hline $\mathrm{CO}_{2}$ & 64.0 & 25.2 & 5.08 & 10.2 & 19.4 & 5.69 & 14.1 & 4.82 \\
\hline Iydrocarbons & 19.7 & 10.4 & 3.55 & 4.57 & 6.17 & 3.05 & 5.51 & 2.41 \\
\hline Oxygenates & .647 & .494 & .176 & .129 & .220 & .138 & .202 & .104 \\
\hline Wax & 2.50 & 3.59 & 1.36 & 3.24 & 3.68 & 1.65 & 3.09 & 1.48 \\
\hline Iield $\left(\mathrm{g} / \mathrm{Nm}^{3} \mathrm{H}_{2}+\mathrm{CO}\right.$ Converted $)$ & & & & & & & & \\
\hline $\mathrm{CH}_{4}$ & 16.2 & 9.06 & 6.93 & $\overline{8.46}$ & 4.52 & 6.11 & 7.66 & 8.89 \\
\hline $\mathrm{C}_{2}-\mathrm{C}_{4}$ Hydrocarbons & 62.6 & 44.1 & 40.5 & 37.7 & 29.4 & 39.2 & 37.9 & 56.1 \\
\hline $\mathrm{C}_{5}-\mathrm{C}_{11}$ Hydrocarbons & 68.0 & 55.3 & 44.4 & 39.9 & 39.6 & 53.1 & 45.3 & 40.7 \\
\hline $\mathrm{C}_{12}+$ Hydrocarbons & 27.5 & 89.0 & 62.1 & 87.8 & 69.7 & 91.6 & 134. & 115. \\
\hline Wax & 19.6 & 50.8 & 42.6 & 72.1 & 53.5 & 66.7 & 80.7 & 83.8 \\
\hline Oxygenates & 5.07 & 7.00 & 5.51 & 2.87 & 3.20 & 5.59 & 5.29 & 5.87 \\
\hline Total & 179. & 204. & 159. & 177. & 146. & 196. & 230. & 226. \\
\hline $1+2$ Olefins/n-Paraffin Ratio & & & & & & & & \\
\hline $\mathrm{C}_{2}$ & .242 & 1.40 & 1.61 & $\overline{2.72}$ & 1.20 & 1.16 & 1.40 & 1.29 \\
\hline $\mathrm{C}_{3}$ & 2.57 & 6.47 & 6.01 & 6.57 & 6.97 & 7.48 & 8.27 & 4.01 \\
\hline $\mathrm{C}_{4}$ & 3.06 & 5.37 & 4.54 & 5.69 & 5.80 & 5.92 & 6.48 & 4.35 \\
\hline $\mathrm{C}_{8}$ & .697 & 2.60 & 2.61 & 2.75 & 3.08 & 2.52 & 3.46 & 1.25 \\
\hline $\mathrm{C}_{10}$ & .345 & 1.86 & 2.82 & 2.64 & 3.17 & 2.61 & 4.33 & 2.19 \\
\hline
\end{tabular}

" Based on unreduced catalyst

- Unanalyzed wax withdrawn from reactor

"Based on static slurry volume 
Table V.2-6 (cont'd). Summary of results for slurry run SA-25-3657.

\begin{tabular}{|c|c|c|c|c|c|c|c|c|}
\hline Period & 1 & 2 & 3 & 4 & 5 & 6 & 7 & 8 \\
\hline \multicolumn{9}{|c|}{ Weight \% of Ilydrocarbons } \\
\hline CII & 9.31 & 4.59 & 4.50 & 4.87 & 3.16 & 3.21 & 3.41 & 4.04 \\
\hline Ethane & 7.22 & 2.59 & 3.82 & 1.59 & 3.11 & 4.77 & 2.95 & 4.28 \\
\hline Ethylene & 1.63 & 3.39 & 5.75 & 4.02 & 3.49 & 5.16 & 3.85 & 5.14 \\
\hline Propane & 4.29 & 1.19 & 1.29 & 1.16 & .934 & .675 & .586 & 1.56 \\
\hline Propylene & 10.5 & 7.35 & 7.37 & 7.29 & 6.21 & 4.82 & 4.63 & 5.99 \\
\hline n-But ane & 2.82 & 1.16 & 1.39 & 1.08 & .958 & .719 & .616 & 1.43 \\
\hline $1+2$ Butenes & 8.32 & 6.03 & 6.08 & 5.93 & 5.36 & 4.11 & 3.85 & 6.01 \\
\hline $\mathrm{C}_{4}$ Isomers & 1.11 & .639 & .604 & .592 & .468 & .388 & .369 & 1.05 \\
\hline$n$-Pentane & 3.11 & 1.64 & 1.68 & 1.52 & 1.18 & 1.04 & .963 & 1.36 \\
\hline $1+2$ Pentenes & 6.75 & 6.30 & 6.93 & 5.18 & 4.18 & 3.72 & 3.54 & 4.82 \\
\hline$C_{3}$ Isomers & .841 & .757 & 1.05 & .384 & .300 & .277 & .260 & .430 \\
\hline n-Hexane & 2.71 & 1.14 & 1.26 & .952 & 1.05 & 1.62 & .911 & 1.59 \\
\hline $1+2$ Ilexenes & 3.87 & 2.88 & 3.86 & 3.13 & 4.52 & 4.50 & 2.94 & 1.99 \\
\hline $\mathrm{C}_{6}$ Isomers & .653 & .620 & .851 & .661 & .899 & .988 & .687 & .640 \\
\hline n-Heptane & 2.52 & .731 & .863 & .898 & 1.09 & 1.46 & .659 & 1.02 \\
\hline 1+2 Heptenes & 2.19 & 1.69 & 2.39 & 1.83 & 2.83 & 2.98 & 1.81 & 1.27 \\
\hline $\mathrm{C}_{\tau}$ lsomers & .642 & .432 & .609 & .490 & .804 & .801 & .530 & .419 \\
\hline$n$-Octane & 2.44 & .609 & .550 & .466 & .631 & .676 & .339 & .429 \\
\hline $1+2$ Octenes & 1.67 & 1.56 & 1.41 & 1.26 & 1.91 & 1.67 & 1.15 & .527 \\
\hline $\mathrm{C}_{8}$ Isomers & .636 & .250 & .329 & .0868 & .651 & .157 & .291 & .423 \\
\hline n-Nonane & 2.31 & .737 & .304 & .303 & .292 & .400 & .179 & .154 \\
\hline $1+2$ Nonenes & 1.29 & 1.65 & 1.07 & 1.06 & 1.39 & 1.30 & 1.06 & .465 \\
\hline $\mathrm{C}_{9}$ Isomers & .468 & .251 & .144 & .111 & .0959 & .242 & .0732 & .0219 \\
\hline$n$-Decale & 2.61 & 1.00 & .588 & .542 & .587 & .668 & .365 & .375 \\
\hline $1+2$ Decenes & .887 & 1.84 & 1.64 & 1.41 & 1.84 & 1.72 & 1.56 & .808 \\
\hline $\mathrm{C}_{10}$ Isomers & .514 & .410 & .280 & .172 & .178 & .383 & .143 & .0655 \\
\hline n-Undecane & 1.64 & 1.18 & .810 & .725 & .877 & .902 & .597 & .504 \\
\hline 1+2 Undecenes & .746 & 1.80 & 1.85 & 1.54 & 2.04 & 1.95 & 1.87 & 1.05 \\
\hline$C_{11}$ Isomers & .483 & .526 & .366 & .234 & .287 & .488 & .243 & .107 \\
\hline $\mathrm{C}_{2}-\mathrm{C}_{4}$ & 35.9 & 22.3 & 26.3 & 21.7 & 20.5 & 20.6 & 16.9 & 25.5 \\
\hline $\mathrm{C}_{3}-\mathrm{C}_{11}$ & 39.0 & 28.0 & 28.8 & 23.0 & 27.6 & 27.9 & 20.2 & 18.5 \\
\hline $\mathrm{C}_{12}+$ & 15.8 & 45.1 & 40.4 & 50.5 & 48.7 & 48.2 & 59.6 & 52.0 \\
\hline Wax & 11.2 & 25.7 & 27.7 & 41.5 & 37.3 & 35.1 & 35.9 & 38.1 \\
\hline
\end{tabular}

= Unanalyzed wax withdrawn from reactor 
Table V.2-7. Major events in run SA-25-3657.

TOS $(h)$

$-28$

0

4

51

94

129

134

138

166

214

260

262

310

357

358

406

430
Event

Catalyst pretreatment

Initiate run

Achieve initial process conditions: $\mathrm{T}=250^{\circ} \mathrm{C}$, $\mathrm{P}=1.48 \mathrm{MPa}, \mathrm{SV}=2.0 \mathrm{Nl} / \mathrm{g}$-cat $\cdot h$, Feed $\left(\mathrm{H}_{2} / \mathrm{CO}\right)=1.0$

Change process conditions: $\mathrm{T}=250^{\circ} \mathrm{C}, \mathrm{P}=1.48 \mathrm{MPa}$

$\mathrm{SV}=4.0 \mathrm{Nl} / g$-cat $\cdot h$, Feed $\left(\mathrm{H}_{2} / \mathrm{CO}\right)=1.0$

Change process conditions: $\mathrm{T}=235^{\circ} \mathrm{C}, \mathrm{P}=1.48 \mathrm{MPa}$

$\mathrm{SV}=2.0 \mathrm{Nl} / \mathrm{g}$-cat $\cdot h$, Feed $\left(\mathrm{H}_{2} / \mathrm{CO}\right)=1.0$

Loss of reactor power

Power to reactor restored

Achieve desired process conditions

Change process conditions: $\mathrm{T}=250^{\circ} \mathrm{C}, \mathrm{P}=1.48 \mathrm{MPa}$

$\mathrm{SV}=2.0 \mathrm{Nl} / \mathrm{g}$-cat $\cdot h$, Feed $\left(\mathrm{H}_{2} / \mathrm{CO}\right)=1.0$

Change process conditions: $\mathrm{T}=250^{\circ} \mathrm{C}, \mathrm{P}=1.48 \mathrm{MPa}$

$\mathrm{SV}=1.0 \mathrm{Nl} / \mathrm{g}$-cat $\cdot h$, Feed $\left(\mathrm{H}_{2} / \mathrm{CO}\right)=0.67$

Leak in reactor feed valve discovered and repaired

Change process conditions: $\mathrm{T}=250^{\circ} \mathrm{C}, \mathrm{P}=1.48 \mathrm{MPa}$

$\mathrm{SV}=2.0 \mathrm{Nl} / \mathrm{g}$-cat $\cdot h$, Feed $\left(\mathrm{H}_{2} / \mathrm{CO}\right)=0.68$

Change process conditions: $\mathrm{T}=265^{\circ} \mathrm{C}, \mathrm{P}=1.48 \mathrm{MPa}$

$$
\mathrm{SV}=2.0 \mathrm{Nl} / g \text {-cat } \cdot h, \text { Feed }\left(\mathrm{H}_{2} / \mathrm{CO}\right)=0.68
$$

Wax plug in reactor feed line repaired

Change process conditions: $\mathrm{T}=235^{\circ} \mathrm{C}, \mathrm{P}=1.48 \mathrm{MPa}$

$\mathrm{SV}=1.0 \mathrm{Nl} / \mathrm{g}$-cat $\cdot h$, Feed $\left(\mathrm{H}_{2} / \mathrm{CO}\right)=0.67$

Change process conditions: $\mathrm{T}=265^{\circ} \mathrm{C}, \mathrm{P}=2.96 \mathrm{MPa}$

$\mathrm{SV}=2.0 \mathrm{Nl} / \mathrm{g}$-cat $\cdot h$, Feed $\left(\mathrm{H}_{2} / \mathrm{CO}\right)=0.67$

End of Run SA-25-3657 
4 at the same nominal process conditions $\left(250^{\circ} \mathrm{C}, 1.48 \mathrm{MPa},\left(\mathrm{H}_{2} / \mathrm{CO}\right)=1,2 \mathrm{Nl} / \mathrm{g}\right.$-cat.h) after catalyst deactivation.

Wax was removed from the reactor at the end of each material balance. The reactor stirring and feed to the reactor were discontinued after purging the reactor for about $5 \mathrm{~min}$ with helium. The catalyst was allowed to settle for approximately $30 \mathrm{~min}$, after which wax was withdrawn through a dipleg in the reactor at a preset height. The wax and catalyst withdrawals made during this run are summarized in Table V.2-8.

\section{V.2.3.3. Run SB $-07-0458$ with the $100 \mathrm{Fe} / 0.3 \mathrm{Cu} / 0.5 \mathrm{~K}$ Catalyst}

This was the first run made in the new slurry reactor unit $B$. The precipitated $100 \mathrm{Fe} / 0.3$ $\mathrm{Cu} / 0.5 \mathrm{~K}$ catalyst was reduced in situ using $\mathrm{H}_{2}$ as the reductant at $280^{\circ} \mathrm{C}$. The catalyst (< 325 mesh) was suspended in a FT-300 wax to obtain a 10 weight $\%$ catalyst slurry. The slurry withdrawal dipleg was preset to give a static slurry volume of $375 \mathrm{cc}$. Ten material balances were performed during the run, and the run was voluntarily terminated after $458 \mathrm{~h}$ on stream. The results obtained during these ten mass balances are summarized in Table V.2-9.

At $4 \mathrm{~h}$ on stream, the inlet feed line had to be repaired due to a block that appeared following the withdrawal of excess wax from the reactor after catalyst reduction. No other major operational problems were encountered during the run. The major events of Run SB07-0458 are summarized in Table V.2-10.

The initial activity of the catalyst was low, which is consistent with previous observations made in fixed bed reactors with $100 \mathrm{Fe} / 3 \mathrm{Cu} / 0.2 \mathrm{~K}$ catalyst reduced using $\mathrm{H}_{2}$. The $\left(\mathrm{H}_{2}+\mathrm{CO}\right)$ conversion obtained during balance 1 was $24.8 \%$, which is comparable with the $26.0 \%$ conversion obtained in the fixed bed test with $100 \mathrm{Fe} / 3 \mathrm{Cu} / 0.2 \mathrm{~K}$ catalyst reduced under similar conditions $\left(280^{\circ} \mathrm{C}\right.$ for $24 \mathrm{~h}$, run FB-25-3227, Section V.1.3). The catalyst appeared to have become more active with time on stream, as is evident from the $\left(\mathrm{H}_{2}+\mathrm{CO}\right)$ conversions obtained in balances 1 and 9 at $250^{\circ} \mathrm{C}, 1.48 \mathrm{MPa},\left(\mathrm{H}_{2} / \mathrm{CO}\right)=1$ and a nominal space velocity of $2 \mathrm{NI} / \mathrm{g}$-cat.h. During balance 1 (approximately $45 \mathrm{~h}$ on stream) the $\left(\mathrm{H}_{2}+\mathrm{CO}\right)$ conversion was $24.8 \%$, while during balance 9 (approximately $428 \mathrm{~h}$ on stream) the conversion had increased to $35.5 \%$. Catalyst activity improved following balance 4 , during which a $0.67\left(\mathrm{H}_{2} / \mathrm{CO}\right)$ feed ratio was used, while a $1.0\left(\mathrm{H}_{2} / \mathrm{CO}\right)$ feed ratio was used in the previous three balances. During the period of low catalyst activity (balances 1 through 4 ), the $\left(\mathrm{H}_{2}+\mathrm{CO}\right)$ conversion increased from $24.8 \%$ (balance 1 ) to $30.8 \%$ (balance 3) as temperature increased from $250^{\circ} \mathrm{C}$ to $265^{\circ} \mathrm{C}$, whereas the increase was from $42.5 \%$ (balance 5) to $70.8 \%$ (balance 7 ) once the catalyst 
Table V.2-8. Wax and solids inventory for run SA-25-3657.

$\operatorname{TOS}(h)$

Event

$-48$

$-1$

50

93

164

212

261

308

355

404

430

430
Slurry loading: $424 g$ wax, $38.60 \mathrm{~g}$ solids

Wax removal following reduction: $120 \mathrm{~g}$ wax, $0.24 \mathrm{~g}$ solids

Wax removal: $57 g$ wax, $0.55 g$ solids

Wax removal: $161 \mathrm{~g}$ wax, $0.26 \mathrm{~g}$ solids

Wax removal: $90 \mathrm{~g}$ wax, $0.29 \mathrm{~g}$ solids

Wax removal: $71 \mathrm{~g}$ wax, $0.13 \mathrm{~g}$ solids

Wax removal: $36 g$ wax, $0.09 g$ solids

Wax removal: $43 g$ wax, $0.07 g$ solids

Wax removal: $81 \mathrm{~g}$ wax, $0.16 \mathrm{~g}$ solids

Wax removal: $20 \mathrm{~g}$ wax, $0.05 \mathrm{~g}$ solids

Wax removal: $60 \mathrm{~g}$ wax, $0.11 \mathrm{~g}$ solids

End of run: $289 \mathrm{~g}$ wax, $33.06 \mathrm{~g}$ solids recovered

from reactor. $95 \%$ wax recovery, $96 \%$ solids recovery 
Table V.2-9. Summnary of results for slurry run SB-(17-0458.

Catalyst: $29.8 g^{\mathrm{a}}, 100 \mathrm{Fe} / .3 \mathrm{Cu} / 0.5 \mathrm{~K}$

Slurry liquid: $294 \mathrm{~g}, \mathrm{Fr}-300$

Reactor volume: $375 . c c^{b}$

\begin{tabular}{|c|c|c|c|c|c|}
\hline Period & 1 & 2 & 3 & 4 & 5 \\
\hline Date & $2 / 17 / 88$ & $2 / 19 / 88$ & $2 / 21 / 88$ & $2 / 23 / 88$ & $2 / 25 / 88$ \\
\hline T'ime on Stream $(h)$ & 45.0 & 92.0 & 139.5 & 188.0 & 236.0 \\
\hline Balance Duration $(h)$ & 6.0 & 6.0 & 6.0 & 6.0 & 6.0 \\
\hline A verage Temperature $\left({ }^{\circ} \mathrm{C}\right)$ & 250 . & 250. & 265. & 250 . & 250 . \\
\hline Pressure $(M P a)$ & 1.48 & 1.48 & 1.48 & 1.48 & 1.18 \\
\hline $\mathrm{II}_{2} / \mathrm{CO}$ Peed Ratio & 1.05 & 1.05 & 1.05 & .711 & .735 \\
\hline Space Velocity $(N I / g \text { cat } \cdot h)^{a}$ & 2.16 & 1.07 & 2.13 & 2.13 & 1.06 \\
\hline Space Velocity $(N I / g-\mathrm{Fe} \cdot h)$ & 3.11 & 1.54 & 3.07 & 3.06 & 1.53 \\
\hline $\operatorname{GIISV}\left(h^{-1}\right)^{b}$ & 172. & 83.4 & 166. & 165. & 82.4 \\
\hline CO Conversion (\%) & 29.2 & 44.1 & 36.7 & 23.0 & 45.4 \\
\hline $\mathrm{II}_{2}+\mathrm{CO}$ Conversion (\%) & 24.8 & 36.0 & 30.8 & 21.3 & 42.5 \\
\hline $\mathrm{II}_{2} / \mathrm{CO}$ Usage & .742 & .676 & .717 & .583 & .623 \\
\hline $\mathrm{STY}\left(\mathrm{mols} \mathrm{II}_{2}+\mathrm{CO} / g \text {-cat } \cdot h\right)^{a}$ & .024 & .017 & .029 & .020 & .020 \\
\hline$P_{\mathrm{CO}_{2}} \cdot P_{\mathrm{H}_{3}} / P_{\mathrm{CO}} \cdot P_{\mathrm{H}_{3} \mathrm{O}}$ & 6.06 & 11.2 & 7.49 & 13.4 & 10.9 \\
\hline \multicolumn{6}{|l|}{ Weight \% of Outlet } \\
\hline$\overline{\mathrm{II}_{2}}$ & 5.94 & 5.15 & 5.55 & $\overline{4.12}$ & 3.10 \\
\hline $\mathrm{H}_{2} \mathrm{O}$ & 1.26 & 1.32 & 1.44 & .305 & .971 \\
\hline $\mathrm{CO}$ & 70.2 & 53.3 & 62.1 & 76.5 & 52.0 \\
\hline $\mathrm{CO}_{2}$ & 15.9 & 26.9 & 21.2 & 13.4 & 31.2 \\
\hline Ilydrocarbons & 4.22 & 8.57 & 7.24 & 3.76 & 7.04 \\
\hline Oxygenates & .252 & .805 & .610 & .167 & .555 \\
\hline Wax ${ }^{c}$ & 2.25 & 3.96 & 1.89 & 1.82 & 5.07 \\
\hline \multicolumn{6}{|l|}{ Yield $\left(\mathrm{g} / \mathrm{Nm}^{3} \mathrm{H}_{2}+\mathrm{CO}\right.$ Converted $)$} \\
\hline $\mathrm{CII}_{4}$ & 7.33 & 8.82 & 10.0 & 5.96 & 5.95 \\
\hline $\mathrm{C}_{2}-\mathrm{C}_{4}$ Illydrocarbons & 40.0 & 37.5 & 38.4 & 29.3 & 25.6 \\
\hline $\mathrm{C}_{5}-\mathrm{C}_{11}$ llydrocarbons & 36.3 & 50.1 & 48.2 & 46.0 & 43.0 \\
\hline $\mathrm{C}_{12}+$ llydrocarbons & 76.4 & 126. & 87.5 & 111. & 141. \\
\hline $\operatorname{Wax}^{c}$ & 55.7 & 70.4 & 38.1 & 62.8 & 90.1 \\
\hline Oxygenales & 6.23 & 14.3 & 12.3 & 5.77 & 9.85 \\
\hline Total & 166. & 237. & 196. & 198. & 225. \\
\hline \multicolumn{6}{|l|}{$1+2$ Olefins/n-Paraffin Ratio } \\
\hline $\mathrm{C}_{2}$ & 1.20 & 1.56 & 1.39 & .899 & 1.90 \\
\hline $\mathrm{C}_{3}$ & 4.06 & 4.52 & 5.27 & 4.92 & 5.13 \\
\hline $\mathrm{C}_{4}$ & 3.61 & 3.61 & 4.11 & 3.66 & 3.84 \\
\hline $\mathrm{C}_{8}$ & 3.03 & 2.60 & 2.67 & 3.29 & 2.80 \\
\hline $\mathrm{C}_{10}$ & 2.29 & 2.69 & 2.71 & 2.55 & 2.61 \\
\hline
\end{tabular}

a Based on unreduced calalyst

${ }^{b}$ Based on slatic slurry volume

c Unanalyzed wax wilhdrawn from reactor 
'Table V.2-9 (cont'd). Summary of results for slurry run S13-07-0458.

\begin{tabular}{|c|c|c|c|c|c|}
\hline Period & 6 & 7 & 8 & 9 & 10 \\
\hline Dale & $2 / 27 / 88$ & $2 / 29 / 88$ & $3 / 02 / 88$ & $3 / 04 / 88$ & $3 / 05 / 88$ \\
\hline Time on Stream $(h)$ & 284.0 & 284.0 & 380.0 & 428.0 & 452.0 \\
\hline Balance Duration $(h)$ & 6.0 & 6.0 & 6.0 & 6.0 & 6.0 \\
\hline Average Temperature $\left({ }^{\circ} \mathrm{C}\right)$ & 265. & 205. & 235. & 250. & 265. \\
\hline Pressure $(M P a)$ & 1.48 & 1.48 & 1.48 & 1.48 & 2.96 \\
\hline $\mathrm{II}_{2} / \mathrm{CO}$ Feed Ratio & .703 & .721 & .710 & 1.06 & .727 \\
\hline Space Velocity $(\mathrm{NI} / \mathrm{g}-\mathrm{cat} \cdot h)^{a}$ & 2.15 & 1.08 & 1.08 & 2.19 & 2.04 \\
\hline Space Velocity $(N l / g-F e \cdot h)$ & 3.10 & 1.56 & 1.56 & 3.15 & 2.94 \\
\hline GIISV $\left(h^{-1}\right)^{6}$ & 164. & 80.8 & 79.1 & 157. & 144. \\
\hline CO Conversion (\%) & 55.6 & 75.9 & 31.0 & 44.4 & 79.2 \\
\hline $\mathrm{H}_{2}+\mathrm{CO}$ Conversion (\%) & 51.2 & 70.8 & 29.2 & 35.5 & 73.0 \\
\hline $\mathrm{H}_{2} / \mathrm{CO}$ Usage & .569 & .606 & .611 & .648 & .592 \\
\hline $\mathrm{STY}\left(\mathrm{mols} \mathrm{II}_{2}+\mathrm{CO} / g \text { cat } \cdot h\right)^{a}$ & .049 & .034 & .014 & .035 & .067 \\
\hline$P_{\mathrm{CO}_{2}} \cdot P_{1_{2}} / P_{\mathrm{CO}} \cdot P_{\mathrm{H}_{2} \mathrm{O}}$ & 25.7 & 39.7 & 10.8 & 13.5 & 25.3 \\
\hline \multicolumn{6}{|l|}{ Weight \% of Outlet } \\
\hline $\mathrm{H}_{2}$ & 2.78 & 1.72 & 3.52 & 5.38 & 1.79 \\
\hline $\mathrm{H}_{2} \mathrm{O}$ & .543 & .612 & .616 & 1.23 & 1.12 \\
\hline $\mathrm{CO}$ & 44.3 & 22.1 & 64.7 & 53.5 & 20.1 \\
\hline $\mathrm{CO}_{2}$ & 39.2 & 54.9 & 21.6 & 28.9 & 55.8 \\
\hline Hydrocarbons & 7.12 & 10.5 & 5.05 & 6.58 & 10.5 \\
\hline Oxygenates & .534 & .597 & .305 & .648 & .905 \\
\hline $\mathbf{W a x}^{c}$ & 5.54 & 9.62 & 4.24 & 3.78 & 9.79 \\
\hline \multicolumn{6}{|l|}{ Yield $\left(g / \mathrm{Nm}^{3} \mathrm{H}_{2}+\mathrm{CO}\right.$ Converted $)$} \\
\hline $\mathrm{CII}_{4}$ & 6.11 & 7.29 & 5.23 & 6.76 & 6.69 \\
\hline $\mathrm{C}_{2}-\mathrm{C}_{4}$ Hydrocarbons & 24.6 & 25.7 & 22.2 & 25.4 & 27.2 \\
\hline $\mathrm{C}_{5}-\mathrm{C}_{11}$ Hydrocarbons & 38.2 & 46.2 & 40.3 & 41.3 & 56.7 \\
\hline $\mathrm{C}_{12}+$ IIydrocarbons & 113. & 145. & 180. & 110. & 118. \\
\hline $\operatorname{Wax}^{c}$ & 79.4 & 108. & 113. & 66.9 & 101. \\
\hline Oxygenates & 7.66 & 6.67 & 8.13 & 11.5 & 9.32 \\
\hline Total & 189. & 231. & 256. & 195. & 218. \\
\hline \multicolumn{6}{|l|}{$1+2$ Olefins/n-Paraffin Ratio } \\
\hline$\overline{\mathrm{C}_{2}}$ & 2.07 & $\overline{2.45}$ & 3.99 & $\overline{3.56}$ & 2.29 \\
\hline $\mathrm{C}_{3}$ & 5.63 & 5.79 & 4.48 & 4.35 & 4.47 \\
\hline $\mathrm{C}_{4}$ & 4.13 & 4.44 & 3.33 & 3.27 & 3.42 \\
\hline $\mathrm{C}_{8}$ & 2.59 & 4.05 & 2.79 & 2.47 & 2.65 \\
\hline $\mathrm{C}_{10}$ & 2.61 & 3.78 & 2.69 & 2.24 & 2.42 \\
\hline
\end{tabular}

a Based on unreduced catalyst

b Based on static slurry volume

Unanalyzed wax withdrawn from reactor 
'Table V.2-9 (conl'd). Summary of results for slurry run S13-07-0458.

\begin{tabular}{|c|c|c|c|c|c|}
\hline Period & 1 & 2 & 3 & 4 & 5 \\
\hline \multicolumn{6}{|c|}{ Weight \% of llydrocarbons } \\
\hline $\mathrm{CH4}$ & 4.58 & 3.96 & 5.44 & 3.10 & $\overline{2.76}$ \\
\hline Ethane & 4.78 & 2.56 & 3.73 & 4.03 & 1.57 \\
\hline Ethylene & 5.34 & 3.73 & 4.85 & 3.38 & 2.79 \\
\hline Propane & 1.30 & .988 & 1.03 & .694 & .644 \\
\hline Propylene & 5.05 & 4.27 & 5.19 & 3.26 & 3.15 \\
\hline n-Butane & 1.74 & 1.09 & 1.12 & .792 & .737 \\
\hline $1+2$ Butenes & 6.05 & 3.79 & 4.43 & 2.80 & 2.73 \\
\hline $\mathrm{C}_{4}$ Isomers & .755 & .421 & .487 & .289 & .267 \\
\hline n-Pentane & 1.57 & 1.36 & 1.44 & 1.08 & .990 \\
\hline $1+2$ Pentenes & 3.92 & 3.50 & 4.01 & 2.72 & 2.64 \\
\hline $\mathrm{C}_{5}$ Isomers & .245 & .211 & .236 & 1.18 & .741 \\
\hline$n$-llexane & 1.10 & 1.07 & 1.40 & 2.24 & .817 \\
\hline $1+2$ II exenes & 3.90 & 2.75 & 3.74 & 3.92 & 2.41 \\
\hline $\mathrm{C}_{6}$ Isomers & 1.10 & .514 & .844 & 2.07 & .588 \\
\hline$n$-lleptane & .729 & .632 & .816 & .859 & .685 \\
\hline $1+2$ Ileptenes & 2.26 & 1.64 & 2.07 & 1.87 & 1.67 \\
\hline $\mathrm{C}_{7}$ Isomers & .715 & .413 & .561 & .713 & .513 \\
\hline$n$-Octane & .481 & .671 & .659 & .365 & .526 \\
\hline $1+2$ Octenes & 1.43 & 1.71 & 1.73 & 1.18 & 1.45 \\
\hline $\mathrm{C}_{8}$ Isomers & .297 & .278 & .322 & .0858 & .222 \\
\hline$n$-Nonane & .418 & .644 & .631 & .423 & .548 \\
\hline $1+2$ Nonenes & .896 & 1.65 & 1.62 & .989 & 1.36 \\
\hline $\mathrm{C}_{9}$ Isomers & .0764 & .135 & .204 & .0756 & .105 \\
\hline$n$-Decane & .503 & .681 & .718 & .528 & .608 \\
\hline $1+2$ Decenes & 1.13 & 1.81 & 1.92 & 1.33 & 1.57 \\
\hline $\mathrm{C}_{\mathrm{J} 0}$ Isomers & .105 & .166 & .299 & .120 & .158 \\
\hline$n$-Undecane & .405 & .610 & .630 & .441 & .516 \\
\hline $1+2$ Undecenes & 1.25 & 1.85 & 2.04 & 1.59 & 1.65 \\
\hline $\mathrm{C}_{11}$ Isomers & .136 & .205 & .288 & .160 & .194 \\
\hline $\mathrm{C}_{2}-\mathrm{C}_{4}$ & 25.0 & 16.8 & 20.9 & 15.3 & 11.9 \\
\hline$C_{5}-C_{11}$ & 22.7 & 22.5 & 26.2 & 23.9 & 20.0 \\
\hline $\mathrm{C}_{12}+$ & 47.7 & 57.2 & 47.9 & 58.1 & 65.8 \\
\hline$W_{a x}^{c}$ & 34.8 & 31.6 & 20.7 & 32.6 & 41.9 \\
\hline
\end{tabular}

'Unanalyzed wax withdrawn from reactor 
Table V.2-9 (cont'd). Summary of results for slurry run S13-07-0458

\begin{tabular}{|c|c|c|c|c|c|}
\hline Period & 6 & 7 & 8 & $\overline{9}$ & 10 \\
\hline \multicolumn{6}{|c|}{ Weight \% of Hydrocarbons } \\
\hline CII4 & 3.36 & 3.25 & 2.11 & 3.68 & 3.21 \\
\hline Ethane & 1.75 & 1.10 & .546 & .914 & 1.11 \\
\hline Ethylene & 3.38 & 2.51 & 2.03 & 3.03 & 2.44 \\
\hline Propane & 667 & .618 & .601 & .984 & .924 \\
\hline Propylene & 3.58 & 3.41 & 2.57 & 4.09 & 3.94 \\
\hline n-Butane & .773 & .671 & .697 & 1.06 & .990 \\
\hline $1+2$ Butenes & 3.08 & 2.88 & 2.24 & 3.36 & 3.27 \\
\hline $\mathrm{C}_{4}$ Isomers & .292 & .253 & .263 & .400 & .335 \\
\hline n-Pentane & 1.08 & .928 & .920 & 1.36 & 1.20 \\
\hline $1+2$ Pentenes & 2.97 & 2.71 & 2.19 & 3.10 & 3.07 \\
\hline $\mathrm{C}_{5}$ Isomers & .577 & .140 & .620 & .813 & .600 \\
\hline n-Hexane & .758 & .679 & .435 & 1.22 & 1.05 \\
\hline $1+2$ llexenes & 2.19 & 2.41 & 1.69 & 2.18 & 2.99 \\
\hline $\mathrm{C}_{6}$ Isomers & .817 & .648 & .484 & .519 & .350 \\
\hline n-Heptane & .528 & .486 & .443 & .597 & .954 \\
\hline $1+2$ Ileptenes & 1.33 & 1.42 & 1.22 & 1.16 & 2.13 \\
\hline $\mathrm{C}_{7}$ Isomers & .298 & .252 & .388 & .345 & .258 \\
\hline$n$-Octane & .601 & .436 & .393 & .654 & 1.01 \\
\hline $1+2$ Octenes & 1.53 & 1.74 & 1.08 & 1.59 & 2.62 \\
\hline $\mathrm{C}_{8}$ Isomers & .255 & .191 & .0587 & .109 & .180 \\
\hline$n$-Nonane & .672 & .500 & .450 & .816 & 1.03 \\
\hline $1+2$ Nonenes & 1.65 & 1.86 & 1.14 & 1.65 & 2.49 \\
\hline $\mathrm{C}_{9}$ Isomers & .175 & .124 & .0540 & .0874 & .125 \\
\hline$n$-Decane & .728 & .580 & .582 & .895 & 1.04 \\
\hline $1+2$ Decenes & 1.87 & 2.16 & 1.55 & 1.97 & 2.48 \\
\hline $\mathrm{C}_{10}$ Isomers & .242 & .182 & .0822 & .122 & .165 \\
\hline$n$-Undecane & .608 & .597 & .535 & .754 & .959 \\
\hline $1+2$ Undecenes & 1.95 & 2.27 & 1.81 & 2.10 & 2.31 \\
\hline$C_{11}$ Isoniers & .221 & .254 & .138 & .152 & .176 \\
\hline $\mathrm{C}_{2}-\mathrm{C}_{4}$ & 13.5 & 11.5 & 8.94 & 13.8 & 13.0 \\
\hline $\mathrm{C}_{5}-\mathrm{C}_{11}$ & 21.1 & 20.6 & 16.2 & 22.5 & 27.2 \\
\hline $\mathrm{C}_{12}+$ & 62.4 & 65.0 & 73.0 & 60.5 & 56.6 \\
\hline $\mathrm{Wax}^{\mathrm{c}}$ & 43.7 & 47.9 & 45.7 & 36.5 & 48.3 \\
\hline
\end{tabular}

${ }^{c}$ Unanalyzed wax withdrawn from reactor 
Table V.2-10. Major events in run SB-07-0458.

$\operatorname{TOS}(h)$

Event

Catalyst pretreatment

Initiate run

Wax plug in reactor feed line repaired

Achieved initial process conditions: $\mathrm{T}=250^{\circ} \mathrm{C}$,

$$
\mathrm{P}=1.48 \mathrm{MPa}, \mathrm{SV}=2.2 \mathrm{Nl} / \mathrm{g} \text {-cat } \cdot h,\left(\mathrm{H}_{2} / \mathrm{CO}\right)=1.05
$$

Changed process conditions: $\mathrm{T}=250^{\circ} \mathrm{C}$,

$$
\mathrm{P}=1.48 \mathrm{MPa}, \mathrm{SV}=1.1 \mathrm{Nl} / \mathrm{g} \text {-cat } \cdot h,\left(\mathrm{H}_{2} / \mathrm{CO}\right)=1.05
$$

Changed process conditions: $\mathrm{T}=265^{\circ} \mathrm{C}$,

$$
\mathrm{P}=1.48 \mathrm{MPa}, \mathrm{SV}=2.1 \mathrm{Nl} / \mathrm{g} \text {-cat } \cdot h,\left(\mathrm{H}_{2} / \mathrm{CO}\right)=1.05
$$

Changed process conditions: $\mathrm{T}=250^{\circ} \mathrm{C}$,

$$
\mathrm{P}=1.48 \mathrm{MPa}, \mathrm{SV}=2.1 \mathrm{Nl} / \mathrm{g} \text {-cat } \cdot h,\left(\mathrm{H}_{2} / \mathrm{CO}\right)=0.71
$$

Changed process conditions: $\mathrm{T}=250^{\circ} \mathrm{C}$,

$$
\mathrm{P}=1.48 \mathrm{MPa}, \mathrm{SV}=1.1 \mathrm{Nl} / \mathrm{g} \text {-cat } \cdot h,\left(\mathrm{H}_{2} / \mathrm{CO}\right)=0.74
$$

Changed process conditions: $\mathrm{T}=265^{\circ} \mathrm{C}$,

$$
\mathrm{P}=1.48 \mathrm{MPa}, \mathrm{SV}=2.2 \mathrm{Nl} / \mathrm{g} \text {-cat } \cdot h,\left(\mathrm{H}_{2} / \mathrm{CO}\right)=0.70
$$

Changed process conditions: $\mathrm{T}=265^{\circ} \mathrm{C}$,

$$
\mathrm{P}=1.48 \mathrm{MPa}, \mathrm{SV}=1.1 \mathrm{Nl} / \mathrm{g} \text {-cat } \cdot h,\left(\mathrm{H}_{2} / \mathrm{CO}\right)=0.72
$$

Changed process conditions: $\mathrm{T}=235^{\circ} \mathrm{C}$,

$$
\mathrm{P}=1.48 \mathrm{MPa}, \mathrm{SV}=1.1 \mathrm{Nl} / \mathrm{g} \text {-cat } \cdot h,\left(\mathrm{H}_{2} / \mathrm{CO}\right)=0.71
$$

Changed process conditions: $\mathrm{T}=250^{\circ} \mathrm{C}$,

$$
\mathrm{P}=1.48 \mathrm{MPa}, \mathrm{SV}=2.2 \mathrm{Nl} / \mathrm{g} \text {-cat } \cdot h,\left(\mathrm{H}_{2} / \mathrm{CO}\right)=1.06
$$

Changed process conditions: $\mathrm{T}=265^{\circ} \mathrm{C}$,

$$
\mathrm{P}=2.96 \mathrm{MPa}, \mathrm{SV}=2.0 \mathrm{Nl} / \mathrm{g} \text {-cat } \cdot h,\left(\mathrm{H}_{2} / \mathrm{CO}\right)=0.73
$$

End of run SB-07-0458 
became active, although the differences in space velocity and $\left(\mathrm{H}_{2} / \mathrm{CO}\right)$ feed ratio may have influenced the results.

The catalyst selectivity shifted towards lower molecular weight products with an increase in temperature, once the catalyst became active (i.e., following balance 4 ). For example, the distribution at $235^{\circ} \mathrm{C}, 1.48 \mathrm{MPa}, 1 \mathrm{NI} / \mathrm{g}$-cat.h, $\left(\mathrm{H}_{2} / \mathrm{CO}\right)=0.67$ (nominal) during balance 8 was $2.1\left(\mathrm{CH}_{4}\right), 8.9\left(\mathrm{C}_{2}-\mathrm{C}_{4}\right), 16.0\left(\mathrm{C}_{5}-\mathrm{C}_{11}\right)$, and $73.0 \%\left(\mathrm{C}_{12}{ }^{+}\right)$, as compared to $2.8\left(\mathrm{CH}_{4}\right)$, $11.9\left(\mathrm{C}_{2}-\mathrm{C}_{4}\right), 20.0\left(\mathrm{C}_{5}-\mathrm{C}_{11}\right)$, and $65.3 \%\left(\mathrm{C}_{12}{ }^{+}\right)$at $250{ }^{\circ} \mathrm{C}$ (balance 5), and $3.2\left(\mathrm{CH}_{4}\right), 11.4$ $\left(C_{2}-C_{4}\right), 20.6\left(C_{5}-C_{11}\right)$, and $64.8 \%\left(C_{12}{ }^{+}\right)$at $265^{\circ} \mathrm{C}$ (balance 7 ). The effect of temperature on selectivity at other conditions were not consistent with the above example, probably because of differences in catalyst activity.

During the process variable studies in the test SB-0458, the catalyst was tested under conditions similar to that employed in Mobil's study in a bubble column slurry reactor (Kuo, 1985). Comparison of catalyst performance between our catalyst and Mobil's catalyst 1-B in high wax mode of operation is shown in Table V.2-11. Hydrocarbon product selectivities of the two catalyst are very similar, but the activity of our catalyst was lower. However, the activity of our catalyst can be significantly improved by using a lower activation temperature and/or shorter duration (Sections V.1.3 and V.1.6).

\section{V.2.3.4. Run SA - $07-0468$ with the $100 \mathrm{Fe} / 0.3 \mathrm{Cu} / 0.5 \mathrm{~K}$ catalyst}

Slurry run 5A-07-0468 was made with precipitated $100 \mathrm{Fe} / 0.3 \mathrm{Cu} / 0.5 \mathrm{~K}$ catalyst reduced in situ using $\mathrm{CO}$ as the reductant at $280^{\circ} \mathrm{C}$. The catalyst ( $<325$ mesh) was suspended in FT300 wax to obtain a 10 weight $\%$ catalyst slurry. The slurry withdrawal dipleg was preset to give a static slurry volume of $385 \mathrm{cc}$. Eleven material balances were performed during the run. before being voluntarily terminated after $466 \mathrm{~h}$ on stream. The results obtained are summarized in Table V.2-12.

Beginning at about $20 \mathrm{~h}$ on stream, the $\mathrm{H}_{2}$ mass flow controller began behaving erratically, giving lower than expected flowrates. To achieve the desired flowrates and feed ratios, the feed was switched from pure gas to premixed gas at about $52 \mathrm{~h}$ on stream. At about $78 \mathrm{~h}$ on stream, an improperly mixed feed gas cylinder containing approximately $95 \% \mathrm{H}_{2}$ was installed, exposing the catalyst to nearly pure $\mathrm{H}_{2}$ for about $1 \mathrm{~h}$ before the problem was discovered and 
Table V.2-11. Comparative catalyst performance dala for tests conducted in slurry reactors

\begin{tabular}{|c|c|c|c|}
\hline $\begin{array}{c}\text { Catalyst } \\
\text { Reduction Conditions } \\
\end{array}$ & \multicolumn{2}{|c|}{$\begin{array}{c}\text { TAMU }^{a} \\
100 \mathrm{Fe} / 0.3 \mathrm{Cu} / 0.5 \mathrm{~K}\end{array}$} & $\begin{array}{c}\mathrm{Mobil}^{6} \\
\mathrm{Fe} / \mathrm{Cu} / \mathrm{K}_{2} \mathrm{O} \\
\mathrm{II}_{2} / \mathrm{CO}=0.7,280^{\circ} \mathrm{C}, 12 \mathrm{~h}\end{array}$ \\
\hline Run Designation & SB-0458 & SB-0458 & CT-256-13 \\
\hline Temperature, ${ }^{\circ} \mathrm{C}$ & 265 & 265 & 258 \\
\hline Pressure, atm & 15 & 15 & 15 \\
\hline SV, NI/g-Fe.h & 3.1 & 1.6 & 2.4 \\
\hline$\left(\mathrm{II}_{2} / \mathrm{CO}\right)$ & 0.70 & 0.72 & 0.67 \\
\hline$\left(\mathrm{CO}+\mathrm{II}_{2}\right)$ Conversion (\%) & 51.2 & 70.8 & 82.2 \\
\hline \multicolumn{4}{|l|}{ IIC Selectivities (wt.\%) } \\
\hline $\mathrm{C}_{1}$ & 3.3 & 3.2 & 2.7 \\
\hline $\mathrm{C}_{2} \cdot \mathrm{C}_{4}$ & 13.4 & 11.4 & 11.1 \\
\hline $\mathrm{C}_{5} \cdot \mathrm{C}_{11}$ & 21.0 & 20.4 & 18.1 \\
\hline $\mathrm{C}_{12}+$ & 62.3 & 65.0 & 68.1 \\
\hline
\end{tabular}

a test made in a stirred tank slurry reactor

b test made in a bubble column slurry reactor 
Table V.2-12. Summary of results for slurry run SA-07-0468.

Catalyst: $29.5 g^{a}, 100 \mathrm{lee} / .3 \mathrm{Cu} / 0.5 \mathrm{~K}$

Slurry liquid: $270 g$, FT-300

Reactor volume: $385 . c c^{b}$

\begin{tabular}{|c|c|c|c|c|c|c|}
\hline Period & 1 & 2 & 3 & 4 & 5 & 6 \\
\hline Date & $2 / 18 / 88$ & $2 / 20 / 88$ & $2 / 22 / 88$ & $2 / 24 / 88$ & $2 / 24 / 88$ & $2 / 24 / 88$ \\
\hline Time on Stream $(h)$ & 40.5 & 86.0 & 135.0 & 183.0 & 215.0 & 254.0 \\
\hline Balance Duration $(h)$ & 6.0 & 6.0 & 6.0 & 6.0 & 17.0 & 6.0 \\
\hline Average Tenperature $\left({ }^{\circ} \mathrm{C}\right)$ & 250. & 250. & 265. & 235. & 235 . & 235. \\
\hline Pressure $(\mathrm{MPa})$ & 1.48 & 1.48 & 1.48 & 1.48 & 1.48 & 1.48 \\
\hline $\mathrm{H}_{2} / \mathrm{CO}$ Feed Ratio & 1.10 & .976 & 1.03 & .957 & .985 & .653 \\
\hline Space Velocity $(N l / g \text {-cat.h })^{a}$ & 2.04 & 4.05 & 4.00 & 2.08 & 4.18 & 1.02 \\
\hline Space Velocity $(N l / g-\mathrm{Fe} \cdot h)$ & 2.94 & 5.84 & 5.76 & 3.00 & 6.03 & 1.47 \\
\hline GHSV $\left(h^{-1}\right)^{b}$ & 156. & 301. & 291. & 144. & 277. & 66.4 \\
\hline CO Conversion (\%) & 91.7 & 70.9 & 71.4 & 33.5 & 15.3 & 38.5 \\
\hline $\mathrm{II}_{2}+\mathrm{CO}$ Conversion (\%) & 74.8 & 58.4 & 55.5 & 28.4 & 12.7 & 35.6 \\
\hline $\mathrm{H}_{2} / \mathrm{CO}$ Usage & .710 & .628 & .576 & .661 & .649 & .530 \\
\hline $\mathrm{STY}\left(\mathrm{mols} \mathrm{II}_{2}+\mathrm{CO} / g-\mathrm{cat} \cdot h\right)^{a}$ & .068 & .106 & .099 & .026 & .024 & .016 \\
\hline$P_{\mathrm{CO}_{2}} \cdot P_{\mathrm{I}_{2}} / P_{\mathrm{CO}} \cdot P_{\mathrm{H}_{2} \mathrm{O}}$ & 39.7 & 20.3 & 27.8 & 6.86 & 2.42 & 10.1 \\
\hline \multicolumn{7}{|l|}{$\frac{\mathrm{PCO}_{3} \cdot P_{\mathrm{H}_{2}} / \mathrm{PCO}_{\mathrm{CO}} \cdot \mathrm{P}_{\mathrm{H}} \mathrm{O}}{\text { Weight \% of Outlet }}$} \\
\hline $\mathrm{H}_{2}$ & 3.11 & 3.52 & 4.03 & 4.98 & 6.01 & 3.01 \\
\hline $\mathrm{IH}_{2} \mathrm{O}$ & $\mathbf{3 . 3 4}$ & 1.86 & 1.56 & 1.47 & 1.53 & .827 \\
\hline $\mathrm{CO}$ & 8.07 & 26.8 & 26.1 & 62.6 & 79.8 & 57.3 \\
\hline $\mathrm{CO}_{2}$ & 60.6 & 50.7 & 49.2 & 22.4 & 8.67 & 27.9 \\
\hline llydrocarbons & 12.9 & 8.54 & 8.69 & 3.01 & 2.44 & 3.60 \\
\hline Oxygenates & 1.04 & .638 & .801 & .341 & .207 & .183 \\
\hline Wax & 10.9 & 7.90 & 9.64 & 5.26 & 1.31 & 7.21 \\
\hline \multicolumn{7}{|l|}{$\frac{\text { Wax }^{c}}{\text { Yield }\left(g / \mathrm{Nm}^{3} \mathrm{H}_{2}+\mathrm{CO} \text { Converted }\right)}$} \\
\hline $\mathrm{CH}_{4}$ & 13.4 & 7.06 & 8.37 & 5.20 & 5.82 & 4.90 \\
\hline $\mathrm{C}_{2}-\mathrm{C}_{4}$ Hydrocarbons & 43.6 & 35.9 & 38.0 & 24.9 & 31.6 & 27.1 \\
\hline $\mathrm{C}_{5}-\mathrm{C}_{11}$ Hydrocarbons & 39.9 & 40.1 & 44.6 & 30.4 & 58.7 & 30.7 \\
\hline $\mathrm{C}_{12}+$ Hydrocarbons & 98.7 & 110. & 132. & 137. & 100. & 184. \\
\hline Wax $^{c}$ & 89.6 & 92.7 & 118. & 126. & 68.6 & 164. \\
\hline Oxygenates & 8.55 & 7.48 & 9.76 & 8.16 & 10.9 & 4.17 \\
\hline Total & 204. & 200. & 233. & 206. & 207. & 251. \\
\hline \multicolumn{7}{|l|}{$\frac{\text { Total }}{1+2 \text { Olefins/ } n \text {-Paraffin Ratio }}$} \\
\hline $\mathrm{C}_{2}$ & 1.26 & 2.21 & 2.51 & 6.50 & 1.66 & 4.32 \\
\hline $\mathrm{C}_{3}$ & 6.06 & 6.33 & 6.55 & 5.32 & 5.29 & 5.95 \\
\hline $\mathrm{C}_{4}$ & 5.10 & 4.98 & 5.13 & 4.07 & 4.05 & 4.46 \\
\hline $\mathrm{C}_{8}$ & 3.73 & 4.92 & 3.85 & 2.83 & 1.92 & 2.93 \\
\hline $\mathrm{C}_{10}$ & 3.49 & 5.33 & 4.46 & 3.08 & 3.06 & 3.69 \\
\hline
\end{tabular}

${ }^{a}$ Based on unreduced catalyst $c_{c}$ Unanalyzed wax withdrawn from reactor

${ }^{b}$ Based on static slurry volume 
Table V.2-12 (cont'd). Summary of results for slurry run SA-07-0468.

\begin{tabular}{|c|c|c|c|c|c|}
\hline Period & 7 & 8 & 9 & 10 & 11 \\
\hline Date & $2 / 29 / 88$ & $3 / 02 / 88$ & $3 / 04 / 88$ & $3 / 06 / 88$ & $3 / 07 / 88$ \\
\hline 'Time on Stream (h) & 302.5 & 351.0 & 390.5 & 437.0 & 460.0 \\
\hline Balance Duration $(h)$ & 6.0 & 6.0 & 6.0 & 6.0 & 6.0 \\
\hline A verage Temperature $\left({ }^{\circ} \mathrm{C}\right)$ & 250. & 250. & 265. & 250. & 265. \\
\hline Pressure $(\mathrm{MPa})$ & 1.48 & 1.48 & 1.48 & 1.48 & 2.96 \\
\hline $\mathrm{H}_{2} / \mathrm{CO}$ Feed Ratio & .653 & .689 & .641 & 1.03 & .640 \\
\hline Space Velocity $(N l / g-\text { cat } \cdot h)^{a}$ & 1.01 & 2.05 & 2.03 & 2.03 & 2.04 \\
\hline Space Velocity $(N I / g-\mathrm{Fe} \cdot h)$ & 1.46 & 2.96 & 2.93 & 2.93 & 2.94 \\
\hline $\operatorname{GHSV}\left(h^{-1}\right)^{b}$ & 65.5 & 129. & 126. & 124. & 124. \\
\hline CO Conversion (\%) & 57.4 & 26.2 & 29.8 & 24.6 & 42.4 \\
\hline $\mathrm{II}_{2}+\mathrm{CO}$ Conversion (\%) & 54.2 & 24.0 & 28.2 & 17.4 & 38.9 \\
\hline $\mathrm{II}_{2} / \mathrm{CO}$ Usage & .561 & .548 & .550 & .432 & .503 \\
\hline STY (mols $\mathrm{H}_{2}+\mathrm{CO} / g$-cat $\left.\cdot h\right)^{a}$ & .024 & .022 & .026 & .016 & .035 \\
\hline$P_{\mathrm{CO}_{2}} \cdot P_{\mathrm{H}_{2}} / P_{\mathrm{CO}} \cdot P_{\mathrm{H}_{2} \mathrm{O}}$ & 26.5 & 12.4 & 14.8 & 8.76 & 12.3 \\
\hline \multicolumn{6}{|l|}{ Weight \% of Outlet } \\
\hline $\mathrm{II}_{2}$ & 2.34 & 3.86 & 3.30 & 6.33 & 3.02 \\
\hline $\mathrm{H}_{2} \mathrm{O}$ & .478 & .421 & .399 & .865 & .715 \\
\hline $\mathrm{CO}$ & 41.8 & 72.5 & 67.4 & 72.0 & 56.6 \\
\hline $\mathrm{CO}_{2}$ & 39.9 & 17.3 & 21.2 & 15.2 & 29.1 \\
\hline Hydrocarbons & 6.86 & 2.66 & 3.49 & 3.15 & 5.56 \\
\hline Oxygenates & .422 & .199 & .226 & .261 & .525 \\
\hline Wax $^{c}$ & 8.15 & 3.05 & 3.95 & 2.18 & 4.47 \\
\hline \multicolumn{6}{|l|}{ Yield $\left(g / \mathrm{Nm}^{3} \mathrm{H}_{2}+\mathrm{CO}\right.$ Converted $)$} \\
\hline $\mathrm{CH}_{4}$ & 5.24 & 5.74 & 7.74 & 9.00 & 7.12 \\
\hline $\mathrm{C}_{2}-\mathrm{C}_{4}$ Hydrocarbons & 27.4 & 26.7 & 29.8 & 34.2 & 30.8 \\
\hline $\mathrm{C}_{5}-\mathrm{C}_{11}$ Hydrocarbons & 41.5 & 36.7 & 42.0 & 52.7 & 53.5 \\
\hline $\mathrm{C}_{12}+$ Hydrocarbons & 139. & 110. & 130. & 102. & 108. \\
\hline $\mathrm{Wax}^{c}$ & 116. & 95.4 & 111. & 81.2 & 89.0 \\
\hline Oxygenates & 6.00 & 6.23 & 6.37 & 9.71 & 10.5 \\
\hline Total & 219. & 185. & 216. & 208. & 210. \\
\hline \multicolumn{6}{|l|}{$1+2$ Olefins/n-Paraffin Ratio } \\
\hline$\overline{\mathrm{C}_{2}}$ & 2.12 & 4.83 & $\overline{5.47}$ & 4.29 & 3.24 \\
\hline $\mathrm{C}_{\mathbf{3}}$ & 6.29 & 5.97 & 6.10 & 4.44 & 4.04 \\
\hline $\mathrm{C}_{4}$ & 4.73 & 4.31 & 4.32 & 3.22 & 2.95 \\
\hline $\mathrm{C}_{8}$ & 3.54 & 3.34 & 3.08 & 2.35 & 2.03 \\
\hline $\mathrm{C}_{10}$ & 3.65 & 3.11 & 3.17 & 1.95 & 2.01 \\
\hline
\end{tabular}

a Based on unreduced catalyst $\quad$ Based on static slurry volume

\footnotetext{
c Unanalyzed wax withdrawn from reactor
} 
Table V.2-12 (cont'd). Summary of results for slurry run SA-07-0468.

\begin{tabular}{|c|c|c|c|c|c|c|}
\hline Period & 1 & 2 & 3 & 4 & 5 & 6 \\
\hline \multicolumn{7}{|c|}{ Weight $\%$ of Hydrocarbons } \\
\hline CII4 & 6.86 & 3.66 & 3.75 & 2.63 & 2.97 & 1.99 \\
\hline Ethane & 3.32 & 2.09 & 1.83 & .507 & 2.47 & .794 \\
\hline Ethylene & 3.90 & 4.29 & 4.27 & 3.07 & 3.82 & 3.20 \\
\hline Propane & 1.20 & .891 & .798 & .765 & .822 & .538 \\
\hline Propylene & 6.94 & 5.39 & 4.99 & 3.88 & 4.15 & 3.06 \\
\hline n-Butane & 1.07 & .928 & .782 & .806 & .898 & .590 \\
\hline 1+2 Butenes & 5.27 & 4.46 & 3.88 & 3.17 & 3.51 & 2.54 \\
\hline $\mathrm{C}_{4}$ Isomers & .595 & .571 & .466 & .381 & .433 & .284 \\
\hline$n$-Pentane & 1.31 & 1.12 & 1.08 & 1.10 & 1.34 & .850 \\
\hline 1+2 Pentenes & 4.22 & 3.60 & 3.31 & 3.02 & 3.66 & 2.43 \\
\hline $\mathrm{C}_{5}$ Isomers & .288 & .238 & .222 & .229 & .283 & .157 \\
\hline n-IIexane & .846 & .771 & .742 & 1.66 & 2.50 & .820 \\
\hline $1+2$ Hexenes & 2.61 & 2.31 & 2.47 & 1.95 & 4.06 & 1.86 \\
\hline $\mathrm{C}_{6}$ Isomers & .918 & .559 & .577 & .611 & 1.20 & .528 \\
\hline$n$-Heptane & .464 & .376 & .451 & .438 & 1.50 & .402 \\
\hline 1+2 Heptenes & 1.56 & 1.17 & 1.47 & 1.26 & 3.90 & 1.19 \\
\hline $\mathrm{C}_{7}$ Isomers & .356 & .392 & .490 & .412 & 1.02 & .411 \\
\hline$n$-Octane & .396 & .293 & .391 & .258 & .998 & .199 \\
\hline $1+2$ Octenes & 1.45 & 1.41 & 1.48 & .717 & 1.88 & .571 \\
\hline $\mathrm{C}_{8}$ Isomers & .360 & .253 & .299 & .0773 & .268 & .0669 \\
\hline$n$-Nonane & .357 & .331 & .363 & .196 & .384 & .145 \\
\hline $1+2$ Nonenes & 1.31 & 1.84 & 1.59 & .580 & 1.08 & .505 \\
\hline $\mathrm{C}_{9}$ Isomers & .180 & .221 & .285 & .0779 & .168 & .0555 \\
\hline$n$-Decane & .402 & .424 & .388 & .288 & .570 & .208 \\
\hline $1+2$ Decenes & 1.38 & 2.23 & 1.70 & .876 & 1.72 & .757 \\
\hline $\mathrm{C}_{10}$ Isomers & .182 & .267 & .332 & .122 & .243 & .0812 \\
\hline n-Undecane & .381 & .433 & .383 & .314 & .531 & .201 \\
\hline 1+2 Undecenes & 1.29 & 2.24 & 1.60 & 1.02 & 2.22 & .915 \\
\hline $\mathrm{C}_{11}$ Isomers & .153 & .321 & .347 & .164 & .361 & .116 \\
\hline $\mathrm{C}_{2}-\mathrm{C}_{4}$ & 22.3 & 18.6 & 17.0 & 12.6 & 16.1 & 11.0 \\
\hline $\mathrm{C}_{5}-\mathrm{C}_{11}$ & 20.4 & 20.8 & 20.0 & 15.4 & 29.9 & 12.5 \\
\hline $\mathrm{C}_{12}+$ & 50.4 & 57.0 & 59.3 & 69.5 & 51.3 & 74.6 \\
\hline Wax $^{c}$ & 45.8 & 48.1 & 52.6 & 63.6 & 34.9 & 66.7 \\
\hline
\end{tabular}

c Unanalyzed wax withdrawn from reactor 
Table V.2-12 (cont'd). Summary of results for slurry run SA-07-0468.

\begin{tabular}{|c|c|c|c|c|c|}
\hline Period & 7 & 8 & 9 & 10 & 11 \\
\hline \multicolumn{6}{|c|}{ Weight \% of Hydrocarbons } \\
\hline CII4 & 2.46 & 3.21 & 3.69 & 4.54 & 3.56 \\
\hline Ethane & 1.60 & .853 & .712 & 1.03 & 1.18 \\
\hline Ethylene & 3.16 & 3.84 & 3.64 & 4.12 & 3.57 \\
\hline Propane & .586 & .792 & .752 & 1.17 & 1.11 \\
\hline Propylene & 3.52 & 4.51 & 4.38 & 4.98 & 4.29 \\
\hline$n$-Butane & .652 & .877 & .843 & 1.32 & 1.25 \\
\hline 1+2 Butenes & 2.98 & 3.64 & 3.51 & 4.10 & 3.57 \\
\hline $\mathrm{C}_{4}$ Isomers & .325 & .429 & .392 & .547 & .456 \\
\hline$n$-Pentane & .932 & 1.31 & 1.25 & 1.75 & 1.64 \\
\hline $1+2$ Pentenes & 2.90 & 3.48 & 3.28 & 3.88 & 3.40 \\
\hline$C_{5}$ Isomers & .165 & .266 & .193 & 1.45 & 1.21 \\
\hline n-llexane & .999 & .900 & 1.29 & 1.14 & .882 \\
\hline $1+2$ Ilexenes & 2.25 & 2.73 & 1.98 & 3.31 & 2.50 \\
\hline $\mathrm{C}_{6}$ Isomers & .616 & .900 & .610 & 1.34 & .686 \\
\hline$n$-Heptane & .496 & .706 & .544 & 1.42 & .984 \\
\hline 1+2 Ileptenes & 1.59 & 1.90 & 1.39 & 2.97 & 1.82 \\
\hline $\mathrm{C}_{7}$ Isomers & .442 & .651 & .375 & 1.30 & .469 \\
\hline$n$-Octane & .314 & .397 & .344 & .521 & .865 \\
\hline $1+2$ Octenes & 1.09 & 1.30 & 1.04 & 1.20 & 1.73 \\
\hline $\mathrm{C}_{8}$ Isomers & .138 & .125 & .0799 & .0853 & .211 \\
\hline$n$-Nonane & .353 & .305 & .443 & .454 & 1.05 \\
\hline $1+2$ Nonenes & 1.32 & .889 & 1.33 & .820 & 1.90 \\
\hline $\mathrm{C}_{9}$ Isomers & .0939 & .0558 & .0866 & .0609 & .154 \\
\hline$n$-Decane & .539 & .480 & .633 & .713 & 1.15 \\
\hline $1+2$ Decenes & 1.94 & 1.47 & 1.98 & 1.37 & 2.28 \\
\hline $\mathrm{C}_{10}$ Isomers & .179 & .123 & .163 & .157 & .246 \\
\hline n-Undecane & .622 & .475 & .540 & .601 & .943 \\
\hline $1+2$ Undecenes & 2.23 & 1.86 & 2.30 & 1.79 & 2.40 \\
\hline $\mathrm{C}_{11}$ Isomers & .245 & .193 & .201 & .218 & .248 \\
\hline $\mathrm{C}_{2}-\mathrm{C}_{4}$ & 12.8 & 14.9 & 14.2 & 17.3 & 15.4 \\
\hline $\mathrm{C}_{5}-\mathrm{C}_{11}$ & 19.5 & 20.5 & 20.0 & 26.6 & 26.8 \\
\hline $\mathrm{C}_{12}+$ & 65.4 & 61.4 & 62.1 & 51.9 & 54.4 \\
\hline $\mathrm{Wax}^{e}$ & 54.3 & 53.4 & 53.1 & 40.9 & 44.5 \\
\hline
\end{tabular}

c Unanalyzed wax withdrawn from reactor 
corrected. The exposure to $\mathrm{H}_{2}$ did not appear to harm the catalyst, as the catalyst activity (conversions and contraction) of the catalyst before and after the interruption was comparable. No other major operational problems were encountered during the run. The major events of run SA-07-0468 are summarized in Table V.2-13.

The activity of the catalyst during balance 1 was high, $\left(250^{\circ} \mathrm{C}, 1.48 \mathrm{MPa},\left(\mathrm{H}_{2} / \mathrm{CO}\right)=1.0\right)$, and comparable to the fixed bed test of a similar catalyst composition ( $100 \mathrm{Fe} / 3 \mathrm{Cu} / 0.5 \mathrm{~K}$, run FA-27-2557) at the same nominal conditions. During the test in the fixed bed, the $\left(\mathrm{H}_{2}+\mathrm{CO}\right)$ conversion was $70.4 \%$, as compared to the $74.8 \%$ obtained in the slurry test. Catalyst deactivation occurred when the temperature was increased to $265^{\circ} \mathrm{C}$ between balances 2 and 3 (at $1.48 \mathrm{MPa},\left(\mathrm{H}_{2} / \mathrm{CO}\right)=1,4 \mathrm{NI} / \mathrm{g}$-cat.h). The $\left(\mathrm{H}_{2}+\mathrm{CO}\right)$ conversion dropped from 58.4 $\%$ in balance $2\left(250^{\circ} \mathrm{C}\right)$ to $55.5 \%$ in balance $3\left(265^{\circ} \mathrm{C}\right)$, in spite of the $15{ }^{\circ} \mathrm{C}$ temperature increase. In later balances using $0.67\left(\mathrm{H}_{2} / \mathrm{CO}\right)$ feed gas, the increase in temperature from 250 to $265^{\circ} \mathrm{C}$ also did not significantly increase conversion. In balances $8\left(250^{\circ} \mathrm{C}\right)$ and $9\left(265^{\circ} \mathrm{C}\right)$ the $\left(\mathrm{H}_{2}+\mathrm{CO}\right)$ conversions increased only slightly from 24.0 to $28.2 \%$. The catalyst was severely deactivated by balance 10 , which was a repeat of the conditions used during balance 1 . The conversion dropped from $74.8 \%$ to $17.4 \%$ between the two balances.

Increases in temperature shifted catalyst selectivity to lower molecular weight products. For example, the distribution at $235^{\circ} \mathrm{C}, 1.48 \mathrm{MPa}, 1 \mathrm{NI} / \mathrm{g}$-cat. $\mathrm{h},\left(\mathrm{H}_{2} / \mathrm{CO}\right)=0.67$ (nominal) during balance 6 was $2.0\left(\mathrm{CH}_{4}\right), 11.0\left(\mathrm{C}_{2}-\mathrm{C}_{4}\right), 12.5\left(\mathrm{C}_{5}-\mathrm{C}_{11}\right)$, and $74.5 \%\left(\mathrm{C}_{12}+\right)$, as compared to $2.5\left(\mathrm{CH}_{4}\right), 12.8\left(\mathrm{C}_{2}-\mathrm{C}_{4}\right), 19.5\left(\mathrm{C}_{5}-\mathrm{C}_{11}\right)$, and $65.2 \%\left(\mathrm{C}_{12}+\right)$ at $250^{\circ} \mathrm{C}$ (balance 7 ). Similar shifts in the distribution were observed at other conditions, although catalyst deactivation may have influenced the results. Comparisons of balances 1 and 10 shows the effect deactivation may have on selectivity at $250^{\circ} \mathrm{C}$, where the deactivated catalyst produced fewer molecular weight products $\left(4.5 \% \mathrm{CH}_{4}\right.$ and $\left.17.3 \% \mathrm{C}_{2}-\mathrm{C}_{4}\right)$ than the more active catalyst at the same nominal process conditions during balance $1\left(6.9 \% \mathrm{CH}_{4}\right.$ and $\left.22.3 \% \mathrm{C}_{2}-\mathrm{C}_{4}\right)$. The shift in lower molecular weight products changed the percentage of the $C_{5}-C_{11}$ fraction, while the $\mathrm{C}_{12}+$ products remained constant between the two balances.

Wax withdrawals were made following catalyst reduction, and at the end of each mass balance period, by removing excess accumulated slurry from the reactor to the external settling vessel. After separation by settling, the wax and trace quantities of catalyst were quantified, and are shown in Table V.2-14 for each withdrawal. In all cases, the weight of catalyst removed with the wax (after settling) was small, less than 2 weight $\%$ of the wax. 
Table V.2-13. Major events in run SA-07-0468.

$\operatorname{TOS}(h)$
Event

Catalyst pretreatment

Initiate run

Achieve initial process conditions: $\mathrm{T}=250^{\circ} \mathrm{C}$,

$$
\mathrm{P}=1.48 \mathrm{MPa}, \mathrm{SV}=2.0 \mathrm{Nl} / \mathrm{g} \text {-cat. } h, \text { Feed }\left(\mathrm{H}_{2} / \mathrm{CO}\right)=1.0
$$

Problems with hydrogen flow rate

Switched from pure gases to premixed gas

Repiaced hydrogen flow controller; switched to pure gases

Problems with hydrogen flow rate

Switched from pure gases to premixed gas

Changed process conditions: $\mathrm{T}=250^{\circ} \mathrm{C}, \mathrm{P}=1.48 \mathrm{MPa}$, $\mathrm{SV}=4.0 \mathrm{Nl} / \mathrm{g}$-cat $\cdot h$, Feed $\left(\mathrm{H}_{2} / \mathrm{CO}\right)=1.0$

Replaced feed gas cylinder. Gas not properly mixed; $95 \%$ hydrogen

Replaced problem cylinder, Feed $\left(\mathrm{H}_{2} / \mathrm{CO}\right)=1.0$

Changed process conditions: $\mathrm{T}=265^{\circ} \mathrm{C}, \mathrm{P}=1.48 \mathrm{MPa}$, $\mathrm{SV}=4.0 \mathrm{Nl} / \mathrm{g}$-cat $\cdot h$, Feed $\left(\mathrm{H}_{2} / \mathrm{CO}\right)=1.0$

$15^{\circ} \mathrm{C}$ rise in temperature of reflux condenser

Repeated wax removal twice due to excessive wax production

Changed process conditions: $\mathrm{T}=235^{\circ} \mathrm{C}, \mathrm{P}=1.48 \mathrm{MPa}$, $\mathrm{SV}=2.0 \mathrm{Nl} / \mathrm{g}$-cat $\cdot h$, Feed $\left(\mathrm{H}_{2} / \mathrm{CO}\right)=1.0$

Changed process conditions: $\mathrm{T}=235^{\circ} \mathrm{C}, \mathrm{P}=1.48 \mathrm{MPa}$, $\mathrm{SV}=4.0 \mathrm{Nl} / \mathrm{g}$-cat $\cdot h$, Feed $\left(\mathrm{H}_{2} / \mathrm{CO}\right)=1.0$

Changed process conditions: $\mathrm{T}=235^{\circ} \mathrm{C}, \mathrm{P}=1.48 \mathrm{MPa}$, $\mathrm{SV}=1.0 \mathrm{Nl} / \mathrm{g}$-cat $\cdot h$, Feed $\left(\mathrm{H}_{2} / \mathrm{CO}\right)=0.66$

Changed process conditions: $\mathrm{T}=250^{\circ} \mathrm{C}, \mathrm{P}=1.48 \mathrm{MPa}$, $\mathrm{SV}=1.0 \mathrm{Nl} / \mathrm{g}$-cat $\cdot h$, Feed $\left(\mathrm{H}_{2} / \mathrm{CO}\right)=0.64$

Changed process conditions: $\mathrm{T}=250^{\circ} \mathrm{C}, \mathrm{P}=1.48 \mathrm{MPa}$, $\mathrm{SV}=2.0 \mathrm{Nl} / \mathrm{g}$-cat $\cdot h$, Feed $\left(\mathrm{H}_{2} / \mathrm{CO}\right)=0.69$

Changed process conditions: $\mathrm{T}=265^{\circ} \mathrm{C}, \mathrm{P}=1.48 \mathrm{MPa}$, $\mathrm{SV}=2.0 \mathrm{Nl} / g$-cat $\cdot h$, Feed $\left(\mathrm{H}_{2} / \mathrm{CO}\right)=0.64$

Changed process conditions: $\mathrm{T}=250^{\circ} \mathrm{C}, \mathrm{P}=1.48 \mathrm{MPa}$, $\mathrm{SV}=2.0 \mathrm{Nl} / \mathrm{g}$-cat $\cdot h$, Feed $\left(\mathrm{H}_{2} / \mathrm{CO}\right)=1.0$

Changed process conditions: $\mathrm{T}=265^{\circ} \mathrm{C}, \mathrm{P}=2.96 \mathrm{MPa}$, $\mathrm{SV}=2.0 \mathrm{Nl} / \mathrm{g}$-cat $\cdot h$, Feed $\left(\mathrm{H}_{2} / \mathrm{CO}\right)=0.64$

End of Run SA-07-0468 
Table V.2-14. Wax and solids inventory for run SA-07-0468.

$\begin{array}{ll}\text { TOS }(h) & \text { Event } \\ -48 & \text { Slurry loading: } 400 g \text { wax, } 30.25 g \text { solids } \\ -1 & \text { Wax removal following reduction: } 156 g \text { wax, } 0.80 g \text { solids } \\ 64 & \text { Wax removal: } 241 g \text { wax, } 0.86 g \text { solids } \\ 92 & \text { Wax removal: } 162 g \text { wax, } 0.55 g \text { solids } \\ 141 & \text { Wax removal: } 342 g \text { wax, } 1.37 g \text { solids } \\ 189 & \text { Wax removal: } 94 g \text { wax, } 1.16 g \text { solids } \\ 231 & \text { Wax removal: } 38 g \text { wax, } 0.40 g \text { solids } \\ 260 & \text { Wax removal: } 40 g \text { wax, } 0.23 g \text { solids } \\ 309 & \text { Wax removal: } 75 g \text { wax, } 0.61 g \text { solids } \\ 357 & \text { Wax removal: } 54 g \text { wax, } 0.39 g \text { solids } \\ 396 & \text { Wax removal: } 72 g \text { wax, } 0.37 g \text { solids } \\ 443 & \text { Wax removal: } 31 g \text { wax, } 0.14 g \text { solids } \\ 466 & \text { Wax removal: } 38 g \text { wax, } 0.11 g \text { solids } \\ 466 & \text { End of run: } 241 g \text { wax, } 21.65 g \text { solids recovered }\end{array}$




\section{V.2.3.5. Summary}

No conclusions can be drawn with regard to promoter effects on catalyst activity and/or selectivity due to changes in activity with time on stream. However, some general observations concerning hydrocarbon selectivity can be made. Methane and gaseous hydrocarbon $\left(C_{2}-C_{4}\right)$ selectivities were, in general, rather low and the fraction of liquid products $\left(C_{5}+\right)$ was high in all four tests. Hydrocarbon selectivities were comparable to those reported by workers at SASOL and MOBIL (Section III). In two tests : CO activated $100 \mathrm{Fe} / 0.3 \mathrm{Cu} / 0.2 \mathrm{~K}$ catalyst (Run SA-052957), and $\mathrm{H}_{2}$ activated $100 \mathrm{Fe} / 0.3 \mathrm{Cu} / 0.5 \mathrm{~K}$ catalyst (Run SB-07-0458) the activity increased with time on stream. Both tests were terminated voluntarily after 550 and 460 hours on stream, respectively. On the other hand, a rather rapid deactivation was observed in tests using 100Fe/3Cu/0.2K (Run SA-25-3657) and 100Fe/0.3Cu/0.5K (Run SA-07-0468) catalysts, both of which were activated with $\mathrm{CO}$ at $280^{\circ} \mathrm{C}$. Initial activity was high in both tests, but catalysts started to deactivate after the first or second wax withdrawal. It is not clear whether deactivation was caused or accelerated by the wax withdrawal or by use of improper activation procedures. Catalyst deactivation was also observed in fixed bed tests when $\mathrm{CO}$ activation were employed (Sections V.1.3, V.1.8). Also, frequent changes in process conditions made during slurry reactor tests might have contributed to loss in activity. Tests at a fixed set of process conditions over a long period of time without wax withdrawals are needed to establish causes of catalyst deactivation in slurry reactors. 


\section{V.3. Slurry Reactor Kinetic Studies}

The kinetics of the Fischer-Tropsch (FT) and water-gas shift (WGS) reactions were studied for four different catalysts in the slurry reactor systems. The goal of these tests was to use existing rate models from the literature for the FT and WGS reactions, fit them to our data and obtain parameter estimates, and determine which models best described our experimental results. The catalysts considered were: $100 \mathrm{Fe} / 0.3 \mathrm{Cu} / 0.2 \mathrm{~K}$ (Run SA-05-2957), $100 \mathrm{Fe} / 0.3$ $\mathrm{Cu} / 0.5 \mathrm{~K}$ (Run SB-07-0458, $\mathrm{H}_{2}$ reduced), the commercial Ruhrchemie LP 33/81 catalyst (Run SA-99-0888), and $100 \mathrm{Fe} / 5.0 \mathrm{Cu} / 4.2 \mathrm{~K} / 24 \mathrm{SiO}_{2}$ (Run SB-66-2468). The results from the first two runs were given in section V.2.3, whereas results from the last two runs can be found in section VI.3 of this report.

The data used to estimate the kinetic parameters are summarized in Tables V.3-1 through V.3-4, respectively, for each of the four runs. Only selected balances were used to estimate kinetic parameters. During Run SA-05-2957, catalyst activity was increasing during the initial portion of the run due to incomplete activation, and balances 1-7 were not included in the data set. Also, balance 12 of this run had poor closures, and was excluded as well. The initial periods of the other three runs were also excluded as catalyst activity was not stable during these periods: balances $1-4$ of SB-07-0458, balances $1-6$ of SA-99-0888, and balances $1-4$ of SB-66-2468.

\section{V.3.1. Kinetics Background}

\section{Stoichiometry and Reaction Rates}

The FT synthesis can be approximated as a pair of simultaneous series-parallel reactions for the FT reaction and the WGS:

$$
\begin{aligned}
& \mathrm{CO}+(1+\mathrm{m} / 2 \mathrm{n}) \mathrm{H}_{2} \stackrel{\mathrm{r}_{\mathrm{FT}}}{\longrightarrow} \frac{1}{\mathrm{n}} \mathrm{C}_{\mathrm{n}} \mathrm{H}_{\mathrm{m}}+\mathrm{H}_{2} \mathrm{O} \quad \text { FT } \quad(\mathrm{V} .3-1) \\
& \mathrm{CO}+\mathrm{H}_{2} \mathrm{O} \stackrel{\text { 'WGS }}{=} \mathrm{CO}_{2}+\mathrm{H}_{2} \quad \text { WGS }(\mathrm{V} .3-2)
\end{aligned}
$$

where $n$ is the average carbon chain length of the hydrocarbon product and $m$ is the average number of hydrogen atoms per hydrocarbon molecule. Both $n$ and $m$ vary with the catalyst and process conditions, and were determined experimentally from the gas and liquid product analyses for each balance. In these four tests, $n$ varied between 3.45-6.14 for the $100 \mathrm{Fe} / 0.3$ $\mathrm{Cu} / 0.2 \mathrm{~K}$ catalyst, $3.68-4.23$ for the $100 \mathrm{Fe} / 5.0 \mathrm{Cu} / 4.2 \mathrm{~K} / 24 \mathrm{SiO}_{2}$ catalyst, $4.36-6.00$ for the $100 \mathrm{Fe} / 0.3 \mathrm{Cu} / 0.5 \mathrm{~K}$ catalyst, and 3.18-3.64 for the Ruhrchemie catalyst. The ratio of $\mathrm{m} / \mathrm{n}$ was less sensitive, and varied between $2.16-2.42,2.28-2.36,2.16-2.22$, and 2.27-2.36, respectively. 


\begin{tabular}{|c|c|c|}
\hline$\infty$ & $\mid$ & 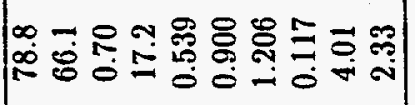 \\
\hline$\approx$ & $\mid$ & 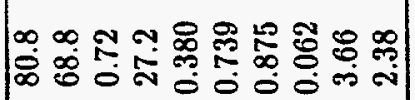 \\
\hline$\because$ & 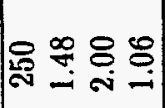 & 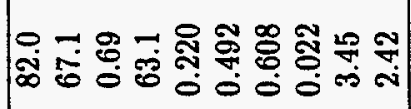 \\
\hline 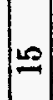 &  & 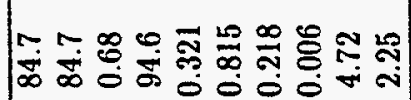 \\
\hline 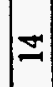 &  & 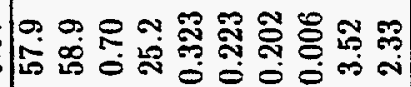 \\
\hline$\approx$ & 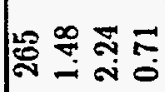 & 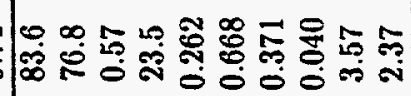 \\
\hline$\equiv$ & $\infty$ & 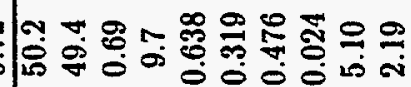 \\
\hline$\approx$ & & 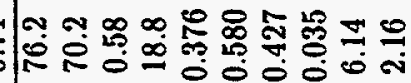 \\
\hline oo & 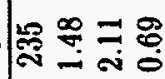 & 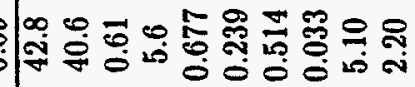 \\
\hline$\infty$ & 赵 & |ج \\
\hline & 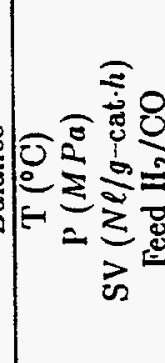 & 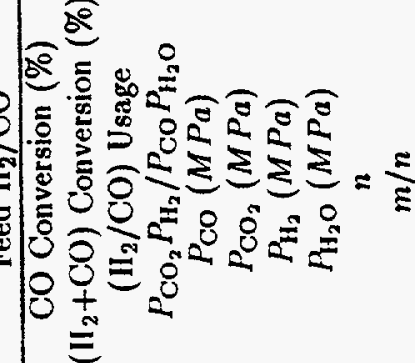 \\
\hline
\end{tabular}




\begin{tabular}{|c|c|c|}
\hline 을 공 & 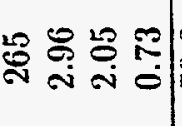 & 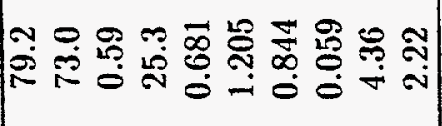 \\
\hline $0 \stackrel{\infty}{\sharp}$ & 旁 & 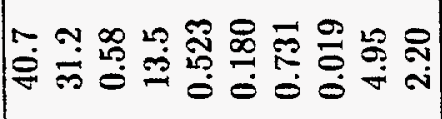 \\
\hline$\infty \underset{\infty}{\mathbb{\infty}}$ & 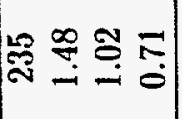 & 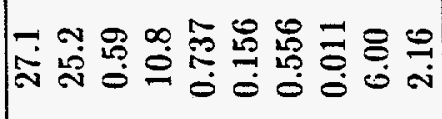 \\
\hline - ָี & 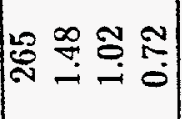 & 茯 \\
\hline 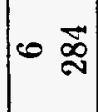 & L & 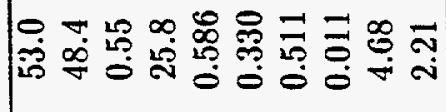 \\
\hline $20 \%$ & 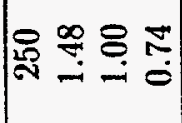 & 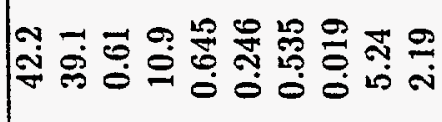 \\
\hline 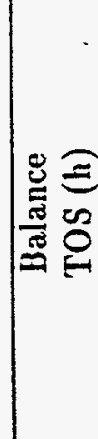 & 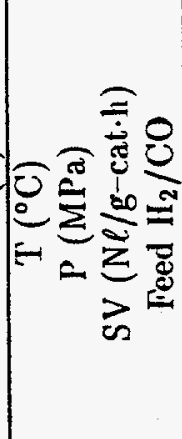 & 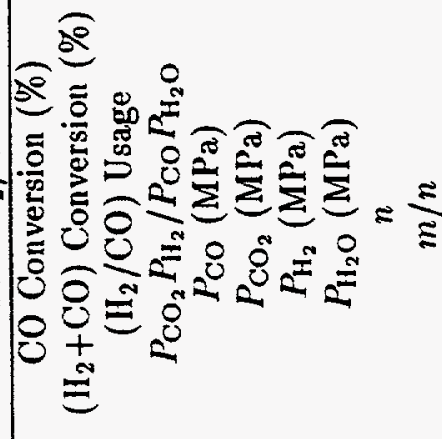 \\
\hline
\end{tabular}




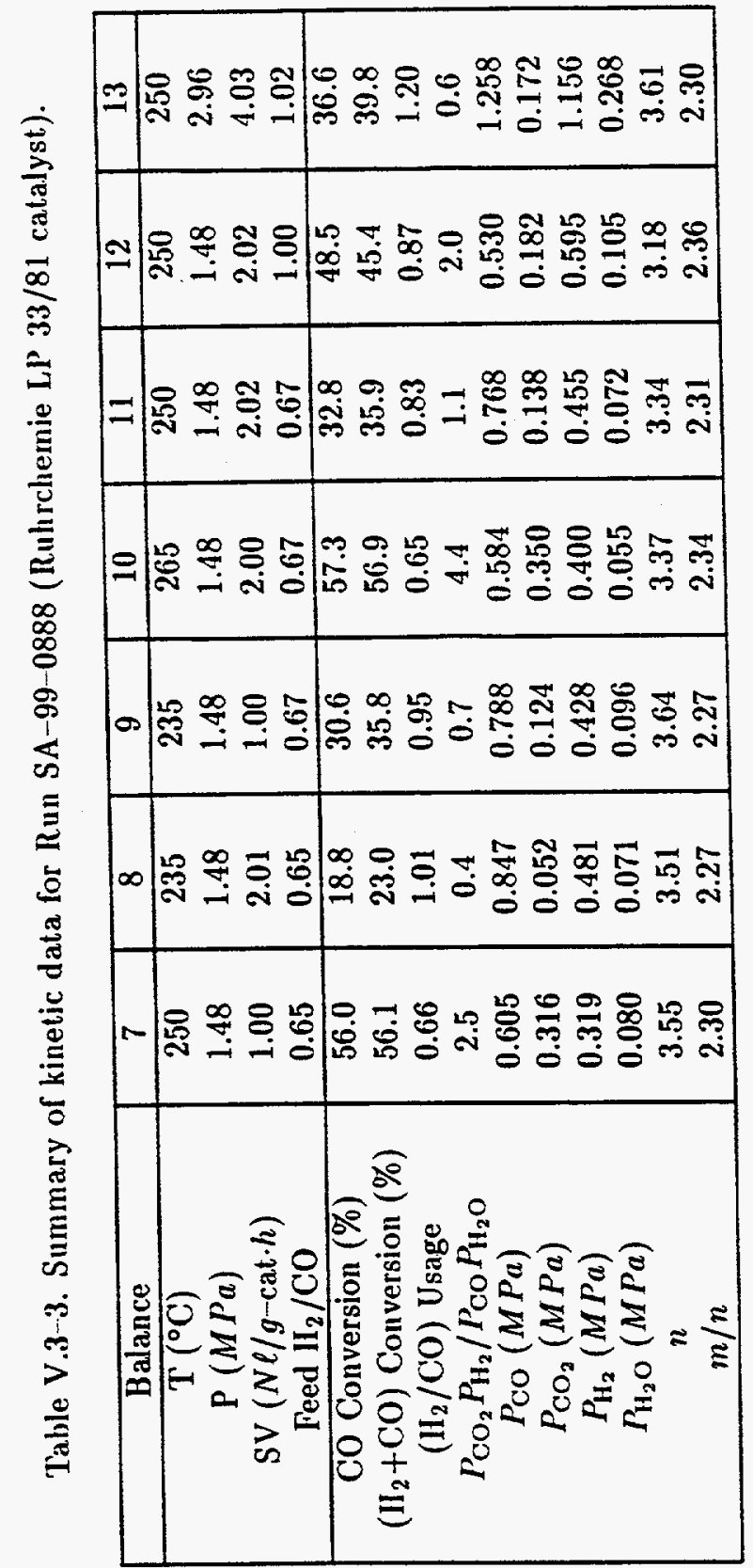


Table V.3 4. Summary of kinetic data for Run SB-66-2468 $\left(100 \mathrm{Fe} / 5.0 \mathrm{Cu} / 4.2 \mathrm{~K} / 24 \mathrm{SiO}_{2}\right.$ catalyst).

\begin{tabular}{|c|c|c|c|}
\hline $\begin{array}{l}\text { Balance } \\
\text { TOS (h) }\end{array}$ & $\begin{array}{c}5 \\
453\end{array}$ & $\begin{array}{c}6 \\
500\end{array}$ & $\begin{array}{c}7 \\
549\end{array}$ \\
\hline $\mathrm{T}\left({ }^{\circ} \mathrm{C}\right)$ & 250 & 250 & 250 \\
\hline$P(\mathrm{MPa})$ & 1.48 & 1.48 & 1.48 \\
\hline $\mathrm{SV}(\mathrm{N} \ell / \mathrm{g}-\mathrm{cat} \cdot \mathrm{h})$ & 2.00 & 4.00 & 1.00 \\
\hline Feed $\mathrm{H}_{2} / \mathrm{CO}$ & 0.69 & 0.69 & 0.69 \\
\hline CO Conversion (\%) & 42.3 & 22.3 & 61.0 \\
\hline$\left(\mathrm{H}_{2}+\mathrm{CO}\right)$ Conversion $(\%)$ & 44.3 & 26.2 & 61.1 \\
\hline$\left(\mathrm{H}_{2} / \mathrm{CO}\right)$ Usage & 0.78 & 0.99 & 0.76 \\
\hline$P_{\mathrm{CO}_{2}} P_{\mathrm{H}_{2}} / P_{\mathrm{CO}} P_{\mathrm{H}_{2} \mathrm{O}}$ & 1.51 & 0.89 & 2.73 \\
\hline$P_{\mathrm{CO}}(\mathrm{MPa})$ & 0.695 & 0.817 & 0.522 \\
\hline$P_{\mathrm{CO}_{2}}(\mathrm{MPa})$ & 0.202 & 0.080 & 0.367 \\
\hline$P_{\mathrm{H}_{2}}(\mathrm{MPa})$ & 0.441 & 0.499 & 0.391 \\
\hline$P_{\mathrm{H}_{2} \mathrm{O}}(\mathrm{MPa})$ & 0.085 & 0.055 & 0.101 \\
\hline$n$ & 4.23 & 3.90 & 3.68 \\
\hline$m / n$ & 2.28 & 2.28 & 2.36 \\
\hline
\end{tabular}


Water is generally believed to be the primary byproduct of the FT reaction, and $\mathrm{CO}_{2}$ is produced by the WGS (Dry et al, 1972). The small amount of oxygenated products, primarily alcohols, and the $\mathrm{CO}_{2}$ formed by the Boudouard reaction, $\left(2 \mathrm{CO} \rightarrow \mathrm{C}(\mathrm{s})+\mathrm{CO}_{2}\right)$, are neglected in the scheme given by Equations V.3-1 and V.3-2. The WGS is particularly important over potassium promoted iron catalysts, which can have significant shift activity. In some cases, the WGS may approach equilibrium during the reaction (Huff and Satterfield, 1984 a, b; Nettelhoff et al, 1985; Bukur and Brown, 1987).

The uniform temperature, pressure, and concentrations achieved in a slurry stirred tank reactor simplifies calculation of reaction rates. Assuming that the reactor is at steady state, the rates of the FT and WGS reactions are given by:

$$
\begin{gathered}
r_{F T}=\left(\frac{P_{S}}{R T_{S}}\right) s \frac{f_{H_{2}+C O}}{2+m / 2 n} \\
r_{W G S}=\left(\frac{P_{S}}{R T_{S}}\right) s \frac{1+m / 2 n-U}{(1+U)(2+m / 2 n)} f_{H_{2}+C O}
\end{gathered}
$$

Note that the rate of syngas consumption $\left(\mathrm{H}_{2}+\mathrm{CO}\right)$ differs from the FT reaction rate only by stoichiometry, $\left(-r_{H_{2}}+\mathrm{CO}\right)=(2+m / 2 n) r_{F T}$, and that the $F T$ and $W G S$ reaction rates are related by the $\mathrm{H}_{2} / \mathrm{CO}$ usage ratio and stoichiometry.

Reaction rates are functions of temperature and liquid phase concentrations in a slurry reactor. Assuming that the gas and liquid phase concentrations are in equilibrium, the gas phase is ideal, and that the gaseous species obey Henry's Law in the liquid phase, partial pressures may be used in the rate equations in place of liquid concentrations or activities. Henry's Law behavior in typical slurry liquids for the principal products and reactants of the $\mathrm{FT}$ synthesis $\left(\mathrm{CO}, \mathrm{CO}_{2}\right.$, $\mathrm{H}_{2}, \mathrm{H}_{2} \mathrm{O}$ ) has been reported in the literature (e.g., Peter and Weinert, 1955; Albal et al, 1984; Matsumoto and Satterfield, 1985; Huang et al, 1988). Preliminary calculations showed that the gas phase behaved ideally. We assumed that the average hydrocarbon product $\left(\mathrm{C}_{n} \mathrm{H}_{m}\right)$ had the physical properties of propylene, and were able to estimate the gas phase fugacity coefficients in the mixture using the Redlich-Kwong equation of state. The values estimated for the fugacity coefficients were better than $1.00=0.05$ for all species at all conditions employed in this report. Under these conditions, the partial pressures and liquid concentrations can be related directly: $C_{l, j}=H_{j} P_{j}$. The use of liquid concentrations, activities, or partial pressures may effect the dimensions of some constants in the rate expression. Furthermore, since Henry's constants are functions of temperature, activation energies may change when different concentration terms are used. If the Henry's constants are assumed to follow an 
Arrhenius temperature dependence, their activation energies are in the range -10.8 to 4.6 $\mathrm{kJ} / \mathrm{mol}$ (Nettelhoff et al, 1985). In this report, we base our estimates using partial pressures in the rate equations. Also, literature values of rate constants were converted to our units for consistency, however, reported activation energies were not adjusted to account for the temperature dependence of the Henry's Law constants.

Kinetic Models

The first order dependence of the FT reaction rate on $\mathrm{H}_{2}$ partial pressure is well known:

$$
\mathrm{r}_{\mathrm{FT}}=\mathrm{k}_{1} \mathrm{P}_{\mathrm{H}_{2}}
$$

Anderson (1956, pp 283-297) found that the first order rate fit the data well, up to $\mathrm{H}_{2}+\mathrm{CO}$ conversions of $60 \%$. The activation energies from the precipitated catalysts tested by Pichler (reported by Anderson) were $87 \mathrm{~kJ} / \mathrm{mol}$, and for the fused or precipitated catalysts tested at the U. S. Bureau of Mines, 84 and $87 \mathrm{~kJ} / \mathrm{mol}$. Nitrided fused iron catalysts had activation energies in the range $80-88 \mathrm{~kJ} / \mathrm{mol}$. Dry et al (1972) studied a fused, promoted iron catalyst in a differential fixed bed reactor, and found that the reaction rate was first order in $\mathrm{H}_{2}$ partial pressure. The activation energy was $70 \mathrm{~kJ} / \mathrm{mol}$. Under the conditions of their study (i.e., low conversions) no rate dependence on $\mathrm{CO}$ partial pressure was observed.

Rate inhibition by water can occur at higher conversions ( $>60 \%$ ). Anderson (1956) proposed a rate equation which included water inhibition, which had the form:

$$
r_{\mathrm{FT}}=\frac{k_{0} \mathrm{P}_{\mathrm{CO}} \mathrm{P}_{\mathrm{H}_{2}}}{\mathrm{P} \mathrm{CO}+\mathrm{aP}_{\mathrm{H}_{2} \mathrm{O}}}
$$

Dry (1976) was able to derive this equation from the enol mechanism (Storch et al, 1951, pp 581-593) by assuming that the hydrogenation of chemisorbed $\mathrm{CO}$ was the rate determining step:

$$
\begin{array}{ccc}
\mathrm{A}_{\mathrm{j}}+\mathrm{M} & \stackrel{\mathrm{K}_{j}}{\rightleftharpoons} & \stackrel{\mathrm{A}_{\mathrm{j}}}{?} \\
\mathrm{CO}+\mathrm{H}_{2} & \stackrel{\mathrm{k}_{0}}{\longrightarrow} & \stackrel{\mathrm{COH}_{2}}{?} \\
\mathrm{M} & & \stackrel{\mathrm{M}}{\mathrm{C}}
\end{array}
$$

where we have used ; to denote a bond of indefinite order.

Dry assumed Langmuir adsorption, and considered competitive adsorption of $\mathrm{CO}, \mathrm{CO}_{2}$, $\mathrm{H}_{2}$, and $\mathrm{H}_{2} \mathrm{O}$. Assuming that the fraction of sites covered by the active intermediate $\mathrm{COH}_{2}$ is small, then the surface fraction of $\mathrm{CO}$ is given by:




and the rate from Equation V.3-8 is:

$$
r_{\mathrm{FT}}=k_{0} \theta_{\mathrm{CO}} \mathrm{P}_{\mathrm{H}_{2}}=\frac{k_{0} K_{\mathrm{CO}} \mathrm{PCO}_{\mathrm{CO}}}{1+\mathrm{K}_{\mathrm{CO}} \mathrm{P}_{\mathrm{CO}}+\mathrm{K}_{\mathrm{CO}_{2}} \mathrm{P}_{\mathrm{CO}_{2}}+\mathrm{K}_{\mathrm{H}_{2}} \mathrm{P}_{\mathrm{H}_{2}}+\mathrm{K}_{\mathrm{H}_{2} \mathrm{O}} \mathrm{P}_{\mathrm{H}_{2} \mathrm{O}}}
$$

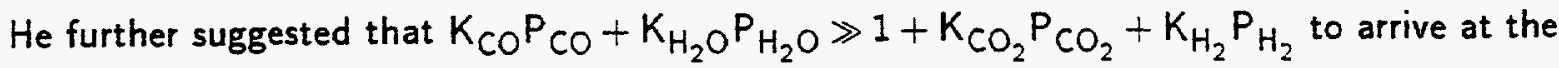
expression given by Equation V.3-6, with $\mathrm{a}=\mathrm{K}_{\mathrm{H}_{2} \mathrm{O}} / \mathrm{K}_{\mathrm{CO}}$.

Atwood and Bennett (1979) used Equation V.3-6 for data taken over a fused, nitrided ammonia synthesis catalyst $(\mathrm{CCl})$. Water inhibition was important only at the highest temperatures and conversions. They determined the activation energy of $k_{0}$ to be $85 \mathrm{~kJ} / \mathrm{mol}$, and for the adsorption term, a, $-9 \mathrm{~kJ} / \mathrm{mol}$. (In our work, we assume that all constants appearing in the rate expressions follow an Arrhenius temperature dependence). Huff and Satterfield (1984a) found that the adsorption term a decreased linearly with $\mathrm{H}_{2}$ partial pressure. A commercial fused iron ammonia synthesis catalyst was used in their work as well (United Catalysts, Inc., C-73). Anderson (1956) also mentioned that the rate constants appearing in Equation V.3-6 showed trends with feed composition.

To account for this dependence, Huff and Satterfield were able to derive an alternate rate form, using two different mechanisms: the carbide mechanism, assuming that the hydrogenation of surface carbon was the rate determining step, and an enol/carbide mechanism, with the hydrogenation of surface enol as the rate determining step. The carbide mechanism proposes that $\mathrm{CO}$ adsorbs dissociatively to form an active surface carbon species. Methylene groups formed by the hydrogenation of the surface carbon polymerize to produce hydrocarbons, and water is produced via the reaction of hydrogen with surface oxygen:

$$
\begin{aligned}
& \mathrm{CO}+2 \mathrm{M} \stackrel{\mathrm{K}_{\mathrm{CO}}}{\rightleftharpoons} \underset{\mathrm{M}}{\mathrm{C}}+\underset{\mathrm{M}}{\mathrm{O}} \\
& \mathrm{O}+\mathrm{H}_{2} \stackrel{\mathrm{K}_{1}}{=} \mathrm{H}_{2} \mathrm{O}+\mathrm{M} \\
& \text { M }
\end{aligned}
$$

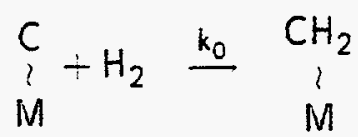

Assuming that the fraction of sites covered by the methylene groups is small, the surface coverage of active carbon is given by:

$$
\theta_{\mathrm{C}}=\frac{\mathrm{K}_{\mathrm{CO}}^{\mathrm{d}} \mathrm{K}_{1} \mathrm{P}_{\mathrm{CO}} \mathrm{P}_{\mathrm{H}_{2}}}{\mathrm{~K}_{\mathrm{CO}}^{\mathrm{d}} \mathrm{K}_{1} \mathrm{P}_{\mathrm{CO}} \mathrm{P}_{\mathrm{H}_{2}}+\left(1+\frac{\mathrm{P}_{\mathrm{H}_{2} \mathrm{O}}}{\mathrm{K}_{1} \mathrm{P}_{\mathrm{H}_{2}}}\right) \mathrm{P}_{\mathrm{H}_{2} \mathrm{O}}}
$$


Assuming that $1+\mathrm{P}_{\mathrm{H}_{2} \mathrm{O}} / \mathrm{K}_{1} \mathrm{P}_{\mathrm{H}_{2}} \approx 1$, then the rate can be written from Equation $\mathrm{V} .3-13$ as:

$$
r_{F T}=\frac{k_{0} P_{C O} P_{H_{2}}^{2}}{P_{C O} P_{H_{2}}+b P_{H_{2} O}}
$$

where $b=1 / K_{C O}^{d} K_{1}$. The assumption that $1+P_{H_{2} O} / K_{1} P_{H_{2}} \approx 1$ is the same as assuming the surface fraction of $O$ to be very small.

The combined enol/carbide mechanism proposes that the methylene groups are formed by eliminating water from the enol in the rate limiting step:

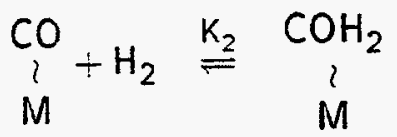

$$
\begin{aligned}
& { }_{\mathrm{M}}^{\mathrm{COH}_{2}}+\mathrm{H}_{2} \stackrel{k_{\mathrm{O}}}{\longrightarrow} \underset{\mathrm{M}}{\mathrm{CH}_{2}}+\mathrm{H}_{2} \mathrm{O}
\end{aligned}
$$

Considering the adsorption of species per Equation V.3-7, the surface concentration of the enol intermediate is given by:

$$
\theta_{\mathrm{COH}_{2}}=\frac{\mathrm{K}_{2} \mathrm{~K}_{\mathrm{CO}} \mathrm{PCO}_{\mathrm{H}_{2}}}{\mathrm{~K}_{2} \mathrm{~K}_{\mathrm{CO}} \mathrm{P}_{\mathrm{CO}} \mathrm{P}_{2}+1+\mathrm{K}_{\mathrm{CO}} \mathrm{P}_{\mathrm{CO}}+\mathrm{K}_{\mathrm{CO}_{2}} \mathrm{PCO}_{2}+\mathrm{K}_{\mathrm{H}_{2}} \mathrm{P}_{\mathrm{H}_{2}}+\mathrm{K}_{\mathrm{H}_{2} \mathrm{O}} \mathrm{P}_{\mathrm{H}_{2} \mathrm{O}}}
$$

If $\mathrm{H}_{2} \mathrm{O}$ adsorbs strongly compared to the other species, such that $\mathrm{K}_{2} \mathrm{~K}_{\mathrm{CO}} \mathrm{P}_{\mathrm{CO}} \mathrm{P}_{\mathrm{H}_{2}}+$ $\mathrm{K}_{\mathrm{H}_{2} \mathrm{O}} \mathrm{P}_{\mathrm{H}_{2} \mathrm{O}} \gg 1+\mathrm{K}_{\mathrm{CO}} \mathrm{P}_{\mathrm{CO}}+\mathrm{K}_{\mathrm{CO}_{2}} \mathrm{P}_{\mathrm{CO}_{2}}+\mathrm{K}_{\mathrm{H}_{2}} \mathrm{P}_{\mathrm{H}_{2}}$, then the rate equation has the same form as Equation V.3-15, where $b$ is now given by $\mathrm{K}_{\mathrm{H}_{2} \mathrm{O}} / \mathrm{K}_{2} \mathrm{~K}_{\mathrm{CO}}$. Furthermore, Equations V.3-6 and V.3-15 have the same form if the constant a (Equation V.3-6) is a function of $\mathrm{H}_{2}$ partial pressure, i.e., $a=b / P_{\mathrm{H}_{2}}$.

For the data of Huff and Satterfield (1984a), Equation V.3-15 gave a better fit. In order to obtain as good a correlation using Equation V.3-6, a constant term had to be included in the denominator. The activation energy for the FT rate constant, $k_{0}$, was $83 \mathrm{~kJ} / \mathrm{mol}$. Nettelhoff et al (1985) considered both Equations V.3-6 and V.3-15 for their data taken over a precipitated, unpromoted iron catalyst. At $270{ }^{\circ} \mathrm{C}$, both rate forms agreed reasonably well with their data, although Equation V.3-6 gave a slightly higher statistical correlation (the $\mathrm{R}^{2}$ correlation coefficient was 0.99 for Equation $V .3-6$ and 0.95 for Equation V.3-15). At conversions below $60 \%$, the rate was first order, with an activation energy of $89 \mathrm{~kJ} / \mathrm{mol}$.

Inhibition by $\mathrm{CO}_{2}$ is generally not as strong as inhibition by water due to the large adsorption coefficient of water relative to $\mathrm{CO}$ and $\mathrm{CO}_{2}$. In slurry reactors, inhibition by water is further enhanced by its high solubility in typical slurry reactor waxes. However, $\mathrm{CO}_{2}$ inhibition may 
become important when a large fraction of the water produced from the FT reaction reacts with $\mathrm{CO}$ to produce $\mathrm{CO}_{2}$ via the WGS (Equation V.3-2). This situation may occur when the catalyst has high WGS activity and/or low $\mathrm{H}_{2} / \mathrm{CO}$ feed ratios are employed. Ledakowicz et al (1985) derived a rate expression which incorporated inhibition by $\mathrm{CO}_{2}$ from the enol mechanism (Equations V.3-7-10), but assumed that $\mathrm{CO}_{2}$ was the dominant term in the denominator of Equation V.3-10 (thus $\mathrm{K}_{\mathrm{CO}} \mathrm{P}_{\mathrm{CO}}+\mathrm{K}_{\mathrm{CO}_{2}} \mathrm{P}_{\mathrm{CO}_{2}} \gg 1+\mathrm{K}_{\mathrm{H}_{2}} \mathrm{P}_{\mathrm{H}_{2}}+\mathrm{K}_{\mathrm{H}_{2} \mathrm{O}} \mathrm{P}_{\mathrm{H}_{2} \mathrm{O}}$ ). Their rate expression was then given by:

$$
r_{F T}=\frac{k_{0} P_{C O} P_{H_{2}}}{P_{C O}+{ }^{C} P_{C O}}
$$

where $\mathrm{c}=\mathrm{K}_{\mathrm{CO}_{2}} / \mathrm{K}_{\mathrm{CO}}$.

For their precipitated catalyst $(100 \mathrm{Fe} / 1.3 \mathrm{~K})$, which showed high WGS activity, most of the water produced from the FT synthesis subsequently reacted to form $\mathrm{CO}_{2}$. Catalyst activity, particularly at higher temperatures, did not follow first order kinetics. The constant $c$ in Equation V.3-19 was estimated at 0.115 , and was relatively insensitive to temperature. The FT activation energy was $103 \mathrm{~kJ} / \mathrm{mol}$. Nettelhoff et al (1985) considered Equation V.3-19 for a commercial fused iron ammonia synthesis catalyst (BASF S6-10). This catalyst also had high WGS activity, and did not show inhibition by product water.

A summary of the rate forms and parameter estimates for the FT reaction appearing in the recent literature is given in Table V.3-5. Some conclusions can be drawn from the previous studies: (1) The activation energy for the FT reaction was about $80-103 \mathrm{~kJ} / \mathrm{mol}$, regardiess of catalyst type, in these recent studies. This is within the range $63-105 \mathrm{~kJ} / \mathrm{mol}$ of Huff and Satterfield (1984a) who reviewed a broader range of reaction studies; (2) Water inhibited the rate more strongly than $\mathrm{CO}_{2} . \mathrm{CO}_{2}$ inhibition was overshadowed by water inhibition, except when the WGS reaction consumed most of the water produced by the FT reaction; (3) All of the proposed $F T$ rate expressions reduced to first order in $\mathrm{H}_{2}$ partial pressure at low conversions. This simple relationship can be used below conversions in the range 40-70\% in a stirred tank reactor (Huff and Satterfield, 1984b).

To account for inhibition by both water and $\mathrm{CO}_{2}$, Ledakowicz et al (1985) proposed a general kinetic model which has the same form as either Equations V.3-6 or V.3-19, and is obtained directly from Equation V.3-10 assuming that both water and $\mathrm{CO}_{2}$ are significant terms in the denominator. (thus $\mathrm{K}_{\mathrm{CO}} \mathrm{PCO}_{\mathrm{CO}}+\mathrm{K}_{\mathrm{CO}_{2}} \mathrm{P}_{\mathrm{CO}_{2}}+\mathrm{K}_{\mathrm{H}_{2} \mathrm{O}} \mathrm{P}_{\mathrm{H}_{2} \mathrm{O}} \gg \mathrm{I}+\mathrm{K}_{\mathrm{H}_{2}} \mathrm{P}_{\mathrm{H}_{2}}$ ):

$$
r_{\mathrm{FT}}=\frac{\mathrm{k}_{\mathrm{O}} \mathrm{P}_{\mathrm{CO}} \mathrm{P}_{\mathrm{H}_{2}}}{\mathrm{P}_{\mathrm{CO}}+\mathrm{aP}_{\mathrm{H}_{2} \mathrm{O}}+\mathrm{CP}_{\mathrm{CO}_{2}}}
$$

$$
\mathrm{V}-10 \mathrm{~T}
$$


Table V.3-5. Summary of FT kinetic expressions and parameter values from the literature.

\begin{tabular}{|c|c|c|c|c|c|}
\hline Atwood and Bennett (1979) & CCI fused iron & $r_{\mathrm{FT}}=\frac{k_{0} P_{\mathrm{CO}} P_{\mathrm{H}_{2}}}{P_{\mathrm{CO}}+a P_{\mathrm{II}_{2} \mathrm{O}}}$ & $\mathrm{T}\left({ }^{\circ} \mathrm{C}\right)$ & $k_{0}^{(a)}$ & a \\
\hline & & & $\begin{array}{l}250 \\
282 \\
315\end{array}$ & $\begin{array}{l}0.0017 \\
0.0049 \\
0.013\end{array}$ & $\begin{array}{l}0.028 \\
0.028 \\
0.028\end{array}$ \\
\hline & & & $E(\mathrm{~kJ} / \mathrm{mol})$ & 85 & -8.8 \\
\hline \multirow[t]{2}{*}{ Leib and Kuo (1984) } & $\mathrm{Fe} / \mathrm{Cu} / \mathrm{K}$ & $r_{\mathrm{FT}}=\frac{k_{0} P_{\mathrm{CO}} P_{\mathrm{H}_{2}}}{P_{\mathrm{CO}}+a P_{\mathrm{H}_{2} \mathrm{O}}}$ & $\mathrm{T}\left({ }^{\circ} \mathrm{C}\right)$ & $k_{0}^{(a)}$ & $\mathbf{a}$ \\
\hline & & & 265 & 0.062 & 0.58 \\
\hline \multirow[t]{3}{*}{ Nettelhoff et al. (1985) } & Precipitated Fe & $r_{\mathrm{FT}}=\frac{k_{\mathrm{O}} P_{\mathrm{Co}} P_{\mathrm{H}_{2}}}{P_{\mathrm{CO}}+a P_{\mathrm{H}_{2} \mathrm{O}}}$ & $\mathrm{T}\left({ }^{\circ} \mathrm{C}\right)$ & $k_{0}^{(a)}$ & a \\
\hline & & & 270 & 0.018 & 4.51 \\
\hline & & & $E(\mathrm{~kJ} / \mathrm{mol})$ & 89 & \\
\hline \multirow[t]{3}{*}{ Huff and Satterfield (1984a) } & C-73 fused iron & $r_{\mathrm{FT}}=\frac{k_{0} P_{\mathrm{CO}} P_{\mathrm{Ii}_{2}}^{2}}{P_{\mathrm{CO}} P_{\mathrm{H}_{2}}+b P_{\mathrm{H}_{2} \mathrm{O}}}$ & $\mathrm{T}\left({ }^{\circ} \mathrm{C}\right)$ & $k_{0}^{(a)}$ & $\mathrm{b}(\mathrm{MPa})$ \\
\hline & 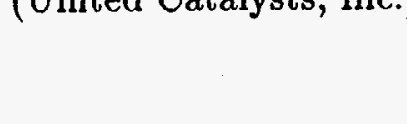 & & $\begin{array}{l}232 \\
248 \\
263\end{array}$ & $\begin{array}{l}0.013 \\
0.025 \\
0.042\end{array}$ & $\begin{array}{l}2.56 \\
1.15 \\
0.67\end{array}$ \\
\hline & & & $E(\mathrm{~kJ} / \mathrm{mol})$ & 83 & -100 \\
\hline \multirow[t]{3}{*}{ Nettelhoff et al. (1985) } & S6-10 fused iron & $r_{\mathrm{FT}}=\frac{k_{0} P_{\mathrm{CO}} P_{\mathrm{H}_{2}}}{P_{\mathrm{CO}}+c P_{\mathrm{CO}_{2}}}$ & $\mathrm{~T}\left({ }^{\circ} \mathrm{C}\right)$ & $k_{0}^{(a)}$ & c \\
\hline & (DADN) & & 240 & 0.010 & 0.19 \\
\hline & & & $E(\mathrm{~kJ} / \mathrm{mol})$ & 81 & \\
\hline \multirow[t]{3}{*}{ Ledakowicz et al. (1985) } & Precipitated & $r_{\mathrm{FT}}=\frac{k_{0} P_{\mathrm{CO}} P_{\mathrm{II}_{2}}}{P_{\mathrm{CO}}+c P_{\mathrm{CO}_{2}}}$ & $\mathrm{~T}\left({ }^{\circ} \mathrm{C}\right)$ & $k_{0}^{(a)}$ & c \\
\hline & $100 \mathrm{Fe} / 1.3 \mathrm{~K}$ & & $\begin{array}{l}220 \\
240 \\
250 \\
260\end{array}$ & $\begin{array}{l}0.0088 \\
0.025 \\
0.049 \\
0.058\end{array}$ & $\begin{array}{l}0.255 \\
0.210 \\
0.229 \\
0.237\end{array}$ \\
\hline & & & $E(\mathrm{~kJ} / \mathrm{mol})$ & 103 & 0 \\
\hline
\end{tabular}

(a) Units of $k_{0}$ are $\mathrm{mol} / \mathrm{g}-\mathrm{cat} \cdot \mathrm{h} \cdot \mathrm{MPa}$ 
This generalized rate expression may be used for catalysts with low WGS activity, where water concentrations are high, as well as for catalysts with high shift activity which show inhibition by $\mathrm{CO}_{2}$.

The WGS is important for slurry processing since it enables $\mathrm{CO}$ rich feeds to be utilized efficiently without the need for an external shift. Both Equations V.3-1 and V.3-2 for the FT and WGS reactions must be considered to accurately predict both $\mathrm{H}_{2}+\mathrm{CO}$ conversions and $\mathrm{H}_{2} / \mathrm{CO}$ usage ratios, which requires knowledge of WGS kinetics. The shift reaction occurs readily over potassium promoted iron catalysts, such as those considered here, and may approach equilibrium in some situations. There have only been a few studies of WGS kinetics in conjunction with the FT synthesis reported in the literature. Kuo (1983) and Leib and Kuo (1984) considered mass action kinetics for the WGS, with a denominator shared with their FT rate expression, which had the form of Equation V.3-6:

$$
r_{W G S}=\frac{k_{w, 0}\left(P_{C O} P_{\mathrm{H}_{2} \mathrm{O}}-P_{\mathrm{CO}_{2}} P_{\mathrm{H}_{2}} / K_{\mathrm{P}}\right)}{\mathrm{P}_{\mathrm{CO}}+\mathrm{aP}_{\mathrm{H}_{2} \mathrm{O}}}
$$

Bohlbro (1969, pp 27-34) derived a rate expression for the WGS from the reactions of CO and $\mathrm{H}_{2}$ with oxidized surface sites (Kulkova and Temkin mechanism):

$$
\begin{aligned}
& \mathrm{CO}+\mathrm{O} \stackrel{\mathrm{O}}{\stackrel{\mathrm{f}_{\mathrm{f}}}{\rightleftharpoons}} \mathrm{CO}_{2}+\mathrm{M} \\
& M k_{-f} \\
& \mathrm{H}_{2} \mathrm{O}+\underset{\mathrm{k}_{-\mathrm{i}}}{\stackrel{\mathrm{Mr}}{\rightleftharpoons}} \mathrm{H}_{2}+\stackrel{\mathrm{O}}{\mathrm{M}}
\end{aligned}
$$

He assumed that the surface concentration of oxygen was described by a Langmuir isotherm. The numerator of the rate equation followed mass action kinetics, while the denominator contained terms for $\mathrm{CO}, \mathrm{CO}_{2}, \mathrm{H}_{2}$, and $\mathrm{H}_{2} \mathrm{O}$ :

$$
{ }_{\text {WGS }}=\frac{k_{\mathrm{r}}\left(P_{C O} P_{\mathrm{H}_{2} O}-P_{\mathrm{CO}_{2}} P_{\mathrm{H}_{2}} / K_{\mathrm{P}}\right)}{P_{\mathrm{CO}}+\frac{k_{-f}}{k_{f}} P_{C O_{2}}+\frac{k_{r}}{k_{f}} P_{\mathrm{H}_{2}} \mathrm{O}+\frac{k_{-r}}{k_{f}} P_{\mathrm{H}_{2}}}
$$

This expression has the same form as Equation V.3-21 if it is assumed that $P_{C O}+\frac{k_{r}}{k_{f}} P_{H_{2}} \mathrm{O} \gg$ $\frac{k_{-} f}{k_{f}} P_{C O_{2}}+\frac{k_{-r}}{k_{f}} P_{H_{2}}$, where $k_{w, 0}=k_{r}$ and $a=k_{r} / k_{f}$. The constants appearing in the denominator of Equation V.3-24 are rate constants, not adsorption coefficients, and the definition of a from Equation V.3-24 differs from the definition using the FT rate expression, Equation V.3-6. Also, there are differences in the surface species and sites between a WGS catalyst and an FT 
catalyst, however, it seems reasonable that for the purpose of kinetics, the FT and WGS rate equations can share the same form of denominator, as was used by Kuo.

Feimer et al (1981) used a first order in CO rate equation for the WGS:

$$
r_{W G S}=k_{w} P_{C O}
$$

They studied a potassium and copper promoted, precipitated iron catalyst $(100 \mathrm{Fe} / 20 \mathrm{Cu} / 0.8$ K), and determined an apparent activation energy of $124 \mathrm{~kJ} / \mathrm{mol}$ for the WGS. Equation V.325 can be derived from Equation V.3-21 when the partial pressure of water is large relative to $\mathrm{CO}$ and $\mathrm{CO}_{2}$, or when water is strongly adsorbed and the reverse WGS reaction is negligible.

\section{V.3.2. Results and Discussion}

\section{First Order Kinetics}

The first order rate constants for the four catalysts were estimated by plotting the FT reaction rate against the $\mathrm{H}_{2}$ partial pressure. These plots are shown in Figure V.3-1 for the unsupported catalysts $(100 \mathrm{Fe} / 0.3 \mathrm{Cu} / 0.2 \mathrm{~K}, 100 \mathrm{Fe} / 0.3 \mathrm{Cu} / 0.5 \mathrm{~K})$ and Figure V.3-2 for the silica-containing catalysts $\left(100 \mathrm{Fe} / 5.0 \mathrm{Cu} / 4.2 \mathrm{~K} / 24 \mathrm{SiO}_{2}\right.$, Ruhrchemie). The rate constant, $k_{1}$, on this type of plot was calculated as the slope of the best line through the origin. The estimated rate constants for the four catalysts are shown on an Arrhenius diagram in Figure V.3-3, and are compared numerically in Table V.3-6. Catalyst activity was highest for the $100 \mathrm{Fe} / 0.3 \mathrm{Cu} / 0.2 \mathrm{~K}$ catalyst, followed by the $100 \mathrm{Fe} / 5.0 \mathrm{Cu} / 4.2 \mathrm{~K} / 24 \mathrm{SiO}_{2}$ catalyst, the Ruhrchemie catalyst, and the $100 \mathrm{Fe} / 0.3 \mathrm{Cu} / 0.5 \mathrm{~K}$ catalyst. The activation energies for the $100 \mathrm{Fe} / 0.3 \mathrm{Cu} / 0.2 \mathrm{~K}$ and Ruhrchemie catalysts were both $86 \mathrm{~kJ} / \mathrm{mol}$, which is within the range expected from the literature. The activation energy for the $100 \mathrm{Fe} / 0.3$ $\mathrm{Cu} / 0.5 \mathrm{~K}$ catalyst was higher, $102 \mathrm{~kJ} / \mathrm{mol}$, which is still within the expected range. The activation energy for the $100 \mathrm{Fe} / 5.0 \mathrm{Cu} / 4.2 \mathrm{~K} / 24 \mathrm{SiO}_{2}$ catalyst was not calculated since data were available at only a single temperature $\left(250^{\circ} \mathrm{C}\right)$. This simple rate expression fit the data fairly accurately for all four catalysts at the conditions employed during our tests.

Inhibition by Water

The effect of water inhibition on the catalysts was evaluated considering Equations V.3-6 and V.3-15. The range of $\mathrm{H}_{2} \mathrm{O}$ partial pressures measured in Run SA-05-2957 (100 Fe/0.3 $\mathrm{Cu} / 0.2 \mathrm{~K}$ ) was $0.006-0.117 \mathrm{MPa}$ and in Run SB-07-0458 (100 Fe/0.3 Cu/0.5 K) was 0.011$0.059 \mathrm{MPa}$, which at similar process conditions were generally lower than those encountered during Run SA-99-0888 (Ruhrchemie), 0.055-0.268 MPa and SB-66-2468 (100 Fe/5.0 Cu/4.2 







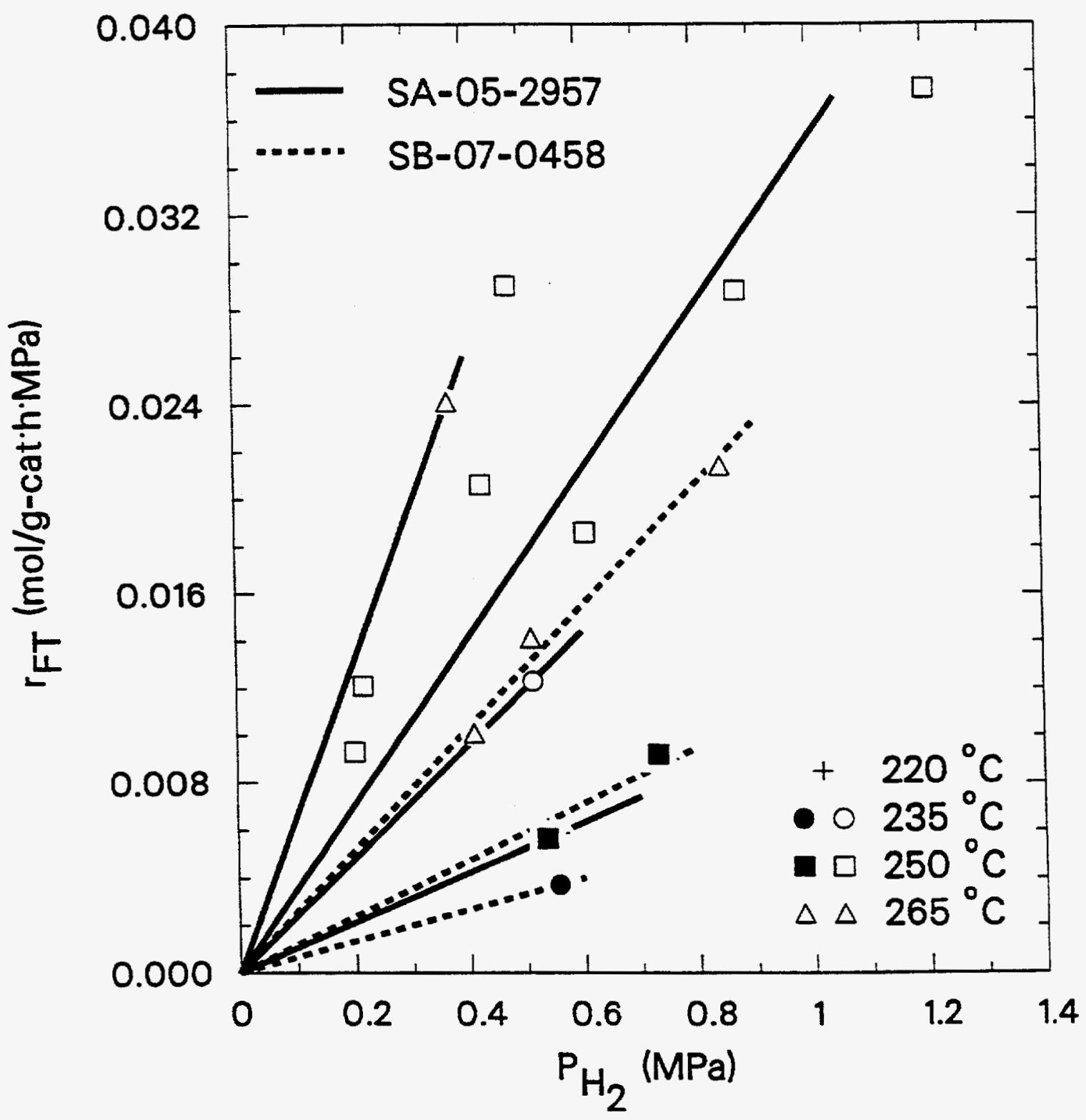

Figure V.3-1. FT first order plot for the $100 \mathrm{Fe} / 0.3 \mathrm{Cu} / 0.2 \mathrm{~K}(\mathrm{SA}-05-2957)$ and 100 $\mathrm{Fe} / 0.3 \mathrm{Cu} / 0.5 \mathrm{~K}(\mathrm{SB}-07-0458)$ catalysts. 


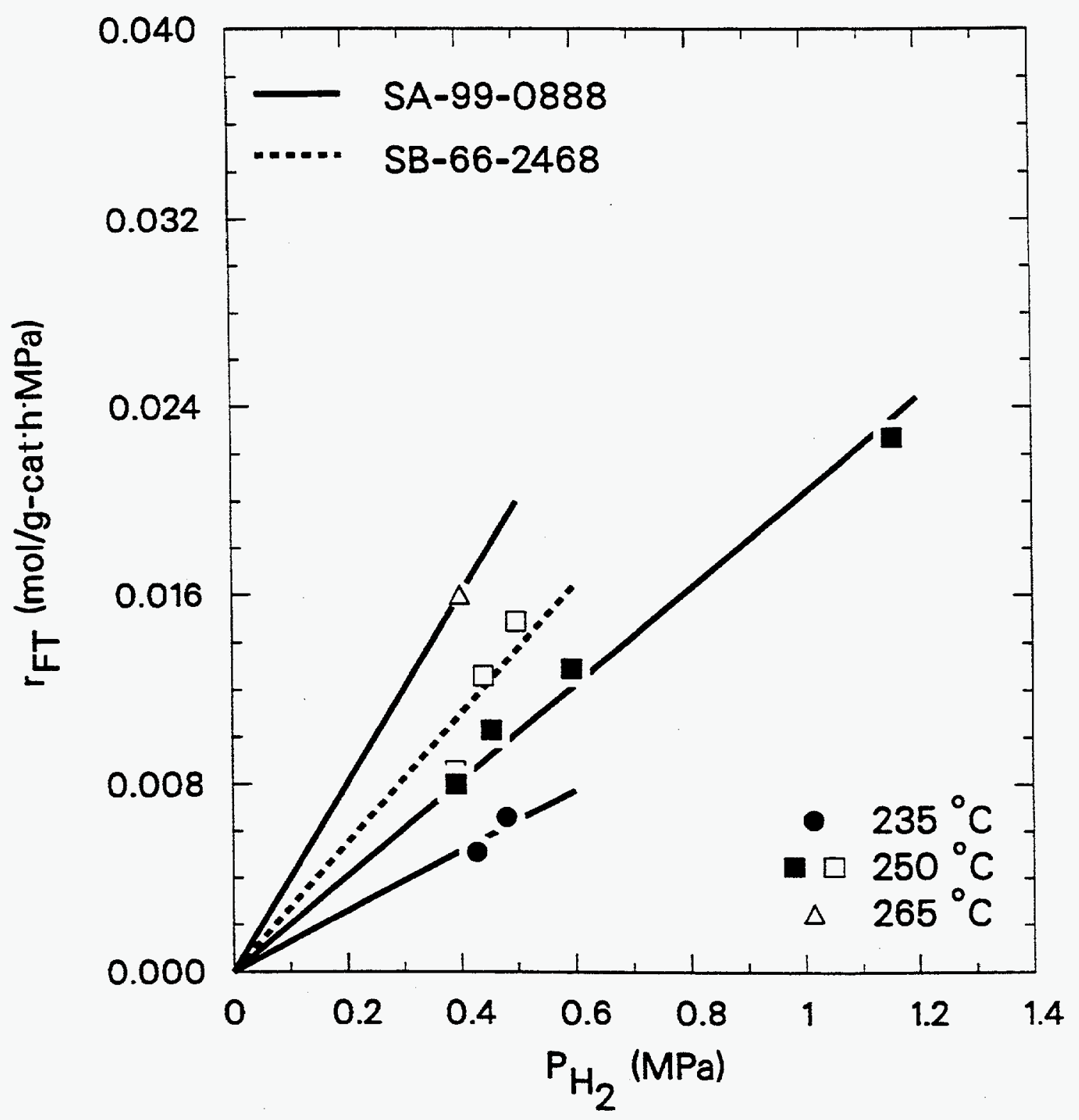

Figure V.3-2. FT first order plot for the Ruhrchemie LP 33/81 (SA-99-0888) and 100 $\mathrm{Fe} / 5.0 \mathrm{Cu} / 4.2 \mathrm{~K} / 24 \mathrm{SiO}_{2}$ (SB-66-2468) catalysts. 


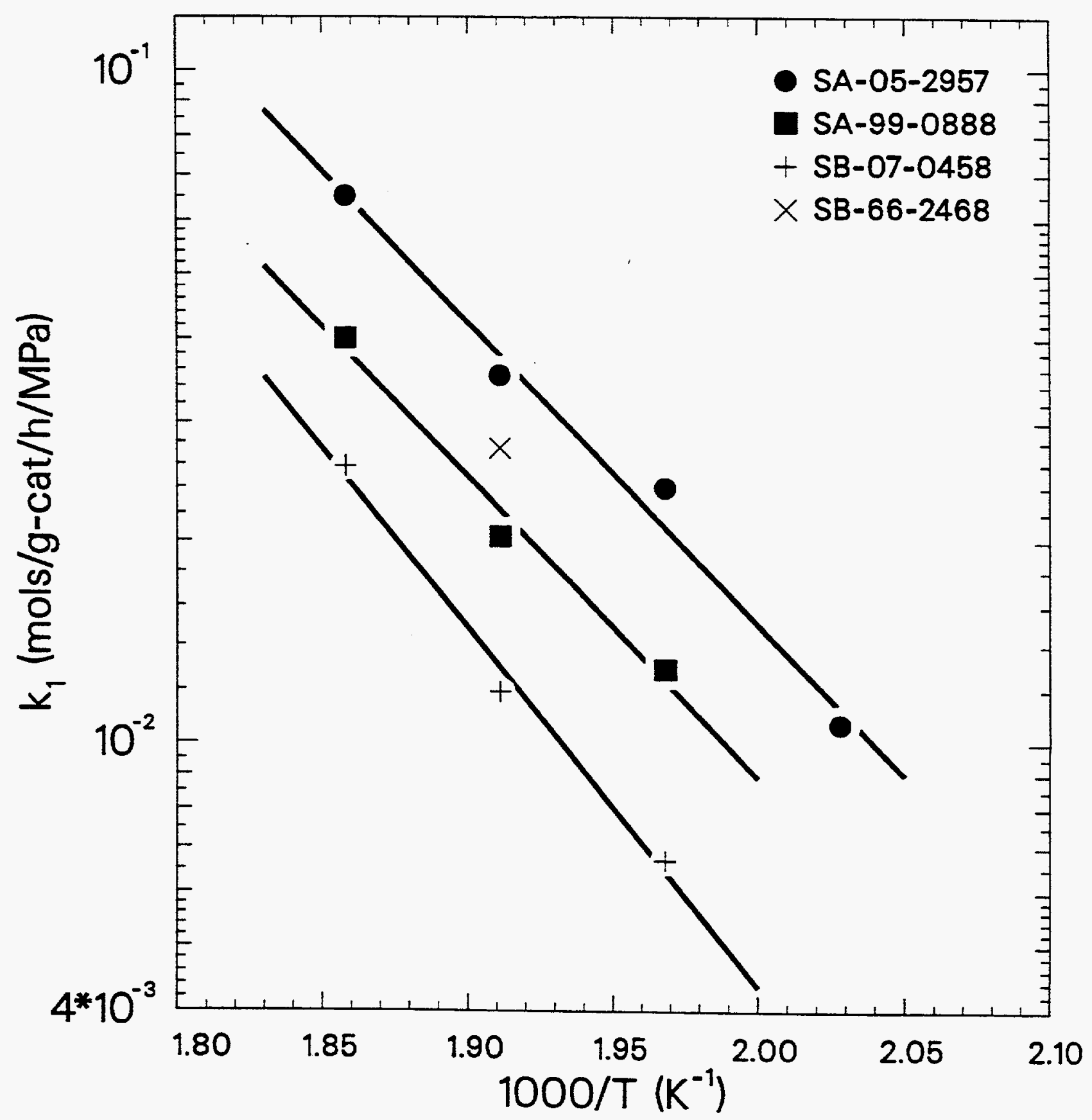

Figure V.3-3. Arrhenius plot of the FT first order rate constants. 
$\mathrm{K} / 24 \mathrm{SiO}_{2}$ ), 0.055-0.101 MPa. Huff and Satterfield (1984a) indicated that inhibition was not important below water partial pressures of $0.1-0.15 \mathrm{MPa}$ for their fused catalyst.

Equations V.3-6 and V.3-15 can be linearized as:

$$
\begin{gathered}
P_{H_{2}} / r_{F T}=\frac{1}{k_{0}}+\frac{a}{k_{0}} \frac{P_{H_{2} O}}{P_{C O}} \\
P_{H_{2}} / r_{F T}=\frac{1}{k_{0}}+\frac{b}{k_{0}} \frac{P_{H_{2} O}}{P_{C O} P_{H_{2}}}
\end{gathered}
$$

Plotting the data in this form, $\mathrm{P}_{\mathrm{H}_{2}} / \mathrm{r}_{\mathrm{FT}}$ versus $\mathrm{P}_{\mathrm{H}_{2} \mathrm{O}} / \mathrm{P} \mathrm{CO}$ (Equation V.3-26) or $\mathrm{P}_{\mathrm{H}_{2} \mathrm{O}} / \mathrm{P}_{\mathrm{CO}} \mathrm{P}_{\mathrm{H}_{2}}$ (Equation V.3-27), should give a straight line which has an intercept $1 / k_{0}$ and a slope a / $k_{0}$ (Equation V.3-26) or $b / k_{0}$ (Equation V.3-27). The constants were calculated from the least squares slope and intercept of the linearized equation for all of Equations V.3-6, V.3-15, and V.3-19. The constants estimated in this manner for all four catalysts are summarized in Table V.3-7. The linear plot of Equation V.3-6 for the four catalysts is shown in Figure V.3-4. The Ruhrchemie and $100 \mathrm{Fe} / 0.3 \mathrm{Cu} / 0.5 \mathrm{~K}$ catalysts show only mild inhibition by water, with $a=0.73$ and 0.99 , respectively. The weak effect of water on the reaction rate may be due to the low conversions and/or the low $\mathrm{H}_{2} \mathrm{O}$ partial pressures obtained under the reaction conditions employed in this study. The $\mathrm{H}_{2}+\mathrm{CO}$ conversions varied between $35.9-56.1 \%$ for the points shown for Ruhrchemie catalyst. The $100 \mathrm{Fe} / 0.3 \mathrm{Cu} / 0.2 \mathrm{~K}$ catalyst was more active than the Ruhrchemie catalyst, and the conversions and $\mathrm{H}_{2} \mathrm{O}$ partial pressures were higher. A stronger inhibition effect was seen for this catalyst $(a=4.2)$, as well as for the $100 \mathrm{Fe} / 5.0 \mathrm{Cu} / 4.2$ $\mathrm{K} / 24 \mathrm{SiO}_{2}$ catalyst $(\mathrm{a}=3.9)$. Catalyst activity followed the same trend seen with the first order rate constants: $100 \mathrm{Fe} / 0.3 \mathrm{Cu} / 0.2 \mathrm{~K}>100 \mathrm{Fe} / 5.0 \mathrm{Cu} / 4.2 \mathrm{~K} / 24 \mathrm{SiO}_{2}>$ Ruhrchemie $>100 \mathrm{Fe} / 0.3 \mathrm{Cu} / 0.5 \mathrm{~K}$. The sesults shown for the $100 \mathrm{Fe} / 0.3 \mathrm{Cu} / 0.5 \mathrm{~K}$ catalyst are at 265 ${ }^{\circ} \mathrm{C}$, but it has comparable activity to the Ruhrchemie catalyst at $250^{\circ} \mathrm{C}$. For each catalyst, $\mathrm{k}_{0}$ was greater than the first order rate constant $k_{1}(0.035,0.027,0.020$, and $0.026 \mathrm{~mol} / \mathrm{g}$-cat.h, respectively). This was expected since $k_{1}$ is an apparent rate constant, which incorporates inhibition by water and/or $\mathrm{CO}_{2}$ (i.e., the denominators of Equations V.3-6, V.3-15, V.3-19, or V.3-20).

The linear plot of Equation V.3-15 is shown in Figure V.3-5. Equation V.3-15 gave a poorer fit to the data for the $100 \mathrm{Fe} / 0.3 \mathrm{Cu} / 0.2 \mathrm{~K}$ catalyst, and the normalized root mean square error (RMSE) value was 0.077 using Equation V.3-15 and 0.058 for Equation V.3-6 (Figure V.3-4). We use the RMSE to compare model predictions of reaction rates to the 
'lable V.3-7. Summary of FT kinetic parameter estimates.

\begin{tabular}{|c|c|c|c|c|}
\hline Run & SA-05-2957 & SB-07-0458 & SA-99-0888 & SB-66-2468 \\
\hline Catalyst & $100 \mathrm{Fe} / 0.3 \mathrm{Cu} / 0.2 \mathrm{~K}$ & $100 \mathrm{Fe} / 0.3 \mathrm{Cu} / 0.5 \mathrm{~K}$ & Ruhrchemie LP $33 / 81$ & $100 \mathrm{Fe} / 5 \mathrm{Cu} / 4.2 \mathrm{~K} / 24 \mathrm{SiO}_{2}$ \\
\hline $\mathrm{T}\left({ }^{\circ} \mathrm{C}\right)$ & 250 & 265 & 250 & 250 \\
\hline $\begin{array}{c}\text { Eq. (V.3-6) } \\
k_{0}^{(1)} \\
a \\
\text { RMSE } \\
\end{array}$ & $\begin{array}{c}0.057 \\
4.2 \\
0.058 \\
\end{array}$ & $\begin{array}{c}0.027 \\
0.99 \\
0.020 \\
\end{array}$ & $\begin{array}{c}0.023 \\
0.73 \\
0.021 \\
\end{array}$ & $\begin{array}{c}0.039 \\
3.9 \\
0.030 \\
\end{array}$ \\
\hline $\begin{array}{c}\text { Eq. (V.3-15) } \\
k_{0}^{(1)} \\
b \\
\text { RMSE } \\
\end{array}$ & $\begin{array}{c}0.073 \\
5.5 \\
0.077 \\
\end{array}$ & $\begin{array}{c}0.029 \\
1.6 \\
0.0093 \\
\end{array}$ & $\begin{array}{c}0.021 \\
-0.049 \\
0.031 \\
\end{array}$ & $\begin{array}{c}0.036 \\
1.3 \\
0.027 \\
\end{array}$ \\
\hline $\begin{array}{c}\text { Eq. (V.3-19) } \\
k_{0}^{(1)} \\
c \\
\text { RMSE } \\
\end{array}$ & $\begin{array}{c}0.054 \\
0.21 \\
0.096 \\
\end{array}$ & $\begin{array}{c}0.029 \\
0.09 \\
0.0095\end{array}$ & $\begin{array}{l}0.021 \\
0.036 \\
0.035 \\
\end{array}$ & $\begin{array}{c}0.033 \\
0.69 \\
0.019 \\
\end{array}$ \\
\hline $\begin{array}{c}\text { Eq. }(V .3-20) \\
k_{0}^{(1)} \\
a \\
c \\
\text { RMSE }\end{array}$ & $\begin{array}{c}0.066 \\
4.6 \\
0.13 \\
0.047 \\
\end{array}$ & (2) & $\begin{array}{c}0.024 \\
0.80 \\
0.08 \\
0.023 \\
\end{array}$ & (2) \\
\hline
\end{tabular}

(1) Units of $k_{0}$ are $\mathrm{mol} / \mathrm{g}$-cat.h.MPa

(2) Zero or negative parameter estimates 


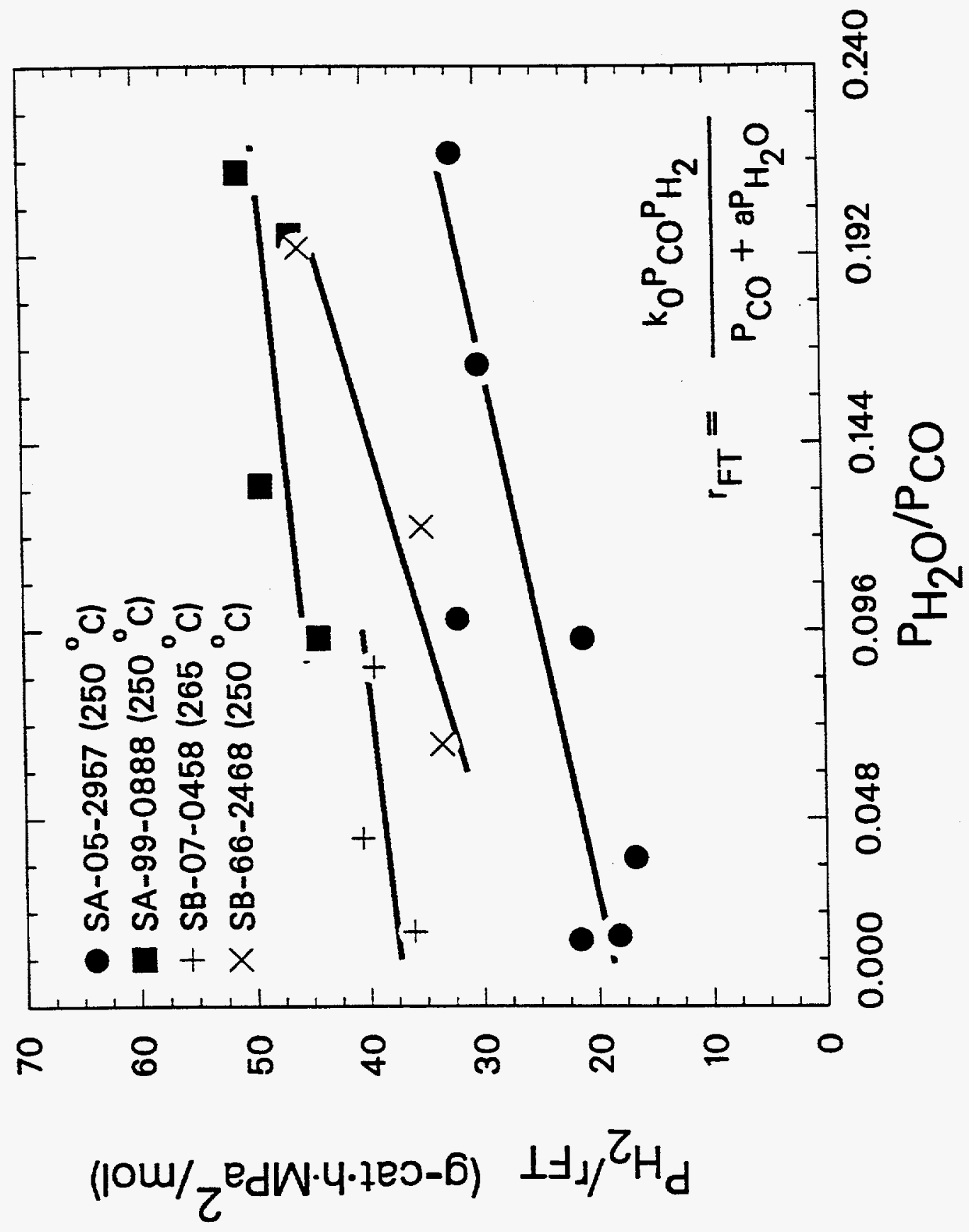

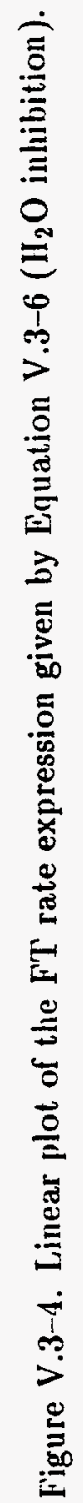




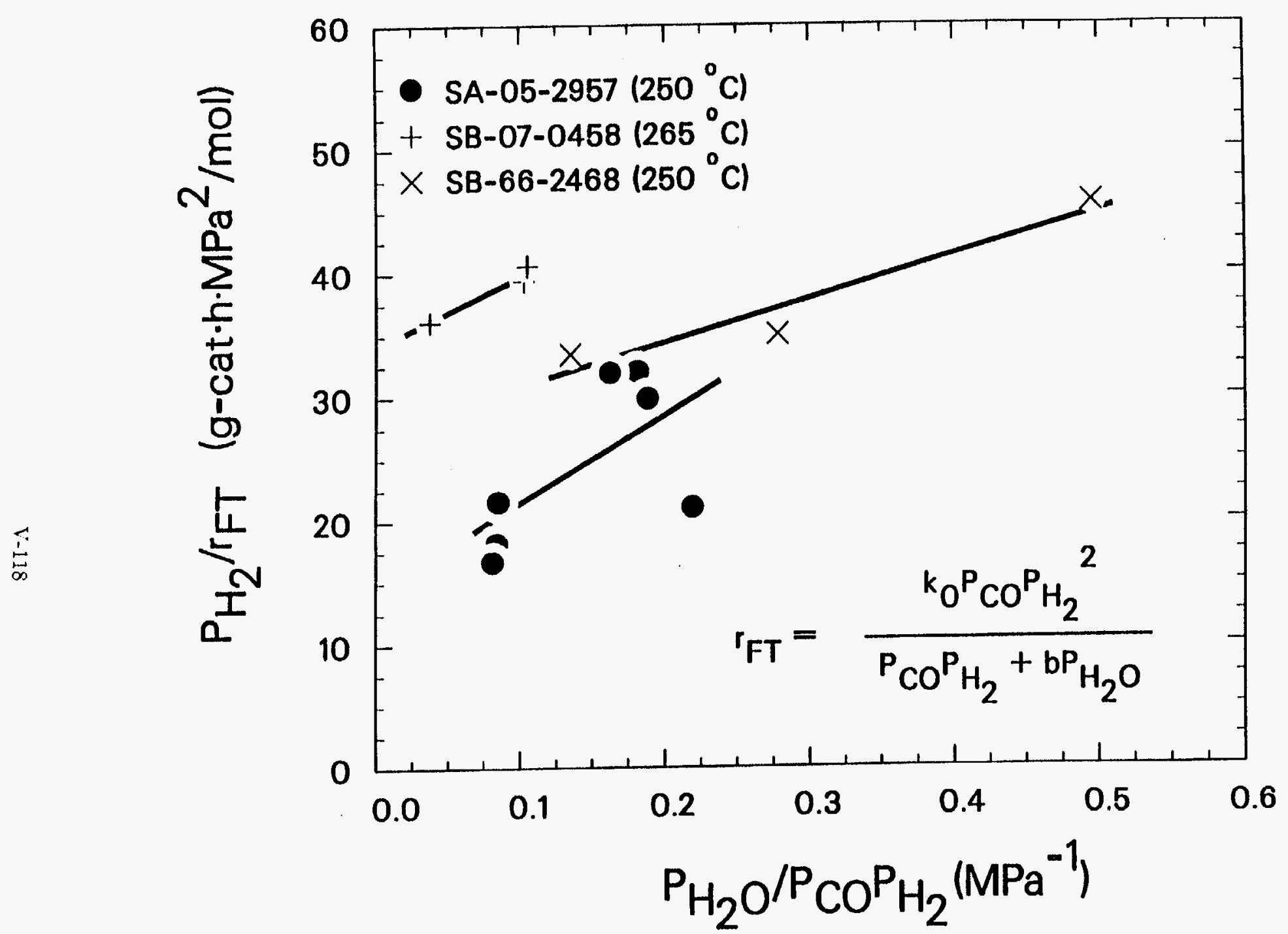

Figure V.3-5. Linear plot of the FT rate expression given by Equation V.3-15 ( $\mathrm{H}_{2} \mathrm{O}$ inhibition). 
experimental values, and have defined RMSE as:

$$
\text { RMSE }=\frac{\sqrt{\sum_{i=1}^{N}\left(r_{k, i}^{\text {meas }}-r_{k, i}^{\text {calc }}\right)^{2}}}{N r_{k, \text { avg }}^{\text {meas }}}
$$

The fit for the $100 \mathrm{Fe} / 5.0 \mathrm{Cu} / 4.2 \mathrm{~K} / 24 \mathrm{SiO}_{2}$ catalyst was approximately the same, with RMSE values of 0.030 (Equation V.3-6) and 0.027 (Equation V.3-15), while the $100 \mathrm{Fe} / 0.3 \mathrm{Cu} / 0.5 \mathrm{~K}$ catalyst showed a strong improvement, RMSE $=0.020$ (Equation V.3-6) and 0.0093 (Equation V.3-15). The $100 \mathrm{Fe} / 0.3 \mathrm{Cu} / 0.2 \mathrm{~K}$ catalyst showed the strongest water inhibition effect and gave $b=5.5 \mathrm{MPa}$, compared to $b=1.3 \mathrm{MPa}$ for the $100 \mathrm{Fe} / 5.0 \mathrm{Cu} / 4.2 \mathrm{~K} / 24 \mathrm{SiO}_{2}$ catalyst and $b=1.6 \mathrm{MPa}$ for the $100 \mathrm{Fe} / 0.3 \mathrm{Cu} / 0.5 \mathrm{~K}$ catalyst. Water inhibition was virtually nonexistent for the Ruhrchemie catalyst when Equation V.3-15 was used; and the rate constant, $k_{1}=0.021 \mathrm{~mol} / \mathrm{g}$-cat.h, was nearly the same as the apparent first order rate constant, with a small negative estimate for $b,-0.049$.

We can compare our results obtained using Equation V.3-6 to those of Atwood and Bennett (1979), Leib and Kuo (1984), and Nettelhoff et al (1985), who all used the same form of rate equation. The catalysts we tested were significantly more active than the fused iron catalyst used by Atwood and Bennett. Their catalyst was also less active than the other catalysts shown in Table V.3-5, which is seen by comparing $k_{0}$ values. Leib and Kuo (1983) estimated their rate constants from experiments conducted in a bubble column reactor using an $\mathrm{Fe} / \mathrm{Cu} / \mathrm{K}$ catalyst ( 67 weight $\% \mathrm{Fe}$ ). Their activity at higher temperature was similar to our $100 \mathrm{Fe} / 0.3$ $\mathrm{Cu} / 0.2 \mathrm{~K}$ catalyst, $\mathrm{k}_{0}=0.062\left(265^{\circ} \mathrm{C}\right)$ versus $0.057\left(250^{\circ} \mathrm{C}\right) \mathrm{mol} / \mathrm{g}$-cat.h. MPa, and had a lower adsorption coefficient. The catalyst tested by Nettelhoff et al (unpromoted $\mathrm{Fe}$ ) was also less active than the catalysts tested in our work. At $270^{\circ} \mathrm{C}$, their rate constant $k_{0}$ was less than the values obtained for our catalyst tests at $250^{\circ} \mathrm{C}$. Our higher activity may be due to the potassium promotion in the catalysts we tested. Their adsorption coefficient $(a=4.51)$ was similar to that for the $100 \mathrm{Fe} / 0.3 \mathrm{Cu} / 0.2 \mathrm{~K}(\mathrm{a}=4.2)$ and $100 \mathrm{Fe} / 5.0 \mathrm{Cu} / 4.2 \mathrm{~K} / 24 \mathrm{SiO}_{2}$ catalysts $(a=3.9)$. The parameters estimated from Equation V.3-15 can be compared to the results of Huff and Satterfield (1984a). The Ruhrchemie catalyst had comparable activity to the fused iron catalyst used in their study, with similar first order rate constants, although we did not find any effect of water using Equation V.3-15. The $100 \mathrm{Fe} / 0.3 \mathrm{Cu} / 0.2 \mathrm{~K}$ catalyst was more active, and at $250^{\circ} \mathrm{C}$, its $k_{0}$ was about 2.9 times greater than that for the fused catalyst, although water inhibited the $F T$ reaction rate more strongly for our catalyst. The 100 $\mathrm{Fe} / 5.0 \mathrm{Cu} / 4.2 \mathrm{~K} / 24 \mathrm{SiO}_{2}$ catalyst showed somewhat higher activity than the fused iron (about 
1.4 times greater) with approximately the same water inhibition effect. At $265{ }^{\circ} \mathrm{C}$, the 100 $\mathrm{Fe} / 0.3 \mathrm{Cu} / 0.5 \mathrm{~K}$ catalyst was less active than their fused iron, with a similar $\mathrm{H}_{2} \mathrm{O}$ adsorption coefficient.

Inhibition by $\mathrm{CO}_{2}$

The rate expression derived by Ledakowicz et al (1985) to account for inhibition by $\mathrm{CO}_{2}$ (Equation V.3-19) was studied in a similar manner. The linear form of Equation V.3-19 is given by:

$$
\mathrm{P}_{\mathrm{H}_{2}} / \mathrm{r}_{\mathrm{FT}}=\frac{1}{\mathrm{k}_{0}}+\frac{c}{\mathrm{k}_{0}} \frac{\mathrm{P}_{\mathrm{CO}_{2}}}{\mathrm{P}_{\mathrm{CO}}}
$$

A linear plot of Equation V.3-19 is shown in Figure V.3-6. The $\mathrm{CO}_{2}$ partial pressures during Run SA-99-0888 (Ruhrchemie) were too low, 0.052-0.350 MPa, to be used with this rate equation, and the estimate for $c$ was nearly zero, $c=0.036$. The data for the other three catalysts show inhibition by $\mathrm{CO}_{2}$, and the constant $\mathrm{c}$ in Equation V.3-19 was estimated at $0.21,0.69,0.09$ for the $100 \mathrm{Fe} / 0.3 \mathrm{Cu} / 0.2 \mathrm{~K}, 100 \mathrm{Fe} / 5.0 \mathrm{Cu} / 4.2 \mathrm{~K} / 24 \mathrm{SiO}_{2}$, and $100 \mathrm{Fe} / 0.3$ $\mathrm{Cu} / 0.5 \mathrm{~K}$ catalysts, respectively. Inhibition by water was much stronger than for $\mathrm{CO}_{2}$, and the adsorption coefficient, $a$, in the analogous Equation V.3-6 was about 20 times greater than that for $\mathrm{CO}_{2}$ with the $100 \mathrm{Fe} / 0.3 \mathrm{Cu} / 0.2 \mathrm{~K}$ catalyst, about 6 times greater for the 100 $\mathrm{Fe} / 5.0 \mathrm{Cu} / 4.2 \mathrm{~K} / 24 \mathrm{SiO}_{2}$ catalyst, and about 11 times greater using the $100 \mathrm{Fe} / 0.3 \mathrm{Cu} / 0.5$ $K$ catalyst.

The $100 \mathrm{Fe} / 0.3 \mathrm{Cu} / 0.2 \mathrm{~K}$ and $100 \mathrm{Fe} / 5.0 \mathrm{Cu} / 4.2 \mathrm{~K} / 24 \mathrm{SiO}_{2}$ catalysts were significantly more active than the S6-10 fused catalyst studied by Nettelhoff et al (1985). The $100 \mathrm{Fe} / 0.3$ $\mathrm{Cu} / 0.2 \mathrm{~K}$ catalyst had comparable activity to the $100 \mathrm{Fe} / 1.3 \mathrm{~K}$ catalyst used by Ledakowicz et al (1985). Our rate constant $k_{0}$ at $250^{\circ} \mathrm{C}$ was approximately the same as for their catalyst, as was our estimate of the $\mathrm{CO}_{2}$ adsorption coefficient, c. Their catalyst was more active than the $100 \mathrm{Fe} / 5.0 \mathrm{Cu} / 4.2 \mathrm{~K} / 24 \mathrm{SiO}_{2}$ catalyst, and showed a weaker $\mathrm{CO}_{2}$ inhibition effect. The S6-10 fused iron was significantly more active than the $100 \mathrm{Fe} / 0.3 \mathrm{Cu} / 0.5 \mathrm{~K}$ catalyst.

The analysis of our data for the $100 \mathrm{Fe} / 0.3 \mathrm{Cu} / 0.2 \mathrm{~K}$ catalyst using Equations V.3-6, V.3-15, and $V .3-19$ showed that both $\mathrm{CO}_{2}$ and water potentially inhibited the reaction rate, thus we also considered Equation V.3-20, which includes inhibition by both product species. Equation V.3-20 was linearized, and the constants estimated via multiple linear regression of the $250^{\circ} \mathrm{C}$ data. A parity plot of experimental and expected rates is shown in Figure V.3-7 for the $100 \mathrm{Fe} / 0.3 \mathrm{Cu} / 0.2 \mathrm{~K}$ and Ruhrchemie catalysts. The $100 \mathrm{Fe} / 5.0 \mathrm{Cu} / 4.2 \mathrm{~K} / 24 \mathrm{SiO}_{2}$ and $100 \mathrm{Fe} / 0.3 \mathrm{Cu} / 0.5 \mathrm{~K}$ catalysts gave negative adsorption coefficients when fit to this equation, 


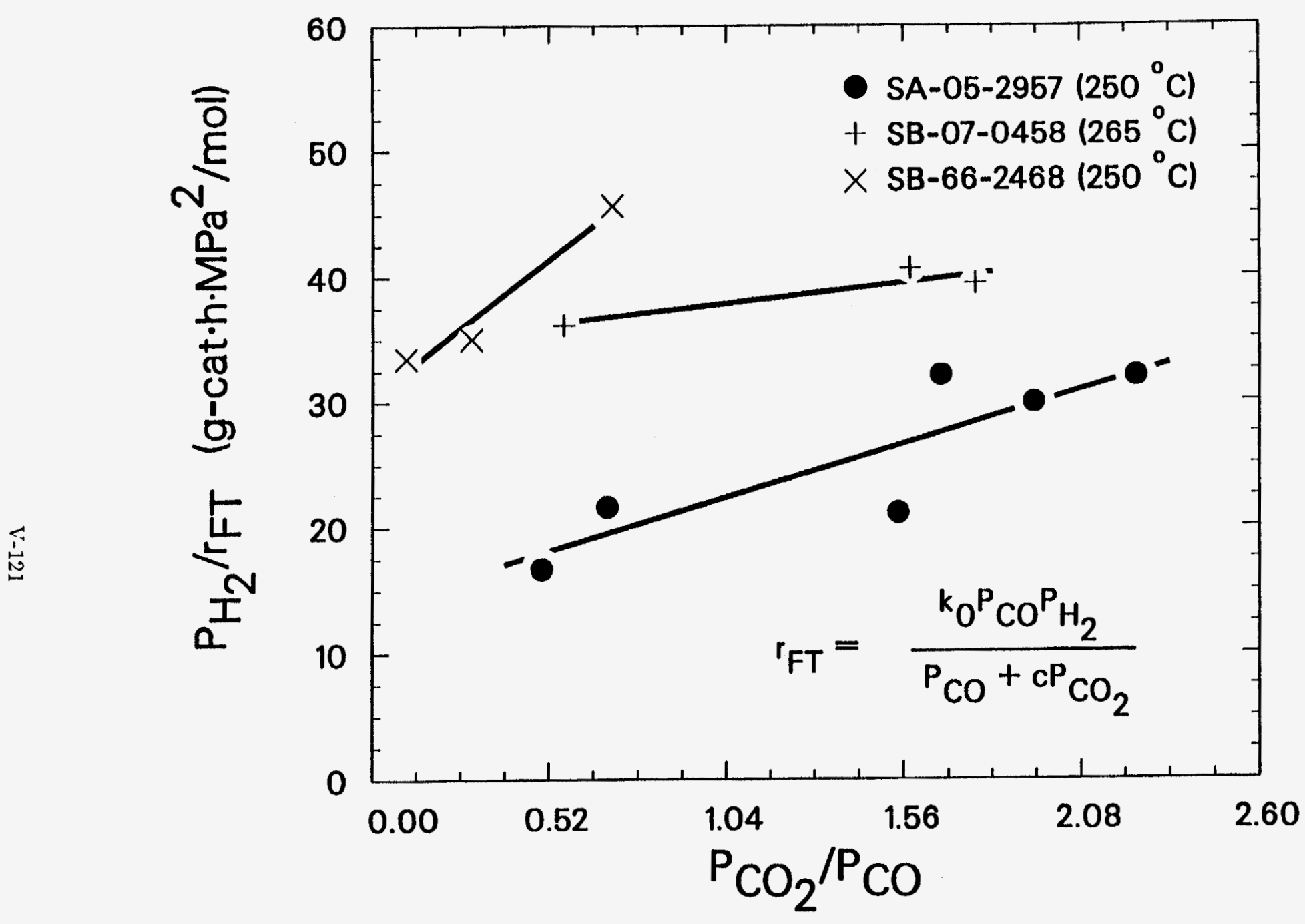

Figure V.3-6. Linear plot of the FT rate expression given by Equation V.3-19 $\left(\mathrm{CO}_{2}\right.$ inhilition). 


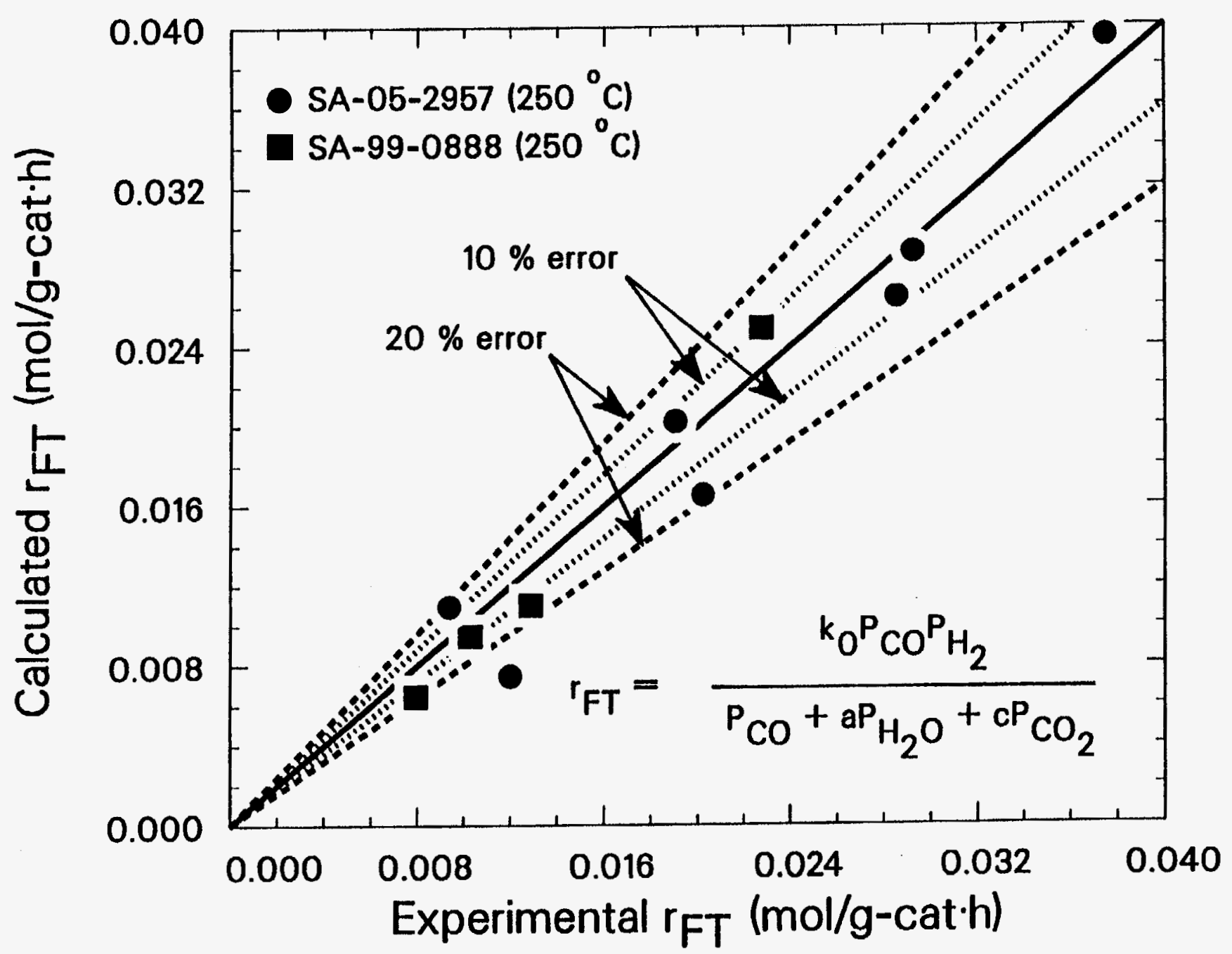

Figure V.3-7. Parity plot of the FT rate expression given by Equation V.3-20 ( $\mathrm{H}_{2} \mathrm{O}$ inhibition). 
thus were not used. The negative rate constants were probably due to the few data points available for these two catalysts. In both cases, the number of data points was equal to the number of constants in the model $(=3)$, which makes the parameter estimates sensitive to small errors in the data. For the other two catalysts, the model fits our data, although some scatter in the data is apparent. The trends seen previously with $\mathrm{CO}_{2}$ and water inhibition were also observed for this model. Water was adsorbed much more strongly than $\mathrm{CO}_{2}$, and the ratio of the adsorption coefficients $(\mathrm{a} / \mathrm{c}$ ) was about 35 for the $100 \mathrm{Fe} / 0.3 \mathrm{Cu} / 0.2 \mathrm{~K}$ catalyst. However, since this catalyst has good WGS activity, the $\mathrm{CO}_{2}$ partial pressures were high enough to cause rate inhibition. The constant $c$ for the Ruhrchemie catalyst was nearly zero, contributing little to the denominator of Equation V.3-20.

\section{Water - Gas Shift Kinetics}

A comparison of the measured $\mathrm{PCO}_{2} \mathrm{P}_{\mathrm{H}_{2}} / \mathrm{P}_{\mathrm{CO}} \mathrm{P}_{\mathrm{H}_{2} \mathrm{O}}$ ratios from our data to the equilibrium constant (Newsome, 1980) is shown in Figure V.3-8. The measured $\mathrm{PCO}_{2} \mathrm{P}_{\mathrm{H}_{2}} / \mathrm{PCO}_{\mathrm{CO}} \mathrm{P}_{2} \mathrm{O}$ ratios generally approach equilibrium at higher temperatures as the WGS reaction rate increases. The $100 \mathrm{Fe} / 0.3 \mathrm{Cu} / 0.2 \mathrm{~K}$ catalyst is also seen to have higher WGS activity than either the Ruhrchemie or $100 \mathrm{Fe} / 5.0 \mathrm{Cu} / 4.2 \mathrm{~K} / 24 \mathrm{SiO}_{2}$ catalysts, and its ratios were closer to equilibrium at all temperatures. Since most of the measured points fall far away from equilibrium, it is important to consider the kinetics of the WGS.

The first order plots for the WGS reaction are shown for the $100 \mathrm{Fe} / 0.3 \mathrm{Cu} / 0.2 \mathrm{~K}$ and $100 \mathrm{Fe} / 0.3 \mathrm{Cu} / 0.5 \mathrm{~K}$ catalysts in Figure V.3-9, and for the Ruhrchemie and $100 \mathrm{Fe} / 5.0$ $\mathrm{Cu} / 4.2 \mathrm{~K} / 24 \mathrm{SiO}_{2}$ catalysts in Figure V.3-10. The slope of the best line through the origin on these plots is the estimate of the rate constant. The first order in $\mathrm{CO}$ rate constants (Equation V.3-25) from our tests are plotted on an Arrhenius diagram in Figure V.3-11, and are compared numerically in Table V.3-8. The rate constants from the $100 \mathrm{Fe} / 0.3 \mathrm{Cu} / 0.2$ $K$ catalyst were higher than those from the other three catalysts by a factor of about 4-5, regardless of temperature. The activation energies measured for the WGS reaction were 132 $\mathrm{kJ} / \mathrm{mol}$ for the $100 \mathrm{Fe} / 0.3 \mathrm{Cu} / 0.2 \mathrm{~K}$ and $100 \mathrm{Fe} / 0.3 \mathrm{Cu} / 0.5 \mathrm{~K}$ catalysts, and $137 \mathrm{~kJ} / \mathrm{mol}$ for the Ruhrchemie catalyst. These values are in good agreement with the $124 \mathrm{~kJ} / \mathrm{mol}$ reported by Feimer et al, who also considered first order in CO WGS kinetics.

The mass action kinetic equation (Equation V.3-21) was also used for the WGS. The rate constant $k_{w, 0}$ was estimated in the following manner: using the same value of a (Equation V.36) obtained for the FT kinetics, Equation V.3-21 was multiplied through by the denominator of 


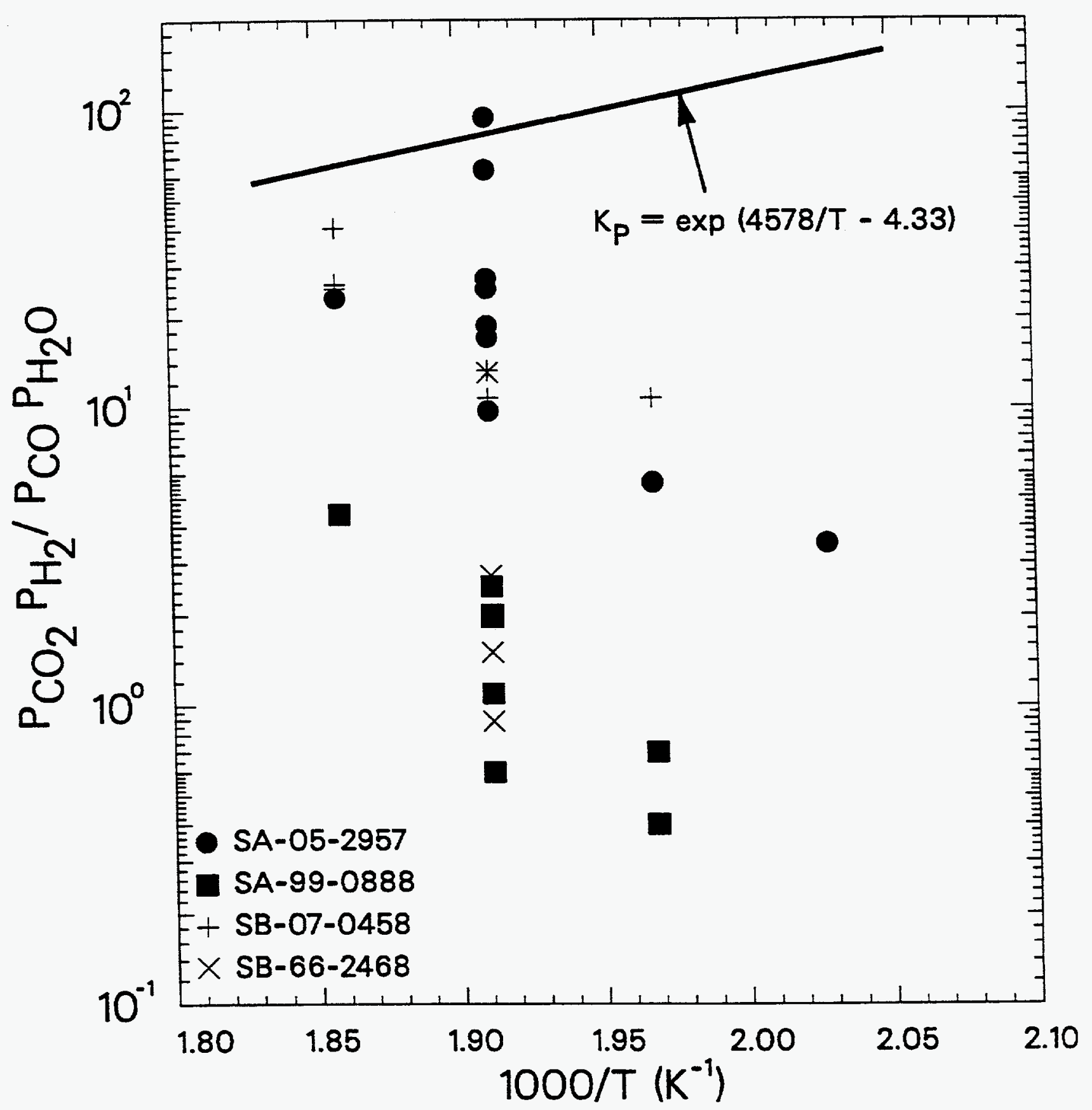

Figure V.3-8. Comparison of measured $P_{\mathrm{CO}_{2}} P_{\mathrm{H}_{2}} / P_{\mathrm{CO}} P_{\mathrm{H}_{2} \mathrm{O}}$ ratios to equilibrium. 


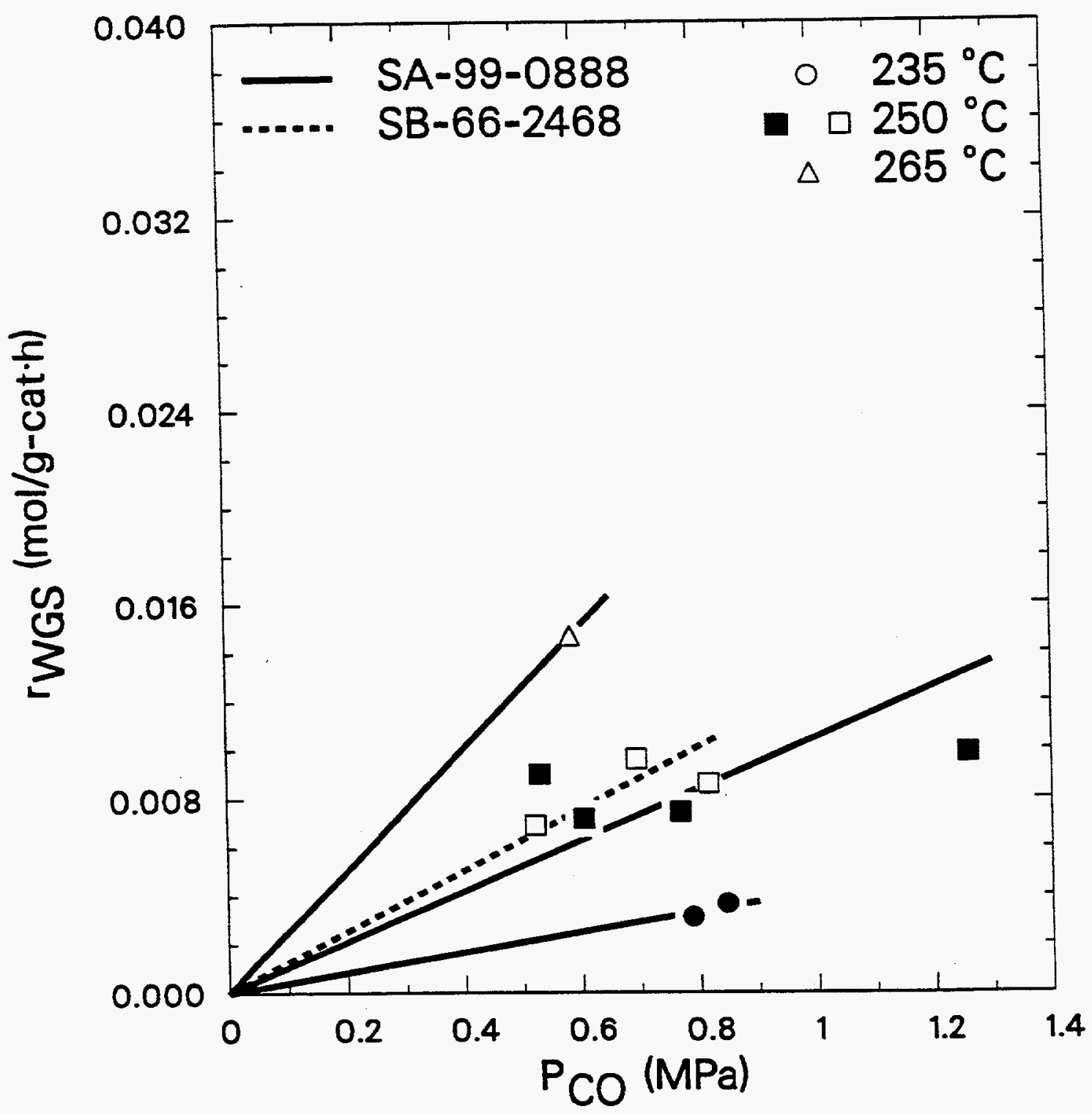

Figure V.3-9. WGS first order plot for the $100 \mathrm{Fe} / 0.3 \mathrm{Cu} / 0.2 \mathrm{~K}(\mathrm{SA}-05-295 \mathrm{i})$ and 100 $\mathrm{Fe} / 0.3 \mathrm{Cu} / 0.5 \mathrm{~K}$ (SB-07-0458) catalysts. 


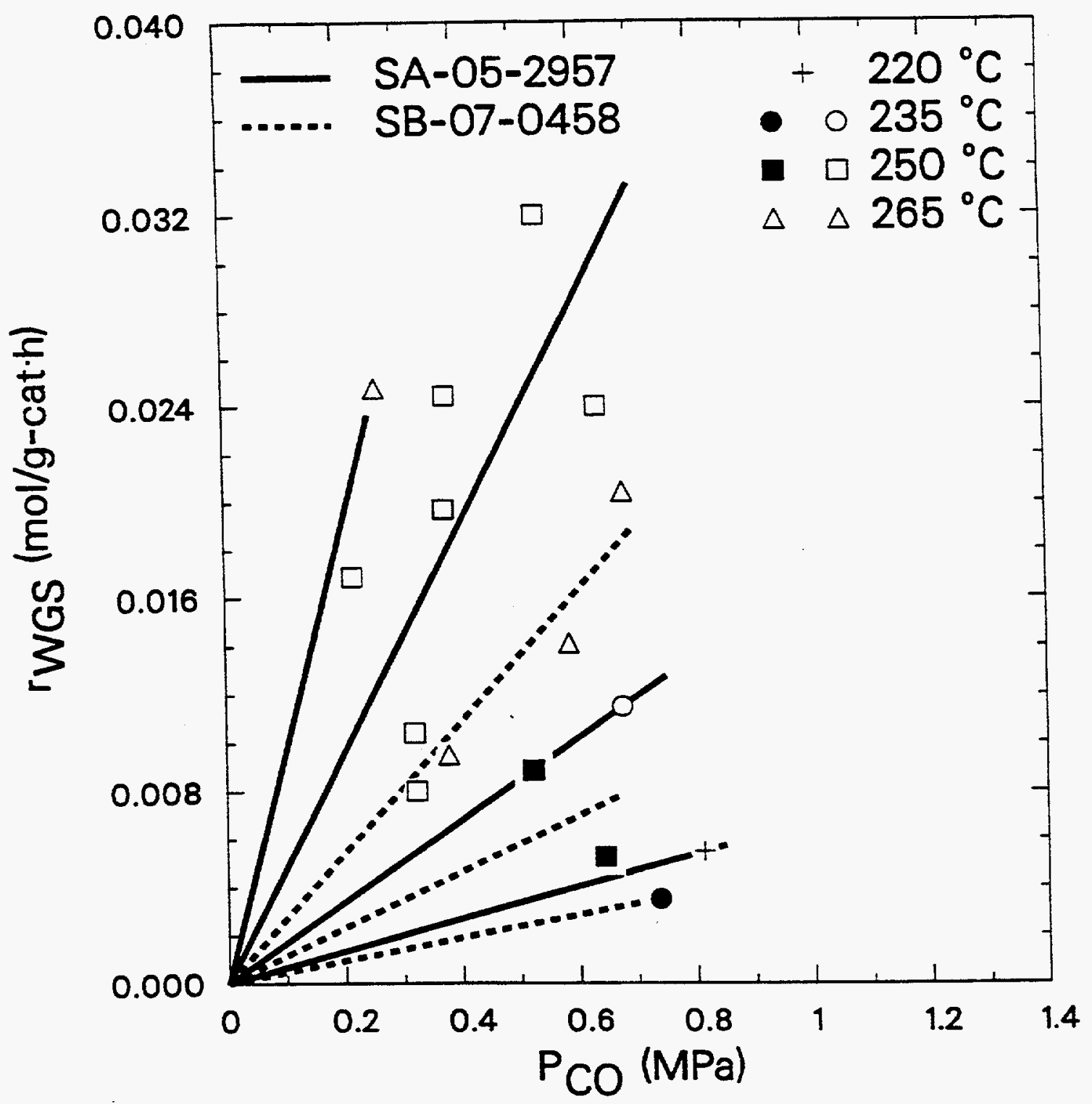

Figure V.3-10. WGS first order plot for the Ruhrchemie LP 33/81 (SA-99-0888) and 100 $\mathrm{Fe} / 5.0 \mathrm{Cu} / 4.2 \mathrm{~K} / 24 \mathrm{SiO}_{2}$ (SB-66-2468) catalysts. 


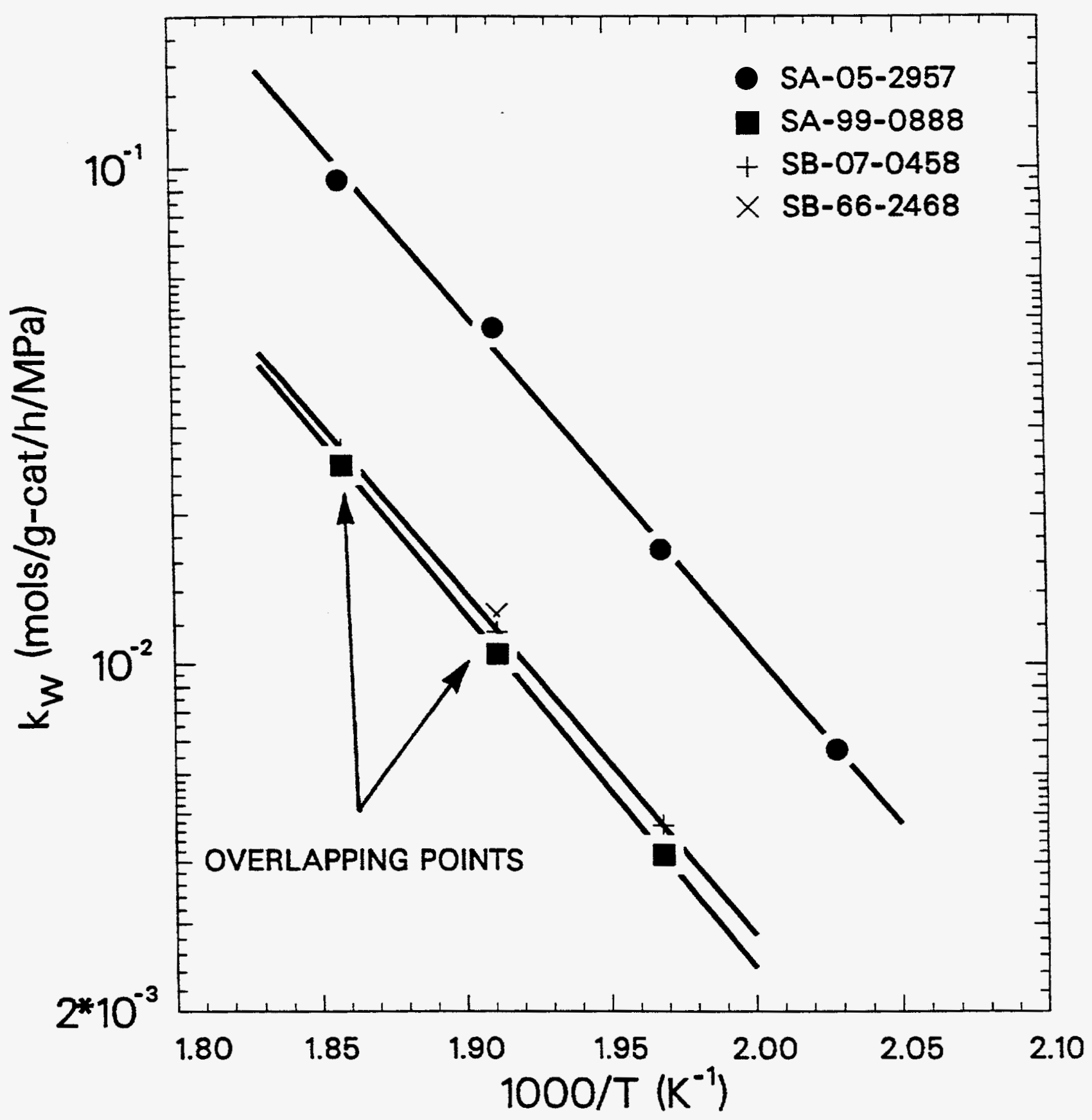

Figure V.3-11. Arrhenius plot of the WG.S first order rate constants. 
Table V.3-8. Summary of WGS first order rate constants.

\begin{tabular}{|c|c|c|c|c|c|c|c|c|}
\hline Run & \multicolumn{2}{|c|}{ SA-05-2957 } & \multicolumn{2}{|c|}{ SB-07-0458 } & \multicolumn{2}{|c|}{ SA-99-0888 } & \multicolumn{2}{|c|}{ SB-66-2468 } \\
\hline Catalyst & $100 \mathrm{Fe}$ & $\mathrm{Su} / 0.2 \mathrm{~K}$ & $100 \mathrm{~F}$ & $\mathrm{Ju} / 0.5 \mathrm{~K}$ & Ruhrc & LP 33/81 & 1001 & $.2 \mathrm{~K} / 24 \mathrm{SiO}_{2}$ \\
\hline $\mathrm{T}\left({ }^{\circ} \mathrm{C}\right)$ & $k_{1}^{(1)} 0$ & RMSE & $\boldsymbol{k}_{w, 0}^{(1)}$ & RMSE & $k_{w, 0}^{(1)}$ & RMSE & $k_{w, 0}^{(1)}$ & RMSE \\
\hline 220 & 0.0068 & (2) & - & - & - & - & - & - \\
\hline 235 & 0.017 & (2) & 0.0047 & (2) & 0.0042 & 0.301 & - & $\begin{array}{lll}- & \\
\end{array}$ \\
\hline 250 & 0.048 & 0.255 & 0.012 & 0.241 & 0.0096 & 0.142 & 0.013 & 0.074 \\
\hline 265 & 0.095 & 0.078 & 0.027 & 0.209 & 0.025 & & - & \\
\hline$E(\mathrm{~kJ} / \mathrm{mol})$ & 132 & - & 132 & - & 136 & - & (2) & - \\
\hline
\end{tabular}

(1) Units of $k_{w, 0}$ are $\mathrm{mol} / \mathrm{g}-\mathrm{cat} \cdot \mathrm{l} \cdot \mathrm{MPa}$

(2) Only 1 data point available 
the right-hand side. The resulting equation is linear with respect to $k_{w, 0}$, and the rate constant was then calculated as the slope of the best line through the origin. The WGS equilibrium constant, $K_{P}$, is a known function of temperature, $K_{P}=\exp (4578 / T-4.33)$, and was not considered to be a variable kinetic parameter. We also considered mass action kinetics with the denominators of the FT rate expressions given by Equations V.3-15, V.3-19, and V.3-20 as well. The resulting WGS kinetic equations have the form:

$$
\begin{aligned}
& r_{W G S}=\frac{k_{w, 0}\left(P_{C O} P_{\mathrm{H}_{2} \mathrm{O}}-P_{C O_{2}} P_{\mathrm{H}_{2}} / K_{\mathrm{P}}\right)}{\mathrm{P}_{\mathrm{CO}} \mathrm{P}_{\mathrm{H}_{2}}+b \mathrm{P}_{\mathrm{H}_{2} \mathrm{O}}} \\
& r_{W G S}=\frac{k_{w, 0}\left(P_{C O} P_{\mathrm{H}_{2} \mathrm{O}}-P_{\mathrm{CO}_{2}} P_{\mathrm{H}_{2}} / K_{\mathrm{P}}\right)}{\mathrm{P}_{\mathrm{CO}}+\mathrm{CP}_{\mathrm{CO}_{2}}} \\
& r_{W G S}=\frac{k_{w, 0}\left(P_{C O} P_{\mathrm{H}_{2} \mathrm{O}}-\mathrm{P}_{\mathrm{CO}_{2}} \mathrm{P}_{\mathrm{H}_{2}} / \mathrm{K}_{\mathrm{P}}\right)}{\mathrm{P}_{\mathrm{CO}}+\mathrm{aP}_{\mathrm{H}_{2} \mathrm{O}}+\mathrm{CP}_{\mathrm{CO}_{2}}}
\end{aligned}
$$

The rate constants $k_{w, 0}$ for these rate forms were estimated in the same manner as described above. The results for the rate constants $k_{w, 0}$ are given in Table V.3-9 for all catalysts. The fit of first order in $\mathrm{CO}$ kinetics was good for all catalysts. Using the $100 \mathrm{Fe} / 0.3 \mathrm{Cu} / 0.2 \mathrm{~K}$ catalyst, the lowest RMSE value was obtained using Equation V.3-30. The other models gave poorer fits. With the other catalysts, the first order in $\mathrm{CO}$ kinetics were superior to the nonlinear kinetics, based on the RMSE values. Leib and Kuo (1984) estimated $k_{w, 0}$ at 0.66 $\mathrm{mol} / \mathrm{g}$-cat.h.MPa for $\mathrm{a}=0.58$ for their iron based catalyst $\left(265^{\circ} \mathrm{C}\right)$. Their rate constant is comparable to our estimate for the $100 \mathrm{Fe} / 0.3 \mathrm{Cu} / 0.2 \mathrm{~K}$ catalyst, and is higher than the constants obtained for the Ruhrchemie, $100 \mathrm{Fe} / 0.3 \mathrm{Cu} / 0.5 \mathrm{~K}$, or $100 \mathrm{Fe} / 5.0 \mathrm{Cu} / 4.2 \mathrm{~K} / 24$ $\mathrm{SiO}_{2}$ catalysts.

\section{V.3.3. Summary}

Several different rate forms were tested for each catalyst to model the FT and WGS reaction rates. Our results show that water inhibits the FT reaction more strongly than does $\mathrm{CO}_{2}$, however, in all cases, the FT rates were approximately first order with respect to $\mathrm{H}_{2}$. Using the $100 \mathrm{Fe} / 0.3 \mathrm{Cu} / 0.2 \mathrm{~K}$ catalyst (Run SA-05-2957), the best FT rate model contained terms for both water and $\mathrm{CO}_{2}$ inhibition, given by Equation V.3-20. The model originally proposed by Anderson (1956), Equation V.3-6, was nearly as good, with a slightly higher RMSE. Equation V.3-6 also gave the best fit for the Ruhrchemie catalyst, although there was little actual difference between any of the models for this catalyst. The Ruhrchemie catalyst had low activity during Run SA-99-0888, which leads to low conversions and $\mathrm{H}_{2} \mathrm{O}$ and $\mathrm{CO}_{2}$ 
Table V.3-9. Summary of WGS kinetic parameter estimates.

\begin{tabular}{|c|c|c|c|c|}
\hline Run & SA-05-2957 & SB-07-0458 & SA-99-0888 & SB-66-2468 \\
\hline Catalyst & $100 \mathrm{Fe} / 0.3 \mathrm{Cu} / 0.2 \mathrm{~K}$ & $100 \mathrm{Fe} / 0.3 \mathrm{Cu} / 0.5 \mathrm{~K}$ & Ruhrchemie LP 33/81 & $100 \mathrm{Fe} / 5 \mathrm{Cu} / 4.2 \mathrm{~K} / 24 \mathrm{SiO}_{2}$ \\
\hline $\mathrm{T}\left({ }^{\circ} \mathrm{C}\right)$ & 250 & $\overline{265}$ & 250 & 250 \\
\hline $\begin{array}{c}\text { Eq. }\left(\begin{array}{c}(1) \\
k_{w, 0}^{(1)} \\
\text { RMSE }\end{array}\right. \\
\end{array}$ & $\begin{array}{c}0.74 \\
0.170\end{array}$ & $\begin{array}{r}0.43 \\
0.347 \\
\end{array}$ & $\begin{array}{l}0.047 \\
0.228 \\
\end{array}$ & $\begin{array}{c}0.17 \\
0.109 \\
\end{array}$ \\
\hline $\begin{array}{c}\text { Eq. }(\mathrm{V} .3-30) \\
k_{w, 0}^{(2)} \\
\text { RMSE } \\
\end{array}$ & $\begin{array}{c}0.84 \\
0.144 \\
\end{array}$ & $\begin{array}{c}0.29 \\
0.370 \\
\end{array}$ & (3) & $\begin{array}{l}0.069 \\
0.164\end{array}$ \\
\hline $\begin{array}{c}\text { Eq. (V.3-31) } \\
k_{w, 0}^{(1)} \\
\text { RMSE } \\
\end{array}$ & $\begin{array}{c}0.56 \\
0.213\end{array}$ & $\begin{array}{c}0.43 \\
0.361\end{array}$ & $\begin{array}{l}0.041 \\
0.234 \\
\end{array}$ & $\begin{array}{c}0.14 \\
0.201\end{array}$ \\
\hline $\begin{array}{c}\text { Eq. (V.3-32) } \\
k_{w, 0}^{(1)} \\
\text { RMSE }\end{array}$ & $\begin{array}{c}0.85 \\
0.169\end{array}$ & (3) & $\begin{array}{l}0.048 \\
0.230\end{array}$ & (3) \\
\hline
\end{tabular}

(1) Units of $k_{w, 0}$ are $\mathrm{mol} / \mathrm{g}-\mathrm{cat} \cdot \mathrm{h} \cdot \mathrm{MPa}$

(2) Units of $k_{w, 0}$ are $\mathrm{mol} / \mathrm{g}$-cat.h

(3) FT parameters less than or equal to zero 
partial pressures. Under these conditions, inhibition effects are negligible. The FT kinetic equation which accounted for $\mathrm{CO}_{2}$ alone, Equation V.3-19, gave the best fit to the data taken over the $100 \mathrm{Fe} / 5.0 \mathrm{Cu} / 4.2 \mathrm{~K} / 24 \mathrm{SiO}_{2}$ catalyst (Run SB-66-2468). However, since inhibition by water is much stronger than $\mathrm{CO}_{2}$, the kinetics which include water should be considered. Both of the water inhibition models (Equations V.3-6 and V.3-15) gave a good fit to the data for this catalyst as well. The FT kinetic model proposed by Huff and Satterfield (1984a) was the best for the $100 \mathrm{Fe} / 0.3 \mathrm{Cu} / 0.5 \mathrm{~K}$ catalyst (Run SB-07-0458). Activation energies based on the first order rate constants were estimated to be approximately $86 \mathrm{~kJ} / \mathrm{mol}$ for the 100 $\mathrm{Fe} / 0.3 \mathrm{Cu} / 0.2 \mathrm{~K}$ and Ruhrchemie catalysts, and $102 \mathrm{~kJ} / \mathrm{mol}$ for the $100 \mathrm{Fe} / 0.3 \mathrm{Cu} / 0.5 \mathrm{~K}$ catalyst. These estimates are in agreement with the range of activation energies reported in the literature, $80-103 \mathrm{~kJ} / \mathrm{mol}$.

The kinetics of the WGS reaction were also studied. Simple first order in CO kinetics (Equation V.3-25) was tested, and this simple model gave the best fit to the data from the $100 \mathrm{Fe} / 0.3 \mathrm{Cu} / 0.5 \mathrm{~K}, 100 \mathrm{Fe} / 5.0 \mathrm{Cu} / 4.2 \mathrm{~K} / 24 \mathrm{SiO}_{2}$ and Ruhrchemie catalysts. For the 100 $\mathrm{Fe} / 0.3 \mathrm{Cu} / 0.2 \mathrm{~K}$ catalyst, the best WGS kinetic model was given by Equation V.3-30, which contained mass action kinetics in the numerator and the denominator proposed by Huff and Satterfield from FT kinetics. The activation energies based on the first order in $\mathrm{CO}$ rate constants for the WGS reaction were $132-136 \mathrm{~kJ} / \mathrm{mol}$ for the $100 \mathrm{Fe} / 0.3 \mathrm{Cu} / 0.2 \mathrm{~K}, 100$ $\mathrm{Fe} / 0.3 \mathrm{Cu} / 0.5 \mathrm{~K}$ and Ruhrchemie catalysts. 


\section{NOMENCLATURE}

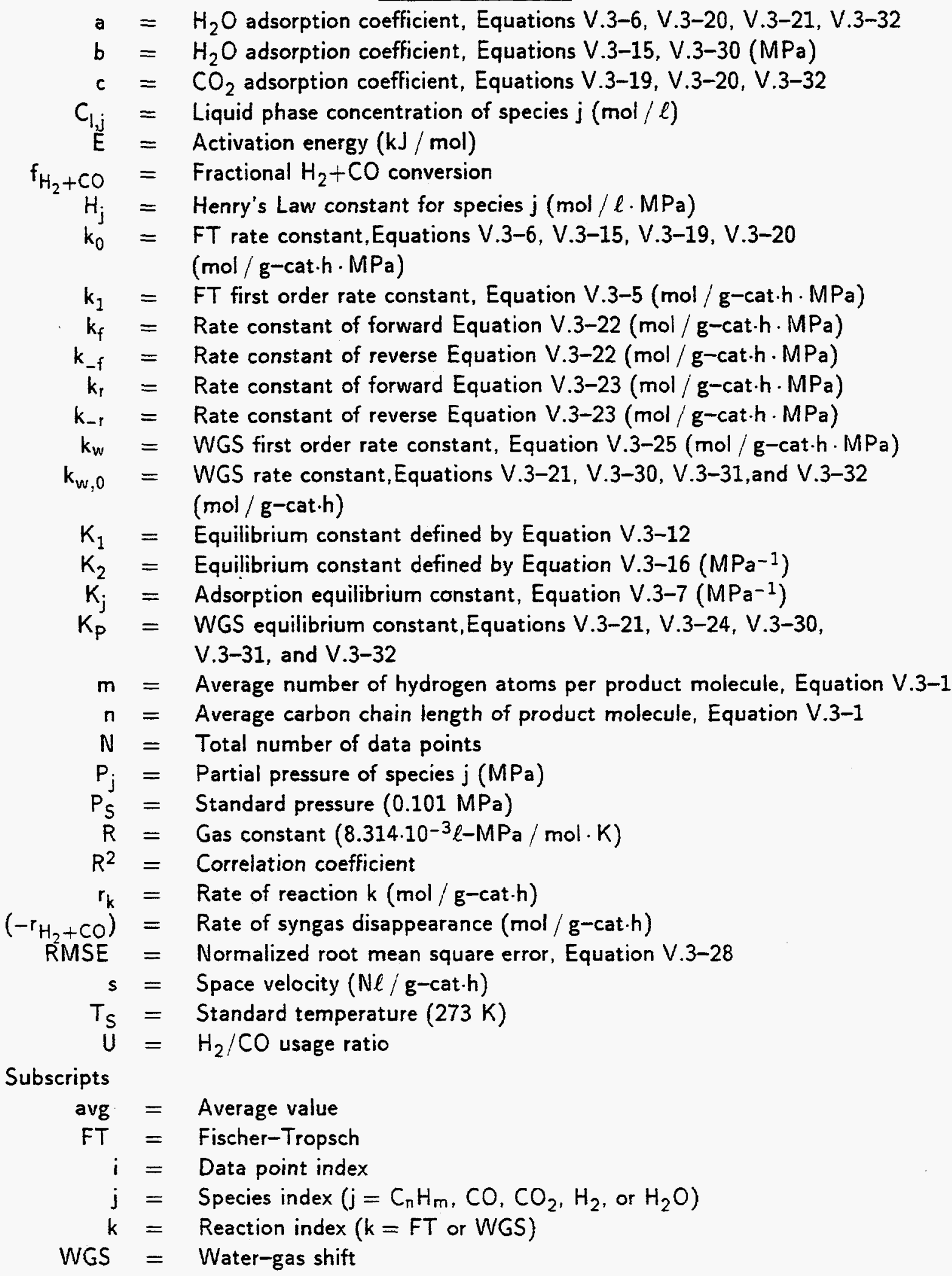




\section{Superscripts \\ calc $=$ Calculated value \\ $d=$ Dissociative adsorption \\ meas $=$ Measured value}




\section{V.4. Binder / Support Effect Research}

Supported catalyst systems with high support-to-metal ratios have not been overly effective in yielding good Fischer-Tropsch synthesis performance. In the slurry phase process, supported catalysts reduce the bulk concentration of metal and thus may hinder mass transfer from gas to liquid as solids loadings are increased to maintain metal concentrations. On the other hand, supported systems may actually increase the concentration of active metal sites by maintaining higher metal dispersions. The nature of the support is also important, since acidic sites on the support can render basic promoters like potassium ineffective, preventing interaction between promoter and metal. Previous work at SASOL (Dry, 1981) in fixed bed reactors, examined the effects of promoters and supports on the performance of Ruhrchemietype precipitated $\mathrm{Fe}$ catalysts. In one set of experiments, a series of $\mathrm{Fe} / \mathrm{Cu} / \mathrm{K}_{2} \mathrm{O}$ precipitates was prepared using $\mathrm{Cr}_{2} \mathrm{O}_{3}, \mathrm{MgO}, \mathrm{Al}_{2} \mathrm{O}_{3}$ or $\mathrm{ZnO}$ in place of silica. None of these catalysts was as active as the standard $\mathrm{SiO}_{2}$ - containing material. An unsupported composition was also less active. Compositions containing both $\mathrm{SiO}_{2}$ and a second support material also showed lower performance. Of all the supports, small amounts of added $\mathrm{Al}_{2} \mathrm{O}_{3}$ resulted in the lowest wax selectivity without excessive deactivation. This concept could be used to control selectivity to some extent.

In our study we have used the Ruhrchemie-type catalyst with the nominal composition of $100 \mathrm{Fe} / 5 \mathrm{Cu} / 4.2 \mathrm{~K} / 24 \mathrm{SiO}_{2}$ as the base case, and then varied amounts of silica $(0,8$ and 100 parts of $\mathrm{SiO}_{2}$ per 100 parts of iron) while keeping promoter levels constant. Also, we synthesized two catalysts containing alumina in place of silica as binder ( 8 and 20 parts $\mathrm{Al}_{2} \mathrm{O}_{3} / 100$ parts $\mathrm{Fe}$ ). The impregnation technique used to prepare the alumina-containing catalysts was limited to a maximum concentration of about 30 parts $\mathrm{Al}_{2} \mathrm{O}_{3} / 100$ parts $\mathrm{Fe}$, so a catalyst with high alumina concentration (i.e., 100 parts) was not available for testing. $A$ sample of commercial Ruhrchemie catalyst, designated LP 33/81, was made available to us through Dr. Cornelius Frohning of Ruhrchemie. This catalyst was used originally at SASOL's fixed bed (ARGE) reactors and its average composition (as per Dr. Frohning) is : $100 \mathrm{Fe} / 4.3$ $\mathrm{Cu} / 4.1 \mathrm{~K} / 25 \mathrm{SiO}_{2}$. Professor Satterfield of M.I.T. has also obtained a sample of Ruhrchemie catalyst and has reported the following composition, determined by Galbraith Laboratories: $100 \mathrm{Fe} / 5 \mathrm{Cu} / 4.1 \mathrm{~K} / 27 \mathrm{SiO}_{2}$ (Satterfield, 1988; Donnelly and Satterfield, 1989). Both of these compositions are similar to that reported by Dry (1981, p.176) for the Ruhrchemie catalyst. The actual composition of our baseline catalyst $\left(100 \mathrm{Fe} / 5.4 \mathrm{Cu} / 4.6 \mathrm{~K} / 28 \mathrm{SiO}_{2}\right)$ is similar to 
that of the Ruhrchemie catalyst.

Catalytic tests were conducted in fixed bed reactors, at different process conditions (Table V.4-1) using synthesis gas with an $\mathrm{H}_{2}: \mathrm{CO}$ molar ratio of about 1 . Approximately $3.5 \mathrm{~g}$ of calcined catalyst was crushed to $30 / 60$ mesh, and mixed with glass beads (1:7 volume ratio, catalyst:inert particles) of the same mesh size range before loading the reactor. All catalysts were activated with $\mathrm{CO}$ at $280^{\circ} \mathrm{C}$ and atmospheric pressure for 12 hours. The first mass balance was conducted after about 40 hours on stream at operating conditions.

\section{V.4.1. Results and Discussion}

A summary of the selectivity and activity results is given in Table V.4-2 for the three silicacontaining catalysts (Runs FA-63-0418, FA-66-0548, and FA-69-0668), the two aluminacontaining catalysts (Runs FA-73-0828, and FA-76-0968), the unsupported catalyst using supported catalyst promoter levels (Run FA-31-1118), and the calcined Ruhrchemie LP 33/81 catalyst (Run FB-99-1348).

Catalyst activity, as measured by $\left(\mathrm{H}_{2}+\mathrm{CO}\right)$ conversion, decreases as the binder concentration increases (Figure V.4-1). The 8 parts $\mathrm{SiO}_{2}$ and the unsupported catalysts had the highest activities, and on a per $\mathrm{Fe}$ basis, gave essentially the same $\left(\mathrm{H}_{2}+\mathrm{CO}\right)$ conversions. The 8 parts $\mathrm{Al}_{2} \mathrm{O}_{3}$ catalyst also had high activity. The similarity in conversions for the unsupported and 8 parts supported catalysts show that the high activity is not due to surface area alone. The very high potassium concentrations are responsible for the increase in catalyst activity over previous unsupported catalyst tests. While the BET surface areas of the reduced $\mathrm{SiO}_{2}$-containing catalysts increase from 94,148 , and $250 \mathrm{~m}^{2} / \mathrm{g}$ at 8,25 , and 100 parts $\mathrm{SiO}_{2} / 100$ parts $\mathrm{Fe}$, the $\left(\mathrm{H}_{2}+\mathrm{CO}\right)$ conversions decrease at all conditions tested. The unsupported catalyst has a BET surface area of $38 \mathrm{~m}^{2} / \mathrm{g}$. The increased BET surface areas are caused by the addition of high surface area binder, and do not necessarily reflect a large increase in active metal surface area. Our measurements by $\mathrm{H}_{2}$ temperature programmed desorption showed that the fractional metal exposures of $\mathrm{CO}$ reduced, silica-containing catalysts are the same as for unsupported catalysts $(\sim 2.3 \%)$, thus crystallite size is constant. When alumina is added to the catalyst, the exposure roughly doubles. Egiebor and Cooper (1985) measured the BET surface areas of both fresh and used silica supported catalysts, with compositions of $100 \mathrm{Fe} / 4.2 \mathrm{Cu} / 6.7 \mathrm{~K}$ with 21,50 , and 73 parts $\mathrm{SiO}_{2}$. Prior to use, these catalysts had surface areas of 151,252 , and $275 \mathrm{~m}^{2} / \mathrm{g}$, which agree with our values, but after use the surface areas decreased to 71,17 and $28 \mathrm{~m}^{2} / \mathrm{g}$, respectively. The authors attributed the decrease in surface areas to carbon deposition on the 
Table V.4-1. Summary of fixed bed tests and testing conditons for binder/support reseach. ${ }^{a}$

\begin{tabular}{|c|c|c|c|c|c|c|c|}
\hline Test ID & Catalyst & $\begin{array}{c}220^{\circ} \mathrm{C} \\
1.48 \mathrm{MPa} \\
2 \mathrm{NI} / \mathrm{g} \text {-cat.h }\end{array}$ & $\begin{array}{c}235^{\circ} \mathrm{C} \\
1.48 \mathrm{MPa} \\
2 \mathrm{~N} 1 / \mathrm{g} \text {-cat.h } \\
\end{array}$ & $\begin{array}{c}235^{\circ} \mathrm{C} \\
1.48 \mathrm{MPa} \\
4 \mathrm{Nl} / \mathrm{g} \text {-cat.h } \\
\end{array}$ & $\begin{array}{c}250^{\circ} \mathrm{C} \\
1.48 \mathrm{MPa} \\
2 \mathrm{NI} / \mathrm{g} \text {-cat.h } \\
\end{array}$ & $\begin{array}{c}250^{\circ} \mathrm{C} \\
1.48 \mathrm{MPa} \\
4 \mathrm{~N} 1 / \mathrm{g} \text {-cat. } \mathrm{h}\end{array}$ & $\begin{array}{c}235^{\circ} \mathrm{C} \\
2.86 \mathrm{MPa} \\
4 \mathrm{NI} / \mathrm{g} \text {-cat. } \mathrm{l}\end{array}$ \\
\hline FA-31-1118 & $100 / 5 / 4.2$ & $120(4)$ & $48(1), 144(5)^{b}$ & $72(2)$ & & $95(3)$ & $169(6)^{b}$ \\
\hline FA-63-0418 & $100 / 5 / 4.2 / 8 \mathrm{SiO}_{2}$ & $121(4)$ & $46(1), 169(6)^{b}$ & $72(2)$ & & $96(3)$ & $145(5)^{b}$ \\
\hline FA-66-0548 & $100 / 5 / 4.2 / 25 \mathrm{SiO}_{2}$ & $120(4)$ & $40(1)$ & $73(2)$ & $96(3)$ & & $145(5)^{b}$ \\
\hline FB-99-1348 & Ruhrchemie LP 33/81 & $144(5)$ & $48(1), 96(3)$ & $72(2)$ & $114(4)$ & & $169(6)^{b}$ \\
\hline FA-69-0668 & $100 / 5 / 4.2 / 100 \mathrm{SiO}_{2}$ & $119(4)$ & $41(1), 143(5)^{b}$ & $72(2)$ & $96(3)$ & & $169(6)^{b}$ \\
\hline FA-73-0828 & $100 / 5 / 4.2 / 8 \mathrm{Al}_{2} \mathrm{O}_{3}$ & $119(4)$ & $48(1), 144(5)^{b}$ & $72(2)$ & & $96(3)$ & $168(6)^{b}$ \\
\hline FA-76-0968 & $100 / 5 / 4.2 / 20 \mathrm{Al}_{2} \mathrm{O}_{3}$ & $120(4)$ & $48(1), 144(5)^{6}$ & $72(2)$ & $96(3)$ & & $168(6)^{b}$ \\
\hline
\end{tabular}

a Time on stream, h (balance period) are indicated; $\mathrm{H}_{2} / \mathrm{CO}=1$ for all tests

${ }^{\circ}$ Catalyst had partially deactivated 
Table V.4-2 Summary of Binder / Support Cal.alysts Tests

\begin{tabular}{|c|c|c|c|c|c|c|c|c|c|c|c|c|c|c|c|}
\hline \multirow[b]{2}{*}{ Catalyst } & \multirow[b]{2}{*}{ Aun } & \multirow[b]{2}{*}{ Bal } & \multirow[b]{2}{*}{$\operatorname{TOS}(h)$} & \multicolumn{4}{|c|}{ Conditions } & \multicolumn{4}{|c|}{$\%$ Conversion } & \multicolumn{4}{|c|}{ Wt \% Hydrocarbons } \\
\hline & & & & $\mathrm{T}\left({ }^{\circ} \mathrm{C}\right)$ & $\mathrm{P}(\mathrm{MPa})$ & $s V^{a}$ & $\mathrm{II}_{2} / \mathrm{CO}$ & STY ${ }^{b}$ & $(\circ)$ & $\mathrm{H}_{2}+\mathrm{CO}$ & Usage & $\mathrm{CH}_{4}$ & $\mathrm{C}_{2}-\mathrm{C}_{4}$ & $\mathrm{C}_{5}-\mathrm{C}_{11}$ & $\left(i_{12}\right)$ \\
\hline $100 \mathrm{Fe} / 5 \mathrm{Cu} / 4.2 \mathrm{~K}$ & FA-31-1118 & $\begin{array}{c}1 \\
2 \\
3 \\
4^{c} \\
5^{c} \\
6^{c} \\
\end{array}$ & $\begin{array}{c}47.5 \\
71.5 \\
94.5 \\
119.8 \\
143.7 \\
168.5 \\
\end{array}$ & $\begin{array}{l}235 \\
235 \\
250 \\
220 \\
235 \\
235 \\
\end{array}$ & $\begin{array}{l}1.48 \\
1.48 \\
1.48 \\
1.48 \\
1.48 \\
3.00 \\
\end{array}$ & $\begin{array}{l}2.00 \\
3.99 \\
3.99 \\
1.99 \\
1.99 \\
3.99 \\
\end{array}$ & $\begin{array}{l}1.03 \\
1.03 \\
1.03 \\
1.03 \\
1.03 \\
1.03 \\
\end{array}$ & $\begin{array}{l}0.070 \\
0.097 \\
0.116 \\
0.029 \\
0.042 \\
0.091 \\
\end{array}$ & $\begin{array}{l}93.6 \\
65.6 \\
78.8 \\
37.3 \\
54.7 \\
55.6 \\
\end{array}$ & $\begin{array}{l}78.3 \\
54.8 \\
65.4 \\
33.0 \\
47.2 \\
51.3 \\
\end{array}$ & $\begin{array}{l}0.70 \\
0.69 \\
0.69 \\
0.80 \\
0.75 \\
0.87 \\
\end{array}$ & $\begin{array}{l}6.4 \\
4.8 \\
5.8 \\
5.7 \\
6.0 \\
4.6 \\
\end{array}$ & $\begin{array}{l}21.8 \\
19.2 \\
22.3 \\
23.6 \\
23.6 \\
23.1 \\
\end{array}$ & $\begin{array}{l}22.2 \\
19.2 \\
22.0 \\
23.2 \\
24.4 \\
19.5 \\
\end{array}$ & $\begin{array}{l}49.6 \\
56.8 \\
49.9 \\
47.5 \\
46.0 \\
52.8 \\
\end{array}$ \\
\hline $100 \mathrm{Fe} / 5 \mathrm{Cu} / 4.2 \mathrm{~K} / 8 \mathrm{SiO}_{2}$ & FA-63-0418 & $\begin{array}{l}1 \\
2 \\
3 \\
4 \\
5^{r} \\
6^{c} \\
\end{array}$ & $\begin{array}{r}49.0 \\
72.0 \\
96.0 \\
121.0 \\
145.0 \\
169.0 \\
\end{array}$ & $\begin{array}{l}235 \\
235 \\
250 \\
220 \\
235 \\
235 \\
\end{array}$ & $\begin{array}{l}1.48 \\
1.48 \\
1.48 \\
1.48 \\
3.00 \\
1.48 \\
\end{array}$ & $\begin{array}{l}2.00 \\
4.01 \\
4.01 \\
2.00 \\
4.01 \\
2.00 \\
\end{array}$ & $\begin{array}{l}1.10 \\
1.10 \\
1.10 \\
1.10 \\
1.10 \\
1.10 \\
\end{array}$ & $\begin{array}{l}0.069 \\
0.094 \\
0.116 \\
0.055 \\
0.076 \\
0.040 \\
\end{array}$ & $\begin{array}{l}93.8 \\
64.5 \\
80.5 \\
73.6 \\
46.4 \\
52.9 \\
\end{array}$ & $\begin{array}{l}76.7 \\
52.8 \\
65.1 \\
62.1 \\
42.7 \\
44.8 \\
\end{array}$ & $\begin{array}{l}0.71 \\
0.71 \\
0.70 \\
0.77 \\
0.93 \\
0.78 \\
\end{array}$ & $\begin{array}{l}3.5 \\
3.2 \\
3.7 \\
2.8 \\
2.8 \\
3.4 \\
\end{array}$ & $\begin{array}{l}16.4 \\
16.9 \\
16.0 \\
16.0 \\
17.5 \\
18.8 \\
\end{array}$ & $\begin{array}{l}20.1 \\
20.3 \\
12.4 \\
15.4 \\
16.7 \\
16.5 \\
\end{array}$ & $\begin{array}{l}60.0 \\
59.6 \\
67.9 \\
65.8 \\
63.0 \\
61.3 \\
\end{array}$ \\
\hline $100 \mathrm{Fe} / 5 \mathrm{Cu} / 4.2 \mathrm{~K} / 25 \mathrm{SiO}_{2}$ & $F A-66-0548$ & $\begin{array}{l}1 \\
2 \\
3 \\
4 \\
5 \\
\end{array}$ & $\begin{array}{c}40.0 \\
72.5 \\
95.5 \\
120.0 \\
144.5 \\
\end{array}$ & $\begin{array}{l}234 \\
235 \\
250 \\
220 \\
235 \\
\end{array}$ & $\begin{array}{l}1.48 \\
1.48 \\
1.48 \\
1.48 \\
2.96 \\
\end{array}$ & $\begin{array}{l}2.00 \\
4.01 \\
2.01 \\
2.01 \\
4.01 \\
\end{array}$ & $\begin{array}{l}1.00 \\
1.00 \\
1.00 \\
1.00 \\
1.00 \\
\end{array}$ & $\begin{array}{l}0.049 \\
0.069 \\
0.061 \\
0.028 \\
0.086 \\
\end{array}$ & $\begin{array}{l}59.6 \\
39.4 \\
78.2 \\
29.7 \\
49.5 \\
\end{array}$ & $\begin{array}{l}55.0 \\
38.5 \\
67.6 \\
31.1 \\
48.1 \\
\end{array}$ & $\begin{array}{l}0.85 \\
0.95 \\
0.73 \\
1.09 \\
0.94 \\
\end{array}$ & $\begin{array}{l}5.7 \\
5.0 \\
8.1 \\
4.8 \\
4.0 \\
\end{array}$ & $\begin{array}{l}22.7 \\
22.4 \\
30.0 \\
23.2 \\
22.8 \\
\end{array}$ & $\begin{array}{l}15.2 \\
17.7 \\
19.9 \\
20.7 \\
15.5 \\
\end{array}$ & $\begin{array}{l}56.4 \\
54.9 \\
42.0 \\
51.3 \\
57.7 \\
\end{array}$ \\
\hline $100 \mathrm{Fe} / 5 \mathrm{Cu} / 4.2 \mathrm{~K} / 100 \mathrm{SiO}_{2}$ & FA-69-0668 & $\begin{array}{l}1 \\
2 \\
3 \\
4 \\
5 \\
6 \\
\end{array}$ & $\begin{array}{c}40.5 \\
72.0 \\
96.0 \\
119.0 \\
143.0 \\
169.0 \\
\end{array}$ & $\begin{array}{l}234 \\
235 \\
250 \\
220 \\
235 \\
235 \\
\end{array}$ & $\begin{array}{l}1.48 \\
1.48 \\
1.48 \\
1.48 \\
1.48 \\
2.96 \\
\end{array}$ & $\begin{array}{l}1.99 \\
3.99 \\
1.99 \\
2.01 \\
1.99 \\
3.99 \\
\end{array}$ & $\begin{array}{l}1.00 \\
1.00 \\
1.00 \\
1.00 \\
1.00 \\
1.00 \\
\end{array}$ & $\begin{array}{l}0.026 \\
0.039 \\
0.031 \\
0.014 \\
0.023 \\
0.052 \\
\end{array}$ & $\begin{array}{l}24.3 \\
17.5 \\
30.8 \\
11.3 \\
20.1 \\
22.4 \\
\end{array}$ & $\begin{array}{l}29.1 \\
22.0 \\
35.2 \\
15.8 \\
25.7 \\
29.4 \\
\end{array}$ & $\begin{array}{l}1.39 \\
1.51 \\
1.29 \\
1.79 \\
1.56 \\
1.63 \\
\end{array}$ & $\begin{array}{l}5.2 \\
4.4 \\
5.8 \\
4.5 \\
5.2 \\
4.5 \\
\end{array}$ & $\begin{array}{l}17.2 \\
14.9 \\
18.6 \\
15.8 \\
16.8 \\
15.6 \\
\end{array}$ & $\begin{array}{l}20.4 \\
16.5 \\
25.9 \\
18.3 \\
18.5 \\
15.5 \\
\end{array}$ & $\begin{array}{l}57.2 \\
64.2 \\
49.7 \\
61.4 \\
59.5 \\
64.4 \\
\end{array}$ \\
\hline $100 \mathrm{Fe} / 5 \mathrm{Cu} / 4.2 \mathrm{~K} / 8 \mathrm{Al}_{2} \mathrm{O}_{3}$ & FA-73-0828 & $\begin{array}{r}1 \\
2 \\
3 \\
4 \\
5^{c} \\
6^{c} \\
\end{array}$ & $\begin{array}{c}47.5 \\
72.0 \\
96.0 \\
118.5 \\
143.5 \\
168.0 \\
\end{array}$ & $\begin{array}{l}235 \\
234 \\
250 \\
220 \\
235 \\
235 \\
\end{array}$ & $\begin{array}{l}1.48 \\
1.48 \\
1.48 \\
1.48 \\
1.48 \\
2.96 \\
\end{array}$ & $\begin{array}{l}2.01 \\
4.02 \\
4.02 \\
2.01 \\
2.01 \\
4.01 \\
\end{array}$ & $\begin{array}{l}1.00 \\
1.00 \\
1.00 \\
1.00 \\
1.00 \\
1.010 \\
\end{array}$ & $\begin{array}{l}0.067 \\
0.084 \\
0.104 \\
0.028 \\
0.038 \\
0.071 \\
\end{array}$ & $\begin{array}{l}90.3 \\
56.0 \\
69.8 \\
36.9 \\
51 . .8 \\
12.2 \\
\end{array}$ & $\begin{array}{l}75.1 \\
47.0 \\
57.8 \\
31.7 \\
42.1 \\
41.11 \\
\end{array}$ & $\begin{array}{l}0.66 \\
0.68 \\
0.66 \\
0.72 \\
0.69 \\
0.40 \\
\end{array}$ & $\begin{array}{l}4.8 \\
4.2 \\
4.9 \\
4.1 \\
4.9 \\
4.6 \\
\end{array}$ & $\begin{array}{l}18.4 \\
17.4 \\
19.2 \\
17.9 \\
19.6 \\
21.9 \\
\end{array}$ & $\begin{array}{l}19.3 \\
18.4 \\
20.2 \\
18.9 \\
18.3 \\
19.3 \\
\end{array}$ & $\begin{array}{l}57.5 \\
60.0 \\
55.7 \\
59.1 \\
57.2 \\
54.2 \\
\end{array}$ \\
\hline $100 \mathrm{Fe} / 5 \mathrm{Cu} / 4.2 \mathrm{~K} / 20 \mathrm{Al}_{2} \mathrm{O}_{3}$ & FA-76-0968 & $\begin{array}{c}1 \\
2 \\
3 \\
4 \\
5^{c} \\
6^{c} \\
\end{array}$ & $\begin{array}{c}47.5 \\
71.8 \\
95.5 \\
120.0 \\
143.5 \\
168.0 \\
\end{array}$ & $\begin{array}{l}235 \\
235 \\
250 \\
220 \\
235 \\
235 \\
\end{array}$ & $\begin{array}{l}1.48 \\
1.48 \\
1.48 \\
1.48 \\
1.48 \\
3.00 \\
\end{array}$ & $\begin{array}{l}2.03 \\
4.03 \\
2.03 \\
2.03 \\
2.03 \\
4.03 \\
\end{array}$ & $\begin{array}{l}1.00 \\
1.00 \\
1.00 \\
1.00 \\
1.00 \\
1.00 \\
\end{array}$ & $\begin{array}{l}0.062 \\
0.063 \\
0.066 \\
0.020 \\
0.028 \\
0.055 \\
\end{array}$ & $\begin{array}{l}82.2 \\
41.2 \\
88.8 \\
24.7 \\
37.1 \\
33.0 \\
\end{array}$ & $\begin{array}{l}68.3 \\
35.3 \\
73.4 \\
22.1 \\
31.5 \\
30.5 \\
\end{array}$ & $\begin{array}{l}0.66 \\
0.71 \\
0.65 \\
0.79 \\
0.70 \\
0.87 \\
\end{array}$ & $\begin{array}{l}3.6 \\
3.7 \\
4.8 \\
4.0 \\
5.1 \\
4.8\end{array}$ & $\begin{array}{l}16.7 \\
16.9 \\
21.0 \\
19.5 \\
21.5 \\
21.9\end{array}$ & $\begin{array}{l}19.2 \\
17.4 \\
21.5 \\
21.8 \\
20.2 \\
19.2\end{array}$ & $\begin{array}{l}60.5 \\
62.0 \\
52.7 \\
54.7 \\
53.2 \\
54.1\end{array}$ \\
\hline $\begin{array}{c}\text { Ruhrchemie LP 33/81 } \\
\left(100 \mathrm{Fe} / 5 \mathrm{Cu} / 4.2 \mathrm{~K} / 24 \mathrm{SiO}_{2}\right)\end{array}$ & FB-99-1348 & $\begin{array}{l}2 \\
3 \\
4 \\
5^{c} \\
6^{e} \\
\end{array}$ & $\begin{array}{c}48.0 \\
96.0 \\
120.0 \\
144.0 \\
168.5 \\
\end{array}$ & $\begin{array}{l}235 \\
234 \\
250 \\
220 \\
235 \\
\end{array}$ & $\begin{array}{l}1.48 \\
1.48 \\
1.48 \\
1.48 \\
2.96 \\
\end{array}$ & $\begin{array}{l}4.06 \\
1.99 \\
1.99 \\
1.99 \\
3.99 \\
\end{array}$ & $\begin{array}{l}0.98 \\
0.98 \\
0.98 \\
0.98 \\
0.98 \\
\end{array}$ & $\begin{array}{l}0.061 \\
0.044 \\
0.054 \\
0.023 \\
0.065 \\
\end{array}$ & $\begin{array}{l}30.8 \\
46.9 \\
64.5 \\
22.9 \\
33.4 \\
\end{array}$ & $\begin{array}{l}33.8 \\
49.1 \\
60.3 \\
25.9 \\
36.7 \\
\end{array}$ & $\begin{array}{l}1.18 \\
1.07 \\
0.85 \\
1.24 \\
1.17 \\
\end{array}$ & $\begin{array}{l}3.8 \\
4.3 \\
5.3 \\
4.7 \\
3.9\end{array}$ & $\begin{array}{l}14.5 \\
17.6 \\
20.8 \\
18.8 \\
17.1\end{array}$ & $\begin{array}{l}17.1 \\
17.0 \\
19.2 \\
19.6 \\
16.1\end{array}$ & $\begin{array}{l}64.6 \\
61.1 \\
51.7 \\
56.9 \\
62.9\end{array}$ \\
\hline
\end{tabular}

aSpace Velocity (SV) | $=\mid N I / g-$ cat $\cdot h$

${ }^{b}$ Space Time Yield (STY) $|=|$ mols $\left(\mathrm{H}_{2}+\mathrm{CO}\right) / g$-cal $\cdot h \quad$ 'Balance made with partially deactivaled calalyst 




Figure V.4-1 Comparison of $\left(\mathrm{H}_{2}+\mathrm{CO}\right)$ conversions for the binder/support catalysts and Ruhrehemie LP 33/81: $250^{\circ} \mathrm{C}, 1.48 \mathrm{MPa},\left(\mathrm{H}_{2} / \mathrm{CO}\right)=1.0$. 
catalyst during synthesis. Wax accumulation in catalyst pores may also contribute to low used catalyst surface areas. The high surface area catalysts have smaller pore diameters, increasing intraparticle diffusional limitations. Also, the catalysts with high support concentrations show stronger resistance to reduction and may not be fully activated.

The increase in silica concentration improves catalyst stability as can be seen from Table V.4-3. In this table, values of $\left(\mathrm{H}_{2}+\mathrm{CO}\right)$ conversion obtained at the baseline conditions in the early part of the test (40-49 h) and near the end of the test (143-169 h on stream) are listed. Between these two periods of time the process conditions were varied. Catalysts containing 25 and 100 parts of $\mathrm{SiO}_{2}$ (per 100 parts of $\mathrm{Fe}$ ) had a rather small loss in activity, whereas the catalysts with 8 parts or less of a binder $\left(\mathrm{SiO}_{2}\right.$ or $\left.\mathrm{Al}_{2} \mathrm{O}_{3}\right)$ had a more significant loss in activity. Alumina containing catalysts were less stable than the corresponding silica containing catalysts.

The WGS activity, measured by $\mathrm{CO}_{2}$ selectivity (percent of $\mathrm{CO}$ converted to $\mathrm{CO}_{2}$ ), of different catalysts as a function of reaction temperature is shown in Figure V.4-2. The unsupported catalyst, the two alumina containing catalysts, and the catalyst containing 8 parts of $\mathrm{SiO}_{2}$ per 100 parts of $\mathrm{Fe}$ have high WGS activity even at low reaction temperatures (220 and $235^{\circ} \mathrm{C}$ ), whereas the catalysts with higher silica content $\left(25\right.$ or more parts of $\mathrm{SiO}_{2}$ per 100 parts of $\mathrm{Fe}$ ) have low WGS activity which increases with temperature. The lower WGS activity of the silica containing catalysts may be explained by the fact that silica reacts with the potassium and thereby reduces its promotional effect, i.e., the catalyst behaves as if it had a lower potassium loading (see Section V.2.1.3). Apparently, the interactions between the potassium and alumina were much weaker, and therefore there was no loss in the WGS activity with increase in the alumina concentration.

The weight $\%$ hydrocarbon distributions of the supported catalysts and Ruhrchemie LP $33 / 81$ (run FB-99-1348) are compared in Figs. V.4-3 $\left(235^{\circ} \mathrm{C}, 1.48 \mathrm{MPa}, 2 \mathrm{NI} / \mathrm{g}\right.$-cat.h) and V.4-4 $\left(250^{\circ} \mathrm{C}, 1.48 \mathrm{MPa}, 2\right.$ or $4 \mathrm{NI} / \mathrm{g}$-cat.h). The addition of a small amount of support ( 8 parts/100 parts $\mathrm{Fe}$ ) had a minor effect on conversion, but improved the selectivity by decreasing methane and $C_{2}-C_{4}$ formation. The calcined Ruhrchemie catalyst showed good $\mathrm{C}_{12}+$ selectivity as well. An increase in the alumina concentration from 8 to 20 parts/100 parts Fe had no significant effect on the hydrocarbon distribution at any of the conditions tested. The selectivity of the catalyst with 8 parts $\mathrm{SiO}_{2} / 100$ parts $\mathrm{Fe}$ was better than (low methane, high $\mathrm{C}_{12}+$ ) or comparable to the selectivities of all the supported catalysts, calcined 
'Iable V.4-3. Catalyst stability comparison - before and after process variable studies ${ }^{a}$

\begin{tabular}{|c|cc|cc|}
\hline Catalyst & $\begin{array}{c}\text { TOS } \\
(\mathrm{h})\end{array}$ & $\begin{array}{c}\text { \% Conversion } \\
\left(\mathrm{H}_{2}+\mathrm{CO}\right)\end{array}$ & $\begin{array}{c}\text { TOS } \\
(\mathrm{h})\end{array}$ & $\begin{array}{c}\text { \% Conversion } \\
\left(\mathrm{H}_{2}+\mathrm{CO}\right)\end{array}$ \\
\hline $100 \mathrm{Fe} / 5 \mathrm{Cu} / 4.2 \mathrm{~K}$ & 48 & 78.3 & 148 & 47.2 \\
$100 \mathrm{Fe} / 5 \mathrm{Cu} / 4.2 \mathrm{~K} / 8 \mathrm{SiO}_{2}$ & 49 & 76.7 & 169 & 44.8 \\
$100 \mathrm{Fe} / 5 \mathrm{Cu} / 4.2 \mathrm{~K} / 24 \mathrm{SiO}_{2}$ & 40 & 55.0 & $145^{b}$ & $48.1^{b}$ \\
$\mathrm{Ruhrchemie} \mathrm{LP} \mathrm{33/81}$ & 48 & 50.5 & $169^{b}$ & $31.0^{b}$ \\
$100 \mathrm{Fe} / 5 \mathrm{Cu} / 4.2 \mathrm{~K} / 100 \mathrm{SiO}_{2}$ & 41 & 29.1 & 143 & 25.7 \\
$100 \mathrm{Fe} / 5 \mathrm{Cu} / 4.2 \mathrm{~K} / 8 \mathrm{Al}_{2} \mathrm{O}_{3}$ & 48 & 75.1 & 144 & 42.9 \\
$100 \mathrm{Fe} / 5 \mathrm{Cu} / 4.2 \mathrm{~K} / 20 \mathrm{Al}_{2} \mathrm{O}_{3}$ & 48 & 68.3 & 144 & 31.5 \\
\hline
\end{tabular}

a tests made at $235^{\circ} \mathrm{C}, 200 \mathrm{psig}, \mathrm{SV}=2 \mathrm{Nl} / \mathrm{g}$-cat.h, $\left(\mathrm{II}_{2} / \mathrm{CO}\right)=1.0$

${ }^{b} \mathrm{SV}=4 \mathrm{NI} / \mathrm{g}$-cat.h, $\mathrm{P}=417 \mathrm{psig}$ for these tests 


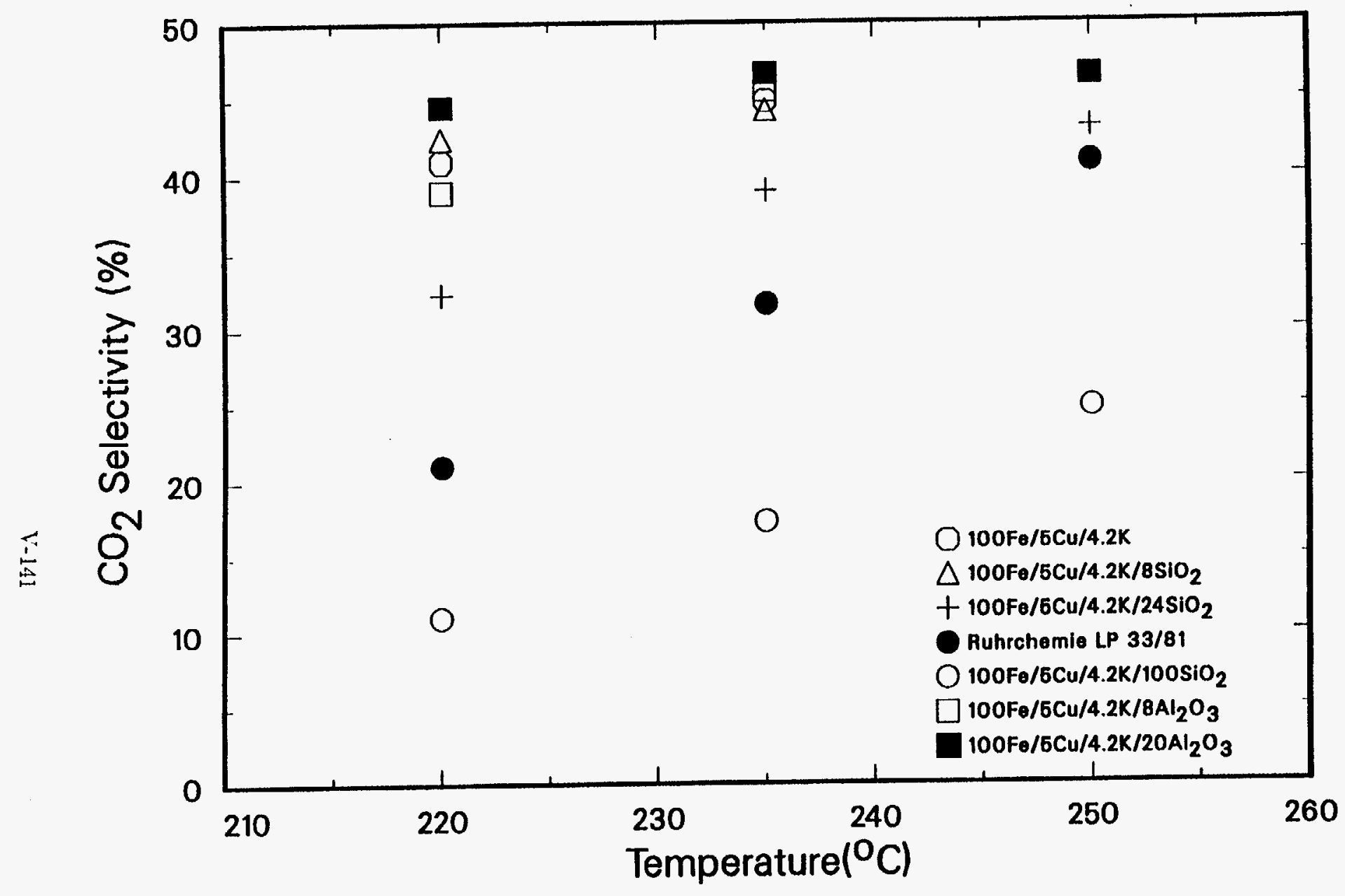

Figure V.4-2 Effect of Binder / Support and Jemperature on Water - Gas - Shift Aclivily (1.48 $\mathrm{MPa}, 2 \mathrm{NI} / \mathrm{g}$-cat.h, $\left.\mathrm{H}_{2} / \mathrm{CO}=1\right)$ 


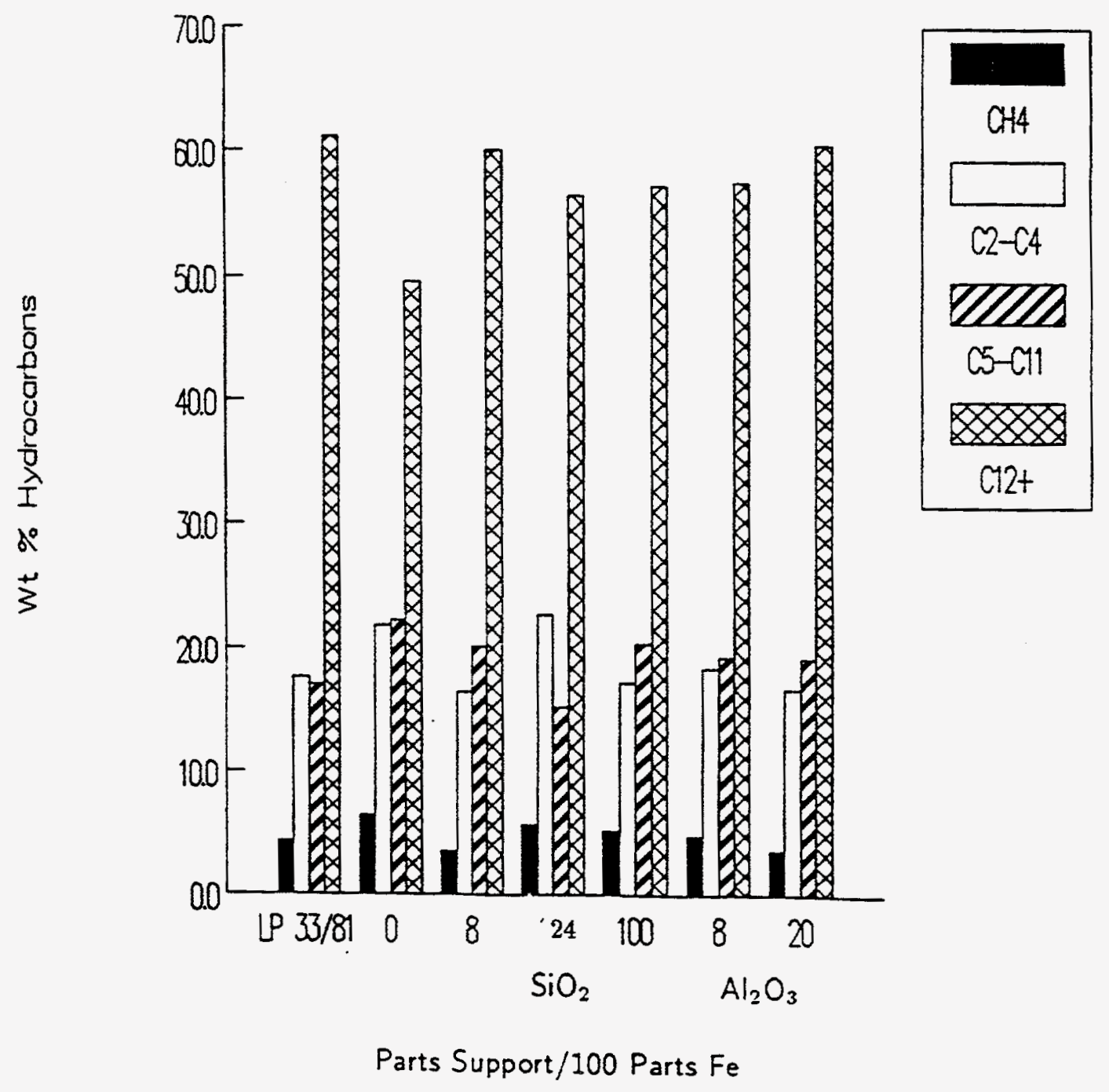

Figure V.43 Weight percent hydrocarbon distribution of binder/support catalysts and Ruhrchemie LP 33/81: $235{ }^{\circ} \mathrm{C}, 1.48 \mathrm{MPa}, 2 \mathrm{Nl} / \mathrm{g}$-cat $\cdot h,\left(\mathrm{H}_{2} / \mathrm{CO}\right)=1.0$. 


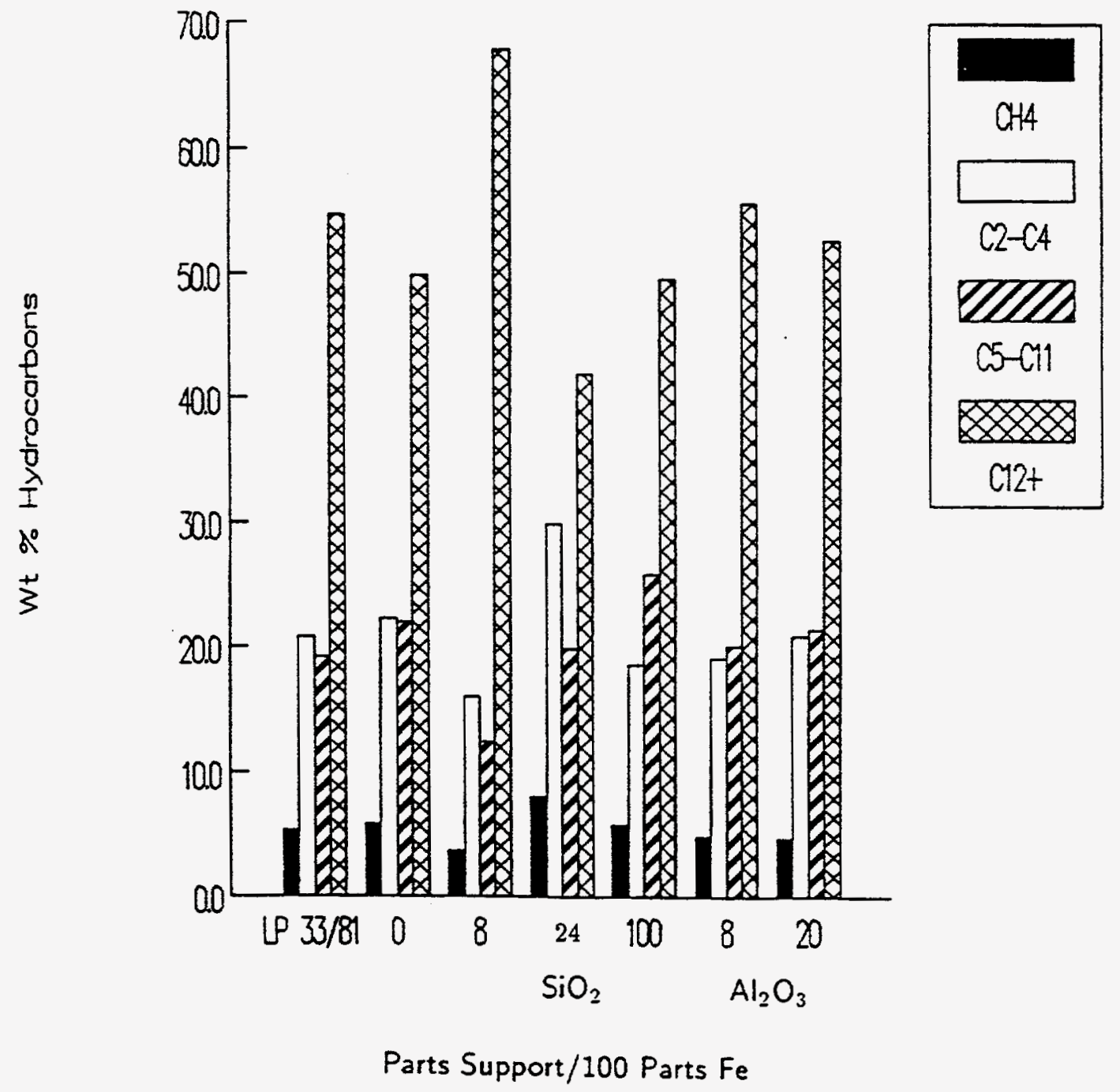

Figure V.4-4 Weight percent hydrocarbon distribution of binder/support catalysts and Ruhrchemie LP 33/81: $250^{\circ} \mathrm{C}, 1.48 \mathrm{MPa}, 2 \mathrm{Nl} / \mathrm{g}$-cat. $h,\left(\mathrm{H}_{2} / \mathrm{CO}\right)=1.0$. 
Ruhrchemie LP 33/81, and unsupported catalyst. This catalyst is also one of the most active of all the catalysts tested in our laboratory.

Our $100 \mathrm{Fe} / 5.4 \mathrm{Cu} / 4.6 \mathrm{~K} / 28 \mathrm{SiO}_{2}$ catalyst and the Ruhrchemie LP $33 / 81$ catalyst (100 $\mathrm{Fe} / 5 \mathrm{Cu} / 4.1 \mathrm{~K} / 27 \mathrm{SiO}_{2}$ ) have similar compositions, yet showed some differences in activity and selectivity at the same operating conditions. Our catalyst was more active than the Ruhrchemie catalyst, but produced more gaseous hydrocarbons. At $235^{\circ} \mathrm{C}, 2.0 \mathrm{NI} / \mathrm{g}$-cat.h, the $\left(\mathrm{H}_{2}+\mathrm{CO}\right)$ conversions were $55.0 \%$ for our catalyst and $49.1 \%$ for the Ruhrchemie catalyst, while the methane was 5.7 and $4.3 \%$ and the $C_{2}-C_{4}$ was 22.7 and $17.6 \%$, respectively. Similar differences were present at other conditions, as shown in Table V.4-2. The 24 parts $\mathrm{SiO}_{2}$ catalyst was also somewhat more selective towards lighter products than either of our 8 or 100 parts $\mathrm{SiO}_{2}$ catalysts, regardless of differences in catalyst activity. Alumina containing catalysts had hydrocarbon selectivities similar to that of the silica containing catalysts. In general, they produced less $\mathrm{CH}_{4}$ and $\mathrm{C}_{2}-\mathrm{C}_{4}$ hydrocarbons than the unsupported catalyst.

Dry (1981) discusses the results obtained at SASOL with supported catalysts. It is not possible to make quantitative comparisons between our work and SASOL, as Dry reports only relative values for potassium content, activity and hard wax selectivity, but some qualitative comparisons can be made. Using an $\mathrm{Fe} / \mathrm{Cu}$ catalyst containing a relative $\mathrm{K}_{2} \mathrm{O}$ concentration of 10 with 24 parts $\mathrm{SiO}_{2} / 100$ parts $\mathrm{Fe}$ (by weight), he reported a relative activity of 45 and a relative hard wax selectivity (i.e., high molecular weight products) of 34 . This was the most active catalysts of the series reported and had the highest hard wax selectivity. With an alumina supported catalyst $\left(100\right.$ parts $\left.\mathrm{Al}_{2} \mathrm{O}_{3}\right)$ with a similar potassium loading (12), the activity decreased to 18 while the hard wax selectivity remained constant. With a second alumina catalyst, containing 23 parts $\mathrm{Al}_{2} \mathrm{O}_{3}$ and a potassium level of 3 , activity increased to 35 and hard wax selectivity decreased to 10 . Since higher potassium loading should increase activity at the levels reported, the decrease in activity with 23 and 100 parts $\mathrm{Al}_{2} \mathrm{O}_{3}$ can be attributed to the increase in support concentration, which is what we have observed for both alumina and silica supported catalysts. (Dry shows that high potassium concentrations, above 12, cause decreases in activity for $\mathrm{SiO}_{2}$ supported iron). The decrease in hard wax selectivity is due to the change in potassium loading.

The work of Egiebor and Cooper (1985) with $100 \mathrm{Fe} / 4.2 \mathrm{Cu} / 6.7 \mathrm{~K}$ and 21,50 , and 73 parts $\mathrm{SiO}_{2}$ catalysts can also be compared to our results. They did not report their hydrocarbon distribution per se, but they noticed that the $C_{5}-C_{11}$ fraction remained constant regardless 
of support concentration at a fixed set of conditions $\left(300^{\circ} \mathrm{C}, 0.71 \mathrm{MPa}, \mathrm{H}_{2} / \mathrm{CO}=1.0,240\right.$ $\mathrm{h}^{-1}$ ) and was $40-50$ weight $\%$ of the total condensed products. They found that the reactant conversions changed only slightly as the support concentration increased, with no significant difference between the three catalysts, which is not what we have experienced in our studies of supported catalysts.

\section{V.4.2. Summary}

Major findings from binder/ support studies are summarized below.

(1) The FT activity of silica (or alumina) containing catalysts decreased with increasing concentration of binder.

(2) The addition of binder improved catalyst stability (lower rate of deactivation).

(3) The WGS activity decreased with the addition of silica due to its interaction with potassium. As a result the overall "basicity" of the catalyst decreased and the promotional effect of potassium on the WGS activity was reduced.

(4) Catalyst with composition $100 \mathrm{Fe} / 5 \mathrm{Cu} / 4.2 \mathrm{~K} / 8 \mathrm{SiO}_{2}$ displayed high activity and excellent hydrocarbon selectivity (low $\mathrm{CH}_{4}$ and high $\mathrm{C}_{5}+$ content), but its stability needs to be improved.

(5) Catalyst with nominal composition $100 \mathrm{Fe} / 5 \mathrm{Cu} / 4.2 \mathrm{~K} / 24 \mathrm{SiO}_{2}$ displayed about $25 \%$ higher activity and had better stability than the Ruhrchemie LP $33 / 81$ catalyst, but the Ruhrchemie catalyst produced less gaseous hydrocarbons.

(6) The yield of methane and gaseous hydrocarbons decreased upon addition of small amounts of binder (either silica or alumina). Hydrocarbon selectivity did not change markedly upon further addition of alumina ( 8 vs. 20 parts of $\mathrm{Al}_{2} \mathrm{O}_{3}$ ). With silica binder the yield of $\mathrm{CH}_{4}$ and $\mathrm{C}_{2}-\mathrm{C}_{4}$ increased initially ( 8 vs. 24 parts of $\mathrm{SiO}_{2}$ ) but then decreased again upon further addition of silica (24 vs. 100 parts of $\mathrm{SiO}_{2}$ ). 


\section{Task 3. PROCESS EVALUATION RESEARCH}

The original purpose of this task was to evaluate several of the most improved catalysts developed during this contract, in slurry bed reactors with following objectives: (1) to determine catalyst aging and deactivation with time on stream (long term stability tests), and (2) to perform process variable studies over a wider range of conditions than in Task 2 (Promoter Effect Research and Kinetic Studies), and to obtain improved kinetic parameters. On the basis of results obtained from slurry reactor tests in Task 2, which showed significant catalyst deactivation, it was decided to focus primarily on the first objective and to pursue the second one whenever feasible (i.e., in the absence of significant deactivation). Also, it was decided to evaluate catalysts in our fixed bed reactors with objective to obtain information on the intrinsic loss of catalyst activity, i.e., the loss which is not caused or accelerated by the wax withdrawal. Our fixed bed reactors operate under nearly isothermal conditions, and it is believed that they provide a good indication of catalyst stability and selectivity.

Five catalysts were evaluated in fixed bed reactors: three tests were made with silica containing catalysts (Ruhrchemie LP 33/81-the state-of-the-art catalyst and $100 \mathrm{Fe} / 5 \mathrm{Cu} / 4.2 \mathrm{~K} / \mathrm{x}$ $\mathrm{SiO}_{2}$ catalysts, $\mathrm{x}=8$ or 24 ), and four tests with unsupported precipitated iron catalysts (100 $\mathrm{Fe} / 1 \mathrm{Cu} / 0.2 \mathrm{~K}$ and $100 \mathrm{Fe} / 3 \mathrm{Cu} / 0.5 \mathrm{~K}$ ). Four tests were conducted in slurry bed reactors with Ruhrchemie LP $33 / 81,100 \mathrm{Fe} / 5 \mathrm{Cu} / 4.2 \mathrm{~K} / 24 \mathrm{SiO}_{2}, 100 \mathrm{Fe} / 3 \mathrm{Cu} / 0.2 \mathrm{~K}$ and $100 \mathrm{Fe} / 3$ $\mathrm{Cu} / 0.5 \mathrm{~K}$ catalysts. As can be seen, several catalysts were tested both in fixed bed and slurry bed reactors, and this provides additional information on the effect of reactor type on catalyst activity and product selectivity.

\section{VI.1. Fixed Bed Reactor Tests with Silica containing Catalysts}

VI.1.1. Run FA - $63-1308$ with the $100 \mathrm{Fe} / 5 \mathrm{Cu} / 4.2 \mathrm{~K} / 8 \mathrm{SiO}_{2}$ Catalyst

Run FA-63-1308 was made as a long term fixed bed stability test of the catalyst containing 8 parts $\mathrm{SiO}_{2} / 100$ parts $\mathrm{Fe}$, which was among the most active of the catalysts tested during this contract and it also showed desirable selectivity behavior (Section V.4). The catalyst was reduced in situ at $280^{\circ} \mathrm{C}$ for $16 \mathrm{~h}$ with CO. Stability testing was conducted over a $552 \mathrm{~h}$ period, at $235^{\circ} \mathrm{C}, 1.48 \mathrm{MPa}, 2.0 \mathrm{NI} / \mathrm{g}$-cat. $h$, using $\left(\mathrm{H}_{2} / \mathrm{CO}\right)=1.0$ synthesis gas (up to $271 \mathrm{~h}$ ) and $\left(\mathrm{H}_{2} / \mathrm{CO}\right)=0.67$ synthesis gas $(272-552 \mathrm{~h})$. Three mass balances were completed with each feed ratio tested. A single mass balance was made at $250^{\circ} \mathrm{C}$ during balance 7 , and a repeat of the original conditions was made in balance 8 . The results obtained during these balances are summarized in Table VI-1. 
Table VI-1 . Summary of results for fixed bed run FA-63-1308.

Catalyst: $3.40 g^{\mathfrak{a}}, 100 \mathrm{Fe} / 5 \mathrm{Cu} / 4.2 \mathrm{~K} / 8 \mathrm{SiO} 2$

Diluent: $35.1 \mathrm{~g}$, Glass beads Catalyst volume: $3.60 \mathrm{cc}$

Diluent Volume: $23.0 \mathrm{cc}$

\begin{tabular}{|c|c|c|c|c|c|c|c|c|}
\hline Period & 1 & 2 & 3 & 4 & 5 & 6 & 7 & 8 \\
\hline Date & $5 / 11$ & $5 / 15$ & $5 / 19$ & $5 / 23$ & $5 / 27$ & $5 / 31$ & $6 / 3$ & $6 / 6 / 88$ \\
\hline Time on Stream $(h)$ & 48.0 & 144.0 & 240.0 & 336.5 & 432.0 & 528.0 & 600.0 & 662.0 \\
\hline Balance Duration $(h)$ & 6.0 & 6.0 & 6.0 & 6.0 & 6.5 & 7.5 & 6.5 & 7.2 \\
\hline Average Temperature $\left({ }^{\circ} \mathrm{C}\right)$ & 235. & 235 . & 235. & 235. & 235. & 235. & 250 & 235 . \\
\hline Maximum $\Delta$ Temperature $\left({ }^{\circ} \mathrm{C}\right)^{b}$ & 2.30 & 1.50 & 1.40 & 2.00 & 1.40 & 1.50 & 1.50 & 2.40 \\
\hline Pressure $(\mathrm{MPa})$ & 1.48 & 1.48 & 1.48 & 1.48 & 1.48 & 1.48 & 1.48 & 1.48 \\
\hline $\mathrm{H}_{2} / \mathrm{CO}$ Feed Ratio & 1.03 & 1.03 & 1.03 & .689 & .689 & .689 & .689 & 1.03 \\
\hline Space Velocity $(N l / g \text {-cat } \cdot h)^{a}$ & 1.99 & 1.99 & 1.99 & 1.99 & 1.99 & 1.99 & 1.99 & 1.99 \\
\hline Space Velocity $(\mathrm{NI} / \mathrm{g}-\mathrm{Fe} \cdot \mathrm{h})$ & 3.24 & 3.24 & 3.24 & 3.24 & 3.24 & 3.24 & 3.24 & 3.24 \\
\hline GHSV $\left(h^{-1}\right)^{c}$ & 251. & 251. & 251. & 251. & 251. & 251. & 251. & 251. \\
\hline CO Conversion (\%) & 94.6 & 87.5 & 68.1 & 48.6 & 43.7 & 41.2 & 48.7 & 37.1 \\
\hline $\mathrm{H}_{2}+\mathrm{CO}$ Conversion (\%) & 77.9 & 71.8 & 56.9 & 46.0 & 42.1 & 40.1 & 46.4 & 31.7 \\
\hline $\mathrm{H}_{2} / \mathrm{CO}$ Usage & .669 & .664 & .693 & .598 & .630 & .647 & .609 & .740 \\
\hline STY (mola $\left.\mathrm{H}_{2}+\mathrm{CO} / g-\mathrm{cat} \cdot h\right)^{a}$ & .069 & .064 & .051 & .041 & .037 & .036 & .041 & .028 \\
\hline$P_{\mathrm{CO}_{2}} \cdot P_{\mathrm{H}_{2}} / P_{\mathrm{CO}} \cdot P_{\mathrm{H}_{3} \mathrm{O}}$ & 34.1 & 13.7 & 6.63 & 4.52 & 3.71 & 3.56 & 4.48 & 2.99 \\
\hline Weight \% of Outlet & & & & & & & & \\
\hline$\overline{\mathrm{I}_{2}}$ & 2.70 & 3.04 & 3.76 & 2.75 & 2.88 & 2.92 & 2.71 & 5.11 \\
\hline $\mathrm{H}_{2} \mathrm{O}$ & 5.53 & 6.01 & 4.69 & 2.29 & 2.34 & 2.32 & 2.36 & 3.71 \\
\hline $\mathrm{CO}$ & 5.11 & 11.8 & 29.9 & 49.3 & 54.4 & 56.5 & 49.1 & 59.0 \\
\hline $\mathrm{CO}_{2}$ & 62.7 & 55.8 & 43.6 & 32.6 & 28.9 & 28.1 & 33.8 & 22.5 \\
\hline Hydrocarbons & 15.0 & 15.6 & 11.2 & 8.10 & 7.20 & 6.86 & 8.60 & 6.95 \\
\hline Oxygenates & 1.33 & 1.58 & 1.11 & .519 & .427 & .346 & .416 & .602 \\
\hline$W_{a x}^{d}$ & 7.58 & 6.17 & 5.75 & 4.39 & 3.84 & 2.96 & 2.97 & 2.10 \\
\hline Yield $\left(g / \mathrm{Nm}^{3} \mathrm{H}_{2}+\mathrm{CO}\right.$ Converted $)$ & & & & & & & & \\
\hline $\mathrm{CH}_{4}$ & 8.01 & 6.91 & 7.88 & 6.67 & 7.46 & 8.19 & 12.0 & 13.1 \\
\hline $\mathrm{C}_{2}-\mathrm{C}_{4}$ Hydrocarbons & 33.6 & 32.4 & 32.4 & 27.4 & 29.4 & 30.3 & 38.3 & 46.2 \\
\hline $\mathrm{C}_{5}-\mathrm{C}_{11}$ Hydrocarbons & 40.3 & 38.7 & 36.8 & $\mathbf{3 4 . 5}$ & 31.2 & 27.3 & 30.0 & 33.9 \\
\hline $\mathrm{C}_{12}+$ Hydrocarbons & 106. & 120. & 118. & 141. & 133. & 123. & 113. & 94.1 \\
\hline Waxd & 63.1 & 56.1 & 66.4 & 73.6 & 69.8 & 56.8 & 49.6 & 43.4 \\
\hline Oxygenates & 11.1 & 14.3 & 12.9 & 8.70 & 7.76 & 6.64 & 6.93 & 12.5 \\
\hline Total & 199. & 212. & 208. & 218. & 208. & 195. & 200. & 200. \\
\hline $1+2$ Olefins/ $n$-Paraffin Ratio & & & & & & & & \\
\hline $\mathrm{C}_{2}$ & 2.68 & 2.84 & 2.70 & 2.59 & 2.27 & 2.08 & 1.62 & 1.94 \\
\hline $\mathrm{C}_{3}$ & 6.49 & 6.59 & 6.44 & 7.52 & 7.35 & 7.40 & 7.78 & 6.28 \\
\hline$C_{1}$ & 5.23 & 5.28 & 5.28 & 6.17 & 6.05 & 6.12 & 6.56 & 5.16 \\
\hline $\mathrm{C}_{8}$ & 5.00 & 4.17 & 3.72 & 4.62 & 5.59 & 4.20 & 4.98 & 3.86 \\
\hline $\mathrm{C}_{10}$ & 3.99 & 3.33 & 3.35 & 3.79 & 3.87 & 3.48 & 2.91 & 2.92 \\
\hline
\end{tabular}

a Based on unreduced catalyst

Maximum axial temperature difference

Based on unreduced catalyst

d IInrecnvered nroducts from wax analysis 
Table VI-1 (cont'd). Summary of results tor hxed bea tuit ra-0s-1ous.

\begin{tabular}{|c|c|c|c|c|c|c|c|c|}
\hline Period & 1 & 2 & 3 & 4 & 5 & 6 & 7 & 8 \\
\hline \multicolumn{9}{|c|}{ Weight \% of llydrocarbons } \\
\hline CH4 & 4.25 & 3.49 & 4.03 & 3.19 & 3.72 & 4.34 & 6.19 & 6.99 \\
\hline Ethane & 1.48 & 1.33 & 1.49 & 1.24 & 1.55 & 1.78 & 2.74 & 2.94 \\
\hline Ethylene & 3.71 & 3.53 & 3.73 & 2.99 & 3.27 & 3.45 & 4.14 & 5.32 \\
\hline Propane & .940 & .847 & .869 & .591 & .674 & .739 & .873 & 1.30 \\
\hline Propylene & 5.82 & 5.32 & 5.35 & 4.24 & 4.73 & 5.21 & 6.48 & 7.80 \\
\hline n-Butane & .896 & .799 & .773 & .533 & .597 & .655 & .709 & 1.12 \\
\hline $1+2$ Butenes & 4.52 & 4.07 & 3.94 & 3.18 & 3.49 & 3.87 & 4.49 & 5.60 \\
\hline $\mathrm{C}_{4}$ Isomers & .471 & .432 & .414 & .309 & .342 & .375 & .436 & .575 \\
\hline n-Pentane & 1.23 & 1.10 & 1.05 & .779 & .810 & .937 & 1.03 & 1.42 \\
\hline $1+2$ Pentenes & 4.00 & 3.57 & 3.39 & 2.74 & 2.93 & 3.27 & 3.59 & 4.41 \\
\hline $\mathrm{C}_{5}$ Isomers & .270 & .249 & .240 & .167 & .185 & .210 & .235 & .356 \\
\hline$n$-Hexane & .552 & .454 & .633 & .458 & .362 & .477 & .415 & .674 \\
\hline $1+2$ Hexenes & 2.29 & 1.97 & 2.17 & 1.73 & 1.76 & 1.92 & 1.91 & 2.32 \\
\hline$C_{6}$ Isomers & .448 & .381 & .463 & .390 & .416 & .464 & .504 & .555 \\
\hline n-Heptane & .373 & .347 & .480 & .328 & .231 & .299 & .247 & .414 \\
\hline $1+2$ Heptenes & 1.75 & 1.52 & 1.46 & 1.28 & 1.28 & 1.20 & 1.18 & 1.43 \\
\hline $\mathrm{C}_{7}$ Isomers & .267 & .235 & .304 & .276 & .205 & .252 & .299 & .272 \\
\hline n-Octane & .366 & .397 & .376 & .255 & .189 & .194 & .182 & .223 \\
\hline $1+2$ Octenes & 1.80 & 1.62 & 1.37 & 1.16 & 1.04 & .800 & .888 & .847 \\
\hline $\mathrm{C}_{8}$ Isomers & .250 & .130 & .164 & .0542 & .0987 & .0371 & .0651 & .0989 \\
\hline$n$-Nonane & .462 & .457 & .415 & .326 & .282 & .214 & .212 & .241 \\
\hline $1+2$ Nonenes & 2.02 & 1.70 & 1.46 & 1.38 & 1.17 & .839 & .883 & .822 \\
\hline $\mathrm{C}_{\theta}$ Isomers & .154 & .197 & .147 & .110 & .0862 & .0760 & .106 & .0837 \\
\hline$n$-Decane & .522 & .561 & .504 & .475 & .412 & .321 & .424 & .437 \\
\hline $1+2$ Decenes & 2.05 & 1.84 & 1.67 & 1.77 & 1.57 & 1.10 & 1.22 & 1.26 \\
\hline $\mathrm{C}_{10}$ Isomers & .290 & .365 & .257 & .267 & .215 & .190 & .243 & .184 \\
\hline$n$-Undecane & .422 & .517 & .489 & .479 & .452 & .348 & .390 & .442 \\
\hline $1+2$ Undecenes & 1.65 & 1.69 & 1.57 & 1.79 & 1.65 & 1.14 & 1.32 & 1.36 \\
\hline$C_{11}$ Isomers & .232 & .222 & .223 & .243 & .205 & .210 & .222 & .264 \\
\hline$C_{2}-C_{4}$ & 17.8 & 16.3 & 16.6 & 13.1 & 14.7 & 16.1 & 19.9 & 24.7 \\
\hline $\mathrm{C}_{5}-\mathrm{C}_{11}$ & 21.4 & 19.5 & 18.8 & 16.5 & 15.5 & 14.5 & 15.6 & 18.1 \\
\hline $\mathrm{C}_{12}+$ & 56.5 & 60.7 & 60.6 & 67.3 & 66.1 & 65.1 & 58.4 & 50.2 \\
\hline Waxd & 33.5 & 28.3 & 34.0 & 35.2 & 34.8 & 30.1 & 25.7 & 23.2 \\
\hline
\end{tabular}

d Unrecovered products from wax analysis 
A stability plot of the $\left(\mathrm{H}_{2}+\mathrm{CO}\right)$ conversion versus time on stream is given in Fig. VI-1. The catalyst deactivated steadily with the $\left(\mathrm{H}_{2} / \mathrm{CO}\right)=1.0$ synthesis gas, with the $\left(\mathrm{H}_{2}+\mathrm{CO}\right)$ conversion dropping from an initial value of $77.4 \%(24.5 \mathrm{~h})$ to a final value of $55.0 \%(264 \mathrm{~h})$. Deactivation continued after the switch to $\left(\mathrm{H}_{2} / \mathrm{CO}\right)=0.67$ feed gas, but the rate of deactivation decreased. Between 294.5 and $552 \mathrm{~h}$, the $\left(\mathrm{H}_{2}+\mathrm{CO}\right)$ conversion dropped from 47.5 to $39.0 \%$. The average deactivation rates (average change in conversion/unit time) were 0.094 and 0.033 $\% / h$ with $\left(\mathrm{H}_{2} / \mathrm{CO}\right)=1.0$ and 0.67 , respectively.

The difference in deactivation behavior with feed ratio is difficult to explain as we do not know with any certainty the cause of deactivation in the fixed bed reactors. Decreasing the $\left(\mathrm{H}_{2} / \mathrm{CO}\right)$ feed ratio from 1.0 to 0.67 between balances 3 and 4 caused the $\mathrm{CO}$ partial pressure to increase from 0.36 to $0.64 \mathrm{MPa}$ and the $\mathrm{H}_{2}$ partial pressure to decrease from 0.63 to 0.49 $\mathrm{MPa}$ (exit values). The higher $\mathrm{CO}$ partial pressure drives the water-gas shift (WGS) reaction to the right, thus the $\mathrm{CO}_{2}$ and $\mathrm{H}_{2} \mathrm{O}$ partial pressures changed from 0.34 and $0.09 \mathrm{MPa}$ to 0.27 and $0.05 \mathrm{MPa}$, respectively. If the primary cause of deactivation is carbon fouling, higher CO partial pressure should increase the rate of deactivation (Dry, 1981), which is not what is observed. If the primary cause of deactivation is catalyst reoxidation, the higher $\mathrm{CO}$ partial pressures can explain the decreased deactivation in several ways: (1) as we have found that $\mathrm{CO}$ is a more effective reductant than $\mathrm{H}_{2}$ (Section V.1), a lower feed ratio will lend to a stronger reducing environment in the reactor to offset oxidation, (2) the excess $\mathrm{CO}$ consumes oxidizing $\mathrm{H}_{2} \mathrm{O}$ via the WGS and decreases the rate of oxidation, or (3) higher $\mathrm{CO}$ partial pressures compete more effectively with water for surface sites on the catalyst, inhibiting oxidation.

The effect of time on stream on the selectivity of the silica-containing catalyst is shown in Fig. VI-2 for both feed ratios. The lower $\left(\mathrm{H}_{2} / \mathrm{CO}\right)$ feed ratio decreases $\mathrm{CH}_{4}$ and $\mathrm{C}_{2}-\mathrm{C}_{4}$ selectivity, increasing the amount of $\mathrm{C}_{12}+$ products formed. The olefin/paraffin ratios using $\left(\mathrm{H}_{2} / \mathrm{CO}\right)=0.67$ synthesis gas are higher than or comparable to those using $\left(\mathrm{H}_{2} / \mathrm{CO}\right)=1.0$ feed. Little change is seen in the first three balances with $\left(\mathrm{H}_{2} / \mathrm{CO}\right)=1.0$ or the balances using $\left(\mathrm{H}_{2} / \mathrm{CO}\right)=0.67$ feed gas. However, after the catalyst was heavily deactivated (balance 8, 662 h), the product distribution shifted towards lighter products $\left(\mathrm{CH}_{4}\right.$ and $\left.\mathrm{C}_{2}-\mathrm{C}_{4}\right)$ at the expense of $\mathrm{C}_{12}+$. There was no definite trend in the olefin/paraffin ratios with catalyst deactivation.

The ASF plots for active catalyst at $235^{\circ} \mathrm{C},\left(\mathrm{H}_{2} / \mathrm{CO}\right)=1.0$ (balance 1$),\left(\mathrm{H}_{2} / \mathrm{CO}\right)=0.67$ (balance 4 ), and deactivated catalyst at $\left(\mathrm{H}_{2} / \mathrm{CO}\right)=1.0$ (balance 8 ) are shown in Figs. VI-3 to V1-5. The feed ratio had little effect on $\alpha_{2}$, which varied between 0.90 and 0.91 for the three 


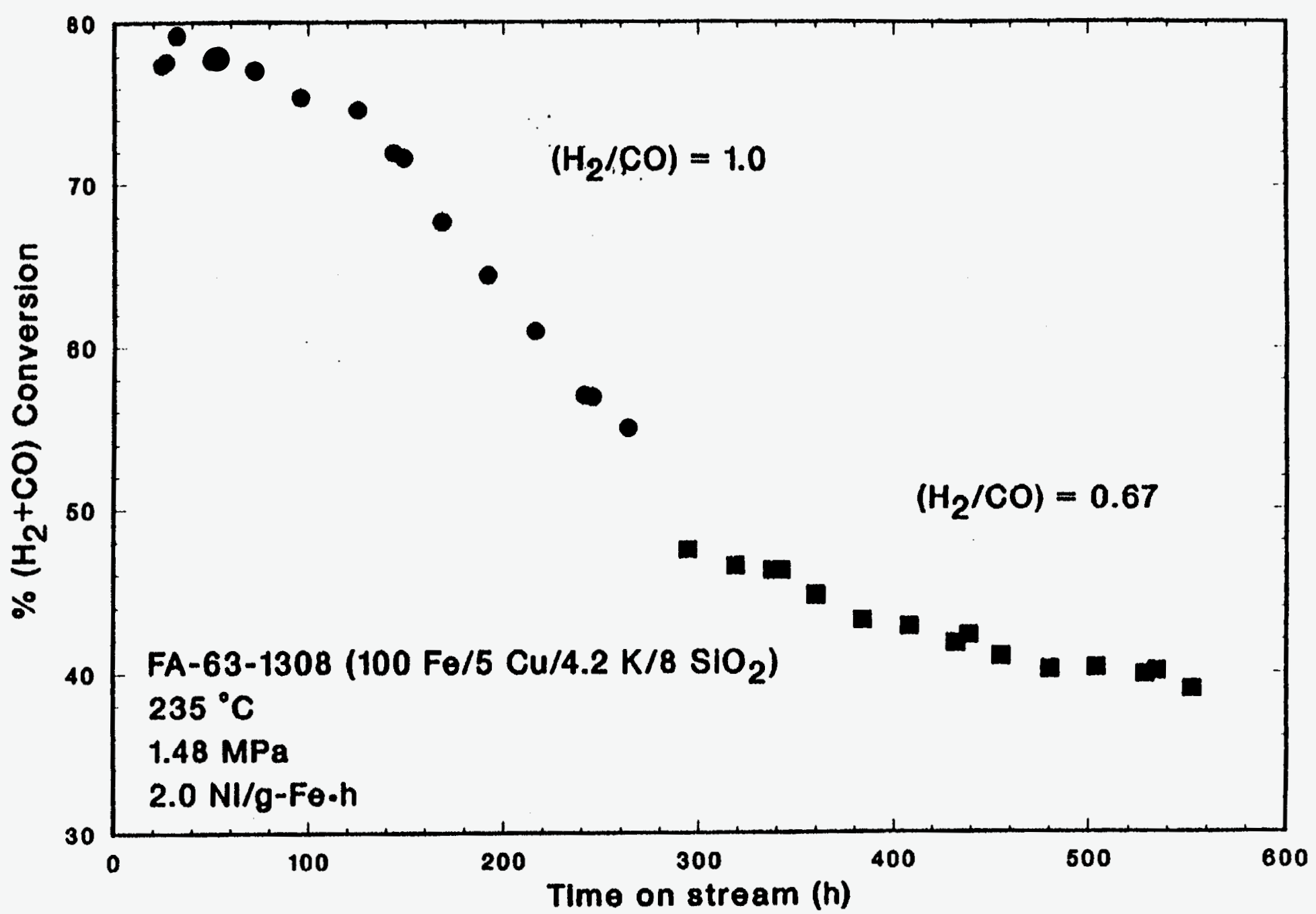

Figure VI-1 Stability plot, $\left(\mathrm{H}_{2}+\mathrm{CO}\right)$ conversion versus time on stream, for run FA-63-1308. 

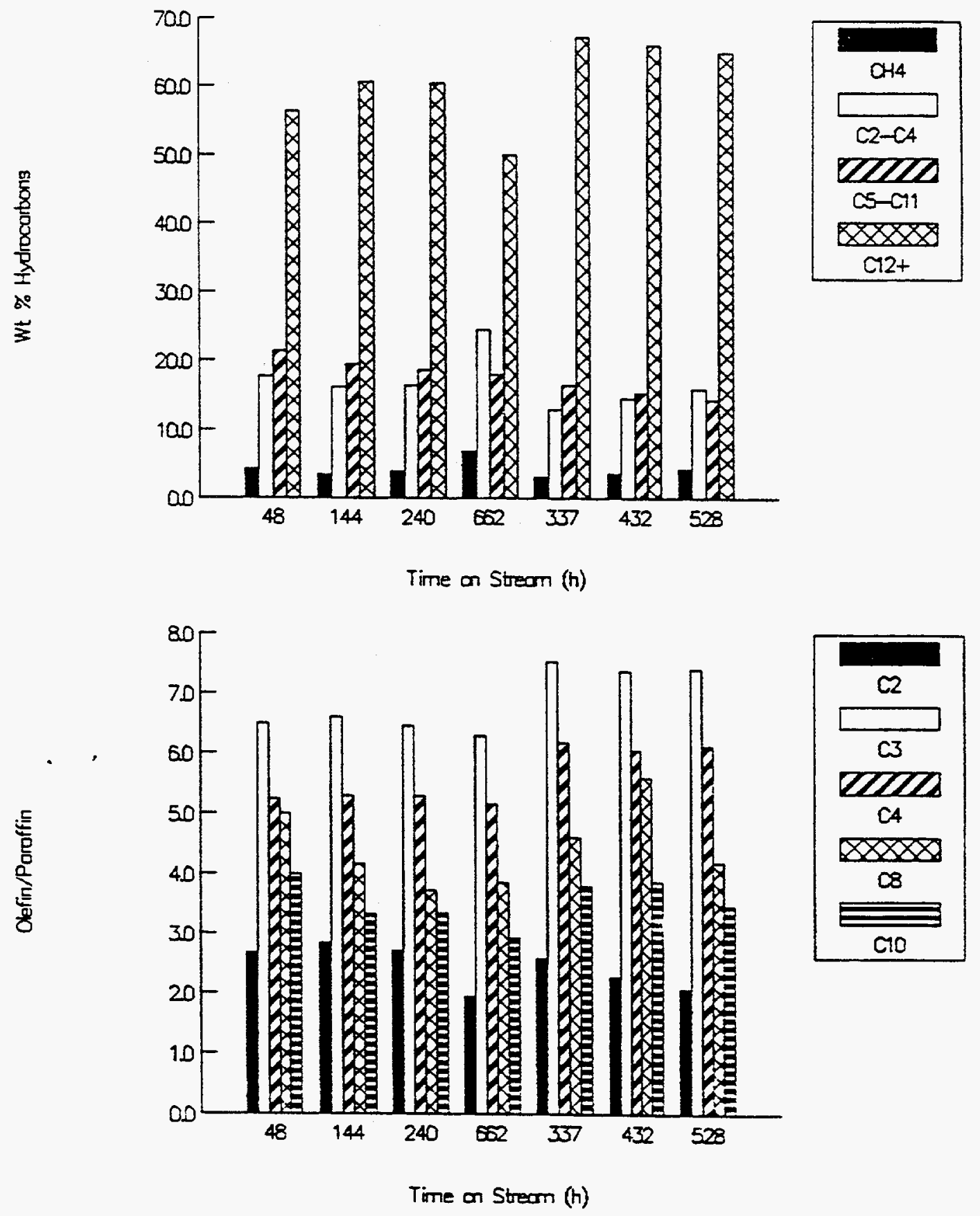

Figure VI-2. Effect of time on stream on $100 \mathrm{Fe} / 5 \mathrm{Cu} / 4.2 \mathrm{~K} / 8 \mathrm{SiO}_{2}$ catalyst selectivity for run FA63-1308: $235{ }^{\circ} \mathrm{C}, 1.48 \mathrm{MPa}, 2 \mathrm{Nl} / \mathrm{g}$-cat $h,\left(\mathrm{H}_{2} / \mathrm{CO}\right)=1.0(48-240,662 h)$ and 0.67 $(337-528 h)$. 


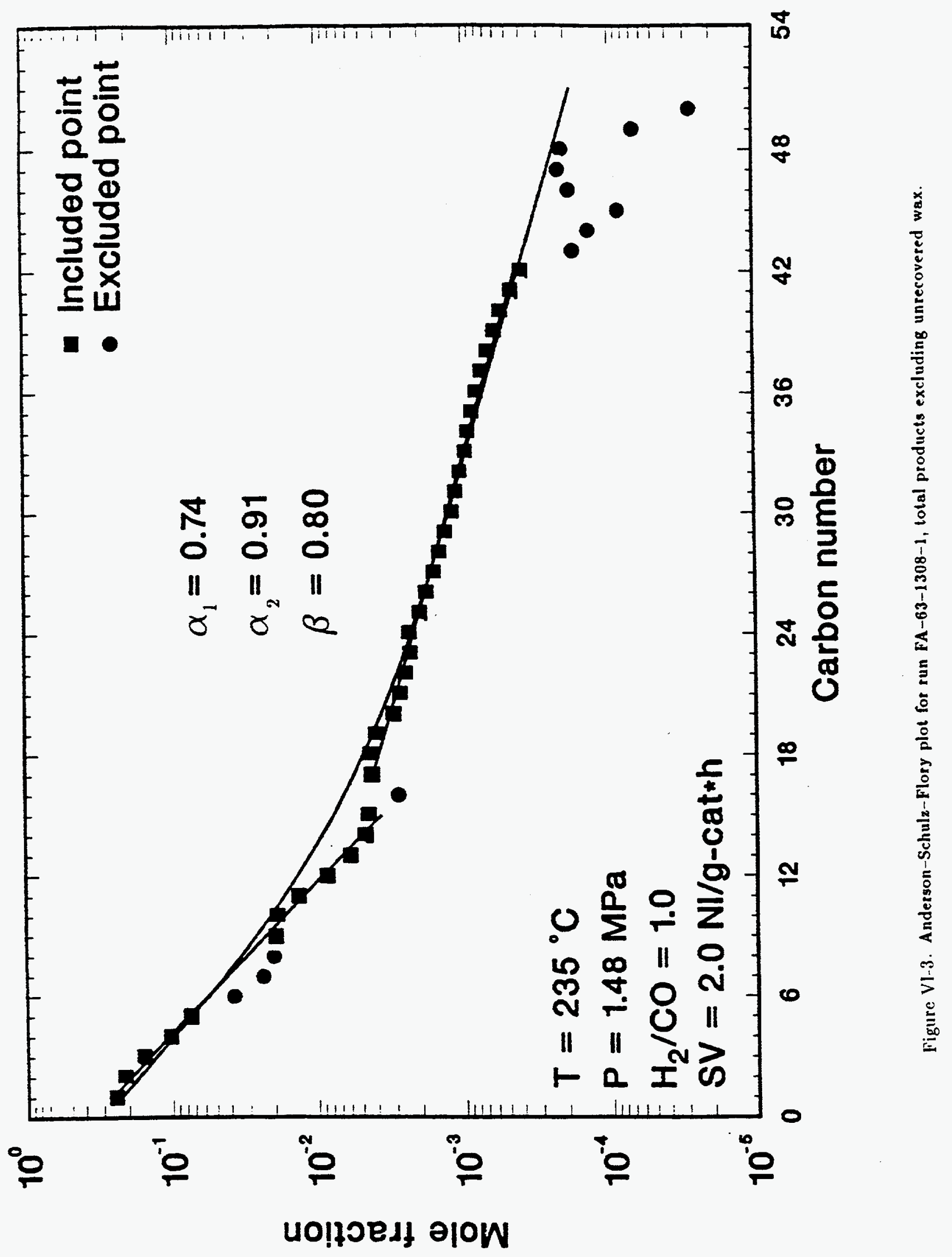

VI- 


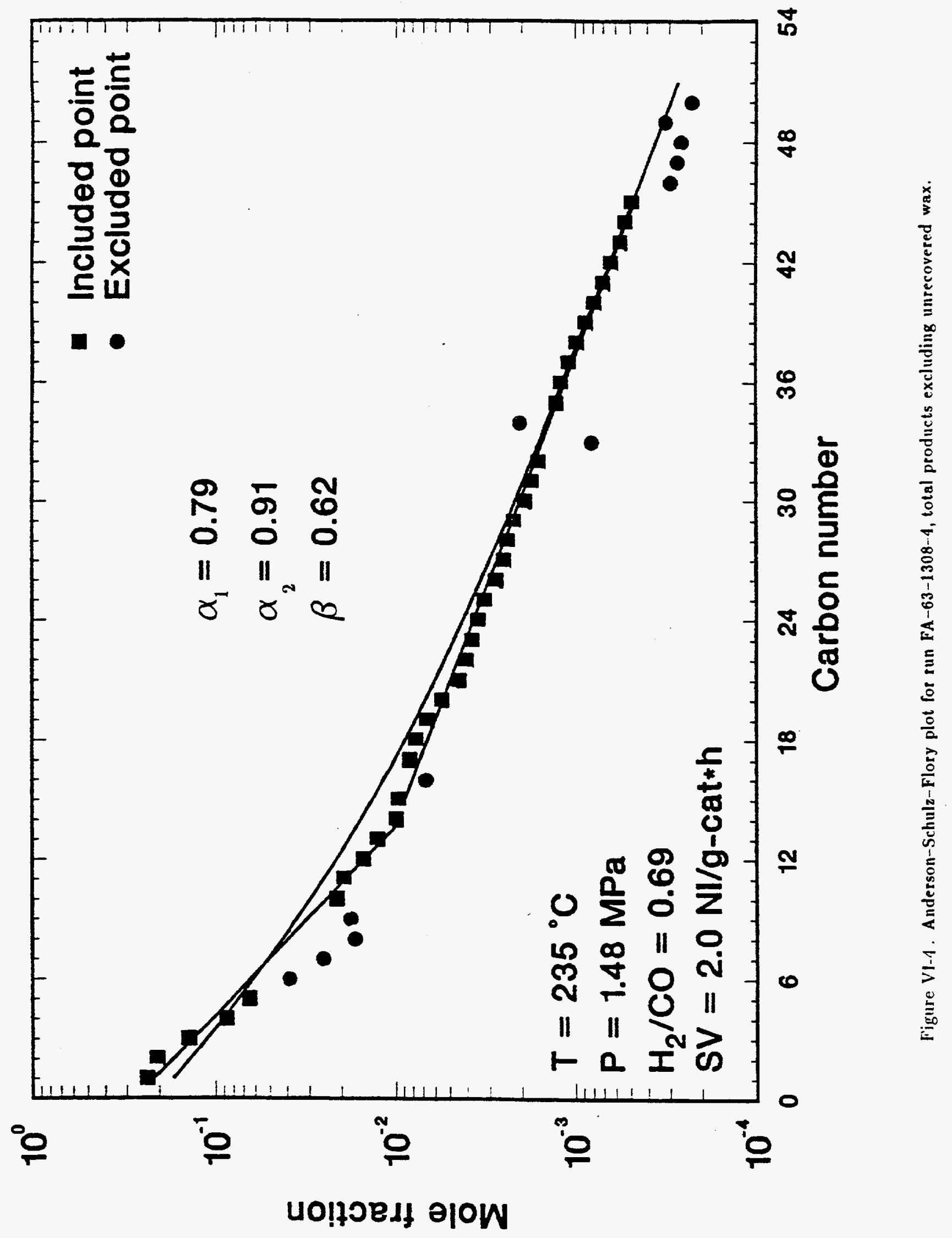




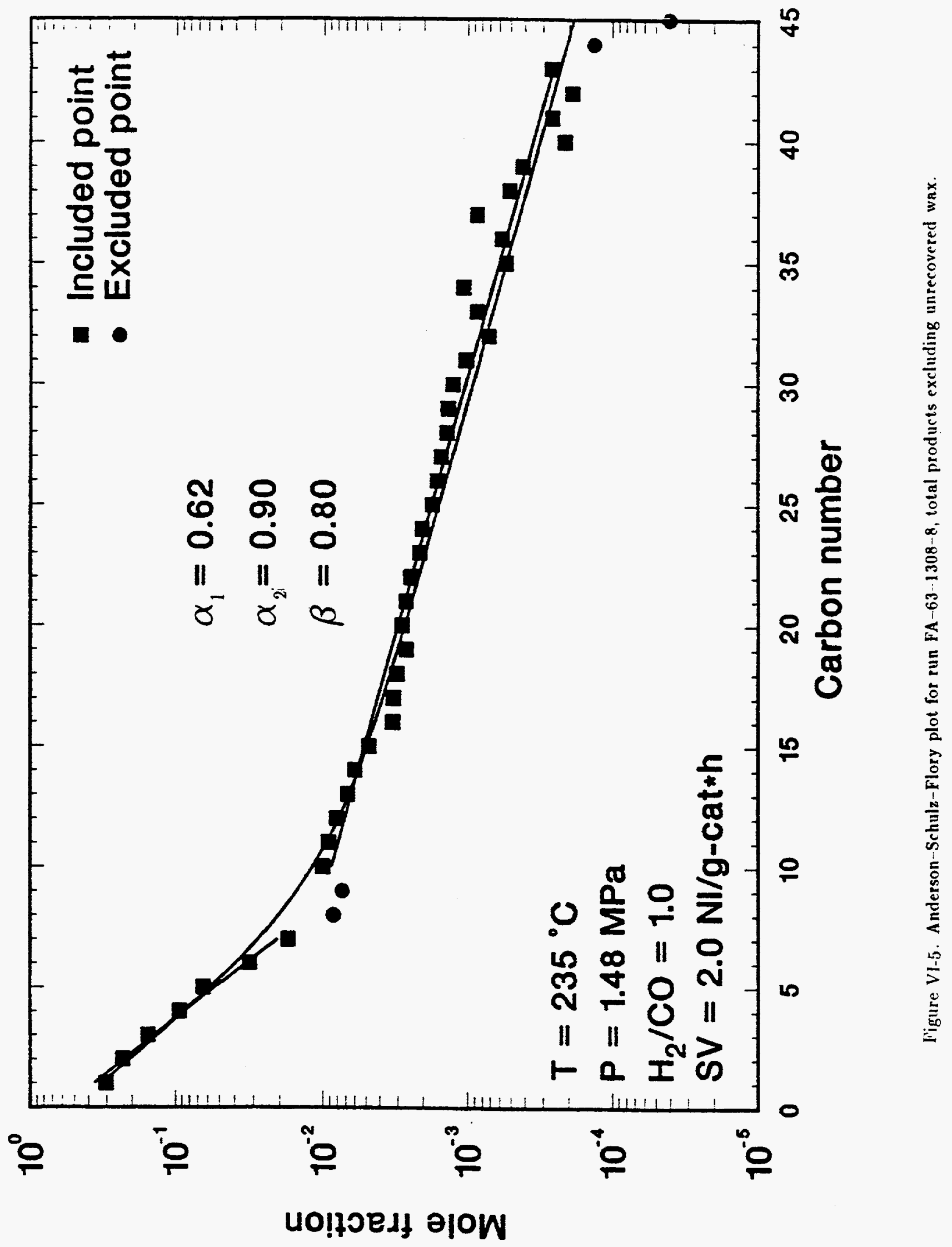

VI- 9 
balances. $\alpha_{1}$ increased from 0.74 to 0.79 and $\beta$ decreased from 0.80 to 0.62 as the feed ratio decreased from 1.0 to 0.69 , which are representative of the higher hydrocarbon selectivity of the lower feed ratio. Deactivation caused a decrease in $\alpha_{1}$, from 0.74 to 0.62 , with minimal change in either $\beta$ or $\alpha_{2}$, thus the gaseous hydrocarbons are the most strongly influenced by deactivation.

In the first balance of the run before deactivation, the catalyst activity and selectivity was similar to the previous test of this catalyst (Run FA-63-0418, Section V.4) at the same conditions $\left(235^{\circ} \mathrm{C}, 1.48 \mathrm{MPa}, 2.0 \mathrm{NI} / \mathrm{g}\right.$-cat.h). The $\left(\mathrm{H}_{2}+\mathrm{CO}\right)$ conversion at these conditions was $77.9 \%$ as compared to the $76.7 \%$ obtained previously. The weight \% hydrocarbon distribution during run FA-63-0418 was $3.5\left(\mathrm{CH}_{4}\right), 16.4\left(\mathrm{C}_{2}-\mathrm{C}_{4}\right), 20.1\left(\mathrm{C}_{5}-\mathrm{C}_{11}\right)$, and 60.0 $\%\left(C_{12}+\right)$, compared to $4.3,17.8,21.4$, and $56.5 \%$ obtained in this run. At $250{ }^{\circ} \mathrm{C}$ (balance 7) the catalyst was deactivated and the $\left(\mathrm{H}_{2}+\mathrm{CO}\right)$ conversion was only $46.4 \%$, while in the previous run the $\left(\mathrm{H}_{2} \div \mathrm{CO}\right)$ conversion at the same temperature and double the space velocity (4 NI/g-cat.h, balance 3) was $65.1 \%$. The hydrocarbon selectivity did not change significantly with deactivation at these conditions.

VI.1.2. Run FB - $99-1588$ with the Ruhrchemie LP 33 / 81 Catalyst

Run FB-99-1588 was a long term stability test of the Ruhrchemie LP $33 / 81$ commercial catalyst, and was intended to complement the slurry run SA-99-0888 (Section VI.3.1). The initial process conditions for the stability test were $250^{\circ} \mathrm{C}, 1.48 \mathrm{MPa},\left(\mathrm{H}_{2} / \mathrm{CO}\right)=0.67,2.0$ $\mathrm{NI} / \mathrm{g}$-cat.h, which are the same as those during the first five balances of slurry run SA-990888. The results of the seven balances of run FB-99-1588 are summarized in Table VI-2. The calcined Ruhrchemie catalyst ( $30 / 60$ mesh particles) was reduced in situ at $280^{\circ} \mathrm{C}$, using $\mathrm{CO}$ reductant for $12 \mathrm{~h}$. The stability plot of $\left(\mathrm{H}_{2}+\mathrm{CO}\right)$ conversion versus time is shown in Fig. VI-6. After an initial rapid decline in catalyst activity, the activity was relatively stable, with the conversion dropping from $58.3 \%$ to $53.6 \%$ between about 100 and $340 \mathrm{~h}$. At $382 \mathrm{~h}$, a power failure occurred, interrupting the run for approximately $50 \mathrm{~min}$, which caused an immediate decrease in the $\left(\mathrm{H}_{2}+\mathrm{CO}\right)$ conversion to $50 \%$ after the process conditions were reestablished. The catalyst was stable, at lower activity, after the interruption. After the fifth mass balance was completed the feed ratio was changed to 1.0 (nominal) at the same temperature, pressure, and space velocity. The $\left(\mathrm{H}_{2}+\mathrm{CO}\right)$ conversion increased to $57.2 \%$ at $49 \mathrm{~h}$ and declined slightly to $55.7 \%$ at $630 \mathrm{~h}$. 
Table VI-2. Summary of results for fixed bed run FB-99-1588.

Catalyst: $3.40 g^{\circ}$, Nuhrchemie LP 33/81

Diluent: $35.6 \mathrm{~g}$, Glass beads Catalyst volume: $5.40 \mathrm{cc}$

Diluent Volume: $23.0 \mathrm{cc}$

\begin{tabular}{|c|c|c|c|c|c|c|c|}
\hline Period & 1 & 2 & 3 & 4 & 5 & 6 & 7 \\
\hline Date & $6 / 9 / 88$ & $6 / 13 / 88$ & $6 / 17 / 88$ & $6 / 21 / 88$ & $6 / 25 / 88$ & $6 / 28 / 88$ & $7 / 2 / 88$ \\
\hline Time on Stream (h) & 71.0 & 167.0 & 262.5 & 360.0 & 426.5 & 528.0 & 622.5 \\
\hline Balance Duration (h) & 7.0 & 7.2 & 7.0 & 6.8 & 7.0 & 7.1 & 7.5 \\
\hline Average Temperature $\left({ }^{\circ} \mathrm{C}\right)$ & 250. & 250. & 250. & 250. & 250. & 250. & 250 \\
\hline Maximum $\Delta$ Temperalure $\left({ }^{\circ} \mathrm{C}\right)^{b}$ & 4.00 & 4.00 & 5.00 & 6.00 & 6.00 & 6.00 & 6.00 \\
\hline Pressure $\left(M P_{a}\right)$ & 1.48 & 1.48 & 1.48 & 1.48 & 1.48 & 1.48 & 1.48 \\
\hline $\mathrm{H}_{2} / \mathrm{CO}$ Feed Ratio & .689 & .689 & .686 & .686 & .686 & .980 & .980 \\
\hline Space Velocity $(N I / g \text {-cal.h })^{\circ}$ & 2.00 & 2.00 & 2.00 & 2.00 & 2.00 & 2.00 & 2.00 \\
\hline Space Velocity $(N I / g \cdot l \cdot e \cdot h)$ & 3.81 & 3.81 & 3.81 & 3.81 & 3.81 & 3.81 & 3.81 \\
\hline $\operatorname{GHSV}\left(h^{-1}\right)^{c}$ & 239. & 239. & 239. & 239. & 239. & 239. & 239. \\
\hline Co Conversion $(\%)$ & 56.4 & 52.4 & 51.6 & 50.1 & 46.9 & 59.1 & 59.1 \\
\hline $\mathrm{H}_{2}+\mathrm{CO}$ Conversion (举) & 58.6 & 55.3 & 54.4 & 53.2 & 50.2 & 56.0 & 55.5 \\
\hline $\mathrm{H}_{2} / \mathrm{CO}$ Usage & .757 & .780 & .778 & .790 & .803 & .878 & .859 \\
\hline STY (mols $\left.\mathrm{H}_{2}+\mathrm{CO} / \mathrm{g} \cdot \mathrm{cat} \cdot h\right)^{a}$ & .052 & .049 & .049 & .048 & .045 & .050 & .050 \\
\hline$P_{\mathrm{CO}_{3}} \cdot P_{\mathrm{H}_{2}} / P_{\mathrm{CO}} \cdot P_{\mathrm{H}_{2} \mathrm{O}}$ & 2.22 & 2.03 & 2.05 & 2.14 & 1.97 & 2.97 & 2.83 \\
\hline Weight \% of Outlet & & & & & & & \\
\hline $\mathrm{H}_{2}$ & 1.88 & 1.99 & 1.99 & 2.01 & 2.14 & 3.16 & 3.24 \\
\hline $\mathrm{H}_{2} \mathrm{O}$ & 3.97 & 3.86 & 3.81 & 3.48 & 3.62 & 5.50 & 5.76 \\
\hline $\mathrm{CO}$ & 43.4 & 47.0 & 47.0 & 48.1 & 51.1 & 39.0 & 39.0 \\
\hline $\mathrm{CO}_{2}$ & 35.8 & 32.5 & 32.4 & 31.2 & 29.9 & 35.5 & 34.5 \\
\hline Hydrocarbons & 11.4 & 9.26 & 9.43 & 9.43 & 8.96 & 13.0 & 12.9 \\
\hline Oxygenates & .645 & .545 & .503 & .396 & .421 & .988 & .906 \\
\hline Wax $^{d}$ & 2.88 & 4.82 & 4.91 & 5.36 & 3.87 & 2.92 & 3.63 \\
\hline Yield $\left(\mathrm{g} / \mathrm{Nm}^{3} \mathrm{H}_{2}+\mathrm{CO}\right.$ Converted $)$ & & & & & & & \\
\hline $\mathrm{CH}_{4}$ & 10.1 & 10.2 & 11.2 & 11.5 & 12.6 & 16.1 & 15.5 \\
\hline $\mathrm{C}_{2}-\mathrm{C}_{4}$ Hydrocarbons & 41.2 & 40.3 & 45.8 & 46.2 & 49.1 & 55.8 & 54.7 \\
\hline$C_{6}-C_{11}$ Hydrocarbons & 33.6 & 35.8 & 40.7 & 42.8 & 46.4 & 47.6 & 45.9 \\
\hline $\mathrm{C}_{12}+$ Hydrocarbons & 96.2 & 104. & 103. & 113. & 88.7 & 69.0 & 81.2 \\
\hline$W_{a x}^{d}$ & 36.5 & 65.2 & 68.8 & 77.3 & 59.4 & 34.6 & 43.2 \\
\hline Oxygenates & 8.18 & 7.37 & 7.05 & 5.72 & 6.46 & 11.7 & 10.8 \\
\hline Total & 189. & 198. & 208. & 219. & 203. & 200. & 208. \\
\hline $1+2$ Olefins/ $n$-Paralfin Ratio & & & & & & & \\
\hline $\mathrm{C}_{2}$ & 1.68 & 1.92 & 1.99 & 2.09 & 2.10 & 1.44 & 1.54 \\
\hline $\mathrm{C}_{3}$ & 7.65 & 7.83 & 7.80 & 7.75 & 7.74 & 6.44 & 6.50 \\
\hline $\mathrm{C}_{4}$ & 6.22 & 6.35 & 6.33 & 6.23 & 6.22 & 5.13 & 5.20 \\
\hline $\mathrm{C}_{8}$ & 3.80 & 4.06 & 3.71 & 4.03 & 4.15 & 3.25 & 3.18 \\
\hline$C_{10}$ & 2.62 & 2.66 & 2.78 & 2.81 & 3.00 & 2.27 & 2.31 \\
\hline
\end{tabular}


Table VI-2 (cont'd). Summary of results for fixed bed run FB-99-1588.

\begin{tabular}{|c|c|c|c|c|c|c|c|}
\hline Period & 1 & 2 & 3 & 4 & 5 & 6 & 7 \\
\hline \multicolumn{8}{|c|}{ Weight \% of Hydrocarbons } \\
\hline CII4 & 5.55 & 5.34 & 5.58 & 5.41 & 6.38 & 8.54 & 7.87 \\
\hline Etliane & 2.48 & 2.18 & 2.25 & 2.00 & 2.33 & $\mathbf{3 . 5 0}$ & 3.12 \\
\hline Ethylene & 3.87 & 3.92 & 4.18 & 3.90 & 4.56 & 4.70 & 4.49 \\
\hline Propane & 1.05 & .975 & 1.04 & .983 & 1.13 & 1.59 & 1.48 \\
\hline Propylene & 7.70 & 7.29 & 7.76 & 7.27 & 8.35 & 9.79 & 9.20 \\
\hline n-Bulane & 1.01 & .878 & .984 & .996 & 1.14 & 1.57 & 1.46 \\
\hline $1+2$ Butenes & 6.05 & 5.39 & 6.01 & 5.99 & 6.85 & 7.78 & 7.35 \\
\hline $\mathrm{C}_{4}$ Isomers & .586 & .509 & .543 & .524 & .598 & .670 & .624 \\
\hline$n$-Pentane & 1.43 & 1.15 & 1.35 & 1.46 & 1.65 & 2.04 & 1.87 \\
\hline $1+2$ Pentenes & 5.11 & 4.18 & 5.10 & 5.51 & 6.21 & 6.85 & 6.38 \\
\hline$C_{5}$ lsomers & .333 & .263 & .305 & .325 & .372 & .499 & .450 \\
\hline$n$-llexane & .634 & .709 & .605 & .665 & .701 & .826 & .755 \\
\hline $1+2$ llexenes & 2.56 & 2.66 & 2.87 & 2.72 & 3.50 & $\mathbf{3 . 3 0}$ & 3.00 \\
\hline $\mathrm{C}_{6}$ Isomers & .578 & .536 & .583 & .594 & .632 & .595 & .517 \\
\hline n-IIeptane & .372 & .392 & .401 & .469 & .469 & .550 & .497 \\
\hline $1+2$ Heptenes & 1.51 & 1.66 & 1.69 & 1.93 & 2.02 & 1.93 & 1.76 \\
\hline $\mathrm{C}_{7}$ Isomers & .343 & .323 & .347 & .377 & .442 & .389 & .306 \\
\hline$n$-Octane & .292 & .311 & .324 & .295 & .363 & .465 & .422 \\
\hline $1+2$ Octenes & 1.09 & 1.24 & 1.18 & 1.17 & 1.48 & 1.48 & 1.32 \\
\hline$C_{8}$ Isomers & .165 & .192 & .174 & .258 & .146 & .163 & .152 \\
\hline$n$-Nonane & .280 & .383 & .370 & .288 & .377 & .553 & .475 \\
\hline $1+2$ Nonenes & .872 & 1.16 & 1.14 & .913 & 1.26 & 1.38 & 1.22 \\
\hline$C_{9}$ Isomers & .0998 & .107 & .110 & .0676 & .0631 & .102 & .126 \\
\hline$n$-Decane & .359 & .457 & .450 & .369 & .472 & .621 & .564 \\
\hline 1+2 Decenes & .927 & 1.20 & 1.23 & 1.02 & 1.40 & 1.39 & 1.28 \\
\hline$C_{10}$ Isomers & .174 & .181 & .224 & .121 & .119 & .190 & .173 \\
\hline$n$-Undecane & .418 & .475 & .473 & .408 & .502 & .602 & .603 \\
\hline $1+2$ IIndecenes & .892 & 1.01 & 1.09 & .959 & 1.26 & 1.16 & 1.15 \\
\hline$C_{11}$ Isomers & .150 & .185 & .195 & .121 & .158 & .175 & .202 \\
\hline$C_{2}-C_{4}$ & 22.7 & 21.1 & 22.8 & 21.7 & 25.0 & 29.6 & 27.7 \\
\hline$r_{5} C_{11}$ & 18.6 & 18.8 & 20.2 & 20.0 & 23.6 & 25.3 & 23.2 \\
\hline $\mathrm{C}_{12}+$ & 53.1 & 54.7 & 51.4 & 52.9 & 45.1 & 36.6 & 41.2 \\
\hline Wax ${ }^{d}$ & 20.2 & 34.2 & 34.2 & 36.2 & 30.2 & 18.4 & 21.9 \\
\hline
\end{tabular}

d Unrecovered products from wax analysis 


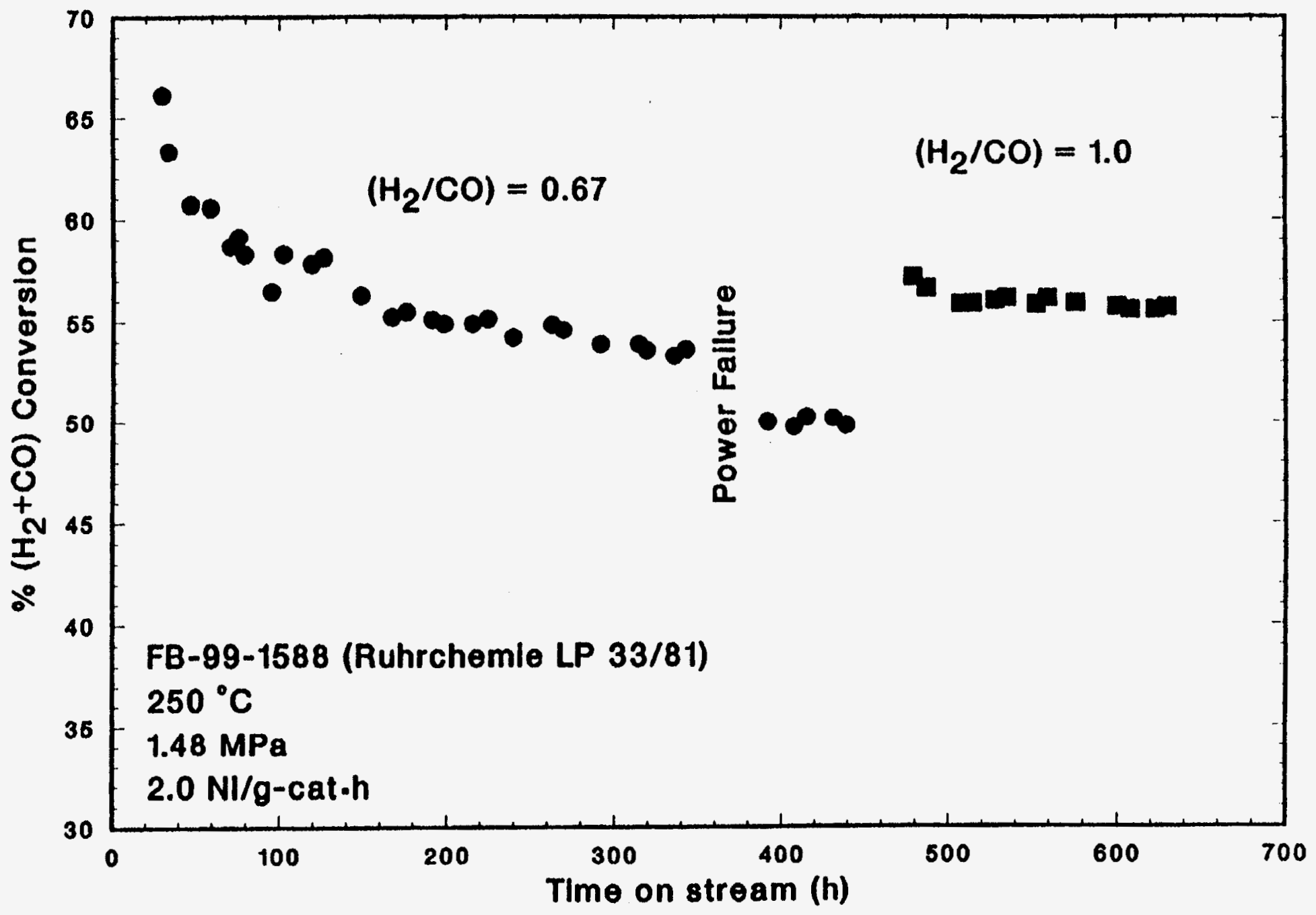

Figure V1-6 . Stability plot, $\left(\mathrm{H}_{2}+\mathrm{C} \mathrm{O}\right)$ conversion versus time on stream, for run FB-99-1588. 
Catalyst selectivity as a function of time on stream is shown in Fig. V1-7 for run FB-991588. The selectivity was not strongly affected by time on stream, and neither the weight $\%$ hydrocarbon distribution nor the olefin/paraffin ratios show any specific trends as the catalyst aged. At higher feed ratio, more gaseous hydrocarbons were formed, increasing from $6.4\left(\mathrm{CH}_{4}\right)$ and $25.0 \%\left(\mathrm{C}_{2}-\mathrm{C}_{4}\right)$ in balance $5\left(\mathrm{H}_{2} / \mathrm{CO}=0.67\right)$ to 8.5 and $29.6 \%$, respectively, in balance $6\left(\mathrm{H}_{2} / \mathrm{CO}=1.0\right)$. The olefin/paraffin ratios decreased as well when the concentration of $\mathrm{H}_{2}$ in the feed was increased.

Catalyst activity was higher in a fixed bed reactor than in a slurry reactor, with a conversion of $53.2 \%$ in the fixed bed (balance 4 ) before the power failure compared to the $44.4 \%$ conversion obtained in the slurry reactor (balance 5) at approximately the same time on stream. With the $\left(\mathrm{H}_{2} / \mathrm{CO}\right)=1.0$ feed gas, the fixed bed run gave a conversion of $56.0 \%$ in balance $6\left(250^{\circ} \mathrm{C}, 1.48 \mathrm{MPa}, 2.0 \mathrm{Nl} / \mathrm{g}\right.$-cat.h $)$ while during balance 12 of run SA-99-0888 at the same conditions, the conversion was $45.4 \%$, although catalyst deactivation occurred before this measurement was made.

The selectivities obtained in the fixed bed and slurry bed tests are compared in Fig. VI-8. The hydrocarbon selectivities in two runs with $\left(\mathrm{H}_{2} / \mathrm{CO}\right)=0.67$ were similar, with the weight $\%$ of hydrocarbons in fixed bed (balance 2$)$ at $5.3\left(\mathrm{CH}_{4}\right), 21.1\left(\mathrm{C}_{2}-\mathrm{C}_{4}\right), 18.8\left(\mathrm{C}_{5}-\mathrm{C}_{11}\right)$, and $54.7 \%\left(\mathrm{C}_{12}+\right)$ while in slurry (balance 3 ) the distribution was $5.1,20.8,21.9$, and $52.2 \%$. respectively. With $\left(\mathrm{H}_{2} / \mathrm{CO}\right)=1.0$, the slurry reactor produced more $\mathrm{CH}_{4}$ and $\mathrm{C}_{2}-\mathrm{C}_{4}$ products than fixed bed. This is probably due to catalyst deactivation which recurred in the slurry reactor prior to tests with $\left(\mathrm{H}_{2} / \mathrm{CO}\right)=1.0$ feed gas. We observed that the deactivated catalyst produces more lower molecular weight products than the fresh catalyst. Also, the differences in the $C_{5}-C_{11}$ and $C_{12}+$ fractions may be due to differences in the product collection procedures for the two systems, as the $C_{5}+$ fractions are not as dissimilar. The olefin/paraffin ratios, which are also compared in Fig. VI-8, were lower in slurry than in the fixed bed, which may be due to differences in flow patterns (i.e., plug flow vs. completely backmixed) of the two reactors.

V1.1.3. Run $F B-66-1948$ with the $100 \mathrm{Fe} / 5.0 \mathrm{Cu} / 4.2 \mathrm{~K} / 24 \mathrm{SiO}_{2}$ Catalyst

Run FB-66-1948 was made as a long term stability test of the $100 \mathrm{Fe} / 5.0 \mathrm{Cu} / 4.2 \mathrm{~K} / 24$ $\mathrm{SiO}_{2}$ catalyst. The first 5 mass balances (up to $457 \mathrm{~h}$ ) were made at a fixed set of process conditions: $250^{\circ} \mathrm{C}, 1.48 \mathrm{MPa}, 2.0 \mathrm{NI} / \mathrm{g}$-cat.h, and $\mathrm{H}_{2} / \mathrm{CO}=0.69$, to determine the catalyst stability. Balance 10 was a repeat of these conditions. The effect of space velocity was studied 


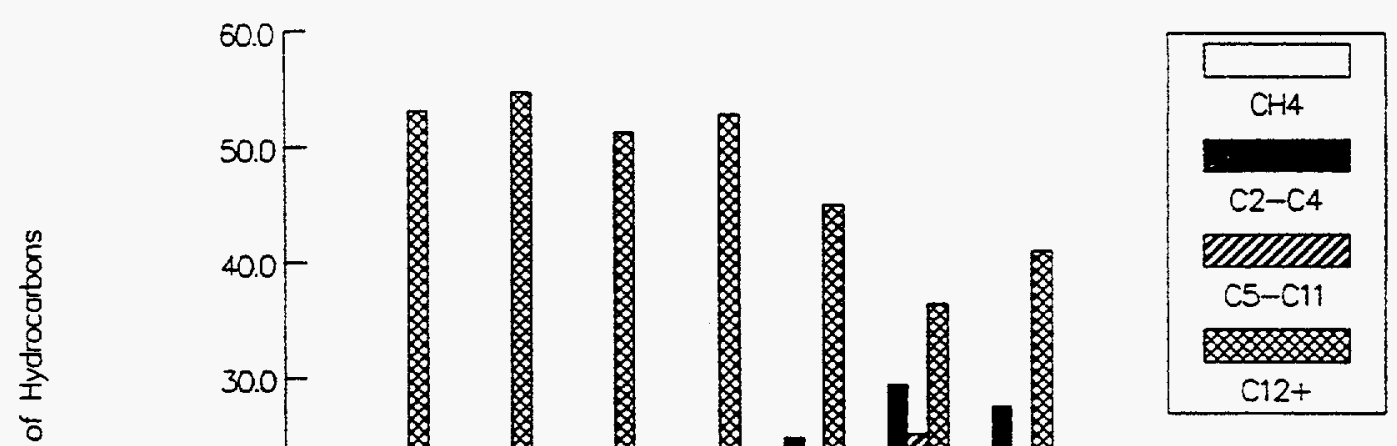

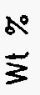

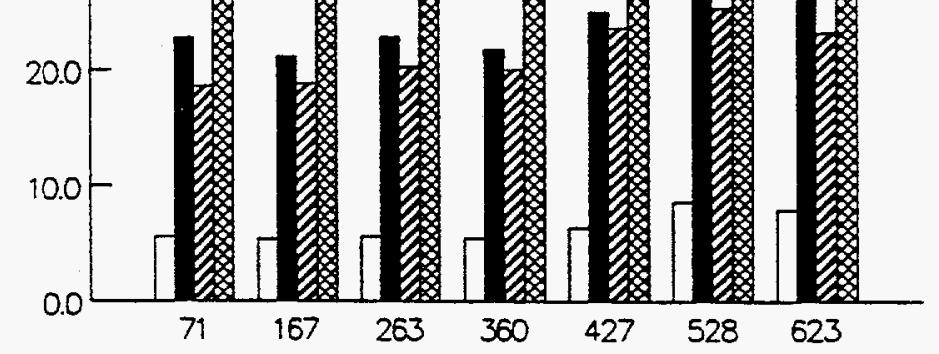

Time on Stream (h)

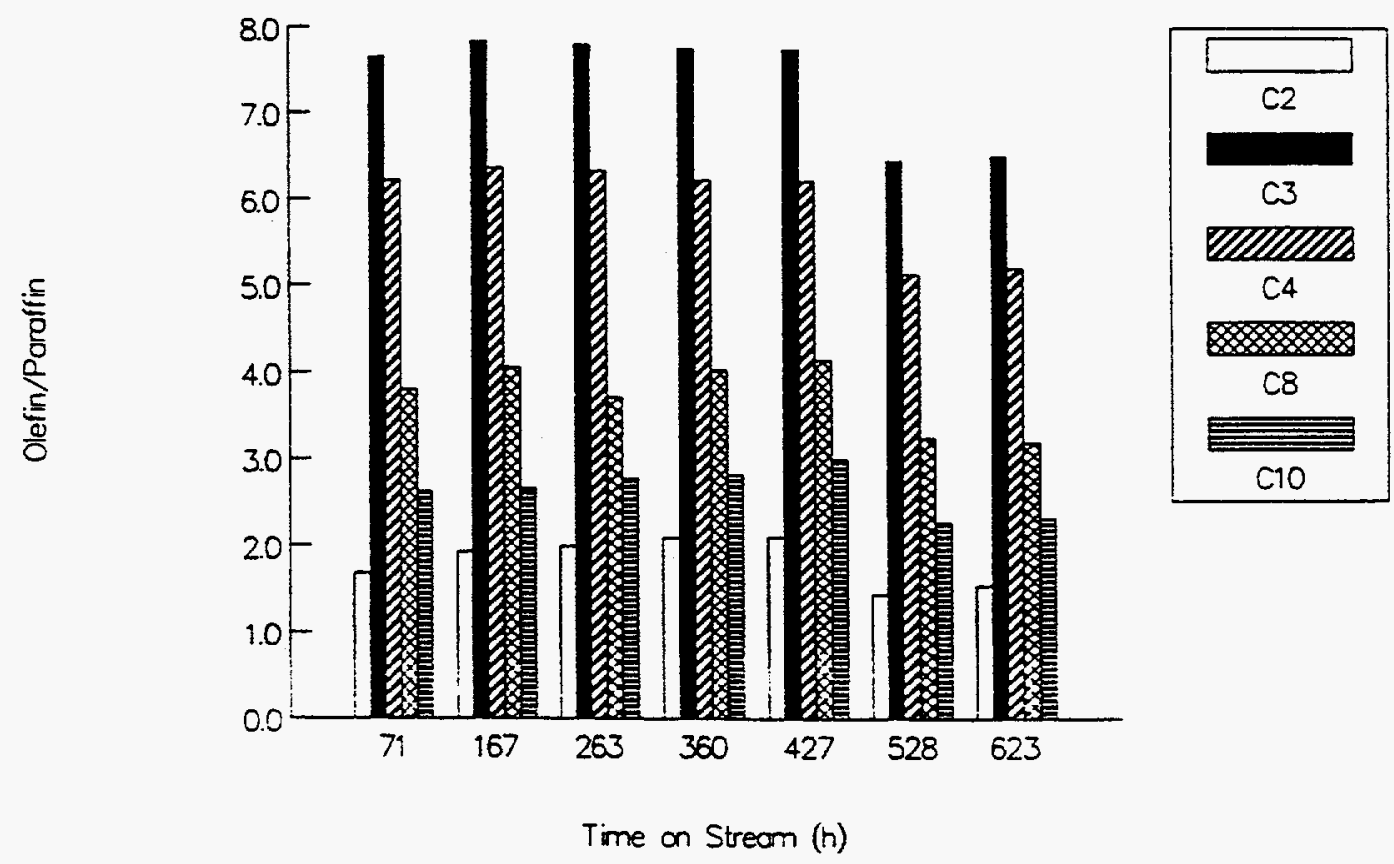

Figure VI- 7 . Effect of time on stream on Ruhrchemie LP 33/81 selectivity for run FB-99-1588: 250 ${ }^{\circ} \mathrm{C}, 1.48 \mathrm{MPa}, 2 \mathrm{Nl} / g$-cat $\cdot h,\left(\mathrm{H}_{2} / \mathrm{CO}\right)=0.67(71-427 h)$ and $1.0(528,623 h)$. 

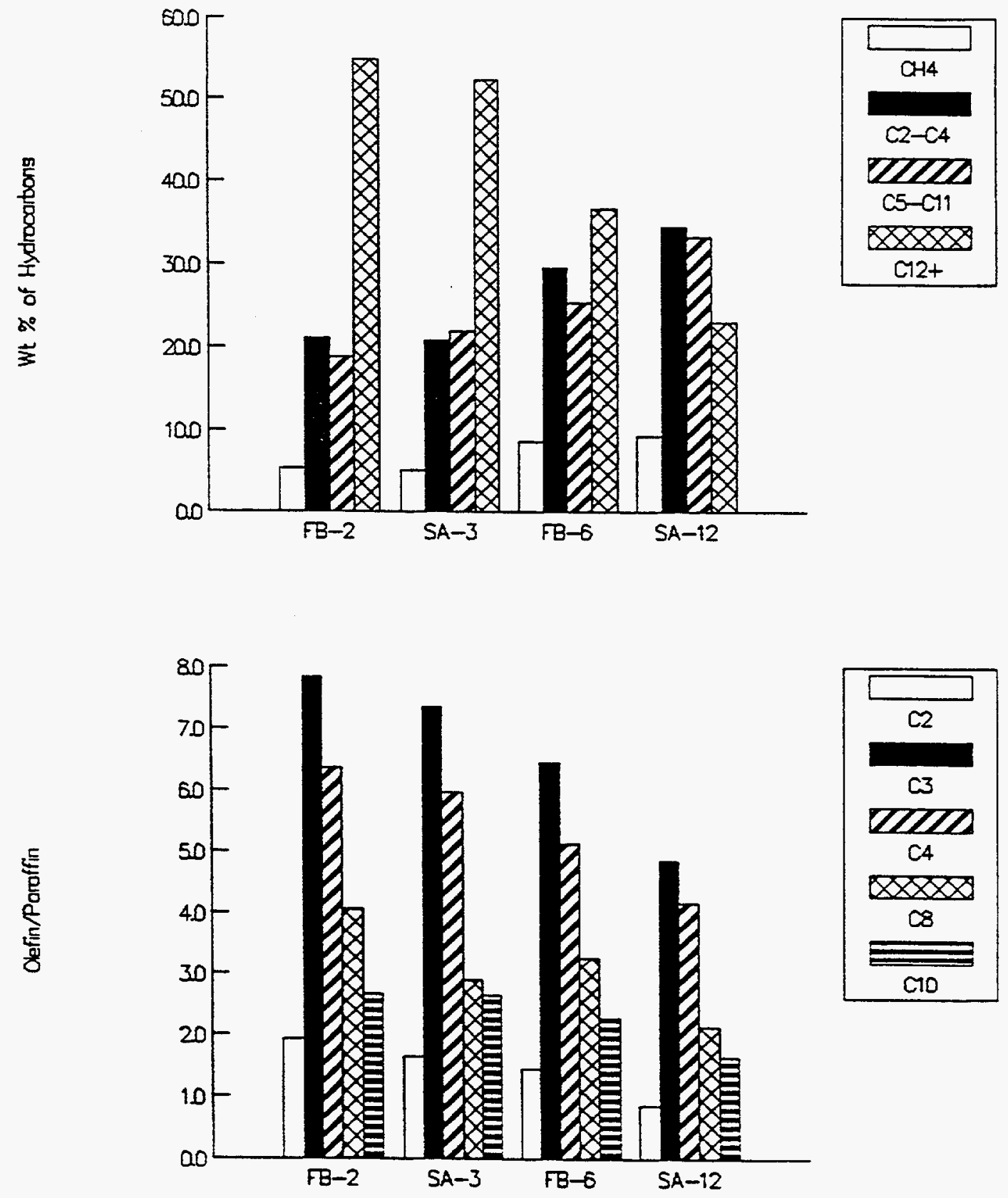

Figure VI- 8 . Comparison of fixed bed and slurry reactor selectivity with Ruhrchemie LP $33 / 81$ catalyst $(\mathrm{FB}=\mathrm{FB}-99-1588, \mathrm{SA}=\mathrm{SA}-99-0888): 250^{\circ} \mathrm{C}, 1.48 \mathrm{MPa} .2 .0 \mathrm{Nl} / \mathrm{g}$-cat $\cdot h,\left(\mathrm{H}_{2} / \mathrm{CO}\right)=$ 0.67 (FB-2 and $\mathrm{SA}-3$ ) and 1.0 (FB-6 and $\mathrm{SA}-12$ ). 
in balances $6(4.0 \mathrm{NI} / \mathrm{g}$-cat.h $)$ and $7(1.0 \mathrm{NI} / \mathrm{g}$-cat.h), and the effect of feed ratio was studied in balances 8 and $9\left(\mathrm{H}_{2} / \mathrm{CO}=1.03\right)$. With an $\mathrm{H}_{2} / \mathrm{CO}=0.70$ feed, temperature was varied in balances $11\left(265^{\circ} \mathrm{C}\right)$ and $12\left(235^{\circ} \mathrm{C}\right)$. The twelve mass balances completed during this run are summarized in Table VI-3.

The $100 \mathrm{Fe} / 5.0 \mathrm{Cu} / 4.2 \mathrm{~K} / 24 \mathrm{SiO}_{2}$ catalyst was very stable, and the stability plot for the run (up to $457 \mathrm{~h}$ ) is shown in Fig. VI-9. The $\left(\mathrm{H}_{2}+\mathrm{CO}\right)$ conversion decreased from an initial value of $68.7 \%$ to $64.3 \%$ after $457 \mathrm{~h}$. In the repeat of conditions (balance 10, $765 \mathrm{~h}$ ) the conversion was still high, $57.7 \%$, although it is clear that varying the process conditions accelerated the rate of deactivation. The activity was superior to that of the Ruhrchemie $L P$ $33 / 81$ catalyst, whose stability plot for run FB-99-1588 is also shown in Fig. VI-9. The initial activities of both catalysts were approximately equal, but at about $340 \mathrm{~h}$, the Ruhrchemie catalyst gave an $\left(\mathrm{H}_{2}+\mathrm{CO}\right)$ conversion of $44.2 \%$ while our $100 \mathrm{Fe} / 5.0 \mathrm{Cu} / 4.2 \mathrm{~K} / 24 \mathrm{SiO}_{2}$ catalyst gave a conversion of $65.5 \%$. The 24 parts $\mathrm{SiO}_{2}$ catalyst was also more stable, but less active, than the catalyst containing only 8 parts of $\mathrm{SiO}_{2}$. The $\left(\mathrm{H}_{2}+\mathrm{CO}\right)$ conversions at $235^{\circ} \mathrm{C}$ $\left(\mathrm{H}_{2} / \mathrm{CO}=1.0\right)$ obtained with the 8 parts $\mathrm{SiO}_{2}$ catalyst, shown in Fig. VI-9, are higher initially than those obtained with either the 24 parts $\mathrm{SiO}_{2}$ catalyst or the Ruhrchemie LP 33/81 at $250^{\circ} \mathrm{C}\left(\mathrm{H}_{2} / \mathrm{CO}=0.69\right)$. However, the catalyst containing 8 parts $\mathrm{SiO}_{2}$ deactivated rapidly, in spite of being tested at milder conditions $\left(235^{\circ} \mathrm{C}\right)$.

The effect of time on stream on catalyst selectivity is shown in Fig. V1-10. There was a very mild shift towards lighter products as the catalyst aged, a trend which has also been seen with other catalysts. Between 71 (balance 1) and $477 \mathrm{~h}$ (balance 5), methane increased from 5.8 to $6.5 \%$ while the $\mathrm{C}_{12}+$ products decreased from 50.9 to $41.0 \%$. There was no effect of time on the olefin/paraffin ratios measured during the stability portion of the run. In balances 6-9, 11 and 12 , the conditions were varied to study catalyst activity and selectivity at different sets of process conditions. The $\left(\mathrm{H}_{2} \div \mathrm{CO}\right)$ conversions and weight percent hydrocarbon distribution at the different process conditions used in these balances are shown in Fig. VI-11. In this figure, the average results from balances $1-5\left(250^{\circ} \mathrm{C}, 2.0 \mathrm{NI} / \mathrm{g}\right.$-cat. $\left.\mathrm{h}, \mathrm{H}_{2} / \mathrm{CO}=0.69\right)$ and balances 8 and $9\left(250^{\circ} \mathrm{C}, 2.0 \mathrm{NI} / \mathrm{g}\right.$-cat.h, $\left.\mathrm{H}_{2} / \mathrm{CO}=1.0\right)$ are shown. The hydrocarbon distribution is shown as a series of bars and the $\left(\mathrm{H}_{2}+\mathrm{CO}\right)$ conversion is shown as symbols connected by a line. Conversion increases with temperature, which is expected, and the hydrocarbon distribution shifts towards lower molecular weight products. The selectivity trend is weak between $235^{\circ} \mathrm{C}$ (balance 12) and $250^{\circ} \mathrm{C}$ (balances 1-5), however the first five balances do not reflect the effect 
Table VI-3. Summary of results for fixed bed run lib- (66-1948.

Catalyst: $3.40 g^{a}, 100 \mathrm{Fe} / 5.0 \mathrm{Cu} / 4.2 \mathrm{~K} / 24 \mathrm{SiO}_{2}$ Catalyst volume: $4.60 \mathrm{cc}$

Diluent: $36.4 \mathrm{~g}$, Glass beads Diluent Volume: $21.0 \mathrm{cc}$

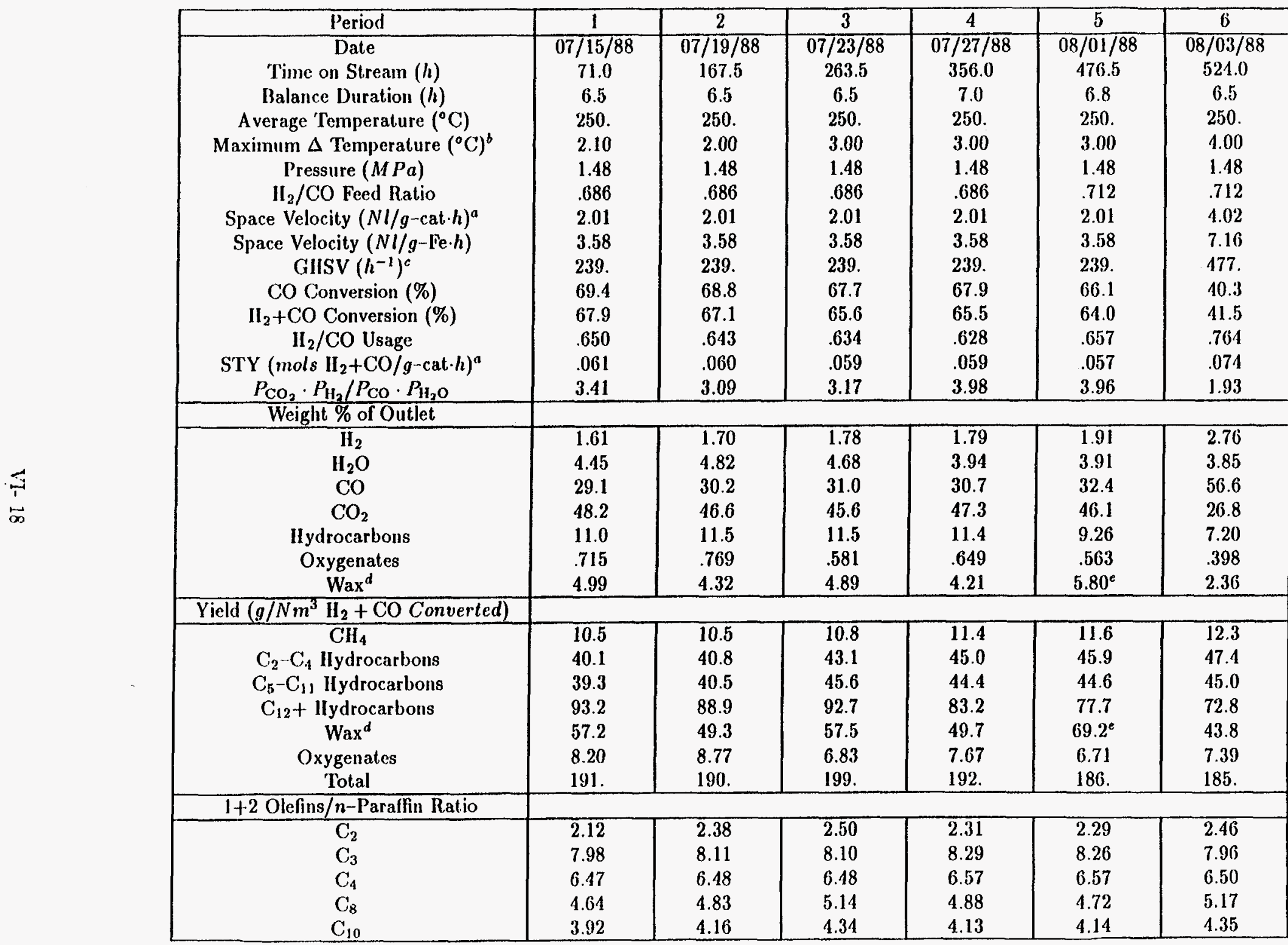

a Based on unreduced catalyst.

Maximum axial temperature difference

${ }^{c}$ Based on catalyst volume

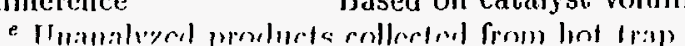


'Table VI-3 (cont'd). Summary of results for fixed bed run FB-66-1948.

\begin{tabular}{|c|c|c|c|c|c|c|}
\hline Period & 7 & 8 & 9 & 10 & 11 & 12 \\
\hline Date & $08 / 05 / 88$ & $08 / 08 / 88$ & $08 / 11 / 88$ & $08 / 13 / 88$ & $08 / 15 / 88$ & $08 / 17 / 88$ \\
\hline Time on Stream $(h)$ & 572.0 & 644.5 & 715.5 & 764.5 & 812.5 & 860.0 \\
\hline Balance Duralion $(h)$ & 8.0 & 6.5 & 7.0 & 6.8 & 6.2 & 6.7 \\
\hline Average Temperature $\left({ }^{\circ} \mathrm{C}\right)$ & 250. & 250. & 250. & 250. & 265 . & 235. \\
\hline Maximum $\Delta$ Temperature $\left({ }^{\circ} \mathrm{C}\right)^{b}$ & 3.00 & 4.00 & 3.00 & 4.00 & 5.00 & 2.00 \\
\hline Pressure $(M P a)$ & 1.48 & 1.48 & 1.48 & 1.48 & 1.48 & 1.48 \\
\hline $\mathrm{II}_{2} / \mathrm{CO}$ Feed Ratio & .712 & 1.03 & 1.03 & .704 & .704 & .704 \\
\hline Space Velocity $(N I / g \text {-cat.h })^{a}$ & 1.01 & 2.01 & 2.01 & 2.01 & 2.01 & 2.01 \\
\hline Space Velocity $(N / / g-\mathrm{Fe} \cdot \boldsymbol{h})$ & 1.79 & 3.58 & 3.58 & 3.58 & 3.58 & 3.58 \\
\hline GIISV $\left(h^{-1}\right)^{c}$ & 120. & 239. & 239. & 239. & 239. & 239. \\
\hline CO Conversion (\%) & 86.4 & 68.5 & 68.3 & 57.7 & 77.7 & 32.4 \\
\hline $\mathrm{H}_{2}+\mathrm{CO}$ Conversion (\%) & 82.3 & 60.6 & 60.6 & 57.7 & 74.1 & 35.5 \\
\hline $\mathrm{II}_{2} / \mathrm{CO}$ Usage & .631 & .800 & .802 & .702 & .626 & .862 \\
\hline $\mathrm{STY}\left(\mathrm{mols} \mathrm{II}_{2}+\mathrm{CO} / \mathrm{g}-\mathrm{cat} \cdot h\right)^{n}$ & .037 & .054 & .054 & .052 & .066 & .032 \\
\hline$P_{\mathrm{CO}_{2}} \cdot P_{\mathrm{H}_{2}} / P_{\mathrm{CO}} \cdot P_{\mathrm{H}_{2} \mathrm{O}}$ & 10.1 & 3.38 & 3.78 & 2.94 & 5.95 & .958 \\
\hline \multicolumn{7}{|l|}{ Weight \% of Outlet } \\
\hline $\mathrm{H}_{2}$ & 1.14 & 3.22 & 3.24 & 2.04 & 1.51 & 2.88 \\
\hline $\mathrm{H}_{2} \mathrm{O}$ & 3.03 & 7.85 & 7.12 & 3.92 & 3.71 & 5.23 \\
\hline $\mathrm{CO}$ & 12.8 & 29.1 & 29.4 & 40.1 & 21.5 & 63.7 \\
\hline $\mathrm{CO}_{2}$ & 60.9 & 42.2 & 43.0 & 40.0 & 55.4 & 19.5 \\
\hline IIydrocarbons & 16.3 & 12.8 & 12.4 & 9.44 & 12.8 & 5.39 \\
\hline Oxygenates & .672 & 1.02 & .907 & .513 & .781 & .625 \\
\hline $\mathrm{Wax}^{d}$ & 5.17 & 3.84 & 3.87 & 4.02 & 4.31 & 2.66 \\
\hline \multicolumn{7}{|l|}{ Yield $\left(g / \mathrm{Nm}^{3} \mathrm{H}_{2}+\mathrm{CO}\right.$ Converted $)$} \\
\hline $\mathrm{CH}_{4}$ & 12.1 & 14.7 & 14.3 & 11.7 & 15.1 & 10.7 \\
\hline $\mathrm{C}_{2}-\mathrm{C}_{4}$ llydrocarbons & 47.9 & 53.6 & 51.8 & 43.8 & 49.6 & 42.9 \\
\hline $\mathrm{C}_{5}-\mathrm{C}_{11}$ Hydrocarbons & 58.6 & 45.8 & 45.0 & 43.4 & 45.5 & 37.3 \\
\hline $\mathrm{C}_{12}+$ Ilydrocarbons & 83.0 & 68.1 & 67.0 & 81.6 & 65.4 & 85.7 \\
\hline $\mathrm{Wax}^{d}$ & 48.6 & 42.2 & 42.3 & 53.9 & 44.2 & 58.4 \\
\hline Oxygenates & 6.32 & 11.2 & 9.91 & 6.88 & 8.01 & 13.7 \\
\hline Total & 208. & 193. & 188. & 187. & 184. & 190. \\
\hline \multicolumn{7}{|l|}{$1+2$ Olefins/n-Paralfin Ratio } \\
\hline $\mathrm{C}_{2}$ & 1.70 & 2.11 & 2.28 & 2.57 & 1.56 & 3.17 \\
\hline $\mathrm{C}_{3}$ & 8.38 & 6.91 & 6.99 & 8.15 & 8.54 & 7.18 \\
\hline $\mathrm{C}_{4}$ & 6.67 & 5.55 & 5.61 & 6.62 & 7.04 & 5.94 \\
\hline $\mathrm{C}_{8}$ & 4.80 & 4.04 & 4.08 & 4.67 & 4.80 & 4.60 \\
\hline $\mathrm{C}_{10}$ & 3.87 & 3.12 & 3.54 & 4.14 & 3.72 & 3.56 \\
\hline
\end{tabular}

a I3ased on unreduced catalyst

c Based on catalyst volume
${ }^{6}$ Maximum axial temperalure difference

${ }^{d}$ Unrecovered products from wax analysis 


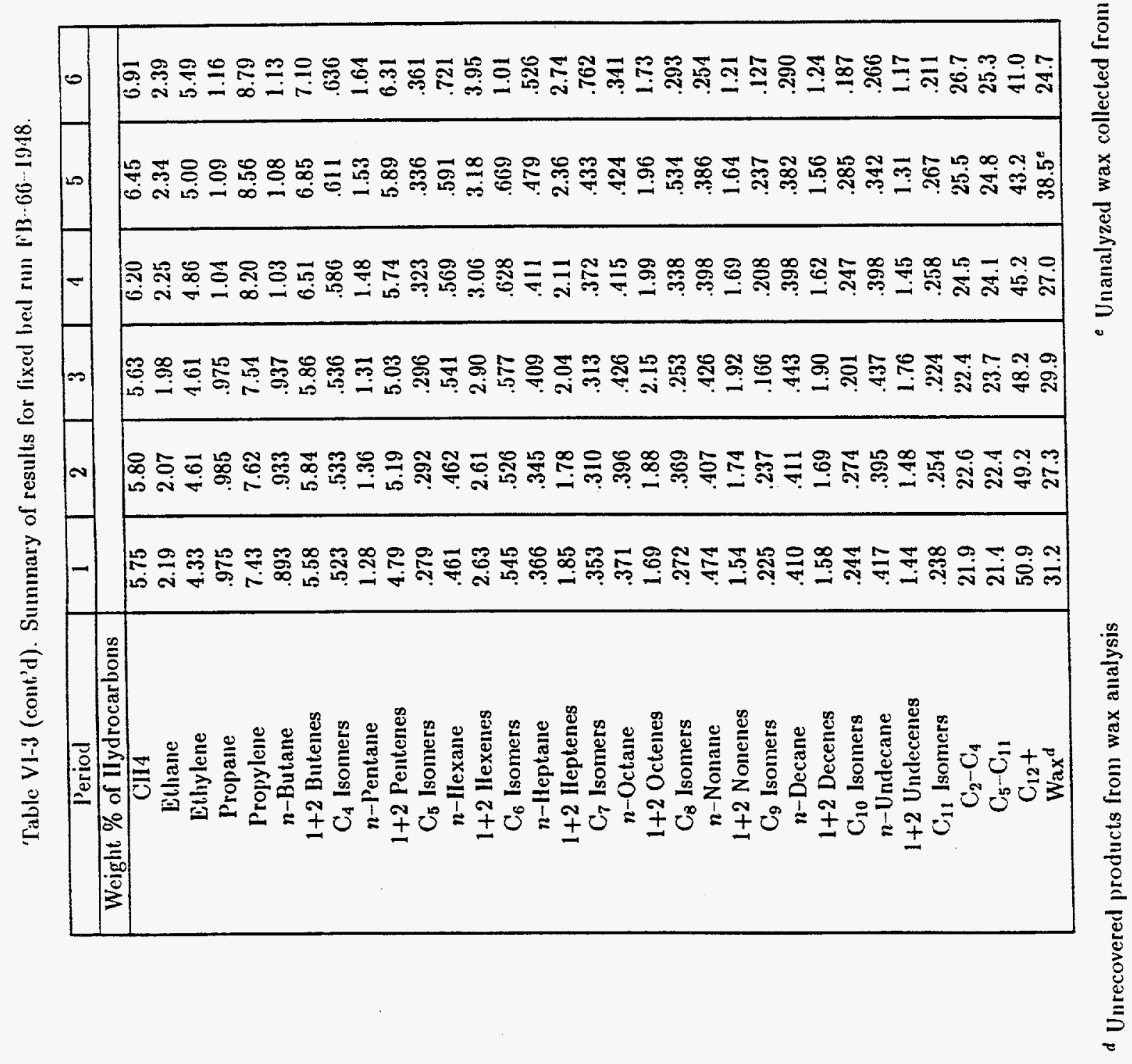




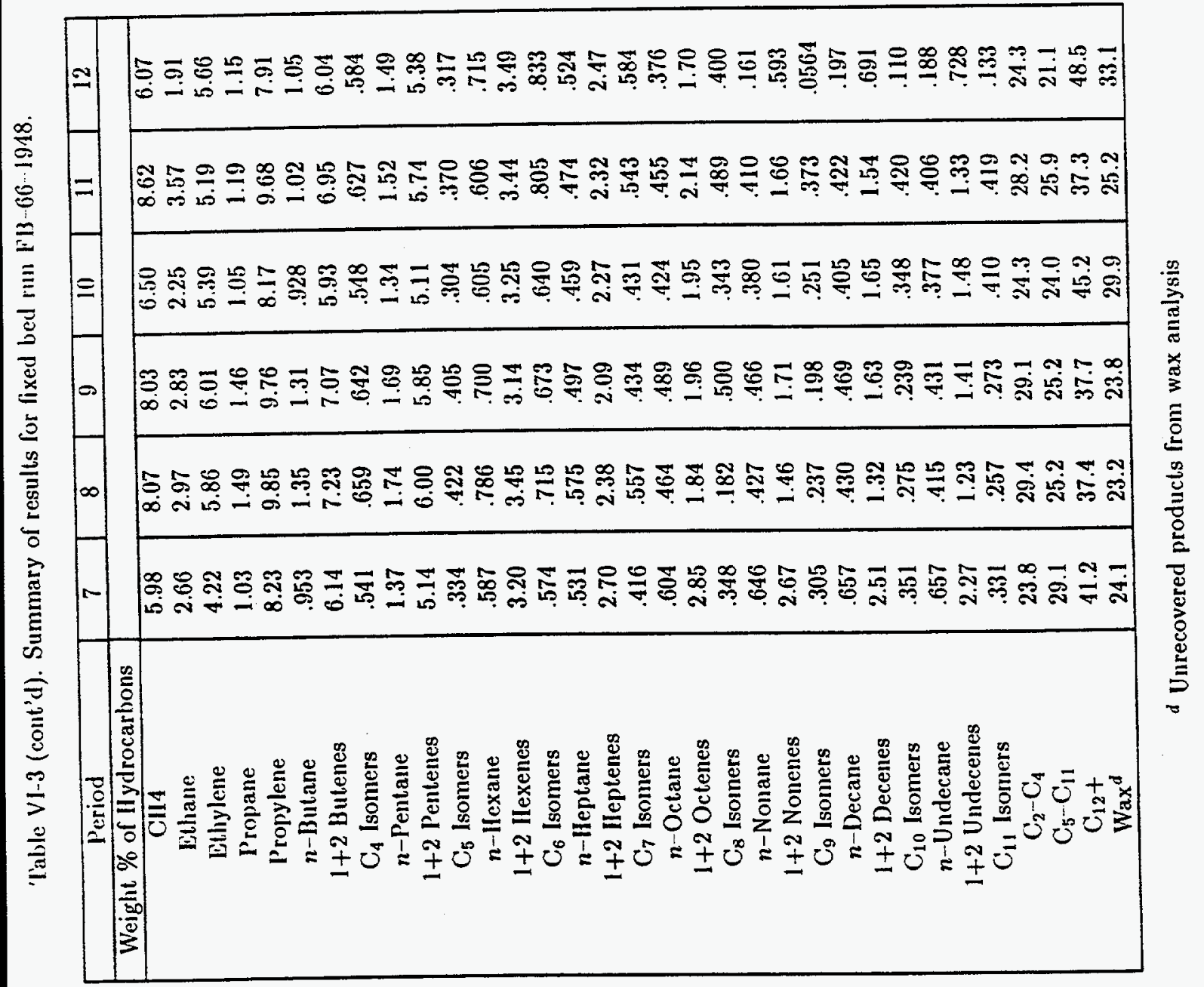




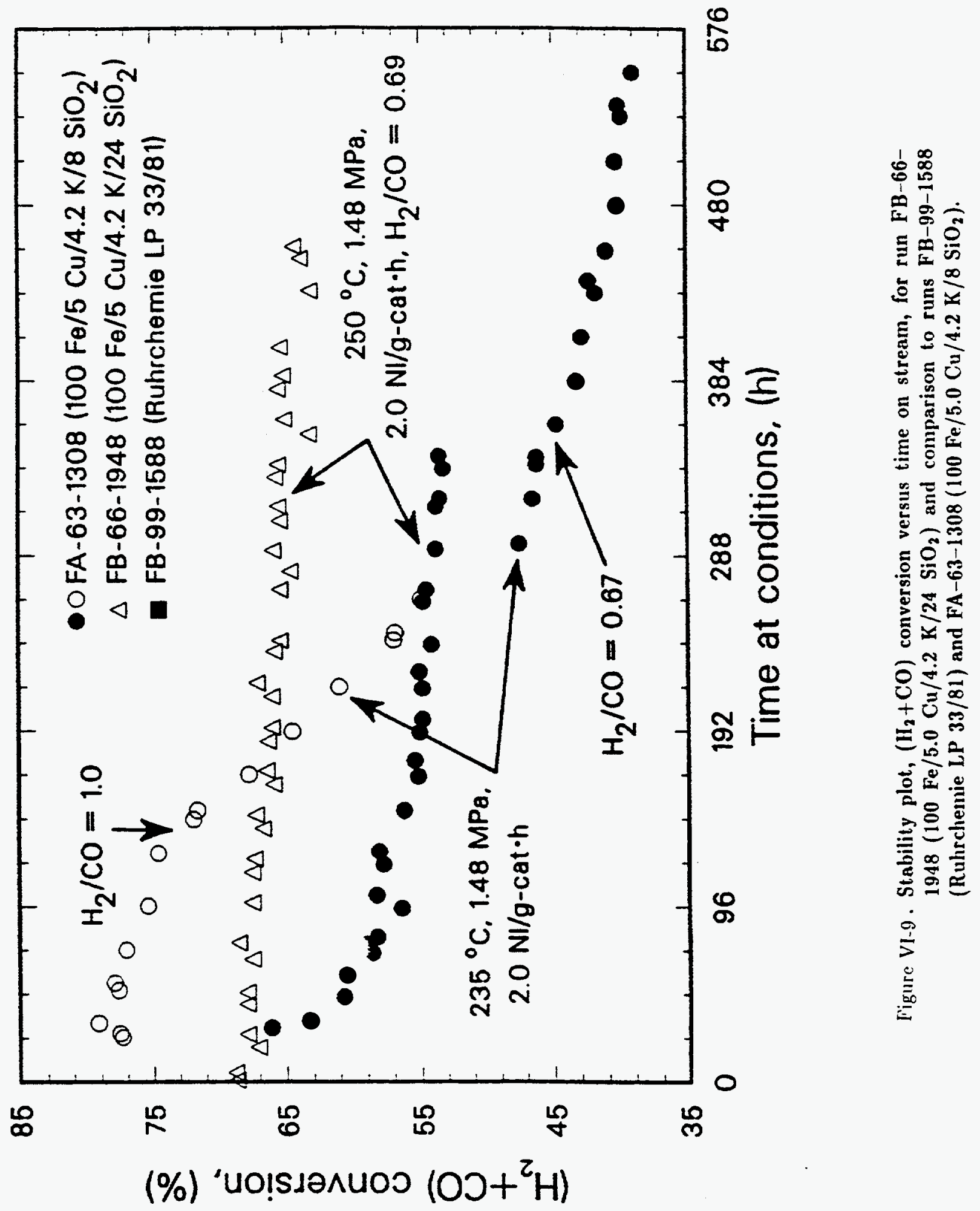



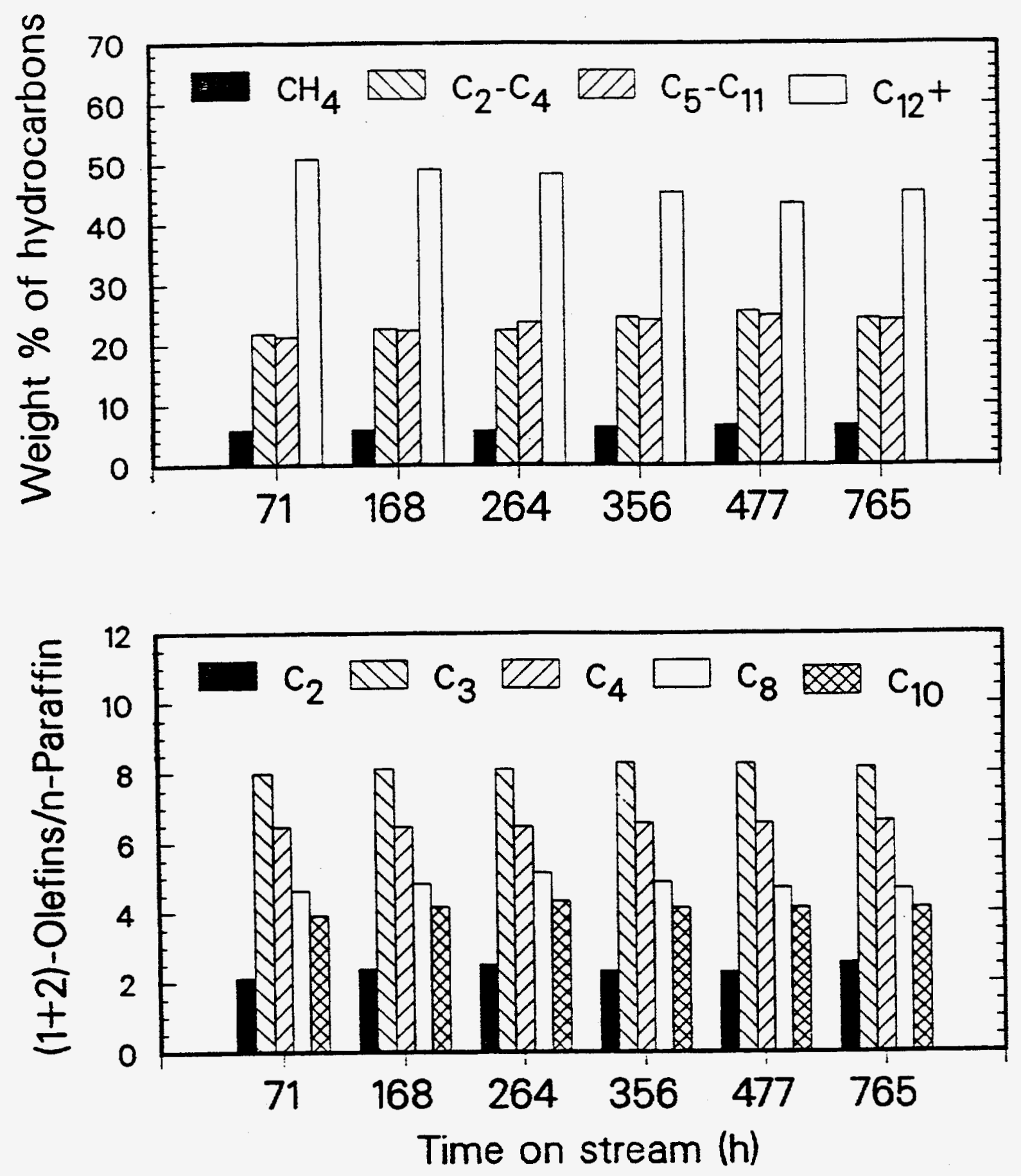

Figure VI-10. Effect of time on stream on catalyst selectivity for run FB-66-1948 (100 Fe/5.0 $\left.\mathrm{Cu} / 4.2 \mathrm{~K} / 24 \mathrm{SiO}_{2}\right) \cdot\left(250^{\circ} \mathrm{C}, 1.48 \mathrm{MPa}, 2.0 \mathrm{Nl} / g\right.$-cat $\left.\cdot h, \mathrm{H}_{2} / \mathrm{CO}=0.69\right)$. 


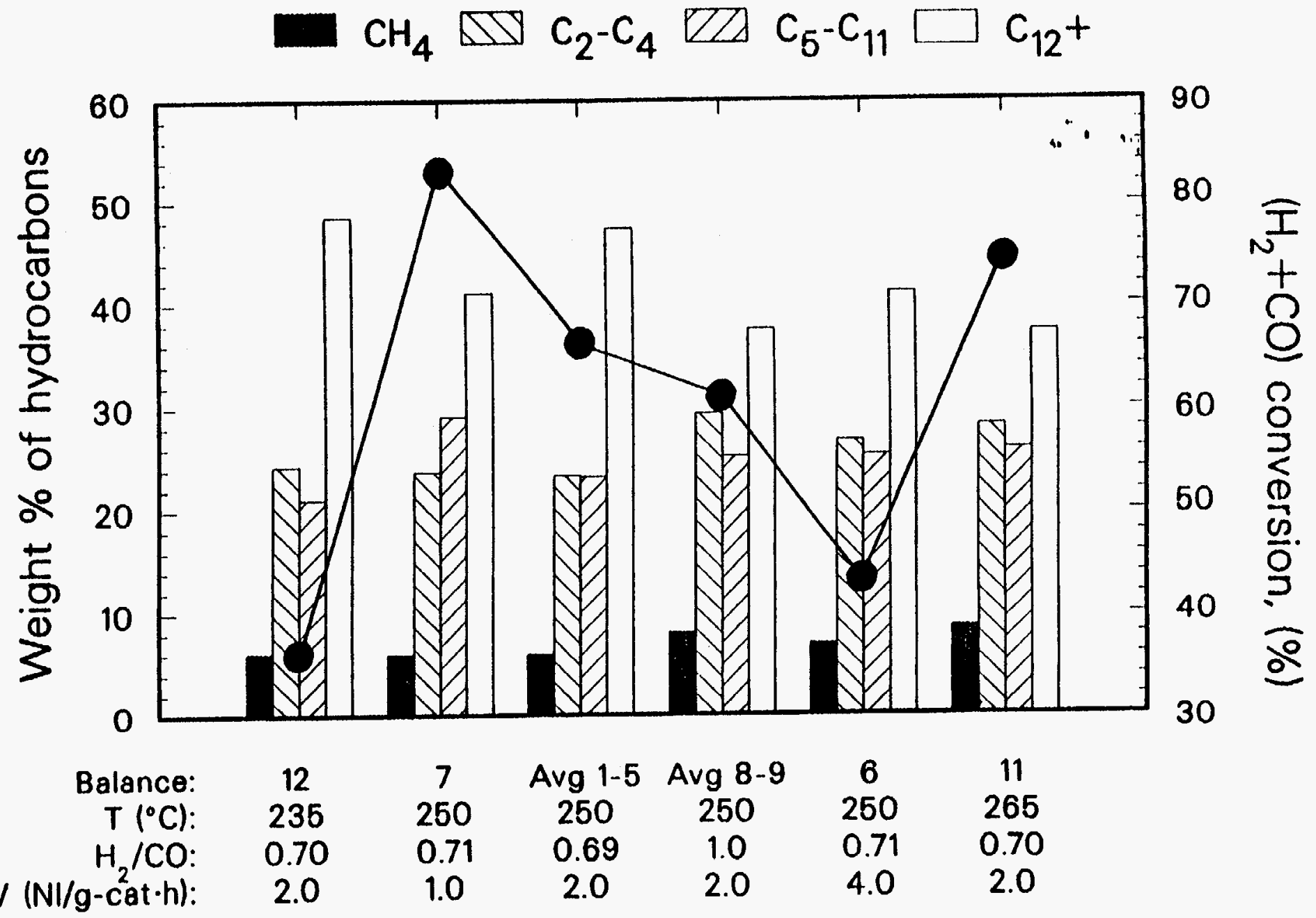

Figure VI-11. Effect of process conditions on catalyst activity and selectivity for run FB-66 $1948\left(100 \mathrm{Fe} / 5.0 \mathrm{Cu} / 4.2 \mathrm{~K} / 24 \mathrm{SiO}_{2}\right)$. 
of deactivation on selectivity. Deactivation causes more methane to be formed. For example, in balances 12,10 , and 11 at 235,250 , and $265^{\circ} \mathrm{C}$, respectively, $\mathrm{CH}_{4}$ increases from 6.1 to 6.5 and $8.6 \%$ while $\mathrm{C}_{12}+$ decreases from 48.5 to 45.2 and $37.3 \%$. The space velocity was varied at $250^{\circ} \mathrm{C}$ in balances $7,1-5$, and 6 at $1.0,2.0$, and $4.0 \mathrm{NI} / \mathrm{g}$-cat.h. Conversion decreased with higher space velocity, and there was no clear effect on the hydrocarbon distribution. The $\mathrm{CH}_{4}$ and $C_{2}-C_{4}$ fractions remained fairly constant, while shifting occurred between the $C_{5}-C_{11}$ and $\mathrm{C}_{12}+$ products. The conversion using a higher $\mathrm{H}_{2} / \mathrm{CO}$ feed ratio was lower than the initial conversion, decreasing from an average $66 \%$ (balances $1-5, \mathrm{H}_{2} / \mathrm{CO}=0.69$ ) to $60.6 \%$ (balances $\left.8-9, \mathrm{H}_{2} / \mathrm{CO}=1.0\right)$, but this may be due to catalyst deactivation. The $\left(\mathrm{H}_{2}+\mathrm{CO}\right)$ conversion obtained in balance 10 at the same conditions with $\mathrm{H}_{2} / \mathrm{CO}=0.70$ was only $57.7 \%$. Less $\mathrm{C}_{12}+$ products and more gaseous hydrocarbons were produced using the $\mathrm{H}_{2} / \mathrm{CO}=1$ feed ratio than in any of the balances $(1-5,10)$ using the lower feed ratio, which we have also observed in tests with other catalysts.

The selectivities obtained during the stability test of the 24 parts $\mathrm{SiO}_{2}$ catalyst are compared to those obtained in the stability tests of 8 parts $\mathrm{SiO}_{2}$ catalyst and Ruhrchemie LP 33/81 catalyst (runs FA-63-1308 and FB-99-1588) in Fig.VI-12. Lower silica concentration improves production of $\mathrm{C}_{12}+$ products and decreases the fractions of $\mathrm{CH}_{4}$ and $\mathrm{C}_{2}-\mathrm{C}_{4}$. Similar results were obtained during the initial tests of these catalysts. The 8 parts $\mathrm{SiO}_{2}$ catalyst also had higher initial activity, but it deactivated more rapidly than the catalyst with 24 parts $\mathrm{SiO}_{2}$. The selectivities of the 24 parts $\mathrm{SiO}_{2}$ catalyst and the Ruhrchemie catalyst are very similar, while our catalyst is more stable.

\section{VI.2. Fixed Bed Reactor Tests with Unsupported Precipitated Iron Catalysts}

\section{VI.2.1. Runs FA - 15 - $1698 / \mathrm{FA}-15-1768$ with the $100 \mathrm{Fe} / 1 \mathrm{Cu} / 0.2 \mathrm{~K}$ Catalyst}

Runs FA-15-1698 and FA-15-1768 were made to evaluate the performance of a precipitated catalyst ( $100 \mathrm{Fe} / 1 \mathrm{Cu} / 0.2 \mathrm{~K}$ ) over the long period of time in a fixed bed reactor. For both runs, $30 / 60$ mesh catalysts were employed and the catalyst was reduced with $\mathrm{CO}$ at $280^{\circ} \mathrm{C}$ for $16 \mathrm{~h}$. Following the activation treatment, the catalyst was tested at a fixed set of operating conditions $\left(235^{\circ} \mathrm{C}, 1.48 \mathrm{MPa}, 2.0 \mathrm{NI} / \mathrm{g}\right.$-cat. $\left.\mathrm{h}, \mathrm{H}_{2} / \mathrm{CO}=0.71\right)$. Rapid deactivation occurred during both tests. Only a single mass balance was completed in run FA-15-1698 before it was terminated due to the deactivation. During the retest, run FA-15-1768, 6 mass balances were completed. The first two mass balances (up to $175 \mathrm{~h}$ ) were made at the conditions above, and balances 3 and 4 (up to $367 \mathrm{~h}$ ) were made using $\mathrm{H}_{2} / \mathrm{CO}=1.03$ feed gas. During balances 5 

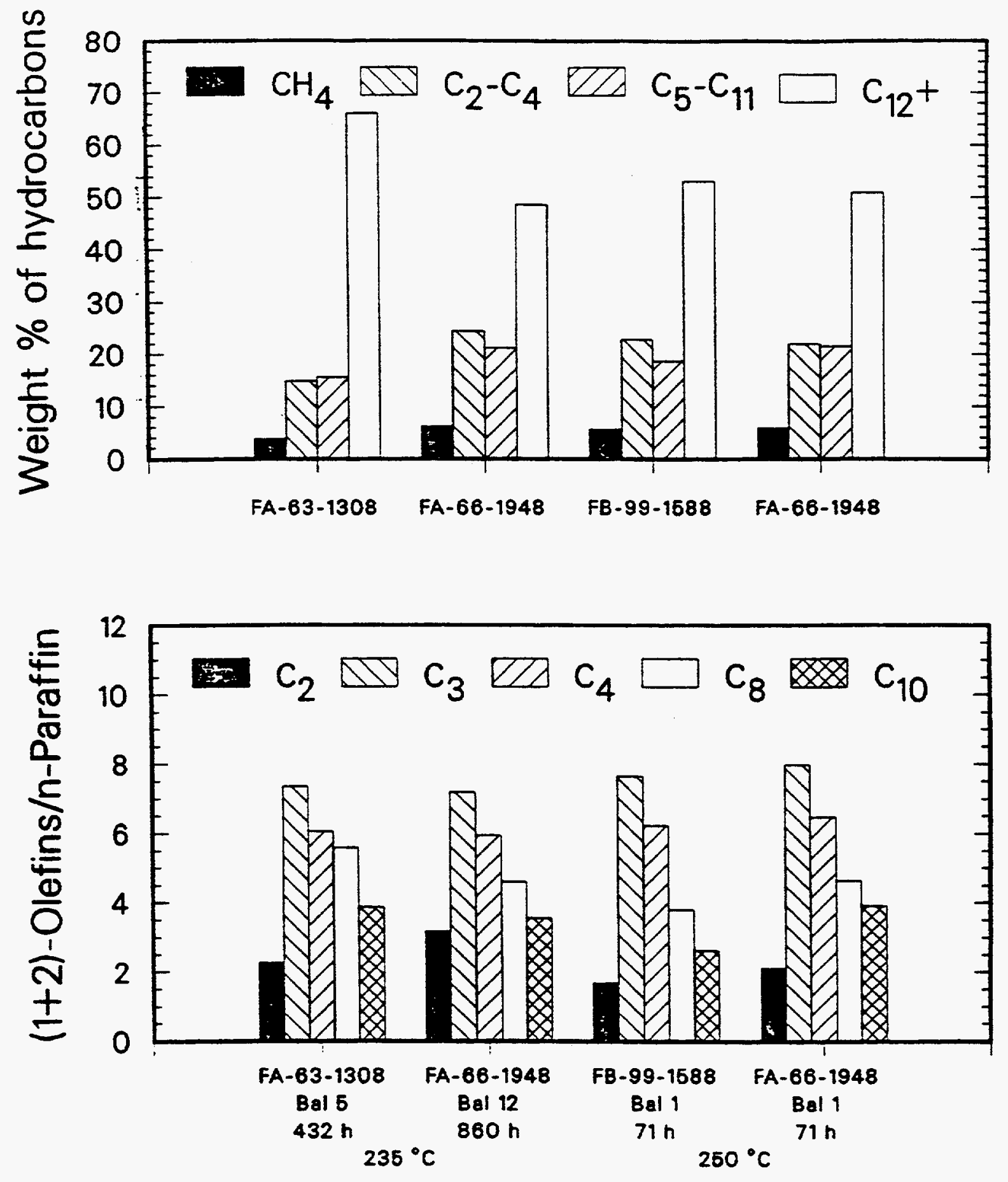

Figure VI-12. Comparison of catalyst selectivity for $100 \mathrm{Fe} / 5.0 \mathrm{Cu} / 4.2 \mathrm{~K} / 8$ and $24 \mathrm{SiO}_{2}$ catalysts and Ruhrchemie LP 33/81. $\left(2.0 \mathrm{Nl} / \mathrm{g}\right.$-cat. $h, 1.48 \mathrm{MPa}, \mathrm{H}_{2} / \mathrm{CO}=$ 0.67 nominal). 


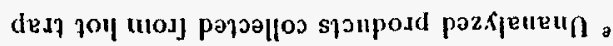

sisfiene xem monj sponposd pajasomajun

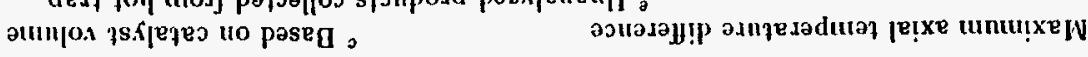

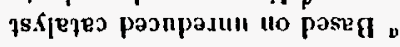

\begin{tabular}{|c|c|c|c|c|c|c|c|}
\hline $\begin{array}{l}6 \varrho^{\prime} \\
\subseteq 8^{\prime} \mathrm{c} \\
68.9 \\
69.2 \\
08^{\circ} 1 \\
\end{array}$ & $\begin{array}{l}08 \cdot V \\
L 1 \cdot C \\
9.9 \\
6 E^{\circ} L \\
6 L 1 \\
\end{array}$ & $\begin{array}{l}86 \% \\
16^{\circ} 6 \\
06^{\circ} \subseteq \\
819 \\
57 \%\end{array}$ & 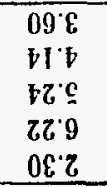 & 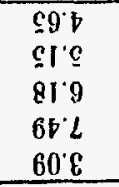 & $\begin{array}{l}007 \\
06 \% \\
86.9 \\
008 \\
918 \\
\end{array}$ & $\begin{array}{l}L ' b \\
Z 0^{\prime} \subseteq \\
2 L 9 \\
20 \% \\
L E Z\end{array}$ & 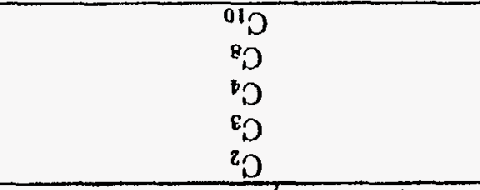 \\
\hline & & & & & & & 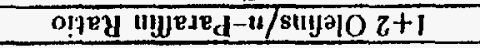 \\
\hline 881 & . & 761 & 561 & 108 & $68 \mathrm{I}$ & 161 & 1E70L \\
\hline 419 & 06 도 & $\mathrm{I} \cdot 6$ & 211 & 186 & $\angle 01$ & $20 L$ & sefeua8,5xO \\
\hline $0.9 \mathrm{c}$ & $\varepsilon z 9$ & $\mathcal{E} L \mathrm{C}$ & 769 & 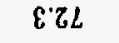 & C. 89 & 2062 & $p^{\mathrm{Xe} M}$ \\
\hline 201 & ' 101 & 801 & $\cdot 901$ & $\cdot \mathbf{I Z I}$ & 101 & 106 & suoqdejosp. $S_{I I}+{ }^{21} D$ \\
\hline$\tau \in \varepsilon$ & $0^{\prime} \mid \mathcal{E}$ & DIE & $68 \varepsilon$ & $6.6 \varepsilon$ & 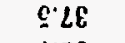 & Let & suoqJesojp. II "D-'D \\
\hline$z: 98$ & 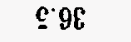 & $\varepsilon \cdot \tilde{E}$ & $0^{\prime}$ bE & 62 & LZ\& & 56 & suoqdesoupsh ${ }^{2}{ }^{2}$ \\
\hline$\underline{\underline{c}} 0 \mathrm{I}$ & $\underline{c} 01$ & $9 \underline{9} 8$ & 628 & E.9 & $8 \mathrm{~T}^{\prime} \mathrm{L}$ & $\lfloor 9 \cdot 8$ & "ID \\
\hline & & & & & & & 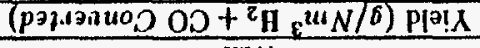 \\
\hline $18: 6$ & 897 & $\overline{D E Z}$ & $88 \cdot 7$ & 267 & $\varepsilon b \cdot \varepsilon$ & .669 & $p^{x e}, M$ \\
\hline$\underline{c} \cdot 0$ & $\mathfrak{q} 0$ & 88.0 & I!n 0 & $0 b^{\prime} 0$ & $80^{\circ} 0$ & 860 & sә\}еแว8.א $x_{O}$ \\
\hline$I Z \cdot c$ & $00 \div$ & EI? & 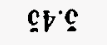 & 68.6 & $6 I^{\circ} 9$ & $6 \mathrm{IL}^{\circ} \mathrm{L}$ & suoqseoosp.fII \\
\hline † ZZ & $I \varepsilon z$ & 6 ו & C.LI & 021 & $Z \varepsilon Z$ & $\mathrm{I} e \mathrm{~g}$ & ${ }^{\varepsilon} \mathrm{OO}$ \\
\hline $9 \div 9$ & 789 & $7: 29$ & $1 \cdot 69$ & $\checkmark 29$ & 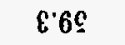 & $b \cdot 0 b$ & OD \\
\hline$\angle 81$ & $0 \mathrm{I} Z$ & $I L \mathcal{E}$ & $6 b^{\circ} b$ & $80^{\circ} \mathrm{b}$ & 896 & $80^{\circ} \mathrm{V}$ & $\mathrm{O}^{2} \mathrm{II}$ \\
\hline $0 \cdot \varepsilon$ & 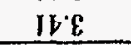 & $\varepsilon \varepsilon$ & $\$ 0^{\circ} \mathrm{C}$ & $\not z \varepsilon$ & $0 L Z$ & $08 \%$ & ${ }^{\mathbf{z}} \mathbf{I}$ \\
\hline & & & & & & & 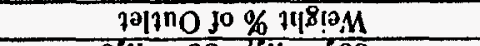 \\
\hline 098 & $0 \bar{Q} \varepsilon$ & $\overline{06.1}$ & 021 & $0 \pi 1$ & $0 \varepsilon^{\prime} 1$ & $00^{\circ} 8$ & 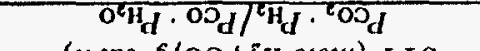 \\
\hline $880^{\circ}$ & $620^{\circ}$ & $620^{\circ}$ & $\angle Z 0^{\circ}$ & $880^{\circ}$ & $\angle \& 0^{\circ}$ & $\angle 0^{\circ}$ & ${ }_{v}\left(4 \cdot p^{e 0-6} / 00+{ }^{\varepsilon} H\right.$ sjou $)$ X.LS \\
\hline $029^{\circ}$ & $099^{\circ}$ & $098^{\circ}$ & $006^{\circ}$ & $088^{\circ}$ & $088^{\circ}$ & $0 Z L$ & วges $0 . /^{z} \mid 1$ \\
\hline 9. IE & $\llcorner: z \&$ & ع.9Z & $8 \cdot 6 z$ & E.18 & III & 9 'Ze & (\%) иo!ssasuop $O D+{ }^{\varepsilon} I I$ \\
\hline 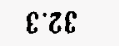 & ole & 066 & 818 & $\subseteq 6 z$ & $78 \varepsilon$ & cze & (\%) "Io!suantoD OD \\
\hline 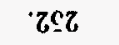 & $z \underline{z}$ & $z \subseteq z$ & $z \subseteq z$ & $z \simeq z$ & z⿻冖 & -9eE & $2(1-4) \Lambda$ SHD \\
\hline $68 \%$ & $68 \%$ & $68 \%$ & 687 & $68 \%$ & $68^{\circ} \%$ & 167 & 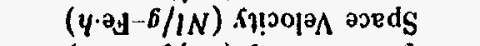 \\
\hline $00 \%$ & $00 \%$ & $00 \%$ & $00 \%$ & 007 & $00 \%$ & 102 & 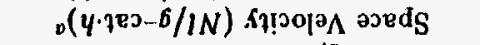 \\
\hline$Z I L$ & 212 & $80^{\circ} 1$ & 80.1 & 212 & 212 & ZIL & o!pey paad $O D /^{\varepsilon} I I$ \\
\hline $8 b^{\prime} 1$ & $8 * 1$ & $80_{1}$ & 86.1 & 86.1 & $86^{\circ} \mathrm{I}$ & $801 \mathrm{~T}$ & $\left(v_{d} W\right)^{2}$ onssedd \\
\hline $0 \mathrm{r} z$ & 091 & $09 \cdot 2$ & $06 \%$ & $0 \notin \varepsilon$ & $0 \varepsilon^{\prime} \varepsilon$ & 012 & $q\left(D_{0}\right)$ arnzesadua $L \nabla$ umu!xe $N$ \\
\hline $0 \subseteq$ & 007 & ' & 'ckz & 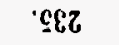 & $\checkmark \varepsilon Z$ & 's\&z & 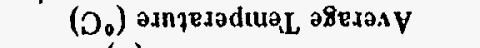 \\
\hline$Z: L$ & $0 \%$ & 8.2 & 12 & 92 & 89 & $\stackrel{c}{c} L$ & 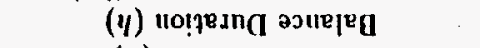 \\
\hline 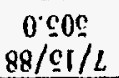 & $\begin{array}{c}0.9 c t \\
88 / \varepsilon 1 / L\end{array}$ & $\begin{array}{c}0.6 \mathrm{c} \varepsilon \\
88 / 6 / 2\end{array}$ & $\begin{array}{c}c \cdot 697 \\
88 / \check{c} / 2\end{array}$ & $\begin{array}{c}0.891 \\
88 / 1 / 2\end{array}$ & $\begin{array}{c}0 Z 2 L \\
88 / L Z / 9\end{array}$ & $\begin{array}{c}26 C \\
88 / 6 \mathrm{I} / 9\end{array}$ & 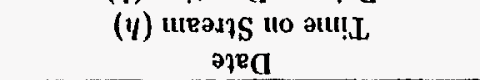 \\
\hline 9 & $\underline{\mathrm{c}}$ & 1 & 8 & 2 & 1 & 1 & po!jod \\
\hline \multicolumn{6}{|c|}{$99 L I-C I-V A$} & $869 \mathrm{~J}-\mathrm{C}=\mathrm{I}-\mathrm{HA}$ & uny \\
\hline
\end{tabular}

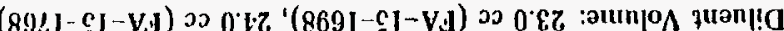

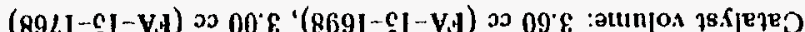

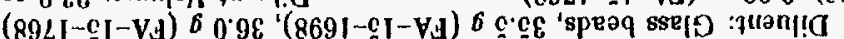

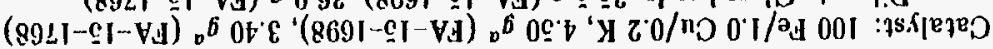

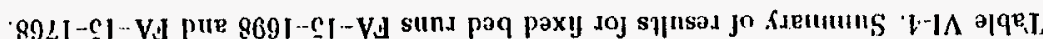


'Table VI-4 (cont'd). Summary of results for fixed bed rums FA $15-1698$ and FA-15-1768.

\begin{tabular}{|c|c|c|c|c|c|c|c|}
\hline Run & $F A-15-1698$ & \multicolumn{6}{|c|}{ FA-15-1768 } \\
\hline Period & 1 & $T$ & $\overline{2}$ & 3 & $\overline{4}$ & $\bar{j}$ & 6 \\
\hline \multicolumn{8}{|c|}{ Weight \% of Ilydrocarbons } \\
\hline$\overline{C 114}$ & 4.72 & 4.03 & 3.42 & 4.54 & 4.68 & $\overline{5.87}$ & $\overline{5.78}$ \\
\hline Ethane & 1.89 & 1.37 & 1.21 & 1.83 & 1.91 & 2.40 & 2.31 \\
\hline Ethylene & 4.17 & 4.01 & 3.49 & 3.93 & 3.98 & 4.01 & 3.88 \\
\hline Propane & .93 & .78 & .69 & 1.00 & 1.00 & .93 & .88 \\
\hline Propylene & 7.12 & 5.98 & 4.90 & 5.91 & 5.90 & 6.47 & 6.39 \\
\hline n-Butane & .89 & .80 & .67 & .90 & .91 & .80 & .75 \\
\hline 1+2 Butenes & $\overline{5} .80$ & 4.89 & 3.98 & 4.54 & 4.56 & 5.09 & 4.97 \\
\hline $\mathrm{C}_{4}$ Isomers & .61 & .51 & .41 &.$\overline{0} 0$ & .51 & .73 & .70 \\
\hline n-Pentane & 1.40 & 1.24 & 1.03 & 1.25 & 1.27 & 1.26 & 1.21 \\
\hline $1+2$ Pentenes & 5.37 & 4.65 & 3.78 & 4.11 & 4.13 & $4.6 \bar{\jmath}$ & 4.57 \\
\hline $\mathrm{C}_{5}$ Isomers & .30 & .25 & .22 & .29 & .31 & .31 & .29 \\
\hline$n$-IIexane & .64 & .58 & .54 & .65 & .56 & .48 & .56 \\
\hline 1+2 Hexenes & 3.24 & 3.01 & 2.78 & 2.88 & 2.34 & 2.37 & 3.20 \\
\hline $\mathrm{C}_{6}$ Isomers & .68 & .61 & .56 & .69 & .54 & .67 & .73 \\
\hline$n$-Ileptane & .48 & .38 & .37 & .41 & .37 & .29 & .31 \\
\hline 1+2 lleptenes & 2.33 & 1.94 & 1.83 & 1.76 & 1.55 & 1.34 & 1.68 \\
\hline $\mathrm{C}_{7}$ Isomers & .49 & .41 & .50 & .35 & .31 & .54 & .67 \\
\hline n-Octane & .41 & .26 & .24 & .36 & .22 & .16 & .17 \\
\hline $1+2$ Octenes & 2.03 & 1.24 & 1.22 & $1.4 \bar{j}$ & .93 & .82 & .91 \\
\hline $\mathrm{C}_{8}$ Isomers & .36 & .09 & .05 & .15 & .06 & .07 & .16 \\
\hline$n$-Nonane & .36 & .31 & .18 & .21 & .16 & .17 & .16 \\
\hline $1+2$ Nonenes & 1.78 & 1.31 & .94 & .81 & .77 & .89 & .77 \\
\hline $\mathrm{C}_{9}$ Isomers & .20 & .11 & .05 & .05 & .05 & .07 & .06 \\
\hline$n$-Decane & .40 & .41 & .31 & .31 & .30 & $.2 j$ & .23 \\
\hline 1+2 Decenes & 1.85 & 1.69 & 1.42 & 1.11 & 1.18 & 1.20 & 1.01 \\
\hline $\mathrm{C}_{10}$ Isomers & .29 & .24 & .12 & .10 & .11 & .12 & .11 \\
\hline n-Undecane & .35 & .42 & .35 & .34 & .35 & .28 & $.2 \overline{0}$ \\
\hline I+2 Undecenes & 1.58 & 1.57 & 1.55 & 1.17 & 1.29 & 1.23 & 1.07 \\
\hline $\mathrm{C}_{11}$ Isoniers & .31 & .29 & .20 & .14 & .15 & .19 & .15 \\
\hline $\mathrm{C}_{2}-\mathrm{C}_{4}$ & 21.4 & 18.3 & 15.3 & 18.6 & 18.8 & 20.4 & 19.9 \\
\hline $\mathrm{C}_{5}-\mathrm{C}_{11}$ & 24.9 & 21.0 & 18.2 & 18.6 & 17.2 & 17.4 & 18.3 \\
\hline $\mathrm{C}_{12}+$ & 49.0 & 56.6 & 63.0 & 58.3 & 59.4 & 56.3 & 56.1 \\
\hline$W_{a x}^{d}$ & $43.0^{e}$ & 35.6 & 37.8 & 34.6 & 31.3 & 34.9 & 30.7 \\
\hline
\end{tabular}

d Unrecovered products from wax analysis

- Unanalyzed wax collected from hot trap 
and 6 (up to $511 \mathrm{~h}$ ), the temperature was increased to $250^{\circ} \mathrm{C}$ and a $\mathrm{H}_{2} / \mathrm{CO}=0.71$ feed gas was used. The results for both runs FA-15-1698 and FA-15-1768 are summarized in Table VI-4.

With the exception of run FA-15-2097 (Section V.2.2), the $100 \mathrm{Fe} / 1.0 \mathrm{Cu} / 0.2 \mathrm{~K}$ catalyst deactivated quickly during catalyst testing. In the last two tests, the initial activity of the catalyst was high, but decreased with time. The stability plot for the two runs is shown in Fig. VI-13. In run FA-15-1768, the $\left(\mathrm{H}_{2}+\mathrm{CO}\right)$ conversion dropped from $59.1 \%$ at $25.5 \mathrm{~h}$ to $31.2 \%$ at $175 \mathrm{~h}$. Switching to an $\mathrm{H}_{2} / \mathrm{CO}=1.03$ synthesis gas increased conversion slightly to $33.7 \%$ at $191 \mathrm{~h}$, but the catalyst continued to deactivate. At these same nominal conditions $\left(235^{\circ} \mathrm{C}\right.$, $1.48 \mathrm{MPa}, 2.0 \mathrm{NI} / \mathrm{g}$-cat.h, $\mathrm{H}_{2} / \mathrm{CO}=1.0$ ) during the successful run $\mathrm{FA}-15-2097$, the $\mathrm{H}_{2} / \mathrm{CO}$ conversion was $72.9 \%$. The increase in temperature to $250^{\circ} \mathrm{C}$ at about $392 \mathrm{~h}$ increased the conversion to only $34.5 \%$.

Product selectivities obtained from these two tests (FA-15-1698/FA-15-1768) of the 100 $\mathrm{Fe} / 1.0 \mathrm{Cu} / 0.2 \mathrm{~K}$ catalyst are shown in Fig. VI- $14\left(235^{\circ} \mathrm{C}, \mathrm{H}_{2} / \mathrm{CO}=0.71\right)$. The hydrocarbon selectivity during the first test was more towards lower molecular weight hydrocarbons than that obtained during the retest, and the $\mathrm{C}_{12}+$ weight percent decreased from $63 \%$ to $49 \%$ (balance 1) between the two runs. A comparison of the selectivity for run FA-15-1768 and the two previous tests (FA-15-2097, Technical Progress Report for 1 July-30 September 1987; FA-15-0278, Technical Progress Report for 1 January-31 March 1988) is shown in Fig. VI-15 $\left(235^{\circ} \mathrm{C}, \mathrm{H}_{2} / \mathrm{CO}=1.0\right.$, nominal). The test results from $\mathrm{FA}-15-1768$ show higher selectivity to high molecular weight products with a substantially greater $\mathrm{C}_{12}+$ fraction of hydrocarbons. The olefin/paraffin ratios are also higher than in previous tests, although this may be due to the deactivation of the catalyst. The $\left(\mathrm{H}_{2}+\mathrm{CO}\right)$ conversions for the four balances shown in Fig. Vl-15 were 29.8 (balance 3 ) and $26.5 \%$ (balance 4 ) in run FA-15-1768, 72.9\% in run FA-152097 , and $44.7 \%$ in run FA-15-0278, and the differences in conversion may have affected the olefin/paraffin ratios. There was no significant effect of time on stream on the weight percent hydrocarbon distribution during Run FA-15-1768 at any of the 3 sets of conditions used.

V1.2.2. Runs FB $-27-2438 / F A-27-2518$ with the $100 \mathrm{Fe} / 3.0 \mathrm{Cu} / 0.5 \mathrm{~K}$ Catalyst

Runs FB-27-2438 and FA-27-2518 were made as long term stability tests of the $100 \mathrm{Fe} / 3.0$ $\mathrm{Cu} / 0.5 \mathrm{~K}$ catalyst. This catalyst was tested previously during the Promoter Effect Research portion of this investigation in runs FA-27-2557 and FB-27-3368 (Technical Progress Reports for 1 July-30 September 1988 and 1 October - December 31, 1988, respectively. Also, see Sections V.2.1.3 and V.2.3). The two most recent runs differed in the procedure used to acti- 


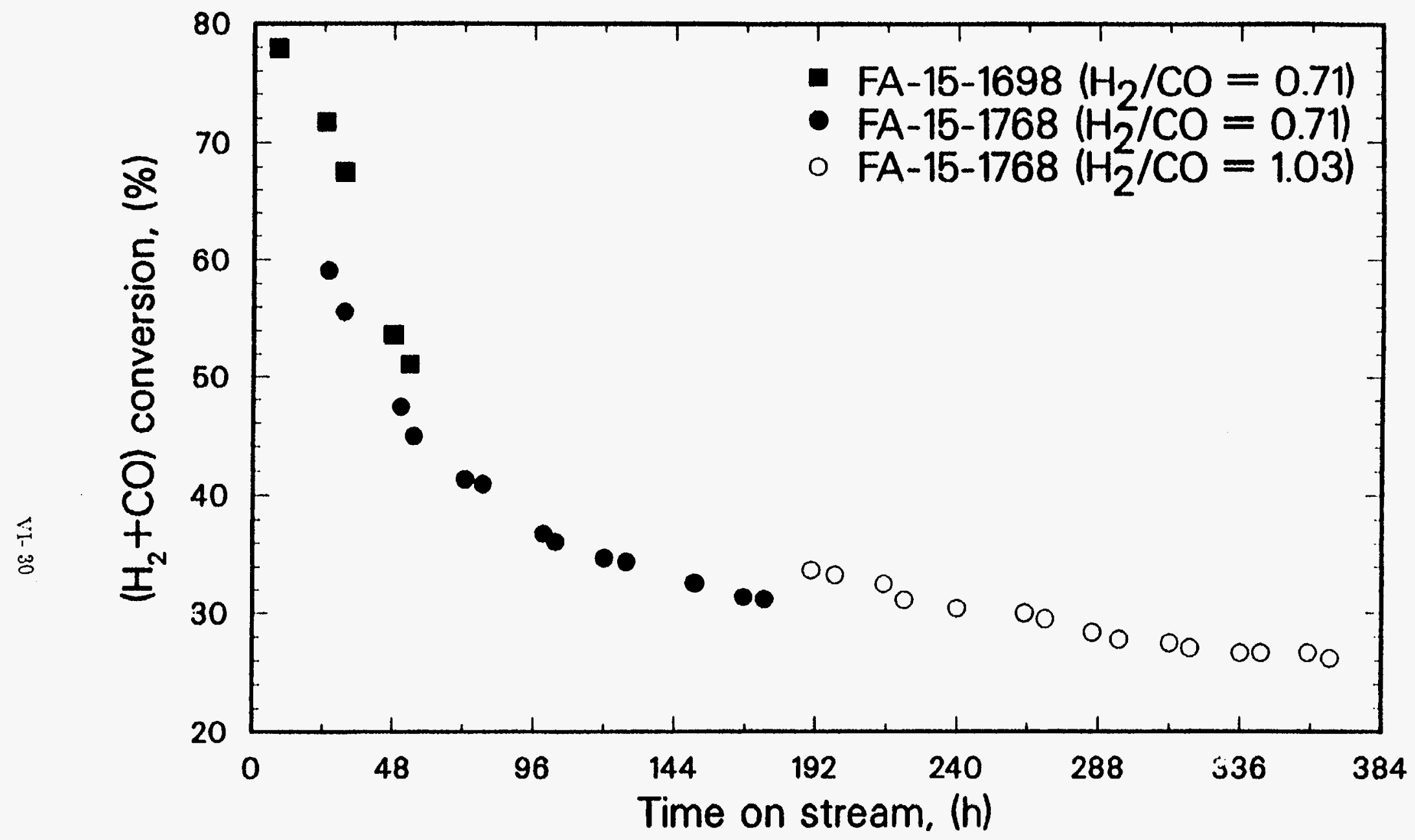

Figure VI-13. Stability plot, $\left(\mathrm{H}_{2} \mid \mathrm{CO}\right)$ conversion versus time on stream, for runs FA-151698 and FA-15-1768 (100 Fe/1.0 Cu/0.2 K calalyst, $235{ }^{\circ} \mathrm{C}, 1.48 \mathrm{MPa}, 2.0$ $N I / g$ rat.hl). 

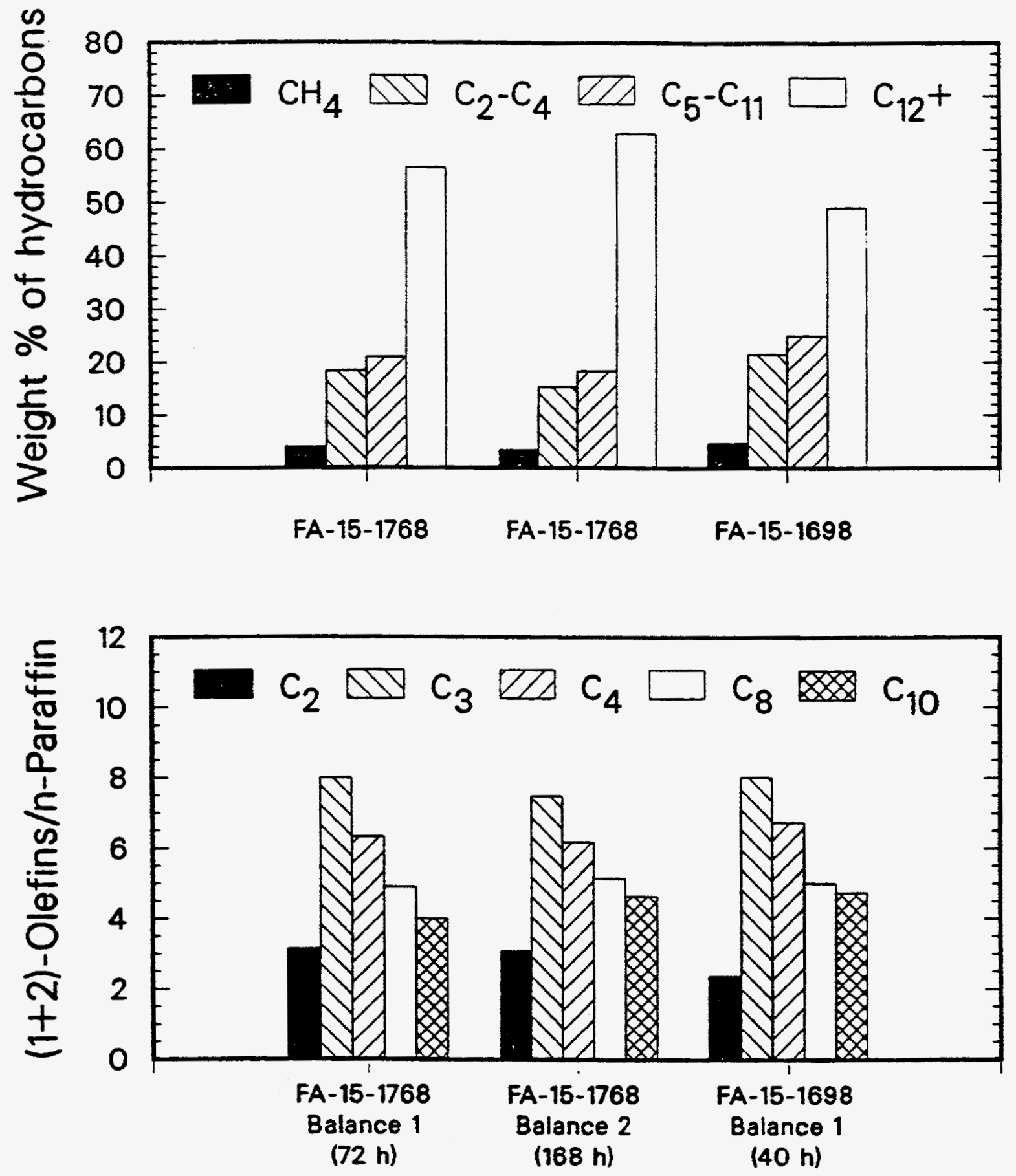

Figure VI-14. Comparison of catalyst selectivity in runs FA-15-1698 and FA-15-1768 (100 $\mathrm{Fe} / 1.0 \mathrm{Cu} / 0.2 \mathrm{~K}$ catalyst, $235^{\circ} \mathrm{C}, 1.48 \mathrm{MPa}, 2.0 \mathrm{Nl} / \mathrm{g}$-cat $\cdot h, \mathrm{H}_{2} / \mathrm{C} \mathrm{O}=0.71$ ). 

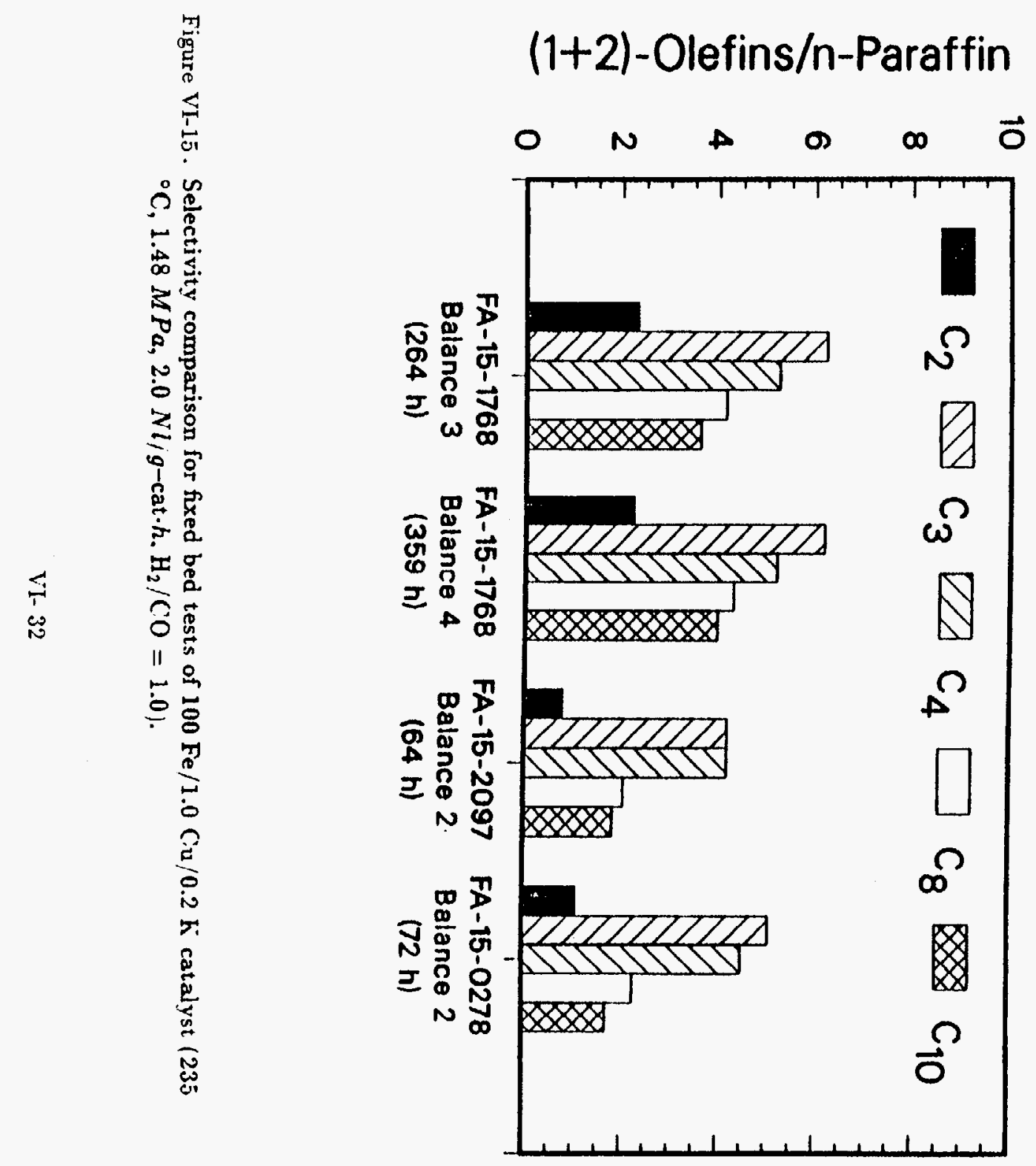

Weight \% of hydrocarbons

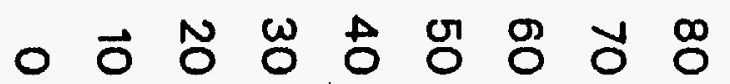

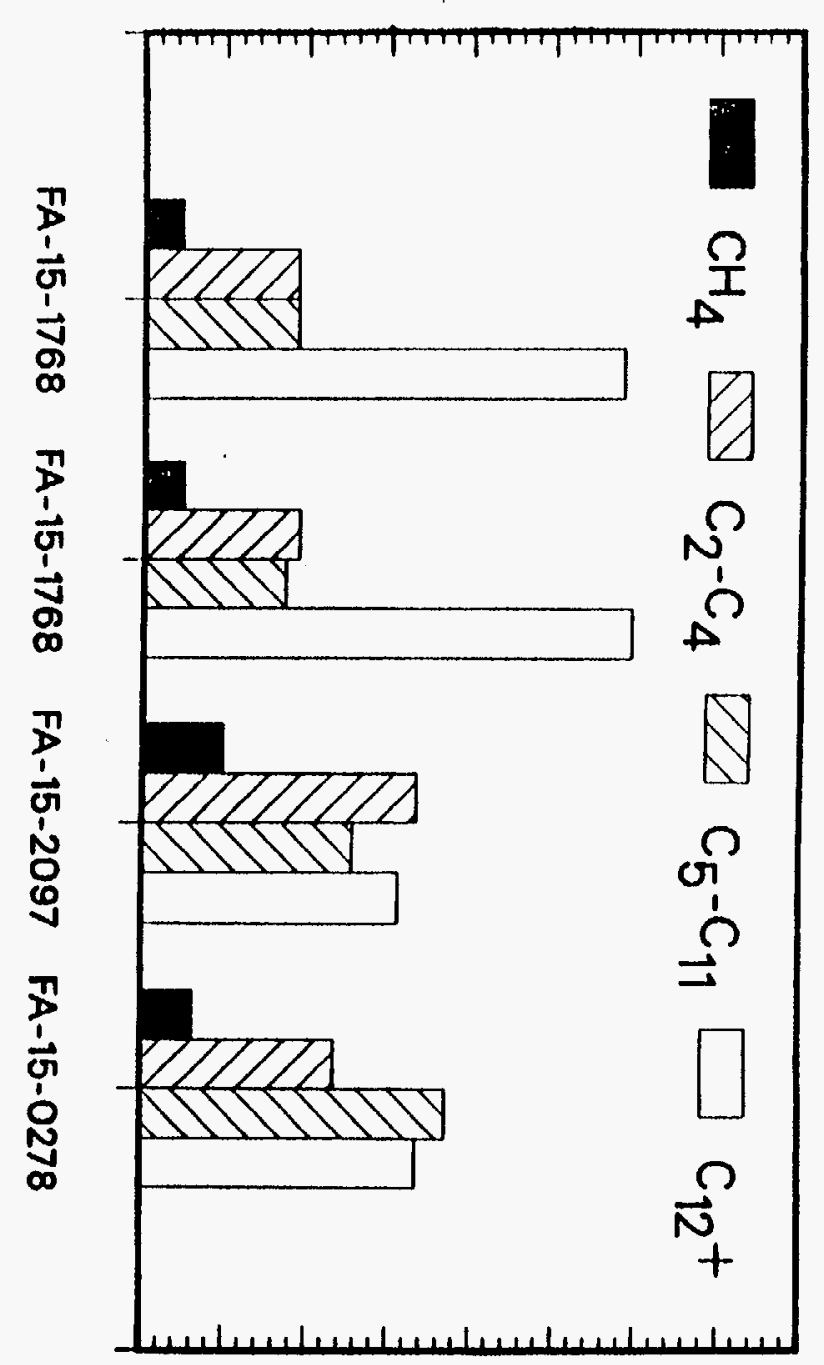


vate the catalyst. In both runs, the reductant used was $\mathrm{CO}$ at ambient pressure, and the catalyst was ground to $30 / 60$ mesh and diluted with glass beads before loading the reactor. In run FB-27-2438, the catalyst was reduced at $280^{\circ} \mathrm{C}$ for $12 \mathrm{~h}$. After the $12 \mathrm{~h}$ pretreatment, the reactor was cooled to $260^{\circ} \mathrm{C}$ in helium $(4.0 \mathrm{NI} / \mathrm{g}$-cat.h), and the reactor pressure was increased to $1.48 \mathrm{MPa}$. Synthesis gas $\left(\mathrm{H}_{2} / \mathrm{CO}=0.69\right)$ was then introduced while continuing to feed $\mathrm{He}$, and the syngas flow rate was gradually increased from 0.5 to $2.0 \mathrm{NI} / \mathrm{g}$-cat.h over a 4 $h$ period. After the full syngas flow was established, the He flow was phased out over a $2.5 \mathrm{~h}$ period. A hot spot $\left(280^{\circ} \mathrm{C}\right)$ developed about $15 \mathrm{~cm}$ below the top of the bed after the He flow was discontinued, and $\mathrm{He}$ was reintroduced at $0.7 \mathrm{NI} / \mathrm{g}$-cat.h to cool the reactor. After 17 $h$ at these conditions, the He was again discontinued and the stability run was begun $\left(260^{\circ} \mathrm{C}\right.$, 1.48 $\mathrm{MPa}, \mathrm{H}_{2} / \mathrm{CO}=0.69,2.0 \mathrm{NI} / \mathrm{g}$-cat. $h$ ). In run $\mathrm{FA}-27-2518$, the catalyst was reduced at $335^{\circ} \mathrm{C}$ for $24 \mathrm{~h}$, which is similar to the optimum procedure studied by Pichler (Anderson, 1956, $\mathrm{pp}$ 176-180). This procedure was reported to give high activity and stability over a long period of time.

Three mass balances were performed during run FB-27-2438 and the results are summarized in Table V1-5. The results for the two mass balances performed during run FA-27-2518 are summarized in Table VI-6. All balances were performed at $260^{\circ} \mathrm{C}, 1.48 \mathrm{MPa}, 2.0 \mathrm{NI} / \mathrm{g}-$ cat.h, using an $\mathrm{H}_{2} / \mathrm{CO}=0.67$ (nominal) feed gas. The stability plot for both runs is shown in Fig. VI-16. The catalyst activated at $335^{\circ} \mathrm{C}$ for $24 \mathrm{~h}$ (FA-27-2518) deactivated rapidly, with the $\left(\mathrm{H}_{2}+\mathrm{CO}\right)$ conversion dropping from an initial $74.2 \%$ to $47.2 \%$ at $143 \mathrm{~h}$ at conditions. The conversion for catalyst activated at $280^{\circ} \mathrm{C}$ for $12 \mathrm{~h}$ (FB-27-2438) initially increased to a maximum $88.2 \%$ at $7.5 \mathrm{~h}$ at conditions, then began deactivating. The deactivation was less severe than during run FA-27-2518 and the conversion was still $72 \%$ at $143 \mathrm{~h}$. After $265 \mathrm{~h}$, the $\left(\mathrm{H}_{2}+\mathrm{CO}\right)$ conversion dropped to $66.7 \%$.

The hydrocarbon selectivity and olefin/paraffin ratios as a function of time are compared in Fig. VI-17 for both runs. During run FB-27-2438, the weight percent hydrocarbon distribution shifted towards lower molecular weight products as the catalyst deactivated with time. The shift to lighter products was not significant during run FA-27-2518, although the catalyst was already deactivated during both balances (the average conversions were 57.5 and $47.3 \%$, respectively, during the two balances). No strong trend in the olefin/paraffin ratios occurred for either catalyst test. While it is difficult to distinguish between the effects of deactivation and reduction procedure in these two runs, it appears that the higher reduction temperature 
Table VI-5. Summary of results for fixed bed run FB-27-2438. Catalyst reduced using $\mathrm{CO}$ at $280^{\circ} \mathrm{C}$ for $12 h, 3.0 \mathrm{Nl} / \mathrm{g}$-cat. $h$.

Catalyst: $3.80 g^{a}, 100 \mathrm{Fe} / 3.0 \mathrm{Cu} / 0.5 \mathrm{~K}$

Catalyst volume: $3.40 \mathrm{cc}$

Diluent: $38.1 \mathrm{~g}$, Glass beads

Diluent Volume: $25.0 \mathrm{cc}$

\begin{tabular}{|c|c|c|c|}
\hline Period & $\overline{1}$ & 2 & 3 \\
\hline Date & $09 / 02 / 88$ & $09 / 06 / 88$ & $09 / 10 / 88$ \\
\hline Time on Stream $(h)$ & 72.0 & 167.0 & 264.0 \\
\hline Balance Duration $(h)$ & 6.8 & 7.0 & 6.8 \\
\hline Average Temperature $\left({ }^{\circ} \mathrm{C}\right)$ & 260. & 260. & 260. \\
\hline Maximum $\Delta$ Temperature $\left({ }^{\circ} \mathrm{C}\right)^{b}$ & 3.00 & 2.00 & 2.00 \\
\hline Pressure $(M P a)$ & 1.48 & 1.48 & 1.48 \\
\hline $\mathrm{H}_{2} / \mathrm{CO}$ Feed Ratio & .704 & .704 & .704 \\
\hline Space Velocity $(N l / g \text {-cat } \cdot h)^{a}$ & 2.01 & 2.01 & 2.01 \\
\hline Space Velocity $(N l / g-\mathrm{Fe} \cdot h)$ & 2.95 & 2.95 & 2.95 \\
\hline GHSV $\left(h^{-1}\right)^{e}$ & 268. & 268. & 268. \\
\hline CO Conversion (\%) & 83.3 & 76.5 & 72.3 \\
\hline $\mathrm{H}_{2}+\mathrm{CO}$ Conversion $(\%)$ & 78.4 & 72.1 & 67.8 \\
\hline $\mathrm{H}_{2} / \mathrm{CO}$ Usage & .604 & .606 & .598 \\
\hline $\mathrm{STY}\left(\text { mols } \mathrm{H}_{2}+\mathrm{CO} / g \text {-cat. } h\right)^{a}$ & .070 & .065 & .061 \\
\hline$P_{\mathrm{CO}_{2}} \cdot P_{\mathrm{H}_{2}} / P_{\mathrm{CO}} \cdot P_{\mathrm{H}_{2} \mathrm{O}}$ & 15.2 & 12.8 & 17.5 \\
\hline \multicolumn{4}{|l|}{ Weight \% of Outlet } \\
\hline $\mathrm{H}_{2}$ & 1.36 & 1.63 & 1.84 \\
\hline $\mathrm{H}_{2} \mathrm{O}$ & 1.97 & 1.81 & 1.23 \\
\hline $\mathrm{CO}$ & 15.7 & 22.2 & 26.2 \\
\hline $\mathrm{CO}_{2}$ & 60.8 & 55.6 & 53.7 \\
\hline Hydrocarbons & 14.4 & 15.0 & 14.4 \\
\hline Oxygenates & .408 & .302 & .236 \\
\hline Wax & 5.37 & 3.47 & 2.41 \\
\hline \multicolumn{4}{|l|}{ Yield $\left(\mathrm{g} / \mathrm{Nm}^{3} \mathrm{H}_{2}+\mathrm{CO}\right.$ Converted $)$} \\
\hline $\mathrm{CH}_{4}$ & $\overline{12.6}$ & $\overline{14.4}$ & 15.4 \\
\hline $\mathrm{C}_{2}-\mathrm{C}_{4}$ Hydrocarbons & 49.8 & 53.7 & 55.3 \\
\hline $\mathrm{C}_{5}-\mathrm{C}_{11}$ Hydrocarbons & 63.4 & 74.2 & 74.3 \\
\hline $\mathrm{C}_{12}+$ Hydrocarbons & 70.2 & 56.8 & 47.7 \\
\hline $\operatorname{Wax}^{d}$ & 53.3 & 37.4 & 27.7 \\
\hline Oxygenates & 4.05 & 3.25 & 2.71 \\
\hline Total & 200. & 202. & 195. \\
\hline \multicolumn{4}{|l|}{$1+2$ Olefins $/ n$-Paraffin Ratio } \\
\hline $\mathrm{C}_{2}$ & 1.25 & .974 & 1.00 \\
\hline $\mathrm{C}_{3}$ & 8.31 & 7.04 & 7.28 \\
\hline $\mathrm{C}_{4}$ & 7.27 & 6.01 & 6.11 \\
\hline $\mathrm{C}_{8}$ & 4.58 & 3.18 & 3.09 \\
\hline$C_{10}$ & 3.74 & 2.40 & 2.25 \\
\hline
\end{tabular}

a Based on unreduced catalyst

${ }^{\circ}$ Maximum axial temperature difference

${ }^{c}$ Based on catalyst volume

d Unanalyzed products collected from hot trap 
Table VI-5 (cont'd). Summary of results for fixed bed run FB-27-2438. Catalyst reduced using $\mathrm{CO}$ at $280^{\circ} \mathrm{C}$ for $12 h .3 .0 \mathrm{Nl} / \mathrm{g}$-cat. $h$.

\begin{tabular}{|c|c|c|c|}
\hline Period & 1 & 2 & $\overline{3}$ \\
\hline \multicolumn{4}{|c|}{ Weight \% of Hydrocarbons } \\
\hline$\overline{\mathrm{CH} 4}$ & 6.41 & 7.25 & 7.99 \\
\hline Ethane & 3.34 & 3.83 & 4.06 \\
\hline Ethylene & 3.90 & 3.48 & 3.79 \\
\hline Propane & 1.10 & 1.35 & 1.38 \\
\hline Propylene & 8.74 & 9.04 & 9.56 \\
\hline n-Butane & .951 & 1.25 & 1.32 \\
\hline 1+2 Butenes & 6.68 & 7.23 & 7.77 \\
\hline $\mathrm{C}_{4}$ Isomers & .709 & .780 & .826 \\
\hline$n$-Pentane & 1.55 & 1.90 & 2.04 \\
\hline 1+2 Pentenes & 5.82 & 6.22 & 6.74 \\
\hline $\mathrm{C}_{5}$ Isomers & .440 & .610 & .680 \\
\hline$n$-Hexane & .622 & .918 & .807 \\
\hline 1+2 Hexenes & 3.41 & 4.03 & 3.48 \\
\hline $\mathrm{C}_{6}$ Isomers & .726 & .814 & .693 \\
\hline$n$-Heptane & .591 & 1.000 & .864 \\
\hline 1+2 Heptenes & 2.96 & 3.50 & 3.06 \\
\hline $\mathrm{C}_{7}$ Isomers & .842 & 1.17 & .629 \\
\hline$n$-Octane & .644 & .997 & 1.15 \\
\hline $1+2$ Octenes & 2.90 & 3.12 & 3.50 \\
\hline $\mathrm{C}_{8}$ Isomers & .785 & 696 & .706 \\
\hline$n$-Nonane & .659 & 1.03 & 1.30 \\
\hline $1+2$ Nonenes & 2.66 & 2.75 & 3.35 \\
\hline $\mathrm{C}_{9}$ Isomers & .706 & .587 & .679 \\
\hline$n$-Decane & .639 & 1.05 & 1.30 \\
\hline 1+2 Decenes & 2.35 & 2.47 & 2.87 \\
\hline$C_{10}$ Isomers & .795 & .643 & .701 \\
\hline$n$-Undecane & .608 & 1.04 & 1.20 \\
\hline $1+2$ Undecenes & 1.97 & 2.09 & 2.22 \\
\hline $\mathrm{C}_{11}$ Isomers & .668 & .620 & .589 \\
\hline $\mathrm{C}_{2}-\mathrm{C}_{4}$ & 25.4 & 27.0 & 28.7 \\
\hline$C_{5}-C_{11}$ & 32.3 & 37.3 & 38.6 \\
\hline $\mathrm{C}_{12}+$ & 35.8 & 28.5 & 24.8 \\
\hline $\mathrm{Wax}^{d}$ & 27.2 & 18.8 & 14.4 \\
\hline
\end{tabular}

VI- 35 
Table VI-6. Summary of results for fixed bed run FA-27-2518. Catalyst reduced using $\mathrm{CO}$ at $335^{\circ} \mathrm{C}$ for $24 \mathrm{~h} .3 .0 \mathrm{Nl} / \mathrm{g}$-cat. $h$.

Catalyst: $3.45 g^{a}, 100 \mathrm{Fe} / 3.0 \mathrm{Cu} / 0.5 \mathrm{~K}$

Catalyst volume: $2.50 \mathrm{cc}$

Diluent: $37.2 g$, Glass beads Diluent Volume: $24.5 c c$

\begin{tabular}{|c|c|c|}
\hline Period & 1 & 2 \\
\hline$\overline{\text { Date }}$ & $09 / 10 / 88$ & $09 / 14 / 88$ \\
\hline Time on Stream $(h)$ & 77.0 & 166.0 \\
\hline Balance Duration $(h)$ & 6.5 & 6.8 \\
\hline Average Temperature $\left({ }^{\circ} \mathrm{C}\right)$ & 260. & 260. \\
\hline Maximum $\Delta$ Temperature $\left({ }^{\circ} \mathrm{C}\right)^{b}$ & 1.80 & 1.70 \\
\hline Pressure $(\mathrm{MPa})$ & 1.48 & 1.48 \\
\hline $\mathrm{H}_{2} / \mathrm{CO}$ Feed Ratio & .639 & .639 \\
\hline Space Velocity $(N l / g \text {-cat } \cdot h)^{a}$ & 2.00 & 2.00 \\
\hline Space Velocity $(N l / g-\mathrm{Fe} \cdot h)$ & 2.95 & 2.95 \\
\hline GHSV $\left(h^{-1}\right)^{e}$ & 256. & 256. \\
\hline CO Conversion (\%) & 57.6 & 46.5 \\
\hline $\mathrm{H}_{2}+\mathrm{CO}$ Conversion (\%) & 57.5 & 47.3 \\
\hline $\mathrm{H}_{2} / \mathrm{CO}$ Usage & .637 & .667 \\
\hline $\mathrm{STY}\left(\text { mols } \mathrm{H}_{2}+\mathrm{CO} / g-\mathrm{cat} \cdot h\right)^{a}$ & .051 & .042 \\
\hline$P_{\mathrm{CO}_{2}} \cdot P_{\mathrm{H}_{2}} / P_{\mathrm{CO}} \cdot P_{\mathrm{H}_{2} \mathrm{O}}$ & 5.76 & 3.53 \\
\hline \multicolumn{3}{|l|}{ Weight \% of Outlet } \\
\hline $\mathrm{H}_{2}$ & 1.87 & 2.26 \\
\hline $\mathrm{H}_{2} \mathrm{O}$ & 1.92 & 2.31 \\
\hline $\mathrm{CO}$ & 40.5 & 51.0 \\
\hline $\mathrm{CO}_{2}$ & 42.1 & 32.3 \\
\hline Hydrocarbons & 10.1 & 8.91 \\
\hline Oxygenates & .274 & .265 \\
\hline Wax $^{d}$ & 3.25 & 2.95 \\
\hline \multicolumn{3}{|l|}{ Yield $\left(\mathrm{g} / \mathrm{Nm}^{3} \mathrm{H}_{2}+\mathrm{CO}\right.$ Converted $)$} \\
\hline $\mathrm{CH}_{4}$ & 18.2 & 18.7 \\
\hline $\mathrm{C}_{2}-\mathrm{C}_{4}$ Hydrocarbons & 48.7 & 53.9 \\
\hline $\mathrm{C}_{5}-\mathrm{C}_{11}$ Hydrocarbons & 51.4 & 58.4 \\
\hline $\mathrm{C}_{12}+$ Hydrocarbons & 66.3 & 70.0 \\
\hline $\mathrm{Wax}^{d}$ & 45.0 & 50.0 \\
\hline Oxygenates & 3.79 & 4.48 \\
\hline Total & 188. & 205. \\
\hline \multicolumn{3}{|l|}{$1+2$ Olefins/ $n$-Paraffin Ratio } \\
\hline $\mathrm{C}_{2}$ & 1.27 & 1.40 \\
\hline $\mathrm{C}_{3}$ & 7.84 & 8.11 \\
\hline $\mathrm{C}_{4}$ & 7.08 & 7.41 \\
\hline $\mathrm{C}_{8}$ & 4.67 & 5.51 \\
\hline $\mathrm{C}_{10}$ & 4.13 & 4.59 \\
\hline
\end{tabular}

a Based on unreduced catalyst

c Based on reactor volume b Maximum axial temperature difference

${ }^{d}$ Unanalyzed products collected from hot trap 
Table VI- 6 (cont'd). Summary of results for fixed bed run FA-27-2518. Catalyst reduced using $\mathrm{CO}$ at $335{ }^{\circ} \mathrm{C}$ for $24 h, 3.0 \mathrm{Nl} / \mathrm{g}$-cat.h.

\begin{tabular}{|c|c|c|}
\hline Period & 1 & 2 \\
\hline \multicolumn{3}{|c|}{ Weight \% of Hydrocarbons } \\
\hline $\mathrm{CH} 4$ & 9.86 & 9.29 \\
\hline Ethane & 3.91 & 3.98 \\
\hline Ethylene & 4.63 & 5.20 \\
\hline Propane & 1.13 & 1.10 \\
\hline Propylene & 8.47 & 8.51 \\
\hline$n$-Butane & .959 & .900 \\
\hline $1+2$ Butenes & 6.55 & 6.43 \\
\hline $\mathrm{C}_{4}$ Isomers & .722 & .707 \\
\hline$n$-Pentane & 1.46 & 1.41 \\
\hline $1+2$ Pentenes & 5.93 & 7.00 \\
\hline $\mathrm{C}_{5}$ Isomers & .459 & .807 \\
\hline$n$-Hexane & .586 & .475 \\
\hline 1+2 Hexenes & 3.57 & 3.53 \\
\hline $\mathrm{C}_{6}$ Isomers & .660 & .805 \\
\hline$n$-Heptane & .479 & .434 \\
\hline 1+2 Eeptenes & 2.66 & 2.53 \\
\hline $\mathrm{C}_{7}$ Isomers & .489 & .514 \\
\hline$n$-Octane & .482 & .402 \\
\hline $1+2$ Octenes & 2.21 & 2.18 \\
\hline $\mathrm{C}_{8}$ Isomers & .511 & .497 \\
\hline$n$-Nonane & .469 & .405 \\
\hline $1+2$ Nonenes & 1.97 & 1.95 \\
\hline $\mathrm{C}_{9}$ Isomers & .387 & .349 \\
\hline$n$-Decane & .476 & .448 \\
\hline 1+2 Decenes & 1.94 & 2.02 \\
\hline $\mathrm{C}_{10}$ Isomers & .502 & .530 \\
\hline$n$-Undecane & .451 & .439 \\
\hline 1+2 Undecenes & 1.73 & 1.84 \\
\hline $\mathrm{C}_{11}$ Isomers & .425 & .491 \\
\hline $\mathrm{C}_{2}-\mathrm{C}_{4}$ & 26.4 & 26.8 \\
\hline $\mathrm{C}_{5}-\mathrm{C}_{11}$ & 27.8 & 29.1 \\
\hline $\mathrm{C}_{12}+$ & 35.9 & 34.8 \\
\hline $\operatorname{Wax}^{d}$ & 24.4 & 24.9 \\
\hline
\end{tabular}

d Unanalyzed products collected from hot trap 


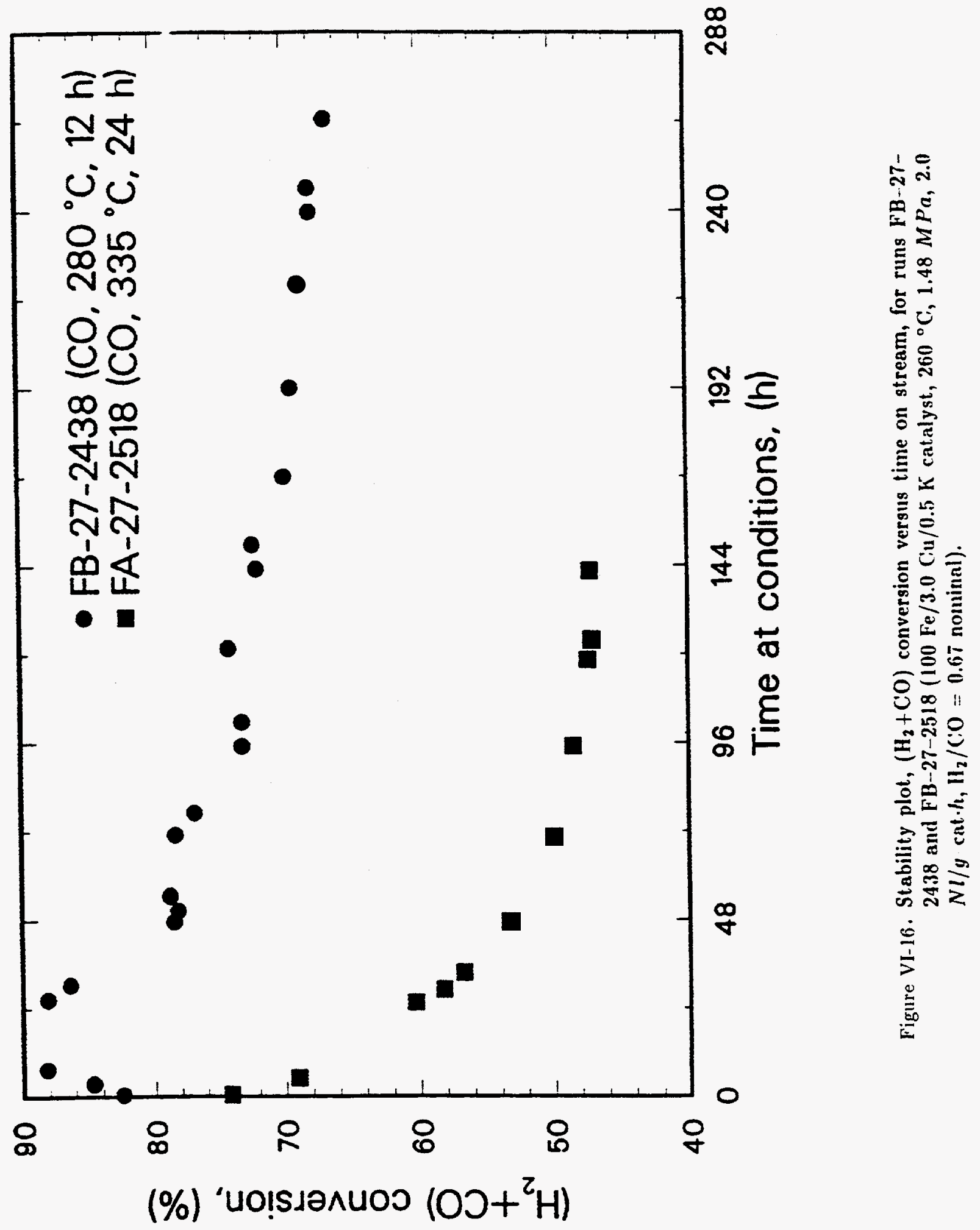




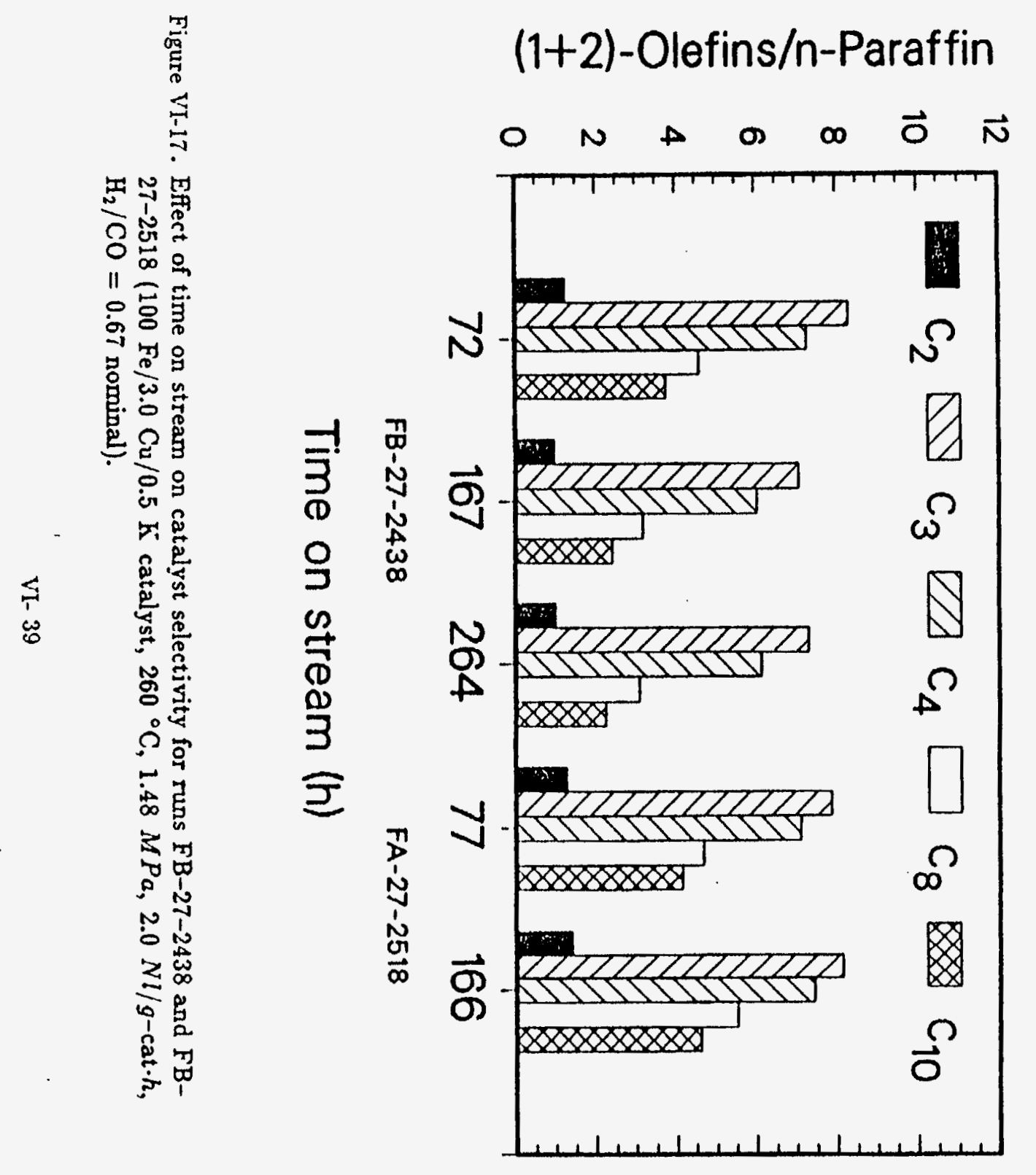

Weight \% of hydrocarbons

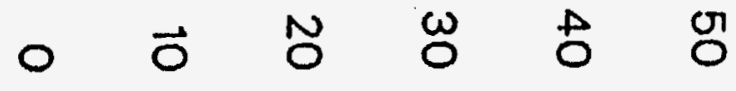

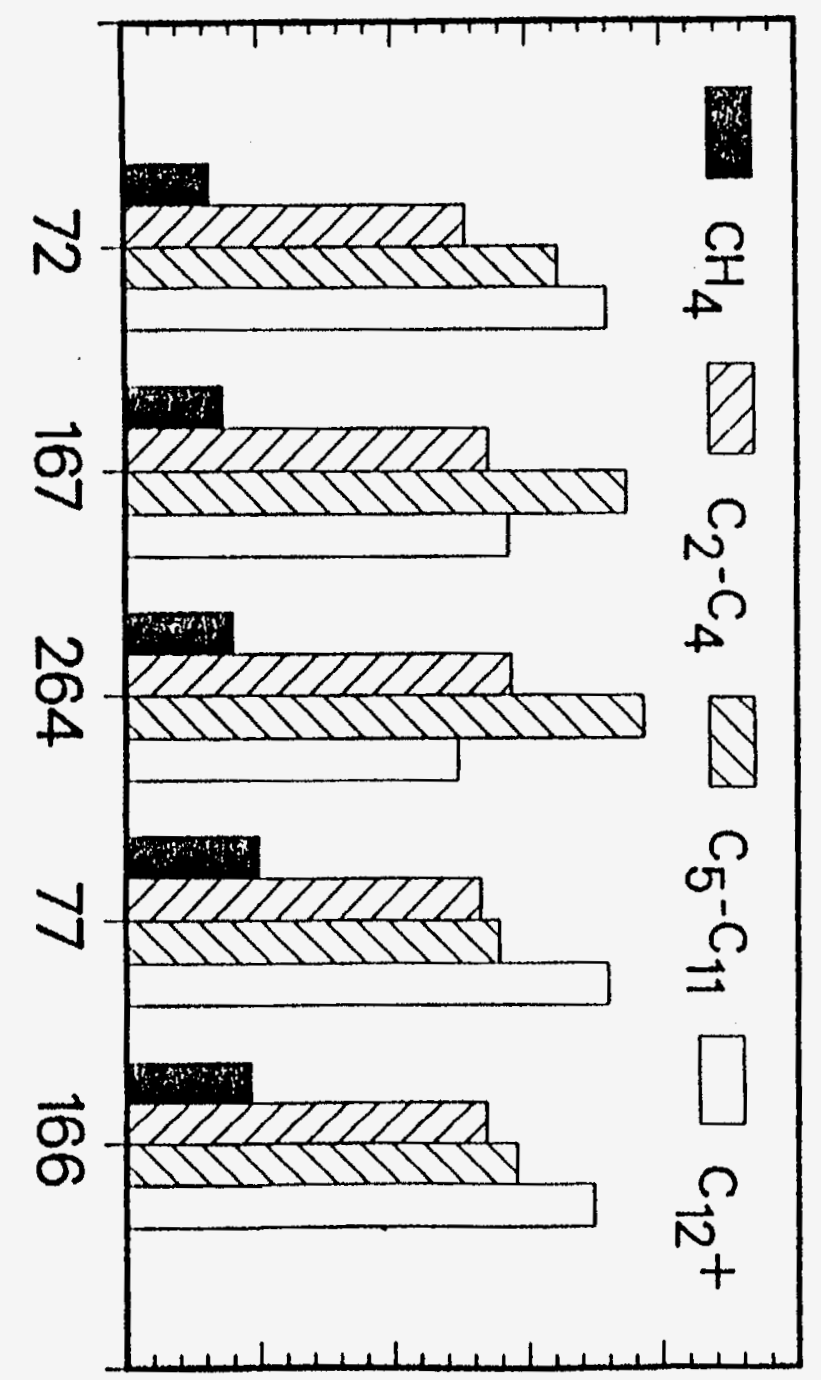


$\left(335^{\circ} \mathrm{C}, \mathrm{FA}-27-2518\right)$ causes the catalyst to produce more lower molecular weight products. For example, the lowest methane percentage, $9.3 \%$ (FA-27-2518, balance 2, $166 \mathrm{~h}$ ), for the high temperature reduction was greater than the highest methane percentage, $8.0 \%$ (FB-27-2438, balance 3, $240 \mathrm{~h}$ ), for the lower reduction temperature.

\section{VI.3. Stirred Tank Slurry Reactor Test with Silica containing Catalysts}

VI.3.1. Run SA - $99-0888$ with the Ruhrchemie LP $33 / 81$ Catalyst

Run SA-99-0888 was a long term test of the commercial, state-of-the-art, Ruhrehemie LP $33 / 81$ catalyst. The calcined catalyst was reduced in situ with $\mathrm{CO}$ at $280^{\circ} \mathrm{C} .34 .6 \mathrm{~g}$ of the catalyst was charged to the reactor, and purified n-octacosane was used as the initial slurry liquid. The run was divided into two portions: during the first part of the run (up to $343 \mathrm{~h}$ on stream), catalyst stability was evaluated at a fixed set of conditions: $250^{\circ} \mathrm{C}, 1.48$ $\mathrm{MPa},\left(\mathrm{H}_{2} / \mathrm{CO}\right)=0.67,2.0 \mathrm{NI} / \mathrm{g}$-cat.h; during the last part of the run, process conditions were varied to evaluate their effect on catalyst activity and selectivity: $235-265^{\circ} \mathrm{C}, 1.48-2.96 \mathrm{MPa}$, $\left(\mathrm{H}_{2} / \mathrm{CO}\right)=0.67-1.0,1.0-4.0 \mathrm{Nl} / \mathrm{g}$-cat.h. The major events occurring during run SA-99-0888 are summarized in Table VI-7. Five mass balances were performed during the stability portion of the run and 8 mass balances were performed during the process variable studies. The results obtained during these balances are summarized in Table VI-8.

A stability plot, $\left(\mathrm{H}_{2}+\mathrm{CO}\right)$ conversion versus time on stream, is shown in Fig. VI-18 for the first part of the run. The catalyst was very stable, and no significant deactivation occurred during $343 \mathrm{~h}$ on stream. At $46 \mathrm{~h}$, the $\left(\mathrm{H}_{2}+\mathrm{CO}\right)$ conversion was $46.0 \%$, and at $338 \mathrm{~h}$, the conversion was $44.2 \%$. The conversions obtained during the stability test varied between 42.6 and $46.4 \%$. Wax was withdrawn after the catalyst activation and at the end of balances 2 , 3,4 , and 5 using the external settling tank system. The selectivity of the catalyst changed with time on stream, with more gaseous products formed as the catalyst aged. The effect of time on catalyst selectivity is shown in Fig. VI-19. During balance 1 ( $49 \mathrm{~h}$ ) the weight $\%$ hydrocarbon distribution was $4.3 \mathrm{CH}_{4}, 17.8 \mathrm{C}_{2}-\mathrm{C}_{4}, 22.1 \mathrm{C}_{5}-\mathrm{C}_{11}$, and $55.8 \% \mathrm{C}_{12}+$ while during balance $5\left(336 \mathrm{~h}\right.$ ) the distribution was $4.6 \mathrm{CH}_{4}, 21.3 \mathrm{C}_{2}-\mathrm{C}_{4}, 29.5 \mathrm{C}_{5}-\mathrm{C}_{11}$, and 44.6 $\% \mathrm{C}_{12}+$. The olefin/paraffin ratios decreased with time, for example, the $C_{2}$ ratio decreased from 1.8 in balance 1 to 1.5 in balance 5 . A repeat of the baseline conditions was made in balance $11(619 \mathrm{~h})$, after 5 balances at different process conditions. The $\left(\mathrm{H}_{2}+\mathrm{CO}\right)$ conversion dropped to $35.9 \%$ in balance 11 , showing that the process variable studies had accelerated deactivation of the catalyst. The trends in selectivity seen in balances $1-5$ were also evident 
Table VI- -6 . Major events occurring in run SA-99-0888.

$\operatorname{TOS}(h)$

Event

- 17 Catalyst pretreatment:

$\mathrm{C} 0,280^{\circ} \mathrm{C}, 0.79 \mathrm{MPa}, 16 \mathrm{~h}$.

$0 \quad$ Initiated synthesis gas.

4.0 Achieved desired operating conditions:

$250^{\circ} \mathrm{C}, 1.48 \mathrm{MPa},\left(\mathrm{H}_{2} / \mathrm{CO}\right)=0.67,2.0 \mathrm{Nl} / \mathrm{g}$-cat $\cdot h$

49.0 Conditions stable, $\left(\mathrm{H}_{2}+\mathrm{CO}\right)$ conversion $=45.9 \%$.

94.5 Conditions stable, $\left(\mathrm{H}_{2}+\mathrm{CO}\right)$ conversion $=46.1 \%$.

166.5 Conditions stable, $\left(\mathrm{H}_{2}+\mathrm{CO}\right)$ conversion $=43.1 \%$.

264.0 Conditions stable, $\left(\mathrm{H}_{2}+\mathrm{CO}\right)$ conversion $=43.8 \%$.

336.0 Conditions stable, $\left(\mathrm{H}_{2}+\mathrm{CO}\right)$ conversion $=44.4 \%$.

343.0 Changed process conditions:

$250^{\circ} \mathrm{C}, 1.48 \mathrm{MPa},\left(\mathrm{H}_{2} / \mathrm{CO}\right)=0.67,4.0 \mathrm{Nl} / \mathrm{g}$-cat $\cdot h$

391.0 Changed process conditions:

$250^{\circ} \mathrm{C}, 1.48 \mathrm{MPa},\left(\mathrm{H}_{2} / \mathrm{CO}\right)=0.65,1.0 \mathrm{Nl} / \mathrm{g}$-cat $\cdot \mathrm{h}$

439.0 Changed process conditions:

$235^{\circ} \mathrm{C}, 1.48 \mathrm{MPa},\left(\mathrm{H}_{2} / \mathrm{CO}\right)=0.65,2.0 \mathrm{Nl} / \mathrm{g}$-cat $\cdot h$

488.0 Changed process conditions:

$235^{\circ} \mathrm{C}, 1.48 \mathrm{MPa},\left(\mathrm{H}_{2} / \mathrm{CO}\right)=0.67,1.0 \mathrm{Nl} / \mathrm{g}$-cat $\cdot h$

531.0 Changed process conditions:

$265^{\circ} \mathrm{C}, 1.48 \mathrm{MPa},\left(\mathrm{H}_{2} / \mathrm{CO}\right)=0.67,2.0 \mathrm{Nl} / \mathrm{g}$-cat $\cdot h$

584.0 Changed process conditions:

$250^{\circ} \mathrm{C}, 1.48 \mathrm{MPa},\left(\mathrm{H}_{2} / \mathrm{CO}\right)=0.67,2.0 \mathrm{Nl} / \mathrm{g}$-cat $\cdot h$

619.0 Replication of initial process conditions:

$\left(\mathrm{H}_{2}+\mathrm{CO}\right)$ conversion $=36.0 \%$.

627.0 Changed process conditions:

$250^{\circ} \mathrm{C}, 1.48 \mathrm{MPa},\left(\mathrm{H}_{2} / \mathrm{CO}\right)=1.0,2.0 \mathrm{Nl} / \mathrm{g}$-cat $\cdot h$

699.0 Changed process conditions:

$250^{\circ} \mathrm{C}, 2.96 \mathrm{MPa},\left(\mathrm{H}_{2} / \mathrm{CO}\right)=1.0,4.0 \mathrm{Nl} / \mathrm{g}$-cat $\cdot h$

721.5 Voluntary termination of run SA-99-0888. 
Table VI-8. Summary of results for slurry run SA-99-0888.

Catalyst: $34.6 g^{a}$, LP 33/81

Slurry liquid: $270 \mathrm{~g}$, Purified n-octacosane

Reactor volume: $385 c c^{b}$

\begin{tabular}{|c|c|c|c|c|c|c|c|}
\hline Period & 1 & 2 & 3 & 4 & 5 & 6 & 7 \\
\hline Date & $3 / 30 / 88$ & $4 / 1 / 88$ & $4 / 4 / 88$ & $4 / 7 / 88$ & $4 / 10 / 88$ & $4 / 13 / 88$ & $4 / 15 / 88$ \\
\hline Time on Stream $(h)$ & 49.0 & 94.5 & 166.5 & 264.0 & 336.0 & 385.0 & 385.0 \\
\hline Balance Duration $(h)$ & 7.0 & 6.0 & 6.0 & 6.0 & 6.0 & 6.0 & 6.0 \\
\hline Average Temperature $\left({ }^{\circ} \mathrm{C}\right)$ & 250. & 250. & 250. & 250. & 250. & 250. & 250. \\
\hline Pressure $(M P a)$ & 1.48 & 1.48 & 1.48 & 1.48 & 1.48 & 1.48 & 1.48 \\
\hline $\mathrm{H}_{2} / \mathrm{CO}$ Feed Ratio & .667 & .667 & .667 & .667 & .667 & .667 & .652 \\
\hline Space Velocity $(N l / g \text {-cat.h })^{0}$ & 2.00 & 2.00 & 2.00 & 2.00 & 2.01 & 4.00 & 1.00 \\
\hline Space Velocity $(\mathrm{Nl} / \mathrm{g}-\mathrm{Fe} \cdot h)$ & 3.81 & 3.81 & 3.81 & 3.81 & 3.82 & 7.62 & 1.91 \\
\hline GHSV $\left(h^{-1}\right)^{b}$ & 180. & 180. & 172. & 171. & 171. & 336 . & 82.9 \\
\hline CO Conversion $(\%)$ & 42.7 & 43.2 & 41.2 & 41.1 & 40.4 & 25.7 & 56.0 \\
\hline $\mathrm{H}_{2}+\mathrm{CO}$ Conversion (\%) & 45.9 & 46.1 & 43.1 & 43.8 & 44.4 & 28.3 & 56.1 \\
\hline$\quad \mathrm{H}_{2} / \mathrm{CO}$ Usnge & .790 & .779 & .740 & .774 & .835 & .835 & .655 \\
\hline STY (mols $\left.\mathrm{H}_{3}+\mathrm{CO} / \mathrm{g} \cdot \mathrm{cat} \cdot h\right)^{a}$ & .041 & .041 & .038 & .039 & .040 & .050 & .025 \\
\hline$P_{\mathrm{CO}_{2}} \cdot P_{\mathrm{H}_{2}} / P_{\mathrm{CO}} \cdot P_{\mathrm{H}_{2} \mathrm{O}}$ & 1.21 & 1.26 & 1.19 & 1.35 & 1.20 & .706 & 2.54 \\
\hline \multicolumn{8}{|l|}{ Weight \% of Outlet } \\
\hline $\mathrm{H}_{2}$ & 2.33 & 2.34 & 2.52 & 2.45 & 2.28 & 3.21 & 2.01 \\
\hline $\mathrm{H}_{2} \mathrm{O}$ & 4.86 & 4.86 & 5.13 & 4.31 & 4.48 & 4.16 & 3.69 \\
\hline $\mathrm{CO}$ & 56.3 & 55.8 & 56.9 & 57.7 & 57.2 & 73.2 & 43.1 \\
\hline $\mathrm{CO}_{2}$ & 25.0 & 25.7 & 24.2 & 24.0 & 23.7 & 11.8 & 35.4 \\
\hline Hydrocarbons & 5.85 & 5.63 & 5.81 & 6.18 & 7.34 & 5.23 & 10.9 \\
\hline Oxygenates & .505 & .407 & .552 & .643 & .366 & .252 & .676 \\
\hline Wax ${ }^{c}$ & 5.24 & 5.24 & 4.83 & 4.78 & 4.61 & 2.14 & 4.23 \\
\hline \multicolumn{8}{|l|}{ Yield $\left(g / N m^{3} \mathrm{H}_{2}+\mathrm{CO}\right.$ Converted) } \\
\hline $\mathrm{CH}_{4}$ & 7.86 & 8.33 & 9.73 & 9.86 & 9.67 & 10.5 & 12.0 \\
\hline $\mathrm{C}_{2}-\mathrm{C}_{4}$ Hydrocarbons & 32.9 & 37.5 & 39.7 & 42.8 & 44.9 & 43.6 & 55.3 \\
\hline $\mathrm{C}_{5}-\mathrm{C}_{11}$ Hydrocarbons & 40.7 & 35.0 & 41.9 & 43,8 & 62.0 & 61.6 & 67.4 \\
\hline $\mathrm{C}_{12}+$ Hydrocarbons & 103. & 98.8 & 99.8 & 95.3 & 93.8 & 82.8 & 72.9 \\
\hline Wax ${ }^{c}$ & 87.1 & 86.6 & 86.8 & 83.6 & 81.1 & 57.6 & 58.2 \\
\hline Oxygenates & 8.40 & 6.72 & 9.92 & 11.2 & 6.44 & 6.79 & 9.30 \\
\hline Total & 193. & 186. & 201. & 203. & 217. & 205. & 217. \\
\hline \multicolumn{8}{|l|}{$1+2$ Olefins/n-Parafin Ratio } \\
\hline$\overline{C_{2}}$ & 1.82 & 1.68 & 1.64 & 1.52 & 1.45 & 2.21 & .843 \\
\hline $\mathrm{C}_{3}$ & 7.51 & 6.61 & 7.33 & 7.02 & 6.91 & 7.32 & 5.73 \\
\hline $\mathrm{C}_{4}$ & 6.21 & 5.61 & 5.96 & 5.82 & 5.58 & 6.00 & 4.97 \\
\hline $\mathrm{C}_{8}$ & 3.32 & 3.39 & 2.89 & 2.95 & 2.85 & 3.39 & 2.28 \\
\hline $\mathrm{C}_{10}$ & 2.80 & 2.77 & 2.63 & 2.44 & 2.36 & 2.78 & 1.85 \\
\hline
\end{tabular}

- Based on unreduced catalyst

based on static slurty volume

Unanalyzed wax withdrawn from renctor 
Table Vl-8 (cont'd). Summary of results for slurry run SA-99-0888.

\begin{tabular}{|c|c|c|c|c|c|c|}
\hline Perion & 8 & 9 & 10 & 11 & 12 & 13 \\
\hline Dale & $4 / 17 / 88$ & $4 / 19 / 88$ & $4 / 21 / 88$ & $4 / 23 / 88$ & $4 / 25 / 88$ & $4 / 27 / 88$ \\
\hline Time on Strealu $(h)$ & 481.5 & 528.0 & 571.0 & 619.0 & 667.5 & 715.5 \\
\hline Balance Duration $(h)$ & 6.0 & 6.0 & 6.0 & 6.0 & 6.0 & 6.0 \\
\hline Average Temperature $\left({ }^{\circ} \mathrm{C}\right)$ & 235. & 235 . & 265. & 250 . & 250. & 250. \\
\hline Pressure $\left(M P_{a}\right)$ & 1.48 & 1.48 & 1.48 & 1.48 & 1.48 & 2.96 \\
\hline $\mathrm{H}_{2} /$ CO Feed Ratio & .652 & .667 & .667 & .669 & 1.00 & 1.02 \\
\hline Space Velocity $(N I / g \text {-cat } \cdot h)^{a}$ & 2.01 & 1.00 & 2.00 & 2.02 & 2.02 & 4.03 \\
\hline Space Velocity $(\mathrm{N}(/ \mathrm{g}-\mathrm{Fe} \cdot h)$ & 3.83 & 1.91 & 3.82 & 3.85 & 3.85 & 7.68 \\
\hline GHSV $\left(h^{-1}\right)^{b}$ & 165. & 82.3 & 164. & 163. & 162. & 321. \\
\hline CO Conversion (\%) & 18.8 & 30.6 & 57.3 & 32.8 & 48.5 & 36.6 \\
\hline $\mathrm{H}_{2}+\mathrm{CO}$ Conversion (\%) & 23.0 & 35.8 & 56.9 & 35.9 & 45.4 & 39.8 \\
\hline $\mathrm{H}_{2} / \mathrm{CO}$ IIsage & 1.01 & .946 & .653 & .829 & .869 & 1.20 \\
\hline $\operatorname{STY}\left(\mathrm{mols}_{\mathrm{s}} \mathrm{H}_{2}+\mathrm{C} . \mathrm{O} / g-\mathrm{cal} \cdot h\right)^{a}$ & .021 & .016 & .051 & .032 & .041 & .071 \\
\hline$P_{\mathrm{CO},} \cdot P_{\mathrm{H}_{2}} / P_{\mathrm{CO}} \cdot P_{\mathrm{H}_{2} \mathrm{O}}$ & .418 & .706 & 4.38 & 1.13 & 1.95 & .590 \\
\hline \multicolumn{7}{|l|}{ Weight \% of Outlet } \\
\hline $\mathrm{II}_{2}$ & 3.23 & 2.60 & 2.06 & 2.80 & 4.04 & 4.11 \\
\hline $\mathrm{H}_{2} \mathrm{O}$ & 4.26 & 5.19 & 2.52 & 3.97 & 6.35 & 8.53 \\
\hline $\mathrm{CO}$ & 78.9 & 66.6 & 41.9 & 65.7 & 50.0 & 62.2 \\
\hline $\mathrm{CO}_{2}$ & 7.66 & 16.5 & 39.4 & 18.5 & 27.0 & 13.4 \\
\hline Hydrocarbons & 4.54 & 6.65 & 11.0 & 6.53 & 10.0 & 9.01 \\
\hline Oxygenates & .318 & .479 & .426 & .527 & .670 & .835 \\
\hline$W_{a x}{ }^{e}$ & 1.10 & 2.02 & 2.63 & 2.05 & 1.90 & 1.91 \\
\hline \multicolumn{7}{|l|}{ Yield $\left(\mathrm{g} / \mathrm{Nm}^{3} \mathrm{H}_{2}+\mathrm{CO}\right.$ Converted $)$} \\
\hline $\mathrm{CH}_{4}$ & 11.1 & 10.7 & 15.0 & 12.8 & 15.8 & $\mathbb{1 1 . 6}$ \\
\hline $\mathrm{C}_{2}-\mathrm{C}_{4}$ Hydrocarbons & 57.4 & 61.1 & 64.0 & 52.6 & 58.3 & 60.8 \\
\hline $\mathrm{C}_{8}-\mathrm{C}_{11}$ Hydrocarbons & 70.8 & 67.9 & 64.9 & 59.8 & 56.1 & 60.4 \\
\hline $\mathrm{C}_{12}+$ Hydrocarbons & 51.8 & 59.6 & 49.6 & 57.6 & 39.0 & 50.3 \\
\hline Waxe & 37.3 & 44.1 & 35.3 & 43.6 & 27.0 & 30.3 \\
\hline Oxygenates & 10.8 & 10.5 & 5.73 & 11.2 & 9.49 & 13.2 \\
\hline Tolal & 202. & 200. & 189. & 194. & 179. & 186. \\
\hline \multicolumn{7}{|l|}{$1+2$ Olefins/ $n$-Pataffin Ratio } \\
\hline $\mathrm{C}_{2}$ & 2.19 & 1.70 & .700 & 1.47 & .865 & 1.44 \\
\hline $\mathrm{C}_{3}$ & 6.61 & 6.58 & 5.12 & 6.59 & 4.85 & 4.62 \\
\hline $\mathrm{C}_{4}$ & 5.33 & 5.01 & 4.68 & 5.43 & 4.16 & 3.81 \\
\hline $\mathrm{C}_{\mathrm{B}}$ & 2.98 & 2.85 & 2.23 & 2.53 & 2.13 & 2.50 \\
\hline $\mathrm{C}_{10}$ & 2.39 & 2.34 & 1.71 & 2.05 & 1.63 & 1.92 \\
\hline
\end{tabular}

- Based on unreduced catalyst Based on static slurry volume 


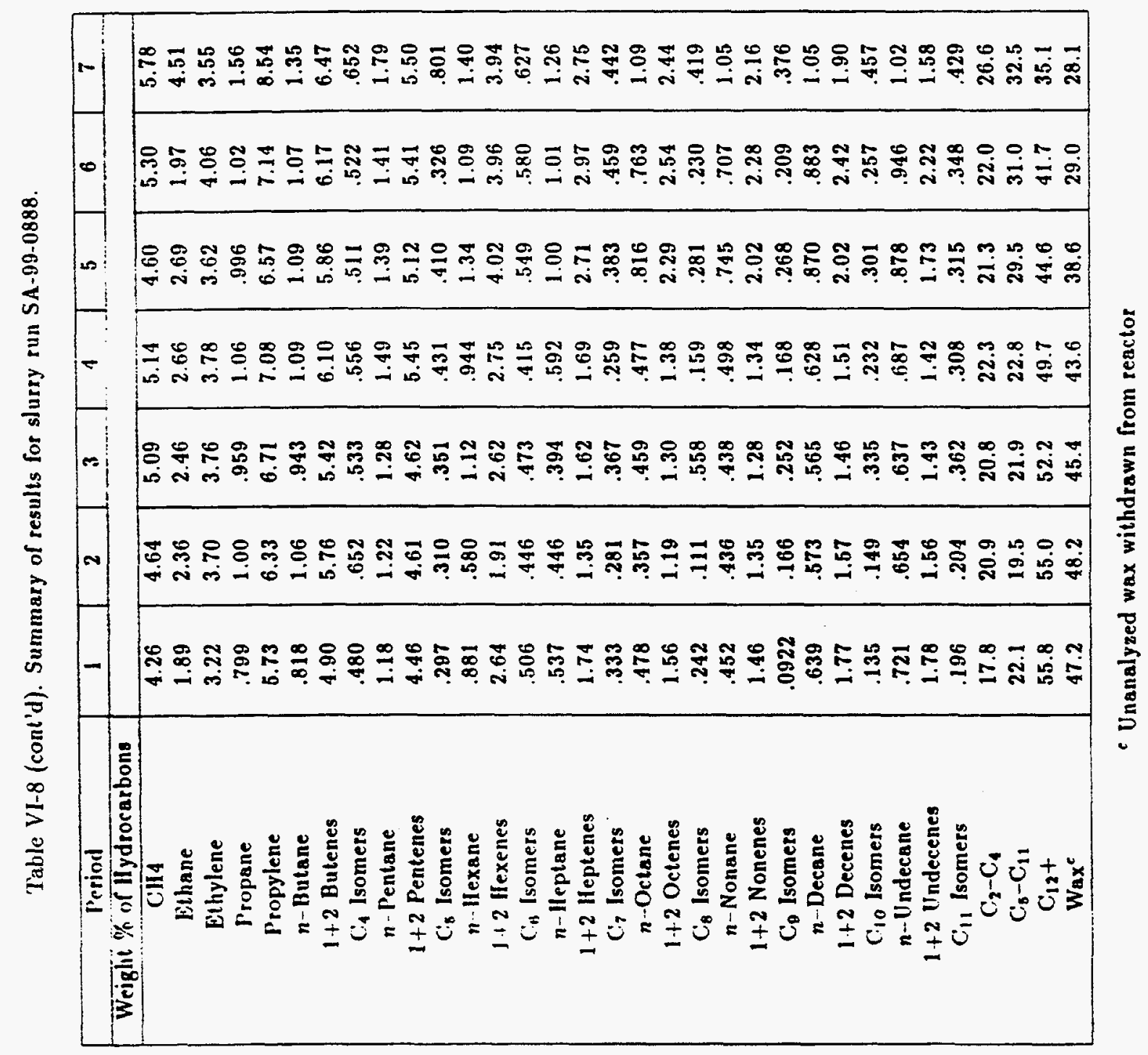


Table VI-8 (cont'd). Sunımary of results for slurry run SA-99-0888.

\begin{tabular}{|c|c|c|c|c|c|c|}
\hline Period & 8 & 9 & 10 & 11 & 12 & 13 \\
\hline \multicolumn{7}{|c|}{ Weight \% of Hydrocarbons } \\
\hline CH 4 & 5.83 & 5.63 & 8.15 & 7.00 & 9.35 & 6.68 \\
\hline Ethane & 3.39 & $\mathbf{3 . 3 1}$ & 5.35 & 3.86 & 5.78 & 3.82 \\
\hline Ethylene & 6.93 & 5.26 & 3.50 & 5.29 & 4.66 & 5.15 \\
\hline Propane & 1.42 & 1.34 & 1.87 & 1.42 & 2.28 & 2.01 \\
\hline Propylene & 8.93 & 8.38 & 9.14 & 8.94 & 10.5 & 8.86 \\
\hline n-Butane & 1.42 & 1.38 & 1.61 & 1.38 & 2.07 & 1.87 \\
\hline $1+2$ Butenes & 7.30 & 6.70 & 7.28 & 7.23 & 8.31 & 6.87 \\
\hline $\mathrm{C}_{4}$ Isomers & .664 & .637 & .681 & .663 & .841 & .752 \\
\hline$n$-Pentane & 1.85 & 1.69 & 2.17 & 1.92 & 2.45 & 2.13 \\
\hline $1+2$ Pentenes & 8.32 & 6.53 & 6.58 & 7.54 & 7.23 & 6.80 \\
\hline$C_{6}$ Isomets & .978 & .670 & 1.14 & .889 & 1.02 & .823 \\
\hline$n$-Hexane & 2.80 & 1.76 & 1.70 & 1.57 & 1.66 & 1.53 \\
\hline $1+2$ Hexenes & 5.03 & 4.24 & 3.63 & 4.43 & 4.07 & 4.86 \\
\hline $\mathrm{C}_{6}$ Isomers & .963 & .694 & .787 & .893 & .784 & .852 \\
\hline$n$-Heptane & 1.05 & 1.53 & 1.43 & 1.06 & 1.14 & 1.15 \\
\hline $1+2$ Heptenes & 2.85 & 3.07 & 2.52 & 2.67 & 2.41 & 3.02 \\
\hline $\mathrm{C}_{7}$ Isomers & 1.03 & .442 & .679 & .647 & .515 & .626 \\
\hline$n$-Octane & .724 & 1.04 & 1.05 & .779 & .894 & .962 \\
\hline $1+2$ Octenes & 2.12 & 2.92 & 2.29 & 1.93 & 1.87 & 2.36 \\
\hline $\mathrm{C}_{\mathrm{B}}$ Isomers & .283 & .288 & .507 & .334 & .393 & .398 \\
\hline$n$-Nonane & .698 & .911 & 1.06 & .643 & .848 & .860 \\
\hline $1+2$ Nonenes & 1.88 & 2.46 & 2.03 & 1.47 & 1.52 & 1.82 \\
\hline $\mathrm{C}_{9}$ Isomers & .280 & .310 & .535 & .256 & .383 & .308 \\
\hline$n$-Decane & .809 & 1.03 & 1.18 & .806 & 1.000 & .983 \\
\hline $1+2$ Decenes & 1.91 & 2.38 & 1.98 & 1.63 & 1.60 & 1.86 \\
\hline $\mathrm{C}_{10}$ Isomers & .473 & .409 & .648 & .386 & .463 & .385 \\
\hline n-Undecane & .823 & 1.05 & 1.16 & .880 & 1.02 & 1.04 \\
\hline $1+2$ Undecenes & 1.66 & 2.01 & 1.68 & 1.52 & 1.39 & 1.71 \\
\hline$C_{11}$ Isomers & .488 & .418 & .624 & .459 & .509 & .437 \\
\hline $\mathrm{C}_{2}-\mathrm{C}_{4}$ & 30.0 & 27.0 & 29.4 & 28.8 & 34.5 & 29.3 \\
\hline$C_{5}-C_{11}$ & 37.0 & 35.9 & 35.4 & 32.7 & 33.2 & 34.9 \\
\hline $\mathrm{C}_{12}+$ & 27.1 & 31.5 & 27.0 & 31.5 & 23.0 & 29.1 \\
\hline $\mathrm{Wax}^{c}$ & 19.5 & 23.3 & 19.2 & 23.9 & 15.9 & 17.5 \\
\hline
\end{tabular}

c Unanalyzed wax withdrawn from reactor 


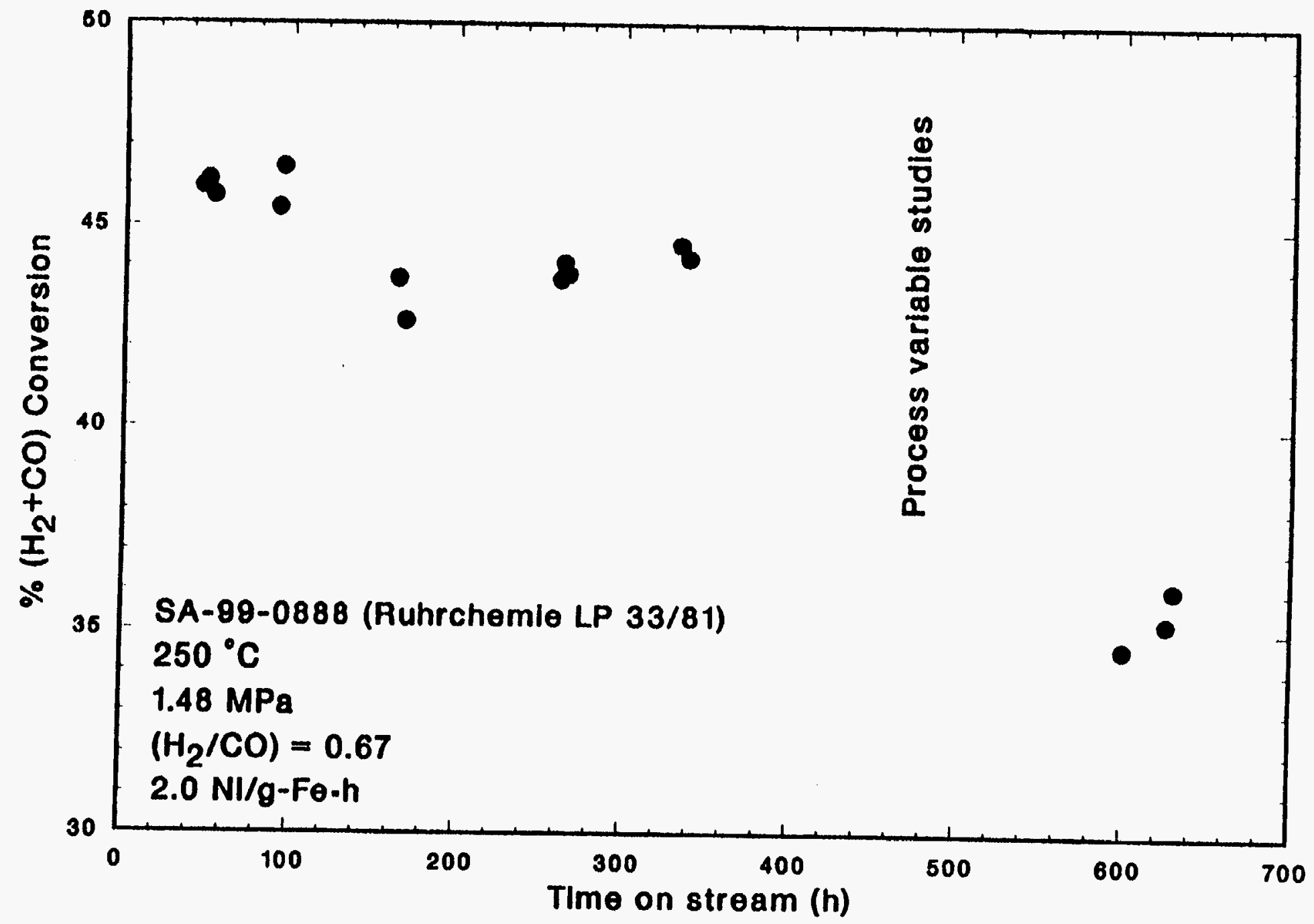

Figure VI-18. Stability plol, $\left(\mathrm{H}_{2}+\mathrm{CO}\right)$ conversion versus time on stream, for run SA-99-0888. 

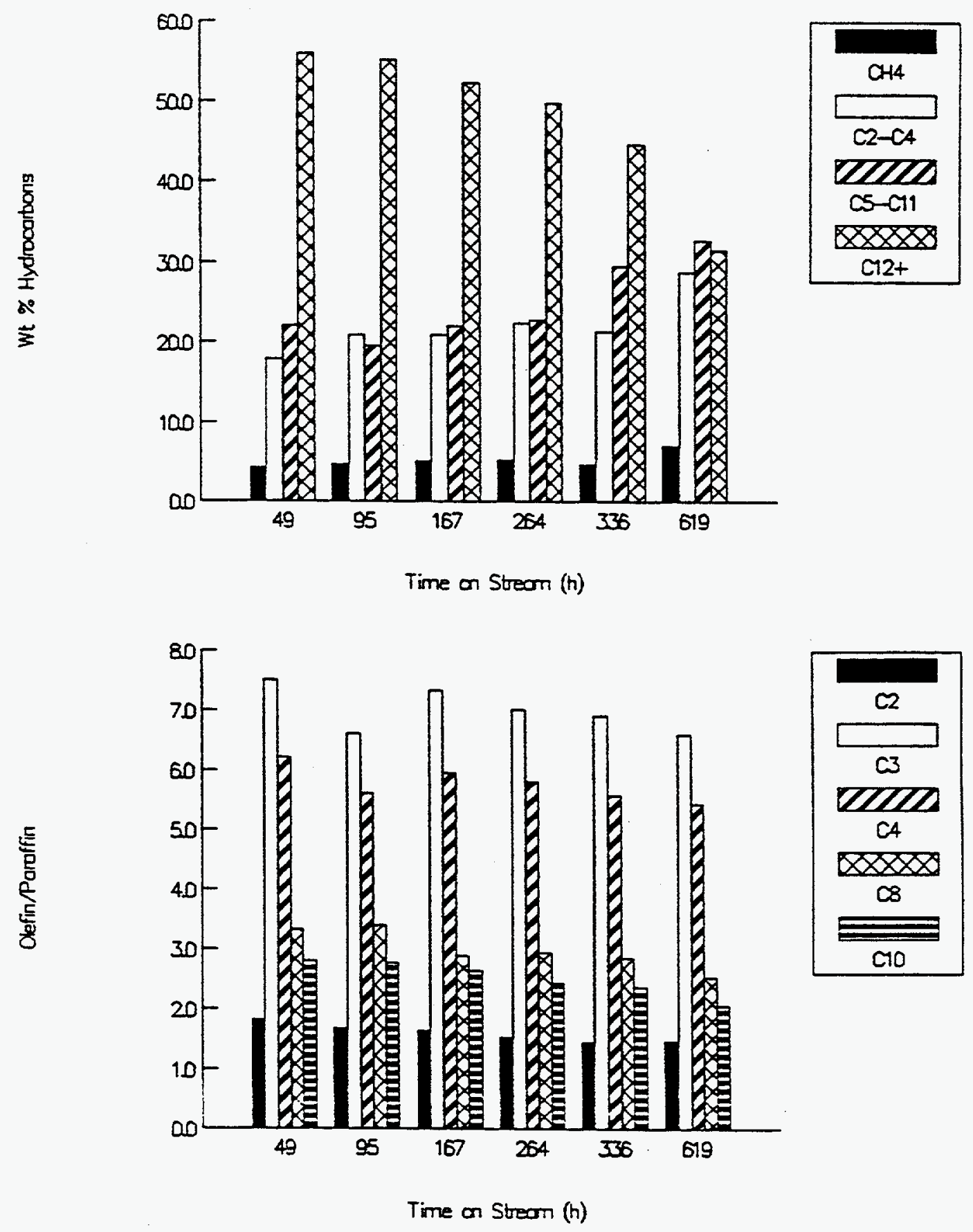

Figure VI-19. Effect of time on stream on Ruhrchemie LP 33/81 selectivity for run SA-99-0888: 250 ${ }^{\circ} \mathrm{C} .1 .48 \mathrm{MPa}, 2 \mathrm{Nl} / g$-cat $\cdot h,\left(\mathrm{H}_{2} / \mathrm{CO}\right)=0.67$. 
during balance 11 . The weight $\%$ of methane increased to $7.0 \%$ and $\mathrm{C}_{12}+$ decreased to 31.5 $\%$. The weak trend in decreasing olefin/paraffin ratios continued as well.

During the process variable studies, the effect of temperature was studied at $2.0 \mathrm{NI} / \mathrm{g}$-cat.h in balances $8\left(235^{\circ} \mathrm{C}\right), 5\left(250^{\circ} \mathrm{C}\right)$, and $10\left(265^{\circ} \mathrm{C}\right)$, and at $1.0 \mathrm{NI} / \mathrm{g}$-cat.h in balances $9\left(235^{\circ} \mathrm{C}\right)$ and $7\left(250^{\circ} \mathrm{C}\right)$, with all balances at $1.48 \mathrm{MPa}$ and $\left(\mathrm{H}_{2} / \mathrm{CO}\right)=0.67$. A comparison of catalyst selectivity at these conditions appears in Fig. VI-20. Conversion increases as expected with temperature: $23.0\left(235^{\circ} \mathrm{C}\right), 44.4\left(250^{\circ} \mathrm{C}\right)$, and $56.9 \%\left(265^{\circ} \mathrm{C}\right)$ at $2.0 \mathrm{NI} / \mathrm{g}$-cat.h, and 35.8 $\left(235^{\circ} \mathrm{C}\right)$ and $56.1 \%\left(250^{\circ} \mathrm{C}\right)$ at $1.0 \mathrm{NI} / \mathrm{g}$-cat.h. Temperature had little effect on the weight $\%$ hydrocarbon distribution between 235 and $265^{\circ} \mathrm{C}\left(2 \mathrm{NI} / \mathrm{g}\right.$-cat.h) and 235 and $250^{\circ} \mathrm{C}(1.0$ $\mathrm{Nl}$ / g-cat.h). Olefin/paraffin ratios decreased with increase in temperature, indicating that hydrogenation activity increases with temperature.

The feed gas space velocity was varied at $235^{\circ} \mathrm{C}$ in balances $9(1.0 \mathrm{NI} / \mathrm{g}$-cat.h $)$ and $8(2.0$ $\mathrm{NI} / \mathrm{g}$-cat.h), and at $250^{\circ} \mathrm{C}$ in balances $7(1.0 \mathrm{NI} / \mathrm{g}$-cat.h $), 5(2.0 \mathrm{NI} / \mathrm{g}$-cat.h $)$ and $6(4.0$ $\mathrm{N} 1 / \mathrm{g}$-cat.h). Space velocity has a minimal effect on the weight \% hydrocarbon distribution, as shown in Fig. V1-21. Olefin/paraffin ratios increased with space velocity at both temperatures. A higher $\left(\mathrm{H}_{2} / \mathrm{CO}\right)$ feed ratio, 1.0 (balance 12) increased the $\left(\mathrm{H}_{2}+\mathrm{CO}\right)$ conversion from 35.9 $\%\left(\mathrm{H}_{2} / \mathrm{CO}=0.67\right.$, balance 11$)$ to $45.4 \%$. The $\left(\mathrm{H}_{2} / \mathrm{CO}\right)=1.0$ feed also increased the amount of methane formed from 7.0 to $9.4 \%$ and decreased the percentage of $\mathrm{C}_{12}+$ products, as shown in Fig. VI-22. An increase in pressure to $2.96 \mathrm{MPa}$ in balance 13 showed a decrease in $\left(\mathrm{H}_{2}+\mathrm{CO}\right)$ conversion to $39.8 \%$ which indicates that some catalyst deactivation occurred at the higher pressure. The higher pressure suppressed the formation of gaseous hydrocarbons, and the selectivities at the two pressures are also compared in Fig. VI-22.

VI.3.2. Run SB $-66-2468$ with the $100 \mathrm{Fe} / 5.0 \mathrm{Cu} / 4.2 \mathrm{~K} / 24 \mathrm{SiO}_{2}$ Catalyst

Run SB-66-2468 was made as a long term stability test of the $100 \mathrm{Fe} / 5.0 \mathrm{Cu} / 4.2 \mathrm{~K} / 24$ $\mathrm{SiO}_{2}$ catalyst. Results from this run will also be used to compare the catalyst performance in slurry and fixed bed reactor tests (Run FB-66-1948, Section VI.1.3). The catalyst was reduced in situ using $\mathrm{CO}$ as the reductant at $280^{\circ} \mathrm{C}$. The reactor was charged with $35.1 \mathrm{~g}$ catalyst (270-325 mesh) and $282 \mathrm{~g}$ of purified $\mathrm{n}$-octacosane. The first five mass balances (up to $460 \mathrm{~h}$ on stream) were made at $250^{\circ} \mathrm{C}, 1.48 \mathrm{MPa}, 2.0 \mathrm{NI} / \mathrm{g}$-cat.h, $\mathrm{H}_{2} / \mathrm{CO}=0.67$ to determine catalyst stability. These conditions were repeated following balance 7 . The effect of space velocity was studied in balances $6(4.0 \mathrm{NI} / \mathrm{g}$-cat.h) and $7(1.0 \mathrm{NI} / \mathrm{g}$-cat.h). The run was voluntarily terminated after 582 hours on stream. The major events occurring during the 

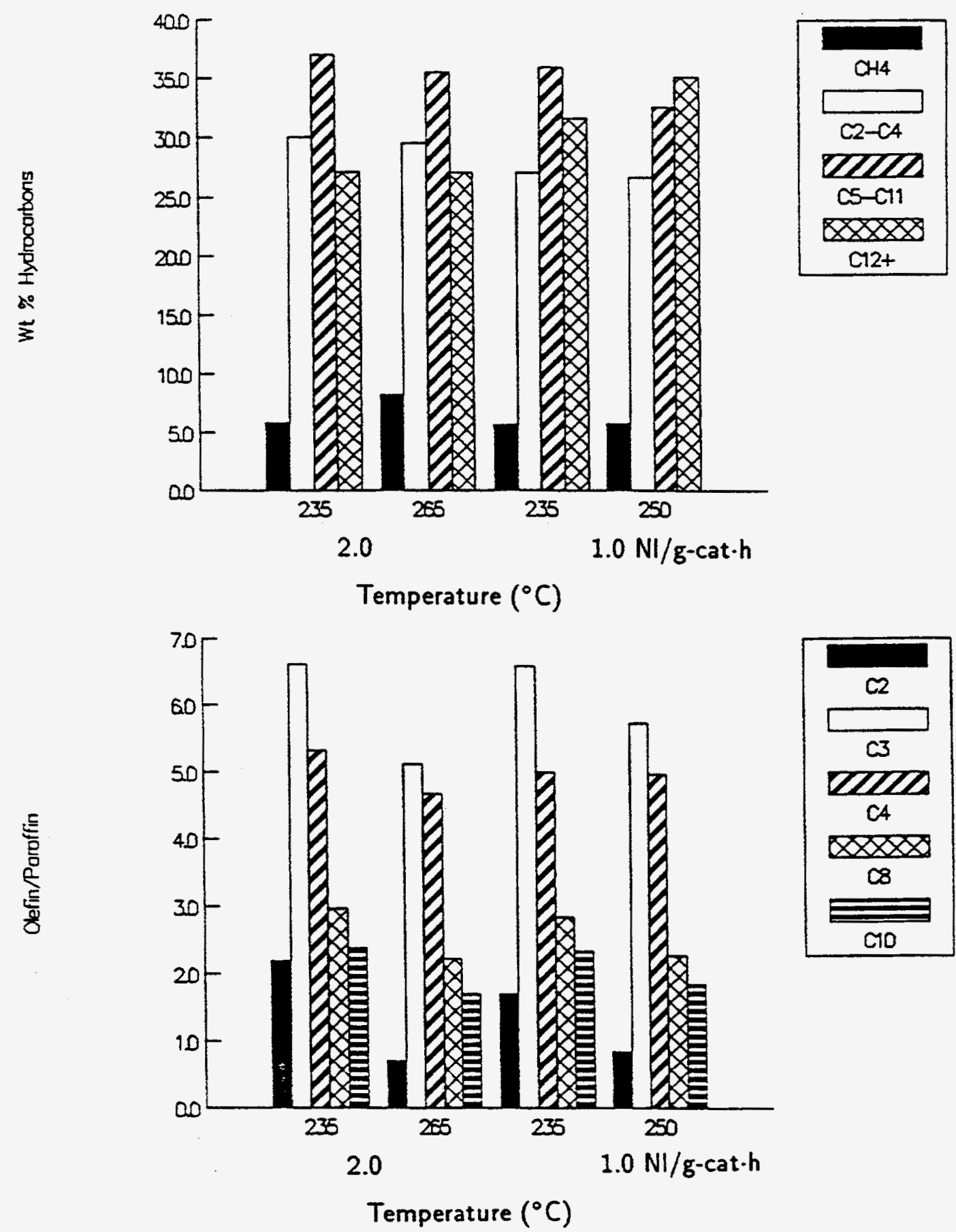

Figure VI-20. Effect of temperature on Ruhrchemie LP 33/81 selectivity for run SA-99-0888: 1.48 $M P a$, $\left(\mathrm{H}_{2} / \mathrm{CO}\right)=0.67$. 

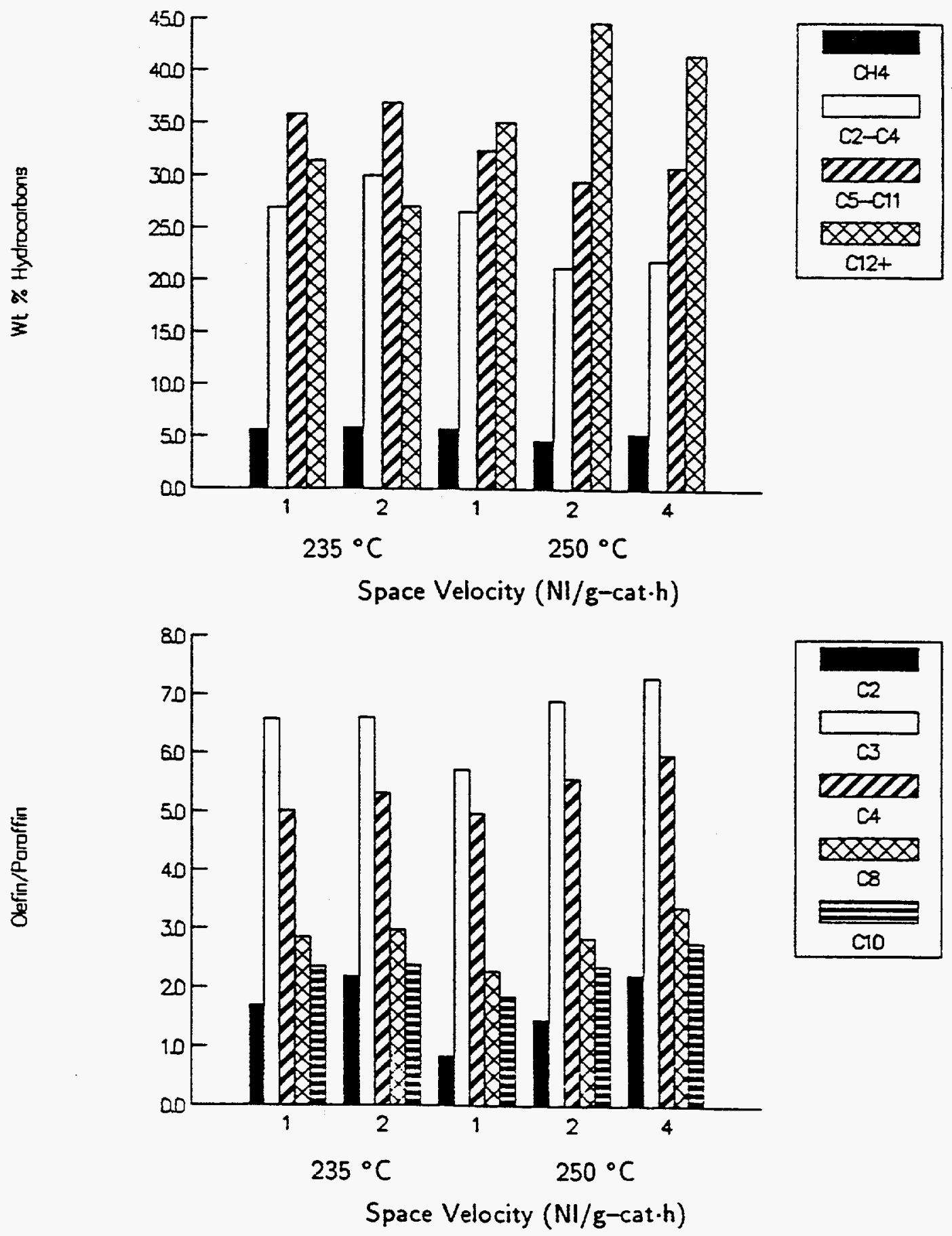

Figure VI-21. Effect of space velocity on Ruhrchemie LP 33/81 selectivity for run SA-99-0888: 1.48 $M P a,\left(\mathrm{H}_{2} / \mathrm{CO}\right)=0.67$. 

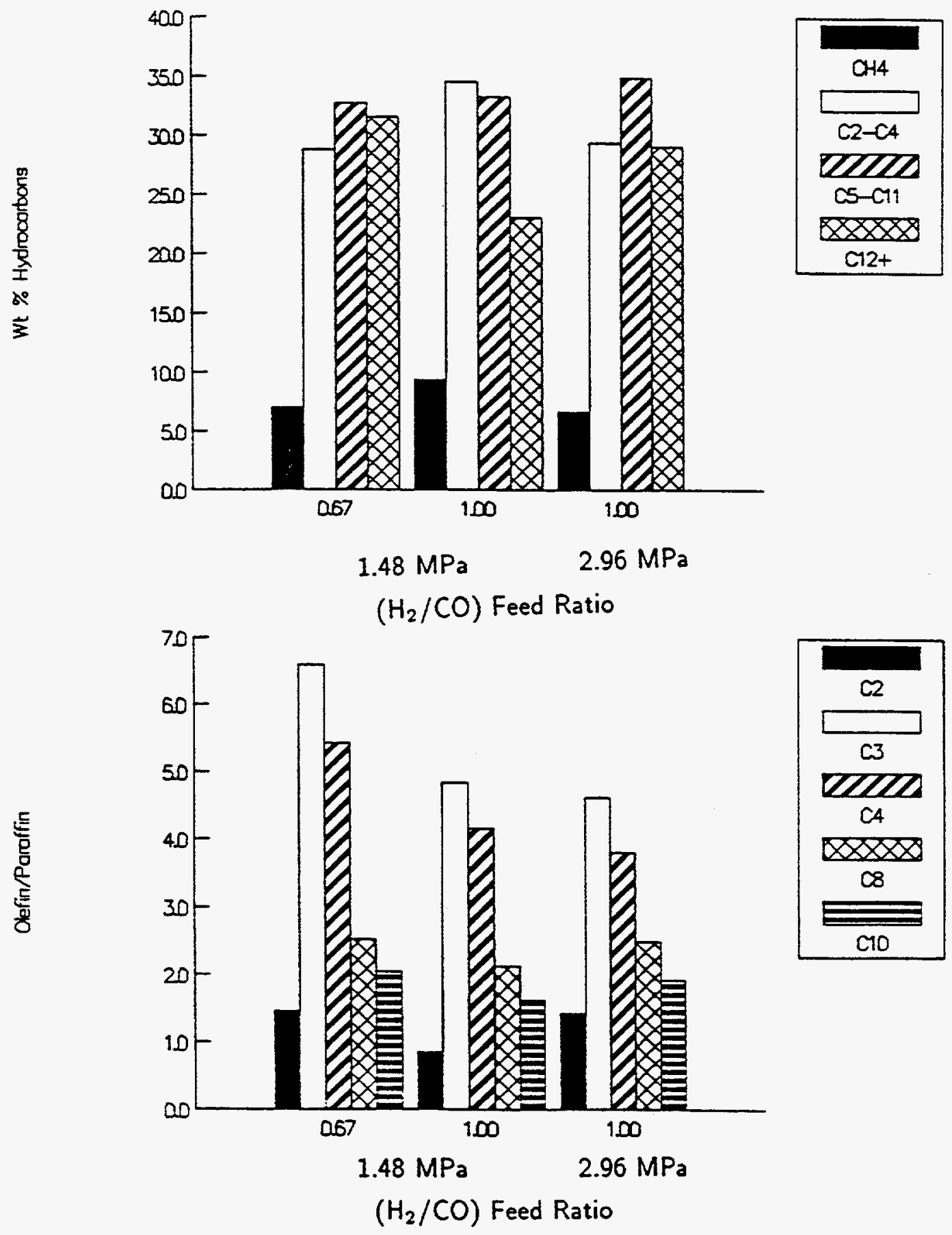

Figure VI-22. Effect of feed ratio and pressure on Ruhrchemie LP 33/81 selectivity for run SA-99-0888: $250^{\circ} \mathrm{C}$. 
run are summarized in Table VI-9. The results obtained from the seven mass balances made during the run are summarized in Table VI-10.

Following reduction the reactor was cooled to $230^{\circ} \mathrm{C}$ with flowing helium and the excess wax was withdrawn through a cylindrical filter element $(1.0-\mathrm{cm} O D$ by $3.8-\mathrm{cm}$ long). The withdrawal of $65 \mathrm{~g}$ of wax took only 5 minutes and the clarity of the wax confirmed successful operation of the filter. After increasing the pressure to $1.48 \mathrm{MPa}$, syngas with $\mathrm{H}_{2} / \mathrm{CO}=0.67$ was introduced at a gas space velocity of $2 \mathrm{NI} / \mathrm{g}$-cat.h and the reactor temperature was gradually raised to $250^{\circ} \mathrm{C}$. These conditions were maintained for 19 days ( 455 hours). Over this period of time, five mass balances and twelve wax withdrawals (through the internal filter) were made. The durations for the wax withdrawals ranged between 5 and 40 minutes, depending on the quantity of wax withdrawn. It was possible to withdraw as much as $150 \mathrm{~g}$ of wax in 30-40 minutes without the need to backflush the filter.

The activity plot for this catalyst (gas contraction versus time on stream) is shown in Figs. VI-23 (0-240 h TOS) and VI-24 (241-460 h TOS). Also shown on these plots are the instances when wax was withdrawn from or added to the reactor together with the respective amounts. Catalyst activity initially increased and the contraction reached $40.4 \%$ at 33 hours on stream at which point in time $142 \mathrm{~g}$ of wax was withdrawn from the reactor through the internal filter. Immediately following the wax withdrawal, contraction dropped sharply from 40.4 to $14.7 \%$ (corresponding to a drop in $\left(\mathrm{H}_{2}+\mathrm{CO}\right.$ ) conversion from 56.6 to $17.9 \%$ ). There appeared to be no catalyst present in the wax withdrawn from the reactor, therefore the sudden loss in activity was probably due to the removal of a large portion of the catalyst from the synthesis zone. Accumulation of the catalyst in the vicinity of the filter element was suspected and corrective measures were taken. During the withdrawal of the wax through the filter, the catalyst must have been left on the reactor wall (as the slurry level dropped gradually) and some of it must have collected in the narrow space between the filter element and the reactor wall. Backflushing of the filter with a small quantity of hexane $(20 \mathrm{cc})$ did not improve the contraction significantly (contraction increased from $14.7 \%$ to $21.3 \%$ ). We then added $98 \mathrm{~g}$ of wax back to the reactor through the external settling tank. The activity was restored to pre-withdrawal level within 18 hours following the addition of the wax (contraction reached $40.5 \%$ ). Apparently the addition of wax increased the slurry volume and the agitation was sufficient to flush the accumulated catalyst back into the slurry. Following the first mass balance (TOS $=76 \mathrm{~h}$ ), wax was again withdrawn from the reactor, however, the withdrawal 
Table VI-9. Major Events occuring in run SB-66-2468.

\begin{tabular}{|c|c|}
\hline $\operatorname{TOS}(h)$ & Event \\
\hline-14 & Catalyst Pretreatment: $\mathrm{CO}$ at $280^{\circ} \mathrm{C}$ \\
\hline-2 & Cooled to $260^{\circ} \mathrm{C}$ and pressurized to $1.48 \mathrm{MPa}$ using $\mathrm{He}$ \\
\hline 0 & Run initiated \\
\hline 5 & $\begin{array}{l}\text { Achieved desired operating conditions: } \\
260^{\circ} \mathrm{C}, 1.48 \mathrm{MPa}, \mathrm{H}_{2} / \mathrm{CO}=0.69,2 \mathrm{Nl} / g \text {-cat } h\end{array}$ \\
\hline 33 & Sharp drop in catalyst activity following wax withdrawal \\
\hline 61 & Activity recovered following addition of wax to reactor \\
\hline 69 & Conditions stable, $\mathrm{H}_{2}+\mathrm{CO}$ conversion $=56.1 \%$ \\
\hline 165 & Conditions stable, $\mathrm{H}_{2}+\mathrm{CO}$ conversion $=51.9 \%$ \\
\hline 171 & Sharp drop in catalyst activity following wax withdrawal \\
\hline 201 & Activity recovered following addition of wax to reactor \\
\hline 261 & Conditions stable, $\mathrm{H}_{2}+\mathrm{CO}$ conversion $=53.2 \%$ \\
\hline 269 & Sharp drop in catalyst activity following wax withdrawal \\
\hline 271 & Activity recovered following addition of wax to reactor \\
\hline 357 & Conditions stable, $\mathrm{H}_{2}+\mathrm{CO}$ conversion $=49.3 \%$ \\
\hline 364 & Small drop in catalyst activity following wax withdrawal \\
\hline 384 & Activity recovered following addition of wax to reactor \\
\hline 453 & Conditions stable, $\mathrm{H}_{2}+\mathrm{CO}$ conversion $=44.3 \%$ \\
\hline 460 & $\begin{array}{l}\text { Changed operating conditions: } \\
260^{\circ} \mathrm{C}, 1.48 \mathrm{MPa}, \mathrm{H}_{2} / \mathrm{CO}=0.69,4 \mathrm{Nl} / \mathrm{g} \text {-cat } \cdot h\end{array}$ \\
\hline 509 & $\begin{array}{l}\text { Changed operating conditions: } \\
260^{\circ} \mathrm{C}, 1.48 \mathrm{MPa}, \mathrm{H}_{2} / \mathrm{CO}=0.69,1 \mathrm{Nl} / \mathrm{g} \text {-cat } \cdot h\end{array}$ \\
\hline 555 & Small drop in catalyst activity following wax withdrawal \\
\hline 557 & Activity recovered following addition of wax to reactor \\
\hline 558 & $\begin{array}{l}\text { Changed operating conditions: } \\
260^{\circ} \mathrm{C}, 1.48 \mathrm{MPa}, \mathrm{H}_{2} / \mathrm{CO}=0.69,2 \mathrm{Nl} / g \text {-cat.h }\end{array}$ \\
\hline 582 & Voluntary termination of run SB-66-2468 \\
\hline
\end{tabular}


'Table VI-10. Summary of results for slurry run S13-66-2168

Reactor volume: $312 c c^{b}$

Slurry liquid: $n$-octacosanc

\begin{tabular}{|c|c|c|c|c|c|c|c|}
\hline Period & 1 & 2 & 3 & 4 & 5 & 6 & 7 \\
\hline Date & $09 / 06 / 88$ & $09 / 10 / 88$ & $09 / 14 / 88$ & $09 / 18 / 88$ & $09 / 22 / 88$ & $09 / 24 / 88$ & $09 / 24 / 88$ \\
\hline Time on Stream $(h)$ & 69.0 & 165.0 & 261.0 & 357.0 & 453.0 & 500.0 & 549.0 \\
\hline Balance Duration $(h)$ & 6.0 & 6.0 & 6.0 & 6.0 & 6.0 & 7.0 & 6.0 \\
\hline$\Lambda$ verage Temperature $\left({ }^{\circ} \mathrm{C}\right)$ & 250. & 250. & 250. & 250. & 250 . & 250. & 250. \\
\hline Pressure $(M P a)$ & 1.48 & 1.48 & 1.48 & 1.48 & 1.48 & 1.48 & 1.48 \\
\hline $\mathrm{II}_{2} / \mathrm{CO}$ Feed Ratio & .69 & .69 & .69 & .69 & .69 & .69 & .75 \\
\hline Space Velocity $(N I / g \text {-cal } \cdot h)^{a}$ & 2.00 & 2.00 & 2.00 & 2.00 & 2.00 & 4.00 & 1.01 \\
\hline Space Velocity $(N ! / g-\mathrm{Fe} \cdot h)$ & 3.57 & 3.57 & 3.57 & 3.57 & 3.57 & 7.13 & 1.80 \\
\hline $\operatorname{GHSV}\left(h^{-1}\right)^{b}$ & 225. & 225 . & 225. & 225. & 225 . & 450. & 113. \\
\hline CO Conversion (\%) & 54.6 & 49.4 & 51.7 & 47.2 & 42.3 & 22.3 & 61.0 \\
\hline $\mathrm{II}_{2}+\mathrm{CO}$ Conversion (\%) & 56.1 & 51.9 & 53.2 & 49.3 & 44.3 & 26.2 & 61.1 \\
\hline $\mathrm{H}_{2} / \mathrm{CO}$ Usage & .74 & .78 & .75 & .77 & .78 & .99 & .76 \\
\hline $\mathrm{STY}\left(m o l s \mathrm{H}_{2}+\mathrm{CO} / g-\mathrm{cal} \cdot h\right)^{a}$ & .050 & .046 & .047 & .044 & .040 & .047 & .027 \\
\hline$P_{\mathrm{CO}_{2}} \cdot P_{\mathrm{H}_{2}} / P_{\mathrm{CO}} \cdot P_{\mathrm{H}_{2} \mathrm{O}}$ & 2.5 & 1.7 & 2.0 & 1.9 & 1.5 & .9 & 2.7 \\
\hline \multicolumn{8}{|l|}{ Weight \% of Outlet } \\
\hline $\mathrm{II}_{2}$ & 2.02 & 2.20 & 2.15 & 2.29 & 2.54 & 3.32 & 1.95 \\
\hline $\mathrm{II}_{2} \mathrm{O}$ & 3.60 & 4.35 & 4.23 & 4.04 & 4.38 & 3.26 & 4.51 \\
\hline $\mathrm{CO}$ & 44.1 & 49.9 & 46.5 & 50.8 & 55.5 & 75.6 & 36.2 \\
\hline $\mathrm{CO}_{2}$ & 35.0 & 29.8 & 32.8 & 29.2 & 25.4 & 11.7 & 40.0 \\
\hline Ilydrocarbons & 8.79 & 8.46 & 9.90 & 9.91 & 9.43 & 5.17 & 12.4 \\
\hline Oxygenates & .19 & .51 & .36 & .50 & .50 & .24 & .70 \\
\hline Wax ${ }^{c}$ & 6.25 & 4.88 & 3.99 & 3.25 & 2.21 & .74 & 4.23 \\
\hline \multicolumn{8}{|l|}{ Yield $\left(\mathrm{g} / \mathrm{Nm}^{3} \mathrm{II}_{2}+\mathrm{CO}\right.$ Converted $)$} \\
\hline $\mathrm{CII}_{4}$ & 7.89 & 7.57 & 8.87 & 11.3 & 12.8 & 13.4 & 15.5 \\
\hline $\mathrm{C}_{2}-\mathrm{C}_{4}$ Hydrocarbons & 36.5 & 34.6 & 40.5 & 44.6 & 44.1 & 47.4 & 51.1 \\
\hline $\mathrm{C}_{5}-\mathrm{C}_{11}$ Iydrocarbons & 42.2 & 40.6 & 50.1 & 49.9 & 47.6 & 37.3 & 49.0 \\
\hline $\mathrm{C}_{12}+$ IIydrocarbons & 117. & 109. & 100. & 98.9 & 97.7 & 73.0 & 93.5 \\
\hline$W^{c}{ }^{c}$ & 84.6 & 70.3 & 57.3 & 50.6 & 38.8 & 21.5 & 53.2 \\
\hline Oxygenates & 2.56 & 7.33 & 5.17 & 7.79 & 8.68 & 7.00 & 8.87 \\
\hline 'Jotal & 206. & 200. & 205. & 213. & 211. & 178. & 218. \\
\hline \multicolumn{8}{|l|}{$1+2$ Olefins/n-Paralfin Ratio } \\
\hline $\mathrm{C}_{2}$ & 1.83 & 2.10 & 1.58 & 1.18 & 1.08 & 1.81 & .44 \\
\hline $\mathrm{C}_{3}$ & 7.34 & 7.34 & 6.58 & 5.50 & 5.02 & 5.38 & 3.54 \\
\hline $\mathrm{C}_{4}$ & 5.97 & 6.03 & 5.40 & 4.48 & 4.82 & 4.53 & 3.05 \\
\hline $\mathrm{C}_{8}$ & 4.29 & 2.52 & 3.16 & 2.46 & 1.96 & 2.56 & 1.42 \\
\hline $\mathrm{C}_{10}$ & 3.09 & 3.07 & 2.49 & 1.81 & 1.63 & 2.10 & 1.15 \\
\hline
\end{tabular}

a Based on unreduced catalyst ${ }_{c}$ Unanalyzed wax withdrawn from reach Based on static slurry volume 


\begin{tabular}{|c|c|c|c|c|c|c|c|}
\hline Period & 1 & 2 & 3 & 4 & 5 & 6 & 7 \\
\hline \multicolumn{8}{|c|}{ Weight \% of Ilydrocarbons } \\
\hline CII4 & 3.88 & 3.94 & 4.44 & 5.53 & 6.32 & 7.82 & 7.40 \\
\hline Ethane & 1.85 & 1.81 & 2.60 & 3.38 & 3.73 & 3.53 & 5.47 \\
\hline Ethylene & 3.16 & 3.54 & 3.83 & 3.72 & 3.74 & 5.95 & 2.23 \\
\hline Propane & .84 & .83 & 1.02 & 1.26 & 1.42 & 1.62 & 2.08 \\
\hline Propylene & 5.87 & 5.82 & 6.39 & 6.62 & 6.79 & 8.33 & 7.01 \\
\hline n-Butane & .84 & .81 & .95 & 1.17 & 1.04 & 1.42 & 1.77 \\
\hline 1+2 Butenes & 4.86 & 4.72 & 4.96 & 5.07 & 4.86 & 6.22 & 5.21 \\
\hline $\mathrm{C}_{4}$ Isomers & .51 & .48 & .53 & .57 & .23 & .66 & .66 \\
\hline$n$-Pentane & 1.16 & 1.17 & 1.32 & 1.52 & 1.65 & 1.86 & 2.12 \\
\hline 1+2 Pentenes & 4.35 & 4.30 & 5.48 & 5.00 & 4.99 & 5.56 & 4.05 \\
\hline $\mathrm{C}_{5}$ Isomers & .27 & .31 & .58 & .63 & .42 & .73 & .54 \\
\hline$n$-Ilexane & .77 & .68 & .90 & 1.06 & .84 & 1.13 & 1.00 \\
\hline $1+2$ Hexenes & 2.15 & 2.11 & 3.01 & 2.69 & 2.13 & 3.11 & 1.59 \\
\hline $\mathrm{C}_{6}$ Isomers & .62 & .47 & .68 & .66 & .52 & .81 & .44 \\
\hline$n$-Heptane & .39 & .45 & .53 & .85 & .65 & .77 & .75 \\
\hline 1+2 Heptenes & 1.64 & 1.48 & 1.92 & 1.86 & 1.50 & 1.62 & 1.28 \\
\hline $\mathrm{C}_{7}$ Isomers & .44 & .36 & .54 & .37 & .40 & .58 & .28 \\
\hline$n$-Octane & .33 & .60 & .50 & .58 & .63 & .34 & .88 \\
\hline $1+2$ Octenes & 1.41 & 1.48 & 1.56 & 1.41 & 1.21 & .85 & 1.23 \\
\hline $\mathrm{C}_{8}$ Isomers & .44 & .28 & .35 & .27 & .13 & .17 & .20 \\
\hline$n$-Nonane & .37 & .42 & .50 & .61 & .76 & .26 & 1.12 \\
\hline $1+2$ Nonenes & 1.33 & 1.42 & 1.34 & 1.23 & 1.36 & .60 & 1.32 \\
\hline $\mathrm{C}_{9}$ Isomers & .14 & .23 & .28 & .18 & .17 & .07 & .25 \\
\hline$n$-Decane & .52 & .58 & .67 & .83 & 1.04 & .44 & 1.31 \\
\hline $1+2$ Decenes & 1.60 & 1.76 & 1.65 & 1.48 & 1.68 & .90 & 1.48 \\
\hline$C_{10}$ Isorners & .25 & .30 & .41 & .37 & .32 & .15 & .46 \\
\hline$n$-Undecalle & .63 & .65 & .74 & .93 & 1.16 & .59 & 1.37 \\
\hline $1+2$ Undecenes & 1.63 & 1.73 & 1.61 & 1.44 & 1.59 & 1.09 & 1.40 \\
\hline $\mathrm{C}_{11}$ Isoniers & .31 & .31 & .46 & .42 & .39 & .19 & .39 \\
\hline $\mathrm{C}_{2}-\mathrm{C}_{4}$ & 17.9 & 18.0 & 20.3 & 21.8 & 21.8 & 27.7 & 24.4 \\
\hline $\mathrm{C}_{5}-\mathrm{C}_{11}$ & 20.7 & 21.1 & 25.1 & 24.4 & 23.5 & 21.8 & 23.5 \\
\hline $\mathrm{C}_{12}+$ & 57.5 & 57.0 & 50.2 & 48.3 & 48.3 & 42.7 & 44.7 \\
\hline $\mathrm{Wax}^{c}$ & 41.6 & 36.6 & 28.7 & 24.7 & 19.2 & 12.6 & 25.4 \\
\hline
\end{tabular}

c Unanalyzed wax withdrawn from reactor 


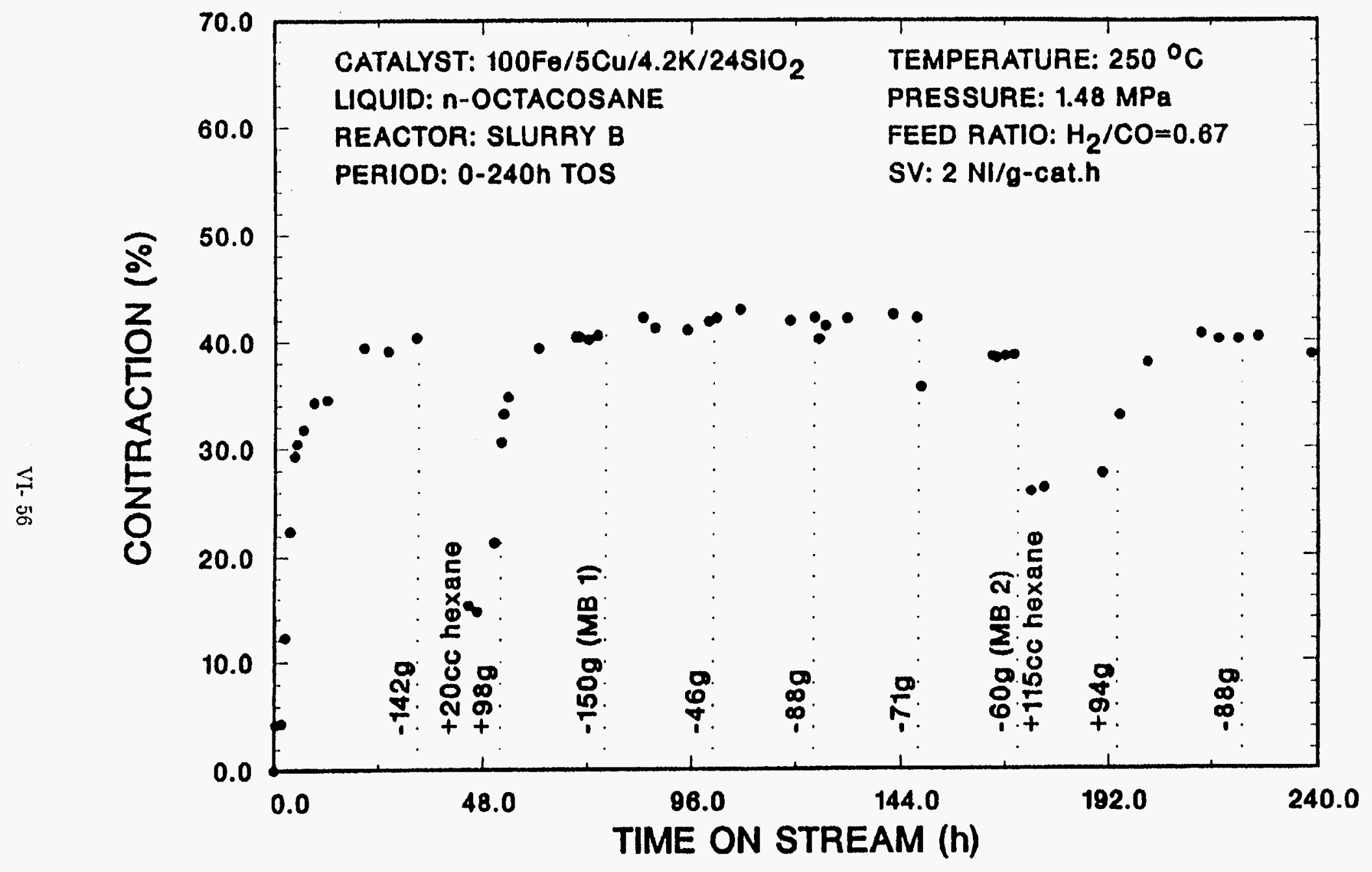

Pigure VI-23. Catalyst activity for run SB-66-2468 (weights indicale amount of wax withdrawn $(-)$ or added $(+))$. 0 to $240 h$ on stream. $\left(250{ }^{\circ} \mathrm{C}, 1.48 \mathrm{MPa}, 2.0\right.$ $\mathrm{Nl} / \mathrm{g}$ cat $\cdot h, \mathrm{H}_{2} / \mathrm{CO}=0.67$ nominal). 


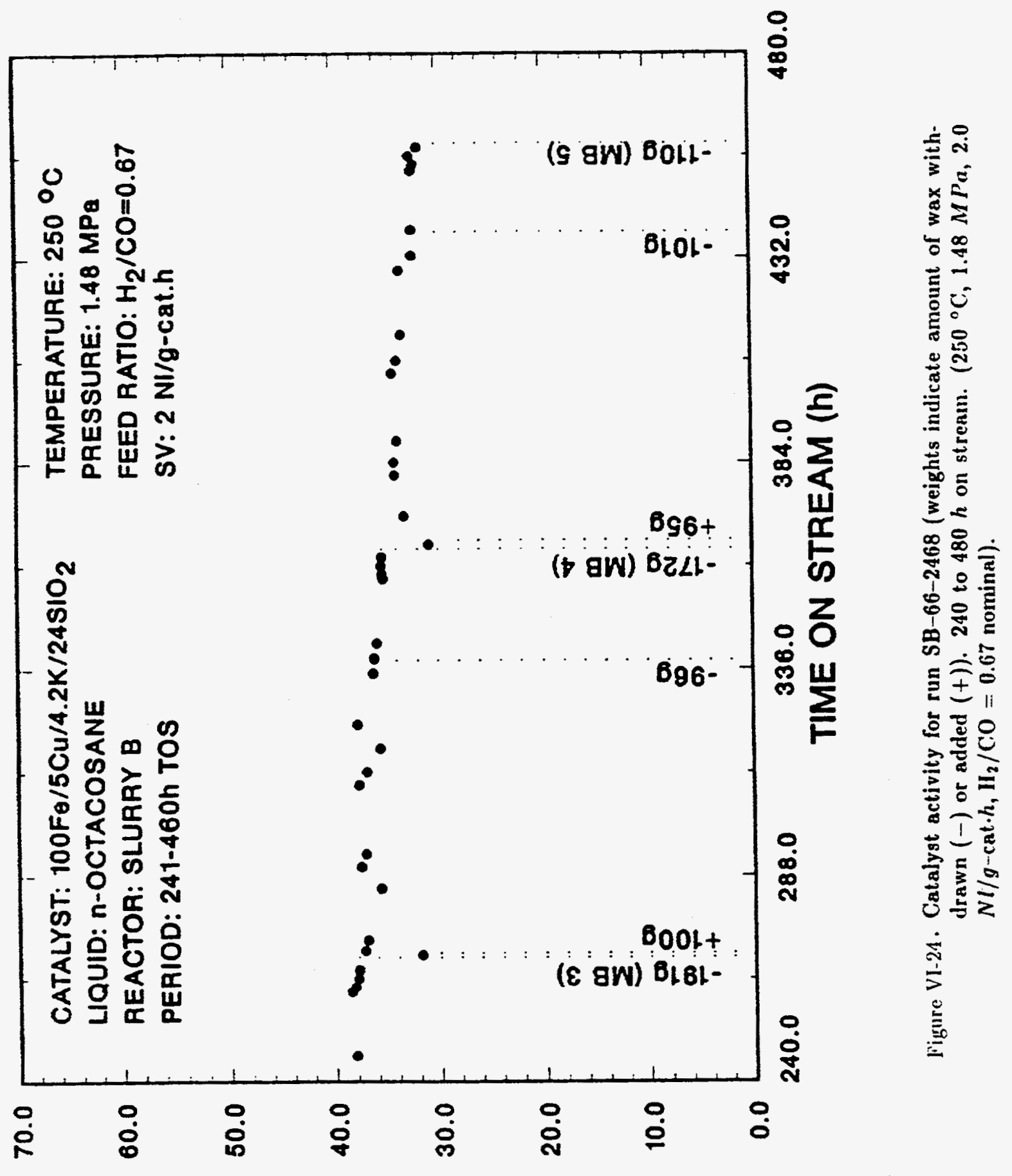

(\%) NOLIO $\forall 4 \perp N O O$ 
procedure was stopped short of complete withdrawal of all excess wax. The contraction did not change following this withdrawal, probably because the slurry level was sufficiently above the filter element to prevent any catalyst accumulation. However, following the majority of the subsequent wax withdrawals, a drop in contraction was observed and wax had to be returned to the reactor. Also, following each wax addition to the reactor, an equivalent amount of wax was withdrawn from the reactor 24 hours following the addition, i.e., after enough wax was produced to cover the filter element. Using this procedure, it was possible to prevent any significant wax withdrawal related losses in catalyst activity. No other operating problems were encountered during the entire run.

The $100 \mathrm{Fe} / 5.0 \mathrm{Cu} / 4.2 \mathrm{~K} / 24 \mathrm{SiO}_{2}$ catalyst was fairly stable in comparison to slurry tests with other catalysts, with some loss in activity over the first 19 days (constant conditions). The stability plot for the run over this period is shown in Fig VI-25. Also included are the $\left(\mathrm{H}_{2}+\mathrm{CO}\right)$ conversion values obtained following the seventh mass balance, when the initial conditions were repeated. Catalyst activity increased initially and reached a maximum at 107 hours on stream $\left(\mathrm{H}_{2}+\mathrm{CO}\right.$ conversion of $\left.58.7 \%\right)$, thereafter it steadily declined and the $\left(\mathrm{H}_{2}+\mathrm{CO}\right)$ conversion at 460 hours on stream was $44 \%$ (a $25 \%$ loss in activity). The reasons for catalyst deactivation are not known. One possibility is that small quantities of air were introduced into the reactor during the wax addition. The wax addition procedure involved the addition of molten wax to the external settling tank, following which the tank was purged with helium. The wax was then forced into the reactor using a slight over pressure in the settling tank. Any air dissolved in the wax, or present in the settling tank would be introduced into the reactor and would have a detrimental effect on catalyst activity. When the same conditions were repeated after mass balance 7 , the $\left(\mathrm{H}_{2}+\mathrm{CO}\right)$ conversion was $35.4 \%$ (at 558 hours on stream), which represents a $20 \%$ drop in activity in comparison to balance 5 conducted at 453 hours on stream. The accelerated catalyst deactivation is probably due to the combined effects of frequent changes in process conditions and the repeated introduction of small quantities of air into the reactor during the wax addition procedure. Another possibility is that deactivation was caused by the catalyst which had accumulated in the vicinity of the filter element and on the reactor wall following each wax withdrawal. The catalyst above the slurry level is in direct contact with the synthesis gas and this may lead to localized hot spots, leading to loss in activity with time on stream. Inspection of the reactor, following the completion of the run, showed that a layer of slurry was adhering to the reactor wall above the slurry level, and it is possible that the 


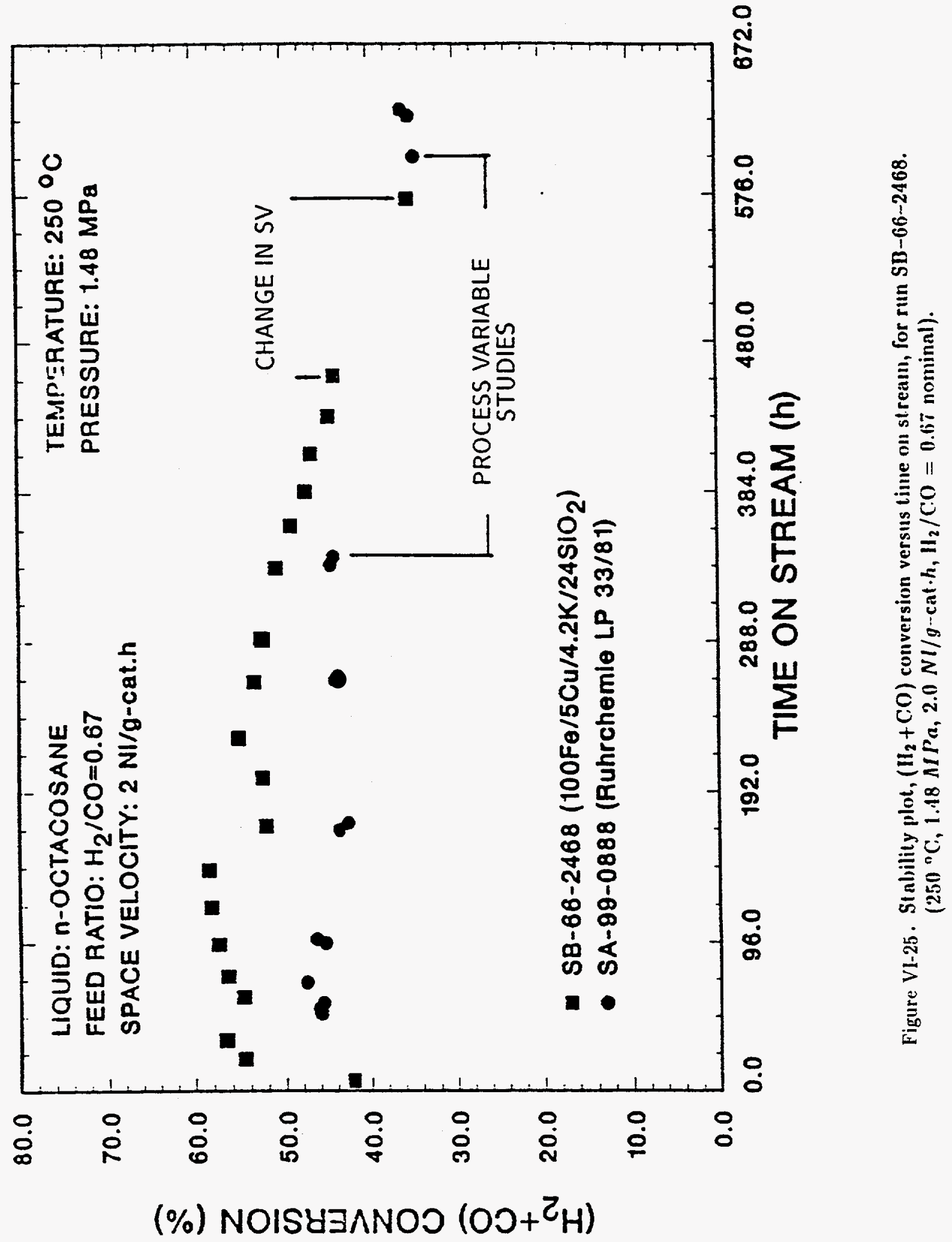


catalyst entrained in this layer would have deactivated more rapidly. When the same catalyst was tested in the fixed bed reactor (Run FB-66-1948, section VI.1.3), it was very stable and more active than in the slurry reactor. $\left(\mathrm{H}_{2}+\mathrm{CO}\right)$ conversion in the fixed bed was $68.7 \%$ initially and declined to $64.3 \%$ after 457 hours on stream, a drop of only $6.4 \%$ in activity.

The activity of this catalyst was higher than that of the Ruhrchemie LP 33/81 catalyst as shown in Fig. VI-25. The initial activity of the Ruhrchemie catalyst was lower (with $\mathrm{H}_{2}+\mathrm{CO}$ conversion of around $46 \%)$ in comparison to our catalyst $\left(\mathrm{H}_{2}+\mathrm{CO}\right.$ conversion of around $56 \%$ ). However, at 336 hours on stream the differences in activities for the two catalysts were smaller. The $\left(\mathrm{H}_{2}+\mathrm{CO}\right)$ conversion with the Ruhrchemie catalyst was about $45 \%$ vs. $51 \%$ with our catalyst. Activities for the two catalysts at the end of the respective runs were the same $\left(\mathrm{H}_{2}+\mathrm{CO}\right.$ conversions of about $\left.35 \%\right)$, as a result of partial deactivation of both catalysts.

With a decline in catalyst activity over the first 19 days (constant conditions), the hydrocarbon selectivity shifted slightly towards lighter products (Fig. VI-26). At 69 hours on stream (balance 1 ) the hydrocarbon fractions were $3.9\left(\mathrm{CH}_{4}\right), 17.9\left(\mathrm{C}_{2}-\mathrm{C}_{4}\right), 20.7\left(\mathrm{C}_{5}-\mathrm{C}_{11}\right)$ and $57.5 \%\left(\mathrm{C}_{12}+\right)$, whereas at 453 hours on stream (balance 5 ) they were $6.3\left(\mathrm{CH}_{4}\right), 21.8$ $\left(C_{2}-C_{4}\right), 23.5\left(C_{5}-C_{11}\right)$ and $48.3 \%\left(C_{12}+\right)$. During the same period, the olefin/paraffin ratios decreased for all carbon numbers (Fig. VI-26). A similar, although weaker, trend for hydrocarbon selectivity was observed when this catalyst was tested in the fixed bed reactor as shown in Fig. VI-10. In general, more light products were produced in the fixed bed than in the slurry reactor test (Fig.VI-27). In balances 5,6 and 7 of this run, the effect of space velocity (1,2 and 4 $\mathrm{NI} / \mathrm{g}$-cat.h) on the catalyst activity and product selectivity was studied. Conversion decreased with higher space velocity, as would be expected, with an $\left(\mathrm{H}_{2}+\mathrm{CO}\right)$ conversion of $26.2 \%$ at $4 \mathrm{NI} / \mathrm{g}$-cat.h at $500 \mathrm{~h}$ (balance 6) compared to $61.1 \%$ at $1 \mathrm{NI} / \mathrm{g}$-cat.h at $549 \mathrm{~h}$ (balance 7). Hydrocarbon selectivity shifted toward lighter products with an increase in space velocity (Fig.VI-28). The olefin/paraffin ratios for most carbon numbers increased at the same time. When a lower space velocity was used ( $1 \mathrm{NI} / \mathrm{g}$-cat.h in balance 7 ), hydrocarbon selectivities were comparable to those obtained in balance 5 at $2 \mathrm{NI} / \mathrm{g}$-cat.h, but the olefin/paraffin ratios showed a significant decrease for all carbon numbers (Table VI-10 and Fig.VI-28). 

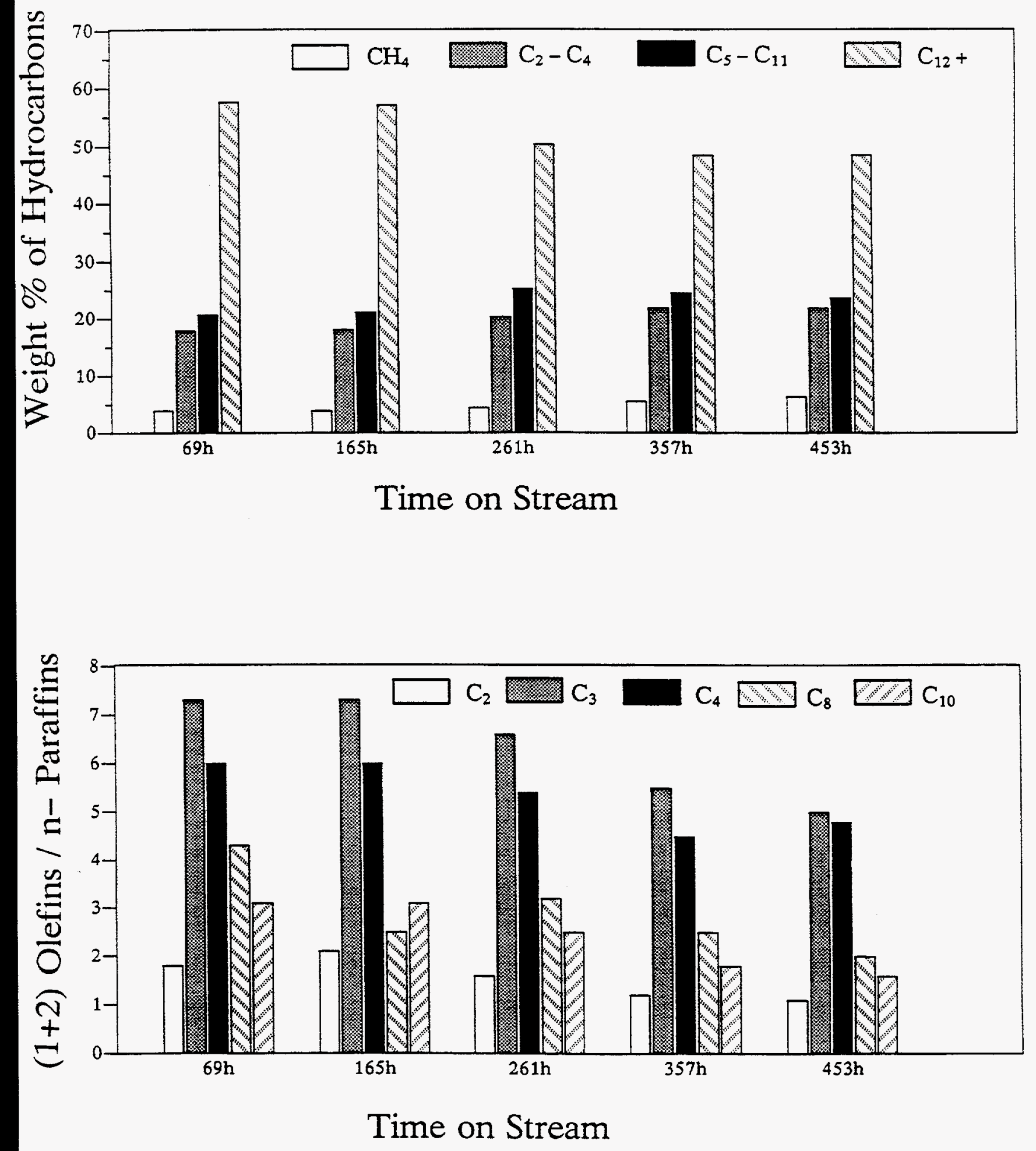

Figure VI-26 Effect of time on stream on $100 \mathrm{Fe} / 5 \mathrm{Cu} / 4.2 \mathrm{~K} / 24 \mathrm{SiO}_{2}$ catalyst selectivity for Run SB-66-2468 ( $250^{\circ} \mathrm{C}, 1.48 \mathrm{MPa} . \mathrm{SV}=2 \mathrm{Nl} /$ g-cat.h. $\left.\mathrm{H}_{2} / \mathrm{CO}=0.69\right)$ 

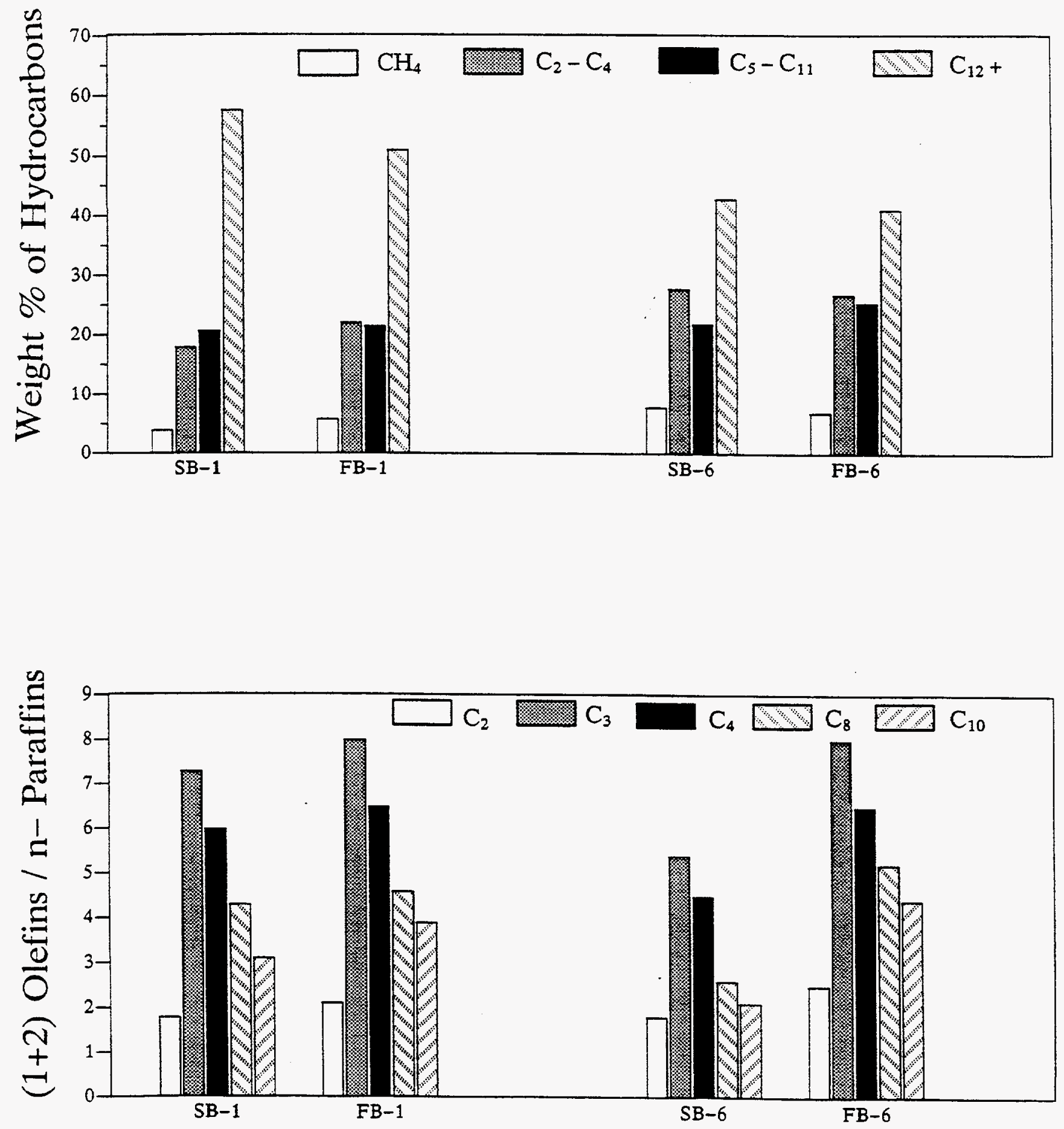

Figure VI-27 Comparison of fixed bed and slurry reactor selectivity with $100 \mathrm{Fe} / 5 \mathrm{Cu} / 4.2 \mathrm{~K} / 24$ $\mathrm{SiO}_{2}$ catalyst $(\mathrm{FB}=\mathrm{FB}-66-1948, \mathrm{SB}=\mathrm{SB}-66-2468)\left(250^{\circ} \mathrm{C}, 1.48 \mathrm{MPa}, \mathrm{H}_{2} / \mathrm{CO}=0.69\right.$ , $\mathrm{SV}=2 \mathrm{Nl} / \mathrm{g}$-cat.h (FB-1 and SB-1) and 4.0 (FB-6 and SB-6)) 

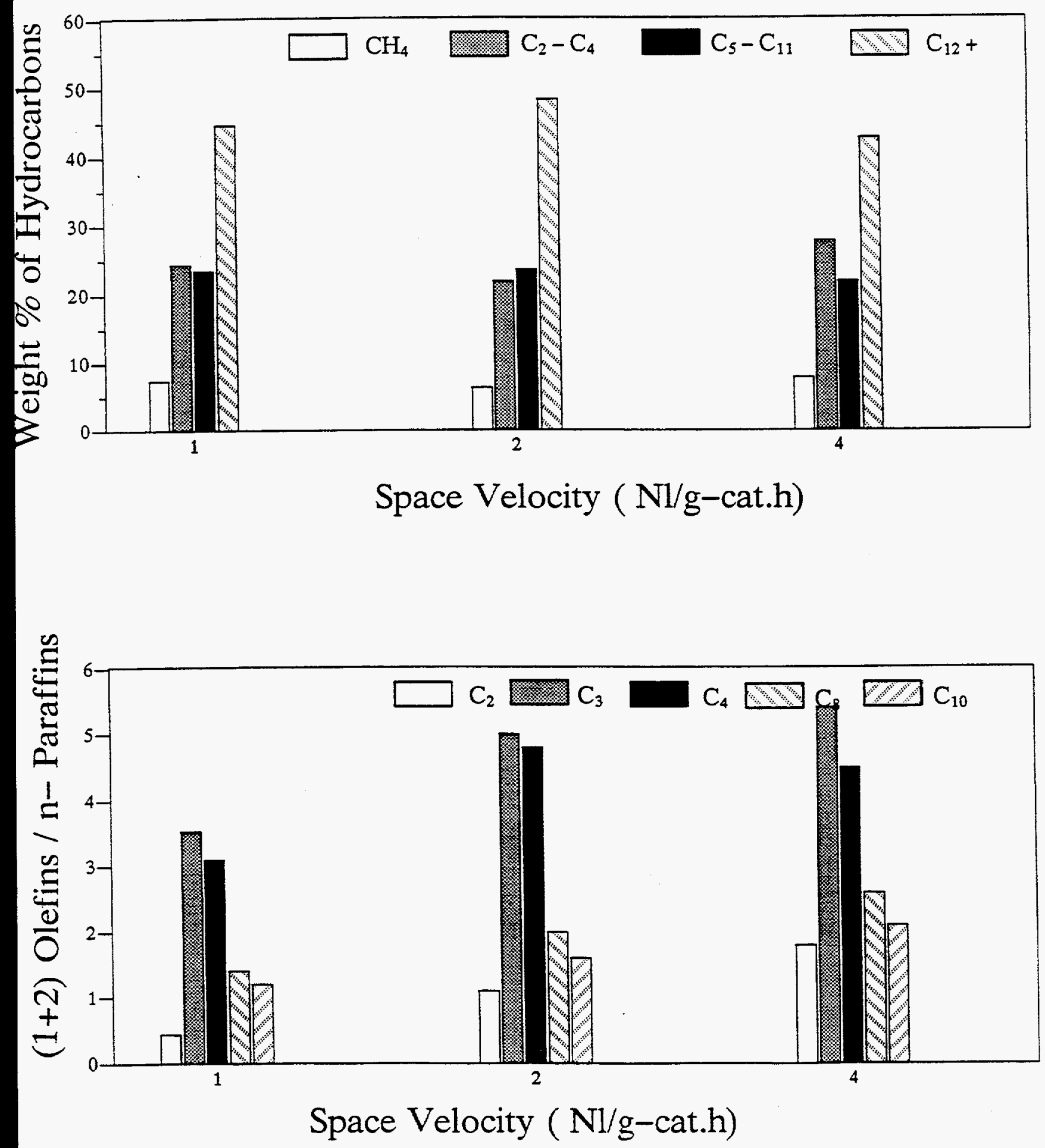

Figure VI-28 Effect of space velocity on $100 \mathrm{Fe} / 5 \mathrm{Cu} / 4.2 \mathrm{~K} / 24 \mathrm{SiO}_{2}$ catalyst selectivity for Run SB-66-2468 ( $\left.250^{\circ} \mathrm{C} .1 .48 \mathrm{MPa} . \mathrm{H}_{2} / \mathrm{CO}=0.69\right)$ 


\section{VI.4. Stirred Tank Slurry Reactors Tests with Unsupported Precipitated Iron Catalysts}

VI.4.1. Run SB $-27-2168$ with the $100 \mathrm{Fe} / 3.0 \mathrm{Cu} / 0.5 \mathrm{~K}$ Catalyst

Slurry run SB-27-2168 was intended to be a long term test of a precipitated $100 \mathrm{Fe} / 3.0$ $\mathrm{Cu} / 0.5 \mathrm{~K}$ catalyst reduced in situ using $\mathrm{CO}$ as the reductant at $280^{\circ} \mathrm{C}$. The reactor was charged with $45.2 \mathrm{~g}$ catalyst (270-325 mesh) and $295 \mathrm{~g}$ of purified $\mathrm{n}$-octacosane to obtain a 13 weight $\%$ catalyst slurry. The slurry withdrawal dipleg, attached to a cylindrical $20 \mu \mathrm{m}$ filter element (1.0-cm OD by $3.8-\mathrm{cm}$ long), was preset to give a static slurry volume of $370 \mathrm{cc}$. Four mass balances were performed during the run, and the run was voluntarily terminated after 339 hours on stream. The process conditions used during the run were: $260^{\circ} \mathrm{C}, 1.48 \mathrm{MPa},\left(\mathrm{H}_{2} / \mathrm{CO}\right)=$ $0.67-1.0,2.0-3.0 \mathrm{NI} / \mathrm{g}$-cat.h. The major events occurring during this run are summarized in Table VI-11. The results obtained from the mass balances are summarized in Table VI-12.

Following catalyst reduction, the reactor was cooled down with flowing helium to $260^{\circ} \mathrm{C}$ and excess wax withdrawn through the filter. The slurry withdrawn was very dark in color and subsequently it has been determined that $6 \mathrm{~g}$ of catalyst was removed together with $42 \mathrm{~g}$ of wax. After increasing the pressure to $1.48 \mathrm{MPa}$, syngas with an $\mathrm{H}_{2} / \mathrm{CO}$ feed ratio of 0.7 was introduced at a space velocity of $0.5 \mathrm{NI} / \mathrm{g}$-cat.h while maintaining the helium flow at $4 \mathrm{NI} / \mathrm{g}$ cat.h. During the next 27 hours the syngas flow rate was gradually increased to $2 \mathrm{NI} / \mathrm{g}$-cat.h and helium flow was phased out. However, the gas contraction was very low, and the feed and tail gas sample analyses showed only $\mathrm{CO}$ in the former and no hydrocarbon products in the latter. At this point it was discovered that the helium purge from the slurry $A$ reactor system was accidentally diverted through the $\mathrm{H}_{2}$ mass flow meter. This means that the catalyst was exposed to a mixture of $\mathrm{CO}$ and $\mathrm{He}$ at $260^{\circ} \mathrm{C}$ and $1.48 \mathrm{MPa}$ for 27 hours, in addition to 12 $h$ activation with pure $\mathrm{CO}$ at $280^{\circ} \mathrm{C}$ and $0.79 \mathrm{MPa}$. After the problem was corrected, gas contraction showed an increase with time on stream. Slurry was again withdrawn through the filter element after 22 hours at the process conditions. The $101 \mathrm{~g}$ of slurry withdrawn was found to contain $8.7 \mathrm{~g}$ of catalyst, providing further evidence of filter malfunction, possibly due to a leak in the filter element (at the end of the run, it was found that the filter had cracked due to its proximity to the stirring shaft in the reactor). All subsequent withdrawals were made through the external settling tank system. No further operational problems were encountered during the remainder of the run.

A stability plot, $\left(\mathrm{H}_{2}+\mathrm{CO}\right)$ conversion versus time on stream, is shown in Fig. VI-29. The initial activity of the catalyst was relatively high, $\left(\mathrm{H}_{2}+\mathrm{CO}\right)$ conversion of $68.3 \%$ at 46 hours on 
Table VI-11. Major events occurring in run SB-27-2168.

$\operatorname{TOS}(h)$

Event

- 44 Catalyst pretreatment:

$\mathrm{CO}$ at $280^{\circ} \mathrm{C}$

- 27 Cooled to $260^{\circ} \mathrm{C}$, pressurized to $1.48 \mathrm{MPa}$ with $\mathrm{He}$

-25 Began blending synthesis gas with $\mathrm{He}$

- 24 Wax plug in high pressure unsteady state trap repaired

-20 First attempt to initiate run

- 18 Reactor exit gas showed no $\mathrm{H}_{2}$ peak

-2 Feed gas difficulty corrected ( $\mathrm{He}$, instead of $\mathrm{H}_{2}$, was flowing into inlet line)

$0 \quad$ Run initiated

2.0 Achieved desired operating conditions:

$260^{\circ} \mathrm{C}, 1.48 \mathrm{MPa},\left(\mathrm{H}_{2} / \mathrm{CO}\right)=0.67,2.3 \mathrm{Nl} / \mathrm{g}$-cat $\cdot h$

46.0 Conditions stable, $\left(\mathrm{H}_{2}+\mathrm{CO}\right)$ conversion $=68.2 \%$

141.0 Conditions stable, $\left(\mathrm{H}_{2}+\mathrm{CO}\right)$ conversion $=31.3 \%$

238.0 Conditions stable, $\left(\mathrm{H}_{2}+\mathrm{CO}\right)$ conversion $=15.8 \%$

246.0 Changed process conditions:

$260^{\circ} \mathrm{C}, 1.48 \mathrm{MPa},\left(\mathrm{H}_{2} / \mathrm{CO}\right)=1.00,2.0 \mathrm{Nl} / \mathrm{g}$-cat $\cdot h$

339.0 Voluntary termination of run SB-27-2168 
'Table VI-12. Summary of results for slurry rum S13-27-2108.

Catalyst: $100 \mathrm{Fe} / 3.0 \mathrm{Cu} / 0.5 \mathrm{~K}$

Slurry liquid: $\boldsymbol{n}$-octacosane

Reactor volume: $370 c c^{b}$

\begin{tabular}{|c|c|c|c|c|}
\hline Period & 1 & 2 & 3 & $\overline{4}$ \\
\hline Date & $08 / 06 / 88$ & $08 / 10 / 88$ & $08 / 14 / 88$ & $08 / 18 / 88$ \\
\hline Time on Stream $(h)$ & 45.5 & 141.0 & 236.8 & 333.0 \\
\hline Balance Duration $(h)$ & 6.0 & 6.0 & 6.2 & 6.2 \\
\hline Average Temperature $\left({ }^{\circ} \mathrm{C}\right)$ & 260. & 260. & 260. & 260. \\
\hline Pressure $(M P a)$ & 1.48 & 1.48 & 1.48 & 1.48 \\
\hline $\mathrm{II}_{2} / \mathrm{CO}$ Feed Ratio & .67 & .67 & .67 & 1.00 \\
\hline Space Velocity $(N I / g-\text { cat } \cdot h)^{a}$ & 2.96 & 2.34 & 2.34 & 2.01 \\
\hline Space Velocity $(N l / g-F e \cdot h)$ & 4.37 & 3.45 & 3.45 & 2.96 \\
\hline GIISV $\left(h^{-1}\right)^{b}$ & 244. & 165. & 165. & 138. \\
\hline CO Conversion (\%) & 72.7 & 33.5 & 16.7 & 13.6 \\
\hline $\mathrm{II}_{2}+\mathrm{CO}$ Conversion (\%) & 68.3 & 31.2 & 15.9 & 10.8 \\
\hline $\mathrm{H}_{2} / \mathrm{CO}$ Usage & .57 & .56 & .58 & .59 \\
\hline $\operatorname{STY}\left(\mathrm{mols} \mathrm{II}_{2}+\mathrm{CO} / g \text {-cat } h\right)^{a}$ & .090 & .033 & .017 & .010 \\
\hline$P_{\mathrm{CO}_{2}} \cdot P_{\mathrm{H}_{2}} / P_{\mathrm{CO}} \cdot P_{\mathrm{H}_{2} \mathrm{O}}$ & 21.0 & 8.1 & 4.9 & 2.6 \\
\hline \multicolumn{5}{|l|}{ Weight \% of Outlet } \\
\hline $\mathrm{II}_{2}$ & 1.77 & 3.32 & 3.96 & 6.24 \\
\hline $\mathrm{H}_{2} \mathrm{O}$ & .97 & .87 & .59 & 1.25 \\
\hline $\mathrm{CO}$ & 26.3 & 63.7 & 80.1 & 81.4 \\
\hline $\mathrm{CO}_{2}$ & 53.6 & 23.9 & 10.3 & 7.33 \\
\hline Hydrocarbons & 9.30 & 4.99 & 2.64 & 1.83 \\
\hline Oxygenates & .27 & .19 & .09 & .11 \\
\hline $\mathrm{Wax}^{\mathrm{c}}$ & 7.78 & 3.04 & 2.36 & 1.82 \\
\hline \multicolumn{5}{|l|}{ Yield $\left(\mathrm{g} / \mathrm{Nm}^{3} \mathrm{H}_{2}+\mathrm{CO}\right.$ Converted $)$} \\
\hline $\mathrm{CH}_{4}$ & 7.46 & 6.16 & 7.10 & 11.6 \\
\hline $\mathrm{C}_{2}-\mathrm{C}_{4}$ llydrocarbons & 29.4 & 28.5 & 28.4 & 36.3 \\
\hline $\mathrm{C}_{5}-\mathrm{C}_{11}$ Ilydrocarbons & 39.6 & 36.1 & 23.2 & 20.1 \\
\hline $\mathrm{C}_{12}+$ llydrocarbons & 118. & 130. & 187. & 156. \\
\hline $\operatorname{Wax}^{c}$ & 88.6 & 76.1 & 116. & 112. \\
\hline Oxygenates & 3.06 & 4.87 & 4.21 & 6.79 \\
\hline Total & 198. & 206. & 250. & 231. \\
\hline \multicolumn{5}{|l|}{$1+2$ Olefins/n-Paraflin Ratio } \\
\hline$\overline{\mathrm{C}_{2}}$ & 2.57 & 4.40 & 4.50 & 2.12 \\
\hline $\mathrm{C}_{3}$ & 7.12 & 6.16 & 4.77 & 3.41 \\
\hline $\mathrm{C}_{4}$ & 5.79 & 4.97 & 4.12 & 2.92 \\
\hline $\mathrm{C}_{8}$ & 5.16 & 4.33 & 4.19 & 1.92 \\
\hline $\mathrm{C}_{10}$ & 4.33 & 3.85 & 3.18 & 2.39 \\
\hline
\end{tabular}

a Based on unreduced catalyst

${ }^{b}$ Based on static slurry volume

C Unanalyzed wax withdrawn from reactor 


\begin{tabular}{|c|c|c|c|c|}
\hline Period & 1 & 2 & 3 & 4 \\
\hline \multicolumn{5}{|c|}{ Weight \% of Ilydrocarbons } \\
\hline CII4 & $\overline{3.84}$ & 3.07 & 2.89 & 5.17 \\
\hline Ethane & 1.30 & .80 & 63 & 1.59 \\
\hline Ethylene & 3.11 & 3.26 & 2.63 & 3.14 \\
\hline Propane & .68 & .72 & 69 & 1.24 \\
\hline Propylene & 4.63 & 4.21 & 3.16 & 4.04 \\
\hline$n$-Butane & .74 & .81 & .80 & 1.42 \\
\hline 1+2 Butenes & 4.16 & 3.87 & 3.18 & 4.01 \\
\hline $\mathrm{C}_{4}$ Isomers & .48 & .53 & .48 & .74 \\
\hline$n$-Pentane & .92 & 1.00 & .81 & 1.23 \\
\hline $1+2$ Pentenes & 3.27 & 3.05 & 2.18 & 2.59 \\
\hline $\mathrm{C}_{5}$ Isomers & .19 & .21 & .18 & .27 \\
\hline$n$-Hlexane & .49 & .53 & .32 & .56 \\
\hline $1+2$ Hexenes & 2.50 & 2.37 & 64 & 1.54 \\
\hline $\mathrm{C}_{6}$ Isomers & .50 & .73 & .30 & .00 \\
\hline n-Ileptane & .43 & 39 & .21 & .53 \\
\hline 1+2 Heptenes & 2.10 & 1.76 & .98 & 1.13 \\
\hline $\mathrm{C}_{7}$ Isonjers & 37 & 49 & .15 & .00 \\
\hline n-Octane & .36 & 31 & .13 & 25 \\
\hline $1+2$ Octenes & 1.82 & 1.30 & .54 & .48 \\
\hline $\mathrm{C}_{8}$ Isomers & .26 & .09 & .02 & .00 \\
\hline$n$-Nonane & .37 & .30 & .17 & .03 \\
\hline $1+2$ Nonenes & 1.71 & 1.14 & .52 & .06 \\
\hline $\mathrm{C}_{9}$ Isomers & 15 & .10 & .04 & .00 \\
\hline$n$-Decane & 42 & .37 & .23 & .04 \\
\hline $1+2$ Decenes & 1.81 & 1.41 & .72 & .09 \\
\hline $\mathrm{C}_{10}$ Isomers & .19 & .17 & .08 & .01 \\
\hline$n$-Undecane & .45 & .39 & .21 & .04 \\
\hline $1+2$ Undecenes & 1.81 & 1.57 & .90 & .11 \\
\hline $\mathrm{C}_{11}$ Isomers & .22 & .26 & .11 & .01 \\
\hline $\mathrm{C}_{2}-\mathrm{C}_{4}$ & 15.1 & 14.2 & 11.6 & 16.2 \\
\hline $\mathrm{C}_{5}-\mathrm{C}_{11}$ & 20.3 & 17.9 & 9.46 & 8.97 \\
\hline $\mathrm{C}_{12}+$ & 60.7 & 64.8 & 76.1 & 69.7 \\
\hline $\mathrm{Wax}^{\mathrm{c}}$ & 45.5 & 37.9 & 47.2 & 49.8 \\
\hline
\end{tabular}

${ }^{c}$ Unanalyzed wax withdrawn from reactor 


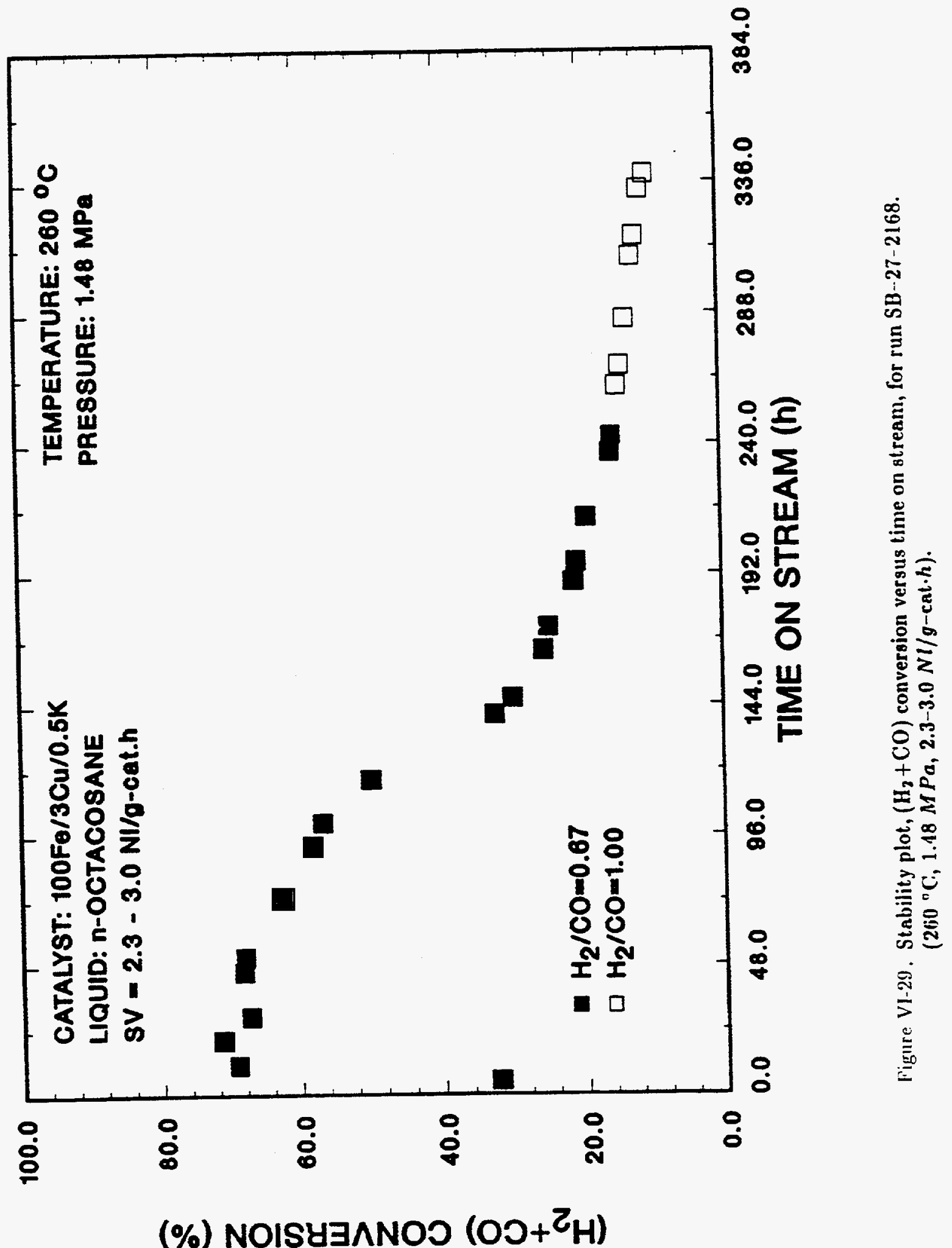


stream, however, the catalyst activity declined rapidly with time on stream, and the $\left(\mathrm{H}_{2}+\mathrm{CO}\right)$ conversion dropped to $13.6 \%$ at 333 hours on stream. During this period, the hydrocarbon distribution shifted toward higher molecular weight products. At 46 hours on stream (balance 1 ) the hydrocarbon fractions were: $3.8\left(\mathrm{CH}_{4}\right), 15.1\left(\mathrm{C}_{2}-\mathrm{C}_{4}\right), 20.3\left(\mathrm{C}_{5}-\mathrm{C}_{11}\right)$ and $60.7 \%\left(\mathrm{C}_{12}+\right)$, whereas at 237 hours on stream (balance 3 ) they were $2.9\left(\mathrm{CH}_{4}\right), 11.6\left(\mathrm{C}_{2}-\mathrm{C}_{4}\right), 9.5\left(\mathrm{C}_{5}-\mathrm{C}_{11}\right)$ and $76.0 \%\left(C_{12}+\right)$. When this catalyst was tested in a fixed bed reactor (run FB-27-2438, Section VI.2.2), the deactivation was slower and the hydrocarbon distribution shifted toward lower molecular weight products with time on stream. In general, more light hydrocarbons were produced in the fixed bed test than in the slurry reactor test under similar operating conditions. Hydrocarbon selectivities during the first mass balances for the two runs were 3.8 and $6.4\left(\mathrm{CH}_{4}\right), 15.1$ and $25.4\left(\mathrm{C}_{2}-\mathrm{C}_{4}\right), 20.3$ and $32.3\left(\mathrm{C}_{5}-\mathrm{C}_{11}\right)$, and 60.7 and $35.8 \%\left(\mathrm{C}_{12}+\right)$ for the slurry and fixed bed tests, respectively. When syngas with $\mathrm{H}_{2} / \mathrm{CO}=1.0$ was used in the slurry run (balance 4), more light products were produced. The rapid deterioration of catalyst activity in the slurry reactor test was probably due to the prolonged exposure of the catalyst to $\mathrm{CO}$. Following the completion of the run, solids were separated from the slurry remaining in the reactor by filtering the slurry. The carbon was then burnt to recover the catalyst (in the oxidized form). Image analysis was used to determine particle size distribution for this catalyst and it was found that almost all of the catalyst was less than $15 \mu \mathrm{m}$ compared to the $45-53 \mu \mathrm{m}$ size cut for the original catalyst that was charged to the reactor.

\section{V1.4.2. Run SB $-25.2-2878$ with the $100 \mathrm{Fe} / 3.0 \mathrm{Cu} / 0.2 \mathrm{~K}$ Catalyst}

Slurry run SB-25.2-2878 was made with a new batch of the $100 \mathrm{Fe} / 3.0 \mathrm{Cu} / 0.2 \mathrm{~K}$ catalyst. Our studies on the effect of pretreatment conditions on subsequent catalytic performance showed that pretreatment in pure $\mathrm{CO}$ or syngas resulted in active catalysts which favored production of liquid products and wax (Section V.1.8). However, these catalysts deactivated fairly rapidly during synthesis. On the other hand, $\mathrm{H}_{2}$ reduced catalysts exhibited good stability, but favored production of methane and other gaseous hydrocarbons. To minimize catalyst deactivation and achieve better stability, an $\mathrm{H}_{2}$ reduction was employed in this run.

The reactor was initially charged with $35 \mathrm{~g}$ of catalyst and $283 \mathrm{~g}$ of purified n-octacosane. The catalyst was activated in the slurry reactor using $\mathrm{H}_{2}$ at $230^{\circ} \mathrm{C}$ for $8 \mathrm{~h}$. Following the activation, $40 \mathrm{~g}$ of wax was withdrawn from the reactor to an external settling tank, and the feed was switched to a $\mathrm{H}_{2} / \mathrm{CO}=0.67$ syngas at $2.0 \mathrm{NI} / \mathrm{g}$-cat.h. The reactor pressure was raised to $1.48 \mathrm{MPa}$, and the temperature was gradually increased to $260^{\circ} \mathrm{C}$. These conditions were 
maintained throughout the run. The major events occurring during this run are listed in Table Vl-13. Three mass balances were completed before the run was terminated at about $245 h$, and the results from these balances are summarized in Table VI-14.

During the first balance at $70 \mathrm{~h}$, the $\left(\mathrm{H}_{2}+\mathrm{CO}\right)$ conversion was $77.2 \%$. An activity plot, which shows gas contraction versus time on stream, is given in Fig. V1-30. This figure also shows the times at which wax withdrawals were made and the amount of wax removed during each withdrawal. A stability plot for this run, $\left(\mathrm{H}_{2}+\mathrm{CO}\right)$ conversion versus time on stream, is shown in Fig. VI-31. Catalyst activity was high and stable up through the first mass balance. Hydrocarbon distribution in the first balance was $10.4\left(\mathrm{CH}_{4}\right), 24.1\left(\mathrm{C}_{2}-\mathrm{C}_{4}\right), 39.2\left(\mathrm{C}_{5}-\mathrm{C}_{11}\right)$, and $26.3 \%\left(\mathrm{C}_{32}+\right)$. Relatively high methane selectivity was expected for an $\mathrm{H}_{2}$ reduced catalyst. Following balance 1 , a withdrawal was made to the external settling tank (40 g removed) and a second withdrawal ( $127 \mathrm{~g}$ removed) was made through an internal filter ( $20 \mu \mathrm{m}, 3 / 8$ " $O D$ by $\left.1.5^{\prime \prime}\right)$. This caused the $\left(\mathrm{H}_{2}+\mathrm{CO}\right)$ conversion to drop to $67.3 \%$, and catalyst activity continued to decline steadily with time from that point on. Catalyst activity improved after about $150 \mathrm{~h}$, but during the second balance $(166 \mathrm{~h})$, the $\left(\mathrm{H}_{2}+\mathrm{CO}\right)$ conversion was only 37.6 $\%$. Hydrocarbon selectivity improved somewhat during the second balance, as less methane and other gaseous hydrocarbons were produced. A withdrawal of $65 \mathrm{~g}$ wax after the second mass balance decreased catalyst activity again, and the $\left(\mathrm{H}_{2} \div \mathrm{CO}\right)$ conversion was only 13.7 $\%$. We attempted to regain activity by adding $59 \mathrm{~g}$ wax in order to suspend any catalyst on the reactor wall and/or the withdrawal filter, but this effort was unsuccessful. During the third balance $(240 \mathrm{~h})$, the $\left(\mathrm{H}_{2}+\mathrm{CO}\right)$ conversion was only $15.2 \%$, and hydrocarbon selectivity shifted toward lower molecular weight hydrocarbons. The run was terminated after this balance due to severe catalyst deactivation.

Inspection of the reactor after the run showed that as the wax level dropped during withdrawal, about $5 \mathrm{~g}$ of the catalyst settled on the filter and adhered to the sides of the reactor. This loss in suspended catalyst can account for some of the decline in activity observed following wax withdrawals. While we knew from the previous slurry run (SB-66-2468) that adding wax after withdrawals restored catalyst activity, we decided not to add wax during this run, but to make more frequent withdrawals to prevent an excessive drop in the slurry level. It was felt that the slow rise in the wax level during the course of reaction would wash the filter element and reactor walls, restoring catalyst activity. In Fig. VI-30 we see a large increase in contraction from 11 to $27 \%$ at about $170 \mathrm{~h}$, and an appreciable increase in contraction after 
Table VI-13. Major events occuring in run SB-25.2-2878.

\begin{aligned} & \hline TOS $(\mathrm{h}) \multicolumn{1}{c}{$ Event } \\ & \hline-3 Catalyst Pretreatment: $\mathrm{H}_{2}$ at $230{ }^{\circ} \mathrm{C} \\ &-1$ Pressurized to $1.48 \mathrm{M} \mathrm{Pa}$ using $\mathrm{H}_{2} \\ & 0$ Run initiated \\ & 5 Achieved desired operating conditions: \\ & $260^{\circ} \mathrm{C}, 1.48 \mathrm{M} \mathrm{Pa}, \mathrm{H}_{2} / \mathrm{CO}=0.69,2 \mathrm{~N} \ell / \mathrm{g}$-cat.h \\ & 71 Conditions stable, $\mathrm{H}_{2}+\mathrm{CO}$ conversion $=77.2 \% \\ & 98$ Drop in catalyst activity following wax withdrawals \\ & 121 Further drop in catalyst activity following wax withdrawal \\ & 167 H + CO conversion $=41.0 \% \\ & 194$ Further drop in catalyst activity following wax withdrawal \\ & 198 Wax added but no improvement in activity observed \\ & 241 Conditions unstable, $\mathrm{H}_{2}+\mathrm{CO}$ conversion $=17.5 \% \\ & 245$ Voluntary termination of run SB-25-2878 \\ & \hline\end{aligned}


Table VI-14. Summary of results for slurry run SB-25.2-2878.

Catalyst: $35.0 \mathrm{~g}^{\mathrm{a}}, 100 \mathrm{Fe} / 3.0 \mathrm{Cu} / 0.2 \mathrm{~K}$

Slurry liquid: $243 g$, n-octacosane Reactor volume: $375 c c^{b}$

\begin{tabular}{|c|c|c|c|}
\hline Period & 1 & 2 & 3 \\
\hline$\overline{\text { Date }}$ & $10 / 17 / 88$ & $10 / 21 / 88$ & $10 / 24 / 88$ \\
\hline Time on Stream $(h)$ & 70.0 & 165 & 239 \\
\hline Balance Duration $(h)$ & 6.00 & 6.00 & 6.00 \\
\hline Average Temperature $\left({ }^{\circ} \mathrm{C}\right)$ & 260 & 260 & 260 \\
\hline Pressure $(M P a)$ & 1.48 & 1.48 & 1.48 \\
\hline $\mathrm{H}_{2} / \mathrm{CO}$ Feed Ratio & 0.79 & 0.72 & 0.72 \\
\hline Space Velocity $(N ! / g \text {-cat } \cdot h)^{a}$ & 2.01 & 2.01 & 2.11 \\
\hline Space Velocity $(N l / g-\mathrm{Fe} \cdot h)$ & 2.95 & 2.95 & 3.10 \\
\hline GHSV $\left(h^{-1}\right)^{b}$ & 187 & 187 & 197 \\
\hline CO Conversion (\%) & 85.3 & 38.8 & 15.7 \\
\hline $\mathrm{H}_{2}+\mathrm{CO}$ Conversion $(\%)$ & 77.2 & 37.6 & 15.2 \\
\hline $\mathrm{H}_{2} / \mathrm{CO}$ Usage & 0.62 & 0.67 & 0.66 \\
\hline $\mathrm{STY}\left(\text { mols } \mathrm{H}_{2}+\mathrm{CO} / g \text {-cat } \cdot h\right)^{a}$ & 0.069 & 0.034 & 0.014 \\
\hline$P_{\mathrm{CO}_{2}} \cdot P_{\mathrm{H}_{2}} / P_{\mathrm{CO}} \cdot P_{\mathrm{H}_{2} \mathrm{O}}$ & 39.0 & 11.4 & 6.50 \\
\hline \multicolumn{4}{|l|}{ Weight \% of Outlet } \\
\hline$\overline{\mathrm{H}_{2}}$ & 1.78 & $\overline{3.12}$ & 4.30 \\
\hline $\mathrm{H}_{2} \mathrm{O}$ & 1.15 & 0.78 & 0.46 \\
\hline $\mathrm{CO}$ & 14.1 & 57.0 & 81.2 \\
\hline $\mathrm{CO}_{2}$ & 62.4 & 28.6 & 9.96 \\
\hline Hydrocarbons & 18.6 & 9.41 & 4.00 \\
\hline Oxygenates & 0.69 & 0.19 & 0.10 \\
\hline Wax ${ }^{e}$ & 1.32 & 0.92 & 0.00 \\
\hline \multicolumn{4}{|l|}{ Yield $\left(\mathrm{g} / \mathrm{Nm}^{3} \mathrm{H}_{2}+\mathrm{CO}\right.$ Converted $)$} \\
\hline $\mathrm{CH}_{4}$ & $\overline{19.6}$ & 21.0 & 32.0 \\
\hline $\mathrm{C}_{2}-\mathrm{C}_{4}$ Hydrocarbons & 45.7 & 48.4 & 54.2 \\
\hline $\mathrm{C}_{5}-\mathrm{C}_{11}$ Hydrocarbons & 74.4 & 66.2 & 55.7 \\
\hline $\mathrm{C}_{12}+$ Hydrocarbons & 49.9 & 78.2 & 55.9 \\
\hline Wax ${ }^{\mathrm{e}}$ & 12.5 & 19.0 & 0.00 \\
\hline Oxygenates & 6.56 & 4.00 & 5.00 \\
\hline Total & 196 & 218 & 203 \\
\hline \multicolumn{4}{|l|}{$1+2$ Olefins/ $n$-Paraffin Ratio } \\
\hline $\mathrm{C}_{2}$ & 0.30 & 1.40 & 1.40 \\
\hline $\mathrm{C}_{3}$ & 2.88 & 4.20 & 3.90 \\
\hline $\mathrm{C}_{4}$ & 2.42 & 3.30 & 2.98 \\
\hline $\mathrm{C}_{8}$ & 1.21 & 2.53 & 2.45 \\
\hline $\mathrm{C}_{10}$ & 0.87 & 1.65 & 1.88 \\
\hline
\end{tabular}

a Based on unreduced catalyst

c Unanalyzed wax withdrawn from reactor

based on static slurry volume 
Table VI-14 (cont'd).Summary of results for slurry run SB-25.2-2878

\begin{tabular}{|c|c|c|c|}
\hline Period & 1 & 2 & 3 \\
\hline \multicolumn{4}{|c|}{ Weight \% of Hydrocarbons } \\
\hline CH4 & 10.4 & 9.83 & 16.2 \\
\hline Ethane & 5.05 & 3.17 & 4.43 \\
\hline Ethylene & 1.41 & 4.15 & 5.77 \\
\hline Propane & 2.46 & 1.59 & 1.95 \\
\hline Propylene & 6.77 & 6.37 & 7.24 \\
\hline n-Butane & 2.36 & 1.61 & 1.89 \\
\hline $1+2$ Butenes & 5.51 & 5.12 & 5.43 \\
\hline $\mathrm{C}_{4}$ Isomers & 0.52 & 0.63 & 0.71 \\
\hline$n$-Pentane & 2.64 & 2.04 & 2.13 \\
\hline $1+2$ Pentenes & 4.38 & 6.00 & 6.34 \\
\hline $\mathrm{C}_{5}$ Isomers & 0.64 & 0.86 & 1.04 \\
\hline n-Hexane & 1.59 & 1.24 & 2.21 \\
\hline $1+2$ Hexenes & 2.11 & 3.30 & 4.27 \\
\hline $\mathrm{C}_{6}$ Isomers & 1.72 & 0.72 & 1.29 \\
\hline$n$-Heptane & 2.42 & 0.81 & 1.18 \\
\hline $1+2$ Heptenes & 3.01 & 2.44 & 2.64 \\
\hline $\mathrm{C}_{7}$ Isomers & 0.26 & 0.47 & 0.96 \\
\hline$n$-Octane & 2.36 & 0.79 & 0.58 \\
\hline $1+2$ Octenes & 2.80 & 1.96 & 1.39 \\
\hline $\mathrm{C}_{8}$ Isomers & 0.34 & 0.17 & 0.13 \\
\hline$n$-Nonane & 2.43 & 0.93 & 0.33 \\
\hline $1+2$ Nonenes & 2.38 & 1.72 & 0.62 \\
\hline $\mathrm{C}_{9}$ Isomers & 0.20 & 0.17 & 0.03 \\
\hline$n$-Decane & 2.58 & 1.27 & 0.47 \\
\hline $1+2$ Decenes & 2.22 & 2.07 & 0.87 \\
\hline $\mathrm{C}_{10}$ Isomers & 0.32 & 0.22 & 0.05 \\
\hline$n$-Undecane & 2.59 & 1.52 & 0.57 \\
\hline $1+2$ Undecenes & 1.90 & 2.12 & 1.00 \\
\hline $\mathrm{C}_{11}$ Isomers & 0.35 & 0.15 & 0.07 \\
\hline $\mathrm{C}_{2}-\mathrm{C}_{4}$ & 24.1 & 22.6 & 27.4 \\
\hline $\mathrm{C}_{5}-\mathrm{C}_{11}$ & 39.2 & 31.0 & 28.2 \\
\hline $\mathrm{C}_{12}+$ & 26.3 & 36.6 & 28.2 \\
\hline $\mathrm{Wax}^{c}$ & 6.60 & 8.89 & 0.00 \\
\hline
\end{tabular}




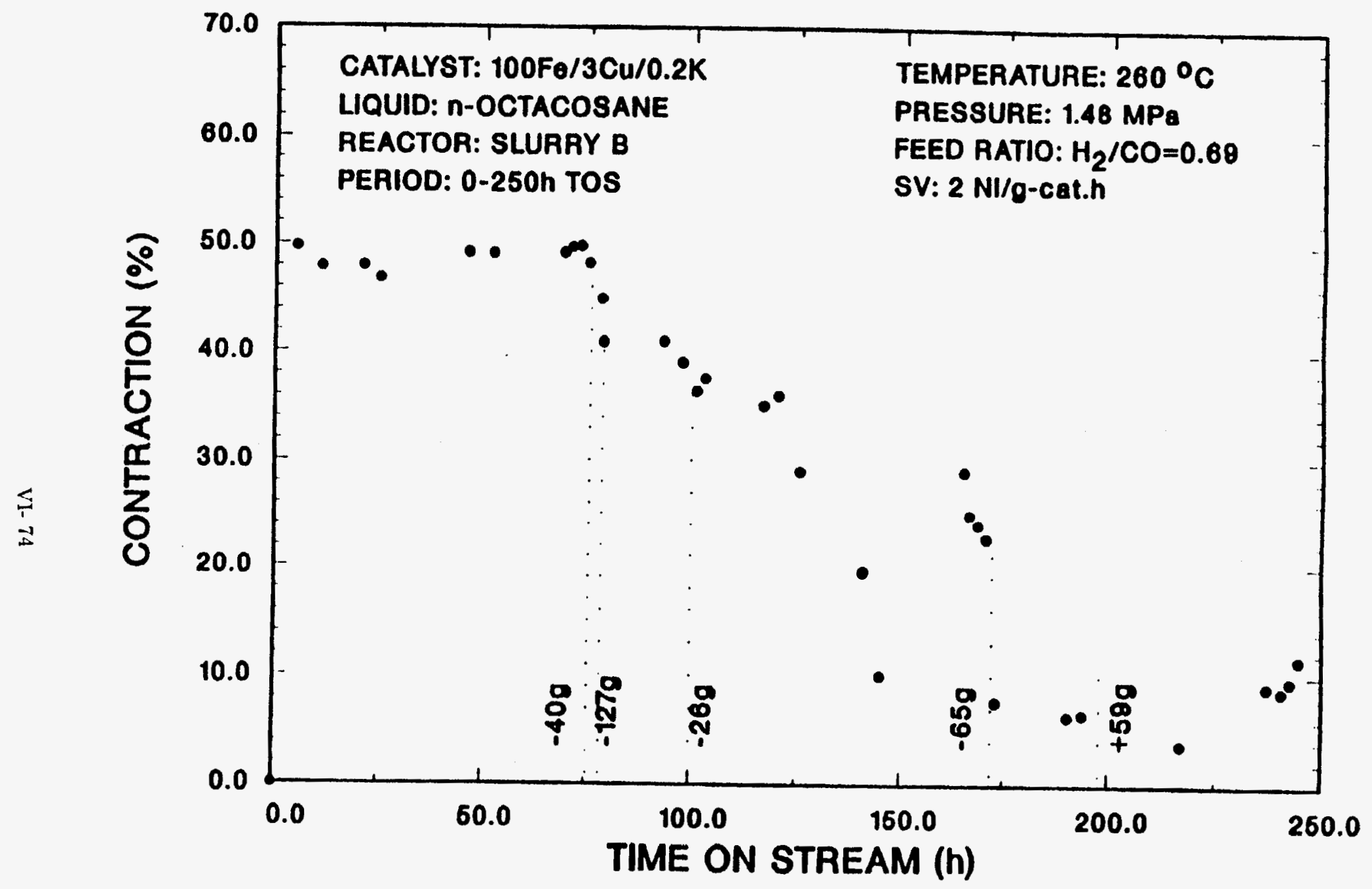

Figure VI-30 Activity plot, \% contraction vs. time on stream, for Run SB-25.2-2878. weights. indicate wax withdrawn $(-)$ or added $(+)$ to reactor 




VI- 75 
$200 \mathrm{~h}$ on stream, which is due to slow buildup of wax in the reactor. It appears from this run that wax needs to be reintroduced immediately following wax withdrawal in order to raise the slurry level to the same position it had prior to the withdrawal. This would bring catalyst that adheres to the filter element and the reactor wall back to the slurry, and thus prevent rapid deactivation caused by development of hot spots.

\section{V1.5. Summary}

Major findings from the above process evaluation studies are summarized below.

(1) Catalysts containing about 24 parts of $\mathrm{SiO}_{2}$ per 100 parts of $\mathrm{Fe}$ exhibited very good stability in both fixed and slurry reactor tests, but they were less active than unsupported catalysts. Also, their selectivity toward liquid hydrocarbon products $\left(C_{5}+\right)$ was not as high as that achieved in Mobil's bubble column slurry reactor in high wax mode of operation (70-75\% vs. $86 \%$ ) and methane yields were higher ( $5-6 \%$ vs. $2.7 \%$ ).

(2) The $100 \mathrm{Fe} / 5 \mathrm{Cu} / 4.2 \mathrm{~K} / 24 \mathrm{SiO}_{2}$ catalyst, synthesized at Texas A\&M University, had higher activity $(\sim 20 \%)$ than commercial Ruhrchemie LP $33 / 81$ catalyst. Both catalysts had similar hydrocarbon selectivities during tests in fixed bed and slurry bed reactors (no effect of reactor type on hydrocarbon selectivity), but the catalyst activity was higher in the fixed bed reactor (Table VI-15).

(3) Catalysts with low silica content $\left(100 \mathrm{Fe} / 5 \mathrm{Cu} / 4.2 \mathrm{~K} / 8 \mathrm{SiO}_{2}\right.$ ) or without any silica (100 $\mathrm{Fe} / 3 \mathrm{Cu} / 0.2 \mathrm{~K}$ or $0.5 \mathrm{~K}$, and $100 \mathrm{Fe} / 1 \mathrm{Cu} / 0.2 \mathrm{~K}$ ) had high initial activity but lacked stability. Catalyst deactivation was fairly rapid in both fixed bed and slurry bed reactor tests. Hydrocarbon selectivities in some of the tests were better (less $\mathrm{CH}_{4}$ and gaseous hydrocarbons) than those obtained in tests with the catalysts having about 24 parts of $\mathrm{SiO}_{2}$ per 100 parts of Fe. However, the stability of these catalysts needs to be improved by using different activation procedures and/or by modifications in their composition.

(4) As demonstrated earlier (Sections V.1.3,V.2.1 and V.2.3) hydrogen reduced, unsupported catalysts have both high activity and long term stability, but they produce more low molecular weight products than the $\mathrm{CO}$ activated catalysts. However, good stability was not achieved in the slurry reactor run SB-25.2-2878 with the $100 \mathrm{Fe} / 3 \mathrm{Cu} / 0.2 \mathrm{~K}$ catalyst reduced with $\mathrm{H}_{2}$. On the other hand the same catalyst displayed remarkable stability and high activity in a fixed bed reactor test (FB-25.2-0029, Section V.2.1.3). It seems that withdrawal of accumulated wax accelerates catalyst deactivation, and further improvements in wax withdrawal procedure are needed. 
Table VI-15. Activity and Selectivity Comparison of $\mathrm{SiO}_{2}$ ('ontaining Catalysts

\begin{tabular}{|c|c|c|c|c|c|c|c|c|c|c|c|c|}
\hline \multirow{3}{*}{$\begin{array}{c}\text { Catalyst/ } \\
\text { Reactor Type }\end{array}$} & \multicolumn{4}{|c|}{ Process Conditions } & \multirow{3}{*}{$\begin{array}{c}\text { TOS } \\
\text { (h) }\end{array}$} & \multirow{3}{*}{$\begin{array}{c}\text { \% Conv. } \\
\left(\mathrm{CO}+\mathrm{H}_{2}\right)\end{array}$} & \multirow{3}{*}{ STYY $^{a}$} & \multirow{3}{*}{$\begin{array}{c}\text { Yield } \\
\left(\mathrm{g}-1 \mathrm{C} / \mathrm{Nm}^{3}\right)\end{array}$} & \multirow{2}{*}{\multicolumn{4}{|c|}{ Weight \% of Ilydrocarbons }} \\
\hline & Pressure & Ternp & SV & $\mathrm{II}_{2} / \mathrm{CO}$ & & & & & & & & \\
\hline & (atm) & $\left({ }^{\circ} \mathrm{C}\right)$ & (NI/g-Fe.h) & feed & & & & & $\mathrm{ClI}_{4}$ & $\mathrm{C}_{2}-\mathrm{C}_{4}$ & $\mathrm{C}_{5}-\mathrm{C}_{11}$ & $\mathrm{C}_{12}+$ \\
\hline Ruhrchemie LP 33/81 & 15 & 250 & 3.6 & 0.69 & 71 & 58.6 & .052 & 181 & 5.5 & 22.7 & 18.6 & 53.1 \\
\hline fixed bed & $"$ & " & $"$ & $"$ & 360 & 53.2 & .048 & 212 & 5.4 & 21.7 & 20.0 & 52.9 \\
\hline Ruhrchemie LP 33/81 & $"$ & $\overline{7}$ & $"$ & 0.67 & 94 & 46.1 & .041 & 182 & 4.6 & 20.9 & 19.5 & 55.0 \\
\hline slurry & $"$ & $"$ & $"$ & " & $\mathbf{3 3 6}$ & 44.1 & .040 & 212 & 5.1 & 22.3 & 22.8 & 49.7 \\
\hline $100 \mathrm{Fe} / 5 \mathrm{Cu} / 4.2 \mathrm{~K} / 24 \mathrm{SiO}_{2}$ & $\pi$ & $\pi$ & $\bar{n}$ & 0.69 & 71 & 67.9 & .061 & 183 & 5.7 & 21.9 & 21.5 & 50.9 \\
\hline fixed bed & $"$ & $"$ & $"$ & " & 356 & 65.5 & .059 & 184 & 6.2 & 24.5 & 24.1 & 45.2 \\
\hline $100 \mathrm{Fe} / 5 \mathrm{Cu} / 4.2 \mathrm{~K} / 24 \mathrm{SiO}_{2}$ & $"$ & $\bar{n}$ & $\bar{"}$ & 0.69 & 69 & 56.1 & .050 & 203 & 3.9 & 17.9 & 20.7 & 57.5 \\
\hline slurry & $"$ & $"$ & $"$ & $"$ & 357 & 49.3 & .044 & 205 & 5.5 & 21.8 & 24.4 & 48.3 \\
\hline Ruhrcliemie LP 33/81 & $\pi$ & $\overline{ }$ & $\bar{"}$ & 0.98 & 528 & 56.0 & .050 & 189 & 8.5 & 29.6 & 25.3 & 36.6 \\
\hline fixed bed & $"$ & $"$ & $"$ & " & 623 & 55.5 & .050 & 197 & 7.9 & 27.7 & 23.2 & 41.2 \\
\hline $100 \mathrm{Fe} / 5 \mathrm{C} / 1 / 4.2 \mathrm{~K} / 24 \mathrm{SiO}_{2}$ & $"$ & $\bar{"}$ & $"$ & 1.03 & 644 & 60.6 & .054 & 182 & 8.0 & 29.3 & 24.9 & 37.8 \\
\hline fixed bed & $"$ & $"$ & $"$ & $"$ & 716 & 60.6 & .054 & 178 & 8.0 & 29.0 & 24.8 & 38.2 \\
\hline $100 \mathrm{Fe} / 5 \mathrm{Cu} / 4.2 \mathrm{~K} / 8 \mathrm{SiO}_{2}$ & $"$ & 235 & 3.2 & 1.03 & 48 & 77.9 & .069 & 188 & 4.2 & 17.8 & 21.4 & 56.5 \\
\hline lixed bed & $"$ & 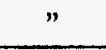 & $"$ & $"$ & 240 & 56.9 & .051 & 195 & 4.0 & 16.6 & 18.8 & 60.6 \\
\hline
\end{tabular}

"STY in moles $\left(\mathrm{II}_{2}+\mathrm{CO}\right)$ converted/g-cat.h 


\section{CATALYST SYNTHESIS AND CHARACTERIZATION METHODS}

\section{VII.1. Catalyst Preparation and Physical Characterization}

\section{Catalyst Synthesis Procedure}

Precipitated iron catalysts were prepared using certified A.C.S. grade $\mathrm{Fe}\left(\mathrm{NO}_{3}\right)_{2} \cdot 9 \mathrm{H}_{2} \mathrm{O}$, $\mathrm{KHCO}_{3}$, and $\mathrm{Cu}\left(\mathrm{NO}_{3}\right)_{2} \cdot 2.5 \mathrm{H}_{2} \mathrm{O}$. Silica and alumina supports were prepared from $C$. $P$. potassium silicate and aluminum sec-butoxide, respectively. Unpromoted and copper-promoted iron catalysts were prepared by a continuous co-precipitation method. An aqueous solution containing $\mathrm{Fe}\left(\mathrm{NO}_{3}\right)_{3}(0.6 \mathrm{M})$ and the required concentration of $\mathrm{Cu}\left(\mathrm{NO}_{3}\right)_{2}$, corresponding to the desired $\mathrm{Fe} / \mathrm{Cu}$ ratio in the final catalyst, and a second solution containing aqueous $\mathrm{NH}_{3}(2.7$ M) were maintained in stirred glass vessels at $83 \pm 3^{\circ} \mathrm{C}$. The two solutions were separately conveyed by fluid pumps to a stirred vertical tubular reaction vessel that was maintained at 82 $\pm 1^{\circ} \mathrm{C}$. Precipitation (to form $\mathrm{FeOOH} / \mathrm{Fe}_{2} \mathrm{O}_{3}$ and $\mathrm{Cu}(\mathrm{OH})_{2}$ ) occurred continuously as the two solutions were pumped upward through the vessel, while an in-line $\mathrm{pH}$ electrode was used to continuously monitor the $\mathrm{pH}$ of the reactor effluent. The flow rate of the $\mathrm{NH}_{3}$ solution was normally fixed at $60 \mathrm{ml} / \mathrm{min}$, while that of the $\mathrm{Fe}^{3+} / \mathrm{Cu}^{2+}$ solution was adjusted (typically to $90 \mathrm{ml} / \mathrm{min}$ ) to give a precipitation $\mathrm{pH}$ value of $6.0 \pm 0.2$. As shown in Figure VII-1, if the reaction $\mathrm{pH}$ exceeded 6.2 , precipitation of copper was incomplete, due to formation of the soluble $\mathrm{Cu}\left(\mathrm{NH}_{3}\right)_{4}{ }^{2+}$ complex.

Collection of the slurried precipitate was made in ice-cooled vessels and was continued until one of the two solutions was consumed. The precipitate was then thoroughly washed by vacuum filtration to remove excess $\mathrm{NH}_{3}$ and $\mathrm{NO}_{3}{ }^{-}$, using 10 liters of deionized, distilled water per $100 \mathrm{~g}$ (dry weight) of final catalyst. If the catalyst contained no $\mathrm{SiO}_{2}$ or $\mathrm{Al}_{2} \mathrm{O}_{3}$ support/binder, the washed precipitate was dried in a vacuum oven for $48 \mathrm{~h}$ at $50^{\circ} \mathrm{C}$ to remove most of the excess water, and then for an additional 12 to $24 \mathrm{~h}$ at $120^{\circ} \mathrm{C}$. Potassium promoter was added by impregnation of the dried $\mathrm{Fe} / \mathrm{Cu}$ precipitate with a $\mathrm{KHCO}_{3}$ solution of appropriate concentration. The final product was dried further in a vacuum oven for $16 \mathrm{~h}$ at $120^{\circ} \mathrm{C}$.

Silica-supported catalysts were prepared by a modification of the above method. Impregnation with $\mathrm{SiO}_{2}$ binder/support was accomplished by re-slurrying a $100 \mathrm{~g}$ aliquot (dry weight basis) of moist, undried precipitate in water, followed by addition of an appropriate amount of a dilute $\mathrm{K}_{2} \mathrm{SiO}_{3}$ solution containing $26.4 \mathrm{wt} \% \mathrm{SiO}_{2}$. Solution $\mathrm{pH}$ after $\mathrm{K}_{2} \mathrm{SiO}_{3}$ addition was 8 to 9 , depending upon the amount of added silicate, and was adjusted to 6.5 by addition of aqueous $\mathrm{HNO}_{3}$. The final $\mathrm{pH}$ adjustment was necessary both to ensure complete decomposition of 


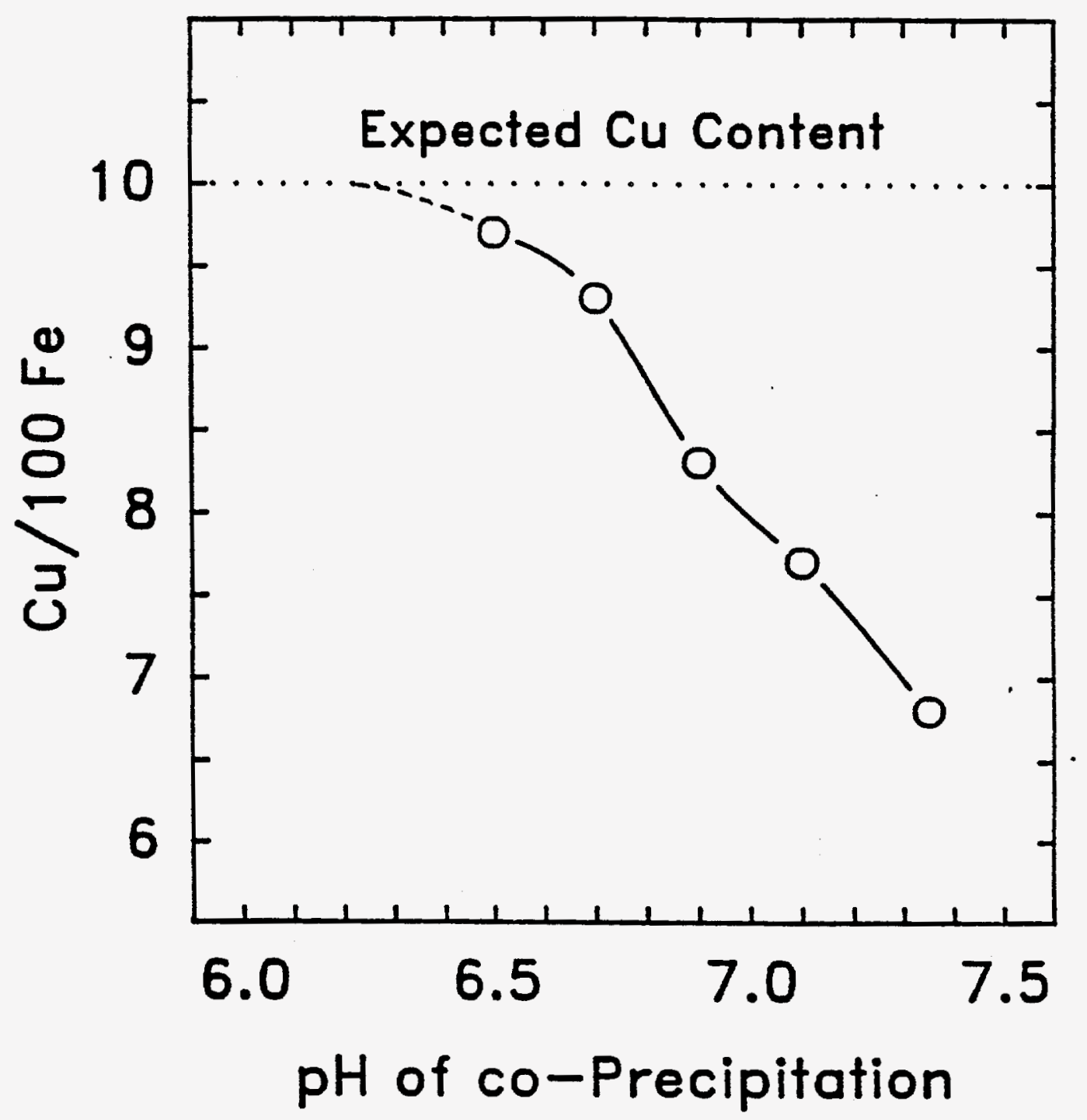

Figure VII-1 Effect of reaction pH on copper content of precipitated iron catalysts at $80^{\circ} \mathrm{C}$ 
$\mathrm{K}_{2} \mathrm{SiO}_{3}$ (with its accompanying deposition of $\mathrm{SiO}_{2}$ ) onto the $\mathrm{FeOOH} / \mathrm{Fe}_{2} \mathrm{O}_{3} / \mathrm{Cu}(\mathrm{OH})_{2}$ precipitate and to prevent loss of copper and/or iron by dissolution. The resulting silica-containing slurry was stirred at ambient temperature for $4 \mathrm{~h}$ to ensure complete penetration of the $\mathrm{K}_{2} \mathrm{SiO}_{3}$ solution into the precipitate pores. After subsequent washing, filtration, and vacuum drying for $48 \mathrm{~h}$ at $120^{\circ} \mathrm{C}$, the silica-containing precipitate was impregnated with $\mathrm{KHCO}_{3}$ in the usual manner and was finally re-dried in a vacuum oven for $16 \mathrm{~h}$ at $120^{\circ} \mathrm{C}$.

The method used to prepare the alumina-containing precipitated iron catalysts employed an $\mathrm{Fe} / \mathrm{Cu}$ precipitate of the desired composition that had already been vacuum dried. Under an atmosphere of dry nitrogen (to prevent exposure to atmospheric water), an appropriate amount of liquid aluminum sec-butoxide was dissolved in a volume of 2-butanol needed to just fill the pores of the precipitate sample and achieve "incipient wetness" (40 m/ per $100 \mathrm{~g}$ of a typical dried $100 \mathrm{Fe} / 5 \mathrm{Cu}$ precipitate). The required amount of dried $\mathrm{Fe} / \mathrm{Cu}$ precipitate was added to the butoxide solution, and the resulting slurry was stirred for $16 \mathrm{~h}$ to ensure complete pore filling by the viscous alkoxide solution. Excess alcohol solvent was then removed by heating the mixture in a vacuum oven for $6 \mathrm{~h}$ at $60^{\circ} \mathrm{C}$. Hydrolytic decomposition of the impregnated aluminum sec-butoxide to form $\mathrm{Al}_{2} \mathrm{O}_{3}$ was accomplished by exposure of the material for $16 \mathrm{~h}$ at $25^{\circ} \mathrm{C}$ to air that was saturated with water vapor. The alumina-containing catalysts, after being thoroughly washed and dried in a vacuum oven for $16 \mathrm{~h}$ at $120^{\circ} \mathrm{C}$, were impregnated with $\mathrm{KHCO}_{3}$ and were re-dried to yield the final catalysts.

\section{Elemental Analyses and Physical Properties}

A total of 24 unsupported precipitated iron catalysts of differing compositions were synthesized (including pure, unpromoted iron), in which copper and potassium promoters were varied in the ranges 0.1 to 20 and 0.01 to 2.0 parts/100 parts of iron (by weight), respectively. In addition, three $\mathrm{SiO}_{2}$-supported and three $\mathrm{Al}_{2} \mathrm{O}_{3}$ - supported catalysts, each containing both copper and potassium promoters, were also prepared. The elemental composition of each prepared material was determined by atomic absorption spectroscopy; Table VII-1 summarizes the intended nominal and actual analyzed composition of each catalyst. For purposes of simplicity, each catalyst will be referred to in this document by its nominal composition.

Total surface areas, as measured by application of the BET method to $\mathrm{N}_{2}$ adsorption at $-196^{\circ} \mathrm{C}$, were obtained for selected catalysts before and after reduction in $\mathrm{H}_{2}$ or $\mathrm{CO}$, and are presented in Table VII-2. Although total surface areas of the unsupported catalysts were relatively large $\left(\sim 180 \mathrm{~m}^{2} / \mathrm{g}\right)$ prior to reduction and increased with increasing copper content 
Table VII-1 Compositions of Synthesized Precipitated Iron Catalysts

\begin{tabular}{|c|c|}
\hline $\begin{array}{l}\text { Nominal Composition } \\
\text { (parts by weight) }\end{array}$ & $\begin{array}{l}\text { Analyzed Composition } \\
\text { (parts by weight) }\end{array}$ \\
\hline $\begin{array}{l}100 \mathrm{Fe} / 0.01 \mathrm{~K} \\
100 \mathrm{Fe} / 0.02 \mathrm{~K} \\
100 \mathrm{Fe} / 0.05 \mathrm{~K} \\
100 \mathrm{Fe} / 0.1 \mathrm{~K} \\
100 \mathrm{Fe} / 0.2 \mathrm{~K} \\
100 \mathrm{Fe} / 0.5 \mathrm{~K} \\
100 \mathrm{Fe} / 1 \mathrm{~K} \\
100 \mathrm{Fe} / 2 \mathrm{~K}\end{array}$ & $\begin{array}{l}100 \mathrm{Fe} / 0.005 \mathrm{~K} \pm 0.001 \\
100 \mathrm{Fe} / 0.016 \mathrm{~K} \pm 0.001 \\
100 \mathrm{Fe} / 0.037 \mathrm{~K} \pm 0.004 \\
100 \mathrm{Fe} / 0.082 \mathrm{~K} \pm 0.005 \\
100 \mathrm{Fe} / 0.19 \mathrm{~K} \pm 0.01 \\
100 \mathrm{Fe} / 1.01 \mathrm{~K} \pm 0.02 \\
100 \mathrm{Fe} / 0.83 \mathrm{~K} \pm 0.06 \\
100 \mathrm{Fe} / 1.7 \mathrm{~K} \pm 0.3\end{array}$ \\
\hline $100 \mathrm{Fe} / 0.1 \mathrm{Cu}$ & $100 \mathrm{Fe} / 0.12 \mathrm{Cu} \pm 0.01$ \\
\hline $\begin{array}{l}100 \mathrm{Fe} / 0.3 \mathrm{Cu} \\
100 \mathrm{Fe} / 0.3 \mathrm{Cu} / 0.05 \mathrm{~K} \\
100 \mathrm{Fe} / 0.3 \mathrm{Cu} / 0.2 \mathrm{~K} \\
100 \mathrm{Fe} / 0.3 \mathrm{Cu} / 0.5 \mathrm{~K}\end{array}$ & $\begin{array}{l}100 \mathrm{Fe} / 0.29 \mathrm{Cu} \pm 0.01 \\
100 \mathrm{~F}=/ 0.27 \mathrm{Cu} \pm 0.01 / 0.040 \mathrm{~K} \pm 0.002 \\
100 \mathrm{Fe} / 0.28 \mathrm{Cu} \pm 0.01 / 0.185 \mathrm{~K} \pm 0.002 \\
100 \mathrm{Fe} / 0.28 \mathrm{Cu} \pm 0.01 / 0.48 \mathrm{~K} \pm 0.07\end{array}$ \\
\hline $\begin{array}{l}100 \mathrm{Fe} / 1 \mathrm{Cu} \\
100 \mathrm{Fe} / 1 \mathrm{Cu} / 0.05 \mathrm{~K} \\
100 \mathrm{Fe} / 1 \mathrm{Cu} / 0.2 \mathrm{~K} \\
100 \mathrm{Fe} / 1 \mathrm{Cu} / 0.5 \mathrm{~K}\end{array}$ & $\begin{array}{l}100 \mathrm{Fe} / 1.04 \mathrm{Cu} \pm 0.06 \\
100 \mathrm{Fe} / 0.94 \mathrm{Cu} \pm 0.04 / 0.049 \mathrm{~K} \pm 0.004 \\
100 \mathrm{Fe} / 0.96 \mathrm{Cu} \pm 0.03 / 0.18 \mathrm{~K} \pm 0.01 \\
100 \mathrm{Fe} / 1.05 \mathrm{Cu} \pm 0.03 / 0.83 \mathrm{~K} \pm 0.04\end{array}$ \\
\hline $\begin{array}{l}100 \mathrm{Fe} / 3 \mathrm{Cu} \\
100 \mathrm{Fe} / 3 \mathrm{Cu} / 0.05 \mathrm{~K} \\
100 \mathrm{Fe} / 3 \mathrm{Cu} / 0.2 \mathrm{~K} \\
100 \mathrm{Fe} / 3 \mathrm{Cu} / 0.5 \mathrm{~K}\end{array}$ & $\begin{array}{l}100 \mathrm{Fe} / 297 \mathrm{Cu} \pm 0.06 \\
100 \mathrm{Fe} / 283 \mathrm{Cu} \pm 0.11 / 0.045 \mathrm{~K} \pm 0.001 \\
100 \mathrm{Fe} / 2.93 \mathrm{Cu} \pm 0.12 / 0.18 \mathrm{~K} \pm 0.01 \\
100 \mathrm{Fe} / 2.95 \mathrm{Cu} \pm 0.04 / 0.45 \mathrm{~K} \pm 0.03\end{array}$ \\
\hline $100 \mathrm{Fe} / 10 \mathrm{Cu}$ & $100 \mathrm{Fe} / 9.7 \mathrm{Cu} \pm 0.3$ \\
\hline $100 \mathrm{Fe} / 20 \mathrm{Cu}$ & $100 \mathrm{Fe} / 18.7 \mathrm{Cu} \pm 0.4$ \\
\hline $\begin{array}{l}100 \mathrm{Fe} / 5 \mathrm{Cu} / 4.2 \mathrm{~K} / 8 \mathrm{SiO}_{2} \\
100 \mathrm{Fe} / 5 \mathrm{Cu} / 4.2 \mathrm{~K} / 25 \mathrm{SiO}_{2} \\
100 \mathrm{Fe} / 5 \mathrm{Cu} / 4.2 \mathrm{~K} / 100 \mathrm{SiO}_{2}\end{array}$ & $\begin{array}{l}100 \mathrm{Fe} / 5.1 \mathrm{Cu} / 4.0 \mathrm{~K} / 7.8 \mathrm{SiO}_{2} \\
100 \mathrm{Fe} / 5.4 \mathrm{Cu} / 4.6 \mathrm{~K} / 28 \mathrm{SiO}_{2} \\
100 \mathrm{Fe} / 5.3 \mathrm{Cu} / 4.1 \mathrm{~K} / 96.5 \mathrm{SiO}_{2}\end{array}$ \\
\hline $\begin{array}{l}100 \mathrm{Fe} / 5 \mathrm{Cu} / 4.2 \mathrm{~K} / 8 \mathrm{Al}_{2} \mathrm{O}_{3} \\
100 \mathrm{Fe} / 5 \mathrm{Cu} / 4.2 \mathrm{~K} / 25 \mathrm{Al}_{2} \mathrm{O}_{3} \\
100 \mathrm{Fe} / 5 \mathrm{Cu} / 4.2 \mathrm{~K} / 100 \mathrm{Al}_{2} \mathrm{O}_{3}\end{array}$ & $\begin{array}{l}100 \mathrm{Fe} / 5.0 \mathrm{Cu} / 3.9 \mathrm{~K} / 7.7 \mathrm{Al}_{2} \mathrm{O}_{3} \\
100 \mathrm{Fe} / 5.1 \mathrm{Cu} / 4.0 \mathrm{~K} / 20.5 \mathrm{Al}_{2} \mathrm{O}_{3} \\
100 \mathrm{Fe} / 4.7 \mathrm{Cu} / 4.2 \mathrm{~K} / 31.6 \mathrm{al}_{2} \mathrm{O}_{3}\end{array}$ \\
\hline
\end{tabular}


(to $>300 \mathrm{~m}^{2} / \mathrm{g}$ ) for $100 \mathrm{Fe} / 3 \mathrm{Cu}$, reduction in $\mathrm{H}_{2}$ at $300^{\circ} \mathrm{C}$ for $4 \mathrm{~h}$ caused a decrease in surface area to $\sim 10 \mathrm{~m}^{2} / \mathrm{g}$ in all cases. By contrast, the presence of even small amounts of $\mathrm{SiO}_{2}$ support resulted in the retention of relatively high surface areas, even after reduction.

The pore size distribution of the unpromoted, unreduced iron precipitate gave an average pore diameter of $40-45 \AA$, as determined by application of the Kelvin equation to the desorption branch of a $\mathrm{N}_{2}$ adsorption isotherm obtained at $-196^{\circ} \mathrm{C}$. The technique of mercury porosimetry was also employed to obtain the pore size distributions of calcined and reduced catalysts. Calcination for $16 \mathrm{~h}$ in air at $300^{\circ} \mathrm{C}$ caused an increase in the average pore diameter from the initial value of $40-45 \AA$ to $90 \AA$. Subsequent reduction in $\mathrm{H}_{2}$ at $300^{\circ} \mathrm{C}$ led to a bimodal pore size distribution, with the principal maximum at $250 \AA$ pore diameter for the unpromoted precipitate, and at $400 \AA$ for the copper-promoted precipitates containing 0.1 and 0.3 parts copper, with a secondary maximum at $90 \AA$. The distribution of the pore volume for each of the three silica- containing catalysts following calcination for $5 \mathrm{~h}$ at $300^{\circ} \mathrm{C}$ and reduction in $\mathrm{CO}$ for $5 \mathrm{~h}$ at $300^{\circ} \mathrm{C}$ differed, depending upon $\mathrm{SiO}_{2}$ content. The $8 \mathrm{SiO}_{2}$ material exhibited a well-defined maximum at a pore diameter of $150-200 \AA$, while the $25 \mathrm{SiO}_{2}$ and the $100 \mathrm{SiO}_{2}$ precipitates contained a substantial fraction of pores smaller than $60 \AA$ after reduction in $\mathrm{CO}$.

\section{VII.2. Reduction Studies}

Temperature-programmed (TPR) and isothermal reduction studies were performed using both $5 \% \mathrm{H}_{2} / \mathrm{N}_{2}$ and $5 \% \mathrm{CO} / \mathrm{He}$ as reductants. The reactive gas streams were first directed at a constant rate and at a constant pressure through the reference compartment of a thermal conductivity (TC) cell via a two-way injection valve, through the catalyst sample, and finally, via a cold trap, through the other compartment of the TC detection cell. Consumption of $\mathrm{CO}$ or $\mathrm{H}_{2}$ was measured by the change in thermal conductivity of the effluent gas stream. In addition, the reactor effluent was monitored by a quadrupole mass spectrometer to provide continuous chemical identification of reduction/desorption products. A dry ice/acetone bath was used to remove water formed during the hydrogen reductions, and a liquid nitrogen bath was used to remove $\mathrm{CO}_{2}$ formed during the $\mathrm{CO}$ reductions. Catalyst sample weights of 10 to 15 $\mathrm{mgms}$ and reductant flow rates of $12 \mathrm{cc} / \mathrm{min}$ were used for all the experiments. A temperature ramp of $20^{\circ} \mathrm{C} / \mathrm{min}$ from room temperature to $900^{\circ} \mathrm{C}$ was used for all of the temperatureprogrammed reduction experiments. In isothermal reductions, a ramp of $20^{\circ} \mathrm{C} / \mathrm{min}$ was used until a temperature of $300^{\circ} \mathrm{C}$ was reached, the latter temperature then being maintained until total heating times of $12 \mathrm{~h}$ for hydrogen reduction or $8 \mathrm{~h}$ for $\mathrm{CO}$ reduction were achieved. The 
Table VII-2 Surface Areas of Synthesized Precipitated Iron Catalysts

\begin{tabular}{|c|c|c|c|}
\hline \multirow{2}{*}{$\begin{array}{l}\text { Nominal Composition } \\
\text { (parts by weight) }\end{array}$} & \multicolumn{2}{|c|}{ Surface Area $\left(\mathrm{m}^{2} / \mathrm{g}\right)$} & \\
\hline & Unreduced & Reduced & \\
\hline $100 \mathrm{Fe}$ & 180 & $10^{\bullet}$ & \\
\hline $100 \mathrm{Fe} / 0.01 \mathrm{~K}$ & 195 & - & \\
\hline $100 \mathrm{Fe} / 0.02 \mathrm{~K}$ & 205 & - & \\
\hline $100 \mathrm{Fe} / 1 \mathrm{~K}$ & 210 & - & \\
\hline $100 \mathrm{Fe} / 0.1 \mathrm{Cu}$ & 280 & $5^{*}$ & \\
\hline $100 \mathrm{Fe} / 0.3 \mathrm{Cu}$ & 328 & $5^{\circ}$ & \\
\hline $100 \mathrm{Fe} / 0.3 \mathrm{Cu} / 0.5 \mathrm{~K}$ & 285 & - & \\
\hline $100 \mathrm{Fe} / 1 \mathrm{Cu}$ & 234 & - & \\
\hline $100 \mathrm{Fe} / 1 \mathrm{Cu} / 0.05 \mathrm{~K}$ & - & $8^{*}$ & \\
\hline $100 \mathrm{Fe} / 1 \mathrm{Cu} / 0.5 \mathrm{~K}$ & 231 & $9^{*}$ & \\
\hline $100 \mathrm{Fe} / \mathrm{Cu}$ & 300 & $5^{\circ}$ & $38^{* *}$ \\
\hline $100 \mathrm{Fe} / 10 \mathrm{Cu}$ & 380 & - & \\
\hline $100 \mathrm{Fe} / 20 \mathrm{Cu}$ & 374 & $8^{*}$ & \\
\hline $100 \mathrm{Fe} / 5 \mathrm{Cu} / 4.2 \mathrm{~K} / 8 \mathrm{SiO}_{2}$ & & $94^{\circ *}$ & \\
\hline $100 \mathrm{Fe} / 5 \mathrm{Cu} / 4.2 \mathrm{~K} / 25 \mathrm{SiO}_{2}$ & & $150 *$ & \\
\hline $100 \mathrm{Fe} / 5 \mathrm{Cu} / 4.2 \mathrm{~K} / 100 \mathrm{SiO}_{2}$ & & $250^{* *}$ & \\
\hline
\end{tabular}

- In flowing $\mathrm{H}_{2}$ for $4 \mathrm{hrs}$ at $300^{\circ} \mathrm{C}$

* In flowing $\mathrm{CO}$ for $4 \mathrm{hrs}$ at $300^{\circ} \mathrm{C}$ 
reduction of a $\mathrm{CuO}$ wire was used for calibration of the peak areas in reduction results.

Typical TPR results using $\mathrm{H}_{2}$ reductant are shown in Figure VII-2 for a series of copperpromoted iron precipitates containing no potassium. The two peaks in the lowermost thermogram for the unpromoted copper-free sample correspond to the following characteristic two-step reduction of $\mathrm{Fe}_{2} \mathrm{O}_{3}$ that was observed for most of the catalysts studied:

$$
\begin{array}{ll}
3 \mathrm{Fe}_{2} \mathrm{O}_{3}+\mathrm{H}_{2} \rightarrow 2 \mathrm{Fe}_{3} \mathrm{O}_{4}+\mathrm{H}_{2} \mathrm{O} & (\mathrm{VII}-1) \\
\mathrm{Fe}_{3} \mathrm{O}_{4}+4 \mathrm{H}_{2} \rightarrow 3 \mathrm{Fe}+4 \mathrm{H}_{2} \mathrm{O} & (\mathrm{VII}-2)
\end{array}
$$

Because reaction ( $\mathrm{VII}-2$ ) consumes eight times as much $\mathrm{H}_{2}$ per mole of $\mathrm{Fe}$ as does reaction (VII-1), it is clear from the relatively small area of the second peak in this thermogram that only a small fraction of the iron in the sample is converted to the metallic state by this treatment in $\mathrm{H}_{2}$. Comparison of the thermograms in Figure VII-2 demonstrates that increasing concentrations of copper promoter, up to a level of $3 \mathrm{wt} \%$, decrease the temperatures required for the onset of both reduction steps. Copper contents greater than 3 wt $\%$ had little additional promotional effect on iron reduction. The presence of varying concentrations of potassium promoter, in the absence of copper, had little effect on iron thermograms in $\mathrm{H}_{2}$, as shown by the data in Figure VII-3.

In order to more closely mimic the reduction procedure used during actual catalyst activation, a modified version of the TPR technique was employed, in which the sample temperature was ramped at $20^{\circ} \mathrm{C} / \mathrm{min}$ to $300^{\circ} \mathrm{C}$, and then maintained isothermally at the latter temperature in the flowing reductant stream. Typical results obtained from this "isothermal" reduction process, using $\mathrm{H}_{2}$ reductant, are shown in Figure VII-4 for selected copper-promoted samples. Although the first reduction step occurs rapidly in all cases, as shown by the sharp peak at $50 \mathrm{~min}$, it is again evident that the presence of even small concentrations of copper promoter greatly decreases the time required for completion of the second reduction step. Whereas more than 900 min were required to complete reduction of the unpromoted sample (a), reduction was complete in $400 \mathrm{~min}$ in the presence of $3 \mathrm{wt} \%$ of copper (d). The presence of potassium promoter, in the absence of copper, actually decreased the rate of the first reduction step, as shown in Figure VII-5 by the increased broadening of the first peak with increasing potassium content. This effect was probably due to nucleation site blockage by potassium which, because 


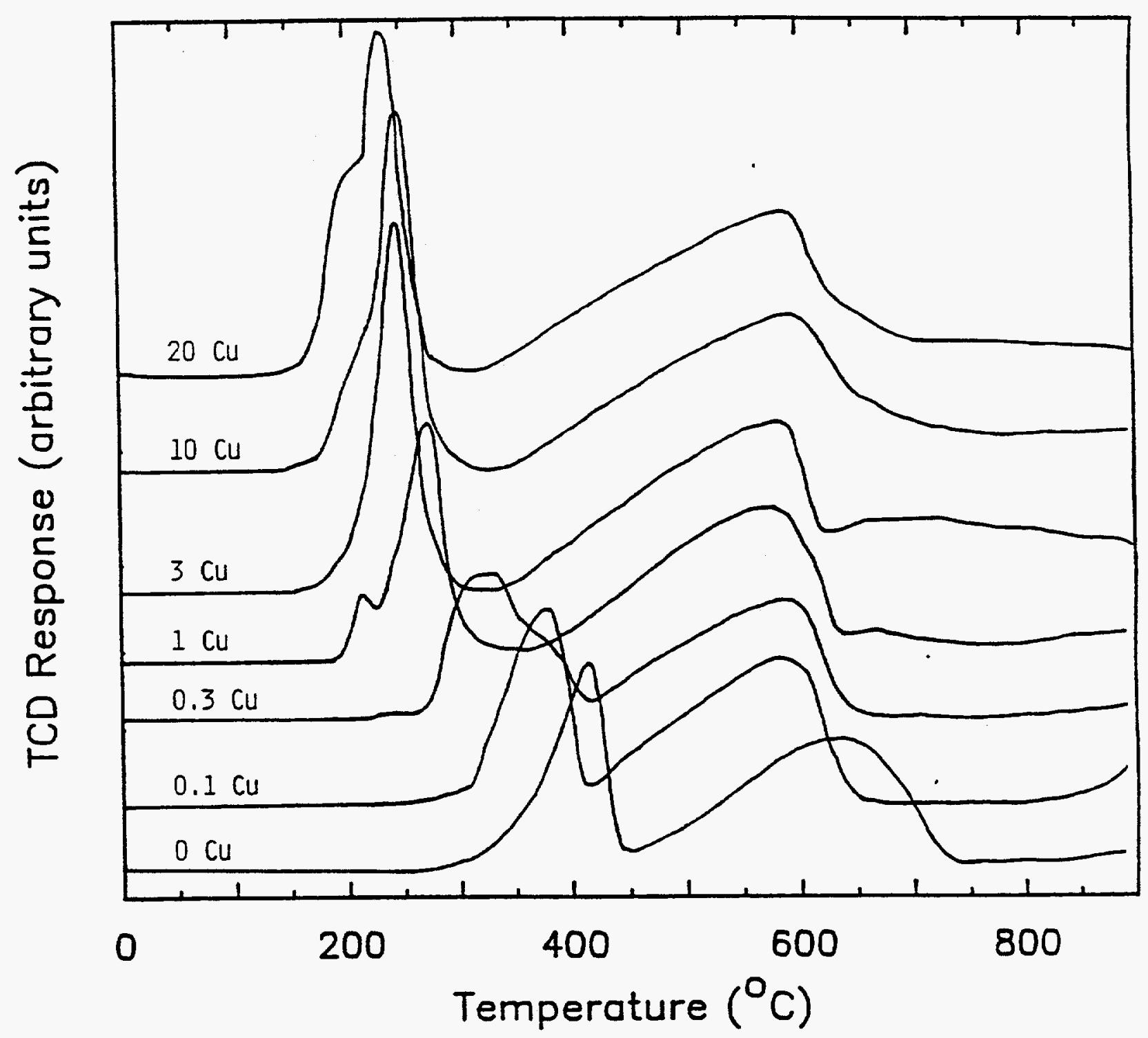

Figure VII-2 TPR profiles of potassium-free, pre-calcined iron catalysts containing the indicated levels of copper promoter (in parts by weight per 100 parts of $\mathrm{Fe}$ ) 


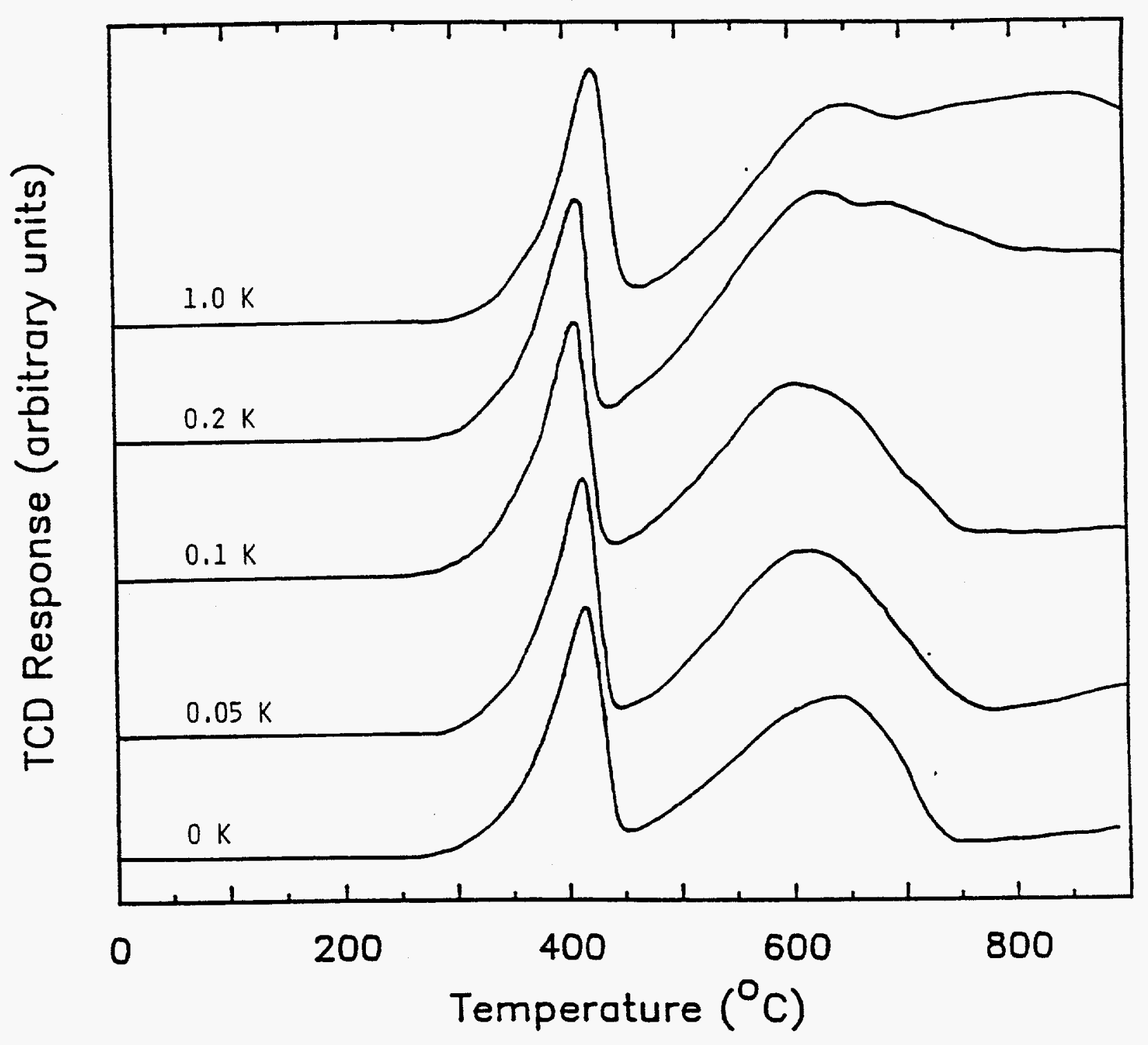

Figure VII-3 TPR profiles of copper-free, pre-calcined iron catalysts containing the indicated levels of potassium promoter (in parts by weight per 100 part of $\mathrm{Fe}$ ) 


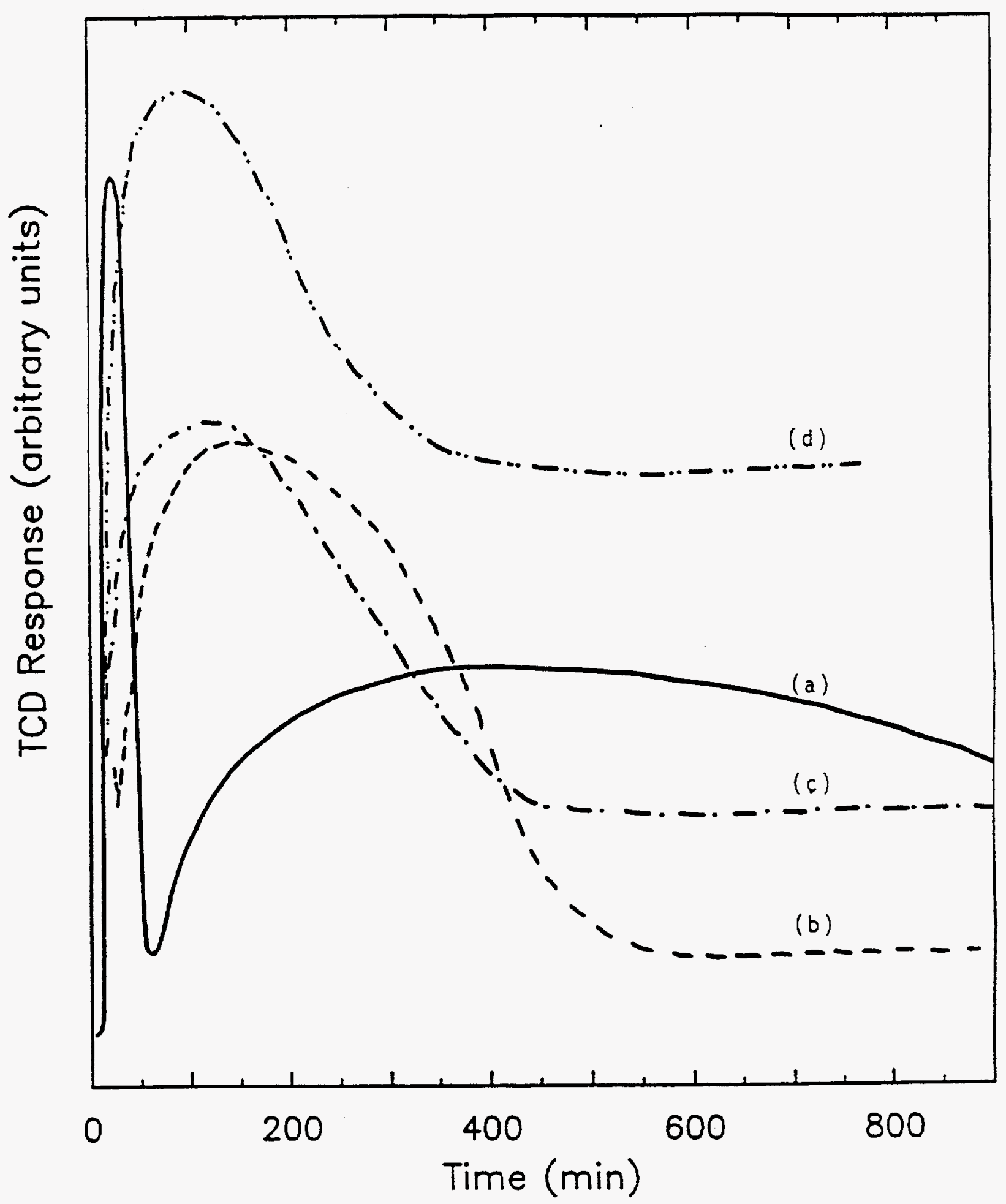

Figure VII-4 Isothermal reduction profiles in $\mathrm{H}_{2}$ at $300^{\circ} \mathrm{C}$ of: (a) $100 \mathrm{Fe}$; (b) $100 \mathrm{Fe} / 0.3 \mathrm{Cu}$ : (c) $100 \mathrm{Fe} / 1.0 \mathrm{Cu}$; (d) $100 \mathrm{Fe} / 3.0 \mathrm{Cu}$ 
of the presence of water vapor generated during $\mathrm{H}_{2}$ reduction of iron, had redistributed into a thin surface layer.

Carbon monoxide proved to be a much more effective reducing agent for precipitated iron than was $\mathrm{H}_{2}$, as demonstrated by the results shown in Figure VII-6. (Note the different abscissa scale from that in Figures VII-4 and VII-5.) The second reduction step, that required $>900$ min to complete for the unpromoted sample when treated in $\mathrm{H}_{2}$, was complete in 240 min using $\mathrm{CO}$ as the reducing agent (a). The presence of $1 \mathrm{wt} \%$ copper promoter further decreased the time required for complete reduction to $100 \mathrm{~min}$ (d). In marked contrast to the reduction behavior observed using $\mathrm{H}_{2}$, potassium promoter, in the absence of copper, appeared to increase the rate of iron reduction, as shown in thermograms (b) and (c). Moreover, the addition of potassium to a copper-containing catalyst resulted in more rapid reduction than that observed in the presence of copper alone (e).

\section{VII.3. Surface Characterization}

$X$-ray photoelectron spectroscopy (XPS) measurements were used to study the surface compositions and oxidation states of the precipitated iron catalysts before and after calcination and reduction treatments. Samples used in the XPS measurements were pressed into thin wafers to fit the copper sample holder and the sample probe of the spectrometer. After either reduction or reaction, samples were evacuated for one hour and were transferred, without exposure to the air, to the antechamber of the glove box attached to the spectrometer. The antechamber was evacuated and back-filled with nitrogen before the sample was admitted to the glove box. An aluminum sample cover with a rectangular opening, plated with a $50 \mathrm{~nm}$ thickness of gold by a high-voltage evaporation method, was placed on top of the sample. A stainless steel spring placed under the sample holder ensured electrical contact of the sample with the instrument. Typical analysis chamber pressure during measurements was $<1 \times 10^{-9}$ torr. The beam power of the $X$-ray was 600 watts, and a flood gun, set at $0.1 \mathrm{~mA}$ and $0 . \mathrm{eV}$, was used to eliminate sample charging. Adventitious carbon and the support oxygen species were used as references. Various scan numbers and binding energies were obtained for the major peaks of the elements of interest, depending on the amount present and the cross-section.

The type of information obtainable by XPS measurements is illustrated in Figure VII-7, which shows spectra in the $\mathrm{Fe} 2 \mathrm{p}$ region for an unpromoted iron sample before and after reduction in $\mathrm{H}_{2}$. It is clear that treatment in $\mathrm{H}_{2}$ at $300^{\circ} \mathrm{C}$ results in only a small fraction of zero-valent surface iron. Treatment in $\mathrm{CO}$ at $300^{\circ} \mathrm{C}$, on the other hand, effects almost 


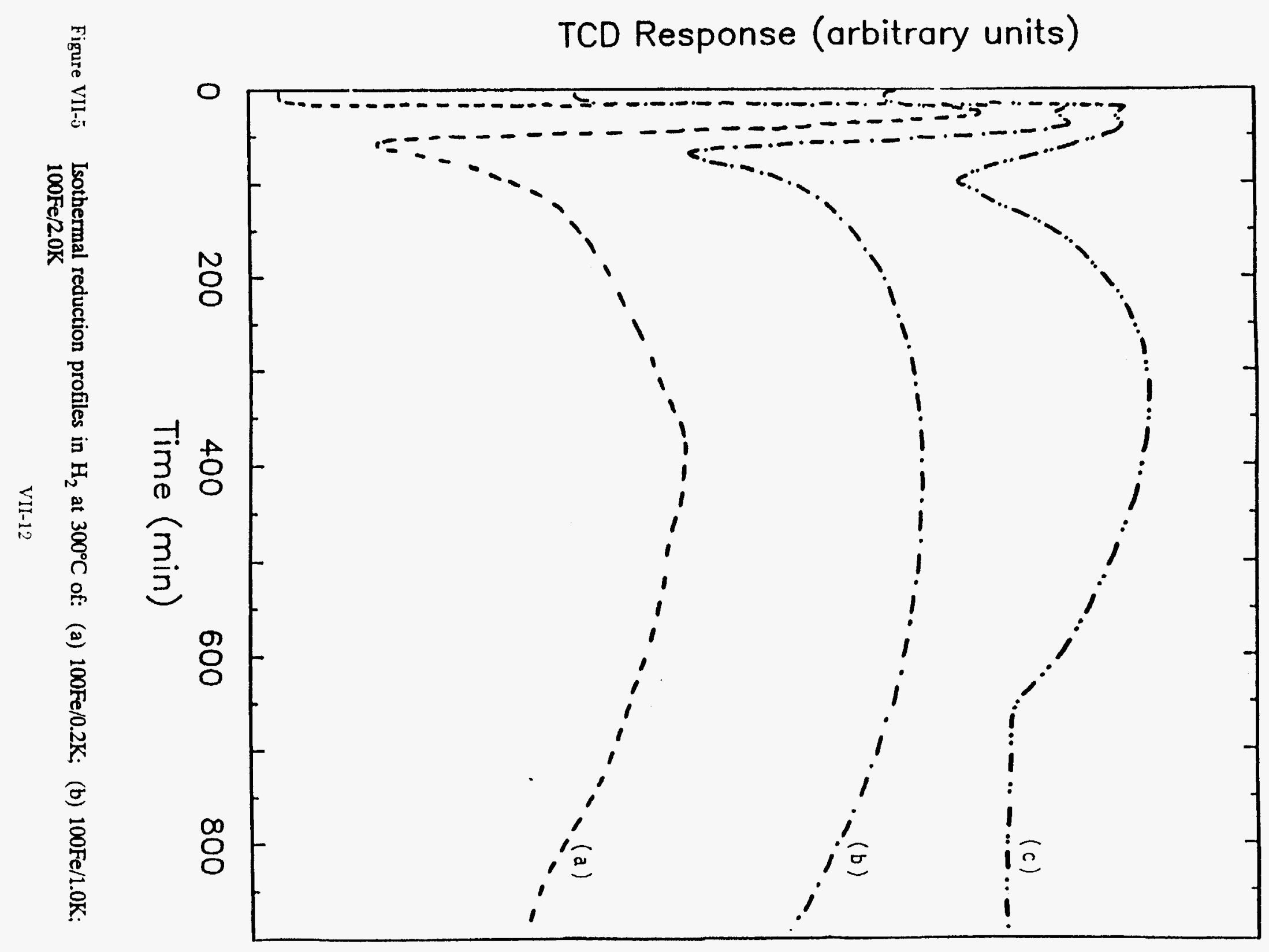




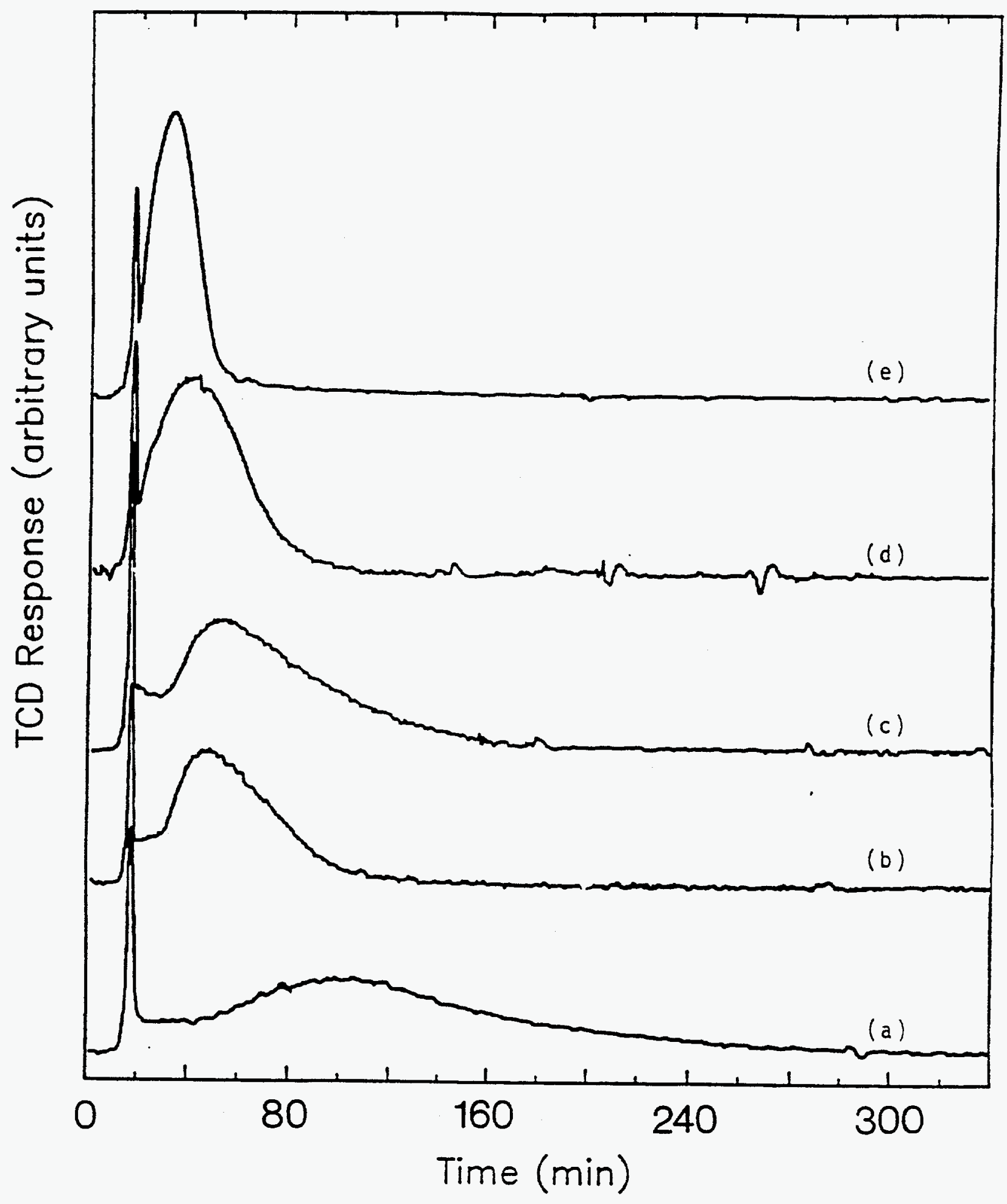

Figure VII-6 Isothermal reduction profiles in $\mathrm{CO}$ at $300^{\circ} \mathrm{C}$ of: (a) $100 \mathrm{Fe}$; (b) $100 \mathrm{Fe} / 0 \mathrm{Cu} / 0.2 \mathrm{~K}$; (c) $100 \mathrm{Fe} / 0 \mathrm{Cu} / 1.0 \mathrm{~K}$; (d) $100 \mathrm{Fe} / 1.0 \mathrm{Cu} / 0 \mathrm{~K}$; (e) $100 \mathrm{Fe} / 1.0 \mathrm{Cu} / 0.2 \mathrm{~K}$ 
complete surface reduction to the metallic state, as shown in Figure VII-8. It is also apparent from spectrum (b) in the latter Figure that subsequent exposure of the reduced catalyst to a $2 / 1 \mathrm{H}_{2} / \mathrm{CO}$ reaction mixture at $250^{\circ} \mathrm{C}$ results in re-oxidation of a portion of the surface iron by water formed during $\mathrm{CO}$ hydrogenation.

As expected, the presence of copper promoter increased the extent of surface iron reduction to the metallic state, even with supported catalysts, as shown by spectrum (a) in Figure VII. 9 for the $100 \mathrm{Fe} / 5 \mathrm{Cu} / 4.2 \mathrm{~K} / 8 \mathrm{SiO}_{2}$ composition. Subsequent exposure to a $\mathrm{H}_{2} / \mathrm{CO}$ reaction mixture again caused partial re-oxidation of surface iron (spectrum b). Although treatment of the promoted catalyst in $\mathrm{CO}$ did not result in more extensive surface reduction than that observed following $\mathrm{H}_{2}$ treatment, the $\mathrm{CO}$-treated material underwent much less subsequent oxidation during $\mathrm{H}_{2} / \mathrm{CO}$ reaction, as shown in Figure VII-10. Reduction in $\mathrm{CO}$ caused extensive deposition of surface carbon (Figure VII-11), which was removed, presumably by hydrogenation, during exposure of the reduced catalyst to a $\mathrm{H}_{2} / \mathrm{CO}$ reaction mixture at $250^{\circ} \mathrm{C}$.

VII.4. Summary of Results and Discussion

The results obtained during this investigation have demonstrated that reduction studies under either isothermal conditions or a constant temperature-programming rate can differentiate reducibilities of bulk compositions, but not of surface compositions of iron catalysts. Figures VII-12 and VII-13 summarize the temperature locations of the peak corresponding to the first step of iron reduction in TPR profiles for the copper-, potassium-, and silica-containing catalysts. Isothermal reduction results are summarized in Table VII-3, which shows approximate times required for completion of the second step of iron reduction to $\mathrm{Fe}(0)$. XPS studies, whose results are summarized in Table VII-4, have complemented these reduction studies by providing information about the identities of the surface iron phases.

VII.4.1. Reduction Behavior of Precipitated Iron Catalysts

TPR results obtained for precipitated iron catalysts are dependent on both the amounts and identities of promoters and on pretreatment. Figure VII-12 summarizes the peak locations $\left(T_{m}\right)$ of the first step of iron reduction for the precalcined copper-promoted catalysts, and illustrates the decrease in $T_{m}$ with increasing copper content. $T_{m}$ 's for the second step of iron reduction of precipitated iron catalysts do not change appreciably with copper content, but the temperature at which the second step commences decreases. The more facile reduction of copper oxide could be attributed to the relatively lower molar free energy of reduction for the copper oxide $\left(-100 \mathrm{~kJ} /\right.$ mole at $\left.25^{\circ} \mathrm{C}\right)$ compared to that for the corresponding iron compound 


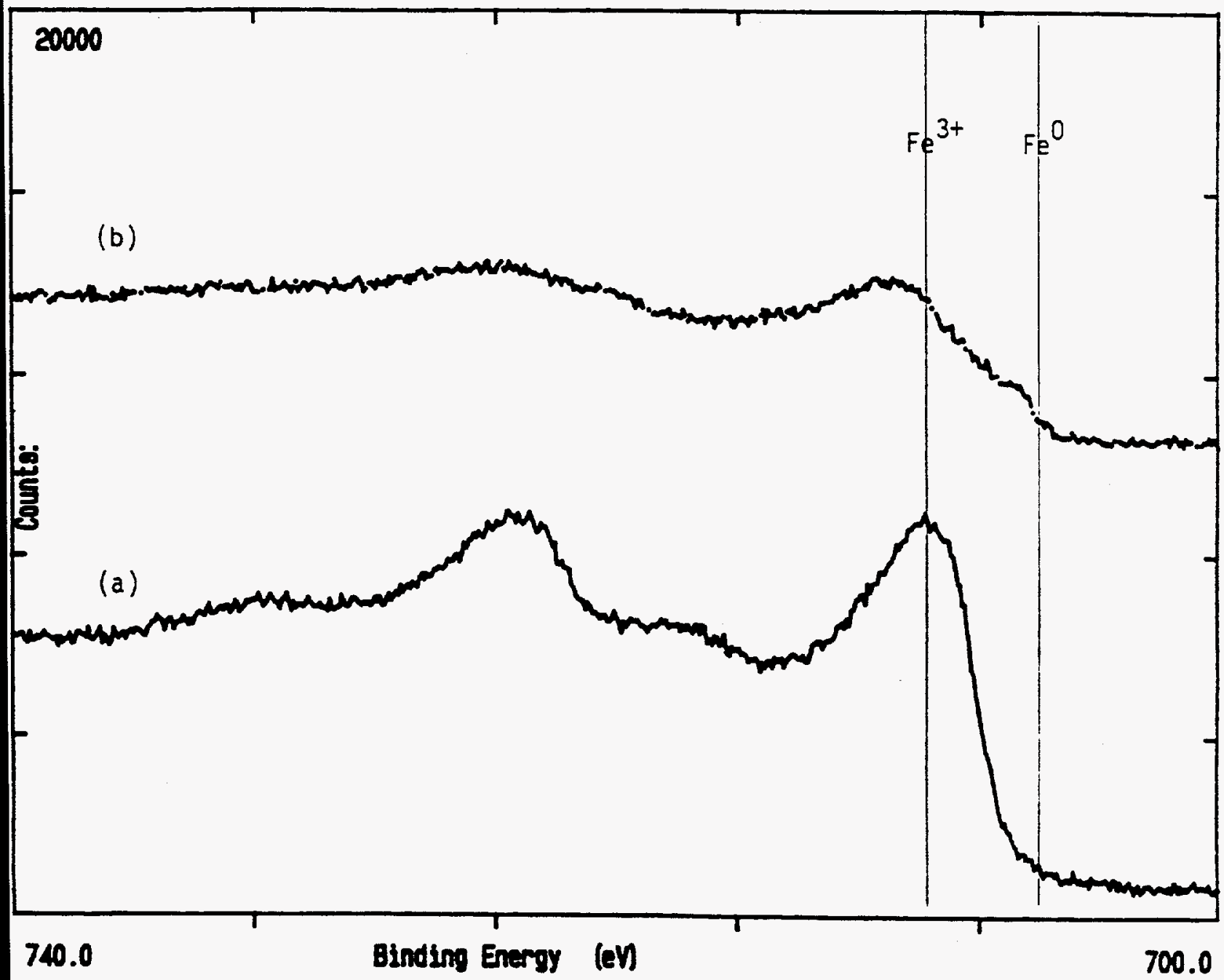

Figure VII-7 XPS spectra of unpromoted $100 \mathrm{Fe}$ precipitate in $\mathrm{Fe} 2 \mathrm{p}$ region: (a) following calcination for $5 \mathrm{hrs}$ at $300^{\circ} \mathrm{C}$; (b) following subsequent exposure to $\mathrm{H}_{2}$ for $5 \mathrm{hrs}$ at $300^{\circ} \mathrm{C}$ 


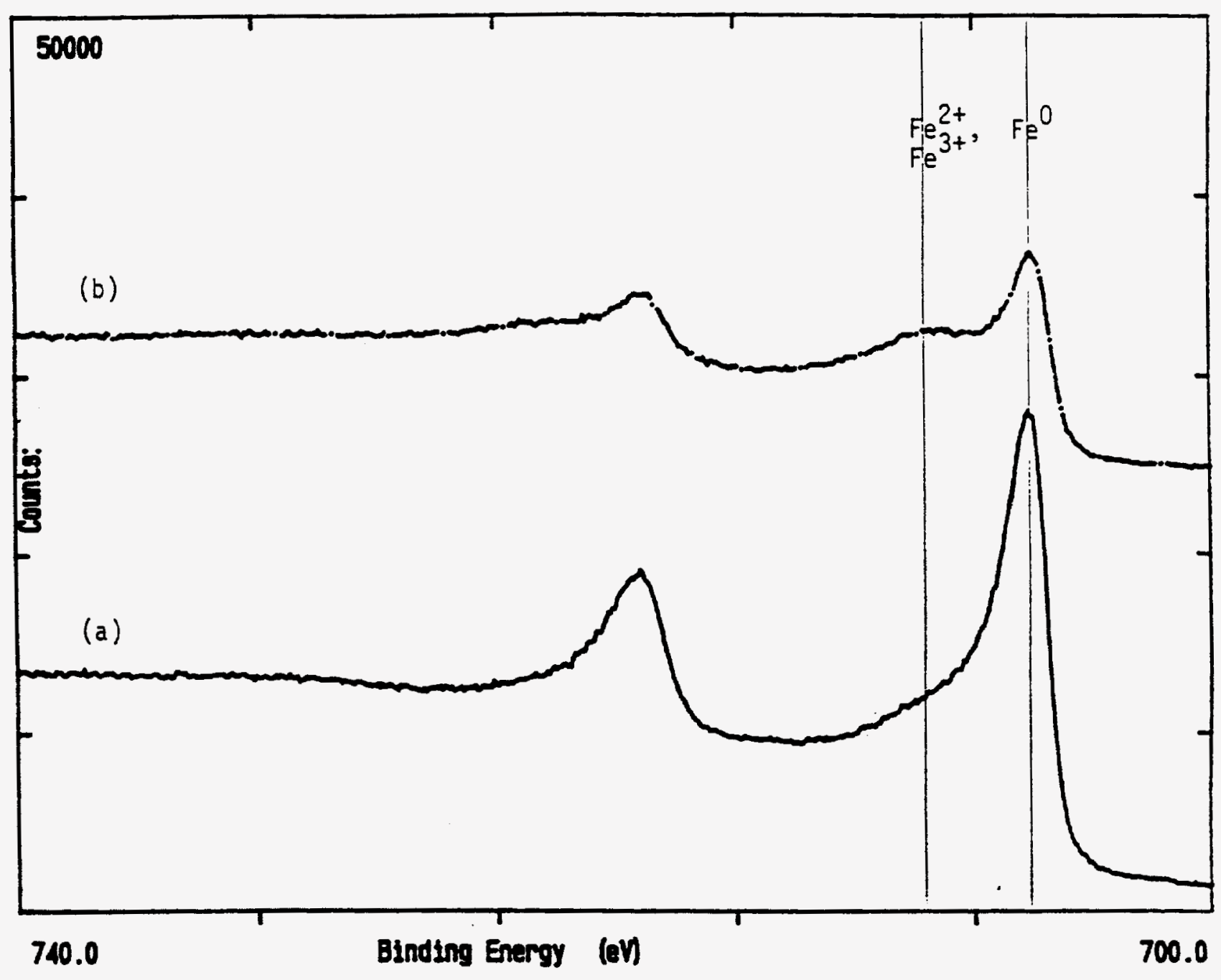

Figure VII-8 XPS spectra of unpromoted $100 \mathrm{Fe}$ precipitate in $\mathrm{Fe} 2 \mathrm{p}$ region: (a) following calcination for $5 \mathrm{hrs}$ at $300^{\circ} \mathrm{C}$ and subsequent reduction in $\mathrm{CO}$ for $5 \mathrm{hrs}$ at $300^{\circ} \mathrm{C}$; (b) following subsequent exposure to $2 / 1$ mixture of $\mathrm{H}_{2} / \mathrm{CO}$ at $250^{\circ} \mathrm{C}$ and $1 \mathrm{~atm}$ 


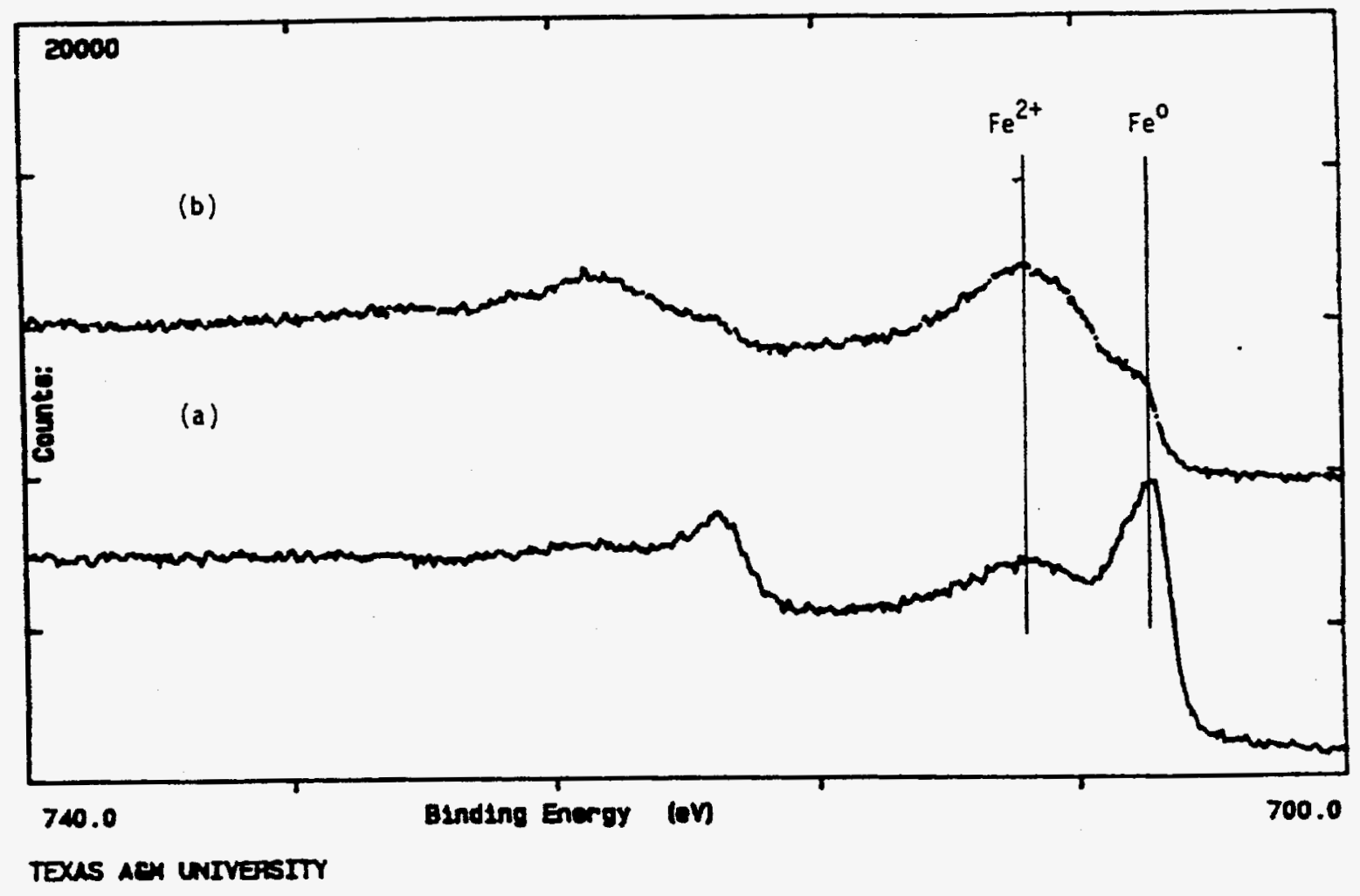

Figure VII-9 XPS spectra of $100 \mathrm{Fe} / 5 \mathrm{Cu} / 4.2 \mathrm{~K} / 8 \mathrm{SiO}_{2}$ in $\mathrm{Fe} 2 \mathrm{p}$ region: (a) following exposure to $\mathrm{H}_{2}$ at $300^{\circ} \mathrm{C}$; (b) following subsequent exposure to $\mathrm{H}_{2} / \mathrm{CO}$ at $250^{\circ} \mathrm{C}$ 


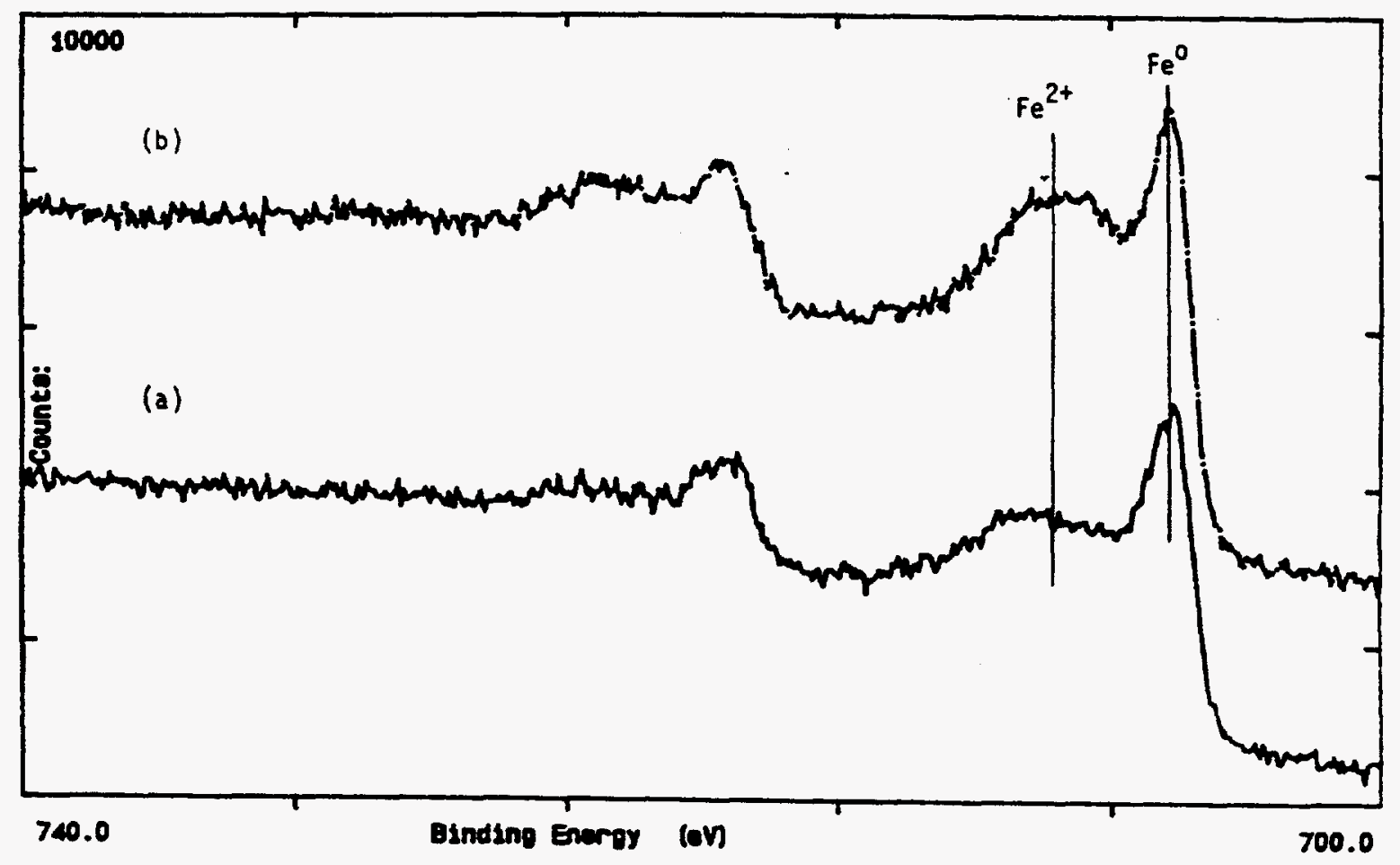

TEXS AEN LNIVESITY

Figure VII-10 XPS spectra of $100 \mathrm{Fe} / 5 \mathrm{Cu} / 4.2 \mathrm{~K} / 8 \mathrm{SiO}_{2}$ in $\mathrm{Fe} 2 \mathrm{p}$ region: (a) following exposure to $\mathrm{CO}$ at $300^{\circ} \mathrm{C}$; (b) following subsequent exposure to $\mathrm{H}_{2} / \mathrm{CO}$ at $250^{\circ} \mathrm{C}$ 


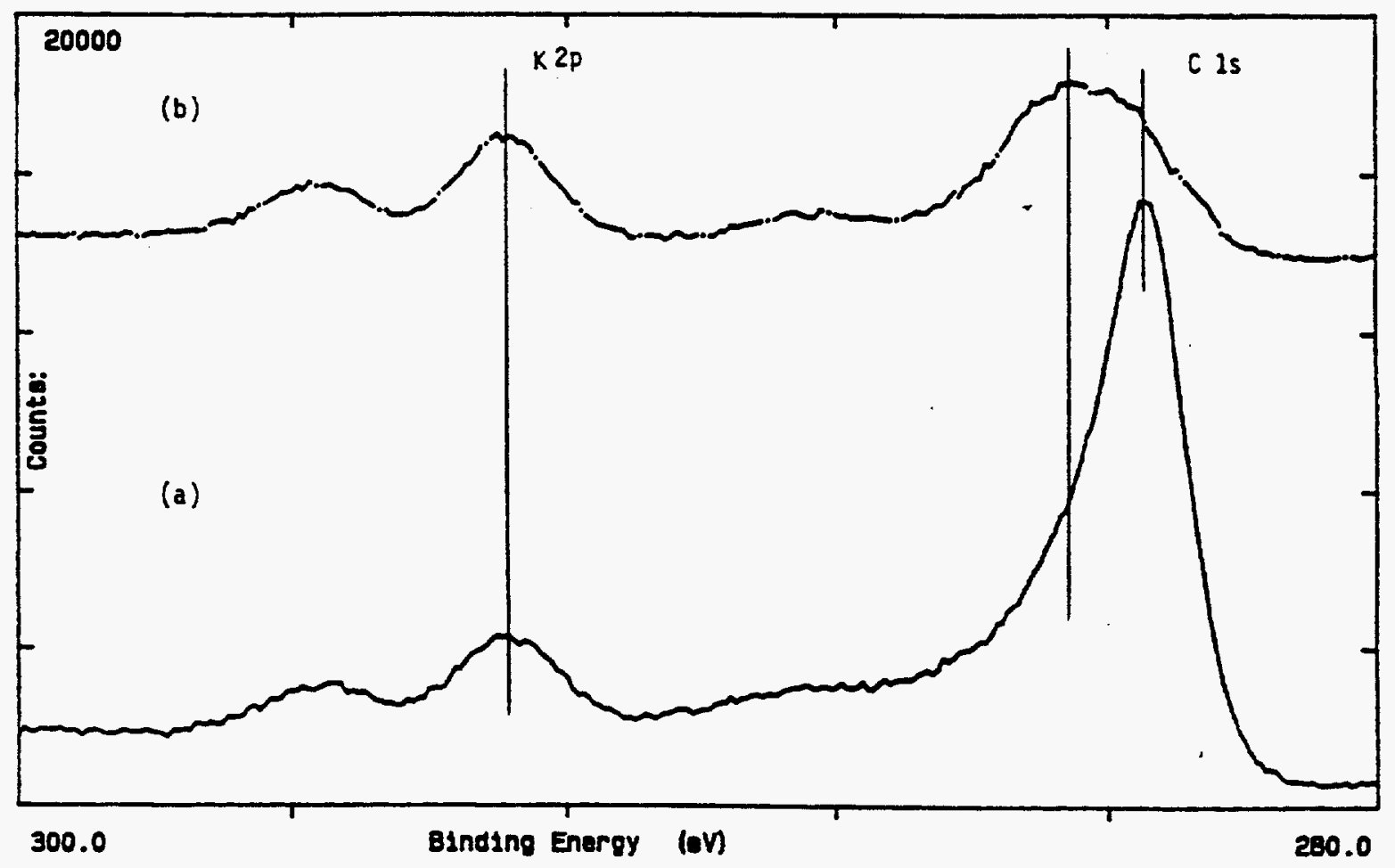

TEXAS AEM UNIVERSITY

Figure VII-11 XPS spectra of $100 \mathrm{Fe} / 5 \mathrm{Cu} / 4.2 \mathrm{~K} / 8 \mathrm{SiO}_{2}$ in $\mathrm{K} 2 \mathrm{p}$ and $\mathrm{C}$ 1s regions: (a) following exposure to $\mathrm{CO}$ at $300^{\circ} \mathrm{C}$; (b) following subsequent exposure to $\mathrm{H}_{2} / \mathrm{CO}$ at $250^{\circ} \mathrm{C}$ 


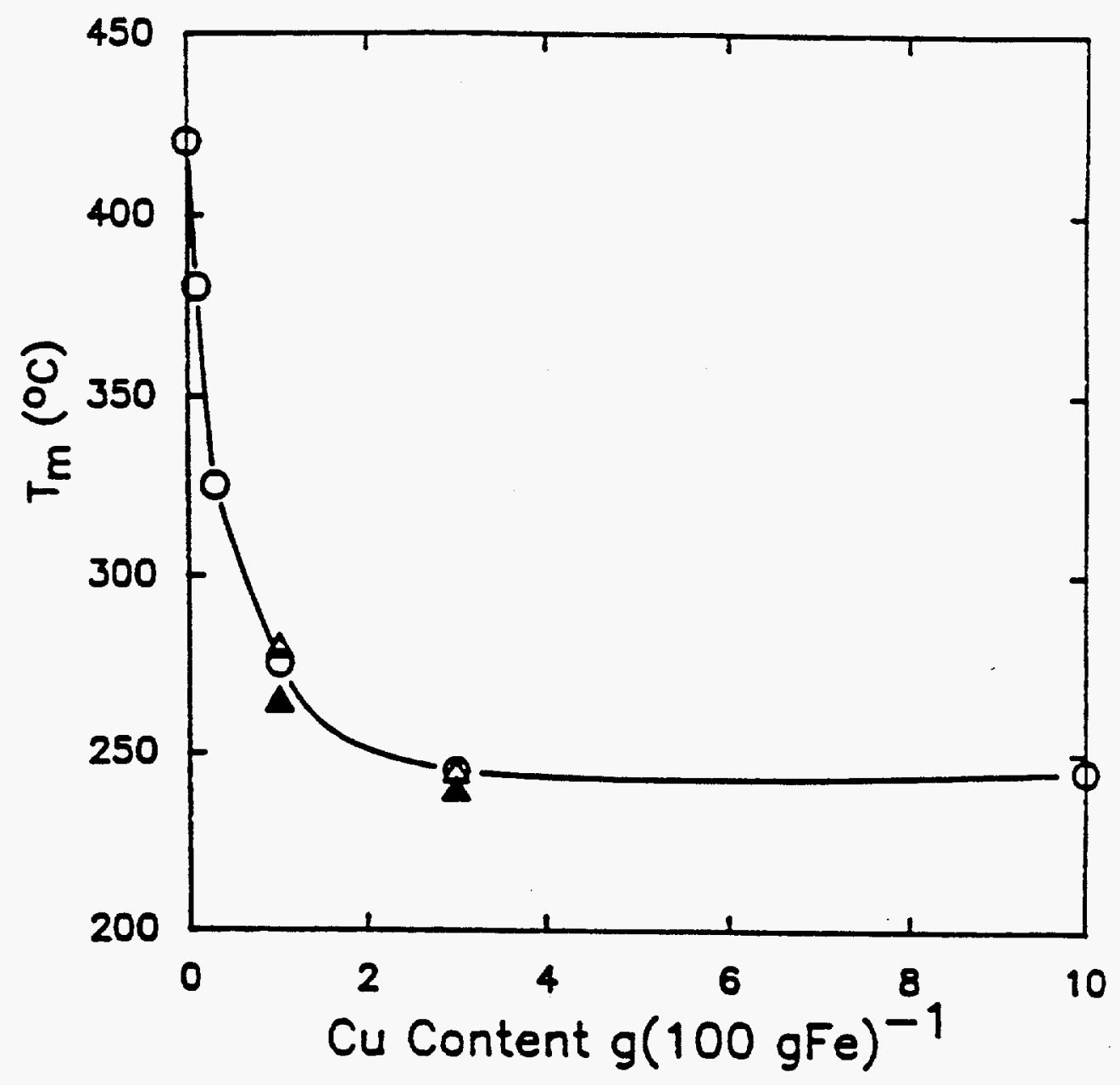

Figure VII-12 Influence of copper promoter on TPR peak maximum for the first step of iron reduction: open circle, potassium-free catalysts; filled triangle, catalysts containing 0.05 part potassium; open triangle, catalysts containing 0.2 part potassium 


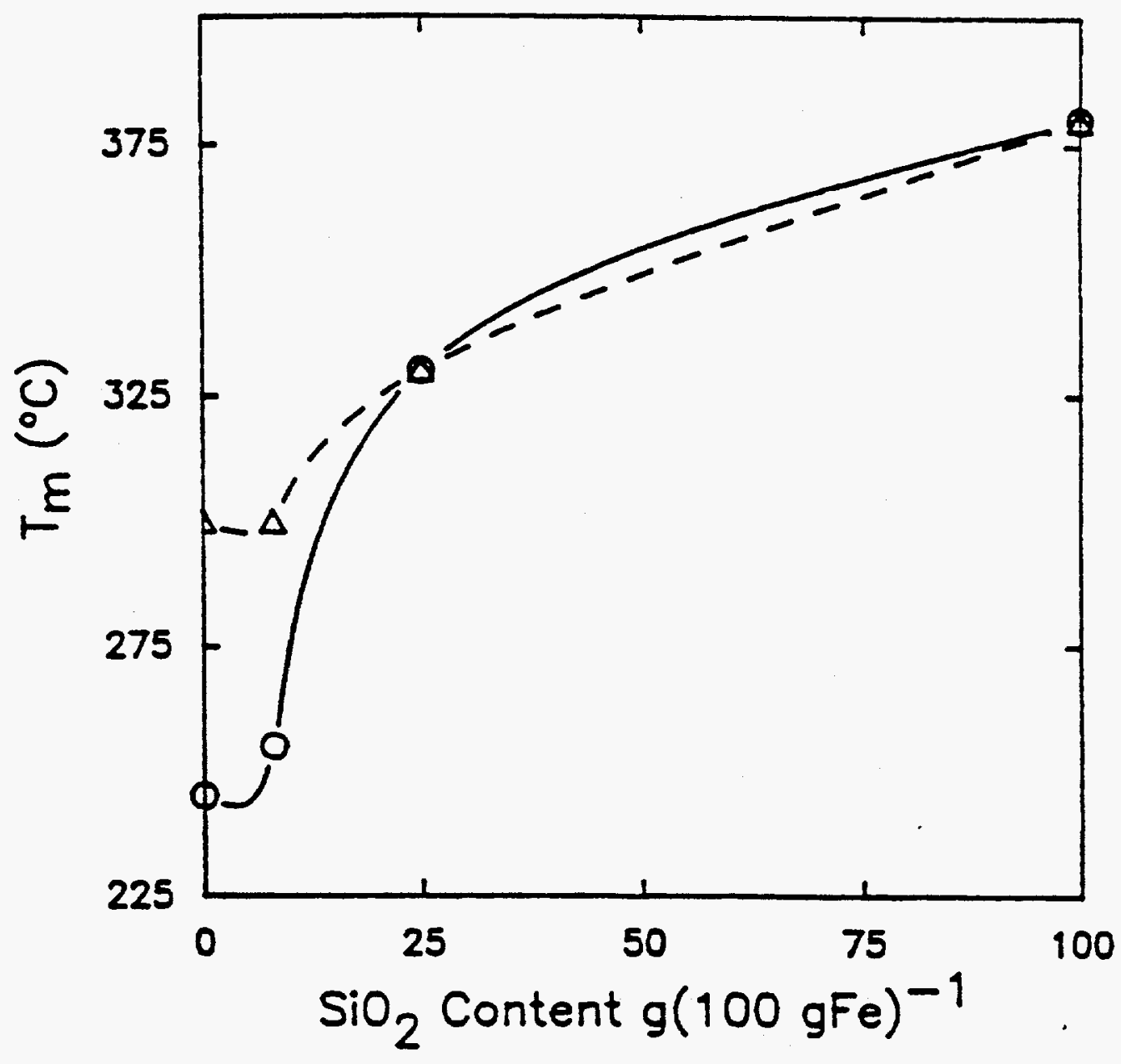

Figure VII-13 Influence of $\mathrm{SiO}_{2}$ support on TPR peak maximum for the first step of iron reduction: open circle, catalysts containing 5 parts copper; open triangle, catalysts containing 5 parts copper and 4.2 parts potassium 
$\left(20 \mathrm{~kJ} /\right.$ mole at $25^{\circ} \mathrm{C}$ ) (Jones and McNicol, 1986). According to the nucleation mechanism of oxide reduction, the reduction of oxide accelerates as the first metal nuclei are formed (Madon and Taylor, 1981). The lower reduction temperature required for copper oxide relative to iron oxide leads to formation of nucleation sites in metallic copper at temperatures where metallic iron would not normally be formed; an increase in the number of nucleation sites accelerates the subsequent reduction of iron oxide. It is evident from Table VII-3 that the time required for the completion of iron reduction in either $\mathrm{H}_{2}$ or $\mathrm{CO}$ decreases with increasing copper content.

Copper-promoted iron catalysts were prepared by the co-precipitation of copper nitrate solution with iron nitrate solution, resulting in a uniform distribution of copper throughout the catalysts. Even at very low levels $(0.1 \mathrm{wt} \%)$, copper exerts a significant effect as a structural promoter to prevent precipitated iron oxide from forming large particles, resulting in an increase in total surface area (Table VII-2). Catalyst surface areas decrease considerably, however, after calcination, both with and without copper promoters. The TPR profiles before and after calcination illustrate the dependence of the bulk composition on catalyst pretreatment. In addition, removal of water and nitrate by pre-calcination also cause a composition change in the surface phase which can be observed from XPS results. Since the basic two-stage iron reduction feature in TPR profiles for the copper-promoted iron catalysts is similar to that observed for the unpromoted iron catalyst, it is unlikely that true alloying between iron and copper occurred. This observation is in agreement with previous results, which indicate that alloying between copper and iron becomes significant only at temperatures above $700^{\circ} \mathrm{C}$ (Hansen, 1958). The presence of potassium causes a change in the TPR profiles for the copper-promoted catalysts, suggesting that the potassium is capable of influencing the reduction of copper.

Unlike copper oxide, potassium oxide cannot be reduced in either $\mathrm{H}_{2}$ or $\mathrm{CO}$ (at the temperatures employed in this study), compared to the reduction temperature of iron, to form nucleation sites. The temperature locations of the first step of iron reduction in the TPR results do not change with potassium content, as shown in Figure VII-3. In the absence of copper, the time required for completion of the first step of iron reduction in $\mathrm{H}_{2}$ increases with increasing potassium content, suggesting that a blockage of nucleation sites by potassium may inhibit the reduction of iron. However, a different effect is observed in the treatment of catalysts using $\mathrm{CO}$. Table VII-3 indicates that the time required for the completion of iron reduction in $\mathrm{CO}$ decreases in the presence of potassium. This promotional effect may be attributed to the facilitation of $\mathrm{CO}$ dissociation in the presence of potassium on the surface of iron. 
Table VII-3 Time Required for Completion of Second Step of Iron Reduction at $300^{\circ} \mathrm{C}$

\begin{tabular}{lcc}
\hline $\begin{array}{c}\text { Catalyst } \\
\text { (parts by weight) }\end{array}$ & in $\mathrm{H}_{2}$ & in $\mathrm{CO}$ \\
\hline $100 \mathrm{Fe}$ & $>1000$ & 360 \\
$100 \mathrm{Fe} / 0.2 \mathrm{~K}$ & $>1000$ & 120 \\
$100 \mathrm{Fe} / 1 \mathrm{~K}$ & $>1000$ & 180 \\
$100 \mathrm{Fe} / 0.3 \mathrm{Cu}$ & 600 & 120 \\
$100 \mathrm{Fe} / 1 \mathrm{Cu}$ & 480 & - \\
$100 \mathrm{Fe} / 3 \mathrm{Cu}$ & 400 & 80 \\
$100 \mathrm{Fe} / 1 \mathrm{Cu} / 0.05 \mathrm{~K}$ & 560 & 60 \\
$100 \mathrm{Fe} / 1 \mathrm{Cu} / 0.2 \mathrm{~K}$ & 560 & 60 \\
$100 \mathrm{Fe} / 3 \mathrm{Cu} / 0.2 \mathrm{~K}$ & 300 & 60 \\
\hline
\end{tabular}


The reduction results in Figure VII-13 show that the reduction of iron is inhibited by the addition of a support, suggesting an interaction between metal and support, which has been proposed by many investigators (Dry, 1981; Anderson, 1984; Lund and Dumesic, 1981). The promotional effect of copper is gradually eliminated by increasing contents of both silica and alumina, due to the interaction between metal and support. The addition of potassium magnifies the inhibition effect of support on the reduction of copper and iron because the presence of potassium suppresses the promotional effect of copper on the reduction, due to the covering of nucleation sites by potassium. The transport of $\mathrm{SiO}_{2}$ on iron oxide in $\mathrm{H}_{2} \mathrm{O}$-containing environments has been proposed by Lund and Dumesic (1981). They measured the movement of $\mathrm{SiO}_{2}$ over the surface of an oxidized iron foil at $400^{\circ} \mathrm{C}$ and atmospheric pressure in different gas environments by scanning Auger electron microscopy. Silica migration was observed upon treatment in $\mathrm{H}_{2} \mathrm{O} / \mathrm{CO}$ or $\mathrm{H}_{2} \mathrm{O} / \mathrm{H}_{2}$ gas mixtures, while significant migration was not observed upon treatment in $\mathrm{CO}_{2} / \mathrm{CO}$ or $\mathrm{O}_{2}$. In the current investigation, the calcination/drying procedure may cause this type of support migration.

\section{VII.4.2. The Oxidation States of Surface Iron}

The XPS results summarized in Table VII-4 indicate that the surfaces of the $\mathrm{H}_{2}$-treated iron samples are largely covered by a layer of iron oxide. Although the isothermal reduction results for the $\mathrm{H}_{2}$-reduced catalysts indicate extensive reduction of iron to $\mathrm{Fe}(0)$, the absence of metallic iron on the catalyst surface after $\mathrm{H}_{2}$ treatment can be explained by the re-oxidation of iron by water, a by-product of reduction in $\mathrm{H}_{2}$. By contrast, the XPS results indicate that the surfaces of the $\mathrm{CO}$ - treated samples possess the same compositions as those of the bulk, viz., zero-valent iron. One of the reasons for the absence of oxidized iron phases can be attributed to the formation of $\mathrm{CO}_{2}$, instead of $\mathrm{H}_{2} \mathrm{O}$ as in the $\mathrm{H}_{2}$ reduction, as a by-product of reduction in $\mathrm{CO}$.

For potassium-promoted iron catalysts, the $K 2 p$ regions in XPS spectra indicate that reduction in $\mathrm{H}_{2}$ leads to a pronounced spreading of potassium on the surface, compared to $\mathrm{CO}$ treatment (Table VII-4). The addition of potassium to the iron catalysts in this study was performed by impregnation with $\mathrm{KHCO}_{3}$ solution. After drying in a vacuum oven at $120^{\circ} \mathrm{C}$, the potassium formed an oxidized compound, as indicated by the lack of an increase in the carbonate carbon peak at $289 \mathrm{eV}$ compared to that for the potassium-free catalyst. Similar experiments have been performed on a potassium-promoted iron catalyst which was prepared by impregnating a passivated iron powder with $\mathrm{K}_{2} \mathrm{CO}_{3}$ (Dwyer and Hardenberg, 1984; 
Table VII-4 Summary of XPS results for Precipitated Iron Catalysts

\begin{tabular}{|c|c|c|c|c|}
\hline $\begin{array}{l}\text { Catalyst } \\
\text { (parts by weight) }\end{array}$ & Reductant & $\% \mathrm{Fe}(0)$ & $\% \mathrm{Fe}^{\mathrm{n}+}$ & $\begin{array}{l}\mathrm{K} 2 \mathrm{p}_{3 / 2}: \\
\mathrm{Fe} 2 \mathrm{p}_{3 / 2}\end{array}$ \\
\hline \multirow[t]{2}{*}{$100 \mathrm{Fe}$} & $\mathbf{H}_{2}$ & 5 & 95 & - \\
\hline & $\mathrm{CO}$ & 100 & - & - \\
\hline \multirow[t]{2}{*}{$100 \mathrm{Fe} / \mathrm{Cu}$} & $\mathrm{H}_{2}$ & 7 & 93 & - \\
\hline & $\mathrm{CO}$ & 95 & 5 & - \\
\hline \multirow[t]{2}{*}{$100 \mathrm{Fe} / 0.2 \mathrm{~K}$} & $\mathrm{H}_{2}$ & - & 100 & - \\
\hline & $\mathrm{CO}$ & 90 & 10 & - \\
\hline \multirow[t]{2}{*}{$100 \mathrm{Fe} / 2 \mathrm{~K}$} & $\mathbf{H}_{2}$ & - & 100 & 0.9 \\
\hline & $\mathrm{CO}$ & 100 & - & 0.3 \\
\hline \multirow[t]{2}{*}{$100 \mathrm{Fe} / 3 \mathrm{Cu} / 0.2 \mathrm{~K}$} & $\mathrm{H}_{2}$ & 55 & 45 & 0.5 \\
\hline & $\mathrm{CO}$ & 100 & . & - \\
\hline \multirow[t]{2}{*}{$100 \mathrm{Fe} / 5 \mathrm{Cu} / 4.2 \mathrm{~K} / 8 \mathrm{SiO}_{2}$} & $\mathrm{H}_{2}$ & 45 & 55 & 1.2 \\
\hline & $\mathrm{CO}$ & 60 & 40 & 0.2 \\
\hline \multirow[t]{2}{*}{$100 \mathrm{Fe} / 5 \mathrm{Cu} / 4.2 \mathrm{~K} / 25 \mathrm{SiO}_{2}$} & $\mathrm{H}_{2}$ & 50 & 50 & $<0.1$ \\
\hline & $\mathrm{CO}$ & 30 & 70 & $<0.1$ \\
\hline \multirow[t]{2}{*}{$100 \mathrm{Fe} / 5 \mathrm{Cu} / 4.2 \mathrm{~K} / 8 \mathrm{Al}_{2} \mathrm{O}_{3}$} & $\mathrm{H}_{2}$ & 55 & 45 & 0.9 \\
\hline & $\mathrm{CO}$ & 50 & 50 & 0.2 \\
\hline \multirow[t]{2}{*}{$100 \mathrm{Fe} / 5 \mathrm{Cu} / 4.2 \mathrm{~K} / 25 \mathrm{Al}_{2} \mathrm{O}_{3}$} & $\mathrm{H}_{2}$ & 4 & 96 & 0.1 \\
\hline & $\mathrm{CO}$ & 40 & 60 & 0.5 \\
\hline
\end{tabular}

for 12 hrs at $300^{\circ} \mathrm{C}$ 
Dwyer, 1985). Using XPS spectra, these workers have shown that $\mathrm{K}_{2} \mathrm{CO}_{3}$ was present on the surface of the catalyst before hydrogen reduction. They proposed that a surface $\mathrm{KOH}$ layer was formed from the partial decomposition of $\mathrm{K}_{2} \mathrm{CO}_{3}$. The same conclusion was first reached by Bonzel and Krebs (1987) in investigating the effects of $\mathrm{K}_{2} \mathrm{CO}_{3}$ coverage of an iron foil on Fischer-Tropsch synthesis. Using XPS measurements in the $K 2 p$ region, they showed that the potassium, associated in some form with oxygen, appeared not to be covered by the deposited carbon but rather resided on top of the carbon layer. However, an increase in the intensity of the carbonate carbon peak after $\mathrm{H}_{2}$ reduction in this study seems not to be associated with potassium, because no corresponding increase in this peak intensity is observed after $\mathrm{CO}$ treatment.

The appearance of potassium on the surfaces of catalysts is complicated by the presence of a support. As the silica content increased to 25 parts per 100 parts of iron, no significant surface enrichment in potassium is observed after $\mathrm{H}_{2}$ reduction at $300^{\circ} \mathrm{C}$, indicating that the homogeneously distributed silica matrix inhibits the potassium migration process. For aluminasupported iron catalysts, a complicated K $2 p$ XPS peak feature indicates that potassium can be associated with iron and with alumina as well. Arakawa and Bell (1983) postulated that a significant proportion of the potassium was consumed by acidic sites on the alumina support, leaving little available for interaction with the iron. Therefore, unlike the silica-supported iron catalysts, the presence of 20 parts of alumina per 100 parts of iron still shows a significant surface migration of potassium.

\section{VII.5. Conclusions}

In this study, precipitated iron catalysts were characterized using temperature-programmed reduction, isothermal reductions and $X$-ray photoelectron spectroscopy. The following conclusions may be drawn from the results on this investigation:

1. $\mathrm{H}_{2}$ and $\mathrm{CO}$ treatments of precipitated iron catalysts result in different surface compositions of catalysts. Water, a by-product of $\mathrm{H}_{2}$ reduction, is a principal factor determining the reducibility of catalysts and the effects of promoters.

2. The promotional effect of copper on the reduction of iron increases with increasing copper content, up to $3 w t \%$.

3. The presence of potassium influences the reducibility of the precipitated catalysts, with or without copper.

4. The inhibition effect of silica and alumina supports on the reduction of iron increases with 
increasing support content. The inhibition effect is less pronounced for alumina than for silica. 
VIII. Task 4. ECONOMIC EVALUATION

\section{VIII.1. EXECUTIVE SUMMARY}

A study of the economics of liquid fuel production by Fischer-Tropsch ( $F-T$ ) processing was originally initiated for two reasons. The first was to provide assistance in assessing the near- to immediate-term potential for commercial production of liquid fuels by indirect liquefaction based on relatively inexpensive remote natural gas. The second was to examine the economics of slurry F-T processing versus two existing processes, entrained bed Synthol and fixed bed ARGE. This study was completed in 1985 by the Technical Diversification Department of Air Products and a report (Appendix 1 ) was written and distributed internally.

The principal results of that study were:

(1) None of the cases appeared profitable for a nominal 40,000 bbl/day facility coming onstream in 1990, regardless of the value assigned to natural gas.

(2) The slurry case appeared to have an advantage over both Synthol and ARGE. This advantage was primarily rooted in the relatively lower capital costs of the F-T synthesis areas.

In this context, further work on characterizing and developing iron-based $F-T$ catalysts was continued under a subcontract by researchers at Texas A\&M University. This work identified several promising slurry phase catalysts. Air Products' personnel performed Task 4, the Economic Evaluation.

Several important points resulted from this additional work. Catalyst performance improved substantially, giving improved conversions and similar yields as the previous catalysts, but at much lower pressures. The increased conversions required a reduced recycle stream in the $F-T$ synthes is section. However, the lower pressure resulted in little reduction in the F-T synthesis equipment even with the reduced recycle stream; thus, equipment and operating costs were similar to the original study. Combined with depressed prices for liquid fuels, this resulted in nearly the same revenue shortfall as the original estimate ( $\$ 22$ vs $\$ 25 / \mathrm{bbl})$.

\section{VIII.1.1. Background}

The work done by Air Products for a new slurry phase F-T catalyst and process was evaluated and documented in 1985 (Appendix 1). In this study, several new catalysts were developed and tested against known catalysts for use in the slurry mode. Existing F-T based processes (i.e. Sasol) operate in two modes; a fixed bed (ARGE) process, or an entrained bed (Synthol) process. The synthesis gas was derived from natural gas ( $\$ 1.00 / \mathrm{MMBtu}$ ) by partial oxidation (POX) for the slurry and ARGE cases, and steam methane reforming (SMR) for the Synthol case. The major difference between the cases was the $\mathrm{H}_{2} / \mathrm{CO}$ ratio of the synthesis gas; 0.92 using POX for the slurry case, 1.7 using SMR for the ARGE case, and 2.0 for synthol. In all cases, the synthesis gas feed rate was 875 MMscfd and the synthesis gas transfer price varied from \$1.15/MSCF for the 
Synthol case to $\$ 1.44 / \mathrm{MSCF}$ for the slurry case. As a sensitivity, synthesis gas production costs from coal gasification were developed, and the synthesis gas cost was estimated to be $\$ 5.00 / \mathrm{MSCF}$ based on midwestern coal costing $\$ 1.50 /$ MMBtu.*

Computer simulations using a process simulator were performed for the synthesis loop in each case. With this information, the next step of the evaluation was to develop economics for the F-T synthesis loop and the product upgrading section. Costs were developed for each major piece of equipment in the F-T synthesis section for each case. The product upgrading unit costs, however, were developed on a "macro" basis, that is, costs were scaled from the earlier evaluation based on the total flow to the unit. The product rate was set at $40,000 \mathrm{bbl} /$ day of 1 iquid fuels, which includes liquid petroleum gas ( $L P G$ or $\left.C 3^{\prime} s\right)$, butanes ( $\left.C 4^{\prime} s\right)$, gasoline $(C 5-C 11)$, and diesel fuel $\left(\mathrm{Cl}_{2+}\right)$. No credit was allowed for alcohols. Since only liquid products were considered, $\mathrm{Cl}^{\prime} \mathrm{s}$ and $\mathrm{C} 2$ 's from $\mathrm{F}-\mathrm{T}$ synthes is were sent to an autothermal reformer where they were processed to synthesis gas and returned to the F-T synthes is section. Based on these results, the slurry route was the most attractive. However, none of the cases appeared to be profitable. Below is a summary of the findings.

\begin{tabular}{lrrr} 
& \multicolumn{3}{c}{40,000 bbl/day } \\
\cline { 2 - 2 } & Slurry & Synthol & ARGE \\
Capital Investment (MM \$) & 1,270 & 1,955 & 1,810 \\
Required Annual Revenues (MM \$) & 852 & 979 & 964 \\
( $\$ /$ bbl) & 61 & 72 & 70 \\
Projected Revenues (MM \$) & 495 & 481 & 495 \\
(\$/bb1) & 36 & 36 & 36 \\
Revenue Shortfall (MM \$) & 357 & 498 & 469 \\
(\$/bbl Output) & 25 & 36 & 34
\end{tabular}

With these costs, these cases remain unprofitable even with natural gas costs assigned a value of zero ( $\$ 0 / \mathrm{MMBtu})$. The sensitivity cases based on coal gasification proved prohibitively expensive, losing over $\$ 1$ billion annually. For comparison purposes, liquid fuel production from syngas using the Mobil MTG process was also evaluated and found to be less profitable than the slurry route. An SRI report issued in July, 1989, on liquid fuels using the Mobil MTG process also found this process to be unprofitable.

Since the 1985 report, Professor Burkur at Texas A\&M has done extensive work characterizing and developing catalysts for the slurry mode of operation. Several improvements were made, leading to catalysts that have much higher conversion rates with little loss of selectivity, and operate at significantly lower pressures ( 225 psia vs. $315 \mathrm{psia}$ ). A follow-on evaluation was requested to assess the economic viability of these new catalysts. The scope of this evaluation follows the original work done in 1985. The total amount of product remains at $40,000 \mathrm{bbl} /$ day of 1 iquid fuels. With this production rate, the product upgrading and offsite sections remain consistent. Therefore, only

${ }^{\star} A$ revised Product Cost Summary is located in Appendix 2. 
the F-T synthesis section was estimated in any detail. This is consistent with the original analysis. Also, in this study only the slurry process is evaluated given the original findings. Three cases, each based on a different catalyst, were evaluated. The first case assumes a catalyst developed at Air Products that was used for the original study (original case). The second case assumes a commercial catalyst developed by Ruhrchemie and tested by Professor Burkur (commercial case). The third case assumes a catalyst developed and tested by Professor Burkur that is somewhat similar to the commercial catalyst (new case). To complete the analysis, projected revenues were based on current prices for the products and the estimate was done in 1990 dollars. Costs and revenues were projected to 1995 and 2000 for forecasting purposes.

\section{VIII.1.2 Synthesis Gas Production}

In the 1985 study, the syngas molar $\left(\mathrm{H}_{2} / \mathrm{CO}\right)$ ratio was assumed to be 0.92 for both the feed gas and usage requirement. In the recently completed catalyst characterization work, the syngas molar ratio was assumed to be 0.67 , possibly reflecting syngas produced from coal-based sources. However, in the original study, synthes is gas from coal was found to be over three times more expensive than the synthesis gas from methane. Given the past finding, synthesis gas cost for this case was assumed to be that for remote natural gas $(\$ 1.00 / \mathrm{MMBt}$ ). With the required molar ratios, synthesis gas is produced by POX of methane. With the lower $\mathrm{H}_{2} / \mathrm{CO}$ ratio the synthesis is somewhat more expensive, but less feed is required with the improved product split produced by the new catalyst. The synthesis gas costs are reported as an operating cost including capital equipment. Therefore, the total plant cost reported does not include the synthesis gas plant. In this way, different syngas production methods can be evaluated easily. Synthesis gas costs ranged from $\$ 1.26 / \mathrm{MSCF}$ for the commercial and original catalysts to $\$ 1.29 / \mathrm{MSCF}$ for the new catalyst. These values assume that credits for $\mathrm{H}_{2}$ in the purge and steam from the syngas plant are obtained. Without these credits, the syngas costs are about $\$ 0.17 / \mathrm{MSCF}$ higher.

\section{VIII.1.3 F-T Synthesis and Product Upgrading}

The next step in the evaluation was to develop economics for the F-T synthesis loop and the product upgrading sections. Computer simulations were performed for the synthesis loop for the slurry case in the original study, which allowed some preliminary equipment sizing for the F-T synthesis area. This methodology was then used to determine equipment sizing for the F-T synthesis section for the commercial catalyst and new catalyst cases.

While costs were developed for major pieces of equipment in the synthesis loop itself, costs were developed on a macro basis (i.e., total flow to a untt) for the product upgrading costs. Since it was desirable to produce all liquid product slate, $\mathrm{Cl}^{\prime}$ 's and $\mathrm{C} 2$ 's from $\mathrm{F}-\mathrm{T}$ synthes is were sent to an autothermal reformer, processed to synthesis gas and returned as F-T synthesis feed.

The results of the economic analysis are presented below. The table gives capital costs and annual required revenues for $F-T$ synthesis, and product upgrading for three catalysts based on the slurry mode for a nominal 
$40,000 \mathrm{bbl} /$ day facility. The required revenues provide for covering costs plus a $7.5 \%$ net profit after tax. Also tabulated are projected 1990 revenues and the revenue shortfall for each case. The projected revenues are based on product prices obtained from Air Products' Corporate Energy Department.

\begin{tabular}{|c|c|c|c|}
\hline & \multicolumn{2}{|c|}{1990 Onstream Slurr } & Mode \\
\hline & Original & Commercial & New \\
\hline $\begin{array}{l}\text { Capital Investment (MM } \$ \text { ) } \\
\text { Required Annual Revenues (MM } \$ \text { ) } \\
(\$ / \text { bbl) }\end{array}$ & $\begin{array}{r}827.5 \\
621.6 \\
47.1\end{array}$ & $\begin{array}{r}840.6 \\
650.6 \\
49.3\end{array}$ & $\begin{array}{r}800.3 \\
621.3 \\
47.1\end{array}$ \\
\hline $\begin{array}{l}\text { Projected Revenues (MM } \$) \\
(\$ / \text { bb } 1)\end{array}$ & $\begin{array}{r}320.5 \\
24.4\end{array}$ & $\begin{array}{r}317.2 \\
23.8\end{array}$ & $\begin{array}{r}322.1 \\
24.9\end{array}$ \\
\hline $\begin{array}{l}\text { Revenue Shortfall (MM } \$) \\
(\$ / \text { bbl Output) }\end{array}$ & $\begin{array}{r}301.1 \\
22.7\end{array}$ & $\begin{array}{r}333.4 \\
25.5\end{array}$ & $\begin{array}{r}299.2 \\
22.2\end{array}$ \\
\hline
\end{tabular}

Although there seems to be substantial improvement in catalyst performance, with much lower operating pressures, slightly lower temperature and much higher conversion, the overall cost benefit is negligible. The higher conversion gives much smaller recycle streams, but the $F-T$ synthesis section equipment remains about the same size because the pressure reduction actually increases the acfm (actual cubic feet per minute) of the feed stream. The product upgrading section costs remain nearly constant since the quantity of product remains constant. The actual escalation to 1990 was much less than that predicted in the initial study. However, the product prices and cost of oil are also much less than that predicted, which results in the revenue shortfall remaining about the same ( $\$ 22$ vs $\$ 25 / \mathrm{bb} 1)$. 


\section{VIII.2. INTRODUCTION/BACKGROUND}

The objective of the project undertaken by Air Products, under contract to the U.S. Department of Energy (DOE), was to develop a consistent technical/ economic data base on the use of iron-based catalysts in F-T synthesis reactions. This data base was developed to allow the unambiguous comparison of the performance of these catalysts with each other and with state-of-the-art iron catalyst compositions. Particular attention was devoted to generating reproducible kinetic and selectivity data and to developing reproductble improved compositions. The aim of Task 4 (Economic Evaluation) was to develop the relative economic impact for the improved catalyst compositions and compare these economics with the base case catalyst economics. Product yield structure, F-T reactor residence time, and key process flow rates were obtained from data determined in Tasks 2 and 3 . These economic studies included relative capital costs, operating costs, and required revenues for the catalyst, as well as a sensitivity study of the relative assigned values of the principle products (i.e., diesel and gasoline).

The original catalyst development work, in which several catalysts were tested in the slurry mode, was done at Air Products. An economic analysis

(Appendix 1) was completed in late 1985 that examined the economics of the slurry phase F-T process and catalyst versus the economics of two existing commercial F-T processes, entrained bed Synthol and fixed bed ARGE. These analyses assumed the synthesis gas source to be remote natural gas valued at $\$ 1.00 / \mathrm{MMBtu}$. As a sensitivity, the three F-T processes were al so compared to a case where the source of the synthesis gas was midwestern coal. In addition, the economics of these three cases were compared to the economics of liquid fuels production from the Mobil Methanol-to-Gasoline (MTG) process and al so to the economics of LNG.

The size of the proposed commercial facility evaluated was chosen based on the flow of synthesis gas $\left(\mathrm{CO}+\mathrm{H}_{2}\right)$ to the $\mathrm{F}-\mathrm{T}$ synthesis units. This was set at 96,00016 mole/hour ( 875 MMscfd), and essentially matched the plant size chosen for an earlier F-T economic study performed for DOE by the Mitre Corporation $(1)$ which was based on the amount of coal fed to the plant. Since light gases ( $C C^{\prime} s$ and $C^{\prime} 2^{\prime} s$ ) formed in the $F-T$ synthesis reaction are also reformed to synthesis gas and sent back to the F-T reactors, the total amount of synthesis gas fed to the F-T reactors was somewhat different for each case. However, in terms of liquid product output, each F-T case was considered to be nominally $40,000 \mathrm{bbl} / \mathrm{day}$. The costs of producing synthesis gas by steam methane reforming and partial oxidation (POX) of methane were evaluated, and POX was found to be most economical when the $\mathrm{H}_{2} / \mathrm{CO}$ ratio was 1.7 (or less when the natural gas price is $\$ 1.00 / \mathrm{MMBtu}$ ). Syngas sourcing is sensitive to gas cost, in that $\mathrm{POX}$ is cheaper at lower $\mathrm{H}_{2} / \mathrm{CO}$ ratios and higher natural gas costs push the POX advantage to higher $\mathrm{H}_{2} / \mathrm{CO}$ ratios. The coal-based synthesis gas process used in the study was based on Shell pressurized gasifiers operating at $400 \mathrm{psi}$ with a $0.5 \mathrm{H}_{2} / \mathrm{CO}$ ratio at gasifier outlet. However, synthesis gas costs were approximately three times that of natural gas.

(1) Mitre Corporation, "Impact of Developmental Technology on Indirect Liquefaction," Government Report for Department of Energy, Contract No. EF-77-C-01-2783, MTR-80W326.

$0257 \mathrm{C}$

VIII -5 
The $F-T$ reaction areas studied were the major difference from the original study. The Air Products case used a slurry reactor; the reactor was essentially a bubble column with the liquid phase consisting of molten wax in which a coprecipitated $\mathrm{Fe} / \mathrm{Cu} / \mathrm{K}$ catalyst is suspended by motion of the gas bubbles traveling up the column operating at $500^{\circ} \mathrm{F}$ and $315 \mathrm{psia}$. The Synthol process uses entrained bed reactors where feed gas and fused iron catalyst are entered as a mixture with the reaction carried out at $600^{\circ} \mathrm{F}$ and $315 \mathrm{psia}$. The ARGE reactor is similar to those used in Sasol I, which used a promoted iron catalyst in tubes that operates from $390^{\circ}$ to $480^{\circ} \mathrm{F}$ and $355 \mathrm{psia}$. The reaction product processing sections were similar for all cases, since the reaction products are the same and only the relative quantities of each product change.

The capital cost estimates for each of these cases are summarized in Table VIII-1. The slurry case required approximately two-thirds the capital of the other F-T synthesis methods, with the largest savings in the reaction area itself. Synthesis gas production area capital costs were not included and synthesis gas costs were treated as operating costs. Production costs and required annual revenue for the $F-T$ cases are summarized in Table VIII- 2 . The required revenues were such that operating costs were covered and a $7.5 \%$ after-tax return on investment was realized. The required revenues were then compared to the projected revenues. The net result showed shortfall revenues of $\$ 25 / \mathrm{bbl}$ for the slurry case, which was much lower than the other cases, but still not economical. The projected product prices would have to be about $\$ 60 / \mathrm{bbl}$ for breakeven in 1990 rather than the $\$ 35 / \mathrm{bbl}$ actually projected for the slurry case. Liquid fuels from the Mobil MTG process were projected to have a revenue shortfall of about $\$ 28 / \mathrm{bbl}$; somewhat greater than the slurry case.

\section{VIII.3. SCOPE OF THE PRESENT STUDY}

Since the previous study showed that the F-T slurry mode offered a significant advantage over the Synthol and ARGE modes, only the slurry case was evaluated. Since that study, Professor D. B. Burkur and his associates at Texas A\&M University developed iron-based F-T catalysts for this slurry phase reaction. Significant improvements in catalyst activity and selectivity were made and will be discussed shortly. Professor Burkur also tested several commercial catalysts, one of which, Ruhrchemie LP $33 / 81$, demonstrated good properties. The scope of this report will encompass three cases, all using the slurry mode for the F-T reactor. The first case assumes the coprecipitated $\mathrm{Fe} / \mathrm{Cu} / \mathrm{K}$ catalyst developed by Air Products (original case). The second case assumes the Ruhrchemie catalyst, Fe/Cu/K supported on silica, and the results reported by Professor Burkur (commercial case). The third case assumes the catalyst developed by Professor Burkur, $\mathrm{Fe} / \mathrm{Cu} / \mathrm{K}$ also supported on silica, and the results reported by Professor Burkur, et al. (new case). The differences between the commercial case and the new case are the specific elemental and silica ratios, and the activation conditions. 


\section{Table VIII-1}

Capital Investment Summary for Liquid Fuels Synthes is (MM\$) (1) (1990 START-UP)

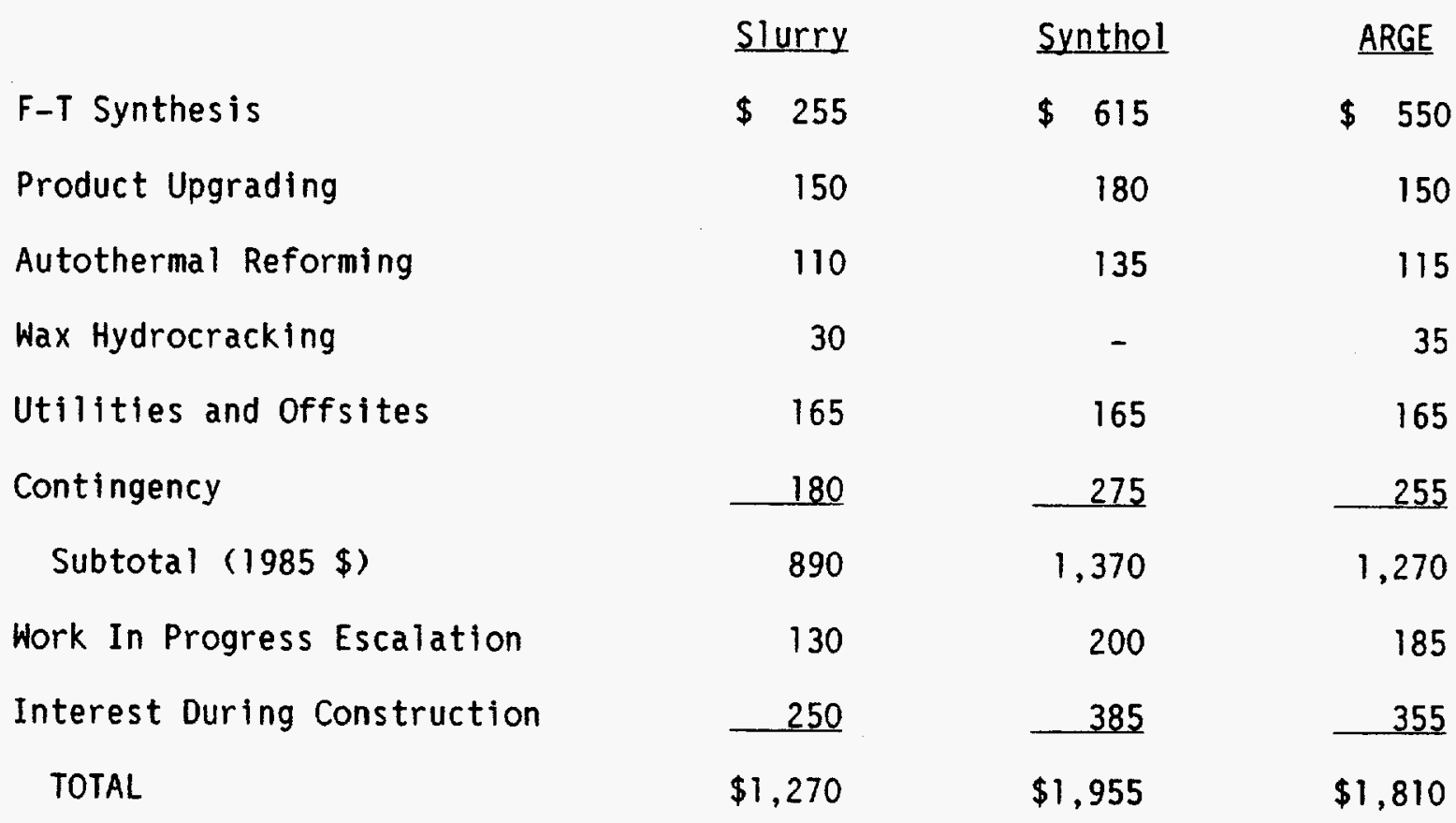

NOTE:

(1) Excludes investment for synthesis gas production. Purchase of synthesis gas is treated as an operating cost in Table VIII-2. 


\section{Table VIII-2}

Annual Costs for Fischer-Tropsch Synthes is (MM $\$ / Y e a r)$ Nominal Plant Capacity 40,000 bbl/day

(1990 Onstream)

\begin{tabular}{|c|c|c|c|}
\hline & slurry & Synthol & ARGE \\
\hline Synthes is Gas $(1)$ & 416 & 332 & 352 \\
\hline Other Operating & 106 & 139 & 141 \\
\hline Capital Related(2) & $\underline{330}$ & $\underline{508}$ & $\underline{471}$ \\
\hline Total 1990 Required Revenue & 852 & 979 & 964 \\
\hline Projected 1990 Revenues & 495 & 481 & 495 \\
\hline Revenue Shortfall & 357 & 498 & 469 \\
\hline Revenue Shortfall ( $\$ / b b l$ Product) & 25 & 36 & 34 \\
\hline
\end{tabular}


The facility was sized to produce a nominal $40,000 \mathrm{bbl} /$ day of liquid fuels. This was done to keep the product upgrading section in the same relative size and keep the required equipment consistent. The required offsites and utilities also remained constant. In addition, only the equipment in the $F-T$ reaction section was estimated, since this is the section of the plant where major changes took place. This method is consistent with the previous study. There was also a difference in the process conditions of the $F-T$ synthesis section that had an impact on the F-T section only. A flow sheet depicting the overall process flow diagram is presented in Figure VIII-1.

The cost basis for the capital estimate was in 1990 dollars with costs and revenues projected to 1995 and 2000 . The projected revenues will be recalculated to reflect current costs.

\section{VIII.4. CATALYST COMPARISON}

A comparison of each catalyst in each case is summarized in Table VIII-3. One important difference is the $\mathrm{H}_{2} / \mathrm{CO}$ ratio of 0.92 used in the original study compared to the $\mathrm{H}_{2} / \mathrm{CO}$ ratio of 0.67 used in the other two cases. One effect of the lower $\mathrm{H}_{2} / \mathrm{CO}$ ratio is that the original catalyst would probably not function effectively with this syngas feed composition. This lower ratio reflects syngas produced from coal rather than natural gas, and is somewhat more expensive than the higher ratio syngases when all are produced from natural gas.

An important result of Professor Burkur's work is that the silica-supported, iron-based catalysts operated in the slurry mode at much lower pressures (225 psia vs. $315 \mathrm{psia}$ ) and that the conversions were much higher $(50 \%$ vs. $14 \%$ ) in the experimental apparatus. One drawback based on these results was the slightly lower conversion to hydrocarbons $(28 \%$ vs. $31 \%)$. The higher conversion rate caused the recycle stream to be much smaller, about $12 \%$ of the feed stream, than the original case, about $60 \%$ of the feed stream. In all cases, $95 \%$ of the syngas fed from the syngas unit was converted per pass (excluding the recycle stream) and $5 \%$ was purged. The F-T synthes is reactor output, though not exact, was very similar for each catalyst under the conditions tested. Approximately $10 \mathrm{wt} \%$ of the hydrocarbon products were $\mathrm{Cl}^{\prime} \mathrm{s}$ and $C 2$ 's recycled back to synthes is gas through the autothermal reformer.

\section{VIII.5. SYNTHESIS GAS PRODUCTION}

For the original catalyst case, the $\mathrm{H}_{2} / \mathrm{CO}$ ratio was assumed to be 0.92 based on the lab experiments made for the 1985 study. These conditions were kept the same for this study. Given the past finding, where the cost of synthesis gas from coal was up to three times that for synthesis gas from natural gas, this study also assumed natural gas as a feedstock to the synthesis gas production unit. In the catalyst testing work reported earlier, the new and commercial catalysts were tested with syngas streams having a $\mathrm{H}_{2} / \mathrm{CO}$ feed ratio of 0.67 . The 1985 report also found that, in cases with $10 \mathrm{~W} \mathrm{H}_{2} / \mathrm{CO}$ ratios $(<2)$, and this synthesis gas, a POX of natural gas was the preferred route. The crude synthesis gas is then treated in a $\mathrm{CO}_{2}$ removal unit (i.e., $M E A)$, where a $\mathrm{CO}_{2}$ stream is recycled to the POX unit, and is further treated in a cryogenic unit (HYCO) to achieve the above $\mathrm{H}_{2} / \mathrm{CO}$ ratio. 


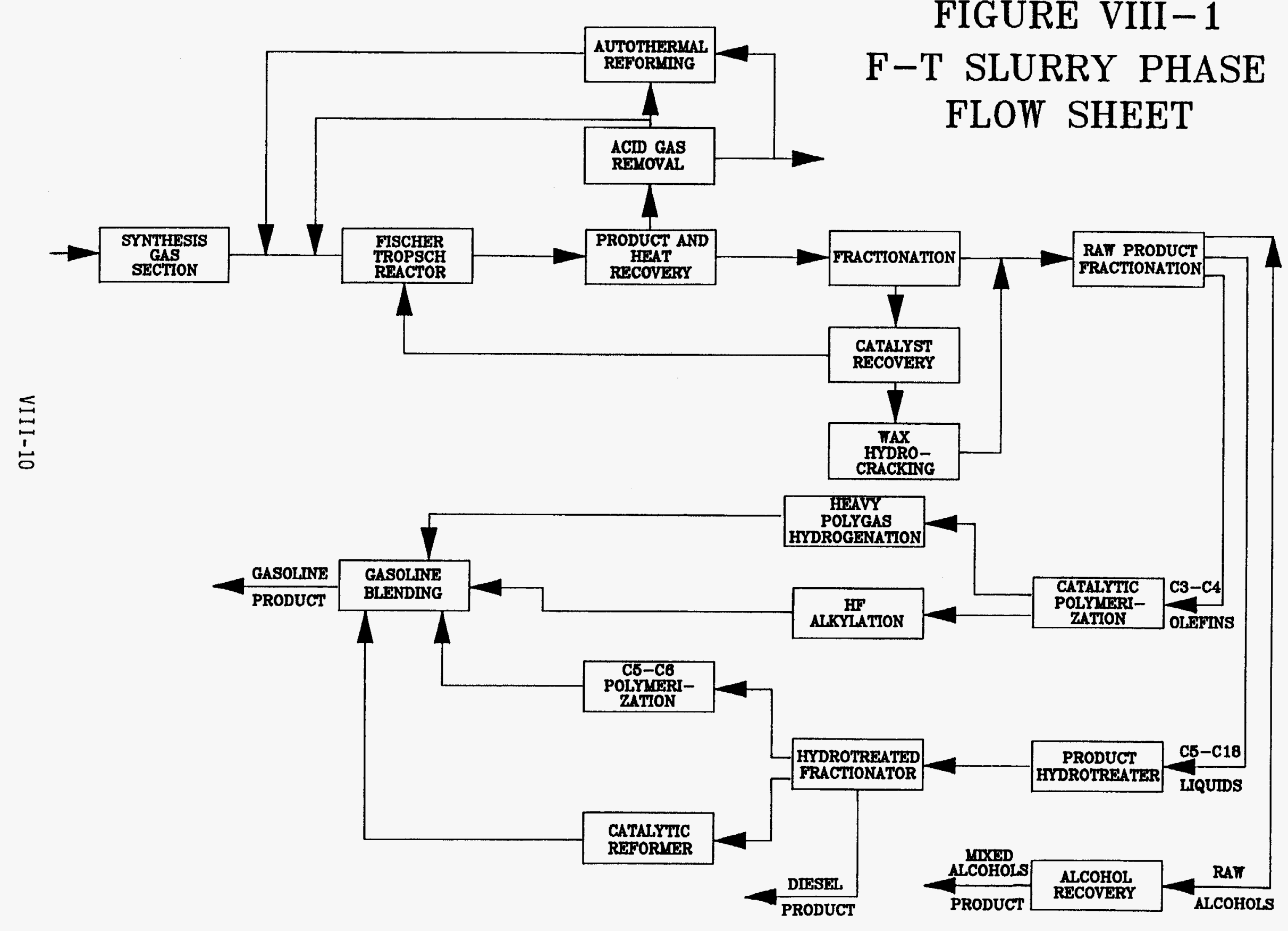


Table VIII-3

\section{Catalyst Comparison}

\section{Catalysts:}

$\mathrm{H}_{2} / \mathrm{CO}$ Ratio (molar)

Reactor Pressure (psia)

Reactor Temperature $\left({ }^{\circ} \mathrm{C}\right)$

Experimental Conversion (\%)

Products (wt\%)

$\mathrm{CO} 2$

$\mathrm{H}_{2} \mathrm{O}$

Alcohols

Hydrocarbons
Original

.92

315

260

14

54.9

13.4

1.2

30.5
Commercial

.67

225

250

44

52

New

.67

225

250

59.9

62.0

11.7

9.1

1.5

1.1

26.9

27.8 
Synthesis gas costs are reported in this study as an operating cost, including the capital equipment. Therefore, the total plant cost reported does not include the synthesis gas plant. In this way, different syngas production methods can be evaluated easily. Synthesis gas costs ranged from $\$ 1.26 /$ MSCF for the commercial and original catalysts to $\$ 1.29 / \mathrm{MSCF}$ for the new catalyst. These values assume that credits for $\mathrm{H}_{2}$ in the purge as a fuel valve and steam from the syngas plant are obtained. Without these credits, syngas costs are about $\$ 0.17 / \mathrm{MSCF}$ higher. The syngas cost has two components: the capital equipment portion is about $\$ 0.27 /$ MSCF of syngas and the balance is natural gas feedstock cost.

\section{VIII.6. CAPITAL INVESTMENT}

The summary of the capital investment for each of the three cases is given in Table VIII-4. The methodology for developing this estimate is similar to that used to develop the original estimate. Only the equipment found in the F-T synthesis section was individually estimated based on computer simulations to size equipment and flow schemes. The estimates were made on a mid-1990 cost basis for the F-T synthesis section based on the experimentally determined performance of each catalyst. Costs for the remaining sections of the plant were determined on a 'macro' basis, that is, costs for these sections were based on total flow to that unit. Table VIII-4 gives the investment summary for the original case catalyst for both the 1985 estimate and this estimate. From this comparison, the difference in the projected and actual escalation is significant. Capital equipment is estimated to cost $27 \%$ less in actual 1990 dollars than what was projected in 1985, and represents a substantial savings. In comparing the three cases, the new catalyst case has an $11 \%$ cost savings in the F-T section and an overall capital equipment savings of $3 \%$.

These savings are not as great as one would expect from the large reduction in the recycle stream. This results from lowering the reactor's operating pressure from $315 \mathrm{psia}$ to $225 \mathrm{psia}$, which increases the actual gas volumetric flow to the point where it nearly offsets the flow rate reduction resulting from the decrease in the recycle flow rate. The net result is nearly equal to the capital equipment costs.

\section{VIII.7. REQUIRED REVENUES}

Required revenues are the amount of money that has to be generated to cover operating costs, interest related costs, and to provide a $7.5 \%$ return on investment on an after-tax basis. Operating costs are split into two categories: synthesis gas cost (includes syngas plant investment), and other operating costs, which include power, water, labor and plant overheads. These required revenues are given in Table VIII-5 for two scenarios. The first shows required revenues for natural gas valued at $\$ 1.00 / \mathrm{MMBtu}$. The second case shows required revenues for natural gas with no value ( $\$ 0 . M M B t u$ ). The original catalyst case shows the required revenues calculated for both studies. There is a large reduction in required revenues between the estimates, again largely reflecting the change in projected versus actual escalation observed. There is little difference in the required revenue between the new catalyst and the original catalyst cases. The capital related 


\section{Iable VIII-4 \\ $\frac{\text { Capital Investment Summary - \$MM }}{\text { Basis: } 1990}$}

\begin{tabular}{|c|c|c|c|c|}
\hline & oris & nal & & \\
\hline Catalysts: & $\begin{array}{l}1985 \\
\text { Study }\end{array}$ & $\begin{array}{l}1990 \\
\text { Study }\end{array}$ & Commercial & New \\
\hline F-T Synthesis & 255. & 195.2 & 185.7 & 174.0 \\
\hline Product Upgrading & 150. & 114.8 & 114.8 & 114.8 \\
\hline Autothermal Reforming & 110. & 84.2 & 102.4 & 92.2 \\
\hline Wax Hydrotreater & 30 . & 23.0 & 22.9 & 18.3 \\
\hline Utilities \& Offsites & 165. & 126.3 & 126.3 & 126.3 \\
\hline Contingency & 180. & 137.8 & 140.0 & 133.3 \\
\hline Subtotal & 890. & 681.3 & 692.1 & 658.9 \\
\hline Interest & 250. & 146.2 & 148.5 & 141.4 \\
\hline Total & 140 & 827.5 & 840.6 & 800.3 \\
\hline
\end{tabular}


Table VIII-5

$\frac{\text { Requtred Revenues (\$MM/Year) }}{\text { Basis: } 1990}$

- Natural Gas Cost e $\$ 1.00 / \mathrm{MMBtu}$

\begin{tabular}{|c|c|c|c|c|}
\hline \multicolumn{5}{|c|}{ Original } \\
\hline Catalysts & $\begin{array}{l}1985 \\
\text { Study }\end{array}$ & $\begin{array}{l}1990 \\
\text { Study }\end{array}$ & Commercial & New \\
\hline Synthesis Gas & 416. & 362.5 & 390.3 & 370.5 \\
\hline Other Operating & 106. & 48.5 & 48.5 & 48.5 \\
\hline Capital Related & 330. & 210.6 & 211.8 & 202.3 \\
\hline Total 1990 Req Revenue & 852. & 621.6 & 650.6 & 621.3 \\
\hline
\end{tabular}

- Naturar Gas cost e $\$ 0.00 / \mathrm{MMBtu}$

\begin{tabular}{lcccc} 
Catalysts: & Original & Commercial & New \\
\cline { 1 - 2 } Synthesis Gas & 89.2 & 96.0 & 94.8 \\
Other Operating & 48.5 & 48.5 & 48.5 \\
Capital Related & $\underline{210.6}$ & $\underline{211.8}$ & $\underline{202.3}$ \\
Total 1990 Req Revenue & 348.3 & 356.3 & 345.6
\end{tabular}


savings are offset by the higher syngas costs that result from the lower $\mathrm{H}_{2} / \mathrm{CO}$ ratio in the new catalyst case. The synthesis gas costing only $\$ 1.00 / \mathrm{MMBtu}$ accounts for more than $50 \%$ of these required revenues.

Table VIII-6 gives projected required revenues for 1995 and 2000 . The natural gas cost for these timeframes remains at $\$ 1.00 / \mathrm{MM}$ BTU. Natural gas costs still account for $50 \%$ of the required revenues, even though they remain constant.

\section{VIII.8. PRODUCT REVENUES}

The projected product prices and revenues based on the 1985 and 1990 estimates are shown in Table VIII-7. These values show the same result as the capital equipment estimates. That is, the actual 1990 product prices are not as high as those predicted in 1985, resulting in lower revenues. The revenue breakdown by product type for each of the three catalysts is shown in Table VIII-8 and does show that there is a slight difference in the product mix. This results from the larger price differential between gasoline and diesel fuels now than what was projected. The average price of liquid fuels is now about $\$ 24 / \mathrm{bb}$ l versus the projected price of $\$ 36 / \mathrm{bbl}$. Crude oil prices are estimated to escalate at the normal inflation rate for the next five years and about $2 \%$ in real terms for the five years beyond that (to 2000). Of course, oil and other fuel prices are a large determinate of the overall inflation rate and therefore it is somewhat difficult to predict large revenue increases without a correspondingly large, albeit lagging, increase in costs.

\section{VIII.9. RESULTS}

The results of the economic analysis are presented in Table VIII-9. The projected revenue shortfall originally estimated at $\$ 25 / b b l$ for the $F-T$ slurry mode has been reduced to $\$ 22.5 / \mathrm{bbl}$. As discussed earlier, the capital costs are estimated to be less than previous studies have shown. The catalysts have been improved, but because of pressure changes the actual equipment sizing remains about the same, so the apparent reduction in costs resulted in actual escalation being less than projected in 1985. Accordingly, this had the same effect on product revenues, which resulted in the revenue shortfall remaining about the same. In 2000, revenue shortfall is estimated to be reduced to $\$ 18 / \mathrm{bbl}$ assuming constant natural gas costs.

If natural gas were available at no cost ( $\$ 0 / \mathrm{MMBtu}$ ) the revenue shortfall in 1990 dollars is reduced to about $\$ 2 / \mathrm{bbl}$ (see Table VIII-10). For this plant to have break-even economics, product prices would have to increase by $\$ 23 / \mathrm{bbl}$ to an average price of $\$ 47 / \mathrm{bb}$ for gasoline and diesel fuels. 
Table VIII-6

Projected Revenues in 1990/1995/2000 (\$MM/Year)

Basis: Natural Gas Cost 8 \$1.0/MMBTU

\section{Catalysts:}

- 1990 Cost Basis

Synthesis Gas

Other Operating

Capital Related

Total Req Revenue

- 1995 Cost Basis

Synthesis Gas

Other Operating

Capital Related

Total Req Revenue

- 2000 Cost Basis

Synthesis Gas

Other Operating

Capital Related

Total Req Revenue

\section{Original}

Commerctal

New

48.5

210.6

621.6

390.3

48.5

211.8

650.6

370.5

48.5

202.3

621.3
390.1

63.5

272.0

725.6

426.4

83.2

361.0

870.6
420.1

399.9

63.5

63.5

276.1

263.6

759.7

727.0

459.0

438.4

83.2

83.2

366.0

350.0

908.2

871.6 


\section{Table VIII-7}

1990 Product Prices \& Revenues Based on 1985 Projection Vs 1990 Projection

- 1990 Product Price ( $\$ / \mathrm{bbl})$

1985 Projection

C3

C4

$\mathrm{C} 5-\mathrm{Cll}$

$\mathrm{C} 12-\mathrm{Cl} 8$

17.40

21.00

36.60

36.12

- 1990 Projected Revenue (\$MM/Year)

Catalysts:

1985 Projected

1990 Projected
Original

475.1

320.5
Commercial

474.8

317.2
New

475.0

322.1 
Table VIII-8

Product Revenue Breakdown $(\%)$

1990 Cost Basis

$\begin{array}{lccc}\text { Catalysts: } & \text { Original } & \text { Commercial } & \text { New } \\ \text { C3 } & 1.1 & 1.2 & 1.1 \\ \text { C4 } & 0.2 & 0.3 & 0.2 \\ \text { C5 }- \text { C11 } & 45.0 & 51.5 & 48.8 \\ \text { C12 - C18 } & 53.7 & 47.1 & 49.8 \\ \text { TOTAL } & 100.0 & 100.0 & 100.0\end{array}$




\section{Table VIII-9}

\section{Product Cost Summary - \$MM \\ Basis: Natural Gas Cost $\$$ \% $\$ 1.0 /$ MBtu}

\section{Catalysts:}

- 1990 Cost Basis

Annual cost

Product Revenue

Revenue Shortfall (\$MM)

$\langle \$ / \mathrm{bbl})$
Original

621.6

$\underline{320.5}$

301.1

22.7

725.6

418.9

306.7

23.1

$(\$ / b b 1)$
Annual Cost

Product Revenue

Revenue Shortfall (\$MM)

- 2000 Cost Basis

Annual cost

Product Revenue

Revenue Shortfall (\$MM)

$(\$ / \mathrm{bbl})$
870.6

629.9

240.7

18.1
Commercial

New
621.3

$\underline{322.1}$

299.2

22.5

25.5

759.7

727.0

414.6

421.0

345.1

26.0

306.0

23.1

$908.2 \quad 871.6$

$\underline{623.4}$

633.0

284.8

21.5

238.6

18.0 


\section{Table VIII-10 \\ $\frac{\text { Product Cost Summary }-\$ M M}{\text { Basis: } 1990 \text { Cost }}$}

Catalysts: $\quad$ Original Commercial New

- Natural Gas Cost $\$ 11.00 / M M B t u$

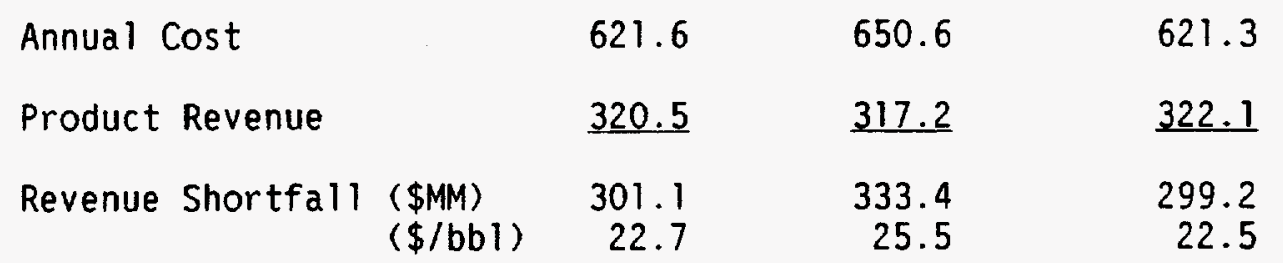

- Natural Gas Cost e \$0.00/MMBtu

$\begin{array}{lrrrr}\text { Annual Cost } & & 348.3 & 356.3 & 345.6 \\ \text { Product Revenue } & \underline{320.5} & \underline{317.2} & \underline{322.1} \\ \text { Revenue Shortfall }(\$ M M) & 27.8 & 39.1 & 23.5 \\ & (\$ / \mathrm{bb}) & 2.1 & 2.9 & 1.8\end{array}$




\section{REFERENCES}

Albal, R. S.; Shah, Y. T.; Carr, N. L.; Bell, A. T. "Mass Transfer Coefficients and Solubilities for Hydrogen and Carbon Monoxide under Fischer-Tropsch Conditions", Chem. Eng. Sci. $1984,39,905-907$.

Amelse, J. A.; Butt, J. B.: Schwartz, L. J. "Carburization of Supported Iron Synthesis Catalysts". J. Phys. Chem. 1978, 82, 558-563.

Anderson, R. B.; Seligman, B.; Schultz, J. F.; Elliot, M. A. "Fischer-Tropsch Synthesis. Some important variables of the synthesis on iron catalyst". Ind. Eng. Chem. 1952, 44, 391-397.

Anderson, R. B. "Catalysts for the Fischer-Tropsch Synthesis". In Catalysis; Emmett, P. H., Ed.; Van Nostrand-Reinhold: New York, 1956; Vol. IV, 29-255.

Anderson, R. B. The Fischer-Tropsch Synthesis; Academic Press: Orlando, Fla., 1984.

Arakawa, H.; Bell, A. T. "Effect of potassium promotion on the activity and selectivity of iron Fischer-Tropsch Catalyst". Ind. Eng. Chem. Proc. Des. Dev. 1983, 22, 97-103.

Atwood, H. E.; Bennett, C. O. "Kinetics of the Fischer-Tropsch Reaction over Iron", Ind. Eng. Chem. Process Des. Dev. 1979,18, 163-170.

Benziger, J.; Madix, R. "The Effects of Carbon, Oxygen, Sulfur and Potassium adlayers on CO and $\mathrm{H}_{2}$ adsorption on Fe (100)". Surf. Sci. 1980, 94, 119-153.

Blanchard, F.; Reymond, J. P.; Pommier, B.; Teichner, S. J. "On the Mechanism of the Fischer-Tropsch Synthesis Involving Unreduced Iron Catalyst". J. Mol. Catal. 1982, 17, 171-181.

Bohlbro, H. "An Investigation on the Kinetics of the Conversion of Carbon Monoxide with Water Vapour over Iron Oxide Based Catalysts", Haldor Topsøe, Vadbak, Denmark (1969).

Bonzel, H. P.; Krebs, H. "Enhanced Rate of Carbon Deposition during Fischer-Tropsch Synthesis on K Promoted Fe". Surf. Sci. 1981, 109, L527-L531.

Bukur, D. B.; Brown, R. F. "Fischer-Tropsch Synthesis in a Stirred Tank Reactor - Reaction Rates", Can. J. Chem. Eng. 1987, 65, 604-612.

Bukur, D. B.; Lang, X.; Rossin, J. A.; Zimmerman, W. H.; Rosynek, M. P.; Yeh, E. B.; Li, C. "Activation Studies with a Promoted Precipitated Iron Fischer-Tropsch Catalyst". Ind. Eng. Chem. Res. 1989, in press.

Deckwer, W.-D.; Serpemen, Y.; Ralek, M.; Schmidt, B. "Fischer-Tropsch Synthesis in the Slurry Phase on Mn/Fe Catalysts". Ind. Eng. Chem. Process Des. Dev. 1982, 21, 222-231.

Dictor, R. A.; Bell, A. "Fischer-Tropsch Synthesis over Reduced and Unreduced Iron Oxide Catalysts". J. Catal. 1986, 97, 121-136.

Donnelly, T. J.; Yates, 1. C.; Satterfield, C. N. "Analysis and Prediction of Product Distributions of the Fischer-Tropsch Synthesis". Energy and Fuels 1988, 2, 734-739.

Donnelly, T. J.; Satterfield, C. N. "Product Distributions of the Fischer-Tropsch Synthesis on Precipitated Iron Catalysts". Appl. Catal. 1989, in press.

Dry, M. E.; Oosthuizen, G. J. "The Correlation between Catalyst Surface Basicity and Hydrocarbon Selectivity in the Fischer-Tropsch Synthesis". J. Catal. 1968, 11, 18-24.

Dry, M. E.; Shingles, T.; Boshoff, L.; Oosthuizen, G. J. "Heat of Chemisorption on Promoted Fe Surfaces and the Role of Alkali in Fischer-Tropsch Synthesis". J. Catal. 1969, 15, 190-199. 
Dry, M. E., Shingles, T.; Boshoff, L. J. "Rate of the Fischer-Tropsch Reaction Over Iron Catalysts", J. Catal. 1972 25, 99-104.

Dry, M. E. "Advances in Fischer-Tropsch Chemistry", Ind. Eng. Chem. Prod. Res. Dev. $1976,15,282-286$.

Dry, M. E. "The Fischer-Tropsch Synthesis". In Catalysis Science and Technology 1; Anderson, J. R.; Boudart, M., Eds.; Springer-Verlag:New York, 1981, 159-255.

Dweyer, D. J.; Hardenbergh, J. H. "The Catalytic Reduction of Carbon Monoxide over Iron Surfaces: A Surface Science Investigation". J. Catal. 1984, 87, 66-76.

Dwyer, D. J., in "Catalyst Characterization Science" (Deviney, M. L., and Gland, J. L., eds.), ACS Symposium Series 288, ACS, Washington (1985).

El Sawy, A.; Gray, D.; Neuworth, M.; Tomlinson, G. "A Techno-Economic Assessment of the Mobil Two-Stage Slurry Fischer-Tropsch/ZSM-5 process", The MITRE Co., DOE Final Report, Contract No. 58-0336, 1984.

Farley, R.: Ray, D. J." The Design and Operation of a Pilot-Scale Plant for Hydrocarbon Synthesis in the Slurry Phase". J. Inst. Petroleum 1964, 50, 27-31.

Feimer, J. L.; Silveston, P. L.; Hudgins, R. R. "Steady-State Study of the Fischer-Tropsch Reaction", Ind. Eng. Chem. Prod. Res. Dev. 1981,20, 609-615.

Gray, D.; Lytton, M.; Neuworth, M.; Tomlinson, "The Impact of Developing Technology on Indirect Liquefaction", The MITRE Co., DOE Final Report, Contract No. EF-77C01-2738, 1984

Hansen, M. "Constitution of Binary Alloys", McGraw-Hill, New York (1958).

Hofer, L. J. E. "Crystalline Phases and Their Relation to Fischer-Tropsch Catalysts". In Catalysis; Emmett, P. H., Ed.; Van Nostrand-Reinhold: New York, 1956; Vol. IV, 373-441.

Huang, S. T.; Lin, H.; Tsai, F.; Chao, K. "Solubility of Synthesis Gases in Heavy n-Paraffins and Fischer-Tropsch Wax", Ind. Eng. Chem. Res. 1988, 27, 162-169.

Huff, G. A., Jr.; Satterfield, C. N. "Intrinsic Kinetics of the Fischer-Tropsch Synthesis on a Reduced Fused-Magnetite Catalyst", Ind. Eng. Chem. Process Des. Dev. 1984a, 23, 696-705.

Huff, G. A., Jr.; Satterfield, C. N. "Some Kinetic Design Considerations in the Fischer-Tropsch Synthesis on a Reduced Fused-Magnetite Catalyst". Ind. Eng. Chem. Process Des. Dev. 1984b, 23, 851-854.

Huff, G. A., Jr.; Satterfield, C. N. "Evidence for Two Chain Growth Probabilities on Iron Catalysts in the Fischer-Tropsch Synthesis". J. Catal. 1984c, 85, 370-379.

Itoh, H.; Hosaka, H.; Ono, T.; Kikuchi, E. "Properties and Product Selectivities of Iron Ultrafine Particles as a Catalyst for Liquid Phase Hydrogenation of Carbon Monoxide". Appl. Catal. 1988, 40, 53-66.

Jones, A.; McNicol, B. "Temperature-Programmed Reduction for Solid Materials Characterization". Marcel Dekker, Inc., New York (1986).

Kölbel, H.; Engelhardt, F. "The Reaction Mechanism of the Fischer-Tropsch Synthesis". Erdoel Kohle 1949, 2, 52-59.

Kölbel, H.; Ackermann, P.; Ruschenburg, E., Langheim, R.; Engelhardt, F. "Beitrag zur Fischer-Tropsch Synthese on Eisenkontakten". Chem. Ing. Technik. 1951, 23, 153-157. 
Kölbel, H.; Ackerman, P.; Engelhardt, F. Proc. Fourth World Petroleum Congress, Section IV/C. P. 227, Carlo Colombo Publishers, Rome (1955).

Kölbel, H. "Kalium als Strucktureller und Energetischer Promotor in Eisenkatalysatoren". In Actes du Deuxieme Congres International de Catalyse, Vol. II, Paris 1960, 2075-2099.

Kölbel, H.; Giehring, H. "Zur Wirkung von Alkali-Promotoren auf Eisenkatalysatoren ". Brennstoff-Chemie 1963, 44, 343-369.

Kölbel, H.; Ralek, M. "The Fischer-Tropsch Synthesis in the Liquid Phase". Catal. Rev.-Sci. Eng. 1980, 21, 225-274.

Kuo, J. C. W., et al. Slurry Fischer-Tropsch/Mobil Two Stage Process of Converting Syngas to High Octane Gasoline; Final Report DOE Contract No. DE-AC22-80PC30022; Mobil Research and Development Corp: Paulsboro, N. J. 1983.

Kuo, J. C. W. "Two Stage Process for Conversion of Synthesis Gas to High Quality Transportation Fuels". Final Report DOE Contract No. DE-AC22.83PC 600 019, 1985.

Leib, T. B.; Kuo, J. C. W. "Modeling the Fischer-Tropsch Synthesis in Slurry Bubble-Column Reactors", Paper presented at the AIChE Annual Meet., San Francisco, Calif. (Nov. 25-30, 1984).

Li, C. Effect of Potassium and Copper Promoters on Reduction Behavior of Precipitated Iron Catalysts; Ph.D. Thesis; Texas A\&M University: College Station, Tex., 1988.

Lund, C. R. F.; Dumesic, J. A."Strong Oxide-Oxide Interactions in Silica-Supported $\mathrm{Fe}_{3} \mathrm{O}_{4}$ ". J. Catal. 1981, 72, 21-30.

Madon, R. J.; Taylor, W. F. "Fischer-Tropsch Synthesis on a Precipitated Iron Catalyst". J. Catal. 1981, 69, 32-43.

Malessa, R.; Baerns, M. "Iron/Manganese Oxide Catalysts for Fischer-Tropsch Synthesis Activity and Selectivity". Ind. Eng. Chem. Res. 1988, 27, 279-283.

Matsumoto, D. K.; Satterfield, C. N. "Solubility of Hydrogen and Carbon Monoxide in Selected Nonaqueous Liquids". Ind. Eng. Chem. Process Des. Dev. 1985,24, 1297-1300.

Mitra, A.; Roy, A. "Performance of Slurry Reactor for Fischer-Tropsch and Related Synthesis". Indian Chem. Engr. 1963, 127-142.

Murata, Y. J. Soc. Chem. Ind. Japan 1942, 45, 288.

Niemantsverdriet, J. W.; van der Kraan, A. M.; van Dijk, W. L.; van der Baan, H. S. "Behavior of Metallic Iron Catalysts during Fischer-Tropsch Synthesis Studied with Mössbauer Spectroscopy, X-ray Diffraction, Carbon Content Determination, and Reaction Kinetic Experiments". J. Phys. Chem 1980, 84, 3363-3370.

Niemantsverdriet, J. W.; van der Kraan, A. M. "On the Time-Dependent Behavior of Iron Catalysts in Fischer-Tropsch Synthesis". J. Catal. 1981, 72, 385-388.

Nettelhoff, H.; Kokuun, R.; Ledakowicz, S.; Deckwer, D. W. "Studies on the Kinetics of Fischer-Tropsch Synthesis in Slurry Phase". Ger. Chem. Eng. 1985, 8, 177-185.

Newsome, D. S. "The Water-Gas Shift Reaction", Catal. Rev.-Sci. Eng. 1980, 21, 275-318.

Pennline, H. W.; Zarochak, M. F.; Stencel, J. M.; Diehl, J. R. "Activation and Promotion Studies in a Mixed Slurry Reactor with an Iron-Manganese Fischer-Tropsch Catalyst". Ind. Eng. Chem. Res. 1987, 26, 595-601.

Peter, S.; Weinert, M. "Solubility of $\mathrm{H}_{2}, \mathrm{CO}, \mathrm{CO}_{2}$, and Water Vapor in Liquid Hydrocarbons". 
Z. Phys. Chem. N. F. 1955, 5, 114-121.

Pichler, H. "Twenty-five Years of Synthesis of Gasoline by Catalytic Conversion of Carbon monoxide and Hydrogen". In Adv. in Catal. 4; Frankenburg, W. G.; Komarewsky, V. I; Rideal, E. K., Eds.; Academic: New York, 1952, pp. 271-341.

Poutsma, M." Assessment of Advanced Process Concepts for Liquefaction of Low $\mathrm{H}_{2}$ :CO Ratio Synthesis Gas Based on the Kölbel Slurry Reactor and the Mobil-Gasoline Process". Oak Ridge National Laboratory Report 5635 (1980).

Raupp, G. B.; Delgass, W. N. "Mössbauer Investigation of Supported Fe and FeNi Catalysts II. Carbides Formed by Fischer-Tropsch Synthesis". J. Catal. 1979, 58, 348-360.

Reymond, J. P.; Mériaudeau, P.; Teichner, S. J. "Changes in the Surface Structure of an Iron Catalyst of Reduced or Unreduced $\mathrm{Fe}_{2} \mathrm{O}_{3}$ during the Reaction of Carbon Monoxide and Hydrogen". J. Catal. 1982, 75, 39-48.

Sakai, T.; Kunugi, T. "Liquid Phase (Slurry) method for Fischer-Tropsch Synthesis". Sekiyu Gakkai Shi 1974, 17 (10), 863-868.

Satterfield, C. N.; Hanlon, R. T.; Tung, S. E.; Zou, Z.; Papaefthymiou, G. C. "Initial Behavior of a Reduced Fused-Magnetite Catalyst in the Fischer-Tropsch Synthesis". Ind. Eng. Chem. Prod. Res. Dev. 1986a, 25, 401-407.

Satterfield, C. N.; Hanlon, R. T.; Tung, S. E.; Zou, Z.; Papaefthymiou, G. C. "Effect of Water on the Iron-Catalyzed Fischer-Tropsch Synthesis". Ind. Eng. Chem. Prod. Res. Dev. 1986b, 25, 407-414.

Satterfield, C. N. "Fischer-Tropsch Slurry Phase Process Variations to Understanding Wax formation". Proc. of 7th Indirect Liquefaction Contractors Meeting, Pittsburgh, Dec. 7-9, 1987, 69-85.

Schultz, J. F.; Hall, W. K.; Seligman, B.; Anderson, R. B. "The Fischer-Tropsch Synthesis. XIV. Hägg Carbide as Catalyst". J. Am. Chem. Soc. 1955, 77, 213-221.

Schulz, H.; Rosch, S.; Gokcebay, H. "Selectivity of the Fischer-Tropsch Co-Hydrogenation" Proc. 64th C. I. C. Coal Symp.; Taweed, A. M. Al., Ed.; Ottawa, 1982.

Schulz, H.; Gokcebay, H. "Fischer-Tropsch CO-Hydrogenation as a Means for Linear Olefins Production" In Catalysis of Organic Reactions, Kosak, J. R., Ed., Dekker: New York, 1984.

Storch, H. H.; Golumbic, H.; Anderson, R. B. The Fischer-Tropsch and Related Syntheses; Wiley: New York, 1951.

Thompson, G. J.; Riekena, M. L.; Vickers, A. G. Comparison of Fischer-Tropsch Reactor Systems - Phase 1; Final Report DOE Contract No. DE-AC01-78ET10159; UOP, Inc: Des Plains, III., 1981.

Wachs, I. E., Duyer, D. J., Iglesia, E. "Characterization of Fe, Fe- $\mathrm{Cu}$, and Fe-Ag FischerTropsch Catalysts". Appl. Catal. 1984, 12, 201-217.

Zarochak, M. F.; McDonald, M. A. "Slurry-Phase Fischer-Tropsch Synthesis". In Sixth DOE Indirect Liquefaction Contractors' Meet. Proc.; Pittsburgh, Dec 2-4, 1986; 58-82.

Zarochak, M. F.; McDonald, M. A. "A Study of Iron Fischer-Tropsch Catalysts". In Seventh DOE Indirect Liquefaction Contractors' Meet. Proc.; Pittsburgh, Dec 7-9, 1987; 96-121. 
Appendix 1

ECONOMIC COMPARISON

OF

INOIRECT LIQUEFACTION PROCESSES

A. R. Kuhns/C. Ebihara

20 November 1985

A.1-1 


\section{EXECUTIVE SUMMARY}

A study of the economics of liquid fuels production by Fischer-Tropsch ( $F-T$ ) processing was initiated for two purposes. The first was to provide assistance in assessing the near to intermediate term potential for commercial production of liquid fuels by indirect liquefaction based on relatively cheap remote natural gas. The second was to examine the economics of slurry $F-T$ processing versus the economics of two existing processes, entrained bed Synthol and fixed bed ARGE.

The principal results of this study are:

(1) None of the cases appears profitable for a nominal 40,000 88L/0 facility coming onstream in 1990, regardless of the value assigned to natural gas.

(2) The slurry case appears to have an advantage over synthol and ARGE. This advantage is primarily rooted in the relative capital costs of the $F-T$ synthesis areas.

These results are discussed further below.

\section{Synthesis Gas Production}

The initial step in this evaluation was to choose the appropriate synthesis gas production process for each F-T process. The plant size for this commercial production facility was chosen as 875 MM SCFD of synthesis gas for each case. This choice was based on some recently published studies of commercial F-T plants. Both steam methane reforming followed by a Prism membrane and partial oxidation of the natural gas were investigated. The results indicated that for a natural gas price of $\$ 1.00 / M M B T U$, the slurry and ARGE synthesis gas compositions could best be supplied by partial oxidation of the gas while the Synthol synthesis gas composition could best be supplied by steam methane reforming. The synthesis gas production economics are tabulated below for plants coming onstream in 1990 .

\section{Slurry Synthol ARGE}

Molar $\mathrm{H}_{2} / \mathrm{CO}$ Ratio Required Preferred Process

Required Investment (MM \$)

0.9

POX

$\$ 871$

Synthesis Gas Transfer Price (\$/MSCF)
2.0

SMR

$\$ 453$

$\$ 1.15$
1.7

POX

$\$ 772$

$\$ 1.22$

Additional synthesis gas production cases based on coal gasification were also developed as a sensitivity. These cases were based on a midwestern coal valued at $\$ 1.50 / M M B T U$. The synthesis gas from the gasification facilities costs nearly $\$ 5.00 / M S C F$. The synthes is gas for the slurry case from coal was somewhat cheaper relative to the other cases since the low $\mathrm{H}_{2} / \mathrm{CO}$ ratio requites less CO shifting. 


\section{F-T Synthesis and Product Upgrading}

The next step in the evaluation was to develop economics for the $F-T$ synthes is loop and the product upgrading sections. Computer simulations were performed for the synthesis loop for the slurry. Synthol and ARGE cases. This enabled some preliminary equipment sizing to be done for this area.

While costs were developed for major pieces of equipment in the synthesis loop itself, costs were developed on a macro basis (i.e., total flow to a unit) for the product upgrading units. Since it was desirable to produce an all liquid product slate, $C_{1}$ 's and $C_{2}$ 's from $F-T$ synthesis were sent to an autothermal reformer where they were processed to synthes is gas which would be sent to F-T synthesis for additional liquids production.

The results of the economic analysts are tabulated below. The table gives capital costs and annual revenues required for $F-T$ synthesis and product upgrading for the three cases based on a nominal $40,000 \mathrm{BBL} / 0$ facility coming onstream in 1990. The required revenues provide for covering the costs plus a 7.5\% net profit after tax on investment. Also tabulated are projected 1990 revenues and the revenue shortfall for each case. The projected revenues are based on product prices obtained from Corporate Energy.

\begin{tabular}{lccc} 
& \multicolumn{3}{c}{40,000 BBL/D } \\
\cline { 2 - 4 } & Siurry & Synthol & ARGE \\
& & & \\
Capital Investment (MM \$) & 1,270 & 1,955 & 1,810 \\
Required Annual Revenues (MM \$) & 852 & 979 & 964 \\
Projected Revenues (MM \$) & 495 & 481 & 495 \\
Revenue Shortfal1 (MM \$) & 357 & 498 & 469 \\
Revenue Shortfal1 (\$/BBL Output) & 25 & 36 & 34
\end{tabular}

Although the slurry case appears to be the most attractive of the three cases, the above tabulation predicts that none would be profitable. In fact, none would be profitable even if natural gas was assigned a value of zero. The projected 1990 revenues for each case are about $\$ 35 / B B L$. The revenues need to be about \$60/BBL for the slurry case and about \$70/BBL for the synthol and ARGE cases. The advantage for the slurry case is based on a distinct capital cost advantage in the $F-T$ synthesis loop.

The sensitivity cases based on coal gasification proved to be prohibitively expensive. For each of these cases a revenue shortfall in excess of one billion dollars annually was predicted for a 1990 onstream plant.

\section{Total Plant Investment}

The synthesis gas production and $F-T$ synthesis and product upgrading sections have been treated separately in an effort to better fllustrate the differences among the cases. The approximate total capital investment for the gas based facllities are as follows for 1990 onstream:

$\begin{array}{ll}\text { Slurry } & \$ 2.7 \text { b } 117 \text { ion } \\ \text { Synthol } & \$ 2.4 \text { billion } \\ \text { ARGE } & \$ 2.6 \text { b } 171 \text { ion }\end{array}$


Comparison with Mobil MTG and LNG

A comparison was also made involving the Mobil MTG process and the $F-T$ processes. A revenue shortfall approximately equivalent to the slurry case was predicted for the MTG process on a dollars per barrel of output basis. since it was not possible to ensure that the economic data for the $F-T$ cases and the Mobil MTG case were on a totally consistent basis, some reservations must be expressed concerning the conclusion of economic equivaience between MTG and F-T slurry.

The distinction between indirect liquefaction and LNG appears to be more clear-cut. A recent SRI International (9) study indicated that \$1.00/MMBTU natural gas could be liquefied, delivered and regassified for as little as $\$ 3.00 / M M B T U$ in 1983 dollars, depending on the shipping distance. Escalation to a 1990 basis, with natural gas remaining at $\$ 1.00 / M M B T U$, would put the LNG costs in the \$3.50-4.00/MMBTU range. These LNG values were corroborated by other informatian obtained from sources within APCI. By contrast, the cost of liquid product from the slurry case in 1990 is more than $\$ 11.00 /$ MMBTU, excluding delivery. Transportation fuels should have a higher form value than gas, but this difference would not be enough to significantiy close the above gap.

\section{Recommendations for Future Work}

Further study should involve the confirmation of the projected capital cost advantage of the slurry process. In addition, even though the product yield structure for the slurry case does not appear to be a critical factor in the relative economics, these yields should be confirmed by further experimental work since the current data base at the conditions chosen for this study is somewhat limited. If initiated, this work would have to be aimed at achieving a long term payout under a scenario which shows large increases in energy values in general and diesel prices in particular over today's levels. 


\section{INTRODUCTION}

The purpose of this economic analysis is twofold. The first is to assist in the assessment of the near to intermediate term potential for commercial production of liquid fuels by indirect liquefaction based on relatively cheap remote natural gas. The second is to examine the economics of the slurry phase Fischer-Tropsch ( $F-T)$ process and catalyst versus the economics of two existing commercial F-T processes, entrained bed Synthol and fixed bed ARGE. As a sensitivity, the three F-T processes are also compared for the case where the source of the synthesis gas is gasification of midwestern coal. In addition, the economics of these three $F-T$ processes are compared to the economics of liquid fuels production from the Mobil Methanol-to-Gasoline process and also to the economics of $L N G$.

The size of the commercial facilities to be evaluated was chosen based on the flow of synthesis gas $\left(\mathrm{CO}+\mathrm{H}_{2}\right)$ to the $\mathrm{F}-\mathrm{T}$ synthesis units. This was set at 96,000 lb mole/hr (875 MM SCFD) and essentially matches the plant size chosen for an earlier F-T economic study performed for the Department of Energy by the Mitre Corporation(1). The actual parameter fixed in the Mitre study was the coal fed to the plant, however. Since the light gases ( $C_{1}$ 's and $C_{2}{ }^{\prime} s$ ) formed in the $F-T$ synthesis reaction are also reformed to synthesis gas and sent to $F-T$ reactors, the total amount of synthesis gas fed to $F-T$ reactors is somewhat different for each case. This difference is established by the relative reaction yield structures with respect to $c_{1}$ and $c_{2}$ make. The increment in liquid production resulting from the decision to reform and recycle the 1 ight gases is $15 \%$ for the slurry case, $16 \%$ for the ARGE case and $23 \%$ for the synthol case. In terms of liquid product output, each F-T case can be considered to be nominally $40,000 \mathrm{BBL} / 0$ in size.

\section{SYNTHESIS GAS PRODUCTION}

Approximately 875 MM SCFO of synthesis gas $\left(\mathrm{H}_{2}+\mathrm{CO}\right)$ is required for the three fischer-Tropsch cases which were examined. The base cases used natural gas as a feedstock. Both steam methane reforming and partial oxidation were evaluated as synthesis gas production methods. As a sensitivity, coal based synthesis gas production cases were also developed. These cases used the She 11 pressurized gasifier with midwestern coal as the synthesis gas source. Summary economics for these cases appears in Table 1.

\section{Steam Methane Reforming Versus Partial Oxidation}

Initially, it was decided that steam methane reforming of natural gas would be used. The required $\mathrm{H}_{2} / \mathrm{CO}$ molar rattos are 2.0 for Synthol, 1.7 for ARGE and 0.92 for the slurry case. PSG Economic Evaluation provided economics for these three cases. The processing scheme involved a reformer which is fed natural gas and some recycle $\mathrm{CO}_{2}$. This is followed by a Benfield acid gas removal system. At this point in the process the $\mathrm{H}_{2} / \mathrm{CO}$ molar ratio is about 3.2. A Prism membrane is used to purge sufficient hydrogen such that the required product compositions are met. It is envisioned that this hydrogen rich purge stream would be used as reformer fuel. The fuel heating value of the purge streams does not exceed the reformer fuel demand in the synthol and 
ARGE cases, but for the slurry case, the purge stream is so large that it cannot all be consumed as reformer fuel. It is uncertain that an alternate use for this hydrogen could be found in a remote location - thus, some of the fuel credits taken in the slurry case may prove to be invalid. Even with the full fuel credits, the slurry synthesis gas cost is significantly higher than the costs for the other two cases since the front end of the plant is also larger.

For these reasons, it was later decided to re-examine the route to synthesis gas production, looking instead at partial oxidation of natural gas with $\mathrm{CO}_{2}$ recycle and perhaps $\mathrm{CO}_{2}$ import. Avallable data indicated that partial oxidation with no $\mathrm{CO}_{2}$ recycle would yield an $\mathrm{H}_{2} / \mathrm{CO}$ ratio of about 1.8 . Thus, shifting a small portion of the $\mathrm{CO}$ production to $\mathrm{H}_{2}$ would be necessary to meet the composition requirements of the Synthol case $\left(2.0 \mathrm{H}_{2} / \mathrm{CO}\right)$ while recycling $\mathrm{CO}_{2}$ at a rate of about .05 mole $\mathrm{CO}_{2}$ per mole of hydrocarbon feed satisfied the ARGE composition requirement $\left(7.7 \mathrm{H}_{2} / \mathrm{CO}\right)$. The slurry case composition $(.92 \mathrm{H} / \mathrm{CO})$ can be reached by feeding imported $\mathrm{CO}_{2}$ to the unit such that the molar $\mathrm{CO}_{2}$ per mole of hydrocarbon fed is about 0.6 . Sufficient $\mathrm{CO}_{2}$ will be avaliable since it. is a product of the Fischer-Tropsch synthes is as well as the partial oxidation reaction.

PSG Economic Evaluation also provided synthesis gas economics via partial oxidation of natural gas for the three molar ratios of interest. As is evident from the table below, partial oxidation appears to be the economic cholce for facilities of this size for the slurry and ARGE cases, but the steam methane reforming option is more attractive for the Synthol case.

Molar $\mathrm{H}_{2}$ /CO Ratio

\begin{tabular}{|c|c|}
\hline \multicolumn{2}{|c|}{$\begin{array}{l}1990 \text { Onstream } \\
\text { Synthesis Gas Price (S/MSCF) (1) }\end{array}$} \\
\hline SMR/Pr $15 \mathrm{~m}$ & POX \\
\hline $\begin{array}{l}\$ 1.55 \\
\$ 1.24 \\
\$ 1.15\end{array}$ & $\begin{array}{l}\$ 1.44 \\
\$ 1.22 \\
\$ 1.22\end{array}$ \\
\hline
\end{tabular}

(1) Natural Gas Cost $=\$ 1.00 /$ MMBTU

The data for partial oxidation shown in Table 1 and summarized above may be slightiy confusing since the same synthesis gas price is projected for both the 1.7 and 2.0 molar ratios. A plot of synthesis gas price versus $\mathrm{H}_{2} / \mathrm{CO}$ ratio shown in Figure 2 shows that the minimum cost will occur at a $\mathrm{H}_{2} / \mathrm{CO}$ ratio of about 1.8 . This minimum occurs where netther $\mathrm{CO}$ shifting nor $\mathrm{CO}_{2}$ recycle is required to produce the desired molar ratio.

The chotce between synthesis gas production methods is quite sensitive to the natural gas price. Higher natural gas prices would favor partial oxidation since less gas is consumed per MM SCF of synthesis gas produced relative to 
reforming. At the chosen natural gas price of $\$ 1.00 / M M B T U$, it appears that a $1.7 \mathrm{H}_{2} / \mathrm{CO}$ molar ratio is close to the point of indifference between choosing partial oxidation or steam methane reforming. At higher $\mathrm{H}_{2} / \mathrm{CO}$ ratios, reforming would become increasingly attractive since less purging of hydrogen would be required and more co shift would be necessary with partial oxidation.

\section{Coal Gasification}

A coal based facility for synthesis gas production was investigated as a sensitivity to the base cases. The coal cases are not intended to be directly compared to the base cases since a midwestern location is envisioned for the coal based plant versus a remote location for the gas based plants. In fact, the coal price assumed for this sensitivity study ( $\$ 1.50 / M M$ BTU) is $50 \%$ more than the base price ( $\$ 1.00 / M M$ BTU) assumed for the remote gas.

It is nevertheless interesting to compare the relative synthes is gas prices for the three F-T cases resulting from coal. As the table shows, the least expensive synthesis gas is produced for the slurry case.

\author{
1990 Onstream \\ Coal Based Synthesis \\ Gas Price (\$/MSCF)
}

$\$ 4.57$

4.85

4.91

The coal cases are based on shell pressurized gasifiers which produce synthesis gas at about $400 \mathrm{psi}$. The advantage for the slurry case stems from the $0.5 \mathrm{H}_{2} / \mathrm{CO}$ ratio which is present at the gasifier outlet. Some shifting of $\mathrm{CO}$ is necessary in all cases to attain the appropriate $\mathrm{H}_{2} / \mathrm{CO}$ ratio, but the slurry case requires the lowest amount. The differences in relative costs shown above are all due to differences in capital and operating costs occurring in the shift unit and the subsequent acid gas removal. The gasification areas are identical for all three cases.

\section{FISCHER-TROPSCH PROCESS DESCRIPTION}

\section{Reaction Area}

Synthesis gas with the appropriate $\mathrm{H}_{2} / \mathrm{CO}$ ratio is fed to the $\mathrm{F}-\mathrm{T}$ reactors. A slurry reactor is used for the slurry process while the Synthol process uses an entrained bed and the ARGE process employs a fixed bed.

The slurry reactor essentially acts as a bubble column. The liquid phase is molten wax. Preheated feed gas is sparged into the reactor at the bottom of the column. The coprecipitated $\mathrm{Fe} / \mathrm{Cu} / \mathrm{K}$ catalyst in the liquid phase is suspended by the motion of the gas bubbles. The heat generated is removed by stean generating heat exchangers located in the slurry. The slurry process was designed to operate at $500^{\circ} \mathrm{F}$ and $315 \mathrm{ps}$ la. The catalyst is separated from the molten wax by sequential settling and filtration operations. The recycle gas to feed gas ratio is about 0.6 . 
The Synthol process uses entraineo bed reactors. The feed gases and catalyst mixture enters at the bottom and are entrained overhead following the reaction. Heat exchangers using recirculating ofl for cooling are installed in the reaction zone. Following the reaction zone is a catalyst setting hopper. Within this hopper are cyclones which serve to separate the reaction gases from the catalyst. To contain the circulating catalyst, a standpipe is also necessary. This process uses a fused iron catalyst. The catalyst recirculation rate is about 27,500 tons $/ \mathrm{hr}$. The synthes is reaction is carried out at temperatures of about $600^{\circ} \mathrm{F}$. The reaction pressure is about 315 psia. The recycle gas to feed gas ratio is about 2. Both these conditions suppress the formation of higher liquid hydrocarbons which would prevent stable operation of the reactors.

The ARGE reactor design for this evaluation is 5 imilar to that of the existing ARGE reactors at Sasol I except that each reactor in the current design contains two tube bundles in series compared to one bundle for the Sasol I reactors. Each bundle contains about 2800 tubes of 2 inches diameter and 40 feet length. The tubes are filled with promoted iron catalyst. The reaction temperature varies from about $390^{\circ} \mathrm{F}$ to $480^{\circ} \mathrm{F}$ and is slowly increased during operation in order to maintain a constant degree of synthesis gas conversion. Reaction pressure is about 355 psia. The heat generated is removed by steam generating heat exchangers in the reaction zone. Gas is recycled such that the recycle to feed gas ratio is about 2.5 . Some of the main products of the fixed bed are waxes $\left(\mathrm{C}_{19}+\right.$ material) which are collected immediately after the reactor.

Key design parameters for each process are given in Table 2, and the reaction yield structures are shown in Table 3. Major utllities for each process are summarized in Table 4. The overall processing scheme is shown in figure 1.

\section{Reaction Product Processing}

The reaction products are sent through a series of separation steps where the gaseous and liquid products are separated. The steam recovered from the highly exothermic reaction can be used to satisfy plant energy requirements, especially those of the air separation units which provide oxygen for the partial oxidation units and the autothermal reformers.

The iqquid hydrocarbion products are sent to fractionation and product upgrading units. Gaseous reaction products and unconverted synthesis gas are fed to a $\mathrm{CO}_{2}$ removal unit. Part of the clean gas is combined with makeup synthesis gas, compressed, and recycled to the $F-T$ reactors. The remaining $\mathrm{C}_{2}$ and lighter products are sent to an autothermal reformer where further synthesis gas is made. The synthesis gas is then sent to the F-T reactors to increase the overall yield of liquid products. The autothermal reformer was selected instead of partial oxidation due to the presence of olefinic components in the $F-T$ reaction products. Import $\mathrm{CO}_{2}$ is used in the autothermal reforming step to produce the required $\mathrm{H}_{2} / \mathrm{CO}^{2}$ ratio. Sufficient $\mathrm{CO}_{2}$ is formed in the $\mathrm{F}-\mathrm{T}$ reaction to satisfy any import needs of the partial oxidation and autothermal reformer units. This processing scheme produces no salable products lighter than $\mathrm{C}_{3}$. 
In the slurry and ARGE processes, substantial amounts of wax $\left(C_{79+)}\right.$ are produced. The waxes are fed to a hydrocracker, producing about $80 \%$ diesel and $15 \%$ gasoline with the remainder being gases. Since much less waxy material is made by the synthol process, it was decided to sell the $c_{19}$ - material made by this process directly without further processing.

\section{Product Upgrading Process Description}

The product upgrading scheme used in this evaluation has been modelled after the product upgrading flowsheet used in the previousiy mentioned Mitre study(1). This processing scheme is shown in Figure 3 . The raw product is split into three streams in the $F-T$ product fractionator. The light ends are sent to be autothermally reformed to produce additional synthesis gas.

Another stream, containing the $c_{3}$ and $c_{4}$ olefins, is catalytically polymerized to dimers and trimers and blended into gasoline. Isobutane and remaining $C_{3} / C_{4}$ olefins from catalytic polymerization are fed to an $H F$ alkylation unit. The product alkylate is also blended with the gasoline fractions. The light polygas from catalytic polymerization is added directly to the gasoline pool while the heavy polygas from the same unit is first hydrogenated before it is blended into gasoline.

The third major stream from the F-T product fractionator, the liquids, is sent to a hydrotreater. The hydrotreated product is then fractionated into three streams. The 1ightest fraction, composed of $C_{5}$ and $C_{6}$ components, is fed to a catalyzed isomerization unit where pentanes and hexanes are isomerized to enhance the antiknock quality of the gasoline. The $C_{7}-C_{11}$ fraction goes to a catalytic reformer, whose product is sent to gasoline blending. The heavy fraction is diesel fuel.

Alcohols are recovered in an alcohol recovery unit. Gases from catalytic and $\mathrm{C}_{5} / \mathrm{C}_{6}$ isomerization are sent to a hydrogen purification unit where hydrogen is separated from other light ends. The light ends from catalytic reforming, $C_{5} / C_{6}$ isomerization, and the hydrogen purification unit are fed to a light ends recovery unit where a gasoline blend stream is separated from LPG.

The upgraded products for the three cases are given in Table 5 . Total products are essentially the same, both on a volume basis and on a weight basis. As expected, the Synthol case has a large advantage in gasoline production whtle the slurry and ARGE cases provide more diesel fuel.

\section{ECONOMIC ANALYSIS ANO OISCUSSION OF F-T SYNTHESIS AND PRODUCT UPGRADING}

\section{Process Simulation Unit Sizing and Cost Estimation}

Process simulations of the F-T synthesis areas were developed for the three cases(11). From these simulations it was possible to estimate preliminary major equipment sizes for the F-T synthesis areas. Capital costs were then developed by roughiy estimating prices for the major equipment and factoring this major equipment estimate to obtain a total installed cost. 
Capital costs for areas outside of the synthesis loop were prepared by scaling available data for similar untts based on total flows to the unit. Process units handied in this manner include wax hydrocracking, autothermal reforming and product upgrading. Utflities and offsites were estimated as a percentage of onsites capital cost although it was decided not to attempt to differentiate among the three cases in this area.

\section{Oiscussion of Capital Costs}

The capital cost estimates for the three cases are given in Table 6 . Capital costs are shown for a plant coming onstream in 1990 and exclude the cost of the synthesis gas plant. An investment of about $\$ 1.3$ billion is estimated for the slurry plant with the ARGE and Synthol cases requiring about $50 \%$ greater capital. Each plant will produce about $40,000 \mathrm{BBL} / 0$ liquid fuels.

The primary area of projected savings for the slurry case is in the reaction area itself. Synthol is estimated to be more expensive mainly due to the tall reactors, large catalyst settling hopper and standpipe, and the extensive structure needed to support them. Higher investment for the entrained bed relative to slurry is also supported by a UOP study performed for DOE(3). Another factor in the higher investment for synthol is the higher recycle to fresh feed ratio relative to the slurry case. The higher recycle to fresh feed ratio is also a factor in the estimated higher cost of the ARGE process relative to the slurry case. The main factor in the higher ARGE cost, though, is the requirement for twice as many reactors as the slurry case and four times as many as the Synthol case. Equipment parameters for the F-T synthesis section are given in Table $A .1$ of the Appendix for each case. This table lllustrates the differences in number and size of reactors, heat exchanger surface areas, and recycle compressor sizes which are major factors in establishing the projected capital cost differences among the $F-T$ synthesis areas.

The Synthol case product upgrading and autothermal reforming sections cost more than these sections for the other processes since it produces relatively greater amounts of light ends. Conversely, the slurry and ARGE cases require wax hydrocracking because they make relatively large amounts of $\mathrm{C}_{19^{+}}$.

A specific remote location for the F-T comparison has not been selected. It has been suggested, though, that if the location were Alaska, considerable investment and operating costs could be saved by shipping the raw product in the Alaska pipeline and upgrading it at an existing refinery. Although no attempt has been made to evaluate this option, it is assumed that much of the savings would be eroded by having to accept lower prices for the raw products.

\section{Product Prices and Profected Annual Revenues}

Product prices and projected annual revenues for the year 1990 are given in Table 7. The price projections are based on information provided by APCI Corporate Energy. The total projected revenues are nearly the same for all cases with Synthol lagging the other two by about $3 \%$. Because they are so close, both in quantity and in projected value, the relative product slates do 
not significantly affect the relative economic attractiveness of the cases. A change in output for one of the cases by a few percentage points would not significantly affect its standing among the three cases. Note also that according to these price projections, gasoline and diesel are essentially valued the same on a volume basis. This is an advantage for the slurry and ARGE cases and is detrimental to Synthol.

\section{Production Costs and Required Annual Revenues}

Table 8 11lustrates the production costs and required annual revenues for the F-T cases. The required revenues are set such that operating costs are covered plus a $7.5 \%$ after tax return on investment is realized. The required revenues are then compared to the projected revenues. Although the facility is envisioned as one large plant including the synthesis gas production, for illustrative purposes the synthesis gas production costs are treated separately. Synthesis gas is then purchased by the $F-T$ plants at the appropriate transfer price shown in Table 1.

Table 8 shows that the largest operating cost for the F-T plants is the purchase of synthesis gas. Other operating costs include a balance of plant power requirements and steam credits, fuel gas, catalysts and chemicals, operating labor, and maintenance material and labor. Detalls of these costs are presented in Table A.2 of the Appendix.

The net result of these calculations is that each of the cases shows a shortfall of revenues on a 1990 onstream basis. As Table 8 shows, on a dollars per barrel of product basis, the shortfail is $\$ 25 / B B L$ for the slurry case, $\$ 36 / B B L$ for Synthol and $\$ 34 / B B L$ for ARGE. The advantage to the slurry case stems from the projected capttal savings in the F-T synthesis area which significantiy outweighs the extra cost of synthesis gas for this case.

The results essentially say that for natural gas valued at $\$ 1.00 / M M B T U$, products whose projected 1990 value is around $\$ 35 / B B L$ would need to sell at about $\$ 60 / \mathrm{BBL}$ in the slurry case and about $\$ 70 / 8 B \mathrm{~L}$ in the synthol and ARGE cases. It should also be noted that assuming a value of zero for the natural gas would not nearly eliminate the revenue shortfall. Natural gas cost comprises about $\$ 9.00 / B B L$ of the shortfall for the slurry and ARGE cases and about $\$ 13.00$ for the Synthol case.

As would be expected from the results presented above, the decision to further process the light gases formed in the F-T reaction to produce an all 1 iquid product slate is not economic in the sense that the additional capital and operating costs required exceed the additional revenues achieved by upgrading the low value gas. However. It should be pointed out that the per barrel revenue shortfall for the incremental liquids production for each case is less than the average per barrel shortfall for the total liquid production in each case. In other words, given the low value assigned to gas, an ali-liquid producing plant is more attractive economically than one producing a mixture of SNG and liquids, even though netther case is attractive on an absolute basis. In any event, the decision to produce an all-liquid product slate did not affect the ranking of the three cases economically. 
In the recent past, many proposed synthetic fuel projects used energy price projections which significantly outpaced general inflation to justify their existence. For the sake of discussion, this type of analysis can be applied here and the slurry case was chosen as an example. If the 1990 price projections are accepted as valid, and general inflation remains at $5 \%$ per annum, the product values must increase by $12 \%$ per annum over a plant operating $11 \mathrm{fe}$ of 16 years in order for the $7.5 \%$ after tax return on investment to be realized. This differential in product value growth and cost growth may not seem large, but at these escalation rates over the life of the project, revenues would increase by a factor of nearly 5.5 while costs would slightly more than double. In the above analysis the remote natural gas price was also assumed to increase at only $5 \%$ per annum which could be an optimistic assumption.

Figure 4 demonstrates that such rapid growth in energy values has occurred over the last fifteen years as it tracks the pricing of crude oil, gasoline and diesel. Also included for comparison purposes in Figure 4 is the Producer Price Index for all commodities. This index has grown by about a factor of three while crude oil, gasoline and diesel fuel have increased eight or nine fold. The key question facing synthetic fuels development work is if and when we will see a renewal of this explosive growth.

\section{Sensitivity to Coal Based Synthesis Gas Production *}

Table 8 also lliustrates the sensitivity of switching liquid fuel production by $F-T$ synthesis to a coal based plant with coal valued at $\$ 1.50 / M M B T U$. The revenue shortfall becomes much worse for all cases, ranging from about $\$ 90 / \mathrm{BBL}$ in the slurry case to about $\$ 120 / B B L$ for synthol. The slurry case is actually helped relative to other cases by switching to coal since less shifting of $c 0$ is necessary to reach the appropriate $\mathrm{H}_{2} / \mathrm{CO}$ ratio in the feed gas.

\section{Excess Steam Credits}

The F-T reaction is so highly exothermic that more than enough steam is avallable to make the plants (including synthesis gas production) self sufficient in power. Based on the assumption that no user of excess steam or power from steam would be near the remote location, the current cases were credited with only enough steam to exactly balance each plant's steam and power requirements. In reality, by superheating more of the 425 psia saturated steam which is produced in the slurry and synthol cases and condensing the 250 psia saturated steam instead of letting it down to only 30 psta in the ARGE case, the following additional power credits could be realized.

$$
\begin{array}{ll}
\text { Slurry } & 161,000 \mathrm{kw} \\
\text { Synthol } & 132,000 \mathrm{kw} \\
\text { ARGE } & 104,000 \mathrm{kw}
\end{array}
$$

The gross value of these credits at $\$ .03 / \mathrm{kwh}$ ranges from $\$ 25 \mathrm{MM}-\$ 40 \mathrm{MM}$ annually. If these credits were included in the economics, these gross values wouldn't be fully realized since additional capital and fuel gas would be needed to produce this power or power equivalent.

*A revised Product Cost Summary is located in Appendix 2. 
Comparison of F-T Processes with LNG Production

Obviously, another use for the remote gas is its conversion to LNG so that a comparison of this option to indirect liquefaction should prove to be useful. A recent SRI International study (9) indicated that natural gas valued at $\$ 1.00 / M M B T U$ could be liquefled, delivered, and regassified for as low as $\$ 3.00$ MMBTU in 1983 dollars, depending on the shipping distance. Escalation to a 1990 basis, with natural gas remaining at $\$ 1.00$ MMBTU, would put the LNG costs in the $\$ 3.50-4.00 / M M B T U$ range. These LNG values were corroborated by other information obtained from sources within APCI. In contrast, the required 1990 selling price of liquid product from the slurry case is more than $\$ 11.00 / M M B T U$, excluding delivery, so the indirect liquefaction option is not competitive with LNG on an absolute basis.

The preceding discussion does not take into account the form value of the fuel. Transportation fuels should be more highly valued than natural gas to be used as boiler fuel. The point, though, is that this enhanced valued projected for 1990 is not sufficient to make F-T attractive.

Part of what is being illustrated here is the Inherent inefficiency of indirect liquefaction. The inefficiency of synthesis gas manufacture is coupled with the inefficiency of $F-T$ synthesis such that only about one half, or even less, of the original energy is recovered as liquid products, depending on the process scheme used.

ECONOMIC COMPARISON OF THE MOBIL MTG PROCESS AND THE FISCHER-TROPSCH PROCESSES

\section{Process Description}

Figure 5 shows the overall Mobil MTG natural gas to gasoline process. Natural gas, with. Steam in a volume ratio of $1: 3$, is steam reformed to produce synthesis gas at the rate of about 875 MMSCFD. The $\mathrm{H}_{2} / \mathrm{CO}$ ratio of the synthesis gas is $4.92: 1$ and requires no $\mathrm{CO}_{2}$ recycle. The syn gas is cooled and compressed to $470^{\circ} \mathrm{F}$ and $1500 \mathrm{ps}$ i and enters the methanol reactor where it is converted to methanol using a copper based catalyst.

The crude methanol-water solution is vaporized and enters the first stage of the MTG reactor at $600^{\circ} \mathrm{F}$ and $315 \mathrm{psi}$. This reactor contains a fixed bed of activated alumina catalyst. The methanol vapor is partially dehydrated to form dimethy] ether.

The methano7-dimethyl ether stream at $650^{\circ} \mathrm{F}$ enters the second stage reactor which contains a fixed bed of ZSM-5 catalyst. Here, the methanol and dimethyl ether are completely dehydrated to light olefins and then undergo further condensation and rearrangement to form primarily gasoline-cut hydrocarbons. The conversion of methanol is highly exothermic. approximately 740 BTU/lb methanol. This heat is recovered by producing steam or by heat exchange with cooler streams. 
The hydrocarbons enter a separation train. In the first stripping coiumn, $c_{1}-c_{2}$ hydrocarbons are removed. The $c_{1}-c_{2}$ are recycled to the steam reformer. Next, the $\mathrm{C}_{3}-\mathrm{C}_{4}$ hydrocarbons are separated from the $\mathrm{C}_{5}+$ cut and sent to an aikylation unit. The raw $\mathrm{C}_{5}+$ gasoline stream is blended with alkylate and butanes to obtain the desired composition.

\section{Economics}

The economics shown in Table 9 for the MOBIL. MTG process were based on those presented in the SRI PEP Review No. 81-2-3. "Gasoline from Natural Gas Via Methanol by the MOBIL Fixed Bed MTG Process." Due to the limited data presented in the PEP review, it was impossible to accurately separate the syngas cost from the gasoline synthesis cost. For that reason, economics for the three Fischer-Tropsch processes and Mobil MTG process are presented in Table 9 starting with natural gas.

The basis for the economics in Table $g$ is a synthesis gas production rate of $96,160 \mathrm{~mole} / \mathrm{hr}(\sim 875 \mathrm{mmscfd})$. In Table 5 , we see that the three $F-T$ processes generate approximately the same output, $40,000 \mathrm{BBL} / \mathrm{day}$. The MTG process however, produces significantly lower output, $29,000 \mathrm{BBL} / \mathrm{day}$ from the same quantity of syngas. (Refer to Table 10). This results from the significantiy higher $\mathrm{H}_{2} / \mathrm{CO}$ ratio being used for MTG and from different process efficiencies.

The synthests gas cost for the Mobil MTG process $\mathrm{H}_{2} / \mathrm{CO}$ ratio of 4.92 is significantly cheaper than for the ratios required for $F-T$ synthes is and is on the order of $\$ 0.74 / \mathrm{mscf}$. This is due to the absence of a Prism unit and $\mathrm{CO}_{2}$ recycle and the lower natural gas requirements. However, the MTG process would require approximately $35 \%$ more synthesis gas to make the same output as the Fischer-Tropsch processes.

The Mobtl MTG process shows a significant shortfall of revenues between what is required and what is projected. Operation of this process under current assumptions would not be economically viable. Since the Mobil MTG process makes less product, comparison with the Fischer-Tropsch processes shows the MTG process to also have a lower absolute shortfall. However, when revenue shortfalls are compared on a per barrel of product basis or equal output basis, the slurry Fischer-Tropsch process and the MTG process are approximately the same, $\$ 25 / \mathrm{BBL}$ and $\$ 28 / \mathrm{BBL}$ respectively, and are significantly lower than those of either ARGE or synthol. Slurry Fischer-Tropsch and Mobil MTG do not currently appear to be economically viable processes, but they would be preferred over synthol and ARGE. Although we feel relatively confident in the results of this study, we cannot be completeiy assured of the consistency between estimating methods for the Fischer-Tropsch processes and the Mobil processes, due to the lack of detalls provided in the PEP report. 


\section{CONCLUSIONS ANO RECOMMENOATIONS}

(1) Based on 1990 fuel price projections, none of the liquefaction technologies studied is economically attractive.

All of the Fischer-Tropsch cases and the Mobil MTG case exhibit substantial revenue shortfalls when required revenues for profitability and projected 1990 revenues are compared. Process improvements would not provide a means to achieve profitability. What would be needed is a return to the situation where energy price increases significantly outpace general inflation or a quantum jump in prices. For example, a $12 \%$ per annum increase in liquid product values beginning in 1990 coupled with a $5 \%$ per annum escalation in costs, including naturai gas, would yield a 7.5\% NPAT in the slurry case. No natural gas price would make any of the cases profitable at the projected 1990 fuel prices.

(2) The slurry case appears attractive economically relative to the ARGE and Synthol cases.

The advantage for the slurry case is based almost entirely on the estimate of significantly lower capital costs for this synthes is loop.

(3) A corollary to the previous conciusion is that the relative product slates of the three cases are so close in both quantity and projected value that they have little impact on the relative economics. Other things being equal, the liquid yield from the slurry case would have to be decreased by about $25 \%$ to eliminate its current advantage.

(4) Introducing coal gasification as a synthesis gas source for the Fischer-Tropsch processes provides an economic advantage for the slurry case in a relative sense, but on an absolute basis all of the cases become much worse economically.

The relative advantage to slurry for a coal based factlity stems from decreased co shift requirements needed to reach the proper $\mathrm{H}_{2} / \mathrm{CO}$ feed ratio. However, the high capital investment necessary for the coal gasification facility pushes the cost of liquid fuels from any of the Fischer-Tropsch processes to prohibitive levels.

(5) Mobil MTG appears to be roughiy equivalent in economic attractiveness to the slurry F-T case.

This conclusion is based on the simliar revenue shortfall per barrel of product for MTG relative to slurry. Although the MTG information was acquired from a respected source (SRI International), some reservation concerning this conclusion must be expressed since it was difficult to ensure that the economics used were developed on a totally consistent basis. MTG would likely provide stiff competition for slurry F-T anyhow since it is a more proven process. 
(6) LNG appears to be a considerably more attractive market for remote natural gas than producing liquid fuels would be.

Thts conciusion is based on an SRI International study which shows that natural gas at $\$ 1.00 /$ MMBTU can be liquefied, delivered and regassiffed for as low as $\$ 3.00 /$ MMBTU in 1983 dollars, depending on the shipping distance. Escalation to a 1990 basis, with natural gas remaining at $\$ 1.00$ /MMBTU, would put the LNG costs in the \$3.50-4.00/MMBTU range. In contrast, the cost of producing liquid fuels by slurry $F-T$ in 1990 is in excess of $\$ 11.00 / M M B T U$, excluding delivery. Transportation fuels should have a higher form value than gas, but this difference would not be enough to significantly close the above gap, which is solely based on production costs.

Further study could be undertaken to confirm the economic advantage of the slurry versus. other established F-T processes. Such work should probably initially involve confirmation of the currently projected capital cost advantage. Also, even though the relative product yield structures were not a critical factor in determining the relative economics, the projected yielos for the slurry process should be confirmed by further experimental work since the current data base at the conditions chosen for this study is somewhat ilmited. If initiated, this work would have to be aimed toward achieving a long term payout. In addition, it should proceed only under some scenario which shows that the demand for diesel fuels is likely to increase preferentially to other fuels. Otherwise, other process options may possess an advantage over $F-T$ even in a market where liquid fueis are more highly valued. 


\section{REFERENCES}

1. Gray, et al., "The Impact of Developing Technology on Indirect Liquefaction", Mitre Corporation for DOE (EF-77-C-01-2783), November 1980.

2. Holmes, Hemming and Teper, "The Cost of Liquid Fuels from Coal", Part II, IEA Coal Research Report ICEAS/E3/2, November 1984.

3. Thompson, Riekena and Vickers, "Comparison of Fischer-Tropsch Reactor Systems", UOP for DOE (DE-ACOI-78ET10159), Sept. 1981.

4. Deckwer, W.D., "A Comparison of Different Fischer-Tropsch Processes."

5. Jager, Holtkamp and Gaenslen, "Opportunities for Low Temperature Fischer-Tropsch Processing."

6. C.A. Johnson, private communication.

7. Memorandum - R. B. Moore to A. R. Kuhns, 6 August 1985.

8. Memorandum - P. K. Chessher to A. R. Kuhns, 2 October 1985.

9. C. R. Greene, SRI International, private communication with S. C. Weiner.

10. SRI PEP Review No. 81-2-3, "Gasoline from Natural Gas via Methanol by the Mobtl Fixed Bed MTG Process".

11. Memorandum - C. Ebihara/C. L. Yeh to A. R. Kuhns, 5 November 1985.

12. Memorandum - N. Cilen to A. R. Kuhns, 6 November 1985. 
TABLE 1

ECONOMICS OF SYNTHESIS GAS PRODUCTION

875 MM SCFD

(1990 ONSTREAM)

\section{feedstock}

$\mathrm{H}_{2} / \mathrm{CO}$ Molar Ratio

Feedstock cost (\$/MMBTU)

Capital Investment (MM\$)

Annual Costs (MMY)

Feedstock

Other Operating

Capital Related

TOTAL

SYN GAS COST ( $\$ / M S C F)$
Steam Methane Reforming Remote Natural Gas

$\begin{array}{lll}0.92 & 1.7 & 2.0 \\ 1.00 & 1.00 & 1.00\end{array}$

- Partial oxidation

$\begin{array}{lll}0.92 & 1.7 \quad 2.0\end{array}$

$656 \quad 503$

453

$195 \quad 168 \quad 161$

$81 \quad 59 \quad 53$

$171 \quad 131 \quad 118$

$447 \quad 358$

332

$\begin{array}{lll}1.55 & 1.24 \quad 1.15\end{array}$ Remote Natural Gas

1.00

$1.00 \quad 1.00$

121

$\begin{array}{llllll}1.44 & 1.22 & 1.22 & 4.57 & 4.85 & 4.91\end{array}$

$\begin{array}{llllll}1.44 & 1.22 & 1.22 & 4.57 & 4.85 & 4.91\end{array}$

$\begin{array}{llllll}1.44 & 1.22 & 1.22 & 4.57 & 4.85 & 4.91\end{array}$

$\begin{array}{llllll}1.44 & 1.22 & 1.22 & 4.57 & 4.85 & 4.91\end{array}$

\begin{tabular}{|c|c|c|}
\hline \multicolumn{3}{|c|}{ coal } \\
\hline 0.92 & 1.7 & 2.0 \\
\hline 1.50 & 1.50 & 1.50 \\
\hline
\end{tabular}

$$
3,650 \quad 3,910 \quad 3,960
$$

$164 \quad 164 \quad 164$

$231 \quad 251 \quad 256$

$\underline{920} \quad \underline{980} \quad \underline{995}$

$\begin{array}{llllll}416 & 352 & 353 & 1.315 & 1.395 & 1.415\end{array}$ 
TABLE 2

COMPARISON OF F-T PROCESS DESIGN PARAMETERS

\begin{tabular}{ccc}
$\begin{array}{l}\text { Siurry } \\
\text { Reactor }\end{array}$ & $\begin{array}{l}\text { Entrained } \\
\text { Fluidized Bed } \\
\text { (Synthol) }\end{array}$ & $\begin{array}{l}\text { Fixed Bed } \\
\text { (ARGE) }\end{array}$ \\
\hline 315 & 315 & 355 \\
500 & 600 & 450 \\
0.9 & 2.0 & 1.7 \\
0.6 & 2.0 & 2.5 \\
$2000 *$ & 700 & 350 \\
95 & 95 & 95 \\
$(12)$ & $(4)$ & $(4)$
\end{tabular}

Reference

psia

Operating Temperature, ${ }^{\circ} \mathrm{F}$

Feed $\mathrm{H}_{2} / \mathrm{CO}$ Ratio

Recycle/feed Gas Ratio

Catalyst Loading,

SCF Feed/ft. cat. hr

Feed Conversion, $\%$

(12)

(4)

(4)

*25 wt. * catalyst concentration 
TABLE 3

SYNTHESIS GAS COMPOSITION AND PRODUCT YIELD STRUCTURES

(wt.\%)

\begin{tabular}{lrrr} 
FEED & \multicolumn{1}{c}{ SLURRY } & \multicolumn{1}{c}{ SYNTHOL } & ARGE \\
\hline $\mathrm{H}_{2}$ & 6.2 & 12.9 & 10.9 \\
$\mathrm{CO}$ & $\frac{93.8}{100.0}$ & $\frac{87.1}{100.0}$ & $\frac{89.1}{100.0}$
\end{tabular}

\section{PRODUCTS}

$\begin{array}{lrrr}\mathrm{CO}_{2} & 54.9 & 3.6 & 15.0 \\ \mathrm{H}_{2} \mathrm{O} & 13.4 & 52.0 & 43.3 \\ \mathrm{CH}_{4} & 1.3 & 4.4 & 2.5 \\ \mathrm{C}_{2} & 1.4 & 3.6 & 1.2 \\ \mathrm{C}_{3} & 1.7 & 6.2 & 2.2 \\ \mathrm{C}_{4} & 1.4 & 4.9 & 1.7 \\ \mathrm{C}_{5-11} & 6.6 & 17.7 & 6.8 \\ \mathrm{C}_{12-18} & 4.2 & 3.1 & 4.9 \\ \mathrm{C}_{19+} & 13.9 & 1.8 & 19.7 \\ \text { 0xygenates } & 1.2 & 2.7 & -2.7 \\ & 100.0 & 100.0 & 100.0\end{array}$


TABLE 4

UTILITY SUMMARY

Process Steam

Power Import (150 psla or less) Steam

(M LB/HR)

$(M L B / H R)$

Fuel Gas

\section{Slurry Case}

Partial 0xidation

F-T Synthes is

Product Upgrading

Autothermal Reforming

Wax Hydrocracking

(kw)

HLPRI

(MM BTU/HR)

Utilities and offsites TOTAL

$$
\begin{array}{r}
256,300 \\
31,200 \\
10,350 \\
18,450 \\
1,570 \\
10,000 \\
\hline 327,870
\end{array}
$$

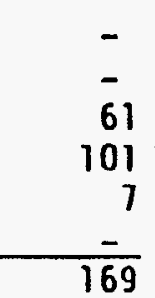

$$
\begin{gathered}
1.820(2) \\
2.890(3) \\
- \\
130(1) \\
- \\
\frac{-}{4.840}
\end{gathered}
$$$$
435(2)
$$

$3,146(5)$ $\overline{197}(4)$

66,300
11,600

23,700

10,000

222,300

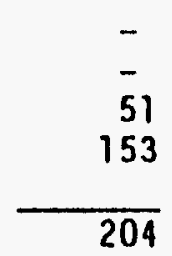

192,700

46,400

9.770

16,970

1.660

$\frac{10,000}{277,500}$

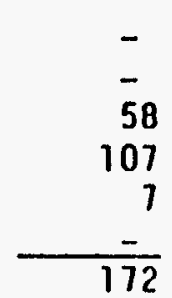

$$
\begin{gathered}
2,360(2) \\
3,020(6) \\
- \\
138(4) \\
- \\
- \\
5,518
\end{gathered}
$$

$\frac{-}{3.778}$

\section{ARGE Case}

\section{F-T Synthesis}

Autothermal Reforming

Wax Hydrocracking

Utilities and offsites

TOTAL$$
\begin{array}{r}
173 \\
550 \\
135 \\
42 \\
100 \\
\hline 1,000
\end{array}
$$

00

, 000

260

760

204

100

$$
1,324
$$

(1) Reformer fuel gas is included with process natural gas

(2) 1500 psla, $850^{\circ} \mathrm{F}$

(3) 425 psia (SAT)

(4) 600 psla (SAT)

(5) $2,786,000 \mathrm{lb} / \mathrm{hr} 425 \mathrm{psja}$ (SAT) and $360,000 \mathrm{lb} / \mathrm{hr} 150 \mathrm{psla}$ (SAT)

(6) 250 psia (SAT) 
TABLE 5

COMPARISON OF FISCHER-TROPSCH PRODUCT SLATES

875 MM SCFD SYNTHESIS GAS

\begin{tabular}{|c|c|c|c|c|c|c|}
\hline & \multicolumn{2}{|c|}{ SLURRY } & \multicolumn{2}{|c|}{ SYNTHOL } & \multicolumn{2}{|c|}{ ARGE } \\
\hline & Ib/hr & $\underline{B B L / D}$ & $10 / h r$ & $B B L / 0$ & Ib/hr & $\underline{B B L / D}$ \\
\hline$c_{3} L P G$ & 7,080 & 960 & 16,420 & 2,220 & $\cdot \quad 7,740$ & 1,050 \\
\hline$C_{4}$ & 1,510 & 180 & 2,570 & 300 & 1,180 & 140 \\
\hline Gasoline & 170,100 & 16,400 & 319,700 & 30,800 & 149,250 & 14,390 \\
\hline Dlesel & 249,400 & 22,670 & 37.780 & 3,430 & 254,630 & 23,150 \\
\hline Heavy 011 & - & - & 21,590 & 1,700 & - & - \\
\hline Alcohols & 17,000 & - & 32,950 & - & 32,580 & - \\
\hline TOTAL & 445,090 & 40,210 & 431,010 & 38,450 & 445,380 & 38,730 \\
\hline
\end{tabular}


TABLE 6

CAPITAL INVESTMENT SUMMARY FOR LIQUIO FUELS SYNTHESIS (1990 START-UP)

MM\$

SLURRY SYNTHOL $\quad$ ARGE

\begin{tabular}{|c|c|c|c|}
\hline Fischer-Tropsch Synthesis & $\$ 255$ & $\$ 675$ & $\$ 550$ \\
\hline Product Upgrading & 150 & 180 & 150 \\
\hline Autothermal Reforming & 110 & 135 & 115 \\
\hline Wax Hydrocracking & 30 & - & 35 \\
\hline Utilities and offsites & 165 & 165 & 165 \\
\hline Contingency & 180 & 275 & 255 \\
\hline Subtotal (1985\$) & 890 & 1370 & 1270 \\
\hline Work In Progress Escalation & 130 & 200 & 185 \\
\hline Interest During Construction & 250 & 385 & 355 \\
\hline TOTAL & $\$ 1,270$ & $\$ 1,955$ & $\$ 1,810$ \\
\hline
\end{tabular}

(1) Excludes investment for synthesis gas production. Purchase of synthesis gas is treated as an operating cost in Table 8. 
TABLE 7

PRODUCT PRICE PROJECTIONS

(1990 DOLLARS)

$\begin{array}{ll}C_{3} \text { LPG } & \$ 17.40 / \mathrm{BBL} \\ C_{4} & \$ 21.00 / \mathrm{BBL} \\ \text { Gasoline } & \$ 36.60 / \mathrm{BBL} \\ \text { Diesel } & \$ 36.12 / 88 \mathrm{C} \\ \text { Fuel 0il } & \$ 25.00 / \mathrm{BBL} \\ \text { Alcohols } & \$ .15 / 1 \mathrm{~b}\end{array}$

ANNUAL REVENUE PROJECTIONS

$\frac{(1990-\text { MILLIONS })}{330 \text { DAY/YR }}$

\begin{tabular}{rrr} 
SLURRY & SYNTHOL & \multicolumn{1}{c}{ ARGE } \\
$\$ 1.2$ & $\$ 12.7$ & $\$ 6.0$ \\
198.1 & 2.1 & 1.0 \\
270.2 & 372.0 & 173.8 \\
- & 40.9 & 275.9 \\
20.2 & 14.0 & - \\
$\$ 495.2$ & 39.1 & 38.7 \\
\hline 480.8 & $\$ 495.4$
\end{tabular}


TABLE 8

ANNUAL COSTS FOR FISCHER-TROPSCH SYNTHESIS * NOMINAL PLANT CAPACITY 40,000 BBL/D

(1990 ONSTREAM)

MMS

SLURRY SYNTHOL $\quad$ ARGE

Synthests Gas (1)

$416 \quad 332$

352

Other Operating

106

139

141

Capital Related $(2)$

$\underline{330}$

$\underline{508}$

$\underline{471}$

Total 1990 Required Revenue

852

979

964

Projected 1990 Revenues

495

481

495

Revenue Shortfall

357

498

469

Revenue Shortfall (\$/BBL Product)

25

36

34

Sensitivity to Coal Based

on Synthesis Gas Production

Total 1990 Required Revenues

1.747

2,057

2,012

Revenue Shortfall

1.252

1,576

1,517

Revenue Shortfall (\$/BBL Product)

93

121

176

NATURAL GAS PRICE

$\$ 1.00 / M M$ BTU

COAL PRICE

$\$ 1.50 / M M$ BTU

*A revised Product Cost Summary is located in Appendix 2.

(1) Synthesis gas from partial oxidation for the slurry and ARGE cases and steam methane reforming for Synthol.

(2) Includes an allowance for $7.5 \%$ net profit after tax return on investment. 
TABLE 9

ANNUAL COSTS FOR LIQUID FUEL PRODUCTSA

STARTING WITH NATURAL GAS

(1990 Onstream)

(MM \$)

Natural Gas-Feedstock + Fuel Other Operating

Capital Related $B$

Total 1990 Required Revenues

Projected 1990 Revenues

Revenue Shortfall

Revenue Shortfall/BBL product

Fischer-Tropsch

STurry Synthol ARGE Mobil MTG

121

174

557

852

495

357

$\$ 25$
161

192

$\underline{626}$

979

481

498

$\$ 36$
115

177

$\underline{672}$

$964 \quad 588$

$495 \quad 323$

$469 \quad 265$

$\$ 34 \$ 28$

A All cases produce $96,160 \mathrm{~mole} / \mathrm{hr}$ of syngas as an intermediate.

B Capital investment includes that for producing syn gas (steam reforming for Synthol and Mobil; partial oxidation for ARGE and slurry) and that for producing liquid fuels (F-T or MTG).

C Total investment for Mobil MTG case is $\$ 7572$ MM and is based on SRI PEP Review No. $81-2-3$. 
TABLE 10

MOBIL MTG PRODUCT SLATE

875 MM SCFO SYNTHESIS GAS

\begin{tabular}{lcr} 
& \multicolumn{1}{l}{$1 \mathrm{~b} / \mathrm{hr}$} & $\mathrm{BBL} / 0$ \\
Propane LPG & 14,072 & 1,904 \\
Butanes & 22,960 & 2,697 \\
Gasoline 96 RON & $\underline{252,410}$ & $\underline{24,329}$ \\
TOTAL & 289,442 & 28,930
\end{tabular}


FIGURE 1

OVERALL PROCESS FLOWSCHEME

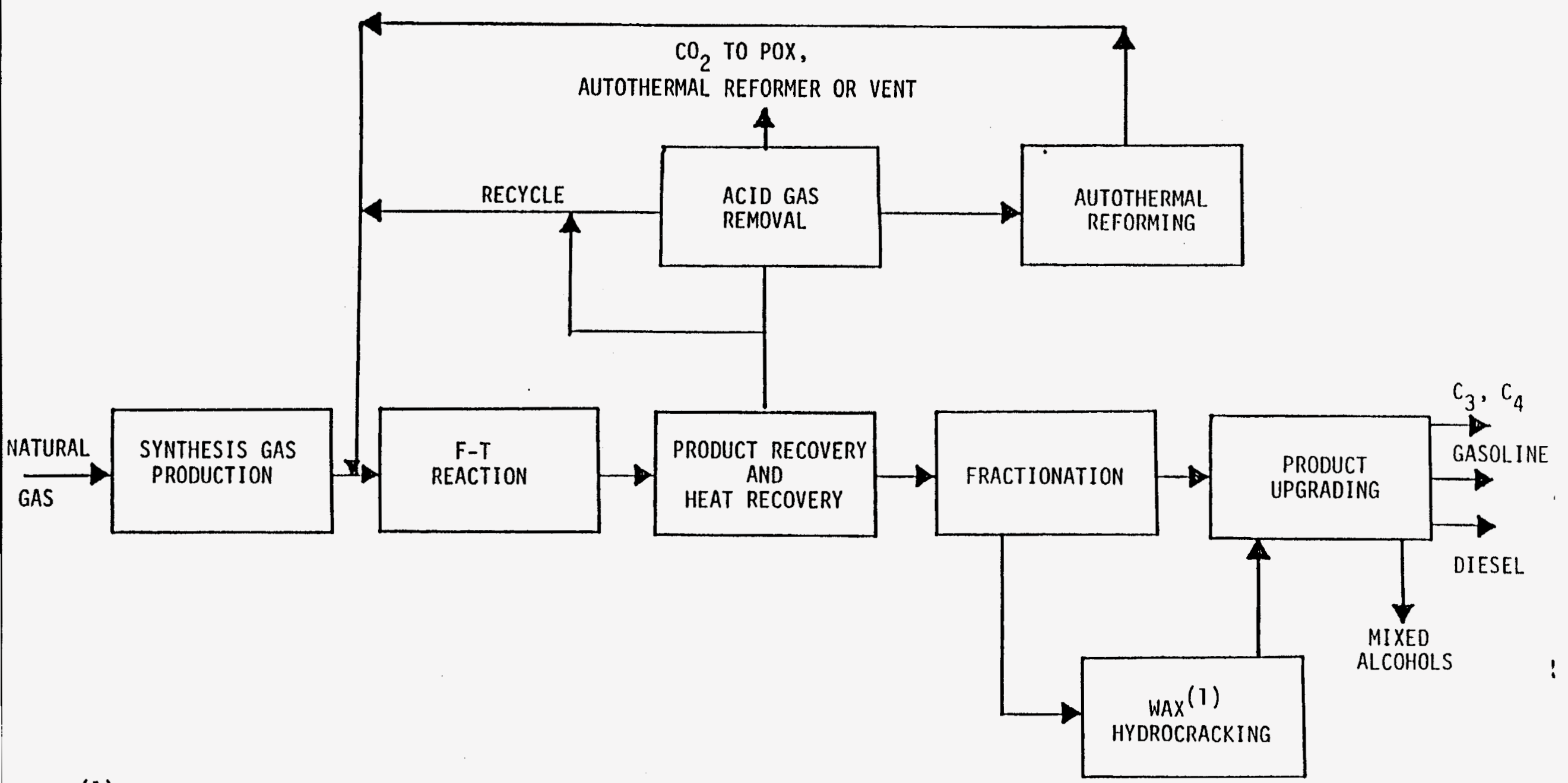

(1) NOT PRESENT IN SYNTHOL CASE 
FIGURE 2

PARTIAL OXIDATION OF NATURAL GAS

SYNTHESIS GAS COST VERSUS $\mathrm{H}_{2} / \mathrm{CO}$ RATIO

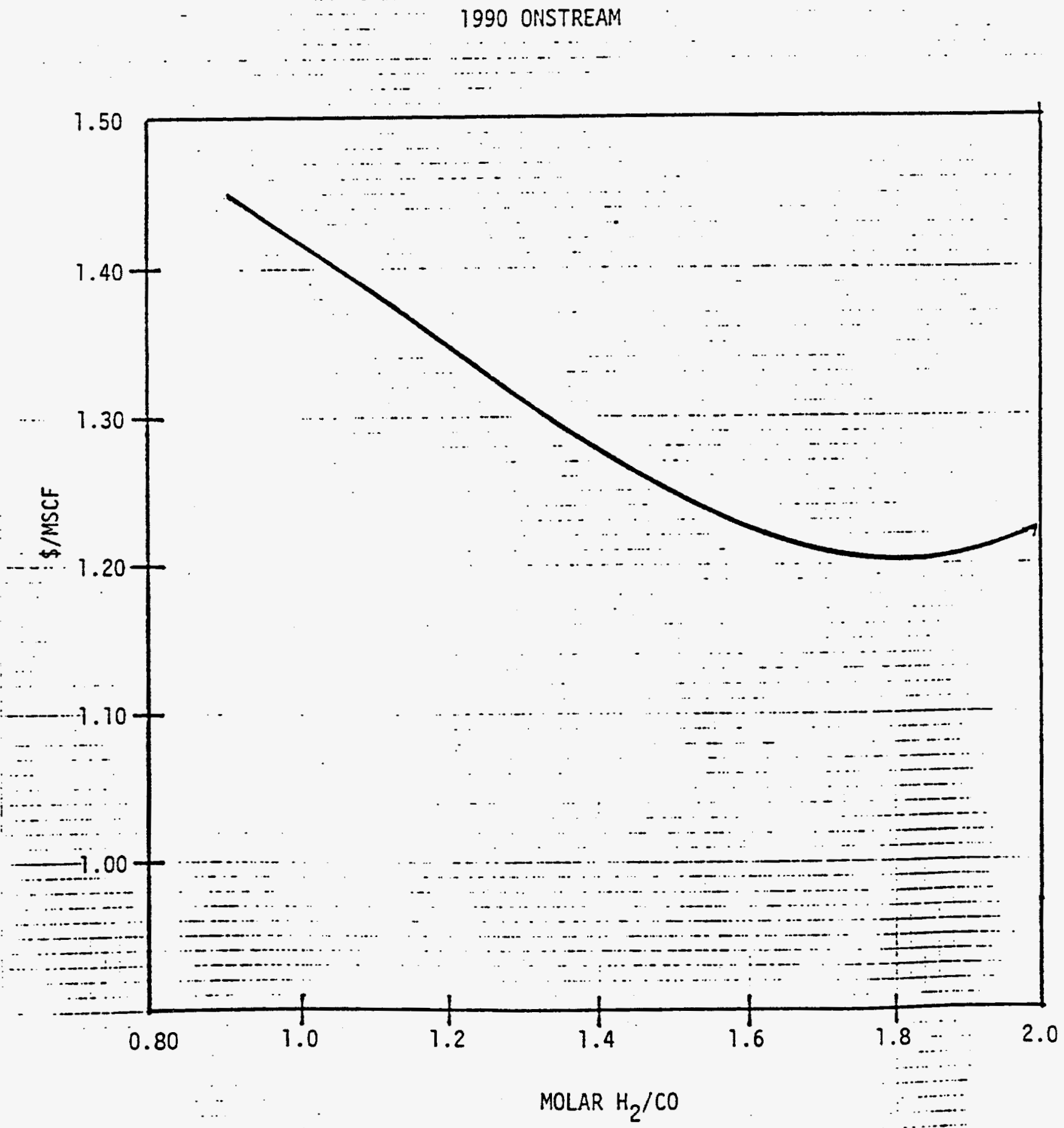

NATURAL GAS PRICE $\$ 1.00 / \mathrm{MMBTU}$ 
FIGURE 3

FISCHER TROPSCH PRODUCT UPGRADING FLOWSCHEME

$I_{2}$ RICH GASES FROM CATALYTIC REFORMING AND $C_{5} / C_{6}$ ISOMERIZATIOH

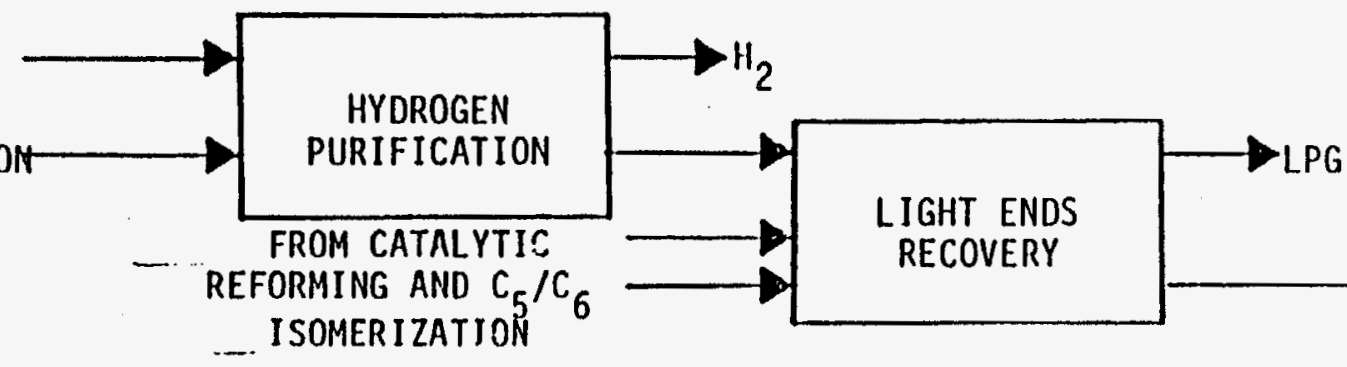

RAW PRODUCT ROM SYNTHESIS AND WAX IYDROCRACKING

RAW PRODUCT FRACTIONATION


HEAVY POLYGAS HYDROGENATION

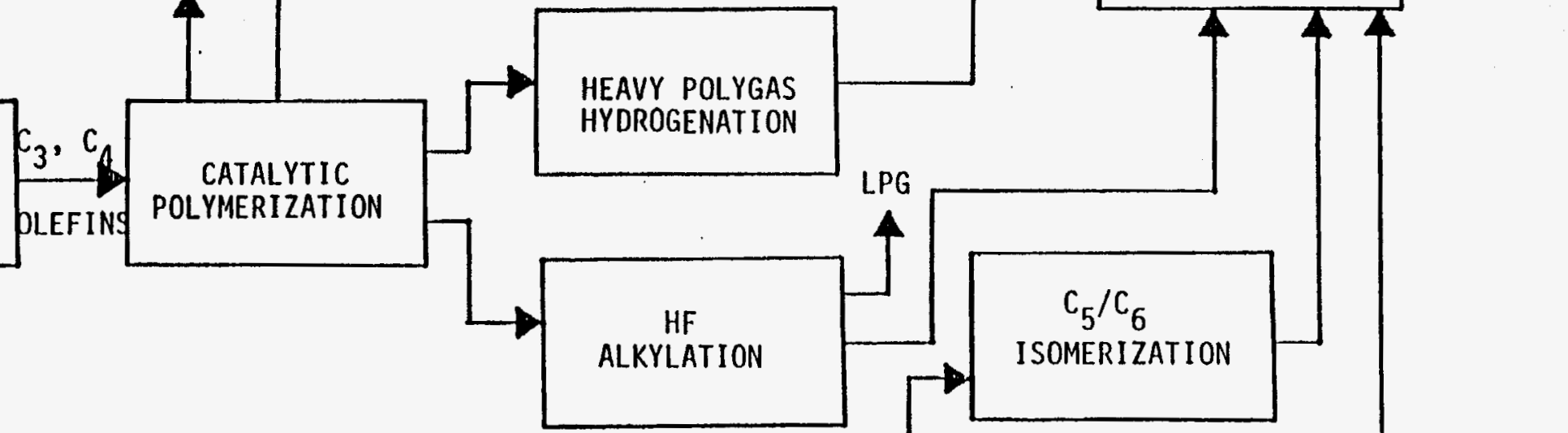

HYDROTREATED PRODUCT FRACTIONATOR
GASOLINE

PRODUCT ALCOHOLS 


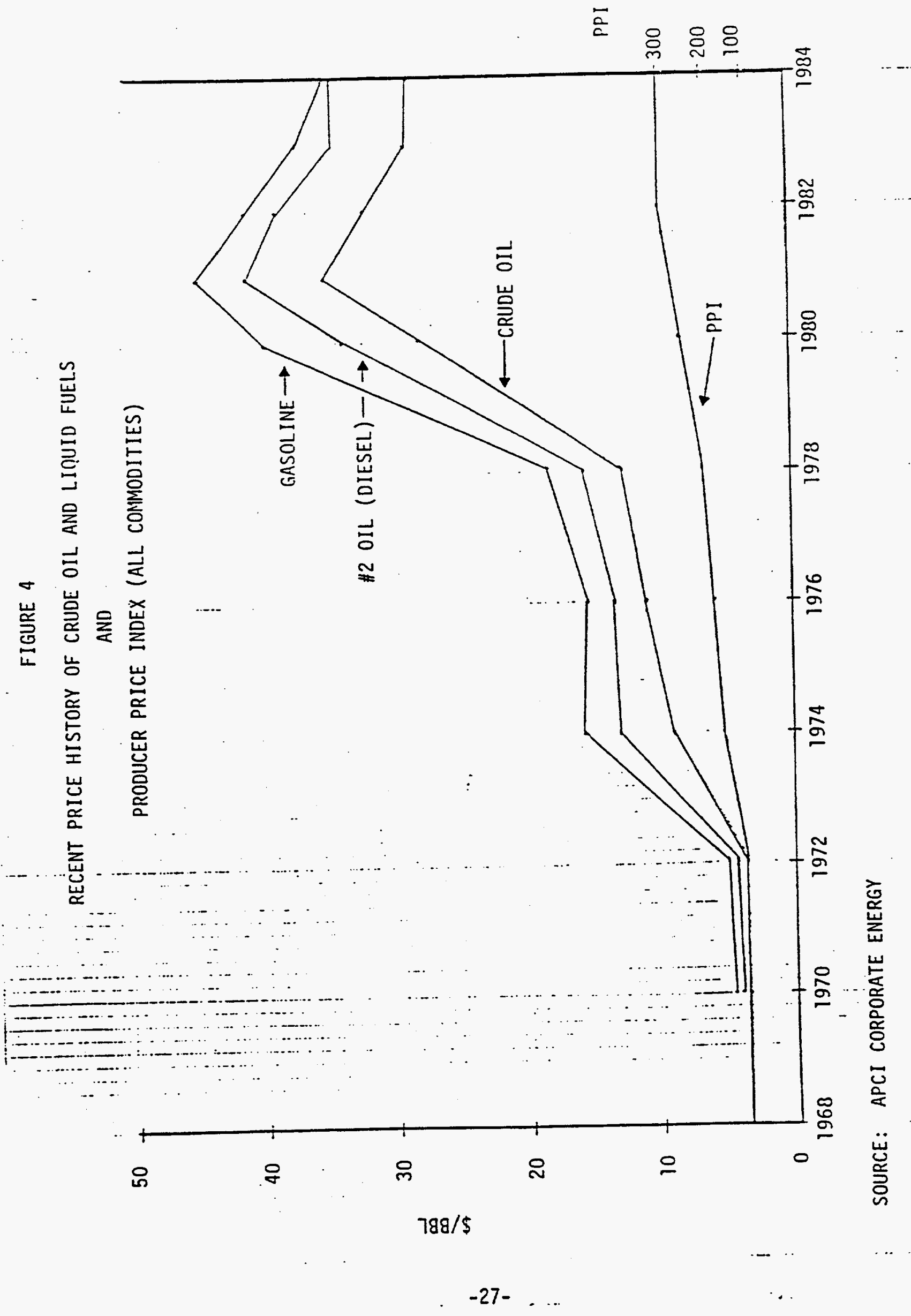


FIGURE 5

MOBILE MTG PROCESS

$\mathrm{C}_{1}-\mathrm{C}_{2}$ RECYCLE

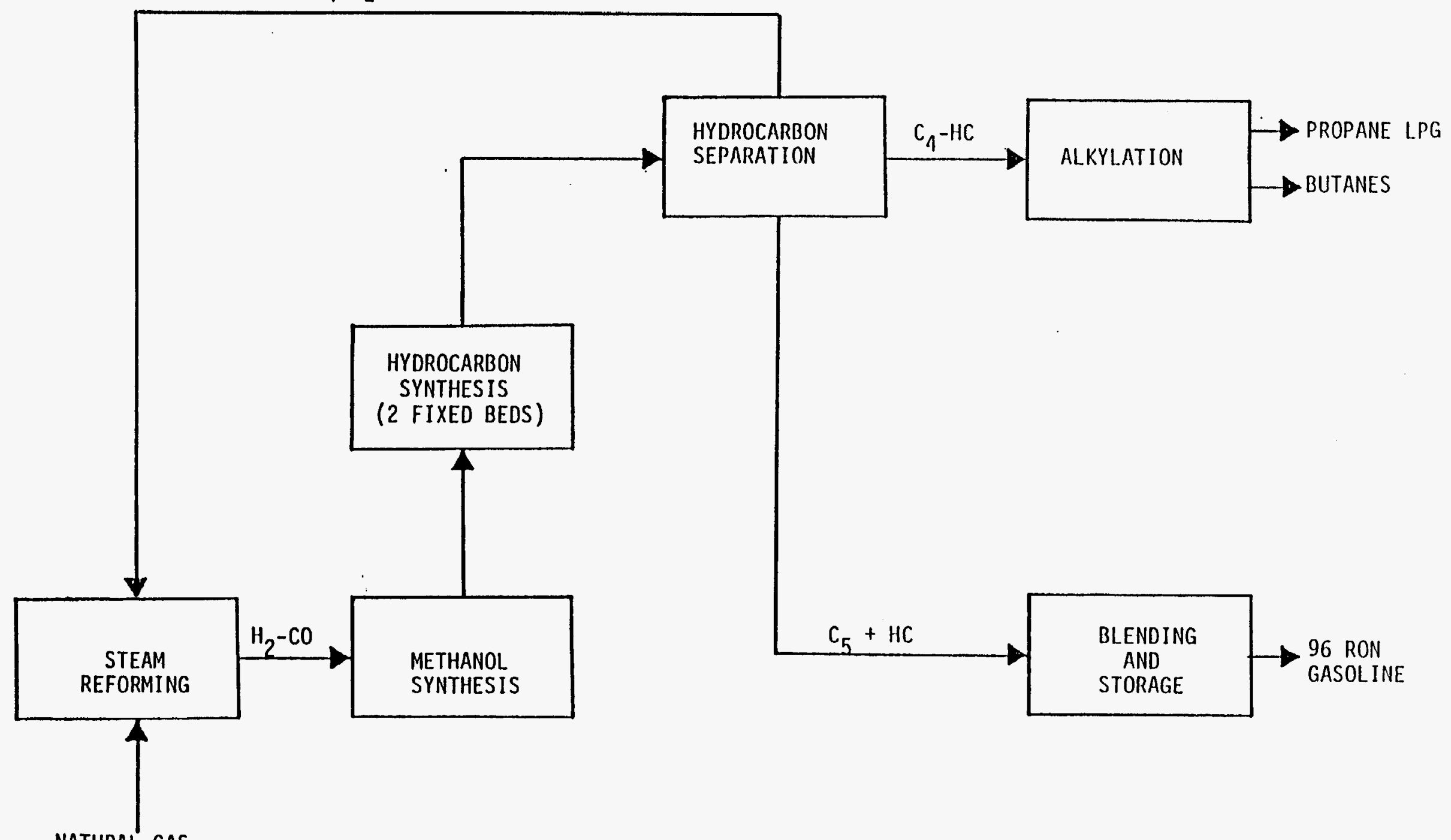

NATURAL GAS 
TABLE A.I

Equipment Parameters in $F-T$ Synthes is Areas

Basis: 875 MM SCFD Synthesis Gas to Reactors

Slurry $\quad$ Synthol

Reactors

Type

Slurry

Entrained Bed

Fixed Bed

Number

12

$6(1)$

24

Size

$12^{\prime} 4^{\prime \prime}$ I.D. $\times 72^{\prime}$

$T \times T$

$10^{\prime} 10 \times 170^{\prime}$

$T \times T$

11 '6" ID $\times 90$ '

$T \times T$

Internal Heat Exchange

Surface Per Reactor (Ft²)

74,700

108,000

117,000

Recycle Compressor BHP

21,600

65.340

47,320

External Heat Exchanger

Surface Area ( $\mathrm{Ft}^{2}$ )

187,000

408,000

549,000

(1) Each reactor also requires a 29'3" ID $\times 30^{\prime} T \times T$ catalyst settling hopper and a $10^{\prime} 10 \times 125^{\prime}$ standpipe. 
TABLE A.2

ANNUAL OPERATING COSTS FOR SYNTHESIS GAS PRODUCTION AND F-T SYNTHESIS

1990 DOLLARS MILLIONS

330 DAYS/YR OPERATION

SYNTHESIS GAS PRODUCTION

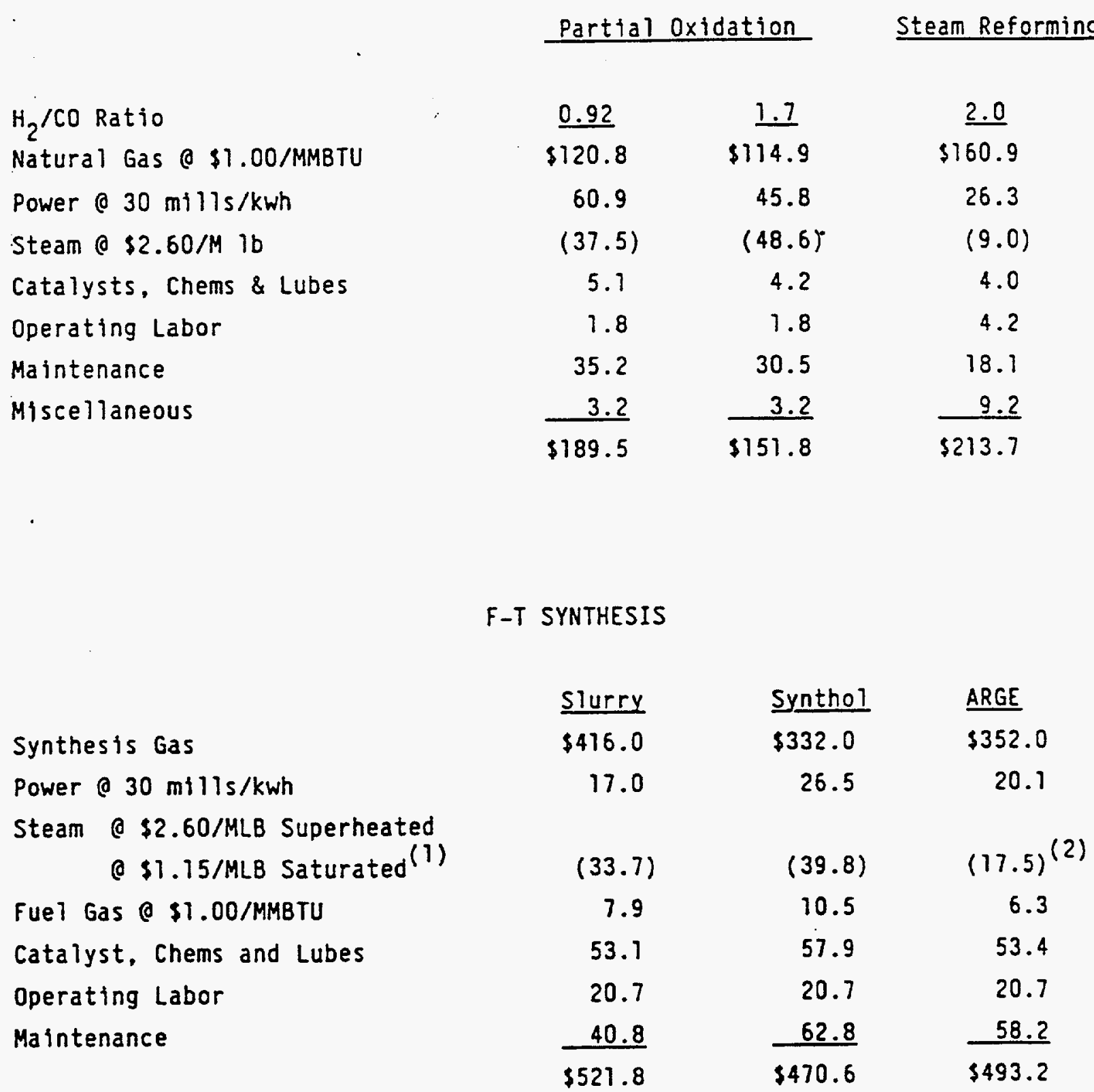

(1) The value of saturated steam was established by the amount of power which could be extracted from it relative to the superheated steam.

(2) Value is reduced since $1,100,000 \mathrm{lb} / \mathrm{hr}$ saturated steam (36\% of total avallable) is condensed without power recovery. 
Appendix 2

REVISED PRODUCT COST SUMMARY 
Mr. George Cinquegrane

U.S. Department of Energy

Pittsburgh Energy Technology Center

P.O. Box 10940, MS 920-L

Pittsburgh, PA 15236

Subject: Contract No. DE-AC22-85PC80011

"Development and Process Evaluation of Improved Fischer-Tropsch STurry Catalyst"

Dear Mr. Cinquegrane:

In response to DOE's comments emanating from the draft final report for the subject contract, Air Products has reviewed the cost to produce synthesis gas from coal and the impact this has on Fischer-Tropsch process economics. The enclosed "Product Cost Summary" shows the crude oil break-even price for F-T product using recently updated coal derived synthesis gas costs. These syngas costs are approximately $1 / 3$ of those that were used in the original draft final report, and are based on extensive data developed under the Liquid Phase Methanol Technology Program (1987-1990).

For the record, the original process and economic evaluations performed under this contract were based on a CO-rich feedstock derived from natural gas. The process had included a water gas shift reactor to adjust the syngas to the Co-rich composition typical of that derived from coal. This approach was used since earlier studies at Air Products (ca. 1985) had indicated that syngas derived directly from coal would cost up to three times that derived from natural gas. The recent studies completed under the LPMEOH program show this assumption to be incorrect, with natural gas and coal-based syngas costs being more equal ( $\$ 4-5.50 \mathrm{MM} / \mathrm{BTU})$.

The Projected Revenues shown in the summary were determined based on a January 1990 crude price of $\$ 18 / \mathrm{BBL}$ and include anticipated (at that time) price increases. As can be seen, Revenue Shortfalls are now similar. The break-even selling price for F-T product compared to crude oil is also shown. If crude oil prices should rise to $\$ 35-40 / B B L$, Fischer-Tropsch processing looks promising, especially since natural gas costs were assumed to be $\$ 1.00 \mathrm{MM}$ BTU and in most instances natural gas prices are higher.

If you have any questions concerning this information, please call me at (215) $481-3352$. 


\section{PRODUCT COST SUMMARY - \$MM}

Basis: Remote Natural Gas $\$ 1.00$ MM Btu

40,000 BBL/day Liquid Fuel Production

Products Selling Prices Based on \$18/BBL Crude 0il

Natural Gas COAL $\$ \$ 4.30 \mathrm{MM} \mathrm{BTU} \$ \$ 5.50 \mathrm{MM}$ BTU

Costs

Syngas
Other
Capital
Total Annual Cost
Projected Shortfall

$\$ M M / Y r$

299.20

324.40

$\$ 503.10$

$\$ 370.50$

$\$ 392.70$

48.50

48.50

48.50

$2 \underline{02.30}$

$\underline{202.30}$

$\underline{202.30}$

753.90

$\$ / B B L$

22.50

24.20

431.80

32.50

Crude oil Price

Required to Break

Even

$\$ 35 / B B L$

$\$ 36 / B B L$

$\$ 42 / B B L$

2605J-IA 